Göttinger Beiträge zur soziologischen Biographieforschung

Miriam Schäfer

\title{
Polizist*in werden - Polizist*in sein
}

Strukturen und Widersprüche polizeilicher Arbeit

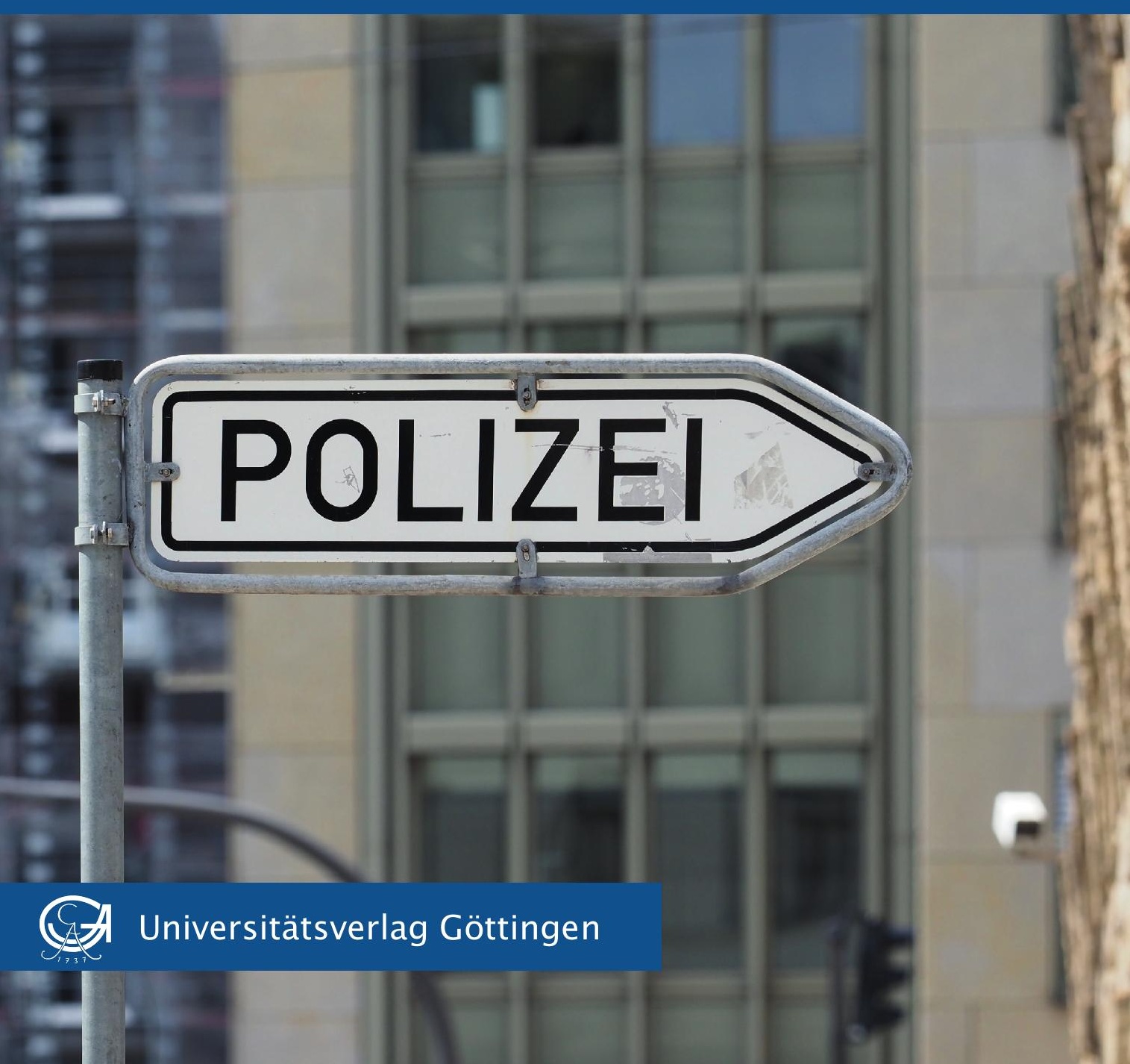



Miriam Schäfer

Polizist*in werden - Polizist*in sein

Dieses Werk ist lizenziert unter einer

Creative Commons

Namensnennung - Weitergabe unter gleichen Bedingungen

4.0 International Lizenz.

(c) $(1)(0)$ 
erschienen als Band 5 in der Reihe „Göttinger Beiträge zur soziologischen Biographieforschung“ im Universitätsverlag Göttingen 2021 
Miriam Schäfer

Polizist*in werden - Polizist*in sein

Strukturen und Widersprüche polizeilicher Arbeit

Göttinger Beiträge zur

soziologischen Biographieforschung Band 5

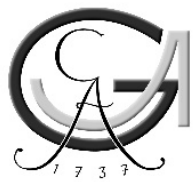

Universitätsverlag Göttingen 2021 


\section{Bibliographische Information der Deutschen Nationalbibliothek}

Die Deutsche Nationalbibliothek verzeichnet diese Publikation in der Deutschen Nationalbibliographie; detaillierte bibliographische Daten sind im Internet über $<$ http://dnb.dnb.de $>$ abrufbar.

„Göttinger Beiträge zur soziologischen Biographieforschung/Göttingen Series in Sociological Biographical Research“"

herausgegeben von

Prof. Dr. Maria Pohn-Lauggas_Ｅ-Mail: maria.pohn-lauggas@uni-goettingen.de

Prof. Dr. Gabriele Rosenthal_ E-Mail: g.rosenthal@uni-goettingen.de

Dr. Nicole Witte_ E-Mail: Nicole.Witte@uni-goettingen.de

Dr. Arne Worm E-Mail: arne.worm@uni-goettingen.de

Georg-August-Universität Göttingen

Methodenzentrum Sozialwissenschaften

Goßlerstr. 19

37073 Göttingen

Zugleich Dissertation an der Sozialwissenschaftlichen Fakultät der Georg-AugustUniversität Göttingen unter dem Titel „Polizist*in werden - Polizist*in sein“

Kontakt

Miriam Schäfer

E-Mail: miriam.schaefer@sowi.uni-goettingen.de

Dieses Buch ist auch als freie Onlineversion über die Homepage des Verlags sowie über den Göttinger Universitätskatalog (GUK) bei der Niedersächsischen Staats- und Universitätsbibliothek Göttingen (https://www.sub.uni-goettingen.de) erreichbar. Es gelten die Lizenzbestimmungen der Onlineversion.

Satz und Layout: Miriam Schäfer

Titelabbildung: ANGHI/Shutterstock.com

(C) 2021 Universitätsverlag Göttingen

https:/ / univerlag.uni-goettingen.de

ISBN: 978-3-86395-483-3

DOI: $10.17875 /$ gup2021-1579

ISSN: 2699-0989

eISSN: 2699-0997 


\section{Vorwort der Herausgeber*innen}

Im Rahmen der sozialkonstruktivistischen und wissenssoziologischen Biographieforschung, die am Methodenzentrum Sozialwissenschaften der Georg-August-Universität Göttingen in den letzten Jahren etabliert wurde, entstehen vielfältige innovative und sorgfältige, empirisch fundierte Forschungsarbeiten. Die Reihe soll dieser Entwicklung Rechnung tragen. Mit ihr wollen die Herausgeber*innen deutsch- und englischsprachigen Qualifikationsarbeiten, Forschungsarbeiten und entsprechenden Sammelbänden ein Forum bieten, die vorrangig im Bereich der Soziologie und methodisch im Umfeld des Methodenzentrums Sozialwissenschaften verortet sind. Veröffentlicht werden in der Reihe sowohl primär auf materiale Themen fokussierte Werke als auch solche, die sich vorrangig auf Methodenforschung und Methodenentwicklung konzentrieren.

Maria Pohn-Lauggas, Gabriele Rosenthal, Nicole Witte, Arne Worm 



\section{Vorwort}

Viele Menschen haben mein Promotionsprojekt und die Entstehung dieses Buches begleitet. Mein Dank gilt zunächst den Polizist*innen, die mir ihre Lebensgeschichten anvertraut haben und mich so aufgeschlossen an ihrem Arbeitsalltag teilhaben ließen. Meine Feldforschung wäre kaum möglich gewesen ohne die Unterstützung von einzelnen Polizist*innen der Polizei Niedersachsens und von Dr. Astrid Jacobsen, die mein Forschungsanliegen (innerpolizeilich) unterstützt haben.

Ganz wesentliche Begleiter*innen während der Promotionsphase waren meine Kolleg*innen am Methodenzentrum. Besonders Ahmad Albaba, Eva Bahl, Dr. Hendrik Hinrichsen, Kristina Meier und Dr. Arne Worm haben den Promotionsprozess in unserer kleinen Auswertungsgruppe durchweg begleitet. Ihnen, genauso wie meinen (ehemaligen) Kolleg*innen und den Teilnehmer*innen an den Forschungswerkstätten, sei gedankt. Den freundschaftlich-kollegialen und kritisch-unterstützenden Austausch, den wir am Methodenzentrum pflegen, schätze ich sehr. Gestaltet wird diese Art Austausch am Methodenzentrum wesentlich auch von meiner Erstbetreuerin Prof. Dr. Gabriele Rosenthal. Ich bin dankbar für diesen offenen und geschützten, wenngleich nicht weniger kritischen Diskussionsraum und die Betreuung meiner Arbeit in genau dieser Weise. 
Meinem Zweitgutachter Prof. Dr. Klaus Schlichte und meiner Drittgutachterin Dr. Astrid Jacobsen danke ich für hilfreiche und ermutigende Rückmeldungen zu meinen Texten und Gedanken.

Letzte Rückmeldungen und Korrekturen habe ich von Dr. Johannes Becker, Dr. Ricarda Schnelle, Dr. Nicole Witte und Dr. Arne Worm erhalten. Vielen Dank.

Besonderer Dank gilt Dr. Nicole Witte und Dr. Ricarda Schnelle, die meine Promotionsphase als Freundinnen und Kolleginnen begleitet haben. Schließlich bedanke ich mich bei Marcel Pohl und meiner Familie. Ihr habt mich immer unterstützt. Dafür bin ich sehr dankbar.

Göttingen, im Dezember 2020

Miriam Schäfer 


\section{Inhaltsverzeichnis}

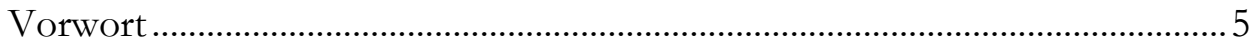

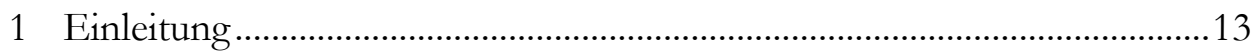

1.1 Konkretisierung des Forschungsthemas und Forschungsverlauf..................15

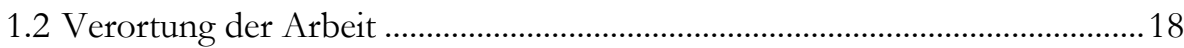

1.3 Aufbau der Arbeit............................................................................................... 20

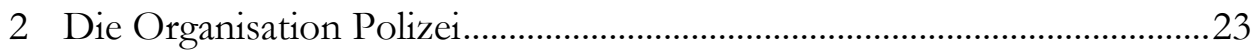

2.1 Theoretische Perspektivierung I: Polizei, Macht und Gewalt ........................24

2.1.1 Die Delegation des Gewaltmonopols ................................................25

2.1.2 Macht und Gewalt als Handeln ............................................................2 28

2.2 Die Geschichte der Organisation.........................................................................33

2.2.1 Die Entstehung der modernen Polizei im Deutschen Kaiserreich ........................................................................................

2.2.2 Tradition, Modernisierung und Straßenkampf: Die Polizei der Weimarer Republik ……………………………………………….......36 
2.2.3 Die Polizei als Organisation der Vernichtungspolitik im Nationalsozialismus

2.2.4 Neubeginn und Kontinuität: Die Polizei in den Nachkriegsjahren.

2.2.5 Gesellschaftliche Dynamiken und polizeiliche Reformen: Die Polizei der Bundesrepublik

2.2.6 Zusammenfassung: Kontinuitäten und Schlussfolgerungen............54

2.3 Die Organisations- und Ausbildungsstruktur der Polizei Niedersachsen ...57

3 Polizei erforschen 61

3.1 Der Forschungsgegenstand im Kontext der Polizeiforschung .62

3.1.1 Entwicklung und Perspektiven der deutschen Polizeiforschung ...63

3.1.2 Forschung zu Biographie und Berufswahl von Polizist*innen .......69

3.2 Theoretische Perspektivierung II: Handeln, Interaktion und Biographie ...71

3.2.1 Die Perspektiven auf Handeln und Interaktion .................................72

3.2.2 Die Perspektive auf Biographie ............................................................ 75

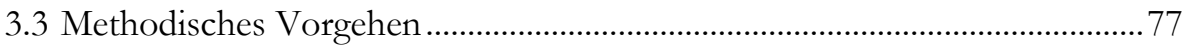

3.3.1 Methodologische Prinzipien...........................................................

3.3.2 Der Forschungsprozess................................................................... 81

3.3.3 Die Forschungsmethoden .............................................................90

3.3.3.1 Teilnehmende Beobachtung, beobachtende Teilnahme und ihre Analyse................................................................. 91

3.3.3.2 Biographisch-narrative Interviews und biographische Fallrekonstruktionen...........................................................95

3.3.3.3 Die Verknüpfung der Untersuchungsebenen..................100

4 Der Handlungs- und Interaktionskontext polizeilicher Arbeit................ 103

4.1 Wir- und Sie-Bilder in der Polizei .................................................................104

4.1.1 Wir-Bilder. Die polizeiliche(n) Konstruktion(en) ,der ${ }^{\varsigma}$ Polizei .....105

4.1.2 Sie-Bilder. Die Typisierungen des Gegenübers ...............................110

4.2 Prozesse polizeilicher Situationsdefinitionen .................................................116

4.2.1 Handlungsstrukturierende Typisierungen und Wissensbestände in Einsatzsituationen..........................................................................116

4.2.2 Situationsdefinitionen in problematischen Situationen...................122

4.3 Strukturen und Ambivalenzen polizeilicher Arbeit......................................125

4.3.1 Routine und Ausnahme. 
4.3.2 Schreiben und Rausfahren..............................................................130

4.3.3 Erfolgreiche polizeiliche Arbeit ......................................................134

4.3.4 (Ir-)relevante polizeiliche Arbeit ........................................................136

4.3.5 Grenzüberschreitungen.................................................................140

4.3.6 Hierarchische Verhältnisse ...............................................................142

4.3.7 Doing police: doing gender ................................................................147

5 Polizist*in werden und Polizist*in sein ..................................................153

5.1 Polizistin-Werden und Polizistin-Sein als Bearbeitung biographischer Unsicherheit: Der Fall von Melanie Wegener...............................................154

5.1.1 Die Präsentation ihrer Lebensgeschichte ...........................................155

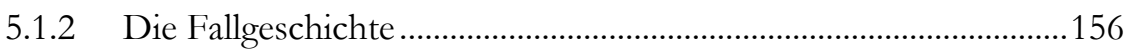

5.2 Polizist-Werden und Polizist-Sein als Ermächtigungsprozess: Der Fall von Markus Holtzmann..................................................................................183

5.2.1 Die Präsentation seiner Lebensgeschichte .......................................184

5.2.2 Die Fallgeschichte ................................................................................185

6 Zentrale Ergebnisse und theoretische Verallgemeinerungen....................207

6.1 Strukturen des Handlungs- und Interaktionskontextes polizeilicher Arbeit

6.1.1 Routine und krisenhafte Momente als typische Situations- und Wahrnehmungsmodi ...........................................................................208

6.1.2 Herstellung und Aufrechterhaltung einer machtvollen Interaktionsposition.

6.1.3 Das schutzpolizeiliche Wir-Bild und die Zugehörigkeit zur

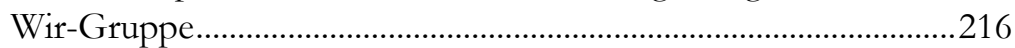

6.1.3.1 Das Wir-Bild als Bearbeitung der Handlungsbedingungen ......................................................216

6.1.3.2 Das Wir-Bild als Voraussetzung für die Interaktionspraxis im Binnenbezug ...

6.2 Biographische Strukturierungen und Handlungsmuster

6.2.1 Die biographische Struktur. Kondensierte Fallzusammenfassungen.. 221

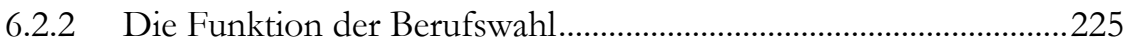

6.2.3 Polizist*in werden: Die Sozialisation in die Berufsrolle..................228

6.2.4 Polizist*in sein: Handlungsmuster im Arbeitskontext ....................231

6.2.4.1 Der Verbleib und die Tätigkeit in der Organisation......232 


\subsubsection{Biographisch bedingte Handlungsmuster im Einsatz-} und Organisationsalltag.....................................................234

6.3 Das Passungsverhältnis von Biographie und Beruf ......................................235

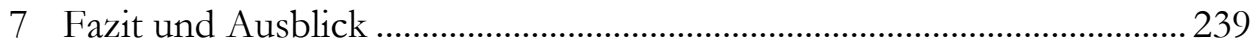

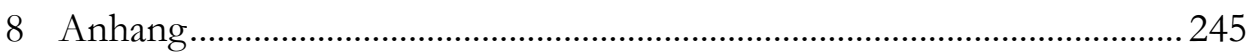

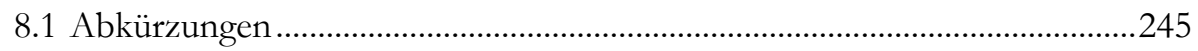

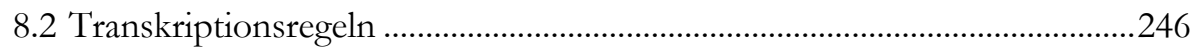

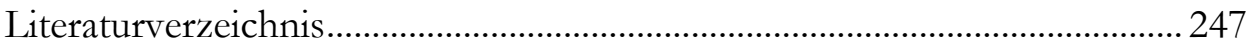




\section{Einleitung}

„Eine Karriere bei der Polizei Niedersachsen ist mebr als nur ein Beruf." (Polizeiakademie Niedersachsen o.J.a)

Mit dieser Aussage wirbt die Polizei Niedersachsen auf ihrer Internetpräsenz um Nachwuchs. Es wird suggeriert, dass Polizist*in zu sein nicht einfach ein Job ist, sondern darüber hinaus geht, vielleicht eher eine Berufung als einen Beruf darstellt. Dies bedeutet implizit auch, dass man seine Berufsrolle nicht einfach verlassen kann, sondern Polizist*in ,durch und durch ${ }^{{ }^{1}}$ ist oder wird. Will man eine Karriere bei der Polizei machen, muss man sich der Polizei ,hingeben'. Es ließen sich jetzt weitere Lesarten bilden - sie alle laufen aber darauf hinaus, dass der Beruf Polizist*in etwas Besonderes ist, verbesondert wird.

Nicht nur die Polizei selbst wirbt mit einem solchen Bild, es ist gesellschaftlich höchst anschlussfähig und steht in Wechselwirkung mit der verbreiteten Faszination für den Arbeitsbereich Polizei, wie er in der Masse und Vielfalt seiner kulturindustriellen Verarbeitung in Büchern, Serien und Filmen aufscheint. Dabei ist

${ }^{1}$ Einfache Anführungszeichen verwende ich, um eine Unterscheidung möglich zu machen. Ich nutze in der Arbeit im Fließtext immer wieder Zitate aus Interviews und aus ethnographischen Protokollen, die im Gegensatz zu Lektüre-Zitaten nicht mit Quellenangaben versehen sind. Damit keine Verwechslung zwischen zitierten Begriffen/Auszügen und Begriffen, die ich ironisch, distanziert oder umgangssprachlich verwenden möchte, aufkommt, nutze ich für letztere einfache Anführungszeichen. 
häufig nicht die Polizei selbst der Fokus, sondern vielmehr Kriminalfälle verschiedenster Art. Dennoch lassen sich in vielen dieser Formate Polizist*innen als Protagonist*innen finden; sie alle haben ihre Eigenarten und üben durch ihre unterschiedlichen Charaktere und Fähigkeiten ihren Beruf sehr unterschiedlich aus. Auch wenn diese, meist fiktiven Charaktere und ihre Ermittlungsarbeit oft wenig mit der Realität polizeilichen Vorgehens zu tun haben, so sind doch mindestens zwei Aspekte daran interessant: Zum einen wird bei den Rezipient*innen eine bestimmte Vorstellung von polizeilicher Arbeit erzeugt. Zum anderen kommt kaum eine dieser zentralen Figuren ohne persönliche Verwicklungen aus, die oft auf ihre Vergangenheit verweisen: Sie hüten ein Familiengeheimnis, sie haben irgendetwas Schlimmes erlitten oder getan etc. All das nimmt in den Büchern und Filmen Einfluss auf ihre Arbeit; ganz konkret, weil sie aktuell manifest davon beeinflusst werden, oder auch nur latent, weil sie etwas mit sich herumtragen, das den Lesenden oder Zuschauenden vielleicht viel bewusster ist als den Figuren. Den Zuschauenden wird dadurch vermittelt, dass die Ausübung dieses Berufs etwas ,Individuelles' ist - die Polizist*innen sind gerade oft erst aufgrund ihrer ,Persönlichkeit', infolge ihrer jeweils besondere Lebensgeschichte erfolgreiche Ermittler*innen. Die ,individuelle Persönlichkeit', die Marotten und Handlungsmuster der Kommissar*innen, so scheint es häufig, sind für die Polizeiarbeit viel relevanter als die organisational vorgegebenen Handlungsweisungen. Ohne die persönliche Note, ohne eine Form von persönlicher Tragik oder Involviertheit der Polizist*innen wären Krimis für das Publikum oft weit weniger interessant und damit auch weniger erfolgreich.

Auch wenn sich polizeiliche Arbeit etwas anders gestaltet als in vielen dieser Formate dargestellt, so sind sie hinsichtlich des zweiten Aspektes strukturell gar nicht so weit von der empirischen Wirklichkeit entfernt: Die Lebensgeschichten der Polizist*innen haben in der Tat Einfluss auf die Art, wie sie ihren Beruf ausüben. Auch die Polizei (Niedersachsen) selbst geht von einem Zusammenhang von Biographie und Berufsausübung aus. Bewerber*innen für den Polizeidienst bzw. das Polizeistudium sollen in einem strukturierten, bis zu einer Stunde dauernden Gespräch Fragen über ihr bisheriges Leben und ihre Motivation beantworten, sich in bestimmte Situationen hineinversetzen und erzählen, wie sie gehandelt haben oder handeln würden (vgl. Polizeiakademie Niedersachsen o. J.). Anhand dieses Interviews soll eine Eignung für den Polizeidienst festgestellt werden. Dieses Vorgehen impliziert die Annahme, dass „Fähigkeiten in Bereichen wie Kontaktverhalten, Berufsmotivation/Einstellung zum Beruf, Sozialverhalten, emotionale Stabilität oder auch Eigeninitiative“ (Polizeiakademie Niedersachsen o. J.) zusammenhängen und relevant für die Berufseignung und -ausübung sind.

Wenn auch dort deutlich strukturierter angelegt und mit anderen Zielen verbunden, so ist von der Grundvorstellung eine deutlich Parallele zu den Annahmen der sozialkonstruktivistischen Biographieforschung, die neben der phänomenolo- 
gisch begründeten Wissenssoziologie den theoretischen Rahmen ${ }^{2}$ dieser Arbeit bildet, festzustellen: Biographische Erfahrungen in der Vergangenheit und Zukunftsperspektiven beeinflussen das Handeln in der Gegenwart. Und: Situationserzählungen geben Auskunft über die Handlungsorientierungen von Personen. Ziel der vorliegenden Studie ist es allerdings nicht, die Eignung ${ }^{3}$ meiner Interviewpartner*innen für den Polizeidienst zu bewerten, sondern herauszuarbeiten, in welchem Passungsverhältnis Biographie und Beruf stehen. Diesem Passungsverhältnis nachzugehen, ist soziologisch auf verschiedenen Ebenen ertragreich: Es trägt bei zum Verstehen von Berufskarrieren, polizeilicher Arbeit und Alltagspraxis und liefert darüber hinaus generelle Erkenntnisse zu den Wechselwirkungen zwischen Organisationen und Biographien.

In einer Arbeit, die sich mit dem Zusammenhang von Biographie und Beruf beschäftigt, ist, so denke ich, eine eigene biographische Notiz erlaubt, ja geradezu angeraten, denn die Wahl meines Themas ist nicht zufällig: Auch für mich war es zwischenzeitlich ein Kindheitswunsch, Polizistin zu werden. Als Kind war ich beeindruckt von Ellen Wegener, der (soweit ich weiß) ersten Figur einer Schutzpolizistin im deutschen Fernsehen. Gespielt von Mareike Carrière ermittelte sie seit Mitte der 1980er Jahre im „Großstadtrevier“ (ARD). Zu dieser Zeit gab es noch (fast) keine Schutzpolizistinnen auf bundesdeutschen Straßen. Und zu Beginn meines Soziologie-Studiums dachte ich kurz darüber nach, es zugunsten eines Studiums bei der Polizei aufzugeben. Die Wahl meines Dissertationsthemas ist damit sicher auch biographisch motiviert.

\title{
1.1 Konkretisierung des Forschungsthemas und Forschungsverlauf
}

\author{
„Ja also zuerst mal bin ich zur Polizei gekommen unter \\ der Voraussetzung, dass es eigentlich schon immer mein Traumberuf war " \\ (Tobias Müller, 24, Polizeikommissar in der Bereitschaftspolizei)
}

So begann ein Interviewpartner, den ich 2011 für meine Masterarbeit interviewt habe, die Präsentation seiner Berufsbiographie. Die Berufswahl wurde in allen diesen Interviews, sofern überhaupt thematisiert, entweder als recht pragmatische Entscheidung gerahmt - ,ich wollte verbeamtet werden“ - oder, wie oben, als Verwirklichung von Kindheitsträumen mit Bedeutung aufgeladen. Aufgrund des Zuschnittes meiner Masterarbeit, die auf die Berufsbiographie und Alltagspraxis

2 Ausführlich zu den theoretischen Konzepten siehe Kapitel 3.

${ }^{3}$ Mir Feldzugang zu gestatten war auf polizeilicher Seite durchaus mit dem Wunsch verbunden, dass meine Ergebnisse hilfreich für die Einstellungs- und Beförderungspraxis sein könnten. Dieser Gedanke wurde nicht nur im Personaldezernat, dass mich unterstützt hat, geäußert, sondern es ist auch ein polizeilicher Vertreter des Innenministeriums eines anderen Bundeslandes an mich herangetreten, der einen Konferenzbericht einer Tagung gelesen hatte, auf der ich mein Vorhaben vorgestellt hatte. 
von Polizist*innen der Bereitschaftspolizei fokussierte, konnte ich der Frage nach der Berufswahl im Zusammenhang der lebensgeschichtlichen Erfahrungen nicht nachgehen. So fand ich zwar Antworten auf die Frage, wie die Polizisten ${ }^{4}$ innerhalb der hierarchisch strukturierten Bereitschaftspolizei Einsätze erleben und mit ihrem jeweiligen Gegenüber interagieren, aber ich konnte nicht erklären, wie es dazu kommt, dass sie es so tun, wie sie es tun, und wie dabei Unterschiede zustande kommen. Es deutete sich aber an, dass ihr Berufsverständnis und ihr berufliches Handeln als Polizisten maßgeblich von ihren lebensgeschichtlichen Erfahrungen und ihrer Position in der Polizei mitbestimmt waren. Die Frage, wie sich ihre unterschiedlichen polizeilichen Handlungsmuster ausgebildet haben, blieb demgegenüber eine Leerstelle.

Ausgehend von dem Interesse daran, wie es dazu kommt, dass jemand diesen Beruf ergreift, schloss sich also die Frage an, wie sich in einer recht strukturierten Ausbildung und innerhalb einer hierarchisch strukturierten Organisation verschiedene Handlungs- und Interaktionsmuster entwickeln können bzw. wie diese aufrechterhalten werden können. Diesem Interesse an dem Zusammenhang von biographischen Erfahrungen, Berufswahl und polizeilichem Handeln gehe ich in dieser Arbeit empirisch fundiert nach.

Auf der Grundlage des interpretativen Paradigmas bzw. der theoretischen Einlassungen von Vertreter*innen, die diesem Paradigma zugeordnet werden können, ist die Annahme, dass polizeiliches Handeln nicht allein auf der Ausbildung beruhen kann, basal. Vielmehr sind es die kollektiven Wissensbestände einer Gesellschaft und ihrer Teilbereiche (wie der Organisation Polizei), die spezifischen Erfahrungen der Handelnden und die Besonderheiten der konkreten Handlungssituation, die unser Handeln bestimmen - so ließe es sich im Anschluss an Peter L. Berger und Thomas Luckmann (1969/2012) formulieren. ${ }^{5}$ Aus dieser Perspektive betrachtet lässt sich feststellen, dass sich (in der Ausbildung) zwar kollektiv geteilte (polizeiliche) Handlungsmuster entwickeln, aber auch, dass diese Handlungsmuster in Zusammenhang mit unseren biographischen Erfahrungen stehen. Auch wenn es eine Grundannahme ist, dass polizeiliches Handeln biographisch und situativ bedingt ist, so muss doch eine empirische Antwort darauf gefunden werden, wie sich dies in der speziellen Organisation Polizei mit ihren spezifischen Strukturen konkret verwirklicht. Daraus ergeben sich verschiedene Fragenkomplexe, die ich mit meiner Forschung beantworten möchte:

- Wer tritt in diese Organisation ein? Oder anders formuliert: Welcher biographische Verlauf führt dazu, dass man Polizist*in wird?

\footnotetext{
${ }^{4}$ Wie an dieser Stelle - ich habe damals nur männliche Polizisten interviewt - nutze ich das Maskulinum oder Femininum nur dann, wenn ich ausschließlich Männer oder Frauen meine, und verwende ansonsten die verschiedene Geschlechtsidentitäten inkludierende Schreibweise „Polizist*innen“. ${ }^{5}$ Diese greife ich hier heraus, weil diese Arbeit im Anschluss an sie und Alfred Schütz sozialkonstruktivistisch und interaktionistisch gerahmt ist. In ganz ähnlicher Weise ließen sich aber Schütz selbst oder z.B. auch Erving Goffmann zitieren.
} 
- Wie ,wird‘ man Polizist*in? Wie verläuft die Sozialisation in die Polizei vor dem Hintergrund der biographischen Erfahrungen?

- Wie ,ist ${ }^{\star}$ man Polizist*in? Wie handelt man als Polizist*in vor dem Hintergrund der biographischen Erfahrungen?

Zur Beantwortung dieser Fragen habe ich verschiedene Blickrichtungen gewählt, um sowohl die situierte polizeiliche Handlungspraxis als auch die Biographie der Polizist*innen einzubeziehen - auf Grundlage dieser Perspektiven lassen sich dann auch die kollektiv geteilten Wissensbestände rekonstruieren. So geben die Biographie und das Handeln einzelner Polizist*innen nicht nur Auskunft über ihr individuelles Handeln und Erleben, sondern, im Hinblick auf eine Konzeption von Individuum und Gesellschaft als sich wechselseitig konstituierend, immer auch über gesellschaftliche Wissensbestände.

Aus einer solchen Perspektive folgt ein methodisches Vorgehen, das einerseits eine prozesshafte Perspektive auf das Polizist*in-Werden und das Polizist*in-Sein einnimmt. Solche Prozesse des Werdens, Seins und auch Veränderns von sozialen Phänomenen lassen sich mithilfe der soziologischen Biographieforschung untersuchen. Andererseits ist ein ethnographisches (hier: teilnehmend-beobachtendes) Vorgehen, das die situierte Handlungspraxis in den Blick nimmt, hilfreich. Auch wenn ich mich zu Beginn meiner Forschung schon für die Praxis polizeilicher Arbeit interessierte, war ich, gemäß dem Prinzip der Offenheit, noch nicht festgelegt, in welche konkrete Richtung mich meine Feldforschung führen würde. Erst im Verlauf der Analyse und weiteren Forschungstätigkeit ergab sich die Konkretisierung meines Gegenstandes. Ich habe immer wieder zwischen der Analyse des ethnographischen und des biographischen Materials gewechselt, nicht nur weil dies im Prozess der Analyse jeweils fruchtbar war, sondern auch weil sich bei mir hier und da gewisse Ratlosigkeit und auch Zweifel einstellten, wie die verschiedenen Daten aufeinander bezogen werden könnten. Wie gut sie harmonierten, zeigte sich erst durch die Konkretisierung der Forschungsfragen:

- Welche Strukturen, Handlungs- und Deutungsmuster polizeilicher Arbeit lassen sich rekonstruieren und welche Interaktions- und Handlungsmöglichkeiten eröffnen und verschließen diese Strukturen polizeilicher Arbeit?

- Welche Handlungsmuster haben die interviewten Polizist*innen biographisch ausgebildet?

- Inwiefern sind die Strukturen der Polizei und die Interaktionsbedingungen polizeilicher Arbeit und die biographisch etablierten Handlungsmuster passfähig?

Neben diesen können weiterhin Fragen zu den Strukturen polizeilicher Arbeit insgesamt und zu polizeilichen Sozialisationsprozessen beantwortet werden.

Es sei vorweggenommen, dass die Polizist*innen in den im Folgenden dargestellten Fällen mit ihrer Berufswahl und der je konkreten Tätigkeit und hierarchischen Position innerhalb der Polizei biographische Erfahrungen bearbeiten. Wie ich in den Falldarstellungen zeigen werde, bietet die Polizei ihnen jeweils die Mög- 
lichkeit, sich in biographisch bedeutsame Situationskonstellationen zu begeben und ihre Handlungsmuster zur Bewältigung dieser Situationen sowohl zu nutzen und aufrechtzuerhalten als auch zu modifizieren.

\subsection{Verortung der Arbeit}

Verortung im Feld der Soziologie. Mit ihrem Forschungsinteresse liegt diese Arbeit in gewisser Weise quer zu diversen anderen Arbeiten: Sie fokussiert weder allein die polizeilichen Binnen- noch die polizeilichen Außenverhältnisse - so eine öfter anzutreffende Unterscheidung im Kontext von (soziologischer) Polizeiforschung -, sondern durch den Blick auf die Biographien der in der Organisation Handelnden werden die Polizist*innen in ihren jeweiligen Figurationen zum Forschungsgegenstand. Der Fokus auf die interdependenten Verflechtungen, in denen Polizist*innen sich befinden, eröffnet den Blick auf die Interaktionsbeziehungen innerhalb der Polizei und unter den Polizist*innen sowie auf die Interaktionsbeziehungen mit den nicht-polizeilichen Anderen ${ }^{6}$, ob in Gestalt von bspw. ,Bürger*innen' oder auch Familienmitgliedern.

Meine Forschung liegt weiterhin quer $\mathrm{zu}$ sogenannten BindestrichSoziologien. Sie kann aus der Perspektive der Polizei-Soziologie, der Organisations-Soziologie oder der Berufs-Soziologie gelesen werden. Sie ist aber keinem dieser Felder allein zuzuordnen, sondern kann in allen diesen Feldern einen Beitrag leisten. Im Bereich der Polizeiforschung eröffnet die Kombination eines wissenssoziologischen und eines biographietheoretischen Ansatzes sowohl theoretisch als auch methodisch eine neue Perspektive. Im Gegensatz zu sozialkonstruktivistisch/wissenssoziologisch ausgerichteten Forschungsbeiträgen existieren meines Wissens keine (im hier verstandenen Sinne) biographietheoretischen Arbeiten zur Polizei.

Auch wenn und gerade weil ein ethnographisches Vorgehen Annäherung und Einlassen auf das Feld und die Teilnehmer*innenperspektiven bedeutet, vielleicht sogar eine zeitweise Übernahme dieser, braucht es ständige (analytische) Distanzierungsbewegungen. (Manche) Polizist*innen werden die Perspektiven, die ich hier auf ihr Handeln eröffne, nicht (alle) teilen - dies war und ist nicht der Anspruch der vorliegenden Arbeit. Ziel war nicht, eine nachempfindende, sehr wohl aber eine verstehende Perspektive auf polizeiliches Handeln einzunehmen. Dabei werden die Perspektiven und Erfahrungen der Polizist*innen selbst rekonstruiert und in den organisationalen und gesellschaftlichen Kontext eingebettet. Von (m)einem wissenssoziologischen Standpunkt aus müssen Organisationen aus der

\footnotetext{
${ }^{6}$ In der Arbeit werde ich in der Regel den Begriff der nicht-polizeilichen Anderen für die Interaktionspartner*innen der Polizist*innen nutzen. Auch Polizist*innen sind Bürger*innen, ich halte die Gegenüberstellung deswegen für problematisch. Andererseits ist der Begriff ,Bürger ${ }^{\circ}$ in der Polizei auch mit einem bestimmten Deutungsmuster/Sie-Bild verbunden ebenso wie der Begriff des polizeilichen Gegenübers (vgl. Kap. 4.1).
} 
Perspektive der Organisationsmitglieder und auf Grundlage ihres Handelns untersucht werden. Ich verstehe Organisationen als soziale Konstruktionen.7 Organisationen sind das Ergebnis von Institutionalisierungsprozessen, bei denen die Bearbeitung von immer wiederkehrenden gesellschaftlichen Problemen gebündelt wird. Organisationen bestehen in diesem Verständnis aus dem Handeln ihrer Mitglieder und sie stehen in Wechselwirkung mit ihrer Umwelt und den gesellschaftlichen Bedingungen und Anforderungen. ${ }^{8}$ Den Perspektiven der Polizist*innen muss also unbedingt Rechnung getragen werden.

Verortung im Feld der Polizei. Bisher habe ich allgemein von ,der ${ }^{\star}$ Polizei gesprochen. Hier müssen nun einige Einschränkungen bzw. Konkretisierungen vorgenommen werden. Ich habe in dieser Arbeit den Bereich der Schutzpolizei untersucht. Die Schutzpolizei, die uniformiert Streife fährt, ist in unserem Alltag der wohl präsenteste Teil der Polizei. Davon unterschieden werden muss der Bereich der Kriminal- und Bereitschaftspolizei. Während die Schutzpolizei allgemeinen Streifendienst versieht - das heißt: präventiv und restriktiv arbeitet - und im Rahmen des ,Erstzugriffs' tätig wird, ist die Kriminalpolizei mit (der darauffolgenden) Ermittlungsarbeit befasst. Die Bereitschaftspolizei wiederum kommt vor allem zur Bewältigung sogenannter Großlagen wie Demonstrationen oder Fußballspielen zum Einsatz. Da in Deutschland auch die Polizei föderal organisiert ist, lassen sich schon in der Bezeichnung dieser polizeilichen Arbeitsbereiche kleine Unterschiede feststellen. So spricht die Polizei Niedersachsen nicht mehr von der Schutzpolizei, sondern vom Einsatz- und Streifendienst, kurz: ESD. Der Begriff der Schutzpolizei verweist hier auf die Vergangenheit (vgl. Kap. 2.2). In anderen Bundesländern ist der Begriff allerdings noch durchaus geläufig. Und auch in Niedersachsen lässt sich von Polizist*innen noch die Unterscheidung von „S“ und „K“ hören - von Schutz- und Kriminalpolizei. Da ich in den empirischen Untersuchungen ausschließlich Interviews mit Beamt*innen des niedersächsischen ESD vorstelle, werde ich überwiegend den in Niedersachsen gängigen und offiziellen Begriff des Einsatz- und Streifendienstes verwenden. Wenn ich von polizeilicher Arbeit spreche, meine ich die Arbeit des Einsatz- und Streifendienstes; bezieht er sich auf andere polizeiliche Arbeitsbereiche, mache ich dies ausdrücklich deutlich. Wenn ich aber hin und wieder auch den Begriff der Schutzpolizei verwende, dann weil die Ergebnisse dieser Arbeit nicht auf die Niedersächsische Polizei beschränkt sind. Auch wenn andere Bundesländer (geringfügig) andere Organisationsstrukturen aufweisen, sind meine Ergebnisse übertragbar.

\footnotetext{
${ }^{7}$ Für eine sozialkonstruktivistische und prozesshafte Perspektive auf Organisationen siehe Froschauer (2006, 2012).

${ }^{8}$ Dies bedeutet, dass Organisationen sich nicht lediglich reproduzieren, sondern sich auch stets im Wandel befinden.
} 


\subsection{Aufbau der Arbeit}

Die Arbeit beginnt mit einer Einführung in die Organisation Polizei (Kapitel 2), die ich aus drei Blickwinkeln betrachte. Zunächst eröffne ich eine theoretische Perspektive, in der ich die Polizei als Institution mit Gewaltlizenz vorstelle. Ich halte es für relevant, die Polizei als eine solche Organisation zu rahmen, um bei dem späteren Fokus auf die Interaktionsebene nicht aus dem Blick zu verlieren, dass die Polizei mit Machtmitteln ausgestattet ist und Polizist*innen aus einer asymmetrisch angelegten Machtposition mit ihrem Gegenüber interagieren. Hier nehme ich auch eine erste Perspektivierung vor, die Macht und Gewalt als Handeln konzipiert. Bis dahin thematisiere ich Polizei als allgemeine Institution. Die zweite Perspektive, unter der ich die Polizei vorstelle, ist ihre historisch konkrete Ausprägung in Deutschland. Hier zeichne ich die Zusammenhänge der gesellschaftlichen und institutionellen Entwicklungen nach und fasse die bis heute wirkmächtigen Prozesse zusammen. Eine dritte Perspektive ist dann auf die spezifischen Organisationsstrukturen der niedersächsischen Polizei gerichtet. Diese sind zum Verständnis der empirischen Kapitel hilfreich, da sie die konkreten Organisationsbedingungen zeigen, unter denen Polizist*innen ausgebildet werden und arbeiten.

In Kapitel 3 richte ich den Blick auf die Polizeiforschung und verdeutliche, wie sich die hier vorliegende Arbeit darin einordnet und welche theoretische und methodische Perspektive ich einnehme. Nach einer Skizzierung, vornehmlich der bundesdeutschen Polizeiforschung und des Forschungstandes, werde ich, nach der theoretischen Verortung in Bezug auf Macht und Gewalt im Kontext von Polizei in Kapitel 2, eine sozialtheoretische Verortung dieser Arbeit vornehmen und die hier vertretenen sozialkonstruktivistisch-wissenssoziologischen Grundannahmen und die Biographieforschung einführen. Auf dieser Grundlage stelle ich sodann die verwendeten Methoden vor und reflektiere den Forschungsprozess.

In Kapitel 4 und 5 folgen die empirischen Untersuchungen. Kapitel 4 widmet sich zunächst der Ebene des Handlungs- und Interaktionskontextes der polizeilichen Arbeit des Einsatz- und Streifendienstes. Hier werde ich zunächst die Wirund Sie-Bilder in der Polizei vorstellen. Sie zeigen die Konstruktion der Eigenund der Fremdgruppe(n) - die Bilder der Polizist*innen über die Polizei und über ihre nicht-polizeilichen Anderen - und ihre interaktive Relevanz in machtasymmetrischen Interaktionsbeziehungen. Wie Deutungsprozesse - auch die Zuschreibungen an Personen - im polizeilichen Arbeitsprozess verlaufen, stelle ich im Anschluss dar. Neben den allgemeinen Deutungsprozessen wird hier ersichtlich, dass Polizist*innen Situationen aus einer machtstärkeren Interaktionsposition als ihre Interaktionspartner*innen definieren können. Nach diesen beiden Unterkapiteln, die den Fokus vor allem auf Typisierungen und Deutungsprozesse legen, zeigt das darauffolgende Unterkapitel Strukturen und Ambivalenzen polizeilicher Arbeit auf. Hier stelle ich sowohl Handlungs- und Deutungsmuster des alltäglichen Arbeitsprozesses des Einsatz- und Streifendienstes vor als auch Bedingungen, unter denen die Polizist*innen ihre Arbeit verrichten. 
Nach dieser ethnographischen Rekonstruktion des Handlungs- und Interaktionskontextes diskutiere ich in Kapitel 5 die biographischen Fallrekonstruktionen zweier Polizist*innen. Beide hier vorgestellten Fälle repräsentieren einen Typus, bei dem die Berufswahl und -ausübung eine Form biographischer Arbeit ist. Beide Fälle bearbeiten mit ihrer Berufswahl Erfahrungen ihrer Kindheit und Jugend. In dem ersten Fall zeige ich, dass die Berufswahl Unsicherheiten und Loyalitätskonflikte innerhalb der Familie bearbeitet. Hier repräsentiert die Polizei eine Organisation, die Sicherheit und Struktur bietet. In dem zweiten dargestellten Fall ermöglicht die Berufswahl eine Bearbeitung von und Ermächtigung über AußenseiterErfahrungen. Hier repräsentiert die Polizei eine Organisation, die Autorität vermittelt.

Die Ergebnisse aus Kapitel 4 und 5 werde ich in Kapitel 6 zunächst zusammenfassen und theoretisch verdichten, um so im Verlauf des Kapitels die Ebenen von Handeln, Interaktion und Biographie systematischer zusammenzufühen. Am Ende der Arbeit ziehe ich ein Fazit zum Passungsverhältnis von Biographie und Beruf. Die Arbeit schließt mit einer Diskussion und einem Ausblick (Kapitel 7). 



\section{Die Organisation Polizei}

Eine Beschäftigung mit dem Zusammenhang von Beruf und Biographie bzw. von beruflichem Handeln und lebensgeschichtlichen Erfahrungen im Feld Polizei erfordert auch einen Blick auf die Organisation Polizei. In ihr bzw. unter ihren Bedingungen handeln Polizist*innen. ,Wer' ist also die Organisation Polizei? Der Kontext, in dem die Polizist*innen arbeiten und handeln und ihn damit auch (re-)produzieren, soll im Folgenden umrissen werden.

$\mathrm{Zu}$ den politisch-gesellschaftlich immer wieder verhandelten Themen gehört, nicht nur aktuell oder in der jüngsten Geschichte, der Einsatz von Gewalt zur Durchsetzung polizeilicher (politisch/juristisch angeordneter) Maßnahmen. Die Polizei ist dabei als Repräsentantin des staatlichen Gewaltmonopols unweigerlich mit ,Gewalt ${ }^{\natural}$ verbunden. Neben den historischen Entwicklungen möchte ich deshalb in diesem Kapitel auch einen theoretischen Blick auf die Polizei als Vertreterin des Gewaltmonopols werfen: Denn Polizist*innen üben in ihrem Arbeitsalltag Gewalt aus und erleiden sie auch. Daher halte ich es für notwendig, Gewalt als Teil ihres Handlungsrepertoires und Arbeitsalltags zu erkennen. Daher werde ich hier auch eine notwendige theoretische Perspektivierung von Macht und Gewalt als Handeln vornehmen (2.1).

Ich möchte mich hier nicht auf die aktuellen Organisationsstrukturen der Polizei beschränken, sondern, so wie ich einen Blick auf die Lebensgeschichten von 
Polizist*innen werfe, auch die Geschichte der Organisation betrachten. Damit soll eine prozesshafte Perspektive auf die Polizei als Organisation, die immer auch mit gesellschaftlich-politischen Entwicklungen verwoben ist, eröffnet werden (2.2). In der Annahme, dass vergangene Ereignisse, als Erfahrungswissen sedimentiert, Eingang in die polizeiliche Praxis finden, werde ich die Organisationsgeschichte nachzeichnen und ihre Brüche und Kontinuitäten aufzeigen. Polizeiliches Handeln wird so nicht nur mit den aktuellen Organisationsstrukturen und Handlungsbedingungen verknüpft, sondern auch eingebettet in historisch-organisationale, gesellschaftliche Entwicklungen.

Als letztes wende ich den Blick den gegenwärtigen konkreten Organisationsstrukturen zu (2.3), unter denen die hier dargestellten Fälle arbeiten und auch meine Forschungstätigkeit stattgefunden hat.

Ziel des Kapitels ist es also, die strukturellen Aspekte des Handlungsfeldes erstens theoretisch, zweitens konkret historisch und drittens regionalorganisatorisch zu umreißen.

\subsection{Theoretische Perspektivierung I: Polizei, Macht und Gewalt}

Im Fokus meiner Arbeit steht der Zusammenhang von Biographie, Handeln und Interaktion in einem konkreten Feld. Dieses konkrete Feld - die Polizei - ist nicht untersuchbar, ohne sich auch mit Fragen von Gewalt und Macht auseinanderzusetzen. So konstatiert Jean-Paul Brodeur mit Blick auf die internationale wissenschaftliche Literatur zur Funktion der Polizei zusammenfassend: „Der Einsatz von Gewalt wird also als Kern der Polizeiarbeit angesehen" (Brodeur 2002: 259). Eine soziologische Untersuchung innerhalb des Gewaltmonopols unter Ausblendung von Gewaltaspekten, und ich ergänze hier: Machtaspekten, kann nicht hinreichend sein.

Auch in der Analyse von biographischen und interaktiven Prozessen müssen die dort jeweils wirksamen Machtdynamiken einbezogen bzw. rekonstruiert werden. Inwiefern Machtungleichheiten und -dynamiken theoretischen Eingang gefunden haben in die hier vertretene Biographieforschung, werde ich in Kapitel 3.2 vorstellen. An dieser Stelle möchte ich zunächst meinen Zugang zu Macht- und Gewaltphänomen vorstellen, um dem Fokus meiner Arbeit auf Biographien und Interaktionen in dem konkreten Feld Polizei Rechnung zu tragen.

Bevor ich eine theoretische Perspektive auf Macht und Gewalt entfalte (2.1.2), werde ich die Polizei als Repräsentantin des staatlichen Gewaltmonopols vorstellen (2.1.1). 


\subsubsection{Die Delegation des Gewaltmonopols}

Die Polizei ist eine Organisation mit „Gewaltlizenz“ (Reemtsma 2003). Ein konstitutives Merkmal der Polizeien gegenüber anderen (staatlichen) Institutionen ist die Ausübung des staatlichen Gewaltmonopols im Inneren mittels Zwangsmaßnahmen, die von „unmittelbarem Zwang" bis zur gezielten Tötung eines Menschen durch einen „finalen Rettungsschuss" reichen (vgl. Groß 2019: 4; \$S 64-79 Niedersächsisches Polizeiordnungsgesetz). ${ }^{9}$ Die Polizei ist somit in gewisser Weise eine besondere (staatliche) Organisation. Sie ist zugleich aber eine weniger besondere, da sie als zutiefst bürokratische Organisation Teil eines legitimen, legalbürokratischen Herrschaftsapparates, wie Max Weber ihn idealtypisch entworfen hat, ist (vgl. Weber 1921/2008: 157-166). Polizeiarbeit steht in einem Spannungsverhältnis von Gewalthandeln und bürokratischem Verwaltungshandeln. Das bedeutet mitnichten, das Verwaltungshandeln prinzipiell weniger , machtvoll' wäre als Gewalthandeln. ${ }^{10}$ Wie Gewalt und Verwaltung zueinander stehen, ist historisch wandelbar und Teil politischer und gesellschaftlicher Aushandlungsprozesse (vgl. Kap. 2.2). Die konkreten historischen Ausprägungen in Deutschland werde ich im folgenden Kapitel verfolgen. An dieser Stelle geht es mir zunächst um die Polizei als Institution mit Gewaltlizenz: Eine „Institution, die es als solche in Demokratien und Diktaturen, in offenen und totalitären Gesellschaften gibt, die an einem Ort der Erde ein Maximum an Zivilität, an einem anderen ein Maximum an Brutalität an den Tag legt" (Reemtsma 2003: 8, Hervorhebungen im Original). Polizeien kann es überall dort geben, wo ein Staat oder Herrschaftsgebilde seine Gewalt delegiert.

In welchem (konstitutiven) Verhältnis Politik, Gewalt bzw. Gewalteinhegung und Gewaltrechtfertigung sowie Staat oder vergesellschaftete Gruppen zueinander stehen, hat politische Theoretiker*innen in verschiedenen historischen Phasen beschäftigt. ${ }^{11}$ Gewalt, Staat und Legitimität(sfragen) sind bei diesen Überlegungen oft auf Engste verknüpft worden. Im Bereich der Soziologie sind es u.a. Max Weber und Norbert Elias, die diese Fragen aufgegriffen haben. Max Weber hat Gewalt als ein konstitutives Merkmal von Staatlichkeit erkannt: „Staat soll ein politischer Anstaltsbetrieb heißen, wenn und insoweit sein Verwaltungsstab erfolgreich das Monopol legitimen physischen Zwanges für die Durchführung der Ordnungen in Anspruch nimmt" (Weber 1921/2008: 39, Hervorhebungen im Original). Drei

\footnotetext{
9 Zwang als ,unmittelbarer Zwang“ ist in diesem Verständnis kein Drohen oder Warnen, wie Koloma Beck und Schlichte den Begriff des Zwanges soziologisch von Gewalt abgrenzen (vgl. Koloma Beck/Schlichte 2014: 40 f.). Das Gesetz versteht unmittelbaren Zwang als „Einwirkungen auf Personen oder Sachen durch körperliche Gewalt“ und „Körperliche Gewalt [als] jede unmittelbare körperliche Einwirkung auf Personen oder Sachen" (\$ 69 Absatz 1 und 2 NPOG). Auch wenn in dieser Definition kein Verletzungsaspekt enthalten ist, kann Zwang hier als eine Verklausulierung von Gewalt verstanden werden.

${ }^{10}$ Vgl. dazu auch Kap. 2.1.2 zu den Machtformen nach Popitz.

${ }^{11}$ Zur Einführung im Zusammenhang mit Gewalt siehe Koloma Beck und Schlichte (2014) und zur allgemeinen Einführung z.B. Reese-Schäfer (2007).
} 
Aspekte möchte ich im Rahmen dieser Arbeit in Bezug auf Webers Definition bzw. seine Herrschafts- und Staatssoziologie allgemein hervorheben:

1. Deutlich wird, dass die (relativ) privilegierte bis monopolistische Kontrolle von Gewaltmittel - hier in Form eines Staates, aber auch bei anderen Herrschaftsgebilden - als konstitutives Merkmal von Herrschaft betrachtet wird. Es braucht bei modernen Staaten des „,bürokratischen“ oder „legalen“ Typus einen Verwaltungsstab, der das Gewaltmonopol durchsetzen kann. Die Ausübung legitimer Gewalt wird delegiert an einen Verwaltungsstab. Polizei ist hier Teil einer solchen Verwaltung, an die dies delegiert wird. Sie ist Teil eines Herrschaftsapparates, der seine Legitimität aus „dem Glauben an die Legalität gesatzter Ordnungen“ (Weber 1921/2008: 159) erhält. ${ }^{12}$

2. Koloma Beck und Schlichte (2014: 112 ff.) betonen weiterhin die Bedeutung von Webers Definition, wenn sie darauf hinweisen, dass das Gewaltmonopol prozesshaft konzipiert ist: Das Gewaltmonopol muss ständig produziert und reproduziert werden, damit der Staat es weiterhin erfolgreich beanspruchen kann. Die Polizei ist als Repräsentantin des Gewaltmonopols Akteurin in diesem (Re-)Produktionsprozess.

3. Trotha (1997: 12) macht darauf aufmerksam, dass Weber immer wieder darauf hinweist, dass Gewalt im Prozess von Herrschaftsbildung und sicherung kein irrationales Machtmittel ist, sondern ein zweckrationales. Auch im Rahmen polizeilicher Arbeit ist Gewalt nicht eine irrationale Ausnahme, sondern muss wie andere Machtdemonstrationen auch als Machtmittel betrachtet werden. Im Rahmen der Diskussionen um ,Polizeigewalt ${ }^{`}$ halte ich es für wichtig, Gewalt als solches Machtmittel zu verstehen und nicht vorschnell und allein unter einer normativen Perspektive als ,polizeiliche Gewalt' zu labeln - womit meistens ein ,Zuviel' an Gewalt gemeint ist und/oder unterstellt wird, dass es nicht legitimierte, willkürliche Gewalt sei. Zwar kann ein solches Label aus der Perspektive, dass die Legitimität des Monopols auf physischen Zwang und seine konkrete Durchsetzung gesellschaftlich kritisierbar sein muss, richtig und wichtig sein, allerdings ist eine solche Kategorisierung auf empirische Analysen angewiesen.

Auch Norbert Elias (1939/1997a; 1939/1997b) hat sich mit diesen Fragen beschäftigt und sich prominent mit den Prozessen von Staatsbildung beschäftigt: Er hat die Bedeutung von Gewalt und (Fremd- und Selbst-)Zwang in Prozessen sozialer Ordnungsbildung diskutiert und die Entstehung und Funktion von Gewaltmonopolen in diesen Prozessen herausgearbeitet. Gewaltmonopole haben für die „Besitzer“ des Gewaltmonopols eine Kontrollfunktion und für die Staatsgesell-

12 Mit dem Legitimitätsaspekt von Herrschaft möchte ich mich hier nicht weiter befassen. Es sei aber darauf verwiesen, dass „Legitimität“ nicht Teil der Weber'schen Grundbegriffe ist, nicht so klar zu definieren ist und verschiedene Dimensionen aufweist. Siehe dazu Müller (2007: 126 ff.). 
schaften u.a. eine innerstaatliche Pazifizierungsfunktion - welche Funktion den Vorrang hat, hängt wiederum mit den jeweiligen (dynamischen) Machtbalancen in einem Staat zusammen (vgl. Elias 1981: 100f.). Wie auch bei Weber ist das Gewaltmonopol bzw. die mit den Machtbalancen zusammenhängende Funktion des Gewaltmonopols prozesshaft und also als labil konzipiert.

Etwas konkreter in Bezug auf die Polizei hat sich Jan Philipp Reemtsma (2003, 2008: 168-175) mit Organisationen mit Gewaltlizenz als einem zivilisatorischen Grundproblem beschäftigt. Er versteht das Gewaltmonopol als regulative Idee (vgl. Reemtsma 2003: 9 ff.). Von diesem könne man sprechen, wenn sich eine Gesellschaft darauf verständigt habe, dass dieses Monopol beim Staat liegt und wenn es weitgehend durchgesetzt ist - unabhängig davon, wie genau es historisch jeweils aufgefasst und durchgesetzt wurde. Er weist darauf hin, dass es dabei unerheblich ist, wie - mit wieviel Gewalt - das Gewaltmonopol durchgesetzt wird, solange es als legitim anerkannt wird. Wenn Gewalt monopolisiert wird, wird die Gewaltausübung von Bürger*innen delegitimiert. Es gehe dann aber nicht darum, dass das Gewaltmonopol Gewaltlosigkeit herstelle, sondern darum, Gewalt zu kontrollieren. Private Gewaltausübung kann in Grenzen durchaus erlaubt sein. Das Gewaltmonopol kontrolliert aber seine Ausdehnung und sanktioniert sie gegebenenfalls - damit setzt es das eigene Monopol um (vgl. Reemtsma 2003: 11, 2008: 169). ${ }^{13}$ Dafür braucht es Einrichtungen wie die Polizei, die die Ausdehnung überwachen und eingreifen können. Die Polizei als eine solche Organisation erhält eine Gewaltlizenz. Reemtsma konstatiert nun ein Problem: „Staatsmonopolisierte Gewalt bedeutet also Delegation von Gewalt an eine Organisation, die weniger kontrolliert ist als der Rest der Gesellschaft" (Reemtsma 2003: 11, Hervorhebungen im Original), weil ihr eben keine weitere Organisation vorgesetzt ist, die diese Gewalt kontrollieren und dabei wiederum mit Gewalt einhegen könnte. Dies setzt ein Vertrauensverhältnis voraus und markiert, so Reemtsma, ein zivilisatorisches Grundproblem (vgl. ebd.: 11 f.): Die Organisationen mit Gewaltlizenz müssen durch das Gewaltmonopol kontrolliert werden, wenn das Monopol seine Macht nicht durch die Delegation dieser verlieren möchte. Sie können aber nur kontrolliert werden, wenn sie es auch zulassen. Dafür ist Vertrauen notwendig. Das Gewaltmonopol muss der Organisation mit Gewaltlizenz vertrauen: Eine Regierung muss dem Militär vertrauen, dass es nicht putscht (vgl. ebd.: 12 ff.), sie muss der Polizei vertrauen, dass diese bzw. Personen in der Polizei nicht selbst kriminelle oder staatsgefährdende Gruppen gründen bzw. dass diese dann auch durch die Polizei selbst verfolgt werden. Auch auf der Ebene der Interaktion zwischen Polizist*innen und Bürger*innen ist dies insofern relevant, als Bürger*innen prinzipiell darauf vertrauen müssen, dass Polizist*innen regelkonform handeln. Dass dies alltagspraktisch nicht immer der Fall ist, zeigt sich in der Empirie deutlich. Das Gewaltmonopol und die Polizei als dessen Vertreterin werden als Institution und/oder in

13 Auch Weber weist darauf hin, „daß es ,legitime‘ Gewaltsamkeit heute nur noch insoweit gibt, als die staatliche Ordnung sie zuläßt oder vorschreibt“" (Weber 1921/2008: 40). 
der Legitimität ihrer Handlungen immer wieder infrage gestellt. So können Klagen gegen Polizist*innen wegen Amtsdelikten als eine Infragestellungen der Legitimität des Handelns verstanden werden. Aber auch jede Nachfrage („Dürfen Sie das überhaupt?") bei Verkehrskontrollen etc. stellt das Handeln infrage. Dies bedeutet aber nicht, dass ein prinzipieller Vertrauensverlust gegenüber der Polizei als Institution vorliegt.

Gesetze und Vorschriften - in gewisser Weise auch als Teil eines Delegationsvertrages - geben Handlungsanweisungen für polizeiliche Arbeit. Liegt ein eindeutiger Fall vor, bei dem polizeiliches Einschreiten notwendig wird, so ist es leicht, ihn unter eine bestimmte Regel zu subsumieren und entsprechend $\mathrm{zu}$ handeln. Weitaus häufiger sind aber - aus meiner empirisch-wissenssoziologischen Perspektive - Fälle, in denen es Deutungsspielräume gibt, Fälle, die interpretationsbedürftig sind (vgl. Kap. 4.2). Hier ist in gewissem Maße Kreativität gefragt. Kreativität im Umgang mit Vorschriften kann aber immer auch Willkür sein. Dies ist laut Reemtsma ein Dilemma, das kennzeichnend für Organisationen mit Gewaltlizenz, wie die Polizei, ist. Weil „die Ausübung von Gewalt zur Begrenzung von Gewalt immer wieder Fälle produziert, wo die Urteilskraft in besonderer Weise gefordert ist, und weil es eine nicht zu beseitigende Spannung zwischen Reglementierung und Kreativität gibt" (Reemtsma 2003: 16), ist polizeiliches Handeln immer auch der Ort, an dem staatlich delegierte Gewalt zu willkürlicher Gewalt werden kann. Das Verhältnis von Bürger*innen zur Polizei bleibt damit immer ein ambivalentes (vgl. ebd.: 22).

In diesem Kapitel habe ich durchweg von Gewalt und Macht gesprochen, ohne dies bisher weiter $\mathrm{zu}$ differenzieren. Im Folgenden möchte ich sowohl eine Unterscheidung der Begriffe einführen als auch ihren Bezug aufeinander nachvollziehen.

\subsubsection{Macht und Gewalt als Handeln}

In der Auseinandersetzung mit dem empirischen Material hat sich gezeigt, dass ich ein theoretisch-begriffliches Instrumentarium in Bezug auf Macht und Gewalt brauche, um beschreiben zu können, wie Macht und Gewalt empirisch prozessiert werden. Wenn sowohl (verbale) Subordinationspraxen als auch ein Schlag ins Gesicht als gewalttätig oder gewaltförmig beschrieben werden, stößt man an Grenzen, wenn Interaktionen differenziert nachvollzogen werden sollen. In Auseinandersetzung mit Empirie und Theorie schärfen sich dabei einerseits die theoretischen Begriffe und andererseits die empirischen Rekonstruktionen.

Gewalt spielt im polizeilichen Arbeitskontext eine wichtige Rolle, aber viel relevanter in Bezug auf den polizeilichen Einzeldienst erscheinen Interaktionen, die auf die Herstellung und Aufrechterhaltung von Machtpositionen zielen, die aber keine Gewalt sind. Gleichzeitig hat sich gezeigt, dass beides miteinander verknüpft gedacht werden muss: Es ist wichtig - sowohl theoretisch als auch empirisch -, Gewalt nicht als Abweichung polizeilichen Handelns zu denken, sondern als eine 
polizeiliche Alltagspraxis. Aus diesen Gründen will ich hier eine Auseinandersetzung mit diesen soziologisch komplexen Begriffen versuchen, sie aber nur so weit führen, wie sie für die empirische Arbeit von Relevanz ist.

Max Weber definiert Macht „als jede Chance, innerhalb einer sozialen Beziehung den eigenen Willen auch gegen Widerstreben durchzusetzen, gleichviel worauf diese Chance beruht" (Weber 1921/2008: 38). Für Weber ist der Begriff der Macht jedoch „soziologisch amorph“ (ebd.: 38) und daher weniger geeignet als der Begriff der Herrschaft, der die Idee von Befehl, Gehorsam und Disziplin bzw. von Forderung und Anerkennung von Autorität und Legitimität beinhaltet (vgl. Müller 2007: 121 ff.). Um aber die die konkreten Praktiken der,Willensdurchsetzung $^{6}$ zu beschreiben und zu erklären, erscheint mir das Konzept von Herrschaft nicht ausreichend, insofern es davon ausgeht, dass der*die Befehlsempfänger*in die Herrschaftsbeziehung, durch Disziplin internalisiert, anerkennt und daher gehorchen will (vgl. ebd.: 122). Auch wenn Weber eine prozesshafte und handlungstheoretische Perspektive anregt, ist es doch schwer, Prozesse auf der Interaktionsebene situationsbezogen mit diesen Begriffen zu fassen (s. auch Treiber 2007). Neben der Eröffnung einer prozesshaften und handlungstheoretischen Perspektive sind Webers Überlegungen aber auch deshalb wichtig, weil sein Machtkonzept darauf verweist, dass Macht relational ist. Macht ist nicht etwas, was Personen besitzen, sondern was Ausdruck in einer sozialen Beziehung findet.

Da im Verlauf der Arbeit die Machtbeziehungen und -dynamiken nicht zuletzt durch Gruppenzugehörigkeiten, wie Norbert Elias sie in seiner EtabliertenAußenseiter-Theorie beschreibt, relevant werden, und Elias vor allem den relationalen Charakter von Macht betont, werde ich später auf dessen Konzept noch dezidierter (vgl. Kap. 4.1) eingehen und dies vor allem auch in meine empirischen Analysen einbeziehen. In der Konzeption von Gesellschaft wird Macht bei Elias konstitutiv mitgedacht. Er beschreibt Gesellschaft oder vergesellschaftete Gruppen als Beziehungsgeflechte von Menschen, die aufeinander angewiesen und voneinander abhängig sind und „demgemäß miteinander Interdependenzgeflechte oder Figurationen mit mehr oder weniger labilen Machtbalancen verschiedenster Art bilden“ (Elias 1970/2004: 12). Wie Weber konzipiert auch Elias Macht als Eigenschaft sozialer Beziehungen. Bogner sieht dies bei Elias noch deutlicher betont als bei Weber, denn für Elias ist Macht „eine strukturelle Eigenschaft aller möglichen Interdependenzen“ (Bogner 1989: 36) und sozialer Beziehungen - auch derer, die nicht auf eine intendierte Willensdurchsetzung zielen. Die (ungleichen) „Machtchancen“ innerhalb sozialer Beziehungen zu betrachten und soziale Beziehungen als „Machtbalancen“ zu untersuchen, wie Elias es vorschlägt, macht deutlich, dass alle sozialen Beziehungen als Machtbeziehungen dynamisch und relational sind. Mit der Konzeption von Macht als einen (bedeutsamen) Aspekt von Beziehungen ist es möglich, Macht nicht verdinglicht zu denken und Macht nicht essentialisierend Personen oder Institutionen (ausschließlich) selbst zuzuschreiben (vgl. Imbusch 2012b: 173). Besonders im Rahmen von Polizeiforschung sollte dies betont werden, und in Kapitel 4 wird sich auch deutlich zeigen: Polizist*innen 
bekommen als Vertreter*innen des Gewaltmonopols zwar eine bestimmte Form von Macht verliehen, weil sie zu bestimmten Praktiken legitimiert sind, aber sie haben sie nicht einfach, sondern sie müssen ihr ständig interaktiven Ausdruck verleihen. Macht haben sie „nur in Bezug auf andere“ (Imbusch 2012a: 13). Um machtvoll handeln zu können und sich so auch ihrer Positionierung versichern zu können, brauchen Polizist*innen ihr Gegenüber.

Auch wenn Weber Gewalt grundlegend als Merkmal von Politik und Staatlichkeit definiert hat und Gewalt damit eine zentrale Rolle zukommt, hat Weber sich weniger damit beschäftigt, Gewalt als soziales Handeln zu betrachten (vgl. Trotha 1997: 12). Daher möchte ich im Folgenden auf die wichtigen Überlegungen von Heinrich Popitz zurückgreifen. Popitz bezieht sich zwar auf Weber und nimmt ebenso wie Weber eine handlungstheoretische und (wie auch Elias) prozesshafte Perspektive ein, folgt ihm aber nicht darin, den Machtbegriff soziologisch amorph zu belassen, sondern ihn analytisch weiter ausdifferenziert und vor allem auch Gewalt als Form von Macht konzipiert. ${ }^{14}$ Dies erweist sich auch deshalb als gewinnbringend, weil die polizeiliche Arbeit des Einsatz- und Streifendienstes nicht ständig von Gewalthandeln bestimmt ist, sondern eher von Machtpraktiken, Gewalt aber dennoch zum ,normalen' polizeilichen Handlungsrepertoire gehört.

Popitz stellt mit Blick auf historische Prozesse fest, dass Macht machbar ist, sie ist Produkt menschlichen Könnens und konstitutiv für Vergesellschaftung; sie ist damit omnipräsent und freiheitsbegrenzend (vgl. Popitz 1992: 12-21). Popitz versucht nun diese ,implizite Anthropologisierung des Macht-Konzepts [...] theoretisch explizit“ zu machen und „Macht als Können und Macht als Erleiden“ (ebd.: 21) zu beschreiben. So definiert er Macht dann als „etwas was der Mensch vermag: das Vermögen sich gegen fremde Kräfte durchzusetzen“ (ebd.: 22). Popitz identifiziert vier anthropologische Bedingungen, die ihn zu einer analytischen Trennung von vier Grundformen von Macht führen: Aktionsmacht, instrumentelle Macht, autoritative Macht und datensetzende Macht.

Gewalt ist so verstanden eine Form von Aktionsmacht. Gewalt umfasst hier und dem möchte ich mich anschließen - alle Stufen physischer Schädigung bis hin zu ihrer absoluten Steigerung, dem Töten. Auch wenn die Möglichkeiten, eine andere Person physisch zu schädigen, ungleich verteilt sind, hat dennoch jede*r grundlegend die Möglichkeit dazu, weil jede*r nicht nur „,verletzungsoffen“, sondern auch „verletzungsmächtig“ ist. Aktionsmächtig ist nun aber nicht nur, wer physisch schädigen kann, sondern auch, wer materiell und sozial schädigen kann, indem eine Person unmittelbar durch die Veränderung ihrer Handlungssituation getroffen wird (vgl. ebd.: 23-25).

Datensetzende Macht kann als Veränderung der Handlungssituation durch materielle Lebensbedingungen verstanden werden. Im Gegensatz zu Aktionsmacht

${ }_{14} \mathrm{Zu}$ den Weiterentwicklungen, die Popitz im Vergleich zu Weber leistet, siehe Koloma Beck/Schlichte 2014: 116-118. 
handelt es sich hier um ein indirektes und objektiviertes Machtverhältnis (vgl. ebd.: 29-31).

Instrumentelle und autoritative Macht entfalten ihr Potenzial aufgrund von Alternativen: Mittels instrumenteller Macht, durch Belohnen und Bestrafen, Drohen und Versprechen, lässt sich das Verhalten einer Person steuern (vgl. ebd.: 25-27). Eine Person mit autoritativer Macht kann das Verhalten und die Einstellungen einer anderen Person durch Geben und Nehmen von Anerkennung steuern (vgl. ebd.: 27-29).

In den Interaktionen zwischen Polizist*innen und ihren Interaktionspartner*innen können sich alle diese Machtformen zeigen; Polizeiliches Handeln kann sich in allen Machtformen vollziehen. Als analytische Unterscheidungen sind sie hilfreich beim Nachdenken über das empirische Material und dem Versuch, an einzelnen Stellen den Machtpraktiken polizeilicher Arbeit nachzuspüren; empirisch zeigen sich Übergänge und Wechsel zwischen diesen analytischen Trennungen. In dem Fall von Markus Holtzmann, den ich in Kapitel 5 präsentiere, lässt sich mithilfe dieses analytischen Instrumentariums z.B. nachvollziehen, dass seine Handlungsentwürfe im Rahmen polizeilicher Einsätze meist auf eine Verhaltensänderung des Gegenübers zielen. Wenn er dies nicht aufgrund von instrumenteller oder autoritativer Macht - die in Einklang mit seinen biographischen Erfahrungen die viel relevanteren Machtformen darstellen - schafft, dann stellt Aktionsmacht für ihn das letzte Mittel dar, um sein Handlungsziel zu erreichen. Die Übergänge sind dabei fließend: Aktionsmacht kann in einer polizeilichen Interaktion als Drohung eingesetzt werden, um instrumenteller Macht Nachdruck zu verleihen.

Was folgt daraus nun für die Analyse polizeilichen Handelns? Zum einen, Macht als relational und prozesshaft zu denken. Zu fragen ist stets: Welche Möglichkeiten haben Polizist*innen machtvoll zu handeln und welche Möglichkeiten haben ihre Interaktionspartner*innen jeweils? Zum anderen, Gewalt als physische Gewalt und Machtpraktik zu verstehen; (aktions-)mächtiges Handeln, also auch Gewalt, nicht als Abweichung zu verstehen, sondern als eine ,normale' soziale Praxis. Für die Polizei ist die Ausübung „lozierender Gewalt“ (Reemtsma 2008)15, bei der über den Ort von Körpern im Raum bestimmt wird, gewissermaßen Teil ihrer Arbeitsroutine, Teil ihrer ,normalen' Alltagspraxis und durchaus nicht abweichend. Wie dies von den verletzungsmächtigen und verletzungsoffenen Polizist*innen sowie den gewalterleidenden und auch gewalttätigen Bürger*innen erlebt wird, ist wiederum eine andere, empirische Frage. Denn auch wenn Gewaltausübung zum Handlungsrepertoire polizeilicher Alltagspraxis gehört, kann Ge-

\footnotetext{
15 Reemtsma (vgl. 2008: 104-124) unterscheidet drei Formen von Gewalt nach ihrem Körperbezug: lozierende, raptive und autotelische Gewalt. Reemtsma interessiert dabei nicht, was Handelnde mit ihrer Tat wollen, sondern wie sich die Tat auf den Körper auswirkt. Lozierende Gewalt zielt nicht auf den Körper als solchen, sondern ein Körper wird aus dem Weg geschafft (dislozierend) oder, dauerhaft, an einen bestimmten Ort verbracht (captiv). Dabei kann es zur Verletzung oder gar Zerstörung des Körpers kommen, das ist aber nicht ihr erklärtes Ziel (im Gegensatz zu autotelischer Gewalt).
} 
waltausübung aus der Perspektive von Polizist*innen durchaus mit Gewalterleiden einhergehen. Es ist also wichtig, Polizist*innen nicht nur als verletzungsmächtig zu betrachten, sondern auch in Betracht zu ziehen, dass sie, trotz ihrer Position als Vertreter*innen des Gewaltmonopols, sich als verletzungsoffen erleben und ebenfalls Gewalt erleiden und Machtlosigkeit erfahren können. Dennoch gehe ich - empirisch begründet - von einer asymmetrischen Machtbalance aus. Auch wenn die nicht-polizeilichen Anderen Möglichkeiten haben, Macht zu demonstrieren, durch Infragestellung der Legitimität und Autorität polizeilichen Handelns oder auch durch Gewalt, verfügen Polizist*innen immer über ein ,Mehr ${ }^{6}$ an Machtmitteln. Sie können verhaften, sie können Unterstützung zur Gewaltanwendung herbeirufen, sie können die Macht, die der Organisation Polizei zukommt, z.B. vor Gericht nutzen etc. Und sie haben mehr Möglichkeiten, wie ich später zeigen werde, ihre Situationsdefinitionen durchzusetzen - dies stellt durchaus ein Machtmittel dar. Empirisch zu untersuchen, welche Machtmittel jeweils wie genutzt werden, erweist sich also unter oder gerade wegen der Voraussetzung einer machtasymmetrischen Interaktionsbeziehung als wichtig.

Im Rahmen dieser Arbeit, die eine phänomenologisch begründete, handlungsund biographietheoretische Perspektive (vgl. Kapitel 3.2) einnimmt, möchte ich abschließend noch ergänzen: Gewalthandeln basiert, ,,wie alles Handeln, auf Weilund Um-zu-Motiven im Sinne von Schütz" (Hitzler 1999: 15). Gewalthandeln ist, wie jedes Handeln, aus der Vergangenheit (biographisch) und (um ein bestimmtes Ziel zu erreichen) mit Blick auf die Zukunft motiviert. ${ }^{16}$ Gewalt ist also mindestens sinnhaft, selbst wenn sie der reinen Lust am Verletzen oder Töten entspränge. Sobald der*die Handelnde durch sein*ihr Gewalthandeln außerdem das Verhalten einer anderen Person beeinflussen will, wird es zum sozialen Handeln (vgl. ebd.: 16).

Da mein Interesse auf dem Handeln und den Interaktionen der Polizist*innen im Zusammenhang ihrer biographischen Erfahrungen liegt, mich also die eben genannten Um-zu- und Weil-Motive interessieren und weniger eine normative Perspektive auf Polizei und Gewalt, habe ich hier, wie auch im vorherigen Kapitel, die Fragen nach der Legitimität polizeilichen (aktions-)mächtigen Handelns nur am Rande thematisiert. Ich werde dies im Folgenden dennoch zumindest implizit verfolgen, wenn ich die historische Entwicklung der Polizei nachvollziehe, die im Kontext gesellschaftlicher Entwicklung - auch des gesellschaftlichen Ringens um die Legitimität polizeilichen Handelns - zu betrachten ist.

${ }^{16}$ In Kapitel 3.2 wird dies ausführlicher erläutert. 


\subsection{Die Geschichte der Organisation}

In diesem Kapitel möchte ich Aspekte der Polizeigeschichte vorstellen. ${ }^{17}$ Auch wenn der empirische Teil meiner Arbeit ohne die historischen Entwicklungen der Polizei zu verstehen ist, halte ich es für wichtig, die heutigen Strukturen der Polizei als historisch gewachsene zu betrachten sowie die Kontinuitäten und Veränderungen herauszuarbeiten und polizeiliches Handeln so auch historisch zu kontextualisieren. Ziel der Darstellung ist es, zentrale Entwicklungen der Polizei im späten 19. und im 20. Jahrhundert im Kontext der gesellschaftlichen Veränderungen zu präsentieren. Beginnen werde ich im Deutschen Kaiserreich, weil sich hier die Polizei im heutigen Verständnis herausbildete. Bis dahin war sie als „Hüterin der guten Ordnung“ mit vielfältigeren Aufgaben betraut, die im Prinzip alles innenpolitische Handeln des Staates betrafen. Die polizeilichen Entwicklungen werde ich im Kontext gesellschaftlicher Veränderungen betrachten. Für das deutsche Kaiserreich ab 1871 möchte ich die gesellschaftlichen Verhältnisse jedoch weitgehend außen vor lassen und mich nur auf die Herausbildung der polizeilichen Strukturen, die für die Entwicklungen ab dem Ersten Weltkrieg relevant sind, beschränken. Sie sind wichtig für die Polizei der Weimarer Republik (2.2.2), deren Entwicklung wiederum wichtig für das Verständnis der Polizei im Nationalsozialismus (2.2.3), in den Nachkriegsjahren und der Bundesrepublik (2.2.4 und 2.2.5) ist.

Konzentrieren werde ich mich auf die uniformierte Polizei. Andere Polizeisparten wie Gendarmerie, Kriminal- und Politische Polizei spare ich weitgehend aus, da sich diese Arbeit mit der uniformierten Schutzpolizei bzw. dem Einsatzund Streifendienst beschäftigt. Da sich die verschiedenen Sparten in Abgrenzung zueinander entwickelten, ist es jedoch nicht immer möglich, sie strikt getrennt zu betrachten.

\subsubsection{Die Entstehung der modernen Polizei im Deutschen Kaiserreich}

Eine geschichtliche Zusammenfassung der Entwicklung und Struktur der Institution Polizei im 19. und frühen 20. Jahrhundert erlaubt kaum generalisierende Aussagen über ,die' Polizei, da ihre Organisationstruktur sehr heterogen war: Die Polizeihoheit lag bei den Einzelstaaten des deutschen Kaiserreichs (vgl. Groß/Frevel/Dams 2008: 12) und es existierten verschiedene polizeiliche Organisationsformen nebeneinander, die außerdem, je nach Urbanisierungsgrad der Regionen, sehr unterschiedlich waren (vgl. Jessen 2003: 20). ${ }^{18}$ Ich konzentriere mich daher vor allem auf die Polizei Preußens, als dem größten Staat des Kaiserreichs und der Weimarer Republik, sowie auf die städtische (Schutz-)Polizei, da in den

\footnotetext{
17 In diesem Kapitel nutze ich überwiegend das Maskulinum, da ich hier über männliche Polizisten schreibe. Polizistinnen gab es zwar mit Unterbrechungen schon seit dem Deutschen Kaiserreich, allerdings nicht in der Schutzpolizei, auf die ich mich hier konzentriere (vgl. Kap. 2.1.4).

18 Geschichtswissenschaftliche Arbeiten beziehen sich vor allem auf einzelne Regionen oder Städte. Eine differenzierte Darstellung der Entwicklungen in unterschiedlichen Regionen halte ich im Rahmen dieser Arbeit nicht für notwendig.
} 
ländlichen Gebieten die Feldgendarmerie zuständig war, die jedoch dem Militär angehörte.

Im späten 19. Jahrhundert beginnt die Polizei sich in ihrem heutigen Sinne herauszubilden. In dieser Periode verengen sich die „Aufgaben der Polizei [...] zunehmend, indem alle übrigen, nicht unmittelbar sicherheitsrelevanten Aufgaben ausgegliedert und den städtischen Sozialdiensten und anderen Einrichtungen überlassen werden" (Knöbl 1998: 306). Für die Sicherung der inneren Ordnung und Herrschaft war im 19. Jahrhundert weitgehend (noch) das Militär zuständig. Eine moderne Polizei sei, so Wolfgang Knöbl, eher zufällig entstanden, als das Militär während der Revolutionszeit in Berlin kurzfristig abgezogen wurde und die Königliche Schutzmannschaft zu Berlin Sicherungsaufgaben übernahm (vgl. ebd.: 284). Diese Institution wurde in den folgenden Jahren ausgebaut und war zunächst als Herrschaftsinstrument „im Kampf gegen die bürgerliche Gesellschaft“ (ebd.) und später auch der Arbeiterklasse gedacht (vgl. Reinke 1997: 93). Mit Erstarken der Arbeiterbewegung wurde sie weiter konsolidiert, um politische Konflikte und Streiks weniger gewaltvoll zu unterdrücken, als es das Militär tat, da sich die Mittel des Militärs als unzureichend erwiesen und der Staat Legitimitätsverluste befürchtete (vgl. Knöbl 1998: 342). Die Polizei sollte das Militär als ,innerstaatliche Ordnungsgewalt" (Funk 2000: 22) ersetzen. Daher unterstand die Polizei der zentralstaatlichen Bürokratie, die über sie als Herrschaftsinstrument verfügen wollte; lokale Polizeien gab es nicht (vgl. Knöbl 1998: 342).

Unter anderem aufgrund der Notwendigkeit der Herrschaftssicherung rekrutierte die Polizei sich allerdings vor allem aus dem Militär und war sowohl im habituellen Auftreten wie in ihrer Ausstattung militärisch geprägt (vgl. Knöbl 1998: 342 f.; Jessen 2003: 21). Diese Rekrutierungspraxis ist Ausdruck einer geringen institutionellen Differenzierung und noch fehlenden Spezialisierung: „Die Polizeitätigkeit hatte sich noch nicht so weit als eigenständiges Berufsfeld ausdifferenziert, dass sie ein spezifisches Anforderungs- und Qualifikationsprofil entwickelt hätte“ (Jessen 2003: 21).

Diese Rekrutierungspraxis hatte neben der Versorgung der Soldaten im Anschluss an in der Regel mehrere Jahre Militärdienst auch die Funktion, die mangelnde Ausbildung der Polizisten zu kompensieren. Da es bis zur Jahrhundertwende kaum Polizeischulen gab, ersetzte die militärische Prägung in Bezug auf Gehorsam und Ordnung die Ausbildung (vgl. ebd.: 22). Die übliche Ausbildung bestand darin, dass es einige einführende und zusammenfassende Handreichungen zu relevanten Gesetzen gab und die neuen Beamten einen älteren und erfahreneren Kollegen begleiteten, von dem sie die Handlungsregeln des Polizeialltages lernten - sowohl die formelle als auch die informelle ,Polizistenkultur'. Für die höheren Polizeioffiziere dauerte die Ausbildung bis zu eineinhalb Jahre und basierte auf Hospitationen in unterschiedlichen Revieren und Abteilungen (vgl. ebd.: 24). Diese Ausbildungspraxis - Arbeiten in verschiedenen Abteilungen und die Begleitung von erfahrenen Kolleg*innen - ist auch heute noch Grundstein der praktischen Ausbildung, neben einem sehr hohen Anteil an theoretischer Wis- 
sensvermittlung bzw. theoretischem Wissenserwerb an den Polizei(fachhoch)schulen.

Diese Form der Rekrutierung konnte jedoch nicht dauerhaft aufrechterhalten werden und bis zum Ersten Weltkrieg erlebte die Polizei, entgegen den Vorstellungen von Polizeiführung und Innenbehörde, eine deutliche Demilitarisierung auf personeller Ebene. Zunehmende Urbanisierung und eine damit zusammenhängende Kriminalitätsfurcht führten zum Ausbau der Polizei und damit zu einem Bedarf an Polizisten. Gleichzeitig gab es nicht genug Unteroffiziere, um die Stellen zu besetzen. An der Basis der kommunalen Polizeikräfte ging, auch durch die Einrichtung von kommunalen Polizeischulen seit ca. 1900, allmählich die enge Bindung an das Militär verloren. Je stärker sich in der Polizeiführung ein Expertenstatus ausbildete, umso stärker wurden auch Qualifikationen und Leistungen der Anwärter auf den Polizeidienst relevant und nicht nur ihre militärische Vorbildung (vgl. Knöbl 1998: 307-309; Jessen 2003: 23). Handwerker und Arbeiter stellten zunehmend die unteren Dienstgrade. Die Polizei wurde dadurch nicht nur ,ziviler“, sondern nahm ,z.T. proletarischeren Charakter“ (Knöbl 1998: 308) an.

Unter anderem diese Entwicklungen sowie eine polizeikritische öffentliche Stimmung im Zusammenhang mit polizeilicher Gewalt setzten eine Professionalisierung der Polizeiausbildung in Gang (vgl. Jessen 2003: 25 f.) Obwohl der Unterricht, so unterschiedlich er organisiert war, streng diszipliniert ablief, entwickelte sich ein Diskurs darüber, den Anwärtern nicht nur militärischen Drill beizubringen, um das Fehlen der Militärangehörigen zu kompensieren, sondern auch Kompetenzen im Umgang mit der Bevölkerung zu vermitteln (vgl. ebd.: 28). Man erkannte, dass die militärische Schulung nicht ausreichend war, um die immer komplexer werdenden Situationen und Problemlagen in Großstädten zu bewältigen, und es wurden Forderungen laut sich bürgernäher zu geben (vgl. ebd.: 33). Wie stark der Einfluss solcher Diskurse auf die Polizeipraxis war, ist jedoch fraglich.

$\mathrm{Zu}$ beobachten sind für das Kaiserreich ineinander verflochtene „Vorgänge von Expansion, Spezialisierung, räumlicher Vernetzung, teilweiser Entmilitarisierung und innerer Bürokratisierung, die langsame Entstehung eines Berufsbildes, die Beschreibung und Entwicklung eines besonderen Wissenskanons und die Entwicklung polizeitypischer Arbeitstechniken und -methoden“ (Jessen 2003: 33). Seit den 1880er Jahren ist insgesamt ein Ausbau der Polizei zu beobachten und damit verbunden auch eine systematischere Polizeipolitik, die um eine Zentralisierung der Polizei bemüht war (vgl. Knöbl 1998: 316).

Der Erste Weltkrieg stellt eine Lücke in der historischen Polizeiforschung dar und die Polizeiarbeit eine Lücke in der Forschung zum Ersten Weltkrieg (vgl. Campion/López/Payen 2019). Es gibt kaum Literatur über polizeiliches Handeln während des Ersten Weltkrieges - weder zur ,normalen` Arbeit der Polizei noch 
zu ihrer Involvierung in das Kriegshandeln. ${ }^{19}$ Der hier zitierte Band von Campion, López und Payen, in dem Aufsätze zur Polizeiarbeit verschiedener Länder während des Ersten Weltkrieges versammelt sind, stellt eine der wenigen Ausnahmen dar. Sie stellen in Bezug auf Frankreich fest: ,nearly all works focused on the first half of the twentieth century give prominence to WWII and tend to ignore the importance of both WWI and the interwar period" (ebd.: 3). Ich vermute dies lässt sich für die meisten der in den Zweiten Weltkrieg involvierten Länder verallgemeinern. Vermutlich bleibt das Interesse an der Polizei auch hinter den umfassenderen Forschungsperspektiven auf den Ersten Weltkrieg sowie das soldatische und militärische Handeln im Ersten Weltkrieg zurück.

Festgehalten werden kann jedenfalls - z.B. für das Rheinland (vgl. Reinke 1992: 230) oder Oldenburg (vgl. Wiechmann/Payen 2019), aber wahrscheinlich auch für andere Regionen - dass ein Großteil der Polizisten zum Kriegsdienst eingezogen und an ihrer Stelle Hilfspolizisten eingestellt und Bürgerwehren gegründet wurden. Diese Ersatzpolizisten waren unerfahren und nicht ausgebildet. Die Polizei bestand gegen Ende des Krieges großteils aus diesen Hilfspolizisten sowie älteren, reaktivierten Beamten. Es kann angenommen werden, dass die Polizei durch den Anteil an Hilfspolizei eine De-Professionalisierung erlebte.

Schon vor Kriegsbeginn war die Polizei nur begrenzt dazu in der Lage, Demonstrationen und Streiks ohne Unterstützung des Militärs einzuhegen (vgl. Evans 1996: 622). Vermutlich waren sie zum Ende des Krieges dazu noch weniger imstande. In den Städten hatte die Polizei, auch während des Ersten Weltkrieges, immer Unterstützung durch Garnisonen des Militärs. Nachdem Truppen(teile) sich den Arbeiter- und Soldatenräten anschlossen, verloren die Polizeieinheiten diese Rückendeckung durch das Militär und zogen sich teilweise tagelang aus dem Dienst zurück. ${ }^{20}$ Die Polizei musste in den folgenden Jahren neu organisiert werden.

2.2.2 Tradition, Modernisierung und Straßenkampf: Die Polizei der Weimarer Republik

Von der Polizei der Weimarer Republik, so konstatiert Richard Bessel, lassen sich zwei Bilder zeichnen, die ,einander ziemlich unvermittelt gegenüberstehen: das Bild einer militarisierten Polizei [...] und das Bild einer modernen Polizei“" (Bessel 1992: 324). Wie die Titel von Veröffentlichungen über die Polizei in der Weimarer Republik andeuten, befindet sich die Polizei zu dieser Zeit zwischen „Streifendienst und Straßenkampf“ (Leßmann 1989), ,Militarisierung und Modernisierung“ (Bessel 1992) oder auch zwischen ,Tradition und Modernisierung“ (Knatz 2003).

\footnotetext{
${ }^{19}$ In Kriegshandlungen involviert war die Geheime Feldpolizei, die zur Spionage(abwehr) und Sabotage sowie zur Kontrolle der Bevölkerung in den Kriegsgebieten eingesetzt wurde. Siehe dazu Sawicki (2019).

20 Siehe dazu und zur Konkurrenz der Polizei mit anderen (revolutionären) Akteuren der inneren Sicherheit Leßmann (1989: 13-26).
} 
Nach Ende des Ersten Weltkrieges standen „der staatliche Ordnungsanspruch als Ganzes und das Monopol der Polizeigewalten im Speziellen zur Debatte“ (Leßmann 1989: 11). Die Frühphase der Weimarer Republik war durch viele (gewalttätige) Streiks und Demonstrationen um die politische Verfasstheit der jungen Republik gekennzeichnet. Die politischen Kräfteverhältnisse waren nicht festgeschrieben und es kam immer wieder zu politischen Unruhen (wie dem KappLüttwitz-Putsch, dem Ruhraufstand oder den rechtsmotivierten Morden an AuBenminister Walter Rathenau und anderen Politikern). In dieser Zeit mussten die Polizei bzw. die innere Sicherheit aufrechterhalten und neu organisiert werden, auch weil sich eine Vielzahl von Polizeien herausgebildet hatten, die dadurch insgesamt ineffektiv waren und sich zum Teil auch gegenseitig behinderten (vgl. Vorwerk 1992: 65). Bis zum Sommer 1919 wurde die uniformierte Polizei in Deutschland vollkommen umgestaltet (vgl. Leßmann 1989: 11). Die „Schutzmänner" des Kaiserreiches, die in ihren Revieren den Dienst versahen, verschwanden innerhalb weniger Monate und wurden durch die neu geschaffene Sicherheitspolizei, die in Verbänden auftrat, ersetzt (vgl. ebd.: 11, 48 ff.).

$\mathrm{Zu}$ einer Auseinandersetzung um die Sicherheitspolizei kam es infolge des Kapp-Lüttwitz-Putsches im März 1920, bei dem „sich kein SicherheitspolizeiKommando eindeutig und demonstrativ zur verfassungsmäßigen Regierung bekannt hat" (Leßmann 1989: 82). Die Loyalität der Sicherheitspolizei war fraglich. Auch wenn die Relevanz der Sicherheitspolizei durch den neuen Innenminister Severing (SPD) nicht infrage gestellt wurde, versuchte er doch den Beruf für Arbeiter attraktiver zu machen, um das Personal zu diversifizieren und zu demokratisieren; eine Eingliederung von Arbeitern in die Polizei wurde auch von einigen Gewerkschaften sowie USPD und SPD gefordert (vgl. Leßmann 1989: 83-88). Attraktiv war der Beruf für Arbeiter (in proletarisch geprägten Stadtteilen) aber nicht, weil sie dann in ihrem sozialen Umfeld mit Ausgrenzung rechnen mussten. Aus diesem, aber auch anderen (politischen) Gründen waren diese personalpolitischen Veränderungsversuche weitgehend erfolglos (vgl. ebd.: 87).

Neben dem Problem der nicht eindeutig geregelten institutionellen Zusammenarbeit von Ordnungs- und Sicherheitspolizei waren es die Entente-Mächte, die auf eine Reform der Polizei drängten. Gefordert wurde unter anderem ein dezentraler Aufbau der Polizei (vgl. Vorwerk 1992: 66). Außerdem wies die Polizei, wie auch schon im Kaiserreich, eine deutliche Nähe zum Militär auf. Sie rekrutierte sich zu großen Teilen aus diesem und war zumindest zunächst auch (mit Waffen) aus Armeebeständen ausgestattet und teilweise weiterhin kaserniert, bis die Entente sich 1920 in der Note von Boulogne gegen diese Praxis aussprachen, da sie die Sicherheitspolizei als zweite Reichswehr ansahen (vgl. Leßmann 1989: 89; Knatz 2003: 39 ff.; Naas 2003: 46). Aus der einzeldienstlichen Ordnungspolizei und der kasernierten Sicherheitspolizei wurde die Schutzpolizei gegründet, die als örtliche und immer ansprechbare Polizei für die Aufrechterhaltung von Sicherheit und Ordnung vorgesehen war (vgl. Vorwerk 1992: 67). Dennoch war die Zweiteilung dadurch nicht aufgehoben. Die Hälfte der Beamten war weiterhin 
kasernierten Hundertschaften zugeteilt und die Sicherheitspolizei bestand unter neuem Namen wenig verändert weiter (vgl. Knatz 2003: 39; Leßmann 1989: 103). Zudem forderten führende Offiziere und Beamte weiterhin eine an militärischen Prinzipien orientierte Ausbildung und Kasernierung der Polizisten (vgl. Leßmann 1989: 51; Bessel 1992: 326). Vor allem die „Polizeiführer in der preußischen Schutzpolizei [rekrutierten sich] aus dem Offizierskorps der wilhelminischen Armee“" (Schmidt 2010: 38).

Die Ausbildung wurde insgesamt ausgebaut. Nach einem Jahr schulischer Ausbildung in polizeipraktischen wie -theoretischen und allgemeinbildenden Fächern wurde die weitere Ausbildung in den (kasernierten) Polizeiverbänden fortgesetzt. Ein Aufstieg, auch in eine Offizierslaufbahn, war durch weitere Qualifikation möglich. Mit diesem System gleicht es dem auch in der späteren Bundesrepublik noch länger gängigen Modell stark. Für viele der Offiziere, die als Polizeischullehrer tätig waren, blieb der militärische Ausbildungsteil der wichtigste und auch Politiker forderten eine Ausbildung für den „Straßenkampf“ (vgl. Leßmann 1989: 231-247). Für den Einzeldienst relevante Ausbildungsinhalte fanden kaum Eingang in die Lehrpläne und die „Prinzipien und Inhalte der infanteristischen Ausbildung des Heeres der Kriegs- und Vorkriegszeit wurden fast bruchlos übernommen“ (ebd.: 247). Die Ausbildung der Schutzpolizisten sollte durch den militärischen Drill auch erzieherische Funktion haben und mutige, tapfere und wehrhafte Männer, die in Kameradschaft verbunden sind, formen (vgl. Weinhauer 2003: 101).

In den 1920er Jahren wurden von den Innenministern Severing und Grzesinski wichtige Polizeireformen angestoßen, die bis heute wirksam sind. Auf rechtlicher Ebene konnte letzterer unter anderem das Polizeiverwaltungsgesetz durchsetzen, dass 1931 in Kraft trat (ausführlich Naas 2003). Dieses sollte auch nach dem Zweiten Weltkrieg wieder gelten und ist bis heute prägend für viele Landespolizeigesetze. ${ }^{21}$ Mit der Personalpolitik im Kontext dieser Reform wollte vor allem Grzesinski die Polizei in ein demokratisches Machtinstrument transformieren (Albrecht 1999: 131). Damit einher ging auch eine Veränderung des Verhältnisses von Polizei und Bürger*innen. Das militärische Auftreten der Polizei(offiziere) sollte verschwinden und das Untertanenverhältnis durch ein bürger-

${ }^{21}$ So finden sich z.B. in den polizeilichen Landesgesetzen Generalklauseln zur Aufgabe und den Eingriffsrechten der Polizei, die auf \14 PVG von 1931 beruhen: „Die Polizeibehörden haben im Rahmen der geltenden Gesetze die nach pflichtmäßigem Ermessen notwendigen Maßnahmen zu treffen, um von der Allgemeinheit oder dem einzelnen Gefahren abzuwehren, durch die die öffentliche Sicherheit oder Ordnung bedroht wird." Diese kommen zur Anwendung, wenn keine spezielleren Gesetze greifen. 
nahes ersetzt werden. Grzesinski prägte den bis heute gängigen Terminus von der Polizei als „Freund und Helfer“'22 (vgl. ebd.).

Konterkariert wird dieser Anspruch von dem polizeilichen Vorgehen bei Demonstrationen bzw. der Einschränkung des Demonstrationsrechts. Die „Auffassung, die Weimarer Republik befinde sich in einem Zustand der Notwehr“ (Weinhauer 1999: 560), führte zu Polizeieinsätzen, die „zur Wahrung der Staatsautorität, [...] auch einer Taktik [folgten], die sich an bürgerkriegsähnlichen Zuständen orientierte“ (Weinhauer 1999: 560; vgl. auch Leßmann 1989: 417). Die ,Notwehr' der Republik richtete sich sowohl gegen links als auch rechts, es waren aber vor allem die kommunistischen Demonstrationen, gegen die die Polizei einschritt, wohingegen Umzügen der Sturmabteilung (SA) der NSDAP zunächst weniger Bedeutung zugemessen wurde (vgl. Leßmann 1989: 267). Unter anderem mit wachsendem Zulauf zu KPD und NSDAP und dem Beginn der Weltwirtschaftskrise ab 1929 nahmen Demonstrationen deutlich zu. Auch die Gewalttätigkeit des Demonstrationsgeschehens stieg deutlich an: Als Berliner „Blutmai“ wurde der vier Tage dauernde Straßenkampf zwischen Schutzpolizei und kommunistischen Demonstranten bekannt, bei dem 1929 die Schutzpolizei massive Gewalt anwandte und mit Waffen in die Menge der Demonstrierenden schoss, so dass mehr als 30 Demonstrierende starben und ca. 200 Personen (schwer) verletzt wurden (vgl. Davis 2011: 93 ff.). In den folgenden Jahren kam es zu weiteren schweren Auseinandersetzungen zwischen Polizei, Kommunisten und Nationalsozialisten, die Tote forderten.

Ein nicht eindeutiges Bild lässt sich, so Christian Knatz, von der politischen Einstellung der Polizisten zeichnen. Unter den Polizisten habe es genauso Republikgegner wie auch entschiedene Republikaner gegeben (vgl. Knatz 2003: 42). Auch wenn die Polizei keine „Hochburg der Republikfeinde“ gewesen sein sollte, so gab es ebenso wenig Bestrebungen die Republik zu verteidigen - wie zum Beispiel der Knapp-Lüttwitz-Putsch zeigt. Leßmann attestiert den leitenden Beamten „ein durch Herkunft und Erziehung überwiegend obrigkeitsstaatliches Denken“

22 Der Slogan „Die Polizei - dein Freund und Helfer“ wurde in den 1920er Jahren entwickelt, als die Polizei reformiert wurde (vgl. dazu ausführlich Leßmann 1989). Aufgegriffen wurde er in nationalsozialistischer Propaganda unter Heinrich Himmler als Reichsführer bzw. Reichsleiter SS, der ab 1936 auch Chef der Deutschen Polizei war. Unter anderem auf Plakaten zum „Tag der deutschen Polizei“ 1937 und 1939 findet sich der Slogan (vgl. Jung 2005: 43, 46). Damit als offizieller Slogan für die Polizei diskreditiert, hält er sich alltagssprachlich dennoch recht hartnäckig unter Polizist*innen wie nicht-Polizist*innen. In offiziellen Polizeipublikationen oder Werbematerialien ist er meines Wissens kaum noch zu finden (z.B. noch auf Homepage der Polizei Hessen, in der Beschreibung der Schutzpolizei (Polizei Hessen 2016)). Der Slogan wird aber durchaus in Veröffentlichungen von Polizist*innen verwendet, wie z.B. eine zum Download zur Verfügung stehende Handreichung der Jungen Polizei in der DPolG (Junge Polizei o. J.), in der z.B. Tatbestände, Übersetzungshilfen und Verkehrszeichen abgedruckt sind, und die „Freund und Helfer“ heißt. Oder in dem von Aurel Voigt und Rainer Wendt, dem späteren Vorsitzenden der Deutschen Polizeigewerkschaft (DPolG), veröffentlichtem Buch „Polizei. Ein fröhliches Wörterbuch“ (Wendt/Voigt 1994), indem auf vermeintlich satirische Weise ein problematisches Bild von Polizei und Gesellschaft bzw. polizeilichem Blick auf Gesellschaft vermittelt wird. 
(Leßmann 1989: 302). Für die Beamtenschaft der Schutzpolizei geht er aber von einer geringeren Hinwendung zum Nationalsozialismus aus als für die übrige Beamtenschaft, auch wenn die NSDAP durchaus Erfolge bei der Unterwanderung der Polizei und Anwerbung von (ehemaligen) Polizisten verzeichnen konnte (vgl. ausführlicher Leßmann 1989: 310 ff.).

Der Wechsel von einem System in das nächste erfolgte vor allem im Mittelbau der Polizei-Offizierskorps eher geräuschlos (Knatz 2003: 43). Dieser Übergang war nicht allein Ausdruck von politischen Überzeugungen, sondern auch bestimmt von dem Wunsch, dass wieder, Ordnung' einkehre nach Jahren politischer Unruhen und gewalttätiger Auseinandersetzungen (vgl. Bessel 1992: 343). Polizei war aber, so Weinhauer (vgl. 2003: 101), auch als Männerbund konzipiert, der bestimmten Ordnungs- und Obrigkeitsvorstellungen unterlag und (dadurch) den republikanischen Staat repräsentierte, aber nicht politisch-demokratisch war Bestandteile dieses Wir-Bildes lassen sich noch heute ausmachen (vgl. 4.1.1). Eine solche Konzeption machte es, zumindest für die, die Polizei in dieser Form verinnerlicht hatten, einfach(er), unter verschiedenen Staatsformen zu dienen (vgl. ebd.: 101).

Es war aber auch die Schutzpolizei, die seit dem Sommer 1932 mit einem starken Autoritätsverlust gegenüber der SA und einer Entwertung ihrer Arbeit zu kämpfen hatte (vgl. Leßmann 1989: 389). Nach dem SA-Verbot oder auch dem „Hemden- und Hosenkrieg“, bei dem die Schutzpolizei das Verbot der Uniformierung der NSDAP durchsetzen musste, erlebten Polizisten immer wieder, dass sie nach einem Einschreiten gegen die SA vor Gericht benachteiligt wurden (vgl. Leßmann 1989: 418). Vor allem nach dem „Preußenschlag“ wurde von einigen leitenden Beamten und (Polizei-)Politikern deutlich gemacht, dass ein Vorgehen gegen die SA nicht erwünscht war (vgl. Leßmann 1989: 370 ff.). Es gab z.B. ab dem Sommer 1932 einen Untersuchungsausschuss „Preußische Polizei“ des preuBischen Landtages, der sich mit Anträgen gegen Polizeipräsidenten und auch einfache Polizisten befassen musste, die gegen SA-Aufmärsche vorgegangen waren (vgl. ebd.: 375 f.). So konnte im Laufe des Jahres 1932 beobachtet werden, dass sich das Verhalten gegenüber der SA veränderte und weniger häufig gegen gesetzeswidriges Handeln der SA eingeschritten wurde sowie verhaftete SA-Männer wieder freigelassen wurden, während an denselben Auseinandersetzungen beteiligte Kommunisten weiterhin strafrechtlich verfolgt wurden. Schon eine Woche vor der sogenannten Machtergreifung wurde die Berliner Schutzpolizei eingesetzt, um einen Aufmarsch der SA abzusichern, indem die Polizei das Gebäude der KPD sperrte (vgl. Leßmann 1989: 348, 376).

Am Ende der Weimarer Republik bleibt das Bild eines Polizeiapparats zurück, der sich im „Kampf um den Bestand der Weimarer Demokratie als unzuverlässig erwies oder in seiner Einsatzbereitschaft durch interne Probleme geschwächt" (Leßmann 1989: 419) war. Es wird aber auch deutlich, so konstatiert Leßmann am Ende seines umfassenden Werkes zur preußischen Schutzpolizei der Weimarer Republik, dass es eine Illusion war, ,von der Schutzpolizei das zu erwarten, was 
den Regierungen in Reich und Ländern und der Justiz nicht gelang oder nicht erstrebenswert erschien“ (ebd.). Waren zu Beginn der Weimarer Republik die Beschreibungen von der Polizei als zwischen „Tradition und Modernisierung“ oder „Militarisierung und Modernisierung“ befindlich treffend, so erscheint am Ende der Weimarer Republik vor allem das „Zwischen“ kennzeichnend. ${ }^{23}$

\subsubsection{Die Polizei als Organisation der Vernichtungspolitik im Nationalsozialismus}

Mit der sogenannten Machtergreifung 193324 änderten sich die Rahmenbedingungen der Polizei zunächst kaum. Eine grundlegende Änderung der Polizeistrukturen stellte die Zentralisierung der Polizei dar. Bis dahin hatten die Kompetenzen in erster Linie bei den Ländern gelegen. In den folgenden Jahren wurde die gesamte Polizei unter der Führung und auf maßgebliches Betreiben von Heinrich Himmler mit der Schutzstaffel (SS) verwoben. Himmler war ab 1936 sowohl Chef der Polizei als auch SS-Führer. Nach seinem Amtsantritt startete Himmler mit der Zentralisierung der Polizei „die größte Polizeireform der deutschen Geschichte“ (Deppisch 2017: 67). Die uniformierte Polizei wurde in der Folge zur Ordnungspolizei, in der neben der Schutzpolizei weitere polizeiliche Arbeitsbereiche zusammengefasst wurden, wie die Gendarmerie oder die Verwaltungspolizei; ihnen wurde die Mitgliedschaft in der SS empfohlen. Die Kriminalpolizei und die Gestapo, die politische Polizei des Regimes, bildeten von nun an die Sicherheitspolizei (vgl. Nitschke 2000: 54 f.).

Nach dem Reichstagsbrand im Februar 1933 wurden qua Verordnung die Möglichkeiten polizeilichen Handelns so weit ausgedehnt, dass „sie jenseits des Verfassungsstaates anzusiedeln“ sind (Nitschke 2000: 53). Von der Polizei wurde eingefordert, restriktiv zu handeln und absolut staatstreu Aufgaben zu erfüllen. Dies kam der Polizei, so vermutet Nitschke, erst einmal entgegen, da ein solches Handeln grundlegend in das polizeiliche Berufsverständnis und Aufgabenfeld eingelassen war und die Polizei sich dadurch in ihrer Funktion im Staat wieder aufgewertet fühlen konnte (vgl. ebd.: 52, 56). Leßmann zitiert einen Polizeioffizier, der 1933 äußerte, dass ,wohl noch niemals ein Polizeiminister den Auffassungen seines Offizierskorps so entsprochen" habe, wie es Innenminister Göring tat

\footnotetext{
${ }^{23} \mathrm{Zu}$ den Krisenjahren und dem Umgang der Schutzpolizei mit der NSDAP und im Dritten Reich siehe Leßmann (1989). Dieses Buch stellt ein, oder das, Grundlagenwerk zur Polizei der Weimarer Republik dar (vgl. Weinhauer 1999: 554). Hier lassen sich die oben angerissenen Überlegungen Reemtsmas zum Vertrauensproblem des Gewaltmonopols gegenüber seinen gewaltlizensierten Institutionen anschaulich nachvollziehen. Von Politikern wurde etwa die Frage diskutiert, ob die Schutzpolizei zur Verteidigung der Regierung beim „Preußenschlag“ eingesetzt werden sollte bzw. ob sie eingesetzt werden könne und wem gegenüber sie sich loyal verhalten würde (ausführlicher: Leßmann 1989: 363-370).

${ }^{24}$ Ich bin mir der problematischen Implikationen des Begriffs „Machtergreifung“ bewusst und wie ja auch der Blick in die Polizeigeschichte zeigt, handelte es sich vielmehr um einen Prozess als um eine plötzliche Veränderung oder ein punktuelles Ereignis.
} 
(Leßmann 1989: 402). Nach den Erfahrungen in der Weimarer Republik schien eine starke und restriktiv handelnde Polizeiführung erwünscht.

Die Polizei des Nationalsozialismus wurde in den folgenden Jahren zum „eigentlichen Kern totalitärer Herrschaft" (Wagner 2009: 28). Durch die Verschmelzung von SS und Polizei zu einem riesigen Apparat, der über ein „einzigartiges Spektrum von Gewaltressourcen“ (ebd.: 47) sowie die Definitionsmacht über Menschen(leben) und Recht und Unrecht verfügte, wird die Polizei zu eben jenem Herrschaftskern. Im Fokus der (wissenschaftlichen) Auseinandersetzung stehen häufig die SS und die Gestapo. Der „Anteil der Schutzpolizei an der Absicherung der nationalsozialistischen Machtübernahme wird häufig übersehen“ (ebd.: 31) möglicherweise auch deshalb, weil sie neben der Kriminalpolizei nach Ende des Zweiten Weltkrieges weiter existierte, wohingegen SS und Gestapo zu „verbrecherischen Organisation“" erklärt und verboten wurden.

Die uniformierte Polizei machte die Verhaftungswellen im Frühjahr 1933 möglich, indem sie die Einsätze der SA und SS absicherte, auch wenn sie (zunächst) nicht aktiv an den Gewaltexzessen gegenüber sogenannten Volksfeinden beteiligt war (vgl. ebd.: 32). Die Polizei lernte zunächst bei Rechtsbrüchen tatenlos zuzusehen, bevor sie später selbst aktiv wurde; ihre Passivität eröffnete einen rechtsfreien Raum (vgl. Matthäus 2002: 142) bzw. führte zu einer Neuinterpretation dieses Raumes (vgl. Heuer 2009: 400). Patrick Wagner konstatiert, dass sich ein Großteil der Schutzpolizisten schnell daran gewöhnte, dass die Normen des Gesetzes außer Kraft gesetzt waren (vgl. Wagner 2009: 32). Es kann allerdings nicht davon ausgegangen werden, dass dies auf alle Ordnungspolizisten zutraf. Auch wenn der Großteil der Polizisten die menschenfeindliche Politik mehr oder weniger überzeugt umsetzte, gab es doch einige wenige, die Hilfe leisteten, und viele, die sich zumindest formal korrekt verhielten. Der Spielraum dafür verengte sich mit Systematisierung und Fortschreiten der judenfeindlichen Politik jedoch zunehmend (vgl. Matthäus 2002: 149). Nun begann eine „Entzivilisierung“ (vgl. Heuer 2009) der Polizei und ein gemeinschaftlicher Lernprozess, in männerbündischen Gewaltkollektiven, zum Massenmord (vgl. Wagner 2009: 45 f.).

SA, SS und Polizei gingen eine ,Arbeitsteilung" ein, die auch darauf beruhte, dass viele Polizisten entweder mit den Ideen Hitlers sympathisierten oder aus Angst vor Sanktionen eine unbestimmte Haltung einnahmen - als im Jahr 1933 die Polizei politisch ,gesäubert' wurde, kam es zu nur sehr wenigen Entlassungen (vgl. Deppisch 2017: 66). Die Verbindung von SS und Ordnungspolizei diente auch der gegenseitigen Reglementierung. Zwar war man von der nationalsozialistischen Gesinnung der SS-Angehörigen überzeugt, doch sollte die SS (zunächst) etwas diszipliniert werden, da sich in ihr die Straßenkämpfer (der SA) aus der Weimarer Republik wiederfanden. Von der Disziplin der Polizei wiederum war man überzeugt, nicht aber von ihren weltanschaulichen Ansichten; aus der Perspektive der Machthaber brauchte die Ordnungspolizei hier, Nachhilfe‘ (Matthäus 
2002: 144). ${ }^{25}$ Himmler legte als Chef der Polizei großen Wert auf eine „weltanschauliche Schulung“, die ab 1937 zur Dienstpflicht wurde (vgl. Harten 2018: 17 f.). Für den heterogenen SS-Polizei-Komplex sollte sie nach innen integrierend wirken (vgl. Matthäus 2003). Während des Krieges wurde sie weiter ausgebaut und an die ,Notwendigkeiten“ angepasst. Zu Beginn waren z.B. „die ,polnischen Greueltaten“ an den Volksdeutschen“ Thema und „mit Beginn des Feldzuges gegen die Sowjetunion [trat] der, jüdische Bolschewismus‘ an die erste Stelle“ (Harten 2018: 22 f.). Polizeiangehörige, vor allem des gehobenen und höheren Dienstes, wurden außerdem aufgefordert, SS-Mitglieder zu werden. Wagner betont, dass man nicht, wie später oft behauptet, automatisch und nur auf dem Papier Mitglied der SS wurde, sondern dass eine Bewerbung notwendig und auch eine Überprüfung von politischen Überzeugungen und anthropologischen Merkmalen durchgeführt wurde (vgl. Wagner 2009: 38).

In dieser ,Arbeitsteilung“ entwickelte sich die Polizei „zum wichtigsten Akteur der nationalsozialistischen Vernichtungspolitik“ (ebd.: 34). Dies gilt auch für die Schutz- bzw. Ordnungspolizei, die Menschen verhaftete und zu den Deportationszügen in die Konzentrationslager drängte. Die ganz ,normale‘ polizeiliche Arbeit umfasste nun andere Aufgaben bzw. erlaubte schon seit 1933 weitergehende Eingriffe gegen Bürger*innen, die als „nicht-arisch“, „asozial“, „Berufsverbrecher" etc. galten. Die Rolle der Ordnungspolizei bei der alltäglichen Umsetzung der ,Judenpolitik“ ist allerdings erst wenig erforscht (vgl. Matthäus 2002: 149). Etwas mehr Aufmerksamkeit haben die ,ganz normalen Männer“ (Browning 1993) der Polizeibataillone erhalten: Der Einsatz der Ordnungspolizei weitete sich mit Kriegsbeginn aus. Sie folgte der Wehrmacht in Form von Polizeibataillonen in die besetzten Gebiete zum „,auswärtigen Einsatz“ zunächst nach Polen, später in andere überfallene und besetzte Länder. ${ }^{26}$ Neben der Bewachung von Objekten und Kriegsgefangenen waren sie auch dafür zuständig, die „Umvolkungspolitik“ umzusetzen: Die Gefangennahme und Ghettoisierung der lokalen (jüdischen) Bevölkerung, brutale Deportationen sowie auch Hilfe bei und Durchführung von Erschießungen (vgl. Deppisch 2017: 72; ausführlich Browning 1993). Die Ordnungspolizei war an dem zunehmend systematisch stattfindenden Massenmord in immer stärkerem Maße beteiligt. Es waren aber nicht nur die mobilen Polizeibataillone, die in den besetzten Gebieten eingesetzt wurden, sondern auch stationäre Polizeieinheiten beteiligten sich am Massenmord - diese und ihre ,Zusammenarbeit ${ }^{\star}$ mit der lokalen (Hilfs-)Polizei sind im Vergleich zu den Bataillonen bisher weniger gut belichtet (vgl. Matthäus 2002: 153). Rund ein Drittel der Ordnungspo-

\footnotetext{
25 Zur Ausbildung der Offiziere der Ordnungspolizei siehe das umfassende Werk von Sven Deppisch (2017), zur ,weltanschaulichen Schulung“ der Polizei ausführlich Hans-Christian Harten (2018) und auch Matthäus et al. (2003).

${ }^{26}$ Zum Beispiel Griechenland (Kalogrias/Dordanas 2009) oder Weißrussland (Rein 2009).
} 
lizei soll an diesen ,auswärtigen Einsätzen“ teilgenommen haben (vgl. ebd.: 153).27 Die Involvierung der (Ordnungs-)Polizei in den Holocaust darf also, trotz der vielen Freisprüche bzw. wenigen Anklagen gegen Polizisten bei späteren Gerichtsverfahren, nicht unterschätzt werden (siehe dazu Klemp 2009: 139).

Beispiele, in denen sich Polizisten weigerten, Erschießungsbefehle auszuführen, gibt es nur wenige - eine Befehlsverweigerung führte allerdings nicht, wie später von Tätern (in Gerichtsverfahren) angeführt, zu (dienstlichen) Konsequenzen, die über moralische Verurteilung und Ausgrenzung oder eine Versetzung hinausgegangen wären (vgl. Browning 1993: 86 ff.; Kwiet 1996: 115; Matthäus 2002: 155 f.; Deppisch 2017: 74). Gleichzeitig sind Siegesfeiern nach Massenerschießungen dokumentiert, die in Zusammenhang mit größeren Mengen Alkohol auch die psychischen Folgen bei einigen der Täter verdecken und insgesamt die ,Moral' aufrechterhalten sollten (vgl. Kwiet 1996: 113 ff.). Auch wenn sich nicht alle Polizisten gleichermaßen beteiligt haben, so ist dennoch „davon auszugehen, dass es in allen Bataillonen Männer gegeben hat, die gern und bereitwillig Menschen erschossen haben. Im Grunde genommen waren sie nicht nur Gehilfen, sondern Mörder“ (Klemp 2009: 194).

$\mathrm{Zu}$ der Frage, warum Polizisten sich loyal zum System verhalten haben, gibt es verschiedene Erklärungsversuche. Angeführt werden unter anderem die militärische Ausrichtung sowie die Erfahrungen der Polizisten der Weimarer Republik als Teil des polizeilichen Selbstverständnisses und die anti-kommunistischen Einstellungen vieler Polizisten (zusammenfassend Reinke 1996: 22 f.). Die organisationalen Veränderungen, die Aufwertung der Polizei im System und die Neudefinition von Rechten und Normen in Verflechtung mit einer ideologischen „Aufladung der Polizeiarbeit durch einen handlungsorientierten Rassenantisemitismus" und einer genetisch begründeten Deutung von Devianz „boten völlig neue Legitimationen und Handlungsimperative für polizeiliches Handeln" (Wagner 2009: 45). Erklären kann dies das massenhafte polizeiliche Töten aber nur bedingt. Für Jürgen Matthäus steht fest, „daß einfache Antworten auf [...] große Fragen' der Holocaustforschung - und hierzu gehören die Verbrechen und Motive der Orpo [Ordnungspolizei, M.S.] zweifelsohne - in Zukunft noch weniger überzeugen werden als bisher“ (Matthäus 2002: 158).

\subsubsection{Neubeginn und Kontinuität: Die Polizei in den Nachkriegsjahren}

Die Hoheit über die Polizei bzw. staatliche Gewalt lag nach der vollständigen Besetzung Deutschlands bei den Alliierten, ausgeübt wurde sie zunächst von deren Militärpolizeien und deutschen Hilfspolizisten (vgl. Stolleis 2018: 29). Die von den Alliierten gemeinsam ausgearbeiteten Pläne und Absprachen bezüglich der Reorganisation der deutschen Polizei waren wenig konkret. Die organisationale

${ }_{27}$ Dies hatte auch zur Folge, dass die Polizei im „Altreich“ zunehmend unter Personalmangel litt und Reservisten und schon pensionierte Beamte eingezogen wurden. Für Niedersachsen vgl. Liebert (2001: 73). 
Neuausrichtung der Polizei vollzog sich in den Besatzungszonen zunächst entlang der jeweiligen nationalen Traditionen der Alliierten (vgl. Fürmetz/Reinke/Weinhauer 2001: 8) - im Folgenden beziehe ich mich weitestgehend auf die Niedersachsen umfassende britische Besatzungszone. ${ }^{28}$ Geeinigt hatte man sich aber auf die, nicht nur für die Polizei geltenden, allgemeinen Grundsätze von Dezentralisierung, Demilitarisierung, Denazifizierung und Demokratisierung Deutschlands und der deutschen Polizei (vgl. Reinke/Fürmetz 2000: 70; Stolleis 2018: 29).

Die unter Himmler vollzogene Zentralisierung der Polizei wurde rückgängig gemacht und die Kompetenzen wieder auf Länderebene übertragen, nachdem die Polizei in den westlichen Besatzungszonen eine längere Phase der Kommunalisierung durchlaufen hatte (vgl. Fürmetz/Reinke/Weinhauer 2001: 8). Dies bedeutete einerseits eine Veränderung der NS-Polizeistrukturen, knüpfte gleichzeitig aber an die Organisationsform der Weimarer Republik an. Bis heute verfügt die Bundesregierung nur begrenzt über polizeiliche Exekutivmacht und wenn, dann vor allem in Hinblick auf kriminalpolizeiliche Ermittlungen (Bundeskriminalamt) und den Grenzschutz (Bundesgrenzschutz bzw. -polizei) (vgl. Fürmetz/Reinke/Weinhauer 2001: 9). ${ }^{29}$

Eine Demilitarisierung der Polizei bedeutete vor allem die Auflösung von kasernierten Polizeieinheiten und eine grundsätzliche Einschränkung der Bewaffnung (vgl. Stolleis 2018: 29).

Die „Entpolizeilichung“ der öffentlichen Ordnung wurde besonders in der britischen Besatzungszone verfolgt. Polizeiliche Aufgaben wurden von Verwaltungsaufgaben, wie dem Meldewesen, getrennt und an andere oder neue Ordnungsbehörden übergeben (vgl. Groß/Frevel/Dams 2008: 16). Diese Trennung war zunächst vor allem organisatorischer Art und nicht alltäglichhandlungspraktisch durchgesetzt. Die britischen Reformversuche der „Entpolizeilichung“ gelangen letztlich erst deutlich später im Zusammenhang mit gesellschaftlicher Differenzierung und Technisierung (vgl. ausführlich Richter 2001).

Insgesamt, und auch verbunden mit den organisationalen Veränderungen, stellte die Entnazifizierung der Polizei eine große Herausforderung dar. Mit Kriegsende wurden Personen, die die Alliierten als Sicherheitsrisiko betrachteten, interniert. Eine Internierung erfolgte nicht aufgrund individueller Schuld bzw. mit deren Nachweis, sondern aufgrund bestimmter festgelegter Kategorisierungen. Bei der Polizei betraf dies unter anderem alle Gestapo-Angehörigen und die Führungspersonen der Ordnungspolizei, aber auch mittlere und untere Ränge. Im Oktober 1946 wurden viele Polizeiangehörige, darunter auch höhere SSDienstränge, vorläufig als „Mitläufer“ oder „Entlastete“ aus der Internierung entlassen (vgl. Liebert 2001: 76), nachdem im Rahmen der Nürnberger Prozesse we-

\footnotetext{
${ }^{28}$ Einen Überblick über die konkrete Ausgestaltung des „,britischen Modells“ liefern Reinke und Fürmetz (2000: 74-77).

${ }^{29}$ Nachrichtendienstlich tätig ist außerdem das Bundesamt für Verfassungsschutz, das aber rechtlich keine polizeilichen Exekutivbefugnisse hat (vgl. § 8 Abs. 3 BVerfSchG (Bundesverfassungsschutzgesetz)).
} 
der die Kriminal- noch die Ordnungspolizei zur verbrecherischen Organisation erklärt wurde. Die so eingestuften Personen konnten in den Polizeidienst zurückkehren, sofern ein regionaler Entnazifizierungsausschuss nicht etwas Anderes entschied. Die in Internierungshaft verbleibenden Personen mussten sich Spruchgerichten unterziehen. Betroffen waren vor allem untere und mittlere Gestapound Sicherheitspolizei-Ränge, die, wenn sie denn verurteilt wurden, ihre Strafe mit der Internierung meistens schon verbüßt hatten (vgl. Liebert 2001: 76 f.). Auch für sie bestand nach einem Entnazifizierungsverfahren die Möglichkeit wieder in den Polizeidienst aufgenommen zu werden (vgl. Fürmetz/Reinke/Weinhauer 2001: 13; Liebert 2001: 77).

Prinzipiell war die Entnazifizierung der Polizei von einem Zielkonflikt bestimmt: Einerseits sollten ,belastete ${ }^{\varsigma}$ Personen aus dem Polizeidienst ausgeschlossen werden, andererseits waren die Alliierten auch darauf angewiesen, dass die Polizei schnell wieder handlungsfähig war (vgl. Liebert 2001: 77). Unter anderem die nach dem Krieg zunehmende Kriminalität, in Form von Subsistenzkriminalität (z.B. um den Bedarf an Lebensmitteln zu decken), machte es notwendig, schnell eine funktionierende deutsche Polizei zu etablieren (vgl. Groß/Frevel/Dams 2008: 15). In der britischen Besatzungszone führten dieser Umstand, das anfängliche Fehlen von Richtlinien sowie die Einflussmöglichkeiten der neu eingesetzten Polizeiführung und ein „schwer zu durchschauendes Beziehungsgeflecht aus freundschaftlicher Gefälligkeit [...] und wechselseitiger Abhängigkeit" (Liebert 2001: 80) (anfänglich) zu einer wenig konsequenten Entnazifizierung der Polizei bzw. ermöglichten es Karrieren unbeschadet fortzusetzen. Auch wenn die Briten in der Folge ${ }^{30}$ weitere Ausschüsse zur (erneuten) Überprüfung aller Polizisten einrichteten, machte die Organisation dieser Ausschüsse - sie durften z.B. nicht selbst ermitteln - fundierte Entscheidungen schwer, da sie teilweise auf die von den zu Überprüfenden selbst vorgebrachten Zeugen angewiesen waren (vgl. Liebert 2001: 84 ff.).

In diesen Verfahren dienten polizeiliche NS-Führungspersonen der Entlastung anderer Polizeibeamter: Durch die Zuweisung von Schuld nach ,oben' und einen Rückzug darauf, nur die Pflicht getan und Befehle befolgt zu haben, wurde die eigene Schuld negiert und es kam zu einer argumentativen Täter-OpferUmkehr (vgl. Liebert 2001: 101 f.; Kwiet 2003). Die umfassende Prüfung und die dann allerdings nicht konsequent umgesetzte bzw. teilweise wieder zurückgenommene Entnazifizierung führten einerseits zum Erleben von Ungerechtigkeit in Bezug auf andere Kollegen, die einfach als entlastet galten, andererseits zu einem kollektiven Gefühl, als Berufsgruppe abgewertet worden zu sein (vgl. Liebert 2001: $101 \mathrm{f}$.).

\footnotetext{
30 Auch in Reaktion darauf, dass der SPD-Parteivorsitzende Kurt Schuhmacher seine ihm zum Schutz zugeteilte Polizeimannschaft aufgrund von Gesprächen überprüfen ließ. Vier der fünf Polizisten waren ehemalige SS-Angehörige. In diesem Zusammenhang geriet auch der neue Polizeichef Hannovers unter Verdacht, der schließlich zu einer Haftstrafe verurteilt wurde, die dann jedoch herabgesetzt und später großteils erlassen wurde (vgl. Liebert 2001: 83 f.)
} 
Unter den Bedingungen des „Kalten Krieges“ und der deutschen Teilung nahm das Interesse der Alliierten an der Verfolgung der Kriegsverbrecher und der Entnazifizierung ab (vgl. Kwiet 2003: 114 f.). Zunehmend wurden auch gesellschaftliche und politische Forderungen laut, einen Schlussstrich zu ziehen und nur die , wirklich 'Schuldigen zu verfolgen (vgl. Liebert 2001: 96). ${ }^{31}$ Der Umgang der Polizei und der Polizisten mit ihrer Vergangenheit kann in den Nachkriegsjahren insgesamt als von Verleugnung, Verdrängung und Umdeutung der eigenen Geschichte gekennzeichnet beschrieben werden. „Man konnte zu dem Eindruck gelangen, die Polizei des Dritten Reiches habe nur Kleinverbrecher verfolgt oder den Verkehr geregelt" (Dams 2008: 9). Auch wenn manchen führenden NSPolizisten Spitzenämter verschlossen blieben, so sind doch entscheidende Positionen mit ihnen besetzt worden; selbst eine durchaus bekannte NS-Vergangenheit und Beteiligung am Massenmord stand dem nicht grundsätzlich entgegen (vgl. Liebert 2001; Baumann/Stephan/Wagner 2012). Insgesamt kann für die Polizei in Bezug auf das Personal von einer hohen Kontinuität ausgegangen werden. Dies trifft in gewisser Weise auch auf die Neueinstellungen zu: Viele von ihnen hatten in der Wehrmacht gedient und/oder waren im Nationalsozialismus sozialisiert worden (vgl. Dams 2008: 10).

Zusammenfassend lässt sich, neben der personellen Kontinuität, festhalten: Mit der Föderalisierung der Polizeipolitik wurde zwar die Kontinuität zum „Dritten Reich" gebrochen, aber auch an Strukturen der Weimarer Republik angeknüpft. So ist nicht nur die dezentrale Organisationsform wiederhergestellt worden, sondern auch ,polizeiliche Praxiskonzepte, [...] Verhaltensmuster und Feindbilder, die schon über 1933 hinaus fortbestanden haben oder während der NS-Zeit gar verstärkt worden sind“ (Reinke/Fürmetz 2000: 68), wurden reaktualisiert. Bereits 1951 wurden wieder kasernierte Bereitschaftspolizeiverbände aufgestellt und eine Demilitarisierung der Polizei damit teilweise aufgegeben (vgl. Fürmetz/Reinke/Weinhauer 2001: 10). Die Polizei stand in den Jahren nach Kriegsende ,in einem markanten Spannungsfeld von Neubeginn und Kontinuität“ (Reinke/Fürmetz 2000: 67).

\subsubsection{Gesellschaftliche Dynamiken und polizeiliche Reformen: Die Polizei der Bundesrepublik}

Die Gründung der Bundesrepublik 1949 hatte auf die Polizei keinen wesentlichen Einfluss, da die Alliierten schon zuvor begonnen hatten, die Kompetenzen auf die Länder zu übertragen, jedoch weiterhin Kontrollrechte besaßen (vgl. Hase-

\footnotetext{
31 Siehe in diesem Zusammenhang auch das vom Bundestag 1949 erlassene „Gesetz über die Gewährung von Straffreiheit" für ,kleinere" Vergehen (Bundesgesetzblatt vom 31.12.1949) sowie den 1951 in Kraft getretenen Art. 131 des Grundgesetzes zur Regelung der Rechtsverhältnisse von Beamten, die vor dem 08.05.1945 verbeamtet wurden, der Beamtenbezüge und auch Wiedereinstellungen möglich machte.
} 
low/Noethen/Weinhauer 2000: 132).32 Teilweise wurde die von den Alliierten vertretene Polizeipolitik (zunächst) aufrechterhalten, längerfristig jedoch auf Strukturen der Weimarer Republik aufgebaut.

In den 1950er Jahren bildeten sich in den Bundesländern, trotz der seit Ende des „Dritten Reichs“ wieder zu einer föderalen Organisation umstrukturierten Polizei und der verschiedenen Prägungen innerhalb der Besatzungszonen, einige gemeinsame Entwicklungen heraus:

In Anbetracht der deutschen Teilung und der Einrichtung von kasernierten Volkspolizeibereitschaften in der DDR sowie unter dem Eindruck des „Kalten Krieges" insgesamt wurde auch in der Bundesrepublik wieder eine kasernierte Polizei eingerichtet (vgl. Fürmetz/Reinke/Weinhauer 2001: 10; Dams 2008: 11). Sie war der jeweiligen Landespolizei unterstellt, wurden aber vom Bund finanziert, da dem Bund weiterhin eine eigene Bereitschaftspolizei durch die Alliierten nicht gestattet wurde (vgl. Stolleis 2018: 34) - dieses Konzept ist im Prinzip bis heute erhalten. ${ }^{33}$

Eingerichtet und vereinheitlicht wurde auch die Ausbildung der Polizisten, die mit einem Grundausbildungsjahr in einer Polizeischule begann und dann in der kasernierten Bereitschaftspolizei für zwei bis drei Jahre fortgesetzt wurde (vgl. Dams 2008: 11). ${ }^{34}$ Entgegen aller Demilitarisierungsvorgaben der Alliierten wurde an bekannte Ausbildungsstrukturen angeknüpft und Polizisten wurden hier weiterhin unter militärischem Drill zu Gehorsam ausgebildet (vgl. ebd.: 11 f.).

Einheitlich hat sich auch eine funktionale Differenzierung der Polizei ausgebildet. In den westdeutschen Bundesländern gab es fortan eine Kriminal-, eine Schutzund eine Bereitschaftspolizei (vgl. Stolleis 2018: 34).

In den 1950er Jahren veränderte sich die Polizeiarbeit durch Motorisierung und Technisierung. Zum einen wurde die Polizei selbst zunehmend mit (Funk-) Streifenwagen ausgestattet und lief nun nicht mehr Streife, sondern fuhr immer häufiger in größer werdenden Einsatzgebieten. Zum anderen veränderte sich durch eine Zunahme an Autos auch die Tätigkeit der (Schutz-)Polizei, die nun vermehrt mit Verkehrsüberwachung und -unfällen beschäftigt war (vgl. Haselow/Noethen/Weinhauer 2000: 135 f.). Mit dieser Entwicklung und nach einiger Euphorie in den 50er Jahren entwickelte sich in den 60er Jahren zunehmend eine Skepsis gegenüber Streifenfahrten, die den direkten Bürger*innenkontakt einschränken und dazu verleiten, ohne auszusteigen oder ohne dienstliche Notwendigkeit einfach ,herumzufahren' (vgl. ebd.: 139 f.). Der in der Weimarer Republik entwickelte, aber auch von den Nazis genutzte Slogan von der Polizei als „Freund

\footnotetext{
32 Für eine mehr juristisch gerahmte Darstellung der Polizeigeschichte der Bundesrepublik siehe Stolleis (2018) und Petri (2018).

33 Der Bundesgrenzschutz kann jedoch als eine Art Bereitschaftspolizei auf Bundesebene verstanden werden (vgl. Stolleis 2018: 35).

34 Grundlegend bliebt dies bis in die 1980er Jahre bestehen. Auf die Veränderungen werde ich im Folgenden nicht eingehen, sondern erst wieder die Ausbildung, wie sie heute erfolgt, darstellen. Zu den Veränderungen in der Ausbildung in den 1970/80er Jahren siehe Busch et al. (1988: 147-169).
} 
und Helfer" 35 wurde wieder verwendet, um eine bürgernahe Polizei zu propagieren (vgl. Fairchild 1988: 44) - möglicherweise auch um der erwähnten Skepsis zu begegnen. Dieses Bild steht in den folgenden Jahren allerdings in Kontrast zu einem zunehmend härteren Vorgehen der Polizei (s.u.). Aus polizeilicher Perspektive sind diese Jahre, vermutlich auch in Verbindung mit dem allgemeinen wirtschaftlichen Aufschwung in Deutschland, ruhig. Die späten 1950er bis Mitte der 1960er Jahre sind für die Polizei insgesamt eine „,era of good-feeling“ (ebd.: 43).

Reformbemühungen sind seit Mitte der 1960er, vor allem aber in den 1970er Jahren festzustellen, die sowohl mit der internen Dynamik der Polizei als auch mit Wandel und Auseinandersetzungen in der Gesellschaft zusammenhängen. Zum einen setzte in der Polizei in den 1960ern ein Generationenwechsel von (leitenden) Polizisten ein. Immer mehr jüngere, während des Krieges geborene Männer, die keine nationalsozialistischen Sozialisationsinstanzen durchlaufen hatten, traten in den Polizeidienst ein. ${ }^{36}$ In Führungspositionen kamen außerdem die „Modernisierer“, die meistens erst nach dem Zweiten Weltkrieg zur Polizei gekommen und nicht ausschließlich in kasernierten Polizeieinheiten ausgebildet worden waren; sie waren weniger an militärischem Drill und Traditionspflege - wohl aber an ,Ordnung $^{6}$ - interessiert (vgl. Weinhauer 2003: 340 f.). Zum anderen scheiterte die Polizei mit ihren Einsatzkonzepten bei den Demonstrationen der 1960er Jahre. Weinhauer spricht daher von einer „doppelten Krise“, in der sowohl die Machtverhältnisse innerhalb der Polizei, zwischen Führung und Untergebenen, als auch die polizeilichen Einsatzkonzepte infrage gestellt wurden (Weinhauer 2001: 304).

In den 1960er Jahren sah sich die Polizei (in den Großstädten, vor allem Berlin) mit der linken Studentenbewegung und ihren Demonstrationen konfrontiert, ${ }^{37}$ die sie teils brutal niederschlugen, unter anderem auch, weil es keine Einsatztaktik jenseits eines solchen Eingreifens gab (vgl. ebd.: 303 f.); seit der Weimarer Republik hatte sich dieses Vorgehen bei Menschenansammlungen (und linkem Protest) etabliert (vgl. ebd.: 315). Dabei zeigte sich auch, dass der Protest und das polizeiliche Handeln vielmehr eine symbolische Dimension hatten, als dass sie konkrete Reaktionen waren: Die Protestierenden äußerten eine grundsätzliche Kritik an (welt-)gesellschaftlichen Verhältnissen und die Polizei verteidigte den Staat und das staatliche respektive ihr eigenes Gewaltmonopol (vgl. Weinhauer 2004: 232). In der polizeiinternen (und auch öffentlichen) Debatte offenbarten sich in diesem

\footnotetext{
35 Siehe zu dem Terminus Kapitel 4.1.1 und die Fn. 22.

36 In den späten 1950er und frühen 60er Jahren gab es außerdem einige Diskussionen um die NS-

Vergangenheit der Polizei, zu einer größeren vergangenheitspolitischen Auseinandersetzung kam es allerdings nicht (vgl. für Nordrhein-Westfalen Weinhauer 2003: 125-141). Ausgelöst wurden die Diskussionen vermutlich auch durch die Gründung der Zentralen Stelle der Landesjustizverwaltungen in Ludwigsburg, die die Aufgabe hatte, nationalsozialistische Verbrechen außerhalb des Bundesgebietes zu ermitteln (vgl. Haselow/Noethen/Weinhauer 2000: 133 f.; Liebert 2001: 98 f.).

${ }_{37}$ Zum Umgang der Polizei mit Protest, politischer Gewalt und sozialen Bewegungen (,,protest policing") zwischen den 1960er und 80er Jahren im Kontext der sozio-historischen und politischen Entwicklungen siehe Della Porta (1995) und auch Winter (1998).
} 
Zusammenhang autoritäre oder auch nationalsozialistische Einstellungen bei gleichzeitigen Forderungen nach einer angemesseneren Ausstattung der Polizei, aber auch nach Reformen von Einsatztaktiken und Ausbildung sowie der hierarchischen Verhältnisse innerhalb der Polizei (vgl. Weinhauer 2001: 324 f.). Weinhauer $(2000,2001,2003)$ rekonstruiert die interne Dynamik der Schutzpolizei in den 60er Jahren und zeigt unter anderem die starken Bezüge auf Traditionen und Männlichkeits- sowie Kameradschaftsideale der Weimarer Republik sowie den Umgang mit der NS-Vergangenheit auf. Diese Traditionspflege der polizeilichen „Patriarchen“, der vor 1912 geborenen Polizisten, kann einerseits als Reaktion auf die internen Spannungen innerhalb der Polizei zurückgeführt werden. Andererseits können durch die „Mythologisierung und Heroisierung der Weimarer Polizei [...] die Belastungen der NS-Vergangenheit" (Weinhauer 2003: 84) verdrängt werden, obwohl die Form der propagierten Kameradschaftlichkeit auch für die NS-Zeit festgestellt werden kann. Die Entwicklung der Polizei ,hinkte' der gesellschaftlichen hinterher (ebd.: 350), so dass Weinhauer für die Polizei der 60er Jahre resümiert: „Weimar war (fast) überall““ (ebd.: 333).38

Durch diese gesellschaftlichen und polizeilich-internen Dynamiken wurden einige Umstrukturierungen angestoßen, die 1970er Jahre wurden dann „das Jahrzehnt polizeilicher Reformen schlechthin“ (Haselow/Noethen/Weinhauer 2000: 140). Diese Reformen umfassten in erster Line organisationale Strukturen, Personal(aufstockung), Ausbildung und technische Ausstattung (vgl. Fürmetz/Reinke/Weinhauer 2001: 22). Durch immer neue Möglichkeiten der Datenerfassung und -sammlung kam es einerseits zu gesteigerter Effizienz. Andererseits wurde dadurch, wie schon durch die Motorisierung der 50er Jahre, der Kontakt zu den ,Bürger*innen' weiter eingeschränkt; Polizisten verloren an sozialen Erfahrungen, die sie einst lokal erworben und eingesetzt hatten (vgl. Haselow/Noethen/Weinhauer 2000: 141 f.). Angestoßen wurden diese Reformen der 1970er Jahre maßgeblich durch die Dynamiken der 60er Jahre, sie sind aber auch im Zusammenhang mit dem Attentat und der Geiselnahme bei den olympischen Spielen 1972 in München, bei dem der Befreiungsversuch ,normaler Polizisten scheiterte und tödlich endete, und dem Terrorismus der RAF ${ }^{39}$ in den 1970er Jahre zu sehen. Nach dem Münchener Attentat wurden in Deutschland sowohl auf Bundesebene wie auch auf Landesebene Sondereinsatzkommandos, unter anderem zur „Terrorismusabwehr“", gegründet - dies kann durchaus als Form der Re-Militarisierung verstanden werden. Vor allem das Bundeskriminalamt wurde in den 1970er Jahren deutlich ausgebaut und auch in seinen Kompetenzen erweitert

\footnotetext{
38 Mit Verweis auf den Buchtitel „Bonn ist nicht Weimar“ des Journalisten Fritz René Allemann, der 1956 die politische Situation der jungen Bundesrepublik skizzierte.

39 Diese Darstellung ist verkürzt. Neben der RAF gab es weitere Gruppierungen (einen Überblick gibt Della Porta 1995: 95-104), und auch die Bewertung als Terrorismus ist für viele der (militanten) Protestaktionen der verschiedenen Gruppierungen vor allem in den frühen 70er Jahren infrage zu stellen. Für einen Überblick über die Entwicklung des Terrorismus in der BRD in den 1970er Jahren im sozio-historischen und politischen Kontext siehe z.B. Weinhauer (2004).
} 
(Groß/Frevel/Dams 2008: 18). Die Polizei avancierte in breiten Teilen der Gesellschaft zur Beschützerin des Staates und der, Ordnung;, erhielt Akzeptanz aus der Bevölkerung und konnte sich nach innen, gegen einen äußeren Feind - den Terrorismus, die Linken, die Studenten - zusammenschließen (vgl. Winter 2000: 213); Kritik an der Ausweitung der polizeilichen Kompetenzen blieb weitgehend aus (vgl. Groß/Frevel/Dams 2008: 18). Das polizeiliche und politische Handeln in diesen Jahren trug aber gleichzeitig dazu bei, dass am Ende der 1970er Jahre in einigen Teilen der Bevölkerung „die Skepsis gegenüber staatlicher Macht“ (Weinhauer 2004: 239) gewachsen war, und gab damit Impulse für die Entwicklung der sozialen Bewegungen der 1980er Jahre (vgl. ebd.: 238 ff.).

In den späten 1970er und 1980er Jahre waren die Friedens- und die AntiAtom-Bewegung aktiv. Im Zuge dieser Demonstrationen ging die Polizei deeskalierender und weniger mit vorbeugender, repressiver Gewalt vor als in den vorangegangenen Jahrzehnten (vgl. Haselow/Noethen/Weinhauer 2000: 145), obwohl ihre Ausrüstung und ihr Auftreten bei Großeinsätzen militärisch wirkten. Trotz deeskalierender Taktiken kam es, vielleicht auch wegen dieses Auftretens, auch hier zu teils massiven Ausschreitungen zwischen Polizei und Demonstrierenden, wie z.B. bei der bis dahin größten Demonstration in der Bundesrepublik gegen den Bau des Atomkraftwerks Brokdorf (vgl. Busch et al. 1988: 328-342) oder auch bei den Demonstrationen um den Bau der Wiederaufbereitungsanlage Wackersdorf 1985. Unterstützt durch den „Brokdorf-Beschluss“ des Bundesverfassungsgerichtes, der die Versammlungsfreiheit regelt, wurde, im Vergleich, trotzdem insgesamt eine deeskalierendere Einsatztaktik zur Leitlinie (vgl. Haselow/Noethen/Weinhauer 2000: 145). Diese Einsätze scheinen Bezugspunkte für polizeiliche Geschichten oder Mythen zu sein, jedenfalls haben die wenigen älteren Beamten, die ich interviewt habe, über diese Einsätze gesprochen, unabhängig davon, ob sie daran teilgenommen haben oder nicht. In den Interviews konnte bzw. sollte je nach Kontext der Argumentation Verschiedenes mit diesen Einsätzen verdeutlicht werden: die Gewalt, die Polizist*innen bei solchen Einsätzen gegen sich erleben, wie sehr Polizist*innen bei solchen Einsätzen ein ,Spielball` der Politik sind, oder ganz allgemein um zu zeigen, wie „krass“ es damals gewesen sei - letzteres wird sicherlich nicht nur mir gegenüber, sondern auch gegenüber jüngeren Kolleg*innen ausgedrückt.

Eine grundlegende Änderung vollzieht sich in den 1980er Jahren, als Frauen zur Schutzpolizei zugelassen werden. Bis dahin hatte es keine Frauen in der uniformierten Schutzpolizei gegeben, sondern ausschließlich eine „Weibliche Kriminalpolizei“. Ausgehend von Forderungen der (internationalen) Frauenbewegung wurden im Deutschen Kaiserreich Frauen als Polizeiassistentinnen in den Zuständigkeitsbereichen Jugendfürsorge und Prostitution eingestellt, jedoch ausdrücklich nicht für, im engeren Sinne, polizeiliche Tätigkeiten (vgl. Nienhaus 1992: 243 ff.; Blum 2009: 512 f.). In der Weimarer Republik entwickelte sich die Weibliche Kriminalpolizei in den Einzelstaaten unterschiedlich, befasste sich aber weiterhin überwiegend mit ,Unzucht‘, Frauen und Kindern. Zwar bedeutete ihr Einsatz in 
diesem Bereich eine Hilfe für Frauen und Kinder, die von (männlichen) Polizeimaßnahmen betroffen waren, allerdings waren ,ihre Konzepte von ,Gefährdung', [...] besonders aber solche von ,Verwahrlosung ${ }^{6}$ autoritäre und teilweise auch zeitgenössisch-präfaschistische“ (Nienhaus 1992: 265).

Auch wenn sich die Weibliche Kriminalpolizei zunehmend etablieren konnte, blieb ihre Position prekär und politischen Interessen unterworfen (vgl. ebd.: 248 ff.). So auch nach der nationalsozialistischen ,Machtübernahme', mit der auch die Frauenbewegung ausgeschaltet wurde, die damit als Unterstützung für die weibliche Polizei verschwand (vgl. Götting 2009: 490 f.). Viele Frauen mussten ihren Posten verlassen, weil sie Jüdinnen waren oder weil die NS-Ideologie Frauen insgesamt eine andere Rolle zudachte. Über ihre Auflösung wurde diskutiert. Es wurden aber Aufgaben gefunden, die an die Tätigkeiten in der Weimarer Republik anknüpften, wie z.B. die „Bewahrung“ von gefährdeten Personen (vgl. Götting 2009: 499 ff.; Blum 2009: 520 f.). Im Rahmen der nationalsozialistischen präventiven Verbrechensbekämpfung bedeutete dies eine zeitlich unbefristete ,Ingewahrsamnahme von z.B. „erziehungsunfähigen“ Jugendlichen oder „erblich belasteten“ Kindern von sogenannten „Berufsverbrechern“, die kriminalbiologisch ${ }^{40}$ beurteilt werden sollten, während sie gleichzeitig Arbeitsdienst verrichteten (vgl. Blum 2009: 521 ff.). Die Weibliche Kriminalpolizei arbeitete in den sogenannten polizeilichen „Jugendschutzlagern“ - den Jugendkonzentrationslagern Moringen und Uckermark - und verwaltete diese (ebd.: 524 ff.).

Von der Entnazifizierung, trotz dieser Tätigkeiten, nur sehr begrenzt betroffen, konnten die Polizistinnen ungebrochen bzw. schnell wieder ihren Dienst versehen (vgl. ebd.: 527). Dennoch wurde eine uniformierte weibliche Polizei Mitte der 1950er Jahre aufgegeben und man kehrte zu den Anfängen - eine Weibliche Kriminalpolizei mit Tätigkeiten im Bereich Kinder- und Jugendarbeit - zurück. In den Ländern der Bundesrepublik entwickelte sich die Beschäftigungspolitik dann unterschiedlich. Im Bereich der uniformierten Schutzpolizei wurden Frauen zwischen 1980 (als erstes: Hamburg und Berlin) und 1990 (als letztes: Bayern) wieder oder erstmals zugelassen (vgl. Pfeil 2006: 51f). ${ }^{41}$

$\mathrm{Zu}$ weiteren Reformen kam es in den 1990er Jahren mit der Wiedervereinigung Deutschlands. Diese Reformen betrafen allerdings fast ausschließlich die ,neuen` Bundesländer, in der die Polizei, wie auch die Gesellschaft, erhebliche Anpassungsleistungen erbrachte und erbringen musste (vgl. Groß/Frevel/Dams 2008: 19 f.). Insgesamt wurde das westdeutsche Polizeisystem auf die östlichen Bundesländer übertragen.

In den 1990er Jahren ist außerdem eine zunehmende Digitalisierung und Vernetzung der deutschen Polizeien sowie eine Internationalisierung der Polizeiarbeit

\footnotetext{
40 Siehe dazu auch Kap. 3.1.1.

41 Auch in der DDR haben Frauen nur eine marginale Rolle in der Volkspolizei zugewiesen bekommen. Sie waren eher im Meldewesen und ab Mitte der 1960er Jahre auch in der Verkehrs- und Kriminalpolizei beschäftigt (vgl. Pfeil 2006: 52).
} 
(z.B. die Gründung des Europäischen Polizeiamtes Europol) festzustellen (vgl. Petri 2018: 47 ff.).

Umfassende Verwaltungsreformen wurden in den 1990er Jahren eingeleitet, die in den 2000er Jahren als umgesetzt gelten. Sie orientierten sich an Fragen der Berufszufriedenheit der Polizist*innen, zielten aber auch auf eine Professionalisierung von Mitarbeitenden und Organisation, eine prinzipielle Effizienzsteigerung und Wirtschaftlichkeit sowie eine Bürger- und ,Kundenorientierung'. Bei dieser Verwaltungsreform, dem „Neuen Steuerungsmodell“ als deutsche Form des „New Public Management“, geht es im „Kern [...] um eine stärkere betriebsökonomische Ausrichtung des Verwaltungsgeschehens" (Lange/Schenck 2003: 248) bzw. eine „Implementierung betriebswirtschaftlicher Elemente von ProfitUnternehmen in ein bürokratisches und zweckrationales sowie nach wie vor entscheidend politikgesteuertes Organisationsmodell" (Haselow/Noethen/Weinhauer 2000: 147, Hervorhebung im Original). Diese Reform wurde in den Bundesländern unterschiedlich umgesetzt (ausführlich Lange/Schenck 2004). Durch verschiedene betriebswirtschaftliche Maßnahmen sollte die niedersächsische Polizei zu einem „modernen Dienstleister“, der sich an seinen „Kunden“ orientiert, ${ }^{42}$ werden (vgl. Lange/Schenck 2004: 174 f.). Diese Ausrichtung auf die ,Kunden“ und eine ökonomistische Output-Steuerung ist nicht unumstritten in der Polizei, da diese Maßnahmen auch Auswirkungen auf das polizeiliche Handeln haben: Themen und Probleme, die polizeiliches Handeln erforderlich machen, werden nun nicht nur durch das Legalitätsprinzip ${ }^{43}$ gestaltet, sondern auch durch eine Problemsetzung von Politik ${ }^{44}$, Medien und lokalen Akteuren. Dies kann sowohl positiv betrachtet werden, etwa wenn ,die ${ }^{6}$ Öffentlichkeit auf Probleme aufmerksam machen kann, bedeutet aber auch, dass Polizist*innen sich einer „Fremdrationalität", die nicht ihren Erfahrungen entspricht, ausgesetzt sehen und diese vor dem Hintergrund einer Kosten-Nutzen-Rechnung von Einsätzen auch zum Entscheidungskriterium über Mittel und Notwendigkeiten eines polizeilichen Einsatzes wird (Lange/Schenck 2003: 257 f.). In diesem Zusammenhang kann auch die Output-Steuerung (durch Controlling-Systeme) betrachtet werden, bei der Quoten zu bestimmten Delikten oder Ordnungswidrigkeiten in einem bestimmten Zeitraum erfüllt werden sollen (z.B. x-mal ,Knöllchen` für Falschparken pro Monat).

\footnotetext{
42 Zum Kundenbegriff siehe Kap. 4.1.2 und Fn. 86.

${ }^{43}$ Das Legalitätsprinzip verpflichtet alle Strafverfolgungsbehörden zu ermitteln, wenn sie Kenntnis von einer Straftat erlangen $\left(\$ 152, \int 160\right.$ und $\$ 163$ StPO). Das Opportunitätsprinzip regelt wiederum Ermessensspielräume für die Verfolgung von Straftaten ( $\$ 153$ StPO) und Ordnungswidrigkeiten ( $(47$ Gesetz über Ordnungswidrigkeiten (OWiG)).

${ }^{44}$ Dadurch, dass die Behörden theoretisch unterschiedliche Zielvereinbarungen verhandeln können, bedeutet das nicht, dass flächendeckend eine von der jeweiligen Landesregierung beschlossenen Strategie umgesetzt wird, da die allgemeinen Strategien interpretationsbedürftig für die konkrete Praxis sind. Dies macht es einerseits möglich, auf lokale Gegebenheiten zu reagieren, andererseits fragen sich Lange und Schenck, ob „der demokratisch gefasste Wille damit nicht unterlaufen und somit die demokratische Legitimation des Verwaltungshandelns sich potentiell auflösen wird“ (Lange/Schenck 2003: 261).
} 
Dies entspricht unter Umständen nicht den lokalen polizeilichen Problemlagen und führt zu einem kreativen und eben nicht kosteneffizienten Umgang bei der Erfüllung der Zahlen (vgl. Lange/Schenck 2003: 259) - wie ich auch in Kapitel 4.3.4 anhand der Deutungsmuster über irrelevante polizeiliche Arbeit zeigen werde.

Im Zuge dieser Reformen wurde in einigen Bundesländern von dem bisherigen System einer dreigeteilten Laufbahn zugunsten einer zweigeteilten Laufbahn Abschied genommen. Nach und nach wurde der mittlere Dienst, die unterste Laufbahnstufe, abgeschafft. Lange und Schenck stellen, für Nordrhein-Westfalen mit der größten Landespolizei und in einer Vorreiterrolle bei dieser Reform, fest, dass in der Folge, „die Hierarchien, in der traditionell sehr hierarchischen Organisation Polizei, erstmals unklar" (Lange/Schenck 2003: 256) waren. Durch die Abschaffung des mittleren Dienstes und die damit einhergehenden Beförderungen in den gehobenen Dienst gab es teilweise keine (sichtbare) Differenz mehr zwischen den Hierarchieebenen (innerhalb einer Dienstabteilung), Vorgesetzte konnten unter Umständen sogar einen niedrigeren Dienstgrad bekleiden als in diesem Zuge beförderte ältere Untergebene. Autorität konnte nun nicht mehr gleichsam naturwüchsig aus dem Dienstgrad bezogen werden, sondern musste verhandelt werden (vgl. Lange/Schenck 2003: 256 sowie Kap. 4.3.6).

\subsubsection{Zusammenfassung: Kontinuitäten und Schlussfolgerungen}

Bevor ich im folgenden Kapitel die heutige Organisationsstruktur der niedersächsischen Polizei skizziere, möchte ich die Kontinuitäten der Entwicklung der modernen Polizei zusammenfassen. Deutlich wird bei diesem Blick in die Polizeigeschichte, dass die Organisationsentwicklung eng mit den politischgesellschaftlichen Entwicklungen verbunden war und ist. Ende der 1980er Jahre schlussfolgerte Erika Fairchild treffend, dass die Geschichte der Polizei die deutsche Geschichte seit 1918 reflektiert: „During the ruthless Nazi dictatorship, a ruthless and brutal police force was developed to support the leadership. During times of prosperity and good feelings, police operations emphasized friendliness, helpfulness, and community education. In times of social stress and disorder, the police response has been one of increasing alienation from the public and a siege mentality" (Fairchild 1988: 55; s. auch Della Porta 1995: 69). Diese Bewegungen lassen sich in der Polizeigeschichte seit dem Deutschen Kaiserreich gut nachvollziehen. Die deutsche Polizei erlebte mehrfach Phasen der De- und Remilitarisierung. Nach beiden Weltkriegen wurde die Polizei umstrukturiert und demilitarisiert - jeweils auch angestoßen oder auferlegt von den Alliierten. Aufrechterhalten wurde dies immer nur für eine begrenzte Zeit. Die Umstrukturierungen und Erfahrungen aus der Zwischenkriegszeit prägten die Polizei auch nach dem Zweiten 
Weltkrieg wieder. ${ }^{45}$ Es wurden sowohl Organisationstrukturen wieder aufgegriffen als auch Deutungsmuster aus und über die Weimarer Republik wiederbelebt. Referenzen dieser Deutungsmuster finden sich im Wir-Bild der Polizei noch heute (vgl. Kap. 4.1).

Für die deutsche (Schutz-)Polizei lässt sich bis zum Beginn der 1990er stark vereinfacht festhalten, dass sie sich bei Protest- und Demonstrationsgeschehen eher mit linkem/kommunistischem Protest befasste, weniger mit rechtsradikalem. Im Kaiserreich und in der Weimarer Republik war es zunächst die republikanische und kommunistische ,Gefahr', die die Polizei beschäftigte. Der Nationalsozialismus wurde weniger als Bedrohung empfunden, auch wenn die Polizei oft die (gewaltvollen) Auseinandersetzungen zwischen Kommunisten und SA begleitete, dabei eingreifen musste und selbst zum Ziel, auch der SA, wurde und gegenüber der SA an Autorität verlor. In der Bundesrepublik waren es dann die linken studentischen Demonstrationen und der Linksterrorismus, der die Polizei beschäftigte. Rechte Aktivitäten in der Bundesrepublik gipfelten häufiger in Anschlägen als in Demonstrationen (vgl. Winter 1998: 361). Sie betrafen einen Großteil der etablierten Bevölkerung nicht direkt, weil diese nicht befürchten musste Ziel zu werden, und konnten so auch keine solche öffentliche Wirkung wie z.B. die RAF entfalten. Mit Anschlägen war außerdem in erster Linie die Kriminalpolizei betraut, daher gab es unter Schutzpolizisten bis in die 1990er Jahre weniger Erfahrungen mit rechtem ,Protest'. Bis zu den Angriffen auf die Unterkünfte von Vertragsarbeiter*innen und Geflüchteten in Hoyerswerda und Rostock-Lichtenhagen wurde rechte, rassistisch motivierte Gewalt im Rahmen von ,Protest' ${ }^{6}$ (erneut) innerpolizeilich unterschätzt und kaum diskutiert (vgl. Winter 1998: 320 ff., 358 ff.). ,Linke' wurden viel stärker als Bedrohung und Störung wahrgenommen als ,Rechte ${ }^{6}$ - und meine Interviews mit Bereitschaftspolizisten deuten an, dass dem noch immer so ist. Ein aktuelles Beispiel (Kapp 2020) findet sich im Zusammenhang mit Fußball: Bei Diskussionen um eine neue Polizeiverordnung für ein Fußballstadion erklärte ein Polizeisprecher, dass Protest, der Kritik an der Polizei übt, linksradikal sei. Auch wenn die Erklärung des Polizeisprechers verkürzt wiedergegeben wurde in dieser Diskussion, wird Polizeikritik häufig umstandslos als linksradikaler Protest aufgefasst, und so ist es nur folgerichtig, dass ,Linke“ als Bedrohung wahrgenommen werden. Unter anderem durch eine Ausbildungsstruktur, in der alte Polizist*innen auf Grundlage ihrer Erfahrungen junge Polizist*innen unterrichten, transformieren sich solche Deutungsmuster nur langsam. Durch die

45 Gewinnbringend wäre sicherlich, die deutsche Polizei- und Militärgeschichte gemeinsam zu betrachten, da die Entwicklung und De- sowie Re-Militarisierung der Polizei oft verbunden war mit der Entwicklung und Beschränkung des Militärs, sowohl auf politisch-legaler Ebene als auch auf personeller Ebene. Auf personeller Ebene ist dies durchaus nicht nur eine historische Feststellung: Manche Bundesländer versuchen (ehemalige) Zeitsoldat*innen gezielt für den Polizeidienst anzuwerben. Unter der Annahme, dass sie schon bestimmte Kompetenzen, die im Polizeidienst relevant sind, mitbringen, ist ihre Ausbildung teilweise deutlich verkürzt. So stehen sie schneller bereit als andere Anwärter*innen. 
Ausbildung bzw. die Sozialisation der Polizist*innen innerhalb der Bereitschaftspolizei (vgl. Kap.2.3 und 5) ist diese Wahrnehmung nicht nur für die Bereitschaftspolizei, die Protest poliziert, relevant, sondern auch für die Schutzpolizei bzw. den Einsatz- und Streifendienst. Die hier tätigen Beamt*innen sind ebenfalls unter diesen Bedingungen polizeilich sozialisiert worden.

Blickt man auf die hier skizzierte Geschichte, zeigt sich, dass die Polizei immer auch Mittel der Politik war. Die Polizei wurde und wird eingesetzt, um politische Entscheidungen abzusichern und durchzusetzen - auch mit Gewalt. Die Polizei begrenzt(e) als gewaltlizensierte Organisation nicht nur Gewalt, sondern sie übt sie auch aus, um das Gewaltmonopol mit seinen Entscheidungen durchzusetzen. Anhand der deutschen (Polizei-)Geschichte lässt sich auch nachvollziehen, dass Polizeien, wie Reemtsma schreibt, in Diktaturen wie in Demokratien zu finden sind - im deutschen Fall handelt es sich dabei um die gleiche Polizei, die das jeweilige Gewaltmonopol (mehr oder weniger) stützt(e). In Bezug auf den Gewaltgebrauch zeigt sich, dass immer dann Reformen angestoßen wurden, wenn sich Gewaltmittel der Polizei (oder im Kaiserreich: des Militärs) als unzureichend für die Lösung von politischen oder gesellschaftlichen Konflikten erwiesen haben und das Gewaltmonopol in der öffentlichen Kritik stand. Im Zusammenhang mit dieser Kritik und steigenden Anforderungen an polizeiliche Arbeit im Kontext gesellschaftlicher Entwicklungen stehen immer auch Professionalisierungsbestrebungen. Verbunden sind damit auch Versuche, die Polizei ,bürgernäher' zu zeigen und/oder zu gestalten. So könnte man das Organisationsbild, das den Reformen im Rahmen des Neuen Steuerungsmodells zugrunde liegt, auch als eine Art vorläufigen Höhepunkt dieser Versuche betrachten: Eine Organisation, die sich an den Kundenwünschen orientiert und moderner Dienstleister ist. In Zeiten „of prosperity and good feelings" verschwindet Gewalt als ,Dienstleistung" der Polizei aus ihren Selbstbeschreibungen. ${ }^{46} \mathrm{Zu}$ beobachten ist insgesamt, dass „die Betonung der Rolle der Gewalt bei der Definition der Polizei-Funktion in den Hintergrund" (Brodeur 2002: 260) getreten ist. Auch für manche Polizist*innen mag durch die Vermarktung der Polizei als Dienstleisterin mit Bürger- oder sogar Kundenorientierung die Rolle von Gewalt und die Rolle der Polizei als Gewaltorganisation, trotz Ausbildung an der Waffe etc., aus dem Blickfeld geraten sein. Denn entgegen der Argumentation z.B. der Polizeigewerkschaften, dass Gewalt gegen Polizist*innen zunehme (z.B. Gewerkschaft der Polizei 2016; siehe dazu auch Behr 2012: 182 f.; Reuter 2014: 107 ff.), zeigt der Blick in die Geschichte der Institution, dass deutsche Polizist*innen selten so wenig Gewalt ausgesetzt waren und Gewalt ausübten wie heute - zumindest nicht in Form von "Straßenkampf“ wie in der Weimarer Republik oder als Mörder für das NS-Regime.

\footnotetext{
46 In den Imagebroschüren der Polizei Niedersachsen (Niedersächsisches Ministerium für Inneres und Sport 2018) oder der Bundespolizei (Bundespolizeipräsidium o.J.) z.B. taucht das Wort Gewaltmonopol nicht auf. Ebenso wenig das Wort „Gewalt" als Nomen, dieses wird nur in Form eines Adjektivs oder Adverbs als „gewalttätig“ oder ,gewaltsam“ genutzt und bezieht sich allein auf die ,Anderen', nicht auf die Polizist*innen und ihr Handeln. Siehe dazu auch Pudlat (2012: 204-206).
} 


\subsection{Die Organisations- und Ausbildungsstruktur der Polizei Niedersachsen}

Im Folgenden möchte ich kurz die grundlegenden Organisationsstrukturen der Polizei Niedersachsens vorstellen. Sie sind zum Verständnis des empirischen Teils der Arbeit hilfreich und sollen an dieser Stelle einen groben Überblick über die Rahmenbedingungen geben. Die alltagspraktische und biographische Re-/Produktion und Relevanz dieser Strukturen werden ausführlicher in Kapitel 4 und 5 rekonstruiert.

Auf den historischen Entwicklungen der Polizei aufbauend, stellt sich die Polizei in Deutschland heute wie folgt dar: Die Polizei ist föderal organisiert. So hat jedes Bundesland eine eigene Polizei mit je eigener Gesetzgebung, hinzu kommen die Bundespolizeien (Bundeskriminalamt und Bundespolizei) sowie die Polizei des Deutschen Bundestages. Damit existieren 19 Polizeien; von ,der ${ }^{6}$ Polizei kann also eigentlich nicht gesprochen werden (vgl. Groß 2019: 4). Innerhalb der Länderpolizeien ist außerdem funktional zwischen drei Sparten zu differenzieren: Schutzpolizei, Kriminalpolizei und Bereitschaftspolizei. Im Fokus dieser Arbeit steht die Schutzpolizei, deren Tätigkeit in Niedersachsen als Einsatz- und Streifendienst (ESD) bezeichnet wird - andere Bundesländer haben für diesen Arbeitsbereich teilweise andere Bezeichnungen gewählt, wie Wach- und Wechseldienst, wieder andere sprechen weiterhin von Schutzpolizei.

Die uniformierten Beamt*innen des Einsatz- und Streifendienstes sind grundsätzlich für die allgemeine Gefahrenabwehr, die Aufrechterhaltung von öffentlicher ,Sicherheit ${ }^{6}$ und ,Ordnung ${ }^{67}$ und den Verkehr zuständig. In den deutschen Landespolizeien sind ca. 80 Prozent der Polizist*innen in der Schutzpolizei tätig (vgl. Groß 2019: 6). Schutzpolizeiliche Arbeit macht damit, im Gegensatz zur kulturindustriellen und medialen Aufbereitung, den Schwerpunkt polizeilicher Arbeit aus. Die Kriminalpolizei hat ihren Zuständigkeitsbereich wiederum vor allem in der Strafverfolgung und Bekämpfung mittlerer und schwerer Kriminalität. Die Bereitschaftspolizei (Bepo) beruht als selbstständige Polizeiorganisation, wie in den 1950er Jahre bei der (Wieder-)Einführung der kasernierten Polizei, auf einer Verwaltungsvereinbarung zwischen Bund und Ländern. Sie ist vor allem zuständig für (länderübergreifende) Großeinsätze, zu denen geschlossene Polizeiverbände angefordert werden (vgl. Groß 2019: 6).

\footnotetext{
47 Beide Begriffe setze ich in Anführungsstriche, da sie interpretationsbedürftig sind. Für das Niedersächsische Polizeigesetz wurden die Begriffe auch aus dem Titel gestrichen. Statt „Niedersächsisches Gesetz über die öffentliche Sicherheit und Ordnung“ heißt es seit 2019 „Niedersächsisches Polizeiund Ordnungsbehördengesetz" (NPOG). Im alten wie im neuen Gesetzestext sind Sicherheit und Ordnung nur insofern definiert, als ein Schaden an ihnen eine „Gefahr“ darstellt (vgl. \ 2 Abs. 1. NPOG). Im Rahmen der Gefahrenabwehr ist die Polizei damit für die öffentliche Sicherheit und Ordnung zuständig. Für die Aufgabenbestimmung werden die Begriffe aber nicht explizit genutzt. Andere Bundesländer, z.B. Hessen, bestimmen die Aufgabe der Polizei (noch) ausdrücklich mit der Aufrechterhaltung von öffentlicher Sicherheit und Ordnung (vgl. $\int 1$ Abs. 1 HSOG (Hessisches Gesetz über die öffentliche Sicherheit und Ordnung)).
} 
In Niedersachsen ist der Polizeidienst nicht mehr, wie nach dem Zweiten Weltkrieg eingeführt, dreigliedrig organisiert, sondern seit 1995 wird nur noch in zwei Laufbahngruppen, in den gehobenen und in den höheren Dienst eingestellt (vgl. Götting/Rose 2008: 285 f.). Verbunden mit dem Wegfall des mittleren Dienstes ist auch eine Akademisierung der Polizeiarbeit bzw. -ausbildung. Beides hat zur Folge, dass die Tätigkeit aufgewertet und höher besoldet wird (vgl. Groß 2019: 8). Das Einstiegsamt des gehobenen Dienstes, das nur durch ein Studium zu erlangen ist, ist das des Polizeikommissars bzw. der Polizeikommissarin. Die Polizei Niedersachsen bildet nicht mehr ,klassisch' aus. Zugangsvoraussetzung ist hier, neben anderen Kriterien, das Abitur oder eine Fachhochschulreife. Schüler*innen, die die Schule nach der mittleren Reife verlassen, können durch ein einjähriges Praktikum bei der Polizei und einen einjährigen Berufsschulbesuch an der Fachoberschule für Wirtschaft und Verwaltung die Fachhochschulreife erlangen und im Anschluss an der Polizeiakademie Niedersachsen studieren.

Die Ausbildung bei der Polizei Niedersachsen ist heute als Bachelor-Studium an einer „monofachlichen Ressortfachhochschule“ (Hochschulrektorenkonferenz 2004: 3) organisiert. 48 In Niedersachsen schließt sie als „Polizeiakademie“ verschiedene Standorte zusammen. Während des Studiums sind die Beamt*innen Studierende und haben gleichzeitig den Status von Beamt*innen auf Widerruf. Löbbecke (2010) bezeichnet sie als „studierende Beamte“. Sie werden schon während des Studiums besoldet, haben aber auch die Pflichten von Beamt*innen wahrzunehmen. Die Lehrveranstaltungen können selten frei gewählt werden, die Stundenpläne ähneln einem Dienstplan, es gibt eine Anwesenheitspflicht und die Pflicht sich krank zu melden, wenn man fehlt. Sie werden aber auch mit einer Unterkunft, Sold, Versicherungen, Berufskleidung etc. versorgt. Die studierenden Beamt*innen sind somit eher Beschäftigte als sich selbst organisierende Studierende (vgl. ebd.: 150 f.). Schon von Beginn der Ausbildung bzw. des Studiums an sind die Beamt*innen stark in die Organisation Polizei eingebunden.

Das Studium selbst ist dual organisiert. Die praktische Berufsausbildung findet in zwei dreimonatigen Praktika (,berufspraktische Studienzeit" ${ }^{\circ}$ ) statt. Die restliche Ausbildung findet an der Polizeiakademie statt, die aber neben der theoretischen Ausbildung auch praktische Module enthält (vgl. Polizeiakademie Niedersachsen o. J.b). Das Studium wird mit einer mündlichen Prüfung und einer Bachelor-

48 Die Fälle, die ich in dieser Arbeit vorstelle, haben beide noch ein Diplomstudium an der Fachhochschule für Verwaltung und Rechtspflege, der Vorgängerorganisation der heutigen Polizeiakademie, absolviert. Ich habe mich trotzdem entschieden an dieser Stelle die Ausbildung, wie sie heute praktiziert wird, darzustellen. Im Vergleich mit den Interviews mit Beamt*innen, die schon einen BA-Studiengang absolviert haben, lassen sich strukturell keine Unterschiede feststellen - auch wenn sich der Aufbau des Studiums im Einzelnen verändert haben mag. Wichtigster Unterschied scheint mir die Länge der Praktika im Studium zu sein. Entgegen allgemeiner Entwicklungen im Zuge der Bologna-Reformen, bei dem Studiengänge mehr (berufs-)praktische/verwertbare Anteile bekommen haben, ist die Zeit der Praktika bei der Polizeiausbildung verkürzt worden: von zwei halbjährigen zu zwei dreimonatigen. Ausführlicher thematisiere ich die Ausbildung innerhalb der beiden Fallrekonstruktionen (vgl. Kap. 5.1 und 5.2). 
Arbeit abgeschlossen. Die Absolvent*innen haben dann einen Bachelor-Abschluss und sind Polizeikommissar*innen. Für eine weitere Qualifikation bzw. den Aufstieg in den höheren Dienst ist ein Masterstudium an der Deutschen Hochschule für Polizei in Münster notwendig. Hier werden alle deutschen Polizist*innen für die Berechtigung zum höheren Dienst zentral ausgebildet (vgl. Deutsche Hochschule der Polizei o. J.). Eine Besonderheit dieses berufsbezogenen Studiums ist, dass es außerhalb der Polizei kaum Verwendungsmöglichkeiten für das im Studium Erlernte gibt; lediglich Sicherheitsdienste kommen als potenzielle andere Arbeitgeber infrage. Das schafft eine gewisse Abhängigkeit vom Dienstherrn. Winter weist darauf hin, dass Kritik an der Polizei, oder auch an einzelnen Kolleg*innen und Vorgesetzten, durch diese (vermeintliche) Alternativlosigkeit einigen Mutes bedarf (Winter 1998: 87 f.).

Im Anschluss an das Studium arbeiten die jungen Polizist*innen im Rahmen ihrer sogenannten „Erstverwendung“ in der Regel für ein bis zwei Jahre, je nach Personallage, in der Bereitschaftspolizei. Auch wenn die Arbeit in geschlossenen Polizeiverbänden nicht mehr Teil der Ausbildung ist, finden die berufliche Sozialisation und die ersten Arbeitserfahrungen jenseits der Praktika so dennoch in diesen Einheiten statt. Die Bepo ist nicht mehr militärisch geprägt wie die kasernierten Polizeieinheiten der Weimarer Republik oder in der frühen Bundesrepublik, dennoch ist die Arbeit durch Befehl und Gehorsam und weniger Autonomie strukturiert als die Arbeit im Einsatz- und Streifendienst.

Nach den umfassenden Reformen der 1990er Jahre und einer weiteren Umstrukturierung 2004, nach dem Regierungswechsel von einer sozialdemokratischen zu einer konservativen Landesregierung in Niedersachsen im Jahr 2003, in dessen Folge unter anderem die Bezirksregierungen abgeschafft und die Polizeibehörden aus diesen herausgelöst werden mussten (vgl. Götting/Rose 2008: 278), stellt sich der organisatorische Aufbau der Polizei - stark vereinfacht - wie folgt dar: Die niedersächsische Polizei wird durch das Landespolizeipräsidium im Innenministerium geleitet. Ihm sind sechs Polizeidirektionen unterstellt. Diesen sind jeweils vier bis sieben Polizeiinspektionen (PI), insgesamt 33, sowie jeweils eine Zentrale Kriminalinspektion, nachgeordnet. Den Polizeiinspektionen sind Polizeikommissariate und Polizeistationen unterstellt (vgl. Landespolizeipräsidium o. J.).

Meine teilnehmende Beobachtung habe ich in einer dieser 33 Polizeiinspektionen im städtischen Raum durchgeführt. Sie ist im Wechselschichtdienst durchgängig besetzt. Die Polizeiinspektion wird von einem Inspektionsleiter geführt. Ihm unterstellt ist ein Führungsstab (aus Beamt*innen des gehobenen und höheren Dienstes) für verschiedene polizeiliche Arbeitsbereiche, darunter der „Leiter Einsatz“, der*die für die Organisation des Einsatz- und Streifendienstes verantwortlich ist. Die Polizeiinspektion hat vier Dienstabteilungen des ESD, die jeweils von einem*einer Dienstabteilungsleiter*in geführt werden, unterstützt durch eine*n $^{*}$ stellvertretende ${ }^{*}$ Einsatzführer*in (wie meine Interviewpartnerin Melanie Wegener, vgl. Kap. 5.1). Ihnen unterstellt sind je nach Personalausstattung und in Voll- oder Teilzeit Tätigen ca. 14-17 Einsatzbeamt*innen (wie mein Inter- 
viewpartner Markus Holtzmann, vgl. Kap. 5.2). Sie alle gehören, in der Regel, dem gehobenen Dienst an. Die Dienstabteilungsleiter*innen sind meistens Polizeihauptkommissar*innen und die Einsatzbeamt*innen Polizeikommissar*innen und Polizeioberkommissar*innen.

Diese erste, etwas trockene Annäherung an die vorgefundenen Organisationsstrukturen werde ich im Laufe der nächsten Kapitel ,mit Leben füllen': In Kapitel 4 mit der polizeilichen Alltagspraxis in diesen Dienstabteilungen des ESD sowie in Kapitel 5 mit den Sozialisationsprozessen in der Organisation Polizei und im Einsatz- und Streifendienst. Im Verlauf des folgenden Kapitels werde ich zunächst jedoch meinen (Feld-)Zugang zu den verschiedenen Organisationsebenen und meine Erfahrungen in und mit diesen schildern und reflektieren. 


\section{Polizei erforschen}

„If anything gets me down it's bloody sociology. I think it's the biggest load of shite, simple as that."

„I think most policemen can't relate to sociology at all, because, you see, the way we're tanght everything is black and white: those who do bad should be punished, those who do good should be rewarded. Sociology just seems to turn all that on its head. It would seem to say that all those who are right and honest are wrong $[\ldots]$ "

(Brewer 1991: 16)

Hier zitiert John Brewer zwei Polizeibeamte, die er im Rahmen seiner Forschung zur Polizeiarbeit in Nordirland getroffen hat. Es deutet sich ein Widerspruch zwischen Polizei und Soziologie bzw. zwischen (polizeilichem) Alltagshandeln und wissenschaftlichem Handeln an: der Widerspruch zwischen Komplexitätsreduktion und Komplexitätsdarstellung oder -nachvollzug. Wie kann man unter solchen Voraussetzungen soziologische Forschung in der Polizei, einer Organisation, die sich gegenüber Einblicken von außen abzuschließen versteht, betreiben? Auch wenn sich das Verhältnis zwischen Polizei und Soziologie bzw. Wissenschaft in den letzten 30 Jahren deutlich gewandelt hat, so lassen sich auch in Forschungsarbeiten zur deutschen Polizei sowie in Gesprächen mit Polizist*innen ähnliche, wenn auch vielleicht weniger drastische, Statements von Beamt*innen finden. Ich selbst habe in der Polizei sowohl Skepsis als auch Unterstützung erfahren - in erster Linie aber wohl so etwas wie Gleichgültigkeit gegenüber meinem Vorhaben. 
Um mein konkretes Vorgehen transparent zu machen, werde ich meinen Forschungsprozess nachzeichnen. Dies unterstützt nicht nur die Nachvollziehbarkeit der Ergebnisse, sondern führt auch in meine Feldforschung und meine Erfahrungen als Soziologin in der Polizei zu forschen ein (3.3). Hier werde ich auch die verwendeten Methoden, teilnehmende Beobachtungen und biographisch-narrative Interviews bzw. Fallrekonstruktionen vorstellen und reflektieren sowie ihre Verknüpfung diskutieren.

Bevor ich aber ins Feld einsteige, beginne ich zunächst mit einer Skizzierung der Entwicklungen der Polizeiforschung und diskutiere darin auch das Verhältnis von Polizei und Wissenschaft (3.1). Ich nehme dabei eine Einordnung meiner Arbeit in den Forschungsstand vor. Auf dessen Grundlage erläutere ich sodann meine theoretische Perspektive auf den Gegenstand: Handeln, Interaktion und Biographie im Kontext der Polizei (3.2). Ich zeige, dass diese sozialkonstruktivistische und biographietheoretische Perspektive nicht nur die polizeiliche Alltagspraxis in den Blick zu nehmen vermag, sondern auch die Genese von beruflichen Handlungsmustern. Arbeiten, die nach der Entwicklung polizeilicher Handlungsmuster (nicht nur) innerhalb der Organisation fragen, stellen eine Forschungslücke dar. Im Kontext bisheriger Forschungen über polizeiliches Handeln ist dies ein theoretisch und methodisch neuer Ansatz.

\subsection{Der Forschungsgegenstand im Kontext der Polizeiforschung}

Das Feld der (deutschen) Polizeiforschung ist divers. Von einer Polizei-Soziologie kann nur begrenzt gesprochen werden. Daher folgt hier keine umfassende Darstellung einzelner Arbeiten zu polizeilichem Handeln, stattdessen stelle ich die Entwicklung und Perspektiven der deutschen Polizeiforschung vor, um die vorliegende Arbeit anschließend darin einordnen zu können. Ich werde einen (wissenschafts-)historischen Blick auf die Polizeiforschung/-soziologie richten, da sie - so wie die Entwicklung der Organisation selbst (vgl. 2.2) - als mit den konkreten politischen Entwicklungen verknüpft betrachtet werden muss. Aufgrund der engen Verknüpfung von Gesellschafts-, Organisations- und Wissenschaftsgeschichte skizziere ich vor allem die (bundes-)deutsche Polizeiforschung. Erkenntnisse aus dem Bereich der anglo-amerikanischen Police Studies ziehe ich zur Kontrastierung heran. 


\subsubsection{Entwicklung und Perspektiven der deutschen Polizeiforschung49}

Im frühen 18. Jahrhundert entwickelte sich die Policeywissenschaft als Lehre von der ,guten Ordnung“ des Gemeinwesens in enger Verbindung „mit der Herausbildung moderner Territorialstaaten“ (Mokros 2013: 8) und unter dem Druck, die Verwaltung zu modernisieren. In Preußen, Österreich und anderen Staaten des Deutschen Bundes behandelte die an Universitäten gelehrte Policeywissenschaft ,alle Verwaltungsbereiche, die sich auf das innenpolitische Handeln des Staates bezogen“" (ebd. 2013: 8). Die Policeywissenschaft beschäftigte sich noch nicht mit der Polizei im engeren Sinne (vgl. Möllers/van Ooyen 2015: 20), sondern mit Verwaltungswissenschaft, Volkswirtschafts- und Gesetzgebungslehre.

Im 19. Jahrhundert differenzierte sich die Policeywissenschaft aus: Mit den politischen, wirtschaftlichen und gesellschaftlichen Veränderungen im Zuge der Industrialisierung wurde es notwendig, Bereiche der Policeywissenschaft zu spezialisieren und zu vergrößern. Statt der „,vorgegebenen Einheit von Staat und Untertan“" bestimmte nun die Trennung von Staat und Gesellschaft verschiedene Politikfelder und führte unter anderem zu der Forderung nach mehr Selbstbestimmungsrechten, auch wenn eine obrigkeitstreue Staatstradition gleichzeitig erhalten blieb (vgl. Möllers/van Ooyen 2015: 23). Die industrielle Revolution veränderte aber nicht nur die gesellschaftlichen Forderungen, sondern auch die sozialen Verhältnisse, was sich unter anderem in einem Anstieg von Kriminalität ausdrückte (vgl. ebd.). Polizei wurde nun zunehmend mit Sicherheitsaspekten verbunden und „meint seit dem frühen 19. Jahrhundert die staatlichen Polizeibehörden“ (Mokros 2013: 9), die für die Gefahrenabwehr zuständig sind.

Im Zuge der Modernisierung der Polizei in der Weimarer Republik (vgl. Kap. 2.2.2) wurde dann die Idee einer Professionalisierung und wissenschaftlichen Fundierung von Polizeiarbeit entwickelt (vgl. ebd.: 10-11). An den Universitäten waren die Bereiche von Kriminalistik und Polizeiwissenschaft jedoch nur als ein Fach der Rechtswissenschaften präsent; die Polizeiführungskräfte wurden an „Höheren Polizeischulen“ ausgebildet (vgl. ebd.: 11). Eine universitär verankerte ,eigene ${ }^{6}$ Polizeiwissenschaft, die im Zusammenhang mit der Akademisierung der Polizei stand, entwickelte sich nicht.

49 Ich beziehe mich in diesem Kapitel nur auf die Entwicklung der Polizeiforschung in der Bundesrepublik, da mir Forschungen aus der DDR über die Polizei nicht bekannt sind, solche eventuell auch nicht existieren. Denn Wissenschaft war in der DDR einerseits als ideologische Grundlage des marxistisch-leninistischen Weltbildes relevant, andererseits stand sie (in Bezug auf die Polizei bzw. Staatssicherheit) immer vor einer Herausforderung: ,Wissenschaftlichkeit durfte niemals die Schwelle zu kritischer Intellektualität überschreiten, die die prinzipielle Richtigkeit der SED-Politik und die Rolle des MfS [Ministerium für Staatssicherheit, M.S] selbst infrage stellen konnte“" (Giesecke 2003: 107). Forschungen bzw. die praktische Nutzung von Wissenschaft für polizeiliche und geheimdienstliche Tätigkeiten gab es im Bereich der Psychologie. An der MfS-Hochschule gab es das Fachgebiet „Operative Psychologie“ unter anderem im Zusammenhang von „Zersetzungsstrategien“ gegen Oppositionelle (vgl. Giesecke 2003: 108). Von (empirischer) Polizeiforschung kann hier inhaltlich wie auch methodisch - jedoch nicht gesprochen werden. 
Nach dem Ende der Weimarer Republik scheint es in Westdeutschland bis in die 1970er Jahre keine Polizeiforschung gegeben zu haben. Diesen Eindruck vermitteln jedenfalls einschlägige Veröffentlichungen, die kommentarlos aus der Weimarer Republik in die 1970er Jahre ,springen' bzw. erst in den 1970er Jahren beginnen, obwohl sie sich dezidiert mit der Entwicklung der Polizeiforschung/wissenschaft beschäftigen (z.B. Ohlemacher 1999; Denkowski/Denkowski 2011; Mokros 2013). Oft wird (z.B. im Rahmen einer Zusammenfassung des Forschungsstandes) der Beginn der Polizeiforschung (als Polizeisoziologie) in die 1970er Jahre datiert, ohne dass auf vorherige Entwicklungen Bezug genommen wird. Dies lässt sich einerseits nachvollziehen, soll der Beginn einer sozialwissenschaftlichen Forschung zur Polizei als Organisation, die in dieser Form eben erst in dieser Zeit entstanden ist, dargestellt werden (s.u.). Andererseits wird so ein Kapitel über Polizei(forschung) während der nationalsozialistischen Herrschaft ausgelassen, als habe es weder Polizei noch Forschung dazu gegeben. Soziologische Forschungsarbeiten zur Organisation Polizei aus dieser Zeit habe ich bei meiner Literaturrecherche nicht gefunden. Die Kriminologie, als eine Disziplin, die Polizeiforschung betreibt, hat jedoch eine schon im 19. Jahrhundert beginnende und unter der nationalsozialistischen Herrschaft sich verschärfende Wende durchgemacht: von einer psychologischen und statistisch arbeitenden soziologischen hin zu einer biologistischen Wissenschaft. Kriminalität wurde in dieser Kriminalbiologie $^{50}$ (häufig und hier etwas verkürzt dargestellt) als genetisch vererbbar betrachtet - eine Annahme, die mit den nationalsozialistischen Vorstellungen von „Rassenhygiene“ vereinbar war (vgl. Streng 1993: 142 f.). Die Perspektive, dass soziale und ökonomische Umweltbedingungen Kriminalitätsraten erhöhen und die Polizei und andere staatliche Organisationen zu Kriminalisierung beitragen (können), fehlt hier weitestgehend. Dass es keine (mir bekannten) Untersuchungen zur Polizei aus dieser Zeit gibt, überrascht insofern nicht. Jedenfalls ist eine entscheidende Leerstelle in der Forschung über die Polizei zu konstatieren. Dass eine wissenschaftliche Aufarbeitung der Polizei und der Polizeiforschung im Nationalsozialismus zunehmend erst seit ca. Mitte der 1990er Jahre zu beobachten ist, ist unter anderem sowohl mit einer personellen Kontinuität in der Polizei zu erklären, die bis in die 70er Jahre andauerte (vgl. Baumann/Stephan/Wagner 2012; Möllers/van Ooyen 2015: 24; Sturm 2015: 27 ff. sowie Kap. 2.1.3), als auch mit einer inhaltlichen Kontinuität (,Kriminalbiologie“), die noch deutlich länger zu verfolgen ist (vgl. Carstens 2011). Durch diese Ausblendung der Polizei als „zentrales Bereitstellung- und Durchführungsorgan des Holocaust in Europa“ (Kersten 2012: 6) und auch der Forschungstätigkeiten in diesem Zusammenhang läuft die Polizeiforschung Gefahr, die Polizei losgelöst von ihrer Geschichte zu

50 Zum Überblick über die Kriminalbiologie (im Nationalsozialismus) und den Forschungsarbeiten siehe Streng (1993) und Hohlfeld (2002). 
betrachten bzw. sich in eine historisch ausgerichtete Polizeiforschung 51 einerseits und eine an aktuellen oder praxisbezogenen Fragen orientierte Polizeiforschung andererseits aufzuspalten.

Im Zusammenhang politischer und gesellschaftlicher Entwicklungen ist es auch zu sehen, dass die deutsche Polizeiforschung recht jung ist: Eine sozialwissenschaftlich orientierte Polizeiforschung entstand in den späten 1960er und frühen 1970er Jahren im Kontext einer kritischer werdenden Öffentlichkeit (vgl. Kap. 2.2.5): „Die größtenteils obrigkeitsstaatliche politische Kultur der Bundesrepublik, als deren Vollzugsorgan die deutsche Polizei zu dienen hatte, wird zu dieser Zeit in vielen Bereichen der Gesellschaft radikal in Frage gestellt" (Kersten 2012: 6). Die Polizeiforschung beschäftigte sich unter anderem mit der Selektivität der Strafverfolgung durch die Polizei und als Instrument der Herrschaftssicherung (z.B. Feest/Lautmann 1971; Feest/Blankenburg 1972; Brusten/Feest/Lautmann 1975): In der anglo-amerikanischen Kriminologie und interaktionistisch orientierten Forschungstradition wurde der „Labeling Approach“ (grundlegend vor allem Becker 1963/1973) hervorgebracht. Vertreten wird dabei die Annahme, dass Devianz, aufgrund von gesellschaftlich hergestellten Regeln, zugeschrieben wird. Dieser Ansatz wurde auch in Deutschland rezipiert - dies stieß auf Seiten der Polizei auf Widerstand und wurde mitunter als ideologische Polizeikritik aufgefasst (vgl. Kersten 2012: 7; Mokros 2013: 13 f.).

Zwischen den 1970er und 1990er Jahren lag der Fokus der bundesdeutschen Polizeiforschung dann vor allem auf dem Thema Kriminalitätsbekämpfung (vgl. Ohlemacher 1999: 8 ff.). Diese Entwicklung kann unter anderem als Reaktion auf die kritischen Forschungsarbeiten der 1970er interpretiert werden. ${ }^{52}$ Die Polizei wurde als Forschungsfeld vermutlich zunehmend schwerer zugänglich bzw. schloss sich nach ,außen' ab. So wurde die Forschung in diesem Zeitraum von Angestellten der Polizei dominiert, die Sekundäranalysen von amtlichen Akten vornahmen (vgl. ebd.), und fand vor allem für die Polizei statt. Diese Forschung fällt eher in den Bereich der Forschung zu öffentlicher Sicherheit und Kriminologie, der Günter Endruweit vorwirft, „,wegen ihrer nichtsozialwissenschaftlichen, einseitig legalistischen Orientierung auf Tat-Täter-Beziehungen jahrzehntelang gar nicht gemerkt zu haben, daß zu einer wissenschaftlichen Erfassung der Kriminali-

\footnotetext{
51 Auch die geschichtswissenschaftliche Forschung zur Polizei im NS hat erst recht spät eingesetzt. Zum Überblick ab den 1990er Jahren siehe Reinke (2012) sowie Kapitel 2.2.3.

52 Siehe dazu auch die Debatte von Alexander Pick, damals Kriminaloberrat, Hochschule für Polizei Villingen-Schwenningen, und den Soziolog*innen Ute Donk, Jo Reichertz und Norbert Schröer. In aufeinander reagierenden Artikeln in der Zeitschrift Kriminalistik (Pick 1995;

Donk/Reichertz/Schröer 1996; Pick 1996) diskutierten sie Mitte der 1990er Jahre die Forschung in der Polizei. Pick bezog sich in dieser Debatte nach wie vor auf die Forschung der 1960/70er Jahre, die er als „polizeisoziologische Erbsünde“ (Pick 1995: 698) bezeichnete.

Für weitere Erklärungen zu der Themenverschiebung wie z.B. die Rationalisierung der Verwaltung und die Steuerbarkeit gesellschaftlicher Prozesse durch wissenschaftliche Erkenntnisse, im Zusammenhang mit dem Interesse der Polizei, ihre eigene Arbeit wissenschaftlich zu fundieren und professionspolitisch aufzuwerten, siehe z.B. Ohlemacher (1999) und Reichertz (2015).
} 
tät auch gefragt werden muß, wer eigentlich institutionell einen Handelnden zum Täter im Sinne des Gesetzes macht" (1979: 15). Eine kritische Polizeiwissenschaft/-soziologie, die sich mit den Strukturen der Polizei, ihrem Handeln oder ihrer gesellschaftlichen Funktion auseinandersetzt, gab es mit Ausnahme der oben genannten Arbeiten in dieser Zeit in Westdeutschland kaum.

Die deutsche Polizeiwissenschaft der 1970er Jahre kann als Polizeisoziologie verstanden werden, die in den folgenden Jahren dann aber nur noch eine marginale Rolle spielte, bis sich in den 1990er Jahren wieder soziologisch relevante Forschung entwickelte, die seitdem eher unter dem Label „Empirische Polizeiforschung ${ }^{653}$ firmiert und teilweise interdisziplinär ausgerichtet ist (vgl. Mokros 2013: 13). Verbunden mit dem Ringen um eine Bezeichnung - Polizeiwissenschaft, soziologie, -forschung - ist auch die Frage nach der inhaltlichen und disziplinären (und auch methodischen) Ausrichtung sowie dem Ziel von Forschung für und/oder über die Polizei verbunden. Zahlreiche Veröffentlichungen zu diesen Fragen zeugen davon (z.B. Lange 2003; Ohlemacher 2010; Denkowski/Denkowski 2011; Möllers/van Ooyen 2015).

Eine gängige Interpretation zur bisherigen geringen Forschungstätigkeit lautet, dass unter anderem vor dem Hintergrund der kritischen Polizeiforschung der 1970er Jahre das Forschungsfeld Polizei länger verschlossen geblieben sei (z.B. Ohlemacher 1999). Zu fragen ist aber auch, wie groß umgekehrt das Interesse der Wissenschaft an der Polizei war und ist. In der universitär verankerten Forschung spielen eine Polizeisoziologie oder -wissenschaft bis heute nur eine marginale Rolle und der Zusammenhang von kritischer Polizeiforschung und darauffolgender Abschottung der Polizei sowie daraus resultierender nur geringer Forschungstätigkeit kann eine vorschnelle Erklärung sein (vgl. Mokros 2013: 15). Es kann sich als Desinteresse der Polizei an Forschung und/oder auch als Desinteresse der Akademia an der Polizei darstellen. Reichertz stellt fest, dass es nur noch schlechte (unabhängige) Förder- und Finanzierungsmöglichkeiten für Forschung zur Polizei gibt und entsprechende Studiengänge und Professuren an Universitäten wieder abgebaut werden (vgl. Reichertz 2015). Diese Entwicklungen mach(t)en das Forschungsfeld Polizei für Soziolog*innen aus Karrieresicht uninteressant. Hinzu kommt, dass die Polizei eben die Macht hat, sich als Forschungsfeld zu verschließen, und ein langwieriger und zu manchen Bereichen polizeilicher Arbeit eher aussichtsloser Feldzugang in zeitlich und ressourcenbegrenzten Forschungsprojekten problematisch sein kann.

Früher als in Deutschland entwickelten sich die anglo-amerikanischen Police Studies als soziologische und kriminologische Disziplin seit ca. den 1960er Jahren.

\footnotetext{
${ }^{53} \mathrm{Zu}$ nennen sind hier die Projektgruppe Empirische Polizeiforschung, der unter anderem Jo Reichertz, Norbert Schröer und Hans-Georg Soeffner angehörten und die aus einer wissenssoziologisch-hermeneutischen Perspektive verschiedene Fragen im Bereich der Polizeiarbeit untersuchte (vgl. Reichertz 2003a). Außerdem der interdisziplinäre Arbeitskreis Empirische Polizeiforschung, der sich zum Ziel gesetzt hat, den Austausch zwischen Wissenschaft und Praxis zu fördern. Seit 1999 veranstaltet der AK jährlich eine Tagung (http://www.empirische-polizeiforschung.de).
} 
Einflussreiche Werke entstanden zwischen den 1960er und 80er Jahren (z.B. Skolnick 1966; Bittner 1970; Manning 1977). Seitdem konnte die Polizeiforschung sich deutlich mehr etablieren als in Deutschland und verfügt(e) über bessere Förderungen und auch universitäre Lehrstühle. Dennoch werden auch in der angloamerikanischen Polizeiforschung in den letzten Jahren ähnliche Fragen und Probleme diskutiert, wie etwa die Nähe zum Forschungsfeld, das Problem kurzfristiger Förderungen für eher praxisrelevante Fragestellungen, in der es nur begrenzt zu Theoriebildung kommt/kommen kann etc. (zum Überblick Loader 2011; Manning 2005). Brodeur (2010) resümiert, dass sich die Forschung von den Fragen „of what the police do“ (163) und „what happens“ (164) seit Ende der 1980er Jahre zu der Frage „what works“ (164) in policing/reducing crime entwickelt habe. 54

In der Bundesrepublik haben seit den 1990er Jahren soziologische Forschungstätigkeiten in diesem Feld und die Variationen an Methoden und Zugängen wieder zugenommen und damit auch eine Forschung in der Polizei über die Polizei (vgl. Reichertz 2003a; Ohlemacher 2010). Seit dieser Zeit etabliert sich auch eine qualitative, verstehende Polizeiforschung. Vor allem die Arbeiten von Jo Reichertz und Norbert Schröer (z.B. Reichertz 1991, 2003a; Reichertz/Schröer 1992; Schröer 2002) eröffnen eine wissenssoziologische Perspektive auf polizeiliches Handeln. Reichertz und Schröer beschäftigen sich mit Interaktionsstrukturen bei Vernehmungen, den Ermittlungen der Kriminalpolizei bei Schwerverbrechen sowie der Struktur polizeilichen Handelns. Neu für die Polizeiforschung war, dass Reichertz und Schröer sich der Polizei aus einer „,wissenssoziologischen verstehenden und strukturanalytisch arbeitenden" (Reichertz/Schröer 1992: 2) Perspektive näherten. Nach diesen Arbeiten von Schröer und Reichertz sind weitere sozialkonstruktivistische/wissenssoziologische Studien über die Polizei entstanden. $\mathrm{Zu}$ nennen sind unter anderem die Arbeiten von Susanne Krasmann, Astrid Jacobsen, Rafael Behr und Anja Mensching, die sich eines qualitativen Forschungsdesigns bedienen und deren Arbeiten im interpretativen Paradigma ${ }^{55}$ zu verorten sind.

Krasmann (1993) nimmt eine phänomenologische Analyse polizeilicher Strukturen vor dem Hintergrund ihrer staatlichen und gesellschaftlichen Einbindung vor. Sie analysiert mithilfe berufsbiographisch-narrativer Interviews den Raum, in dem die Beamt*innen den Beruf ausüben, und wie die Beamt*innen in die Organisation der Polizei eingebunden sind.

Behr (2000) hat - als ehemaliger Polizist - in einer ethnografischen Untersuchung unter anderem die Verschränkung von polizeilichen Handlungsmustern

\footnotetext{
${ }^{54}$ Siehe dazu auch den Beitrag von Erika Fairchild (1990), die die Entwicklung der Polizeiforschung in den USA und Westdeutschland zwischen den 1960er und 80er Jahren hinsichtlich der „political realities“ und der „reality of police-making“ (19) vergleicht und zu einem ähnlichen Schluss wie Brodeur kommt.

55 Das interpretative Paradigma beinhaltet Ansätze, die davon ausgehen, dass Individuen ihre Umwelt und die Handlungen anderer interpretieren und so in Interaktion gemeinsam die soziale Wirklichkeit erzeugen. Wilson (1970) unterscheidet davon das normative Paradigma.
} 
und Männlichkeit untersucht. Anhand der Alltagserfahrungen der Polizisten versucht er die kulturellen Rahmungen der Berufsidentität zu bestimmen: die „Cop Culture" als eine männlichkeitsstrukturierte Subkultur.

Jacobsen (2001) kritisiert in ihrer Untersuchung „Die gesellschaftliche Wirklichkeit der Polizei“", dass eine Definition dessen, was Polizei überhaupt ist, bisher fehle. Sie widmet sich in einer ethnographischen Arbeit diesem Problem. Darin versucht sie eine empirische Bestimmung des Phänomens Polizei und untersucht konkret, wie sich eine sogenannte polizeiliche ,Lage' entfaltet, um vor diesem Hintergrund zu analysieren, wie polizeiliche Wirklichkeit konstruiert und wie auf sie zugegriffen wird. Sie untersucht dies vor allem durch teilnehmende Beobachtungen an Besprechungen von Führungskräften der nordrhein-westfälischen Polizei.

Mensching (2008) untersucht mithilfe von Gruppendiskussionen und der dokumentarischen Methode die Organisationskultur der Polizei. Damit liefert sie einen wichtigen Einblick in die Innenverhältnisse der Polizei. Sie rekonstruiert die hierarchischen Praktiken, die „gelebte Hierarchie“, und Orientierungsmuster innerhalb der Polizei als Organisationskultur, die Differenzen innerhalb der Organisation integrieren kann.

Diese genannten Arbeiten sind phänomenologisch/sozialkonstruktivistisch/wissenssoziologisch orientierte Analysen der polizeilichen Wirklichkeit und Handlungspraxis. Den Zugang zu den untersuchten Phänomenen bilden daher Handlungen und handlungsleitende subjektive und gesellschaftliche Wissensbestände. Sie alle liefern einen Beitrag zur Bestimmung polizeilicher Wirklichkeit und Handlungsfelder sowie der Organisationkultur.

Man könnte nun davon ausgehen, dass diese Art der Forschung, die bei den Akteur*innen ansetzt, von Angehörigen der Polizei als hilfreich aufgenommen würde. Kirchhof (2013) konstatiert jedoch zusammenfassend, dass in der Polizei nach wie vor Skepsis gegenüber externer Forschungstätigkeit herrsche, die den Beamt*innen zu abstrakt für ihre allägliche Arbeit erscheine und mit der Befürchtung verbunden sei, dass diese Forschung ihre praktische Arbeit unterminieren könne (vgl. ebd.: 771). Ohlemacher (2010) sieht dies als strukturelles Problem: Polizei ziele auf die Reduktion von Komplexität, um Irritationen in der Praxis zu vermeiden, Wissenschaft wiederum ziele auf die Erhöhung von Komplexität (vgl. ebd.: 7) - ich würde es als Darstellung und nicht Erhöhung der Komplexität polizeilicher Arbeit bezeichnen. In diesem Kontext verbleibt die Forschung dann eher an den Polizeihochschulen, in denen jedoch schlechte institutionelle Bedingungen für Forschung herrschen, und ist oft an die praktische Relevanz für die Polizeiarbeit gebunden (vgl. Frevel 2008: 7; Kirchhof 2013: 771). ${ }^{56}$ Es ist davon auszuge-

\footnotetext{
56 Brodeur kommt zu dem interessanten Schluss, dass gerade Länder, die bei der Ausbildung ihrer Polizist*innen einen vergleichsweise großen Aufwand betreiben, so wie Deutschland, Frankreich, Spanien oder auch Italien, kein eigenes Feld von soziologischen Police Studies entwickelt haben (vgl. Brodeur 2005: 46).
} 
hen, dass im Bereich der Polizeiforschung theoretische und empirische Arbeiten, die eine konkrete Frage für die polizeiliche Praxis verfolgen und nationalstaatlich ${ }^{57}$ zugeschnitten sind, überwiegen; vergleichende Arbeiten aus Deutschland gibt es kaum (vgl. Mokros 2009: 35; Ausnahmen sind u.a. Hunold 2013; Beek 2019).

Auch wenn inzwischen eine Zunahme an soziologisch-empirischen Arbeiten über Handlungsfelder und Strukturen der Polizei zu beobachten ist, bleibt es unerlässlich, solche Studien voranzutreiben, da die praxisnahen Studien immer nur einen kleinen Ausschnitt polizeilicher Handlungspraxis untersuchen (können). Notwendig ist es, die Polizei weiterhin durch eine Außenperspektive handlungsentlastet zu erforschen und dabei die handelnden Subjekte in der Organisation sowie die Logik von polizeilicher Arbeit innerhalb des gesellschaftlichen Kontextes und ihrer gesellschaftlichen Funktion in den Blick zu nehmen. Im Gegensatz zu Forschung, die den polizeilichen Arbeitsprozess wissenschaftlich zu fundieren und $\mathrm{zu}$ verbessern versucht, ist in diesem Fall auch die „Gesellschaft [...] Klient dieser Forschung“ (Reichertz 2015: 14) und nicht die Polizei alleine.

Die vorliegende Arbeit möchte einen Beitrag dazu leisten. Polizeiliches Handeln wird hier zwar aus einer solchen Außenperspektive untersucht. Dabei werden jedoch die Perspektiven und Erfahrungen der Polizist*innen selbst rekonstruiert und in den organisationalen und gesellschaftlichen Kontext eingebettet. Die Perspektive dieser Arbeit ist eine wissenssoziologische und biographietheoretische. Im Gegensatz zu sozialkonstruktivistisch ausgerichteten Forschungen existieren meines Wissens keine biographietheoretischen Arbeiten - im hier verstandenen Sinne (s.u.) - zur Polizei. Diese Arbeit eröffnet damit auch theoretisch und methodisch eine neue Perspektive im Bereich der empirischen Polizeiforschung (vgl. Kap. 3.2 und 3.3). Bevor ich diese Perspektive eröffne, werde ich die wenigen Arbeiten vorstellen, die sich mit dem Zusammenhang von Biographie und Berufswahl befassen, und die vorliegende Studie in diese Forschungen einordnen.

\subsubsection{Forschung zu Biographie und Berufswahl von Polizist*innen}

Nachdem ich die wichtigsten sozialkonstruktivistisch gerahmten Arbeiten zu polizeilicher Interaktions- und Handlungspraxis kurz vorgestellt habe, möchte ich nun auf die Studien eingehen, die sich mit der Biographie und/oder Berufswahl von Polizist*innen beschäftigen. Die Perspektive, die ich in dieser Arbeit auf Biographien und Berufswahlprozesse einnehme, ist die der sozialkonstruktivistischen Biographieforschung (vgl. 3.2). Aus dieser Perspektive betrachte ich auch die folgenden Studien.

\footnotetext{
${ }^{57}$ Dies hängt eventuell auch mit den institutionellen Bedingungen zusammen: Die meisten der oben genannten Arbeiten sind Dissertationen (die größtenteils ohne Projektanbindung verfasst worden sind). Eine empirisch-vergleichende, qualitativ ausgerichtete Forschung mit Feldaufenthalten und Zugangsproblemen zu polizeilichen Organisationen in verschiedenen Ländern ist alleine kaum zu bewältigen. Und an den Polizeihochschulen der Bundesländer fördern die Rahmenbedingungen der Arbeit für die Lehrenden und Forschenden (längere) Feldaufenthalte (im Ausland) etc. nicht.
} 
Meines Wissens liegen bislang keine Arbeiten vor, die die biographischen Verläufe von Polizist*innen aus einer solchen biographietheoretischen Perspektive untersuchen, welche die Genese eines Falles in seiner Wechselwirkung mit gesellschaftlichen und organisationalen Prozessen analysiert. Zu finden ist eine Untersuchung zur Berufswahl von Polizist*innen, die jedoch mehr die Präsentationen der Interviewten in der Gegenwart als die Genese ihrer Perspektive im Zusammenhang mit den biographischen Erfahrungen rekonstruiert. Diese Studie, die eine biographieanalytische Perspektive proklamiert und sich mit der Berufswahl von Polizist*innen in den neuen Bundesländern beschäftigt, hat Markus Strack (2011) vorgelegt. Sicherheit als Berufswahlmotiv kann als zentrales Ergebnis seiner Untersuchung festgehalten werden. Sicherheit kann dabei sowohl Planungssicherheit als auch Geborgenheit in der Organisation bedeuten (vgl. 2011: 149). Mit einem objektiv-hermeneutischen Ansatz wählt Strack ein sequenziellrekonstruktives Verfahren, das sowohl den Interviewtext als auch objektivbiographische Daten zur Analyse heranzieht. Mit problemzentrierten Interviews, dem Insistieren auf Problemen, nutzt der Autor jedoch eine Interviewform, die es kaum ermöglicht, die Prozesse der Entstehung, Entwicklung und Veränderung von Einstellungen, handlungsleitenden Wissensbeständen oder nicht intendierten Folgen des Verhaltens erheben zu können. Die Erhebung und Analyse orientieren sich daher mehr an der Präsentation der Interviewten in der Gegenwart und weniger an den Erfahrungen der Polizist*innen in der Vergangenheit. Die Analyse bewegt sich damit, wie in dem Titel expliziert, auf der Ebene von Motivanalysen (jedoch nicht im Schütz'schen Sinne (siehe Kap. 3.2)). Allgemeine Aussagen und theoretische Verallgemeinerungen über die biographische Funktion der Berufswahl Polizist*in finden sich jenseits des Motivs der Sicherheit leider nicht.

Insgesamt lassen sich in dem Bereich der polizeilichen Berufswahlforschung in Deutschland vor allem Befragungen von Studienanfänger*innen finden (Liebl 2002, 2006; Groß/Schmidt 2010; Rauber 2013; Rabitz-Suhr 2016). Diese quantitativ angelegten Studien fragen nach den Gründen für die Berufsentscheidungen bzw. nach der Studienmotivation entlang vorgegebener Antworten. Zu ähnlichen Ergebnissen wie die empirisch-quantitativ angelegten Befragungen kommt die qualitativ angelegte Studie von Peter Löbbecke (2004) zu Berufsbildern von studierenden Beamten. Der zentrale Befund steht bereits im Titel von Löbbeckes Studie: „Abgesichert sein und gutes Geld verdienen“. Befragungen aus anderen Ländern kommen ebenfalls zu ganz ähnlichen Ergebnissen: Arbeitsplatzsicherheit und eine gute bzw. verlässliche Bezahlung werden als die wichtigsten Faktoren der Berufswahl identifiziert (z.B. Moon/Hwang 2004; Foley/Guarneri/Kelly 2008; $\mathrm{Wu} /$ Sun/Cretacci 2009). Weitere relevante Faktoren für die Berufswahl scheinen das Ausüben einer interessanten Tätigkeit oder der Kontakt zu Menschen zu sein. Zwar geben diese Faktoren Hinweise auf Berufswahlgründe, bleiben aber recht allgemein und oberflächlich. Für eine Vielzahl weiterer Berufe mit hoher Arbeitsplatzsicherheit, wie Lehramt oder Tätigkeiten im Bereich der öffentlichen Verwaltung, sind die gleichen Motive denkbar. 
Bei Susanne Krasmann (1993) findet sich zwar eine ausführliche Rekonstruktion der Sozialisation innerhalb der Polizei, jedoch steht sie ohne Rückbindung an die biographischen Verläufe. Krasmann fokussiert die Einbindung von Polizist*innen in die Strukturen der Organisation und interessiert sich vor diesem Hintergrund auch nicht für die Berufswahlprozesse im Zusammenhang mit biographischen Erfahrungen und beruflichem Handeln.

Im Bereich der deutschen Polizeiforschung lässt sich zu der Frage der Berufswahl also insgesamt eine deutliche Lücke feststellen. Eine Auseinandersetzung mit dem Zusammenhang von polizeilichem Arbeitshandeln und lebensgeschichtlichen Erfahrungen fehlt vollständig.

Auch in der internationalen Literatur sind mir keine biographietheoretischen Arbeiten bekannt. Studien, die einen Zusammenhang zwischen polizeilichem/beruflichem Handeln und biographischen Daten herstellen, finden sich im Bereich der Psychologie, um z.B. (zu testen, ob sie) Vorhersagen über das Handeln von Polizist*innen treffen (zu) können (z.B. Levy 1967; Brennan/Davis/Rostow 2005).

Im Anschluss an diese Forschungsleerstelle(n) verfolge ich das Ziel, Antworten auf die Fragen, welche lebensgeschichtlichen Verläufe zu der Berufswahl führen und wie diese Verläufe, eingebettet in die organisationalen Strukturen, mit der konkreten beruflichen Handlungspraxis zusammenhängen, zu geben.

\subsection{Theoretische Perspektivierung II: Handeln, Interaktion und Biographie}

Roland Girtler kommt in seiner Untersuchung über die „Strategien, Ziele und Strukturen polizeilichen Handelns" (1980) der Wiener Polizei zu dem Schluss, dass soziales Handeln von Polizist*innen „relativ losgelöst [ist] von persönlichen Gefühlen und Vorstellungen, es ist vielmehr fest an den Situationen orientiert, die der Polizist in einzelnen Fällen auch definieren, d.h. bestimmen kann" (Girtler 1980: 137). Dieser Befund widerspricht meinen empirischen Befunden deutlich. Wie ich unten zeigen werde, haben Polizist*innen tatsächlich die Möglichkeit Situationen aus einer machtvollen Interaktionsposition heraus zu definieren - soweit decken sich meine Ergebnisse mit denen Girtlers. Dass aber diese Situationsdefinition losgelöst von individuellen Gefühlen oder Vorstellungen vollzogen würde, bestätigen meine empirischen Befunde nicht. Im Gegenteil: Die Situationsdefinitionen in polizeilichen Einsatzsituationen sind (auch) biographisch motiviert. Die hier verfolgte sozialkonstruktivistische und biographietheoretische Perspektive ermöglicht es situative und biographische Deutungsprozesse offen zu legen. Bevor ich zu den Vorteilen dieses Zugangs zum Zusammenhang von polizeilichem Handeln und biographischen Erfahrungen komme, werde ich beide Theorietraditionen vorstellen, indem ich (m)eine Perspektive auf Handeln und Interaktion (3.2.1) sowie auf Biographie (3.2.2) entfalte. 


\subsubsection{Die Perspektiven auf Handeln und Interaktion}

Ausgangspunkt für „Wissenschaften, die menschliches Handeln und Denken deuten und erklären wollen", schreibt Alfred Schütz in Anlehnung an Max Weber, muss eine „Beschreibung der Grundstrukturen der vorwissenschaftlichen, für den Menschen selbstverständlichen Wirklichkeit" sein (1979/2003: 29). In Auseinandersetzung mit Webers Verstehender Soziologie und der Phänomenologie Edmund Husserls entwickelt Schütz eine phänomenologische Proto-Soziologie, die Antworten auf die Fragen nach der Aufschichtung von Erfahrung und der Konstitution von Sinn gibt und wie soziale Wirklichkeit durch diese Prozesse konstruiert wird - dies versäume Max Weber, der die Konstitution von Sinn nicht betrachte. Schütz arbeitet heraus, dass Sinn durch das reflexive In-Beziehung-Setzen von Erfahrungen und Erlebnissen konstituiert wird (vgl. Schütz 1932/2003: 184). Dies vollzieht sich im individuellen Bewusstsein. Bewusstseinsinhalte in einem phänomenologischen Verständnis sind aber immer intentional, d.h. sie sind stets auf etwas gerichtet; Schütz zufolge sind die Inhalte damit immer sozial (vgl. Keller 2012: 185), weil die „Zuwendung zum Erleben nicht bei einem außerhalb weltlicher Bezüge stehenden Subjekt stattfindet" (ebd.). Damit ist eine Beschäftigung mit der Konstitution von Sinn hier immer auch eine Auseinandersetzung damit, wie Sinn sozialisiert wird: wie er entsteht, weitergeben und/oder verändert wird.

Zielen die proto-soziologischen Überlegungen von Schütz einerseits „auf die Freilegung der als universell verstandenen Struktur der Lebenswelt", geht es darin andererseits auch „um die Rekonstruktion der jeweiligen sozio-kulturellen Ausprägungen dieser Strukturen: [... als] Untersuchung der Lebenswelt als historischer Kulturwelt in konkreten Gesellschaften“ (Endreß 2006: 48, Hervorhebungen im Original). Der - soziologisch interessante - Wirklichkeitsbereich, in dem Menschen miteinander in Kontakt treten, in dem wir eine Welt teilen, in sozialen Beziehungen stehen und miteinander interagieren, nennt Schütz in Anschluss an Husserl ,alltägliche Lebenswelt“. Eine soziologische Analyse muss bei der alltäglichen Lebenswelt von Akteur*innen ihren Ausgangspunkt nehmen und fragen, wie diese sinnhaft konstituiert ist und konstruiert wird. Eine solche Untersuchung der Polizei als Lebenswelt bzw. als Institution in einer konkreten Gesellschaft soll in dieser Arbeit geleistet werden: Wie ist/wird die polizeiliche Alltagswelt konstituiert und konstruiert und wie vollzieht sich polizeiliches Handeln innerhalb dieser alltäglichen Lebenswelt?

Schütz zeigt, dass Handeln als erfahrungs- und sinnbasiert verstanden werden muss. Handeln basiert auf dem Wissen, den Deutungs- und auch Handlungsmustern bzw. -erwartungen der Handelnden, die im sogenannten Wissensvorrat abgelagert sind. Der Wissensvorrat von Individuen ist biographisch und damit auch sozial(strukturell) und ,kulturspezifisch ${ }^{6}$ geprägt (vgl. Schütz/Luckmann 1979/2003: 331 ff.). „Der lebensweltliche Wissensvorrat ist in vielfacher Weise auf die Situation des erfahrenen Subjekts bezogen. Er baut sich auf aus Sedimentierungen ehemals aktueller, situationsgebundener Erfahrungen. Umgekehrt fügt sich 
jede aktuelle Erfahrung je nach ihrer im Wissensvorrat angelegten Typik und Relevanz in den Erfahrungsablauf und in die Biographie ein. Und schließlich wird jede Situation mit Hilfe des Wissensvorrates definiert und bewältigt" (ebd.: 149).

Das im Wissensvorrat abgelagerte Wissen sind Handlungs- und Deutungsmuster - kurz: Typisierungen - zur Orientierung in der Welt und in sozialen Situationen aller Art. Die im Wissensvorrat sedimentierten Erfahrungen stellen Muster der praktischen Problemlösung dar, die sich in vorherigen Situationen bewährt haben und die als eine Art Gebrauchswissen routiniert genutzt werden können (vgl. ebd.: 37). Deutungen in , neuen' Situationen, die nicht fraglos mit den Typisierungen des Wissensvorrates bewältigt werden können, werden mit den bestehenden Typisierungen in Verbindung gesetzt: Die im Wissensvorrat abgelagerte Typisierung wird ,abgeglichen', erweitert und wiederum in den Wissensvorrat integriert. Der Wissensvorrat bezieht sich also auf Interaktionen und ist aus diesen abgeleitet. In Interaktionen werden die Muster der Deutung und Problemlösung erlernt, lebensgeschichtlich aufgebaut, aufrechterhalten und verändert.

Zentral sowohl für die Konstitution von Erfahrung und Sinn sowie für das darauf aufbauende Handeln ist in Schütz' Analysen Zeitlichkeit. Handeln bzw. die Motive des Handelns verweisen sowohl in die Vergangenheit als auch in die Zukunft. Schütz unterscheidet Handeln, als Prozess der Tätigkeit, und Handlung, als Ergebnis dieses Prozesses. Schütz geht nun davon aus, dass die Handlung als Entwurf zeitlich vor dem Handeln gedacht wird. Der Handlungsentwurf leitet das Handeln; es ist durch ein Um-zu-Motiv motiviert: um etwas Bestimmtes in der Zukunft zu erreichen. Weil-Motive verweisen wiederum auf die Vergangenheit: auf die Erfahrungen, die zum Handeln motivieren, auf die „,biographische Be-

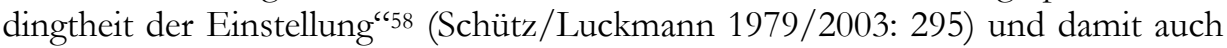
auf die „environmental and socio-historical circumstances in which the actor was involved“" (Santos 2016a: 236)

Will ich also polizeiliches Handeln untersuchen, darf ich mich nicht nur den Um-zu-Motiven, sondern muss mich auch den Weil-Motiven und der „biographischen Artikulation“ des Wissensvorrates bzw. der „Einstellung“ (vgl. Schütz/Luckmann 1979/2003: 163 ff., 295 ff.) widmen. Die proto-soziologischen Analysen von Schütz begründen ein biographietheoretisches Vorgehen. Mit Bezug auf die phänomenologisch-gestalttheoretisch basierten biographietheoretischen Konzeptionen von Gabriele Rosenthal (1995) hat Hermílio Santos (2016a; b) ein solches Vorgehen dezidiert begründet und eingefordert.

Bevor ich die biographietheoretischen Grundannahmen vorstelle, möchte ich zunächst auf die Weiterentwicklung des Ansatzes von Schütz durch Peter L. Berger und Thomas Luckmann zu sprechen kommen. Aufbauend auf den Arbeiten

\footnotetext{
${ }^{58}$ Einstellungen sind ,das ,Resultat' heterogener Erfahrungen, die sich auf verschiedenen Stufen der Bewußtheit sedimentiert und miteinander verflochten haben" (Schütz/Luckmann 1979/2003: 299). Die Erwerbssituationen sind häufig nicht erinnerbar, sie sind reflexiv kaum zugänglich und sie wirken ,gleichsam ,unbewußt als ,Motive“ in der Form spezifischer Weil-Zusammenhänge“ (ebd.: 300).
} 
Schütz' und in Auseinandersetzung mit der klassischen deutschen Wissenssoziologie arbeiten sie ein neues wissenssoziologisches Programm aus: „Die gesellschaftliche Konstruktion der Wirklichkeit“ (1969/2012). Berger und Luckmann beschäftigen sich damit, wie Typisierungen als kollektive Wissensbestände eine etablierte Wirklichkeit erzeugen und wie diese Wissensbestände in Sozialisationsprozessen von Individuen erlernt, aufrechterhalten und transformiert werden. Damit befassen sie sich allgemeinsoziologisch mit der Frage: „Auf welche Weise entsteht gesellschaftliche Ordnung überhaupt?"“ (Berger/Luckmann 1969/2012: 55). Soziale Wirklichkeit wird von ihnen als Ergebnis der Konstruktionsprozesse und -leistungen der Alltagshandelnden begriffen; soziale Wirklichkeit ist eine Konstruktion der Handelnden, sie ist durch Handeln erzeugt. Gesellschaftliche Ordnung ist damit „ein Produkt des Menschen [...], oder genauer: eine ständige menschliche Produktion“" (ebd.: 55). Berger und Luckmann konzipieren Individuum und Gesellschaft bzw. subjektive und objektive Wirklichkeit nicht als Dualismus, sondern als sich wechselseitig konstituierend.

Berger und Luckmann analysieren daher die Prozesse, in denen Wissen als gesellschaftlich - und damit intersubjektiv - relevanter, objektivierter und vermittelter Sinn entsteht (vgl. Knoblauch 2014: 155), wie es objektiviert, legitimiert und in Sozialisationsprozessen ${ }^{59}$ vermittelt und angeeignet wird. Durch Routinisierungsund Habitualisierungsprozesse, die Handeln erleichtern, entstehen Institutionen ${ }^{60}$, die den Akteur*innen als objektive Wirklichkeit gegenüberstehen, obwohl sie ein menschlich hervorgebrachtes Gebilde sind (vgl. Berger/Luckmann 1969/2012: 56 ff.). Über Rollen, als gesellschaftlich typisierte Verhaltens- und Handlungsmuster (der Institutionen), werden die gesellschaftlichen Institutionen handelnd angeeignet (vgl. ebd.: 76 ff.), somit zur subjektiven Wirklichkeit und auch weitergegeben. In Interaktionen mit anderen Menschen greifen wir auf die mit den jeweiligen Rollen verbundenen Handlungsmuster und Wissensbeständen zurück, wir reproduzieren und modifizieren sie. Gesellschaftliche Ordnung ist damit institutionelle Ordnung, die ständig handelnd hergestellt, reproduziert und auch transformiert wird.

Jedes Handeln basiert auf den gesellschaftlich verfügbaren typisierten Wissenselementen des je soziohistorischen Kontextes (vgl. Keller 2012: 214). Will ich herausfinden, wie sich soziales Handeln vollzieht, gilt es demnach herauszufinden, auf Grundlage welcher Deutungen, und damit welchen Wissens, Menschen handeln. Wissen ist dabei gesellschaftlich nicht gleich verteilt: Allgemeinwissen und (an die Rollen und Institutionen geknüpftes) Expertenwissen sind in (arbeitsteilig) differenzierten Gesellschaften unterschiedlich verteilt; sie sind regional- und mili-

\footnotetext{
59 Ganz zentral für die Ausführungen von Berger und Luckmann ist die interaktionistische Sozialisationstheorie von George Herbert Mead (1934/1995).

${ }^{60}$ Dazu zählen die Ehe oder die Familie mit den Rollen von Eltern und Kindern - hier lässt sich die Transformation der Institution deutlich beobachten - genauso wie die Institution des Rechts. Eine Organisation kann hier also eine Institution sein, aber nicht jede Institution ist eine Organisation.
} 
euspezifisch. Das vermittelte Wissen hat einen gesellschaftlichen und biographischen Ort (vgl. Berger/Luckmann 1969/2012: 141).

Will ich hier nun nicht nur die Verteilung von Wissensbeständen und die handlungsleitenden Wissensbestände in der Schutzpolizei untersuchen, sondern gehe in Anlehnung an den Sozialkonstruktivismus von der Annahme aus, dass diese Wissensbestände im Laufe des Lebens internalisiert sowie transformiert werden und subjektive Wirklichkeit einen je unterschiedlichen Wirklichkeits- und Zeitbezug hat, so bedarf es der Rekonstruktion nicht nur der Um-zu-Motive, sondern auch der Weil-Motive im Sinne Schützes. Dies kann mit einer biographietheoretisch-prozesssoziologischen Untersuchung gelingen.

\subsubsection{Die Perspektive auf Biographie}

Die sich in und seit den 1970er Jahren entwickelnde soziologische Biographieforschung ist von der hier vorgestellten phänomenologisch-sozialkonstruktivistischen Theorietradition zentral beeinflusst. Daneben sind theoretische Einflüsse des amerikanischen Pragmatismus ${ }^{61}$, des symbolischen Interaktionismus und der Ethnomethodologie zu verfolgen. Diese Ansätze des interpretativen Paradigmas eint, dass sie das auf Deutungen basierende Handeln in den Blick nehmen.

Ausgehend von der Annahme, dass Gesellschaft und Individuum dialektisch miteinander verbunden sind, werden in der hier vertretenen Biographieforschung Lebensgeschichten als Ausdruck subjektiver und objektiver Wirklichkeit betrachtet; in Lebensgeschichten kann die wechselseitige Konstitution von Individuum und Gesellschaft sichtbar werden: „In der ,biographischen Selbstpräsentation“ finden wir nicht nur Zugang zum lebensgeschichtlichen Prozeß der Internalisierung der sozialen Welt im Laufe der Sozialisation, sondern auch zur Einordnung der biographischen Erfahrungen in den Wissensvorrat und damit zur Konstitution von Erfahrungsmustern, die zur gegenwärtigen und zukünftigen Orientierung in der Sozialwelt dienen“ (Rosenthal 1995: 12-13). Wie oben gezeigt, findet diese Einordnung und Konstitution nun nicht individuell statt, sondern interaktiv und in Auseinandersetzung mit sozial geteilten Deutungsmustern. Die Biographieforschung interessiert sich demnach sowohl für die Perspektiven der Handelnden als auch für die Handlungsmuster, die im Laufe eines Lebens interaktiv herausgebildet werden; sie interessiert sich für das Erleben der Akteur*innen und damit verbunden für die Sinn- und Erfahrungsaufschichtung (vgl. Rosenthal 2011: 177 ff.).

Ich plädiere aus einer biographietheoretischen Perspektive dafür, die ganze Biographie, verstanden als „soziales Konstrukt“ (Kohli/Fischer 1987: 26), in die Analyse von Handeln und in diesem Fall von polizeilichem Handeln mit einzube-

${ }^{61}$ Vom Pragmatismus beeinflusst ist auch die Chicago School, die wiederum Ausgangspunkt für die soziologische Biographieforschung ist. Hier entstand die Studie „The Polish Peasant in Europe and America"von Wiliam I. Thomas und Florian Zaniecki (1918-1920/1958), die unter anderem eine Lebensgeschichte als Datenmaterial nutzte. Ausführlich zur Geschichte der Biographieforschung: Fuchs-Heinritz (2005: 88-127). 
ziehen. Ein zentrales Anliegen der Biographieforschung ist es, die Wechselwirkung gesellschaftlicher Strukturen und der subjektiven Aneignung und Bearbeitung der Individuen offenzulegen (vgl. Rosenthal 1995: 12). Ein biographietheoretischer Zugang macht es möglich, die Genese eines Falles innerhalb seiner historisch-gesellschaftlichen und institutionellen Verflechtungen zu verstehen.

Die Notwendigkeit, einen Fall in seine Beziehungsgeflechte einzubetten - dies ist prinzipielles Anliegen der Biographieforschung -, zeigt Rosenthal noch einmal dezidiert in Auseinandersetzung mit der Figurationssoziologie von Nobert Elias (Rosenthal 2012, 2016). Die hier vertretene wissenssoziologische Perspektive profitiert davon: Ist in ihr zwar die Eingebundenheit von Individuen in gesellschaftliche Strukturen ausdrücklich (als sich wechselseitig konstituierend) angelegt und Macht (z.B. durch die Ungleichverteilung von Wissensbeständen und Legitimationsprozessen) implizit thematisiert, hält die von Bogner und Rosenthal (Bogner/Rosenthal 2017; Rosenthal/Bogner 2019) vorgeschlagene biographietheoretische und figurationssoziologische Perspektive aber verstärkt dazu an, die Machtungleichheiten innerhalb der sich wandelnden Beziehungsgeflechte bzw. „Figurationen" (vgl. Elias 1970/2004: 9 ff., 2010), die Menschen miteinander bilden, zu berücksichtigen.

Eine solche figurationssoziologisch informierte biographietheoretische Perspektive ist nun außerordentlich passfähig mit einer sozialkonstruktivistischwissenssoziologischen. Denn letztere kann die aktive Herstellung der polizeilichen Wirklichkeit und den Zugriff auf sie offenlegen sowie die Wissensbestände, die in dem Feld vorhanden und handlungsleitend sind, herausarbeiten. Eine biographietheoretische Forschungsperspektive wiederum blickt auf den biographischen Verlauf in seiner Wechselwirkung mit gesellschaftlichen Prozessen. Dabei werden nicht nur das institutionelle Wissen, sondern vor allem auch die in die Organisation mit eingebrachten Erfahrungen und Wissensbestände sowie deren Aneignungsprozesse zum Gegenstand. Ebenso betrachtet werden kann, wie die $\mathrm{Zu}$ schreibungsprozesse von anderen Polizist*innen und Bürger*innen auf die Selbstdefinitionen der Polizist*innen wirken und wie sich in diesem Prozess von Selbstund Fremddefinition die Sozialisation in die und in der Polizei vollzieht. Neben der Verflechtung von kollektiver und individueller Geschichte geht es auch um die Frage der organisationalen Interdependenzen. In diesem Kontext bedeutet dies, dass neben den gesellschaftlichen Entwicklungen auch die Entwicklung der Polizei Beachtung finden muss, damit auch die Möglichkeiten und Grenzen von Handelnden und (polizeilichem) Handeln innerhalb gesellschaftlicher und organisationaler Strukturen fokussiert werden können.

Will ich also herausfinden, wie sich polizeiliches Handeln vollzieht, darf der Blick nicht nur auf die Handlungssituation, sondern muss auch auf die kollektiven Wissensbestände und die spezifischen Erfahrungen der Handelnden gerichtet werden. So kann deutlich gezeigt werden, dass die Situationsdefinitionen, im Gegensatz zu Girtlers Befunden, sehr wohl auch biographisch bedingt sind. 
Die vorhandenen Forschungsarbeiten zu der Berufswahl, der Sozialisation und der Handlungspraxis von Polizist*innen nehmen diese Perspektive nicht ein. Auch wenn die oben genannten sozialkonstruktivistischen und wissenssoziologischen Arbeiten eine prozesshafte Perspektive auf soziale Phänomene verfolgen, richtet sich deren Blick auf die den Polizist*innen voran- bzw. entgegengestellte (polizeiliche) Alltagswelt und den Zugriff auf diese sowie auf die Handlungen und Handlungsmöglichkeiten, nicht aber auf die biographische Artikulation des (polizeilichen) Wissensvorrats.

\subsection{Methodisches Vorgehen}

Was folgt nun aus diesen theoretischen Positionen und dem Interesse an den polizeilich und biographisch ausgebildeten Handlungs- und Deutungsmustern konkret für die Forschungspraxis? Auf Grundlage der theoretischen Positionierung verfolge ich eine gewinnbringende Kombination aus Biographieforschung und Ethnographie (Dausien/Kelle 2005; Köttig 2005). Die hier vertretene Biographieforschung stützt sich vor allem auf biographisch-narrative Interviews und biographische Fallrekonstruktionen; im Bereich der sozialkonstruktivistischen Wissenssoziologie wird wiederum oft ein ethnographischer Ansatz verfolgt. ${ }^{62}$ Dies möchte ich allerdings nicht gegenüberstellen, sondern als sich gegenseitig ergänzend und befruchtend verstehen.

Bevor ich die hier verwendeten Methoden konkret vorstelle (3.3.3), werde ich zunächst die aus den theoretischen Grundlagen abgeleiteten methodologischen Prinzipien, die dem Forschungsprozess zugrunde liegen, kurz darlegen (3.3.1) und den Verlauf des Forschungsprozesses skizzieren sowie den Feldzugang reflektieren (3.3.2).

\footnotetext{
${ }^{62} \mathrm{Im}$ Bereich der Biographieforschung existieren weitere Verfahren und ich möchte die Methoden der Biographieforschung keineswegs auf Interviews und deren Analyse beschränkt beschreiben. Verweisen möchte ich auf Arbeiten, in denen verschiedene Materialien (Interviews, Bilder, Videos, Zeichnungen, Dokumente, Beobachtungsprotokolle etc.) und verschiedene Methoden verwendet werden und das so erlangte Wissen mit in die biographischen Fallrekonstruktionen einbezogen oder es methodenplural zur Erweiterung/Ergänzung der Perspektive genutzt wird. Siehe dazu z.B. die Veröffentlichungen unter der Herausgeberschaft von Gabriele Rosenthal (2015) sowie Köttig (2004), Witte (2010), Pohn-Weidinger (2014), Alber (2016), Rosenthal (2016), Becker (2017), Bahl/Worm (2018) und Worm (2019).

Und auch die methodischen Herangehensweisen an unterschiedliche Materialformen im Bereich der Wissenssoziologie sind sehr vielfältig: Neben verschiedenen textanalytischen (hermeneutischen) Verfahren (z.B. Soeffner, 1989; Keller, 2006) sind bild- und videoanalytische Verfahren (z.B. Raab 2008; Breckner 2010; Tuma/Knoblauch/Schnettler 2013) zu nennen. Auch die ethnografischen Arbeiten, die sich in der Wissenssoziologie verorten lassen, setzen unterschiedliche Schwerpunkte (z.B. Honer 1993; Knoblauch 2001).
} 


\subsubsection{Methodologische Prinzipien}

Alfred Schütz zufolge beschäftigen sich Sozialwissenschaftler*innen, im Gegensatz zu Naturwissenschaftler*innen, mit einer schon interpretierten Welt: „Sie hat eine besondere Sinn- und Relevanzstruktur für die in ihr lebenden, denkenden und handelnden Menschen. In verschiedenen Konstruktionen der alltäglichen Wirklichkeit haben sie diese Welt im voraus gegliedert und interpretiert, und es sind gedankliche Gegenstände dieser Art, die ihr Verhalten bestimmen, ihre Handlungsziele definieren und die Mittel zur Realisierung solcher Ziele vorschreiben“ (Schütz 1971: 6). Schütz' Anspruch ist nun, dass die Konstruktionen, die Sozialwissenschaftler*innen vornehmen, auf den Konstruktionen der Alltagshandelnden beruhen sollen: „Die Konstruktionen, die der Sozialwissenschaftler benutzt, sind daher sozusagen Konstruktionen zweiten Grades“" (ebd.: 6). Um diesem Anspruch gerecht werden zu können, müssen wir zunächst offenlegen, wie Menschen ihre Welt konstruieren, also wie sie sie in interaktiven Prozessen, basierend auf ihren Deutungen, herstellen. Um die wissenschaftlichen Konstruktionen auf den Konstruktionen der Alltagshandelnden aufbauen zu können, muss denjenigen, die Gegenstand der Forschung sind, die Möglichkeit gegeben werden, ihre Konstruktionen darzulegen.

Gemäß diesen theoretischen Überlegungen bedarf es einer Erhebungsmethode, die die „Prozesse der interaktiv ausgehandelten und hergestellten Rahmungen und der sich vollziehenden Modifikationen sichtbar werden" (Rosenthal 2011: 43) lässt. Daraus folgen zunächst zwei Prinzipien für die Erhebung und Auswertung von Datenmaterial und die Gestaltung des Forschungsprozesses, die sowohl dem ethnographischen als auch dem Vorgehen der Biographieforschung zugrunde liegen: das Prinzip der Offenheit und das Prinzip der Kommunikation.

Um von den Forschungssubjekten ihre alltagsweltlichen Konstruktionen zu erfahren, muss die Forscherin ,eine Kommunikationsbeziehung mit dem Forschungssubjekt [eingehen] und dabei das kommunikative Regelsystem des Forschungssubjekts in Geltung [lassen]" (Hoffmann-Riem 1980: 346 f.). Für die Forschungssituation bedeutet dies, dass man den Alltagshandelnden die Möglichkeit gibt, ihre Perspektive auf die Welt und auf die Forschungssituation gemäß ihren alltäglichen Kommunikationsregeln aufzuzeigen (Prinzip der Kommunikation) (vgl. Rosenthal 2011: 43). Dadurch erhält man die Möglichkeit, einerseits die im Feld gültigen Kommunikationsregeln zu erheben und damit auch einer späteren Analyse zugänglich zu machen. Andererseits wird anerkannt, dass die Forschungssituation eine interaktive Deutungs- und Kommunikationssituation ist, in der die Interviewten auch ihrerseits die Situation definieren und uns Forschende unterschiedlich adressieren. Davon ausgehend, dass Bedeutungen kontextabhängig an die Entstehungssituation gebunden sind, muss sich die Forscherin also der Bedeutungsproduktion aussetzen und sollte erst auf der Grundlage der Strukturierungsleistungen der Handelnden eine Analyse vornehmen (vgl. Hoffman-Riem 1980: 344 f.). Dies bedeutet konkret, dass Erhebungsverfahren genutzt werden, die die 
Konstruktionsleistungen der Akteur*innen sichtbar machen, dass Hypothesen im Verlauf des Forschungsprozesses gebildet werden und der (offenen) Fragestellung die Möglichkeit zur Veränderung innewohnt (Prinzip der Offenheit).

Diese Prinzipien fordern dazu auf, sich der Forschungssituation auszusetzen und sich die eigenen Vorannahmen, ob wissenschaftlich oder alltagsweltlich, bewusst zu machen. So hatte ich am Anfang meiner Forschung zur Polizei doch recht feste (medial verbreitete) Vorstellungen von dem, was Polizeiarbeit ausmacht. Diese zu hinterfragen und sich auf das Feld und die Vorstellungen der in diesem Feld Handelnden (zunächst) einzulassen, bevor eine analytische Distanzierung und Konzeptualisierung vollzogen wird, ist Ausgangspunkt der Forschung: „Es geht darum, Teilnehmersichten zuerst zu verstehen und dann durch sie ,hindurchzusteigen“" (Strübing et al. 2018: 88).

So wie die konkrete Erhebungssituation durch die Interviewten bzw. Feldakteur*innen strukturiert werden soll, soll auch der Forschungsprozess durch die erhobenen Daten strukturiert werden. Dabei folge ich dem in interpretativen Forschungszusammenhängen etablierten Prinzip des theoretischen Samplings und einer schrittweisen Neuorientierung und Fokussierung der Forschung. Dies bedeutet unter anderem, dass die Phasentrennung von Datenerhebung und Datenauswertung aufgehoben ist. Nach der Logik eines Forschungsprozesses, dessen Ende eine „Grounded Theory“ (Glaser/Strauss 1967/2008) bilden soll, sollen Datengewinnung und -auswertung in einem zirkulären Prozess erfolgen. Damit strukturieren die empirischen Daten die Stichprobe, die im Forschungsprozess auf Grundlage der bis dahin gewonnenen oder (vermeintlich) noch fehlenden Erkenntnisse erweitert werden kann („theoretical sampling") (vgl. Glaser/Strauss 1967/2008: 45 ff.).

Das Ende des Forschungsprozesses wird idealerweise durch eine „theoretische Sättigung“" markiert, d.h. es werden keine weiteren theoretischen Kategorien zur Erklärung des untersuchten Phänomens in den Daten gefunden (Glaser/Strauss 1967/2008: 61). Die vorliegende Arbeit kann eine theoretische Erklärung zur Frage nach dem Zusammenhang von biographisch etablierten Handlungsmustern und dem Handlungs- und Interaktionskontext polizeilicher Arbeit geben. Das bedeutet, dass anhand der konkreten polizeilichen Alltagspraxis typische bzw. für das Handlungsfeld konstitutive Handlungsroutinen, Interaktionsmuster und Typisierungsweisen der beteiligten Akteur*innen rekonstruiert werden. Diese werden mit den rekonstruierten Fallstrukturen zu den Verläufen der Berufswahl systematisch in Beziehung gesetzt und daraus Mechanismen der Wechselwirkung zwischen Strukturen des Berufsfeldes und Strukturen der Lebensgeschichte herausgearbeitet.

Neben den in Kapitel 5 präsentierten biographischen Fallstrukturen sind weitere denkbar, in denen die Berufswahl eine andere Funktion erfüllt als die hier rekonstruierten. Unabhängig davon bleibt die theoretische Erklärung des Zusammenhangs von der Struktur schutzpolizeilicher Arbeit und biographisch etablierter Handlungsmuster aber theoretisch gültig. 
Mit diesen Ausführungen ist die Frage nach der Verallgemeinerung der Ergebnisse verbunden. Bevor ich die konkreten Forschungsmethoden vorstelle (vgl. 3.3.3) und die Verknüpfung der Ergebnisse der beiden Fallebenen konkretisiere (vgl. 3.3.3.3), möchte ich hier noch einige Anmerkungen zur Verallgemeinerungslogik machen.

Alfred Schütz (1971/2004) betont im Anschluss an Alfred North Whitehead (1917) den Konstruktionscharakter sowohl von unserem alltäglichen als auch unserem wissenschaftlichen Denken: Unser alltägliches und wissenschaftliches Denken und Wissen von der Welt enthält Konstruktionen, Abstraktionen und Generalisierungen, oder auch: Typisierungen. Solche Typisierungen als Deutungsund Handlungsmuster sind für Schütz Grundlage sozialen Handelns (vgl. 3.2). Die wissenschaftlichen Rekonstruktionen (von Typisierungen) stellen nun Konstruktionen 2. Grades dar, die auf dem Alltagsdenken und -handeln aufbauen sollen. Diese Konstruktionen oder auch Typen verweisen „,nicht auf einzigartige Handlungen einzigartiger Individuen in einzigartigen Situationen“ (Schütz 1971/2004: 186), sondern auf typische menschliche Wirkensbeziehungen (vgl. ebd.: 187).

Ausgehend von der Annahme einer dialektischen Konstitution von Individuum und Gesellschaft können die am Einzelfall bzw. anhand einzelner Situationen rekonstruierten Strukturen theoretisch verallgemeinert werden. Das Allgemeine kann am Besonderen, dem Einzelfall, ob Biographie oder sozialer Situation, aufgezeigt werden, da der einzelne Fall immer im Allgemeinen konstituiert und eingebettet ist (vgl. Rosenthal 2011: 73 f.). So kann von einzelnen Fällen auf Typen (von Handeln) geschlossen werden: „Die Einzelfallanalysen dienen so der schrittweisen Entdeckung allgemeiner Strukturen sozialen Handelns, während der Einzelfall selbst als historisch-konkrete Antwort auf eine konkret-historische (Problem-)Situation und Strukturformation interpretiert wird“" (Soeffner 2007: 173).

Rosenthal diskutiert diese Verallgemeinerungslogik unter Bezugnahme auf Kurt Lewins wissenschaftstheoretische Ausführungen zur Begriffsbildung und Gesetzlichkeit. Lewin (1930) betont, dass Gesetzlichkeit nicht in Bezug auf die Häufigkeit oder historische Regelmäßigkeit eines Phänomens bezogen werden sollte und dass Einzelfälle auch nicht zufällig seien (vgl. ebd.: 434-438), sondern, dass auch Einzelfälle gesetzlich seien (vgl. ebd.: 450). Einzelfälle werden als vollgültige Beweise eines Gesetzes begriffen: „Bestimmend für die Typik eines Falls sind die Regeln, die ihn erzeugen und die Mannigfaltigkeit seiner Teile organisieren“ (Rosenthal 2011: 75). Die Typenbildung63 bzw. Begriffsbildung zielt auf ei-

${ }^{63}$ Es soll nicht unerwähnt bleiben, dass Max Weber maßgeblichen Einfluss auf die Verallgemeinerungslogik durch Typenbildung hatte. Weber schlug vor, Idealtypen zu konstruieren, die von empirischen Phänomenen ausgehen, dies aber „durch einseitige Steigerung eines oder einiger Gesichtspunkte und durch Zusammenschluss einer Fülle von diffus und diskret [...] vorhandenen Einzelerscheinungen, die sich jenen einseitig herausgehobenen Gesichtspunkten fügen, zu einem in sich einheitlichen Gedankenbilde" (Weber 1904/2004: 81). Die so konstruierten Idealtypen dienen dem Abgleich mit der sozialen Wirklichkeit. Sie sind also Mittel und nicht Ziel der Analyse (vgl. ebd.: 83, Hervorhebungen im Original). 
nen „genetisch-strukturalen Typus“ (Rosenthal 2011: 75) bzw. auf „konditionalgenetische Begriffe“ (Lewin 1930: 431) und nicht auf einen beschreibenden oder „Phänotypen“ (ebd.: 431). Eine Typenbildung bezieht sich also nicht auf die oberflächlichen Merkmale eines Falles, sondern auf die Organisiertheit, auf die konstitutiven Regeln bzw. Strukturen ${ }^{64}$ eines Falles. Damit schließe ich mich der im interpretativen Paradigma vertretenen Verallgemeinerungslogik an, die „Strukturgeneralisierungen“ (Oevermann 1981) und eine „Typenbildung am Einzelfall“ (Rosenthal 2011: 73-82) vornimmt.

Diese Form der Verallgemeinerung beschränkt sich nicht auf Einzelfälle im Sinne einzelner Personen oder biographischer Verläufe, sondern kann auch andere (höhere) Aggregatzustände meinen wie Familien oder Generationen und Stadtviertel, aber auch Deutungsmuster und soziale Situationen.

Meine theoretischen Verallgemeinerungen bzw. Konstruktionen 2. Grades liegen teilweise auf unterschiedlichen Fallebenen. Ich habe Deutungs- und Handlungsmuster sowohl im Bereich schutzpolizeilicher Arbeit als auch auf der Ebene biographischer Verläufe rekonstruiert. Wie ich diese Ebenen verknüpft habe, werde ich im Folgenden erläutern (Kap. 3.3.3.3), nachdem ich die verwendeten Methoden vorgestellt habe (Kap. 3.3.3). Zuvor werde ich aber nun den Forschungsprozess skizzieren.

\subsubsection{Der Forschungsprozess}

Die oben skizzierten methodologischen Prinzipien haben meinen Forschungsprozess grundlegend strukturiert. Am Anfang meiner Forschung stand ein noch vages Interesse an den biographischen Verläufen und Handlungsmustern von Polizist*innen, das sich im Verlauf des Forschungsprozesses und durch die Erfahrungen ,im Feld' konkretisiert und sich am Ende zu einer Theoriebildung zum Passungsverhältnis von biographischer Struktur und der Struktur polizeilicher Arbeit (vgl. Kap. 6) verdichtet hat.

Aus dem anfänglichen Forschungsinteresse ergab sich für mich, dass ich sowohl einen Einblick in die alltägliche polizeiliche Arbeit und Handlungsroutinen benötigte, als auch mittels Interviews etwas über die Biographien von Polizist*innen erfahren musste. Für beides stellte sich die Frage nach einem Feldzugang und damit verbunden nach den allgemeinen Möglichkeiten und Grenzen von Forschung innerhalb der Polizei. Das ,Feld Polizei` und die Möglichkeiten von Forschung im Rahmen eines Dissertationsprojektes geben Beschränkungen vor, die den ,best practice'-Anforderungen an eine ethnographische Arbeit, in der sich

64 Zugrunde gelegt wird hier ein Strukturbegriff, der sich nicht auf formale und statische Strukturen bezieht, im Sinne einer Anzahl von Merkmalen, die in einer bestimmten Relation zueinander stehen. Vielmehr werden Strukturen, angelehnt an die objektive Hermeneutik, als Prozessstrukturen gedacht, die es zu erschließen gilt. Von einer Struktur kann erst dann gesprochen werden, wenn ,bezogen auf ein konkretes Gebilde mindestens eine Phase der Reproduktion von dessen Struktur rekonstruiert wurde“ (Oevermann 1981: 25). 
z.B. Phasen von Feld-Teilnahme und Rückzug an den Schreibtisch abwechseln (vgl. Amann/Hirschauer 1997: 28), nicht immer gerecht werden können. Um den Forschungsprozess nachvollziehbar zu machen und ihn als ,,soziologischen Lernprozess“ (Lau/Wolff 1983) zu reflektieren, soll er hier dargestellt werden. Die Reflexion des Forschungsprozesses bietet einerseits die Möglichkeit, sich nach einer intensiven Feldphase vom Feld zu distanzieren und sich der eigenen Erfahrungen in dieser Zeit bewusst(er) zu werden. Andererseits wird bei der folgenden Darstellung deutlich, wie im Prozess (der Reflexion) des Feldzugangs Hypothesen über das untersuchte Phänomen entstehen und das Forschungsinteresse dadurch konkretisiert werden kann.

Feldzugang und Gatekeeper. Meine wissenschaftliche Auseinandersetzung mit ,der Polizei begann im Rahmen meiner Masterarbeit. Hier habe ich Interviews mit Beamten der Bereitschaftspolizei geführt. Für mich recht überraschend war es kein großes Problem, über den zuständigen Beamten für Öffentlichkeitsarbeit Interviewpartner vermittelt zu bekommen - wenngleich dies mit einigen Auflagen und zwei persönlichen Vorgesprächen verbunden war. Meine, von dem Beamten unterstützte, Anfrage, die Bereitschaftspolizei bei einem Einsatz zu begleiten, wurde jedoch im Innenministerium abgelehnt bzw. durch nicht zu erfüllende ,Vorleistungen' wie z.B. die Weitergabe meiner bisherigen Erkenntnisse mit Bezug auf die Praxisrelevanz nicht zuletzt aus Gründen der Anonymisierung verunmöglicht. 65

Diese Erfahrungen und die in der Literatur allgemein problematisierte Verschlossenheit der Polizei (vgl. Kapitel 3.1) haben mich dazu geführt, mir im Frühjahr 2014 Unterstützung für den Feldzugang im Rahmen des Promotionsprojektes zu suchen. Astrid Jacobsen, Soziologin und Professorin an der Niedersächsischen Polizeiakademie, war mir eine unschätzbare Hilfe. Sie vermittelte Kontakte, hat mich auf Spezifika der Kommunikation hingewiesen und war als Gesprächspartnerin eine große Unterstützung, weil sie mich als Soziologin ,verstehen'konnte.

Aus dem Innenministerium Niedersachsens, an das ich die erste Anfrage gerichtet hatte, erhielt ich zunächst eine offizielle Absage:

„Da wir an unser [sic] Hochschule in Münster auch Absolventen aus den eigenen Reiben haben, die zu Ihren [sic] Masterarbeiten bereits idR die Unterstützung aus unseren nachge-

\footnotetext{
${ }^{65}$ Siehe dazu auch die Beschreibung des Zugangs von Lau und Wolff (1983) zu einer Behörde der Sozialverwaltung. Sie argumentieren, dass das immer wieder neue Einholen von Informationen durch ,die‘ Behörde nicht einer inhaltlichen Auseinandersetzung mit dem Forschungsanliegen diente, sondern vielmehr den Nachweis erbringen sollte, dass die Forschung seriös sei, keinen politischen Schaden anrichte, dass man solidarisch, verschwiegen und nicht anstrengend sei. Geht es also weniger um den Inhalt und vielmehr um die Art der Präsentation des Forschungsprojektes und der Forschungsperson, ist es nur folgerichtig, dass durch immer neue Rückfragen versucht wird, sich ein persönliches Bild von den Forschenden zu machen. Dies bedeutet auch, dass man die für die jeweilige Organisation adäquate Präsentationform erst in der (langwierigen) Zugangsphase lernen kann.
} 
ordneten Polizeidirektionen benötigen, lässt der Umfang der Anfragen aus dem außerpolizeilichen Bereich keine weitere Unterstützung zu. Dem Gleicheitsgrundsatz. [sic] entsprechend muss ich Ihnen daher leider eine Absage erteilen. "

In dieser Absage wird keine prinzipielle Verschlossenheit der Polizei nach außen formuliert, sondern ,lediglich' ein Kapazitätsproblem erwähnt. Die Behörde zeigt sich prinzipiell offen gegenüber Forschung, indem sie betont, dass Masterarbeiten unterstützt werden - jedoch nur die ,eigenen'. Die Argumentation mit einem legaljuristischen Rückzug auf einen Gleichheitsgrundsatz, die das Handeln als legitim und damit nicht angreifbar machen soll, kann als typische Argumentationsfigur polizeilichen Handelns respektive polizeilicher Kommunikation beschrieben werden.

Vermittelt durch eine Kollegin von Astrid Jacobsen erhielt ich Kontakt zu einem Beamten des Personaldezernats. Dieser hatte Interesse an meiner Arbeit und ihrer möglichen Relevanz für die (Einstellungs-/Besetzungs-)Praxis der Polizei. Nach einem zehnmonatigen Prozess bekam ich einen Termin, um mein Anliegen vorzutragen. Auf diese Weise wurde das Innenministerium, das mir ja bereits eine offizielle Absage erteilt hatte, umgangen und ich erhielt Zugang zu einer konkreten Behördeneinheit mit einem Fürsprecher, der die Behördenleitung überzeugen konnte, mir eine teilnehmende Beobachtung zu ermöglichen. Nach nur wenigen Tagen erhielt ich die Zusage für eine „Hospitation“ und die Mitteilung darüber, welche Polizeiinspektion für mich ausgesucht worden war.

Im Anschluss habe ich Kontakt mit dem Leiter dieser Polizeiinspektion aufgenommen, der mich wiederum zu einem Gespräch zwei Wochen später einlud. Anwesend waren außerdem der*die aktuelle und zukünftige Leiter*in Einsatz der Polizeiinspektion - sie sind die allen Dienstabteilungen des ESDs vorgesetzten Personen innerhalb der Inspektion. Hier habe ich, wie in dem Gespräch mit dem Personal-Dezernenten, mein Vorhaben vorgestellt. Auch hier ging es um die Frage der praktischen Anknüpfungsmöglichkeiten: Was will ich eigentlich herausfinden und für wen soll dies gut sein? Außerdem darum, was man mit qualitativer Forschung eigentlich herausfinden könne und inwiefern sie repräsentativ sei. Die Vorstellung eines qualitativen Vorgehens war eine Herausforderung und ein Vorteil zugleich. Den Fragen nach den Verallgemeinerungsmöglichkeiten versuchte ich mit Beispielen zu begegnen. Dass man aber auf der Basis von nur wenigen Fällen allgemeine Aussagen treffen könne, überzeugte nur bedingt. Ein zweiter Erklärungsversuch überzeugte vielleicht auch nicht vollständig, wurde aber akzeptiert: Ich betonte die Komplexität polizeilichen Handelns, die meiner Meinung nach nicht durch vorgefertigte Fragen abgebildet werden könne, dafür benötige ich vielmehr die Perspektiven von den Polizist*innen selbst. Dieses Vorgehen würde dazu beitragen, dass ich zwar keine Aussagen über die gesamte deutsche Schutzpolizei oder alle möglichen und denkbaren Berufswahlgründe treffen könnte, dass aber das, was ich später herausfinde würde, dann auch dem entspräche, was ,wirklich' relevant ist und auf den Perspektiven der Polizist*innen selbst be- 
ruht. Mein offenes Vorgehen, das einerseits schwer zu vermitteln war, da ich noch keine klaren Fragen und Hypothesen, die getestet werden sollen, benennen konnte bzw. wollte, war andererseits ein Vorteil, weil es versprach, die Perspektiven der Teilnehmenden ernst zu nehmen.

Nach diesem eher informellen Treffen war ich erneut eingeladen, mich und mein Vorhaben bei einer Besprechung der Führungskräfte der Polizeiinspektion mit einem kurzen Vortrag vorzustellen. Auch hier wurde ich mit annähernd den gleichen Fragen konfrontiert und der Verlauf war ähnlich wie der zuvor geschilderte. In Einzelgesprächen im Anschluss habe ich auch Zuspruch erhalten, dass mein Vorgehen interessant sei und man mir viel Erfolg wünsche. Es waren vor allem Frauen, die mich ansprachen und mir auch anboten, dass ich mich an sie wenden könne, sollte ich mit den Männern ,nicht klarkommen“.

Der Feldzugang wäre ohne persönliche Unterstützung in dieser Form vermutlich nicht möglich gewesen. Als Fazit aus den beiden Versuchen, Zugang zur Polizei zu erlangen, kann in Kurzform festgehalten werden: Interesse an und Skepsis gegenüber Forschung sind hoch. Beides kommt aber in erster Linie bei Personen in höheren Führungspositionen vor, die vermutlich einerseits den Wert von Forschung (oder den Diskurs um den Wert von Forschung) für die (Akademisierung der) polizeiliche(n) Praxis kennen (vgl. 3.1), andererseits aber Bedenken haben, dass Forschung Kritisches zur polizeilichen Praxis äußern könnte. Zugang zur Polizei zu gewähren bedeutet eventuell auch in gewissem Umfang mitverantwortlich für das Resultat der Forschung zu sein und kann so mit einem gewissen Risiko für die Führungskräfte verbunden sein.

Am Ende dieses Prozesses stand die Verabredung, dass ich sechs Wochen im Sommer, bevor die Studierenden der Polizeiakademie zum Praktikum kommen, hospitieren würde. In der Annahme, dass es für mich interessant sei, verschiedene Dienstabteilungen zu begleiten, sollte ich alle zwei Wochen wechseln. Neben dem Argument, dass dies für mich interessant sei, schien es einen weiteren Beweggrund zu geben, der jedoch nicht vollständig expliziert wurde: Ich sollte sehen, dass die Abteilungen auch ein bisschen unterschiedlich sind und das die „Eigenarten, die die Abteilungen haben“, nicht für die gesamte Polizei stehen. Sollte ich also etwas ,Problematisches' entdecken, sollte es für ein Problem der einzelnen Dienstabteilung und nicht der Polizeiinspektion oder der gesamten Polizei stehen. Dieses Argument passt zur ,Einzelfallargumentation' und zum ,Schwarzes-SchafArgument ${ }^{`}$ bei polizeilichen Übergriffen, denen zufolge ein ,Fehler ${ }^{\star}$ - eine Straftat - von einzelnen Beamt*innen begangen wird und nicht auf die Polizei und ihre Strukturen als solche verweist. Mögliche strukturelle Probleme können so abgewehrt werden.

Die Polizeiinspektion, in der ich hospitierte, liegt in einer niedersächsischen Stadt. Der Einsatz- und Streifendienst arbeitet dort durchgehend in einem Dreischichtsystem, das von vier Dienstabteilungen wechselnd besetzt wird. In einer Dienstabteilung arbeiten ungefähr 15 Beamt*innen - je nachdem wie viele Personen in Teilzeit in einer Abteilung tätig sind. 
Der Forschungsaufenthalt - Der zweite Feldzugang und das Feld. Nach diesem ersten Feldzugang folgte gewissermaßen ein zweiter. Nachdem ich die in erster Linie bürokratischen Hürden genommen hatte, musste ich nun einen Zugang zu den Polizist*innen in der mir zugeteilten Dienstabteilung finden.

„Die Technik besteht meines Erachtens darin, Daten zu erheben, indem man sich selbst, seinen eigenen Körper, seine eigene Persönlichkeit und seine eigene soziale Situation den unvorhersebbaren Einflüssen aussetzt, die sich ergeben, wenn man sich unter eine Reibe von Leuten begibt, ihre Kreise betritt, in denen sie auf ibre soziale Lage, ibre Arbeitssituation, ihre ethnische Stellung oder was auch immer reagieren" (Goffman 1996: 263).

In diesem Sinne möchte ich im Folgenden darstellen, wie ich mich und meinen Körper den unvorhergesehenen Einflüssen des Feldes schutzpolizeilicher Arbeit ausgesetzt habe und wie dies auch meine Forschungsarbeit beeinflusst hat.

Im August 2015 begann meine sechswöchige Beobachtung als „Hospitantin“ in der für mich ausgesuchten Polizeiinspektion. Einige Tage zuvor hatte ich mit dem „Leiter Einsatz“ besprochen, dass es gut wäre, montags zu beginnen, jeweils zwei Wochen in einer Dienstabteilung zu bleiben und dann zu wechseln, und dass es wahrscheinlich gut wäre, zunächst zur Spätschicht am Mittag zu kommen, er würde dann den Abteilungsleiter darüber informieren. Ich sollte um $13 \mathrm{Uhr}$ da sein:

Als ich dann das Gebäude betrete, kann man schon durch eine Glasscheibe in den vorderen Raum, die Anmeldung, schauen. Als ich dort reinschaue, winkt mir schon ein älterer, vielleicht Mitte 50-jähriger Polizist zu und deutet mir hereinzukommen. Als ich in die Anmeldung trete, begrüßst er mich mit Namen. Ich bin erleichtert, dass ich mich nicht irgendwie durchfragen muss, habe aber auch keine Ahnung, wer das ist, der mich dort begrüßt. Er hat drei oder vier Sterne auf der Schulter und ich deute das als irgendeine Art Vorgesetzten. Er sagt, Eberhard (den ich auch nicht kenne und nicht weiß der ist) sei nebenan, sie hätten ja gerade Wechsel gehabt. Er bringt mich in den Raum nebenan, ein kleines Büro. Hier begrïßt mich Eberhard und stellt sich mir vor, der andere verabschiedet sich. Eberhard fragt, ob der Vorname okay sei. Ich bejahe dies und sage ,gerne". Er erklärt mir, dass sie gerade schon das Briefing hatten - er verlässt das Büro und ich folge ibm - und, dass ich heute mit Lukas fahren könne. Lukas sitzt in einem Raum mit zwei Schreibtischen, er begrü̈ß mich mit Handschlag, sowie noch einige andere, die dort sind. Sie sagen mir alle ibre Vornamen, ich denke sofort: Verdammt, wie soll ich mir die jetzt alle so schnell merken. Eberhard sagt, ich könne zu ihm kommen, wenn was sei oder ich Fragen habe. Lukas sagt nach ein paar Minuten Gespräch [...], dass er noch ein bisschen schreiben müsse, dass wir aber bald rausfahren. Er deutet nach nebenan, dort sei der Aufenthaltsraum, da könne ich meine Sachen abstellen. Jan, er hat sich mir auch vorgestellt, erklärt mir den „Kiosk" und die Kaffeemaschine, wie ich mich daran bedienen kann und wie die Bezablung funktioniert. Ich weiß nicht mehr, wie es dazu kam, dass er mir das erklärt. Er redet schnell, wirk.t aufgedreht. [...] Lukas kommt rein, ein bisschen hektisch: „Wir müssen schnell raus", zu den anderen im Raum: „Da steht jemand im Fenster, möglicherweise Suizidgefahr". Ich schnappe meine 
Sachen und laufe einfach hinter ihm her. [...] Am Nachmittag gibt mir Eberhard einen Dienstplan für die nächsten zwei Wochen, in den er meinen Namen unter die der Polizist*innen geschrieben und meine „Dienstzeit“ eingetragen hat.

Plötzlich war ich also im Feld. Es zeigte sich unmittelbar, dass dieses sich räumlich nicht auf die Dienststelle beschränkt, sondern immer da ist, wo schutzpolizeiliche Arbeit stattfindet: überall da, wohin ich hinterherlaufen konnte. Damit sind auch bestimmte Grenzen verbunden. Es handelt sich nicht um eine Ethnographie der Organisation Polizei, sondern um eine ethnographische Rekonstruktion polizeilicher Arbeit, wie die Beamt*innen des Einsatz- und Streifendienstes sie praktizieren. Dies bedeutet, dass mir ein kurzer Einblick in andere polizeiliche Arbeitsbereiche dann möglich war, wenn die Polizist*innen mit ihnen in Kontakt kamen.

Die körperlichen Erfahrungen. An diesem ersten Tag stellte sich, für mich überraschend, heraus, dass ich nun nicht eine Woche lang zur gleichen Uhrzeit kommen musste, um diese Dienstabteilung zu begleiten, sondern dass die Schichtplanung einem anderen System folgt. Dies bedeutete, dass ich an diesem Tag, wollte ich die Schichten vollständig begleiten, und das war mein Plan, bis 20.45 Uhr bleiben würde. Am nächsten Tag hatte diese Dienstabteilung Frühschicht, die immer um 6 Uhr beginnt bzw. jede Schicht jeweils 15 Minuten vorher - das hatte ich an meinem ersten Tag schon ,falsch“ gemacht und das „Briefing“ verpasst. Ich kam an diesem Tag abends gegen 22 Uhr nach Hause und musste morgens um 4.45 Uhr wieder das Haus verlassen, um - noch nicht einmal pünktlich - um 6.15 Uhr wieder auf der Dienststelle zu sein. Am darauffolgenden Tag hatte ich meine erste Nachtschicht von 22 bis 6 Uhr. Bei dieser bin ich gegen Morgen auf dem Rücksitz des Streifenwagens immer wieder in Sekundenschlaf gefallen, hatte dann zu Hause wiederum große Probleme schlafen zu können. Will bzw. kann man dann den restlichen Tag nicht vollkommen verschlafen, muss man nach wenigen Stunden wieder aufstehen. Diese Wochen waren für mich körperlich enorm anstrengend. In Gesprächen mit den Polizist*innen darüber versicherten mir alle, dass man sich daran gewöhnen würde. Diesen Eindruck hatte ich selbst auch, jedoch in dem Sinne, dass ich mich an eine ständige Grundmüdigkeit gewöhnte, und nicht, dass der Körper sich dem nicht vorhandenen Rhythmus angepasst hätte.

Warum nun dieser Exkurs zu den körperlichen Erfahrungen des Schichtdienstes? Zum einen beschreiben sie die körperlichen Erfahrungen, die ,man“ im Schichtdienst macht - nicht nur ich, sondern auch die Polizist*innen sowie andere Menschen, die in einem solch strukturierten Schichtsystem arbeiten. Zum anderen, und das ist im Kontext meines Forschungsverlaufes wichtig, führte es dazu, dass ich in diesen Wochen vollständig damit beschäftigt war ,klarzukommen', zumindest einen kleinen Teil meines sonstigen, nicht an das Schichtsystem ange- 
passten Soziallebens ${ }^{66}$ aufrechtzuerhalten und zur ,Arbeit ${ }^{6} \mathrm{zu}$ fahren. Dies hatte zur Folge, dass ich während meiner Beobachtungsphase dem gefolgt bin, was mir gezeigt wurde und was ich sehen konnte. Vieles habe ich nicht gesehen, habe es übersehen oder bin manchmal auch den Präsentationen der Feldakteur*innen fraglos gefolgt, wie sich in der späteren Auseinandersetzung mit meinen Protokollen zeigte. Ich habe zwar täglich Protokolle über den Tagesverlauf geschrieben und an den freien Tagen der jeweiligen Dienstabteilung versucht diese detaillierter fortzuschreiben, aber ein Rückzug an den universitären Schreibtisch, um einige Tage innezuhalten und zu reflektieren, erfolgte nicht. Er erschien mir nicht möglich bzw. ich kam nicht auf die Idee, von den im Vorfeld vereinbarten Absprachen abzuweichen und nach einer Pause die Beobachtung fortzusetzen - der Verlauf des Feldzugangs und die Polizei an sich vermittelten (mir) den Eindruck eines nur geringen Spielraums dafür.

Ich habe bei meinem späteren Rückzug an den Schreibtisch, dem „coming home“ (Amann/Hirschauer 1997: 28), festgestellt, dass ich (die richtigen) Fragen (Merton 1959) bzw. Probleme (Dewey 1938/2004) gefunden hatte, dass ich sie aber nur teilweise beantworten konnte. An diesem Punkt wäre nun eine zweite (und dritte) Beobachtungsphase sinnvoll gewesen, um manchen Fragen oder Spuren weiter nachzugehen, was aber aus verschiedenen Gründen nicht möglich war. So ist mir z.B. erst nach meiner Beobachtungsphase aufgefallen, dass ich über das ,Treiben' auf der Dienststelle nur sehr wenig geschrieben habe oder dass meine Protokolle von Einsätzen, die für mich aufregend waren, viel detaillierter sind als die von vermeintlicher Routinearbeit wie Verkehrskontrollen oder der Schreibarbeit im Anschluss an Einsätze.

Meine körperlichen Erfahrungen von Aufregung und Anspannung sowie Erschöpfung und Müdigkeit und den unter anderem damit zusammenhängenden erschwerten Reflexionsmöglichkeiten bestimmten so auch, welche Fragen ich gefunden habe und wie sich dadurch mein Gegenstand mitkonstituiert hat. ${ }^{67}$

Meine Feldrolle(n). An dem Auszug aus meinem ersten Beobachtungsprotokoll zeigt sich außerdem, wie ,das Feld' mich empfangen hat. Bei höheren Leitungspersonen war ich eher auf Skepsis gestoßen und der Kontakt war zumeist förmlich. In der Dienstabteilung dagegen wurden Förmlichkeiten schnell durch das übliche kollegiale Du ersetzt und ich wurde in die Kioskliste eingetragen, um mich an Getränken und Süßigkeiten bedienen zu können. Auch wenn mir immer mal wieder Skepsis begegnete, schien sie mehr meinem Interesse an Soziologie („mit Soziologie konnte ich im Studium gar nichts anfangen“) und weniger meiner etwas unkla-

\footnotetext{
66 Dies halte ich nicht nur aus dem Grund eine Pause oder Abwechslung zu haben für wichtig, sondern es hat sich eben auch gezeigt, dass bestimmte Aktivitäten nur eingeschränkt möglich sind: (Team-)Sportarten, die mit festen Trainingsterminen verbunden sind, können nicht regelmäßig betrieben werden, Wochenendverabredungen sind nur an jedem zweiten Wochenende möglich etc. 67 Zur Konstitution des Gegenstandes durch die Empirie, die theoretische Perspektive und die verwendeten Methoden siehe Strübing et al. (2018).
} 
ren Forschungstätigkeit zu gelten - auch, weil meine Rolle eher die einer Praktikantin war, die sich einfach für alles interessierte, als die einer Forscherin, die ein möglicherweise prekäres Thema wie Polizeigewalt etc. untersucht. Immer wieder erhielt ich auch anerkennende Worte, dass ich nicht - wie z.B. Rechtsreferendar*innen - nur für wenige Tage da sei. Für manche war ich eine nette Abwechslung für ein Gespräch, manche hatten offenbar Freude daran, mir Dinge zu erklären, anderen wiederum war meine Anwesenheit, so mein Eindruck, vollkommen egal, für manche war sie vermutlich auch eine Einschränkung. Insgesamt sind die Beamt*innen es jedoch gewohnt, dass sie Begleitung ,von außen' haben: Jahrespraktikant*innen oder auch Rechtsreferendar*innen begleiten sie immer wieder.

So unterschiedlich das Interesse an mir und/oder meiner Arbeit war, so unterschiedlich waren auch meine Rollen. Die, die mir viel erklärten, haben mich auch immer wieder eingebunden in ihre Arbeit. Ich habe Sachen hinterhergetragen, Laufarbeiten bekommen, den Weg ,gegoogelt', einen Alkoholtest gemacht, Formulare mit ausgefüllt und viel nachgefragt. Mit anderen habe ich einfach nur danebengestanden und schweigend im Auto gesessen. Manchmal habe ich von der Arbeit nicht viel mitbekommen, weil ich mit einem*einer der Beamt*innen in ein Gespräch über unser jeweiliges Privatleben verwickelt war.

Meine Feldrolle kann in Bezug auf die Polizist*innen als die einer interessierten ,Mitläuferin“ oder Praktikantin beschrieben werden. Den Polizist*innen war meine Forschungstätigkeit in unterschiedlichem Ausmaß bekannt. Von den Dienstabteilungsleiter*innen wurde ich als Soziologin vorgestellt, die promoviert. In Gesprächen habe ich dann je nach Interesse des Gegenübers mehr darüber erzählt, was mein Promotionsthema ist. Meinen Forschungsaufenthalt habe ich aber vor allem als Hospitation - dieser Begriff wurde von den leitenden Polizist*innen verwendet - gerahmt, während der ich einen Einblick in das polizeiliche Arbeiten erhalten möchte. Ich hatte mich dazu entschieden, mein Forschungsinteresse recht offen darzulegen, wenn es Fragen und Interesse daran gab, ansonsten habe ich es bei der Vorstellung der Dienstabteilungsleiter*innen belassen. In dieser Rolle hatte ich jedoch ständig Kontakt zu den nicht-polizeilichen Anderen, mit denen die Polizist*innen interagierten. Ihnen war meine Rolle nicht bekannt. Je nach Situation wurde ich ignoriert, fragend angeschaut und/oder habe von ihnen eine Rolle, die vermeintlich zu ihrer Situation passte, zugeschrieben bekommen. Bei einem Einsatz wegen Sorgerechtsstreitigkeiten wurde mir zugeschrieben, dass ich als Frau die beiden männlichen Polizisten begleitete, weil Kinder involviert waren. Mir wurde die Rolle einer Art sozialarbeiterischen Polizistin zugeschrieben. In einem anderen Fall, indem eine der Polizist*innen von ihrem Gegenüber genervt war, hat sie mich als Staatsanwältin vorgestellt, womöglich um ihr Gegenüber zu angemessenerem Benehmen ihr bzw. mir gegenüber zu bewegen. Damit ist ein forschungsethisches Problem angesprochen. Bei den ,Bürger*innen' war meine Position verdeckt. Bei den Polizist*innen kann man davon ausgehen, dass sie mehr oder weniger informiert waren bzw. sich informieren 
konnten. Ob sie jedoch informiert einwilligen (vgl. Hopf 2007) konnten bzw. sich dagegen entscheiden konnten mich mitzunehmen ist fraglich.

Abschied. Bei den Wechseln der Dienstabteilung, wie auch an meinem Geburtstag, der in eine Nachtschicht fiel, habe ich jeweils einen Kuchen gebacken und mitgebracht. Er wurde stets dankend angenommen und von manchen wurde mein Kuchen zum ,Ausstand“ kommentiert mit: „Du hast ja schnell gelernt, wie es hier läuft, so macht man das“. Auch wenn meine Mitspielkompetenzen bei polizeilicher Arbeit beschränkt blieben, habe ich doch eine gewisse Kompetenz auf dieser Interaktionsebene erlangen können.

Das Verlassen des Feldes bzw. der Abschied aus der letzten Dienstabteilung verlief ,unspektakulär‘: Auch hier verabschiedete ich mich mit einem Kuchen und einem Dankeschön bei der Besprechung zu Dienstbeginn. Bei Dienstende verabschiedete ich mich von den Anwesenden mit Handschlag, bedankte mich und erhielt von Einigen noch einen guten Wunsch für meine Doktorarbeit. Für mich war es einerseits schade, meine Feldphase nun zu beenden, andererseits auch erleichternd, wieder meinem ,normalen' Leben nachgehen zu können. Für die Beamt*innen ging der nächste Tag aber vermutlich genauso weiter wie sonst auch; ob ich, die „Praktikantin“, nun da war oder nicht, hatte im Feld, von einzelnen Situationen abgesehen, keine grundsätzlichen Auswirkungen. Mein Aufenthalt war nicht mit Wünschen oder Hoffnungen auf Seiten der Polizist*innen oder einer Art freundschaftlicher Beziehungen verbunden.

Sample und Anonymisierung. Im Laufe der teilnehmenden Beobachtung habe ich umfassende Protokolle während der Phase des Feldzugangs sowie Protokolle zu jeder Schicht erstellt. Insgesamt existieren 34 Protokolle, deren Länge zwischen ca. 3 und 18 Seiten variiert. Von diesen habe ich mit unterschiedlichen Methoden (vgl. 3.3.3) 21 teilweise oder vollständig ausgewertet.

Im Anschluss an meine Beobachtungsphase habe ich eine Interviewanfrage per E-Mail an die Dienstabteilungsleiter*innen verschickt, die sie an ihre Dienstabteilung weitergeleitet haben. Zuvor hatte ich auch in Gesprächen immer wieder erzählt, dass ich gerne Interviews führen würde, und einigen, die zumindest ein geringes Interesse signalisierten, meine Visitenkarte oder Handynummer gegeben. Auf die E-Mail-Anfrage reagierten jedoch nur vier Personen. Ich habe dann eine weitere E-Mail verschickt an Personen, mit denen ich während meiner Feldphase darüber gesprochen hatte. Auf diese zweite E-Mail habe ich keine Antworten erhalten. Letztendlich habe ich nur drei Personen aus diesen Dienstabteilungen interviewt, obwohl - oder gerade weil - die Interviews von der Behördenleitung unterstützt wurden und die Interviews als Dienstzeit angerechnet werden konnten. Weitere Interviewpartner*innen habe ich über Facebook gefunden. Außerdem über private Kontakte, unter anderem über eine zivile Angestellte des Landeskriminalamtes, die mir Kontakte vermittelt hat. Das Gesamtsample umfasst sieben biographisch- und vier berufsbiographisch-narrative Interviews mit Beamt*innen des mittleren und gehobenen Dienstes aus drei Bundesländern, vor- 
wiegend aus der Schutzpolizei, aber auch aus Bereitschafts- und Kriminalpolizei. Von diesen Interviews habe ich zwei fallrekonstruktiv, ein weiteres globalanalytisch $^{68}$ ausgewertet. Drei berufsbiographisch-narrative Interviews habe ich im Rahmen meiner Masterarbeit ausgewertet. Diese Ergebnisse, ebenso wie die Me$\operatorname{mos}^{69}$ der nicht ausgewerteten Interviews, sind kontrastierend, jedoch nicht systematisch in die Arbeit eingeflossen.

Die Interviews und Protokollauszüge, die ich hier verwende, wurden nach der Analyse anonymisiert. Bei der Darstellung sind Namen, Wohn- und Arbeitsorte etc. verändert oder weggelassen worden. Ich habe mich entschieden, die Interviews, die ich mit den Beamt*innen aus der Polizeiinspektion, in der ich meine teilnehmende Beobachtung durchgeführt habe, hier nicht darzustellen. Für die Ergebnispräsentation wäre das Kontrastieren von diesen Fallrekonstruktionen mit konkreten Situationen aus den Beobachtungsprotokollen, in denen diese Beamt*innen handelnd vorkommen, gewinnbringend gewesen. Eine ausreichende Anonymisierung ihrer Lebensgeschichten erschien mir gegenüber ihren Kolleg*innen und Vorgesetzten jedoch nicht möglich, da sie sich aus einer sehr kleinen Gruppe von Polizist*innen, die ich dort kennengelernt habe, rekrutieren.

\subsubsection{Die Forschungsmethoden}

Den oben formulierten methodologischen Annahmen und Implikationen sowie der Perspektive auf die Ebene des Alltagshandelns zufolge bedarf es bestimmter methodischer Instrumente. Diese Instrumente respektive empirischen Methoden, die ich in meiner Arbeit verwendet habe, möchte ich nun darstellen.

Ich habe zum einen teilnehmende Beobachtungen durchgeführt, um meinem Interesse an der Alltagspraxis und an polizeilichen Handlungsmustern nachzugehen. Zum anderen habe ich biographisch-narrative Interviews geführt, um die Perspektive auf die biographischen Verläufe und biographisch etablierten Handlungsmuster zu richten.

Mein Ausgangspunkt bei der Planung des Forschungsvorhabens war biographietheoretisch gerahmt und der teilnehmenden Beobachtung hatte ich einen eher ergänzenden Status eingeräumt. Dies hat sich im Verlauf des Forschungsprozesses gewandelt. Beide Ansätze stehen nun gleichberechtigt nebeneinander: Meine Arbeit könnte als eine biographietheoretische beschrieben werden, in der auch teilnehmend beobachtet wurde - im Sinne einer „Biografieforschung als Praxis der Triangulation“ (Alber/Griese/Schiebel 2018) oder im Sinne einer Biographieforschung, die als Feldforschung grundsätzlichen einen ethnographischen Blick hat. Sie ließe sich aber auch als eine ethnographische Arbeit beschreiben, in deren Rahmen, wie in ethnographischen Arbeiten üblich, verschiedene Methoden angewendet wurden: Es wurde teilnehmend beobachtet und interviewt. Die Nutzung

${ }^{68}$ Globalanalysen beruhen auf dem Verfahren der biographischen Fallrekonstruktion (vgl. 3.3.3.2 und Rosenthal 2011, 90-92).

${ }^{69} \mathrm{Zu}$ jedem Interview werden im Anschluss Memos verfasst, siehe dazu Rosenthal (2011: 90-92). 
verschiedener methodischer Zugänge, mittels Methodenkombination, Methodenpluralität oder Triangulation (siehe z.B. Denzin 1970; Flick 2004; Burzan 2016), hat eine lange Tradition in den Sozialwissenschaften. Ein einziges Label - ethnographisch oder biographieanalytisch - möchte ich dieser Arbeit nicht geben, da beide methodischen Ansätze gleichberechtigt nebeneinanderstehen. Wichtig erscheint mit, dass die Methode der teilnehmenden Beobachtung und der biographisch-narrativen Interviews und deren jeweilige Analyseverfahren sich ergänzen. Die eine trägt zum Verständnis der Ergebnisse der anderen bei. Die Ergebnisse des einen methodischen Vorgehens helfen beim Analyseprozess des anderen Vorgehens und vice versa.

\subsubsection{Teilnehmende Beobachtung, beobachtende Teilnabme und ihre Analyse}

Im Rahmen meines Promotionsprojektes habe ich, wie oben dargestellt, eine teilnehmende Beobachtung durchgeführt, um meinem Interesse an der alltäglichen Arbeit der Schutzpolizei nachzugehen. Der Fokus der teilnehmenden Beobachtung richtet sich auf die Praktiken und Routinen in einem Feld und damit verbunden auch auf die impliziten Wissensbestände, die häufig nur schwer oder gar nicht verbalisierbar sind. Durch die Teilnahme und das Miterleben der Beobachterin können sie zum ,Sprechen' gebracht werden. Der Grad der Teilnahme und des Miterlebens kann deutlich variieren, je nach Feld, aber auch innerhalb eines Feldes. Die teilnehmende Beobachtung hat sich für mich im Verlauf des Feldaufenthaltes teilweise zu einer beobachtenden Teilnahme entwickelt.

Teilnehmende Beobachtungen. Die teilnehmende Beobachtung ist die zentrale Methode der Ethnographie bzw. das „ethnographische Basisverhalten schlechthin“ (Hitzler/Eisewicht 2016: 46). Mithilfe der teilnehmenden Beobachtung sollen die Routinen und Handlungspraktiken beobachtet, aber auch selbst (leiblich) erlebt und nachvollzogen werden (vgl. Rosenthal 2011: 103 ff.; Breidenstein et al. 2015: 31 ff.). So konnte ich nicht nur beobachten, was Polizist*innen bei ihrer Arbeit auf der Dienststelle und auf der Straße machen, was sie ganz konkret wie tun, in Interaktion miteinander und mit ihren nicht-polizeilichen Interaktionspartner*innen, sondern es währenddessen auch miterleben. Kennzeichnend und auch notwendig für ethnographische Arbeiten ist eine Gleichörtlichkeit und Gleichzeitigkeit der Beobachterin mit dem Geschehen, sie beobachtet also die sozialen Praktiken am Ort und zum Zeitpunkt ihrer Ausübung (vgl. Amann/Hirschauer 1997: 23).

Statt einzelnen Erhebungspunkten werden außerdem Erhebungsstrecken angestrebt (vgl. ebd.: 16), in denen über einen längeren Zeitraum an den Praktiken des Feldes teilgenommen wird, um dadurch eine Innenansicht des Feldes zu erlangen.

Beobachtende Teilnahme. Bei der teilnehmenden Beobachtung geht es nicht nur um die längerfristige Beobachtung der Praktiken, sondern auch um das Miterleben der sozialen Praktiken. So wird auch in diesem Zusammenhang unter anderem die 
Rolle der Forschungsperson zwischen Involvierung und Distanzierung diskutiert (z.B. Breidenstein et al. 2015: 66 ff.), dennoch wird das Miterleben nicht überall systematisch als Ausgangspunkt soziologischer Erkenntnisgewinnung genutzt. Das eigene subjektive Erleben als Daten einzubeziehen fordert Anne Honer (1993) in ihrem Ansatz der lebensweltlichen Ethnographie, den sie auf Grundlage der phänomenologischen Wissenssoziologie formuliert. Der Unterschied von teilnehmender Beobachtung und der beobachtenden Teilnahme liegt im „Schritt vom ,so tun als ob‘ zum ,mit-tun““ (Honer 1993: 58); man tut, „was zu tun je ,üblich“ist, und [beobachtet] dabei nicht nur andere, sondern auch sich selbst" (Hitzler/Eisewicht 2016: 47). Ziel einer solchen beobachtenden Teilnahme ist die „Produktion von Beobachtungsdaten und von Erlebens- bzw. Erlebnisdaten“ (ebd.: 46).

Im Zweifelsfall soll die Teilnahme Vorrang vor der Beobachtung haben, um existenzielle Innenansichten zu erhalten statt eine distanzierte Außenansicht (vgl. ebd.: 46 f.). Forschungspraktisch birgt dies einige Herausforderungen, die im je konkreten Fall sehr unterschiedlich sein können. Nicht überall kann man mitmachen bei dem, was je üblich ist. So habe ich zwar bei vielem einfach mitgemacht bzw. mitmachen können: Ich bin mitgefahren, habe die Pausen mitgemacht, habe manchmal über Witze gelacht, über die alle lachten, obwohl ich sie nicht witzig fand, ich habe geholfen, wo es ging, und habe auch einmal einen Einsatzwagen gefahren. Aber ich habe eben nicht mit verhört, nicht mit verhaftet, ich bin nicht körperlich in polizeiliche Maßnahmen, verwickelt' gewesen, ich habe fast keinen ,Papierkram' gemacht und nicht erlebt, wie es ist, eine Uniform oder sogar (Schuss-)Waffen zu tragen - hier sind es nicht nur fehlende Fähigkeiten oder auch der Schutz meiner eigenen körperlichen Unversehrtheit (und der anderer), sondern auch rechtlich regulierte Grenzen, die das Mit-Tun beschränken.

Protokollierung. Der Protokollierung der Beobachtungen und eigenen Erfahrungen kommt eine zentrale Rolle zu: Erst durch die Protokollierung entstehen Daten (vgl. Amann/Hirschauer 1997: 30 f.). Die Herausforderungen der Protokollierung und des ethnographischen Schreibens sind viel diskutiert worden: die Frage nach der Autorität und Autorisierung der schreibenden Forschenden (Clifford/Marcus 1986; Berg/Fuchs 1993), das Problem der Selektivität, der Aufzeichnung und des Vergessens (z.B. Bergmann 1985) sowie die Frage der Übersetzung von Beobachtetem in Sprache bzw. der Versprachlichung der „Schweigsamkeit des Sozialen“ (Hirschauer 2001).

Die ganz praktischen Hinweise sind vielfältig. Ich habe mich, den Möglichkeiten des Feldes und dem Vorrang von Teilnahme vor Beobachtung entsprechend, dafür entschieden, während der Beobachtung selbst kaum Feldnotizen zu machen. Wenn der Tagesverlauf es zuließ, habe ich zwischendurch kleine Notizen gemacht, aber erst nach Ende der jeweiligen Schicht Protokolle angefertigt und sie an meinen ,dienstfreien' Tagen nochmals gelesen und ergänzt. Bei der Protokollierung habe ich mich an dem Vorschlag von Gabriele Rosenthal (2011: 108-113) 
orientiert, der eine Beschreibung des Ortes, des Gesamtablaufes und des eigenen Erlebens fordert sowie eine detailreichere Beschreibung einzelner Szenen im Gesamtablauf, in der versucht werden soll, zwischen Beschreibung und Interpretation zu trennen. Diese Form der Protokollierung soll eine spätere rekonstruktive Auswertung möglich machen. Diese Hinweise habe ich als Grundlage meiner Protokollierung genutzt, auch wenn sie für eine länger anhaltende Beobachtung nicht immer praktikabel waren. Mein Beobachtungszeitraum war täglich zwischen 7 und 12 Stunden lang. Hier sind eine Beschreibung des Gesamtablaufs und die detailliertere Beschreibung einzelner Szenen eine grundlegend hilfreiche Anweisung. In diesem langen täglichen Beobachtungszeitraum wechselte der Beobachtungsort jedoch ständig, da schutzpolizeiliche Arbeit an ständig wechselnden Orten stattfindet. Eine Beschreibung der Umgebung bei ständig wechselnden Orten übersteigt die/meine Memorierungsmöglichkeiten, wenn keine oder kaum Notizen angefertigt werden. Meine Protokollierung änderte sich auch innerhalb der sechs Wochen. Von recht umfassenden Protokollen über den gesamten Schichtverlauf, in denen ich recht wenig fokussiert so viel wie möglich protokollierte und vor allem auch sehr stark mein eigenes Erleben thematisierte, fokussierte ich nach einiger Zeit stärker auf einzelne polizeiliche Einsätze und erwähnte anderes nur noch in Stichpunkten. Am Anfang habe ich z.B. noch detaillierter über die Einsätze bei Diebstählen von Airbags und Navigationsgeräten aus PKW, die zu dieser Zeit nächtlich geschahen, geschrieben. Nach zwei Wochen habe ich in einem Protokoll nur noch „fünfmal Diebstahl aus PKW hintereinander“ notiert und dafür z.B. mehr über die Interaktionen auf der Dienststelle geschrieben, die aufgrund der für mich vielen neuen Eindrücke und spannenden Einsätze bis dahin im Hintergrund geblieben waren. Die Entwicklung der Protokolle, ihre Selektivität bzw. die Selektivität meiner Verschriftlichung und Perspektivität, fasse ich allerdings nicht als defizitär auf, sondern vielmehr als ein Zeichen von Vertrautheit mit dem Feld. Nicht nur der Inhalt, sondern auch die Art der Protokolle geben Aufschluss darüber, was mich z.B. gelangweilt oder auch in Anspannung versetzt hat, auch wenn ich dies nicht expliziert habe. Und so wie eine Frühschicht mit 6 Parkunfällen und 5 Diebstählen für mich eher langweilig war, so war es auch für die Polizist*innen unaufgeregte Routine.

Auswertung. Im Gegensatz zu Protokollierung, ethnographischem Schreiben, Feldzugang und Feldrolle wird die Auswertung von Beobachtungsprotokollen weniger ausführlich diskutiert (z.B. Emerson/Fretz/Shaw 1995; Hammersley/Atkinson 2007; Hitzler/Eisewicht 2016): „die Datenanalyse [ist] die black box des ethnografischen Forschungsprozesses“ (Breidenstein et al. 2015: 111, Hervorhebungen im Original). Für die deutschsprachige Diskussion konstatiert Lüders, dass der Auswertung von Protokollen eine stärkere Aufmerksamkeit als in der englischsprachigen Literatur zukomme (vgl. Lüders 2007: 397), dennoch findet sich auch im deutschsprachigen Raum kaum Literatur, die im Vergleich zu anderen qualitativen Methoden ähnlich ,rezepthaft ${ }^{6}$ ausgearbeitet ist. Betont wird hingegen die Rele- 
vanz von reflektiertem Schreiben und von Annäherung an den und Distanzierung von dem Text. Vorschläge zur Analyse orientieren sich häufiger am Kodierparadigma der Grounded Theory (grundlegend Glaser/Strauss 1967/2008) sowie (im deutschsprachigen Raum) an der hermeneutischen Wissenssoziologie (grundlegend Soeffner 1989). Je nach Feld, Ziel der Analyse und Protokollierung stehen also verschiedene Möglichkeiten zur Verfügung.

Mir ging es bei der Analyse zum einen um die „Rekonstruktion der a) strukturellen Probleme, die Individuen bewältigen müssen, wenn sie in einem bestimmten institutionalisierten Rahmen handeln [...], b) und der durch diese spezifische Struktur eröffneten (aber auch verschlossenen) Handlungsmöglichkeiten zur ,LÖsung" dieser Probleme" (Schröer 1997: 115). Die Analyse zielte, zum anderen, auf Grundlage der eigenen Erfahrungen und Erlebnisse, auf die „Rekonstruktion möglichen Erlebens unter den als gegeben erfahrbaren Rahmenbedingungen“ (Hitzler/Eisewicht 2016: 63). Ich habe dazu verschiedene Verfahren genutzt. Zum einen habe ich einige detailliert beschriebene Szenen rekonstruktiv ausgewertet, wie Rosenthal (2011: 113-120) es vorschlägt. ${ }^{70}$ Hier wird zunächst der Kontext des Handelns mit seinen spezifischen Handlungsmöglichkeiten und -beschränkungen rekonstruiert, um dann vor diesem Hintergrund die Handlungsstrukturen zu rekonstruieren. Dieses Vorgehen hilft dabei, das Handeln der Akteur*innen, der Polizist*innen, nicht als rein individuelles zu verstehen, sondern es vor dem Hintergrund der Strukturen der Organisation Polizei und polizeilicher Arbeit (vgl. Kap. 4) zu betrachten. Da eine solche Analyse zum einen sehr zeitaufwändig ist und zum anderen einen bestimmten Detaillierungsgrad des Protokolltextes voraussetzt, habe ich die meisten Protokolle einer an der Grounded Theory orientierten Analyse unterzogen, angelehnt an den Vorschlag von Breidenstein et al. (2015: 109-134). Diese Form der Analyse, die am Vorgehen des offenen Kodierens orientiert ist, besteht in erster Linie aus wiederholtem und intensivem Lesen und Notieren. Die Hypothesenbildung wird geleitet von den Fragen wer was wann wie tut oder auch nicht und wie andere (auch ich) darauf reagieren. Aber auch: Warum habe ich das überhaupt und genau so aufgeschrieben? Ergebnis dieses Prozesses waren theoretische Memos von Protokollen und/oder Situationen, die ich dann kontrastierend miteinander verglichen habe. Sowohl bei der Analyse der detaillierten Szenen wie auch bei der Analyse eines gesamten Protokolls bin ich sequenziell vorgegangen. Auch die theoretischen Memos habe ich immer wieder in der Sequenzialität ihrer Entstehung miteinander in Beziehung gesetzt, um der Veränderung der Inhalte, der Form und meiner Perspektive in den Protokollen Rechnung tragen zu können.

Einige Protokolle habe ich gemeinsam mit Kolleg*innen ausgewertet. Dabei ist besonders hilfreich, nicht nur die eigenen Lesarten ,verteidigen ${ }^{6} \mathrm{zu}$ müssen und sie so zu schärfen oder auch zu verwerfen, sondern gerade im Rahmen eines eth-

\footnotetext{
${ }^{70}$ Dieses Vorgehen orientiert sich an dem Verfahren der biographischen Fallrekonstruktion, das weiter unten vorgestellt wird. Auch hier wird sequenziell und abduktiv vorgegangen (vgl. 3.3.3.2).
} 
nographischen Vorgehens hilft eine gemeinsame Auswertung dabei sich zu distanzieren. Man wird dadurch gezwungen, sein Feldwissen, das man bisher nicht in Protokollen notiert hat, eventuell auch weil man es schnell fraglos übernommen hat, explizit zu formulieren.

\subsubsection{Biographisch-narrative Interviews und biographische Fallrekonstruktionen}

Neben dem Interesse an der schutzpolizeilichen Alltagspraxis richtet sich mein Fokus auf die biographischen Verläufe, die Berufswahlprozesse und die biographisch etablierten Handlungsmuster im Kontext der Organisation Polizei und der Familien- und Lebensgeschichte der interviewten Polizist*innen. Mit diesem Interesse und der biographietheoretischen Perspektive (vgl. 3.2) sind bestimmte methodische Verfahren verknüpft, die es ermöglichen die Perspektiven und Handlungsmuster der Polizist*innen zu erschließen: biographisch-narrative Interviews und biographische Fallrekonstruktionen.

Biographisch-narrative Interviews. Das in den 1970er Jahren von Fritz Schütze (1976, 1977, 1983) entwickelte narrative Interview ermöglicht den Interviewten die Gestaltung der Gesprächssituation und eine an ihren Relevanzen orientierte Darstellung ihrer (Lebens-)Geschichte (vgl. Prinzip der Offenheit, Kap. 3.3.1). Die Interviewten werden hier als Expert*innen ihrer eigenen Biographie adressiert (vgl. Dausien 1994: 143) und erhalten die Möglichkeit, ihre „Erfahrungen [...] mit den Ereignissen und ihre interpretative Verarbeitung in Deutungsmuster eingehend darzustellen" (Schütze 1983: 286).

Im ersten Teil des Interviews ${ }^{71}$ wird dementsprechend versucht, durch eine narrative Eingangsfrage eine Erzählung zu evozieren, die ohne Unterbrechung seitens der Interviewerin abläuft. Von erzählanalytischen Erkenntnissen ausgehend ist die Darstellungsform der Erzählung eine, die eine Annäherung an die Handlungssituation in der Vergangenheit ermöglicht (vgl. Schütze 1977: 1). Im Erzählen von (vergangenen) Handlungsverläufen sollen auch die Handlungsorientierungen in der Vergangenheit deutlich(er) werden. Im Unterschied dazu sind Argumentationen und Beschreibungen viel stärker an der gegenwärtigen Perspektive der Interviewten orientiert (vgl. Kallmeyer/Schütze 1977). Diese Interviewform trägt damit der Differenz von Gegenwarts- und Vergangenheitsperspektive Rechnung: Rosenthal (1995) diskutiert auf Grundlage gestalttheoretischer Annahmen, ${ }^{72}$ dass die gegenwärtige Perspektive sowohl von Erfahrungen und Erlebnissen in der Vergangenheit als auch von dem seitdem Erlebten sowie der gegenwärtigen Lebenssituation und Diskursen bestimmt ist. Erzählungen zu evozieren zielt also darauf $\mathrm{ab}$, sich dieser Vergangenheitsperspektive zu nähern und die

\footnotetext{
${ }^{71}$ Zum konkreten praktischen Vorgehen siehe Rosenthal (2011: 157-165).

72 Rosenthal (1995) diskutiert die dialektische Beziehung von Erleben, Erinnern und Erzählen aus phänomenologischer und gestalttheoretischer Perspektive, unter anderem in der Auseinandersetzung mit den Philosophen und Gestalttheoretikern/-psychologen Aron Gurwitsch, Edmund Hussserl, Kurt Koffka und Max Wertheimer.
} 
Konstitution der Gegenwartsperspektive in Beziehung zu den Perspektiven und dem Erleben in der Vergangenheit setzen zu können.

Auf die narrative Eingangsfrage nach der Familien- und Lebensgeschichte folgt keineswegs immer eine Erzählung der Lebensgeschichte, sondern in der Regel eine Mischung verschiedener Darstellungsformen. Um weiterhin Erzählungen zu evozieren, soll auch der zweite Interviewteil, in dem Nachfragen durch die Interviewerin gestellt werden, erzählgenerierend gestaltet werden (vgl. Schütze 1983: 285; Rosenthal 2011: 161 ff.). Zunächst werden Detaillierungsfragen zu dem Präsentierten gestellt, bevor im Anschluss daran auch Fragen zu bisher nicht Erwähntem oder Fragen, die das konkrete Forschungsinteresse betreffen, gestellt werden.

Unter anderem hinsichtlich der Fragetechnik wurde die Interviewtechnik von Rosenthal (1995, 2011) weiterentwickelt. So schlägt Rosenthal z.B. vor, dass argumentativ Dargestelltes so nachgefragt wird, dass es in Bezug zu einem Handlungsablauf gesetzt wird. Zu einer Argumentation einer interviewten Person, dass das ,polizeiliche Gegenüber' ständig nur provoziere, stellte ich z.B. die Nachfrage: „Kannst du dich an eine Situation erinnern, in der du dich provoziert gefühlt hast, und mir davon erzählen?“‘

Besonders in einem Untersuchungsfeld wie der Polizei ist dies von besonderer Bedeutung. In den Vorarbeiten meiner Forschung habe ich bereits narrative Interviews mit Polizisten geführt. Hier hatte ich zwar eine auf die Berufsbiographie beschränkte Eingangsfrage genutzt, aber dennoch zum Erzählen aufgefordert. In den autonom gestalteten Selbstpräsentationen im ersten Interviewteil gab es kaum erzählerische Anteile, hier dominierten Argumentationen. Die Interviewten übten starke Selbstkontrolle aus. Da sie als Polizisten in ihrer beruflichen Funktion auf Kontrolle spezialisiert sind, ließen sie sich, auch im Nachfrageteil, nur schwer auf Erinnerungsprozesse ein. Die Polizei ist Gegenstand verschiedener Diskurse und steht oft in einem schwierigen Verhältnis zur Öffentlichkeit. An diesen Diskursen und den Zuschreibungen, die sie an mich als Soziologin, Studentin und ,Außenstehende' herantrugen, arbeiteten sich die Polizisten im Interview ab. Die Präsentation waren also stark von ihrer beruflichen Rolle, ihrer gegenwärtigen Perspektive, den Diskurspositionen ${ }^{73}$ und der Interviewsituation strukturiert (vgl. auch Schäfer 2018). Mit diesen Erfahrungen im Hinterkopf suchte ich nach einem anderen Zugang.

\footnotetext{
73 Diskurse verstehe ich im Anschluss an Reiner Kellers Auseinandersetzung mit der Wissenssoziologie und den diskurstheoretischen Arbeiten Michel Focaults: „Als Diskurse werden spezifische, thematisch-institutionelle Bündelungen der Wissensproduktion, Verknüpfungen von Deutungen und (nicht nur kommunikativen) Handlungen unter analytischen Gesichtspunkten aus dem gesellschaftlichen Wissensvorrat , herausgeschnitten' und als Zusammenhang von Wissensproduktionen, Objektivationsbestrebungen und deren gesellschaftlichen Wirkungen - eben der gesamte Bereich institutionalisierter Wissensproduktion und Wissenskonkurrenz - zum Forschungsgegenstand“ (Keller 2006: 128).
} 
Wie geht man mit einer stark kontrollierten und auch institutionalisierten AuBendarstellung um, die gegenüber der Forscherin eine legitimatorische Funktion hat, aber meinem Interesse zuwiderläuft, dessen Fokus auf der Handlungspraxis und den Erfahrungen der Polizist*innen liegt? Mein Versuch bestand in einem veränderten Feldzugang und einer sehr offenen Interviewfrage, die sich nicht nur auf die Berufsbiographie bezog, sondern die gesamte Familien- und Lebensgeschichte einschließt. Diese Rahmung und die erzählgenerierenden Nachfragen trugen zu einer Öffnung bei, wenngleich ,Kontrolle ${ }^{6}$ - der Interviewsituation und als Thema - weiterhin eine wichtige Rolle spielte. Bei den Interviews, die ich nach meinem Feldaufenthalt geführt habe, haben sich die Interviewten aber deutlich stärker auf Erzählungen und damit auch auf Erinnerungsprozesse eingelassen. Nicht nur das Interviewsetting - die ersten Interviews hatten auf der Dienststelle der Polizisten stattgefunden - war nun ein anderes. Auch meine Feldposition brachte Veränderungen mit sich: Es gab (wie auch zuvor) eine Erlaubnis durch die Behörde, diese Interviews zu führen. Diesmal konnte ich sie aber selbst organisieren und sie konnten an einem Ort stattfinden, den die Beamt*innen sich ausgesucht hatten. Hinzu kam, dass ich eine Verschwiegenheitserklärung unterschreiben musste und dies vermutlich teilweise bekannt war. Es gab also wenige formelle Redeverbote. ${ }^{74}$ Außerdem gab es nun auch weniger informelle Redeverbote. Ich hatte den polizeilichen Alltag und die Gespräche der Polizist*innen untereinander miterlebt. Und ich hatte mich in meiner Zeit als ,Hospitantin“ offensichtlich in verschiedener Hinsicht bewiesen. In den Interviews konnte nun über Interna oder Probleme gesprochen werden, da ich sie ja zum Teil schon aus dem Polizeialltag kannte. Es musste auch weniger erklärt werden und die Interviewten hatten weniger das Bedürfnis etwas zu rechtfertigen. Sie argumentierten weniger über die Art, wie sie handeln, sondern ließen sich mehr darauf ein, mir von konkreten Situationen zu erzählen, und argumentierten nicht allgemein über Situationen solcher Art. Dadurch und durch die veränderte Eingangsfrage hatten sie offenbar mehr Raum für die Ausgestaltung biographischer Bereiche außerhalb der Polizei.

Eine konsequente biographisch-narrative Interviewführung und die vorherige teilnehmende Beobachtung trugen dazu bei, dass die spezifischen Zugangsprobleme minimiert werden konnten. Interessanterweise gilt dies auch für die Interviews, die ich mit den Polizist*innen geführt habe, die ich unabhängig von der teilnehmenden Beobachtung kennenlernte. Die Mitspielkompetenz, die ich dort erworben hatte, und die Kenntnis der Interviewten, dass ich sechs Wochen hospi-

\footnotetext{
74 Polizist*innen sind an das Bundesbeamtengesetz $₫ 67$ gebunden:

(1) Beamtinnen und Beamte haben über die ihnen bei oder bei Gelegenheit ihrer amtlichen Tätigkeit bekannt gewordenen dienstlichen Angelegenheiten Verschwiegenheit zu bewahren. Dies gilt auch über den Bereich eines Dienstherrn hinaus sowie nach Beendigung des Beamtenverhältnisses.

(2) Absatz 1 gilt nicht,

1. soweit Mitteilungen im dienstlichen Verkehr geboten sind,

2. Tatsachen mitgeteilt werden, die offenkundig sind oder ihrer Bedeutung nach keiner Geheimhaltung bedürfen, $[\ldots]$.
} 
tiert hatte und von polizeilicher Seite dazu die Erlaubnis bekommen haben musste, wirkte sich auch auf diese Interviews positiv aus.

Biographische Fallrekonstruktionen. Ausgewertet wurden die Interviews mithilfe von biographischen Fallrekonstruktionen, wie sie Gabriele Rosenthal (1995, 2011) vorgestellt hat. Das Verfahren beruht auf einer Verknüpfung mehrerer method(olog)ischer Überlegungen wie der Narrationsanalyse Fritz Schützes (1976), der auf Aron Gurwitsch (1975) aufbauenden gestalttheoretischen Überlegungen zur thematischen Feldanalyse von Wolfram Fischer (1978) und der Objektiven Hermeneutik Ulrich Oevermanns (1979). Forschungspraktisch ist bei diesem rekonstruktiven Verfahren ein sequenziell-abduktives ${ }^{75}$ Vorgehen impliziert (konsequent umgesetzt ist dies z.B. bei Ulrich Oevermann et al. (1979) für die Objektive Hermeneutik). Analog zu der Annahme der prozesshaften Herstellung sozialer Wirklichkeit wird auch konsequent prozesshaft gearbeitet.

Ziel dieses Auswertungsverfahren ist es, sowohl die Präsentation der Biograph*innen in der Gegenwart als auch ihre Erfahrungen in der Vergangenheit zu rekonstruieren und den Zusammenhang beider Ebenen offenzulegen. Dies soll durch die analytische Trennung der „erlebten und erzählten Lebensgeschichte“ (Rosenthal 1995) möglich werden. In getrennten Analyseschritten wird ein Interview daher zum einen in Hinblick auf das vergangene Erleben in einem konkreten Handlungskontext analysiert und zum anderen wird die sequenzielle Gestalt der Präsentation der Lebensgeschichte rekonstruiert; erst im Anschluss werden diese beiden Ebene wieder zusammengeführt. Die konkreten Schritte einer biographischen Fallrekonstruktion sind an anderer Stelle (Rosenthal 2011) umfassend ausgeführt und sollen hier nur komprimiert dargestellt werden:

Die Analyse der biographischen Daten, als erster Auswertungsschritt, zielt auf die Rekonstruktion des Handlungskontextes sowie der Handlungsoptionen und beschränkungen und der getroffenen Wahlentscheidungen - ob bewusst intendiert oder nicht. Hierzu werden nicht die Selbstdeutungen der Biograph*innen als Grundlage genutzt, sondern aus dem Interview gewonnene objektive ${ }^{76}$ Angaben zur Familien- und Lebensgeschichte und soziohistorische Angaben aus dem Interview sowie aus einer zusätzlichen Recherche. Anhand dieser Daten, sortiert nach dem chronologischen Verlauf des Lebens, werden Hypothesen über Handlungsoptionen und -entscheidungen entwickelt (vgl. ebd.: 188 ff.). Davon ausgehend, dass Handlungsmöglichkeiten und die getroffenen Entscheidungen sowie

\footnotetext{
75 Das abduktive Schlussfolgerungsverfahren ermöglicht es Hypothesen am Einzelfall zu bilden und zu prüfen, indem in einem Dreischritt alle möglichen, sinnvollen Hypothesen zu einem Phänomen aufgestellt werden, um dann Folgehypothesen zu deduzieren. In einem letzten Schritt werden die Hypothesen induktiv am Fall geprüft (vgl. Rosenthal 2011: 57-59). Zur Abduktion in der qualitativen Forschung siehe Rosenthal (ebd.) und Reichertz (2003b, 2007), die sich beide auf die Grundlegung durch Charles Sanders Pierce beziehen.

76 Objektive Angaben meint hier die Daten, die kaum an die Selbstdeutung der Interviewten gebunden sind, wie etwa Angaben zur Schule und Ausbildung, Anzahl der Geschwister, Berufe etc.
} 
die Entscheidungsprozesse eine Struktur bezeichnen (vgl. Oevermann 1981), werden die Hypothesen am Ende zu einer Strukturhypothese verdichtet.

Der zweite Auswertungsschritt, die Text- und thematische Feldanalyse, zielt auf die Rekonstruktion der Mechanismen der Themenauswahl im Interview. Rosenthal geht davon aus, dass „einzelne Teile einer erzählten Lebensgeschichte in einem gestalthaften Zusammenhang stehen“ (1995: 22), dass sie auf bestimmte Weise organisiert sind. Diese Organisation von Themen, deren Auswahl und Gestaltung sowie ihr Zusammenhang sollen rekonstruiert werden. Es geht um die Frage, ob einzelne Teile eines „Textes Elemente eines oder mehrerer thematischer Felder sind“ (Rosenthal 2011: 197). Das thematische Feld ist „definiert als die Gesamtheit der mit dem Thema kopräsenten Gegebenheiten, die als sachlich mit dem Thema zusammenhängend erfahren werden und den Hintergrund oder Horizont bilden, von dem sich das Thema als Zentrum abhebt" (Gurwitsch 1975: 4). Das thematische Feld ist also kein beliebiges Zusammenfallen von Gegebenheiten, sondern ein Zusammenhang, in dem das Thema auf das Feld verweist und umgekehrt. Die Verbindung von Thema und thematischem Feld soll als eine Gestaltverbindung rekonstruiert werden (vgl. Rosenthal 1995: 51). Auf Grundlage der Interviewpräsentation in ihrem sequenziellen Verlauf werden Hypothesen darüber gebildet, ,weshalb sich ein Biograph oder eine Biographin - ob nun bewusst intendiert oder latent gesteuert - so und nicht anders darstellt" (Rosenthal 2011: 196), was er*sie auslässt und miteinander verknüpft und welche Funktion diese Darstellung für die interviewte Person in ihrem gegenwärtigen sozialen Kontext hat (vgl. ebd.: 187).

Bei dem dritten Analyseschritt, der Rekonstruktion der Fallgeschichte, wird der lebensgeschichtliche Verlauf mit den Aussagen der Interviewten in Verbindung gesetzt. Ziel ist die Rekonstruktion des erlebten Lebens und damit der Bedeutung des Erlebten und des Erlebens zum jeweiligen Zeitpunkt. Dabei werden die Ergebnisse des zweiten Analyseschrittes als Kontrastfolie zu den Aussagen der Interviewten genutzt.

Der letzte Analyseschritt ist die Kontrastierung der erzählten und erlebten Lebensgeschichte. Hier werden die Ergebnisse der Text- und thematischen Feldanalyse mit der Rekonstruktion der Fallgeschichte kontrastiert, um die Differenz von Vergangenheits- und Gegenwartsperspektive erklären zu können.

An jedem Punkt der Analyse ist es möglich, Feinanalysen (Oevermann et al. 1979) von einzelnen Textstellen durchzuführen. Eine solche Feinanalyse kann zur Überprüfung, Modifizierung und Erweiterung der bisherigen Hypothesen und Ergebnisse dienen. Dafür bieten sich besonders schwer verständliche oder die bisherigen Lesarten scheinbar kontrastierende oder unterstützende Textstellen an.

Mit biographischen Fallrekonstruktionen auf Grundlage der biographischnarrativen Interviews ist es möglich, die Bedeutung vergangener Handlungen zu rekonstruieren und nachzuvollziehen, wie sich die heutige Perspektive auf den Beruf und die Berufswahl daraus konstituiert. Das polizeiliche Handeln und die Perspektiven der in der Organisation handelnden Subjekte können aus eben dieser 
Perspektive verstanden werden. Es kann herausgearbeitet werden, welche Perspektiven die Beamt*innen haben und wie sich diese entwickeln - und wie diese Perspektiven und ihr Handeln verflochten sind mit den gesellschaftlichen und organisationalen Bedingungen und Diskursen.

\subsubsection{Die Verknüpfung der Untersuchungsebenen}

Am Ende der Analyse folgt die theoretische Verallgemeinerung und/oder Typenbildung. Aus der theoretischen Annahme der wechselseitigen Konstitution von Individuum und Gesellschaft (vgl. 3.2) folgt, dass ein einzelner Fall, eine einzelne Biographie oder soziale Situation, nicht nur Aussagen über diesen Fall erlaubt, sondern auch allgemeine Aussagen. Dies gilt sowohl für die biographischen Fallrekonstruktionen als auch für die Rekonstruktion der Handlungsbedingungen. Die methodologische Begründung für die hier vertretene Verallgemeinerungslogik habe ich in Kapitel 3.3.1 vorgestellt. Wie lässt sich dies nun aber konkret bewerkstelligen?

Die beiden methodischen Zugänge ermöglichen es, Deutungs- und Handlungsmuster zu rekonstruieren. Das ethnographische Vorgehen erlaubt es, innerhalb von Interaktionen konkrete Deutungs- und Handlungsmuster - Typisierungen - und Strukturen polizeilicher Arbeit zu rekonstruieren. Das biographietheoretische Vorgehen ermöglicht ebenfalls eine Rekonstruktion von Deutungs- und Handlungsmustern, die allerdings nicht über konkrete Interaktionen zugänglich sind, sondern durch die Rekonstruktion von Erfahrungen und Erlebnissen (in der Vergangenheit). Kann die ethnographische Rekonstruktion die in der gegenwärtigen Praxis situierten Deutungs- und Handlungsmuster rekonstruieren, so kann die Rekonstruktion biographischer Verläufe auch Aussagen über die Genese von Deutungs- und Handlungsmustern treffen. ${ }^{77}$

Im Folgenden rekonstruiere ich zunächst die Strukturen polizeilicher Arbeit als Deutungs- und Handlungsmuster bzw. Typisierungen, die Auskunft über die Bedingungen schutzpolizeilicher Arbeit geben und darüber, wie Polizist*innen diese Bedingungen handelnd deuten. Anschließend arbeite ich anhand zweier biographischer Fallrekonstruktionen heraus, wie sich der Prozess des Polizist*inWerdens und -Seins vollzieht und welche biographischen Handlungsmuster ausgebildet werden. Diese beiden Ebenen können dann aufeinander bezogen werden, z.B. indem ich die Fälle ,befrage': Wie würde der vorliegende Fall bzw. der ihn repräsentierende Handlungs- oder Verlaufstypus in einer bestimmten polizeilichen

\footnotetext{
${ }_{77}$ Natürlich muss sich eine ethnographische Perspektive nicht auf die gegenwärtige Praxis beschränken, auch hier kann die Entstehungsgeschichte und Entwicklung eines Phänomens anhand von Literaturarbeit oder mithilfe anderer Materialien rekonstruiert werden und die situierten Praktiken können darauf bezogen werden (z.B. Knoblauch 1991), sie kann aber keine ,echten' Weil-Motive im Sinne Schützes rekonstruieren. ,Echte' Weil-Motive sind nicht aus der direkten Interaktion und den Um-zu-Motiven ableitbar, sondern nur auf die Vergangenheit des*der Handelnden und seine*ihre sich zur ,Einstellung' (vgl. Fn. 58) abgelagerten Erfahrungen bezogen (vgl. Schütz/Luckmann 1979/2003: 474).
} 
Situation ${ }^{78}$ handeln und warum? Oder umgekehrt gedacht: Wie passen bestimmte typische polizeiliche Situationen zu den biographisch etablierten Handlungsmustern eines Falles oder zu dem ihn repräsentierenden Typus? Am Ende können so theoretische Aussagen über das Passungsverbältnis von den Strukturen polizeilicher Arbeit und biographisch etablierten Handlungsmustern formuliert werden.

Zum konkreten methodischen Mehrwert bei der Untersuchung von beruflichem Handeln und Organisationen werde ich am Ende der Arbeit einige Anmerkungen machen. Im Folgenden werde ich die empirischen Untersuchungen und Ergebnisse vorstellen.

${ }^{78}$ Mit polizeilicher Situation meine ich hier nicht nur Einsatzsituationen, sondern auch Situationen innerhalb der Organisation, wie Interaktionen mit Vorgesetzten und Kolleg*innen. 



\section{Der Handlungs- und Interaktionskontext polizeilicher Arbeit}

In diesem und dem folgenden Kapitel werde ich die empirischen Ergebnisse meiner Untersuchung vorstellen. In einem ersten Teil rekonstruiere ich dabei Strukturen des Handlungs- und Interaktionskontextes des Einsatz- und Streifendienstes (ESD) der Polizei, basierend auf meinen teilnehmenden Beobachtungen. Ich werde zunächst eine weitgehend getrennte Betrachtung der beiden Ebenen - polizeiliches Handeln und Biographie - verfolgen. Das bedeutet aber keineswegs, dass ich hier ,Handeln` und ,Interaktion` und im nächsten Kapitel ,Biographie` und ,Erleben' untersuche. Auch unter der biographietheoretischen Perspektive werde ich Handlungsmuster rekonstruieren und auch in diesem Kapitel werde ich ausschnittweise zeigen, dass lebensgeschichtliche Erfahrungen berufliche Deutungsmuster mit konstituieren. Dieses Kapitel gibt Antworten auf die Fragen, unter welchen Bedingungen polizeiliches Handeln prozessiert wird, was das Typische für den Handlungs- und Interaktionskontext polizeilicher Arbeit ist und welchen Relevanzen polizeiliche Arbeit folgt.

Zunächst werde ich die Wir-Bilder der Polizist*innen und ihre Sie-Bilder innerhalb der machtungleichen Interaktionsbeziehung mit den nicht-polizeilichen Anderen vorstellen und zeigen, inwiefern diese Deutungsmuster über die eigene und die Fremdgruppe handlungsleitend sind (4.1). Dann werde ich detailliert die handlungsstrukturierenden Typisierungen und Wissensbestände in Einsatzsituati- 
onen rekonstruieren (4.2). Wie kommen Deutungen in polizeilichen Einsatzsituationen zustande und wie entwickeln sie sich innerhalb der Interaktionssituation? Dabei wird klar, dass diese Deutungen vor dem Hintergrund verschiedener Machtchancen innerhalb der Interaktionsbeziehungen betrachtet werden müssen. Abschließend werde ich Strukturen und die ambivalenten Anforderungen polizeilicher Arbeit rekonstruieren (4.3). Dabei werden zum einen Handlungs- und Deutungsmuster in der polizeilichen Alltagspraxis und in Bezug auf diese dargestellt. Zum anderen werde ich Interaktionsstrukturen sowohl in der Binnenbeziehung mit Kolleg*innen und Vorgesetzten als auch in der Außenbeziehung mit den nicht-polizeilichen Anderen nachgehen.

\subsection{Wir- und Sie-Bilder in der Polizei}

Polizeiliche Arbeit vollzieht sich strukturell in machtasymmetrischen Interaktionen. Wenn man davon ausgeht, dass nicht „das Sanktionsmittel als solches oder die Verfügung darüber als solche [...] effektiv Machtchancen [begründet], sondern die Ungleichheit der Verfügung über das Sanktionsmittel im Verhältnis der verschiedenen Akteure in einer Beziehung“ (Bogner 2003: 174), dann verfügt die Gruppe der Polizist*innen, die als lizensierte Gewaltinstitution die Gewalt monopolisiert hat, über mehr Machtchancen als andere; nicht nur weil sie zu Gewalt legitimiert ist und mehr Gewalt- und Machtmittel (z.B. in Form von Ausstattung und Information) zur Verfügung hat, sondern auch, weil sie als etablierte soziale Gruppe ein spezifisches Selbstbild ausgebildet hat. Ebenso hat sie Deutungen über diejenigen, die nicht Teil der Gruppe sind, entwickelt.

Diese Selbst- und Fremdtypisierungen der Polizist*innen, die das Handeln in dieser machtasymmetrischen Beziehung mitstrukturieren, lassen sich in Anlehnung an die Etablierten-Außenseiter-Theorie von Norbert Elias als Wir- und SieBilder beschreiben. So verstanden lässt sich die gegenseitige Konstitution der zugeschriebenen Eigenschaften an die eigene Gruppe und an die Mitglieder einer anderen Gruppe als Interaktionsprodukt und Machtmittel rekonstruieren (vgl. Elias/Scotson 1993: 43-49; 184 ff.). Die Wir- und Sie-Bilder ließen sich aus der hier vertretenen sozialkonstruktivistisch-wissenssoziologischen Perspektive auch als Typisierungen fassen. Ich habe mich an dieser Stelle aber entschieden, die figurationssoziologischen Überlegungen von Elias einzubeziehen, um zu verdeutlichen, dass diese Typisierungen als Wir- und Sie-Bilder Machtmittel in Interaktionen darstellen. Die Mitgliedschaft in der (polizeilichen) Wir-Gruppe kann ein WirGefühl hervorbringen, dass nach innen stabilisiert und gegen Kritik und Angriffe von außen wehrhaft macht. Als etablierte Gruppe üben Polizist*innen durch die Stigmatisierung der Außenseitergruppe - ihre Sie-Bilder - Macht über diese aus. Im Folgenden werde ich die Wir- und Sie-Bilder rekonstruieren und auch zeigen, wie sie in Interaktionen (re-)produziert und wirkmächtig werden. Ich stelle die 
Wir- und Sie-Bilder hier getrennt dar. Da sie sich wechselseitig konstituieren, sind Bezüge und Wiederholungen nicht vermeidbar.

\subsubsection{Wir-Bilder. Die polizeiliche(n) Konstruktion(en), der Polizei}

Die Polizei ließe sich in Abgrenzung nach außen folgendermaßen konzipieren: Alle, die nicht Polizist*innen sind, sind nicht Teil der Polizei. Oder positiv formuliert: Polizist*innen bilden die Polizei. Bei dieser zunächst recht banalen Annahme stößt man aber schon auf ein erstes Problem. Die Polizei hat viele (nicht verbeamtete) Angestellte, die zur Arbeit der Organisation Polizei beitragen. Aber sind sie auch ,Polizei'?79 Die konkrete alltagspraktische Herstellung dessen, was Polizei ist und wer in welchem Maße und wie zu ihr gehört, gestaltet sich komplexer.

Unterschieden werden kann zunächst, wie sich ein Wir-Bild diskursiv und alltagspraktisch sowohl in der Interaktion mit dem nicht-polizeilichen Anderen hier: in Abgrenzung - als auch untereinander herstellt. Außerdem lassen sich die Differenzen und Brüche in diesem Wir-Bild zeigen, die zum Teil auf einer rein formalen Unterscheidung von verschiedenen Tätigkeiten und Hierarchieebenen in der Organisation beruhen, aber auch alltagspraktisch hergestellt und reproduziert werden.

Wir Polizist*innen: Das Wir-Bild in der Abgrenzung nach außen. Polizist*innen haben ein starkes und geschlossenes Wir-Bild, das von allen Polizist*innen, mit denen ich im Rahmen meiner Forschung in Kontakt stand, bedient wurde - mit unterschiedlich ausgeprägten Bezugnahmen auf einzelne Bestandteile. Polizist*innen präsentieren sich - im Interview wie auch in der Interaktion - zunächst einmal als die ,Guten', die Gutes wollen und in verschiedener Hinsicht auch Gutes tun. Sie sind die legitimen Vertreter*innen des Gesetzes und vertreten die richtigen Werte Werte, die allgemein in der Gesellschaft gültig sein sollten. Verbunden damit ist die Präsentation, dass sie diese Werte auch stets vertreten, wie sich in folgendem Zitat aus einem Interview mit einem jungen Beamten andeutet:

„Polizei ist ja eben ein ein Machtorgan (_ ) Respekt das hat man so davor so is meine Vorstellung [...] zumal meine Berufsauffassung dahin geht das ich ja dem Bürger belfen will, gut derjenige den ich da festnehme grad dem helfe ich nich aber der hat ja irgendwas gemacht also sonst würd ich ibn ja nich festnehmen und ähm, irgendjemand anderes der eben das Opfer war der freut sich darüber das ich das mache"

Qua ihres Amtes sind Polizist*innen Respektspersonen. Sie sehen sich tätig in Situationen, in denen Menschen Hilfe benötigen und/oder Opfer geworden sind bzw. die Gefahr besteht, dass Menschen Opfer werden könnten. Dieses Ver-

${ }^{79}$ Mit den Angestellten hatte ich kaum Kontakt und kann die Frage daher nur aufwerfen, aber nicht beantworten. Naheliegend ist allerdings die Vermutung, dass sie nicht ,richtig' dazugehören können, wenn sich Polizei auch als Gefahrengemeinschaft und durch die geteilten Erfahrungen auf der StraBe konstituiert (vgl. Behr 2010). 
ständnis entspricht dem Bild von der Polizei als ,Freund und Helfer' (vgl. Fn. 22). Sie werden ebenfalls tätig, wenn Gesetze durch Tun oder Unterlassen infrage gestellt werden, wenn Menschen zu Täter*innen werden. Sie präsentieren sich als Ordnungshüter, die die infrage gestellte Ordnung - was auch immer sie jeweils konkret bedeutet - durch Eingreifen wiederherstellen respektive versuchen wiederherzustellen. Beide Bezugspunkte - Opfer und Täter*innen - dieses Wir-Bildes grenzen Polizist*innen von ihrem Gegenüber ab und idealisieren ihre Tätigkeit.

Die Abgrenzungen nach außen beziehen sich allgemeiner jedoch in erster Linie auf den „Bürger" ${ }^{\prime 80}$ einerseits und das „polizeiliche Gegenüber“ andererseits als zwei Typen von Handlungs- und Interaktionsmustern. Der Bürger hat - aus Sicht der Polizist*innen - normalerweise ein eher positives Bild von der Polizei und ist potenzielles Opfer. Zwar halten sich auch Bürger nicht an alle Gesetze (sie telefonieren beim Autofahren oder fahren alkoholisiert und lügen), aber sie treten mit ihren Handlungen normalerweise nicht aus einem Rahmen von Ordnungswidrigkeiten heraus. Sie sind keine Straftäter*innen und normalerweise nicht gewalttätig, sondern werden gerne belächelt: „na, was hat sich der Bürger denn hier schon wieder geleistet". Solche und ähnlich Äußerungen konnte ich während meiner Feldforschung häufiger hören, z.B. bei kleineren Verkehrsdelikten (ohne Verletzte). Der Bürger ist häufig das Gegenüber der Schutzpolizei. ${ }^{81}$ Der Bürger ist das Gegenüber, von dem die Polizist*innen sich als ,Freund und Helfer' angesprochen fühlen.

Das „polizeiliche Gegenüber“ hingegen spricht Polizist*innen als Ordnungshüter*innen an und ist die „typische Klientel“ der Bereitschaftspolizei. Die Zuschreibungen, die an diesen Typus gemacht werden, können unter die Schlagworte Devianz und potenzielle Gewalttätigkeit gefasst werden. Dem ,polizeilichen Gegenüber ${ }^{\varsigma}$ wird ein abweichendes Verständnis von Rechtsstaatlichkeit zugeschrieben, das sich unter anderem in widerständigem Handeln gegen die Polizei äußert. Vor allem in Bezugnahmen auf Interaktionen mit dem, polizeilichen Gegenüber lassen sich Bestandteile von (heteronormativer) Männlichkeit, Stärke und klarer Freund/Feind-Abgrenzungen in dem Wir-Bild rekonstruieren. ${ }^{82}$

Im Diskurs um die Polizei findet sich das Bild, dass Polizist*innen Vertreter*innen von Recht und Gesetz in einer demokratischen Ordnung sind, dass sie verpflichtet sind auf die freiheitlichen Prinzipien einer Demokratie und als Exeku-

\footnotetext{
${ }^{80}$ Hier verwende ich bewusst das Maskulinum, weil ich in diesem Bezug nie ein Femininum gehört habe. Die Rede war immer von dem Bürger.

${ }^{81}$ Interessant sind die Momente, in denen Polizist*innen zu Bürger*innen werden. In einer Interviewpassage berichtet ein Polizist über seine Erfahrung, Opfer eines Diebstahls geworden zu sein, und argumentiert darüber, wie schlecht er von den ermittelnden Polizist*innen behandelt worden sei und dass er sich von ihnen nicht angemessen als Opfer behandelt gefühlt habe (s. dazu auch Kapitel 4.3.4 und Fn. 90).

82 Der Frage, wie Aspekte dieses Wir-Bildes auch mit Männlichkeitsvorstellungen respektive Männlichkeitspraxen verschränkt sind, könnte weiter nachgegangen werden. Auf Grundlage meines Materials und Fokus meiner Arbeit kann ich dies nicht abschließend beantworten. Zu Polizei und Männlichkeit(spraxen) siehe Behr (2008) und Hunold (2019).
} 
tive eben auch eine der Gewalten des Staates darstellen. Dagegen findet sich dieser explizite Bezug auf demokratische Prinzipien in den interaktiv (re-)produzierten Wir-Bildern der Polizist*innen, die ich interviewt und beobachtet habe, höchstens am Rande - und dann eher als eine Legitimationsstrategie für ein bestimmtes, von ihnen als grenzwertig antizipiertes Vorgehen. Rekonstruieren lässt sich weiterhin, dass Polizist*innen sich als Spielball ,der ' Politik präsentieren und erleben. Auch in diesem Zusammenhang ist es zu verstehen, dass ein expliziter Bezug auf demokratische Prinzipien und die Polizei als Teil des politischen Prozesses kaum erfolgt, sondern es nur Verweise auf sie als Gesetzesvertreter*innen gibt, ohne dabei einen Bezug zur Politik (als Legislative) oder Demokratie herzustellen. Es deutet sich daher auch eine Abgrenzung von ,der ' Politik an. Im Kontext der deutschen (Polizei-)Geschichte kann dies als historisch gewachsenes Selbstbild betrachtet werden (vgl. 2.2). Es steht in Bezug zu dem Erleben, politische Interessen durchsetzen zu müssen, befreit aber zugleich auch von der Verantwortung für das eigene Handeln.

Polizist*innen sind zwar ausgestattet mit dem staatlichen Monopol auf Gewalt, es ist aber nicht Teil ihres Wir-Bildes gewalttätig zu sein. ${ }^{83}$ Diesem Bild zufolge wird ihnen die Ausübung von Gewalt von ihrem (feindlichen) Gegenüber auferlegt. Sich selbst präsentieren sie als Opfer der Gewalt der Anderen, sie üben nicht aktiv Gewalt aus, sondern wehren sich. Gewaltausübung wird als notwendig präsentiert zur Sicherung der allgemeinen Ordnung und der ,Eigensicherung ${ }^{6}{ }^{84}$ Dies kann als eng verschränkt verstanden werden mit dem (polizeiinternen) Diskurs um Polizist*innen als Opfer von Gewalt (vgl. z.B. Apelt und Häberle 2012; Behr 2012).

Die handlungspraktische Wirkung des Wir-Bildes. Auch andere Facetten des Wir-Bildes sind Diskursfragmente, auf die die Beamt*innen Bezug nehmen und/oder von denen sie sich abgrenzen. Die Polizist*innen reproduzieren in ihren Präsentationen (im Interview wie in der Interaktion) aber nicht einfach einen (Organisations-) Diskurs. Es ist ebenso deutlich, dass sich das Wir-Bild in Interaktion miteinander und mit dem nicht-polizeilichen Anderen herstellt und reproduziert. Das beschriebene Wir-Bild wird wirkmächtig im Arbeitsalltag: Eine Verinnerlichung der ,richtigen' Werte, zu ,wissen', was richtig und was falsch ist, und prinzipiell zu den ,Guten' zu gehören, scheint notwendig einerseits in Situationen, in denen sie unmittelbar Handeln müssen, ohne Zeit für Abwägungen zu haben. Polizeiliche Arbeit auf der Straße ist davon gekennzeichnet, schnell und abrupt in neue Ein-

83 Unten werde ich noch interne Differenzierungen des Wir-Bildes diskutieren. Auch in Bezug auf Gewalt sind solche denkbar. Es ist durchaus vorstellbar, dass eine bestimmte Form von,Gewaltfähigkeit ' Bestandteil des Selbstbildes sein kann, z.B. bei spezialisierten, kleineren und ,männlicheren Einheiten wie Sondereinsatzkommandos oder Beweissicherungs- und Festnahmeeinheiten.

${ }^{84}$ Die bisher beschriebenen Aspekte des Wir-Bildes zeigen deutliche Parallelen zu dem, was Apelt und Häberle (2012) als Copingstrategien (von Bundespolizist*innen) im Umgang mit dem Paradox des Gewaltmonopols beschreiben. 
satzsituationen ,geworfen' zu werden. Andererseits ist es nicht möglich, diesen Beruf bei ständiger Infragestellung der eigenen Arbeit auszuführen, wie sich an folgendem Beispiel exemplarisch zeigen lässt: Während einer Spätschicht müssen die beiden Polizisten, mit denen ich an diesem Tag unterwegs bin, einen jungen Mann, der der illegalen Einreise beschuldigt wird, bei einer anderen Dienststelle abholen und eine Anzeige schreiben. Das folgende Prozedere ist für die Beamt*innen erst einmal unbefriedigend. Zum einen schreiben sie eine Anzeige, obwohl sie davon ausgehen, dass das Verfahren entweder nicht eröffnet oder eingestellt wird, sie also lediglich eine bürokratische Pflichtaufgabe erfüllen. Zum anderen sind solche Fälle unter anderem auf Grund von Sprachbarrieren zwischen den Polizist*innen und den Geflüchteten häufig recht zeitintensiv. Selbst Geflüchtete mit guten Englischkenntnissen können auf solche Sprachbarrieren treffen. In diesem Fall spricht der junge Mann Farsi und ein paar Sätze Englisch und die Beamt*innen versuchen mit wenigen englischen Wörtern, Dauer und Route der Flucht zu rekonstruieren. Einer Aufzählung von Ländern folgt ein Datum, an dem er gestartet sei. Einer der dabeistehenden Beamten sagt zu mir:

„Drei Monate zu Fuß unterwegs, überleg dir das Mal, und dann kommen sie bierher und kriegen erstmal ne Strafanzeige, das ist doch totale Scheiße, und erklären kann man es obne Dolmetscher auch nicht, naja was soll's, wir machen es einfach".

Deutlich wird hier eine Frustration darüber, „Asylfälle“ mit nicht ausreichenden Mitteln oder Unterstützung bearbeiten zu müssen. Es zeigt sich neben der Problematik auf rein arbeitspraktischer Ebene aber auch Fassungslosigkeit und Mitgefühl für den Mann und Unverständnis gegenüber der rechtlichen Regelung, eine Strafanzeige schreiben zu müssen. Sie tun es aber „einfach“ trotzdem. Durch die Idealisierung, grundsätzlich - wenn auch vielleicht nicht in dem konkreten Fall - das Richtige zu tun und Ordnung herzustellen, ist es möglich beruflich handlungsfähig zu bleiben. Das bürokratische Prozedere, die Fragen, die gestellt, und die Akten, die angelegt werden müssen, ,helfen' bei der Distanzierung von Einzelfällen und der Frage, ob das, was man tut, eigentlich richtig ist. Eine Reflexion wie oben beschrieben kann nicht in der Handlungssituation stattfinden, sondern nur im Nachhinein, wenn es keinen Handlungsdruck mehr gibt, oder aber wenn man an der Handlung nicht unmittelbar beteiligt ist. Die Aufrechterhaltung von polizeilich-institutionalisierter Handlungsfähigkeit wäre sonst nur eingeschränkt möglich. Durch Bürokratisierung und die unhinterfragte Ausführung der Arbeit wird sie auch entpolitisiert.

Das Wir-Bild kann außerdem als eine Bearbeitung des Paradoxes des Gewaltmonopols verstanden werden: Organisationen mit Gewaltlizenz, wie die Polizei, schützen und repräsentieren das staatliche Gewaltmonopol. Gleichzeitig ist die Polizei aber auch der Ort, an dem Gewalt zur Begrenzung von Gewalt zu willkürlicher Gewalt werden kann (vgl. Reemtsma 2003: 16). Nicht nur das Verhältnis der Bürger*innen zur Polizei ist damit prinzipiell ambivalent (vgl. ebd.: 22), sondern auch das eigene Handeln und Berufsbild von Polizist*innen muss mit 
dieser Ambivalenz auskommen. In einem idealisierten Wir-Bild über die Polizei und polizeiliches Handeln drückt sich eine Bearbeitung dieser Ambivalenz aus, wie in dem Zitat des jungen Beamten oben auch deutlich wird.

An der oben geschilderten Szene zeigt sich, dass Aspekte des zunächst konsistent erscheinenden Wir-Bildes miteinander in Konflikt stehen können. Das Bild eines Ordnungshüters und Gesetzesvertreters kann in einem Spannungsverhältnis zu dem Bild vom Freund und Helfer stehen.

Das Wir-Bild in der Abgrenzung nach innen. Wie fragmentiert das Wir-Bild innerhalb der Organisation ist bzw. welche Wir- und Sie-Bilder innerhalb der funktional differenzierten Organisation Polizei zu finden sind, zeigt sich in den Abgrenzungen nach innen.

Nach einem nächtlichen Diebstabl von Kabeln und Geräten auf einer Baustelle bringen wir, Jan, einer der Beamten mit denen ich an diesem Tag unterwegs bin, und ich, nachträglich gesammelte Beweismittel zu dem zuständigen Fachgebiet für Diebstabl. Es ist mein dritter Tag. Jan erklärt mir auf dem Weg die Zuständigkeiten und das Prozedere. Als wir ankommen, öffnet er die Tür schwungvoll, tritt schnell ein und sagt: „na, alle wach?"

In diesem Moment und auch beim Verfassen des Protokolls hatte diese BegrüBung keine Bedeutung für mich, zumal es auch noch früh am Morgen war. Einige Tage später hatte ein anderer Polizist eine Nachfrage zu einem Vorgang. Er rief daher bei einem Sachbearbeiter eines anderen Aufgabenfeldes an und meldete sich mit: „Entschuldige, ich wollte euch nicht beim Schlafen stören, aber ich habe mal eine Frage zu ..." Nun wurde ich wachsam für die Abgrenzungen und Zuschreibungen untereinander. Die im ESD tätigen Polizist*innen schreiben sich selbst zu, wach, beweglich und aktiv zu sein. Das korrespondiert mit ihrer Tätigkeit, die als abwechslungsreich, spannend und herausfordernd präsentiert wird. Den Polizist*innen, die als Sachbearbeiter*innen Ermittlungsaufgaben in den verschiedenen Aufgabenfeldern übernehmen, wird - wie die beiden Szenen oben zeigen zugeschrieben, nicht ganz „wach“ zu sein. Wach kann hier so gedeutet werden, dass die Arbeit wenig aufregend, mitunter sogar einschläfernd ist. Gleichzeitig wird sie damit als weniger herausfordernd präsentiert. Deutlich wird hier die vorgenommene Abgrenzung zwischen den im Schichtdienst und auf der Straße tätigen ESD-Beamt*innen und den im geregelten Büroalltag mit planbaren Pausenund Bürozeiten tätigen Beamt*innen im Ermittlungsdienst (vgl. auch Mensching et al. 2004: 79-88). Interessant sind diese Abgrenzungen auch auf der Handlungsund Organisationsebene: Der Ermittlungsdienst wird teilweise und fluktuierend mit Polizist*innen aus dem ESD besetzt. Erfahrungen außerhalb der regulären ESD-Tätigkeit sind förderlich für eine Beförderung (wie z.B. der Fall von Melanie Wegener zeigt). Außerdem bedeutet eine begrenzte Zeit im Ermittlungsdienst eine Abwechslung zu der Tätigkeit im Wechselschichtdienst (auch wenn diese als aufregender präsentiert wird). Die Arbeit im Ermittlungsdienst wird also unter anderen von Personen ausgeführt, die kurz vorher und eventuell auch einige Zeit spä- 
ter wieder Teil der eigenen Gruppierung sind. Die Tätigkeiten im Ermittlungsdienst sind zudem sehr unterschiedlich und hier tätige Polizist*innen arbeiten teilweise auch außerhalb des Büros. Die Zuschreibungen sind also nicht konsistent oder, um es phänomenologisch zu wenden: Als Typisierungen beziehen sie sich auf die in der jeweiligen Organisationseinheit ausgeführten Tätigkeiten, abgelöst von personalen Typen (vgl. Schütz/Luckmann 1979/2003: 126 f.).

Weitere Abgrenzungen existieren unter anderem gegenüber der Bereitschaftspolizei (vgl. auch Behr 2008: 46 ff.). Dies ist insofern interessant, da in der Regel alle Polizist*innen nach ihrem Studium zunächst Dienst in der Bereitschaftspolizei (Bepo) versehen. Hier erfolgt eine Distinktion vor allem darüber, dass die Bepo im Vergleich zum ESD keine richtige Polizeiarbeit leiste (vgl. ebd.: 34). Die Bereitschaftspolizei, deren Hauptaufgabe darin besteht, sogenannte Großlagen zu bewältigen, ist unter anderem damit befasst, Demonstrationen oder Fußballspiele $\mathrm{zu}$ begleiten. Solche Einsätze sind durch eine viel deutlichere und direktere Befehlsstruktur geprägt als der polizeiliche Einzeldienst und man kann sich als Polizist*in nur sehr begrenzt als ,Freund und Helfer' verstehen, wenn man sich oft mit einem als eher gewalttätig vermuteten, polizeilichen Gegenüber' konfrontiert sieht. Hier deutet sich aber auch an, dass es nicht Teil des polizeilichen Wir-Bildes ist, an einem demokratischen Prinzip beteiligt zu sein. Denn die Tätigkeit der Bepo, die z.B. Demonstrationsrechte durchsetzt, ließe sich durchaus als relevante polizeiliche Arbeit in diesem Sinne begreifen. Die Erfahrungen in der Bereitschaftspolizei tragen aber vielmehr dazu bei, das polizeiliche Wir-Bild nach außen zu stärken und die ,richtige' polizeiliche Arbeit gedanklich in den ESD zu verlagern, wie sich auch an den beiden ausführlich dargestellten Fällen (Kap. 5) zeigen lässt.

Neben einem übergeordneten polizeilichen, Wir ${ }^{6}$ stehen also fragmentierte Wir- bzw. unterschiedliche Sie-Bilder einzelner Organisationseinheiten. Das oben beschriebene polizeiliche Wir-Bild, in der Abgrenzung nach außen, ist aber wirkmächtiger als die organisationsintern fragmentierten, und die verschiedenen organisationsinternen Sie-Bilder sind durch das geteilte starke Wir-Bild überhaupt nur möglich.

\subsubsection{Sie-Bilder. Die Typisierungen des Gegenübers}

So wie es ein Wir-Bild über die eigene Gruppe und interne Differenzierung gibt, so lassen sich auch verschiedene Sie-Bilder rekonstruieren. Zunächst sind NichtPolizist*innen die andere Gruppierung, die sich durch verschiedene Zuschreibungen differenzieren lässt.

Die Begriffe für und Zuschreibungen an das Gegenüber. Ich werde mich hier mit den Zuschreibungen beschäftigen, die mir in der polizeilichen Alltagspraxis begegnet sind und in diesem Kontext relevant wurden. Die Darstellung ist aber keineswegs vollständig. Neben den vorgestellten Begriffen finden sich weitere, wie etwa „Pappenheimer", „Störer“, „Chaoten“, „Assis“ etc. 
Ein allgemeiner Begriff der Abgrenzung ist der der „Klientel“. Etymologisch leitet er sich von lateinisch „cliens“, dem Schützling, bzw. „clientela“, der Gefolgoder Schutzgenossenschaft, ab. Der Begriff erscheint insofern passend, als die Polizei ihrer Klientel beisteht und sie schützt, bezeichnet (historisch) aber auch ein Abhängigkeitsverhältnis der Klientel von einem Patron (vgl. Pfeifer/Braun/Zentralinstitut für Sprachwissenschaft Berlin 1993: 668-669). Im allgemeinen Sprachgebrauch bezeichnet der Begriff heute vor allem Auftraggeber*innen oder Leistungsempfänger*innen bestimmter freiberuflicher Personen oder Institutionen (vgl. Duden 2007: 529), wie die von Notar*innen, Sozialarbeiter*innen oder manchmal auch Therapeut*innen. Damit wird einerseits der nichtpolizeiliche Andere als Empfänger einer Art Dienstleistung und die Polizei andererseits als Dienstleister konstruiert. So wird es auch vom Ministerium für Inneres und Sport Niedersachsen formuliert: „Die Deutsche Polizei auf dem Gebiet des heutigen Landes Niedersachsen hat sich [...] zu einem modernen Dienstleistungsunternehmen entwickelt, das den Interessen der Bürgerinnen und Bürger Rechnung trägt und seine Aufgaben professionell erfüllt" (Niedersächsisches Ministerium für Inneres und Sport o. J.). Der Begriff passt damit sicherlich zu den organisationalen Versuchen, eine bürgernahe Polizei zu präsentieren, und zum (Wir-) Bild der Polizei als ,Freund und Helfer' bzw. zu den diffusen Rollen, die Polizist*innen nicht nur als Vertreter*innen des Gewaltmonopols zeigen, sondern sie im Rahmen von z.B. präventiver Arbeit auch in die Nähe sozialarbeiterischen Handelns rücken können. ${ }^{85}$ Legt man die Bedeutung des allgemeinen Sprachgebrauchs zugrunde, so verschleiert diese Begrifflichkeit aber die Gewaltlizenz der Polizei - ähnlich wie der Begriff des ,Kunden' bei der Arbeitsagentur, aber auch bei der Polizei86, Machthierarchien verschleiert (siehe dazu auch Behr 2012: $186 \mathrm{ff}$.$) .$

Neben diesen Bedeutungen erhält die „Klientel“ im Polizeijargon des Alltags aber eine andere Konnotation als die der ratsuchenden Person oder Auftraggeber*in. Der Begriff ist dort deutlich negativ konnotiert. Personen oder Gruppie-

\footnotetext{
${ }^{85}$ Polizist*innen sind dafür jedoch nicht ausgebildet und verfolgen u.U. einen der Sozialen Arbeit widersprechenden Auftrag. Geht es bei der Sozialen Arbeit um die Bedürfnisse von (einzelnen) Menschen, orientiert sich die polizeiliche Arbeit an den Bedürfnissen der Gesellschaft und ihrem damit verbundenen gesetzlichen Auftrag (vgl. Eder 2003: 33 ff.). Zu der (innerhalb der Polizei) prekären Position von polizeilicher Präventionsarbeit siehe auch Scheffer (2018).

86 Thomas Ley (2013) rekonstruiert umfassend die Implikationen und Probleme des Kundenbegriffs, kommt dann aber zu dem Ergebnis, dass im polizeilichen Kontext besser von Klienten gesprochen werden sollte. Klienten der Polizei wenden sich, so Ley, in einer Notlage an eben diese; dies gilt auch für Personen, die sich für jemand anderen an die Polizei wenden, um ihm*ihr Hilfe zukommen zu lassen (vgl. ebd.: 67). Gleichzeitig rekonstruiert Ley, bezogen auf den Kundenbegriff, dass die Polizei eben nicht als Agentin des Bürgers handelt, sondern als Institution, die ein allgemeines Prinzip durchsetzt, wenn es verletzt wurde. Die Beeinträchtigung des Geschädigten sei nur insofern relevant, als ,sich in ihr die Verletzung des allgemeinen Prinzips manifestiert“ (ebd.: 59). Im Umkehrschluss wäre aber zu fragen, ob dann der Staat als Volkssouverän der Klient der Polizei ist und eben nicht die für sich oder andere hilfesuchende Person; damit wäre m.E. auch der Begriff des Klienten unpassend.
} 
rungen, die als Klientel bezeichnet werden, sind aus polizeilicher Perspektive prinzipiell problematisch. „Klientel“ bezieht sich nicht auf eine bestimmte Gruppierung, sondern kann recht variabel angewendet werden. Bezeichnet werden können damit in einem sozial-räumlichen Bezug z.B. Wohnviertel, in denen eine bestimmte Klientel wohnt, oder eine Klientel, die sich an bestimmten Orten trifft. Der Bezug kann auch ein ethnischer oder politischer sein, wenn bestimmte (Gruppierungen von) Personen als Klientel bezeichnet werden. Der Begriff ist dabei homogenisierend, bleibt aber weitgehend unspezifisch. ${ }^{87}$

Ein weiterer Begriff zur Bezeichnung des Gegenübers, den ich während meiner teilnehmenden Beobachtung kennengelernt habe, ist der Begriff des „Minusmenschen“. Er könnte angelehnt sein an den Begriff „Minusmann“ oder „Minustyp“, der, laut Duden, Männer bzw. Personen mit „dominant negativen Eigenschaften“ (Duden 2007: 664) bezeichnen soll. Die Bezeichnung scheint weniger verbreitet bzw. unterliegt vermutlich einer organisationalen Sprachregelung, da zweimal, als dieser Begriff in meiner Anwesenheit fiel, betont wurde, dass man das nicht sagen dürfe (ohne zu konkretisieren warum nicht) und ich das nicht gehört haben solle. Bezeichnet werden kann damit jede*r, der*die als irgendwie defizitär konstruiert wird. Als Erklärung des Begriffs auf meine Nachfrage wurde er mir übersetzt mit ,schlechter Mensch“ und unter anderem konkret bezogen auf einen Mann, der schon zu mehreren Haftstrafen wegen Körperverletzung verurteilt worden war, flüchtig war und am Abend zuvor festgenommen worden war, nachdem er seine Ex-Freundin bedroht hatte. In seiner Verwendung scheint der Begriff sich mehr auf einzelne Personen und weniger auf Gruppierungen zu beziehen und bei Taten, die nur damit erklärt werden können, dass jemand „einfach ein schlechter Mensch“ ist. Der Begriff scheint essentialistisch und ist offenbar mit der Idee verbunden, dass von „Minusmenschen“ prinzipiell keine Verhaltensänderung zu erwarten ist.

Eine differenziertere Typisierung von Handlungsmustern, die Polizist*innen von dem nicht-polizeilichen Anderen vornehmen, ist die der „Bürger“"88 und des „polizeilichen Gegenübers“. Das polizeiliche Gegenüber ${ }^{89}$ wird als eher widerständig, abweichend und potenziell gewaltbereit konstruiert und tritt vor allem im

\footnotetext{
${ }^{87}$ Der Begriff wird nicht nur von der Polizei verwendet, sondern auch im öffentlichen Diskurs um die Polizei. Auch im wissenschaftlichen Diskurs wird dieser Begriff von zur Polizei Forschenden immer wieder genutzt. Diese Reproduktion bzw. die Reproduktion der damit zusammenhängenden Deutungen halte ich für sehr problematisch.

88 Polizist*innen sind (staatsrechtlich) natürlich auch Bürger*innen. Die Konstruktion des Bürgers verweist damit evtl. auf eine Vorstellung des Staates von Obrigkeit und Untertanen, in der die Obrigkeit die Macht bzw. Gewalt über die Gruppe der Untertanen besitzt, aus der sich die Polizist*innen ausschließen.

${ }^{89}$ Für die Rekonstruktion der Konstruktion des ,polizeilichen Gegenübers' beziehe ich mich weniger auf meine aktuelle Arbeit, sondern in erster Linie auf die Ergebnisse meiner (unveröffentlichten) Masterarbeit, in der ich Interviews mit Bepo-Beamten geführt habe. Peter Ullrich (Ullrich 2017) beschreibt polizeiliche Kategorisierungen im Protest Policing deutlich differenzierter, als ich es hier leisten kann - seine Ergebnisse decken sich aber stark mit den Ergebnissen meiner Masterarbeit.
} 
Zusammenhang von Protest auf. Diese Konstruktion wird von Polizist*innen der Bereitschaftspolizei stärker bedient, da sie sich häufiger mit diesem Gegenüber konfrontiert sehen. Für den ESD ist der Bürger die relevantere Konstruktion in dieser binären Gegenüberstellung, aber auch die Polizist*innen im ESD kennen die Figur des ,polizeilichen Gegenübers', sehen sie jedoch nicht als ständiges nicht-polizeiliches Anderes. Der ,Bürger ${ }^{6}$ ist in Abgrenzung zum ,polizeilichen Gegenüber' das wünschenswertere Gegenüber. Er hat normalerweise ein positives Bild von der Polizei als Institution und ist potenzielles Opfer und nicht Täter. Zwar halten sich auch Bürger nicht an alle Gesetze, aber sie verlassen mit ihren Handlungen normalerweise nicht den Rahmen von Ordnungswidrigkeiten. Sie sind keine Straftäter*innen und normalerweise nicht gewalttätig. Die Konstruktion des Bürgers schließt es eher aus, dass so typisierte Personen auch unter den Typus Klientel fallen. Dagegen können Personen, die als ,polizeiliches Gegenüber kategorisiert werden, auch als Klientel bezeichnet werden.

Die Typisierungen sind nicht trennscharf, sondern situativ gebunden. Ist die Typisierung einer Person als ,polizeiliches Gegenüber' vor allem an Protestgeschehen gebunden, kann dieselbe Person in einer anderen Situation als Bürger typisiert werden, wenn sie in eine Verkehrskontrolle gerät. In einem Gespräch mit einem Bepo-Beamten nach einem Interview zeigte dieser sich äußerst verwundert, als ich ihm sagte, dass ich die Schilde, die sie zur Abwehr nutzen und von denen er mir gerade einen zeigte, auf Demonstrationen schon aus der Nähe gesehen hatte. Ich passte in diesem Moment nicht in seine Typisierung des ,polizeilichen Gegenübers', könnte es aber auf einer Demonstration durchaus werden, je nachdem wie ich gekleidet bin und mich verhalte. Auch wenn die Typisierungen situativ variabel sind, sind mit beiden Typisierungen auch bestimmte situationsunabhängige Zuschreibungen verbunden: Personen, die Kleidung oder Abzeichen tragen, die die Polizist*innen z.B. linken oder rechten Gruppierungen zuordnen, werden eher als ,polizeiliches Gegenüber' typisiert als ,neutral' gekleidete - selbstverständlich sind aber auch hier interaktive und situative Gegebenheiten relevant.

Handlungspraktische Relevanz der Sie-Bilder. Die Zuschreibungen an das Gegenüber werden handlungspraktisch erzeugt und sind in der Handlungspraxis relevant. Von der Typisierung des Gegenübers hängt die Ansprache des Gegenübers in Face-to-Face-Situationen ab. Die Interaktion mit dem Gegenüber steht wiederum in Wechselwirkung mit der Typisierung, ihrer Aufrechterhaltung, Anpassung oder Veränderung der Zuschreibung. Mit den Typisierungen des Gegenübers (und der Situation) sind bestimmte Handlungserwartungen und -entwürfe verbunden - wie ich in Kapitel 4.2 detailliert zeige.

Die oben beschriebenen Sie-Bilder in der Relation zum Wir-Bild führen zu einer Interaktionsstruktur, in der die nicht-polizeilichen Anderen häufig paternalistisch und bevormundend behandelt werden, unabhängig davon, ob sie ,Täter*in“ oder ,Opfer' sind. Das Wir-Bild, als Polizist*in eine Respektsperson und Autorität zu sein, kann sich in der Handlungspraxis als starke (und diffuse) Einforderung 
von Respekt zeigen (vgl. auch Betterman 2015). Unter Umständen ist damit eine Degradierung des Gegenübers verbunden, die sich zum Beispiel durch Duzen ausdrückt. Deutlicher zeigt sich die Struktur bei der Interaktion mit Personen, denen zugeschrieben wird, sozial schwach zu sein, bzw. mit Personen, die sozial und ökonomisch tatsächlich depriviert sind. Die Interaktion ist deshalb nicht unbedingt unfreundlich, aber dadurch, dass sich die Polizist*innen grundsätzlich in der machtstärkeren Position befinden und die Menschen in aller Regel in Ausnahmesituationen mit der Polizei in Kontakt kommen, ist eine Machtasymmetrie strukturell in die Interaktion eingelassen. Beim Kontakt mit Polizist*innen hat man zumeist etwas ,falsch' gemacht bzw. wird dessen beschuldigt, man benötigt Hilfe, ist Opfer oder Täter*in. Die Asymmetrie, die in solche Situationen eingeschrieben ist, macht es möglich, dass das Gegenüber paternalistisch behandelt wird (und sich (strategisch) auch häufig so behandeln lässt). ${ }^{90}$ Dies kann z.B. dazu führen, dass Polizist*innen ihrem Gegenüber Ratschläge zur Kindererziehung geben und diese unwidersprochen bleiben - zwischen Fremden eine sonst höchst problematische Interaktion. Zu Irritationen kommt es dann, wenn das Wir-Bild ,angegriffen' wird, indem nicht-polizeiliche Andere die Machtasymmetrie nicht fraglos anerkennen, z.B. durch Duzen oder Nachfragen (s. auch 4.3.5).

Es lassen sich, neben den allgemeinen Typisierungen wie der „Klientel“, auch teils sehr manifeste, teils latente Zuschreibungen an einzelne Gruppierungen rekonstruieren. Als Zuschreibung an ganze sozial(räumlich)e (Hunold 2016) oder ethnische Gruppierungen sind sie stigmatisierend oder rassistisch bzw. reproduzieren diskriminierende/rassistische Zuschreibungen. In einem Gespräch, in dem es um Diebstähle von Navigationsgeräten aus Autos ging, hinter denen eine organisierte „Bande“ aus einem osteuropäischen Land vermutet wurde, erzählte mir ein Beamter, dass eine Familie aus eben diesem Land hier viele Einbrüche begehen würde und sie Kinder und sogar eine schwangere Frau in Wohnungen einsteigen lassen würden. Der begründete Verdacht - es hatte wohl schon einzelne Verhaftungen gegeben - und die Erfahrungen mit Mitgliedern einer Familie führten, im Zusammenhang mit ähnlichen Erfahrungen und dem polizeilichen, aber auch öffentlichen Diskurs um Menschen aus diesem osteuropäischen Land, zu der Typisierung, dass sie ,gute ${ }^{6}$ und gerissene Diebe seien. Es wird ein rassistischer Diskurs reproduziert, den die Beamt*innen durch ihre Alltagserfahrungen bestätigt sehen, wodurch sich eine solche Typisierung wiederum verdichten kann. Bestätigen können sich diese Erfahrungen, das polizeiliche Erfahrungswissen, indem Menschen, denen die Polizist*innen etwas Bestimmtes zuschreiben, häufiger kontrolliert werden als andere Personen. Häufigere Kontrollen führen früher oder später auch zu Erfolg und bestätigen die Typisierung. In dem hier geschilderten

\footnotetext{
90 Zum Wir-Bild der spanischen Guardia Civil als Helfer, ihrem homogenisierenden und paternalistischen Sie-Bild der ,Grenzgänger*innen' und ihren Interaktionsstrukturen an der spanischmarokkanischen Grenze in den spanischen Exklaven Ceuta und Melilla konnten Eva Bahl und Arne Worm, trotz des in mehrerlei Hinsicht unterschiedlichen Kontextes, strukturell sehr Ähnliches herausarbeiten (Bahl/Worm 2018).
} 
Fall sind die Kontrollen von Autos aus einem bestimmten Land in einem konkreten Wohngebiet zwar nicht, ,verdachtsunabhängig“, sondern beziehen sich auf polizeiliche Erkenntnisse. Die Erwartung, dass bestimmte Gruppierungen bestimmte Delikte begehen, bleibt dennoch eine rassistische oder klassistische Zuschreibung, die in der Interaktion mit Menschen, die dieser Gruppierung zugerechnet werden, relevant wird. Eben dann, wenn diese Menschen aufgrund einer Zuschreibung stärker kontrolliert werden (vgl. Ruch 2017).

Typisierungen sind für Polizist*innen handlungspraktisch relevant - so wie sie im Alltagshandeln für uns alle relevant sind. Typisierungsprozesse, „Profiling“, sind konstitutiv für große Bereiche polizeilicher Arbeit. ${ }^{91}$ Für die polizeiliche Alltagspraxis sind äußerliche Merkmale oft relevante Indizien. Eine kategoriale Wirklichkeitswahrnehmung scheint bestimmend für polizeiliche Handlungsstrategien zu sein (vgl. Krasmann 1993; Behr 2008: 203). Durch die mit den Typisierungen und Handlungserwartungen zusammenhängende Kontrollpraxis, die tendenziell zur Verdichtung und Bestärkung der Typisierungen führt und seltener zu ihrer Differenzierung, ist polizeiliche Arbeit ständig mit dem Problem diskriminierender und rassistischer Praxis konfrontiert. Jacobsen (2015) beschreibt diskursive Typisierungsprozesse von „kulturell Anderen“ als funktional für die Polizeiarbeit: Die ,Anderen“ sind „dominanter Bestandteil der polizeilichen Identität“ (ebd.: 50). Oder allgemeiner, nicht nur auf rassistische Praktiken bezogen, lässt sich mit van Maanen (1978) feststellen, dass ,assholes [...] as a sort of reified others, representing all those persons who would question, limit [...] the police“ (ebd.: 323), das Wir-Bild und die Wir-Gruppe der Polizist*innen zusammenhalten. Denn: „the existence of an asshole demonstrates and confirms the police view of the importance and worth of themselves both as individuals and as members of necessary occupation“" (ebd.: 322). ${ }^{92}$

Die Herstellung von Differenz hilft bei der Konstruktion von Normalität und Abweichung, von ,normalen Bürgern' und denjenigen, die sie und die öffentliche

\footnotetext{
${ }^{91}$ Unter anderem Behr (2019) beschreibt diese Verdachts- und Kontrollstrategien. Er möchte dem Begriff des „racial profiling“ den des „social profiling“ (und „criminal profiling“) an die Seite stellen, um die erfahrungsbasierten Typisierungsprozesse zu beschreiben, die nicht allein auf einer Zuschreibung von Devianz aufgrund äußerlicher Merkmale (der Hautfarbe) beruhen, sondern z.B. auch situative Merkmale miteinschließen (vgl. Behr 2019: 26). Es ist sicherlich sinnvoll, diese Deutungsprozesse zu beschreiben, ohne Polizist*innen unter den Generalverdacht ständiger rassistischer Praxis zu stellen; ein solches Begriffspaar darf aber nicht dazu dienen, sich vor RassismusVorwürfen schützen zu können, weil nicht nur die Hautfarbe, sondern auch noch Sprache und Ort als ausschlaggebend für eine Kontrolle gelabelt werden. Mit einem Begriff wie „social profiling““ können aber diese Typisierungs- und Deutungspraxen vielleicht eine höhere Aufmerksamkeit in der polizeilichen Praxis/Ausbildung erfahren. Nur durch eine Reflexion dieser Deutungsprozesse in der Ausbildung und später im Arbeitsalltag kann diesem strukturellen Problem begegnet werden. 92 Van Maanen (1978) unterscheidet analytisch drei Typisierungen des Gegenübers: ,assholes“, die die polizeiliche Situationsdefinition nicht akzeptieren, „,suspicious persons“, von denen die Polizei annimmt, dass sie etwas verbrochen haben, und „know nothings“. Letztere gehören weder der einen noch der anderen Kategorie an und haben deswegen eigentlich keine Ahnung, was die Polizei so tut - sie sind eventuell vergleichbar mit dem „Bürger“.
} 
Ordnung bedrohen. Differenzkonstruktionen wirken sinnstiftend für die Konstruktion der eigenen Arbeit. In der wechselseitigen Abgrenzung zu den nichtpolizeilichen Anderen als (verschiedene) Sie-Gruppen konstituiert sich das eigene Wir-Bild.

\subsection{Prozesse polizeilicher Situationsdefinitionen}

Bisher wurde allgemein gezeigt, welche Wir- und Sie-Bilder rekonstruiert werden konnten und wie sie handlungspraktisch hergestellt und relevant werden. Anhand von zwei Einsatzsituationen soll nun detailliert gezeigt werden, wie (diese) Deutungsmuster in der situativen Dynamik eines Einsatzes Relevanz entfalten. Wie wird die Situationsdefinition (Thomas/Thomas 1928) oder Rahmung (Goffman 1980) handlungspraktisch hergestellt und modifiziert? Zunächst werde ich allgemein, aus einer sozialkonstruktivistisch-wissenssoziologischen Perspektive zeigen, welches Wissen in einer Einsatzsituation handlungsstrukturierend ist (4.2.1). Rekonstruiert werden grundlegende Deutungsprozesse in polizeilichen Einsatzsituationen. Kontrastieren werde ich dies mit einer zweiten Situation (4.2.2). In dieser „problematischen Situation“ (Schütz/Luckmann 1979/2003: 169) verhält sich die Situation widerständig gegenüber den interaktiven Situationsdefinitionsversuchen.

\subsubsection{Handlungsstrukturierende Typisierungen und Wissensbestände in Einsatzsituationen}

Im Anschluss an Schütz und Luckmann (1979/2003) sowie Berger und Luckmann (1969/2012) lässt sich zeigen, dass in einer Einsatzsituation

(1) die Typisierungen, die schon vor der konkreten Einsatz-Interaktions-Situation relevant werden,

(2) die Deutungen in der und über die Situation selbst sowie

(3) die biographischen Situationen der Beamt*innen handlungsstrukturierend sind.

(1) Typisierungen, die schon vor der Interaktionssituation relevant werden

In diesem Abschnitt zeige ich, mit welchem Vorwissen Polizist*innen einen Einsatz beginnen und wie dieses das Handeln vorstrukturiert.

Die folgenden Auszüge sind dem Beobachtungsprotokoll entnommen, das ich über meinen zehnten Beobachtungstag geschrieben habe. In dieser Frühschicht war ich den beiden Polizisten Jan und Sebastian zugeteilt und begleitete die beiden. An dem Einsatz waren außerdem Sabrina und Dieter sowie zwei Beamte einer anderen Dienststelle beteiligt.

Jan zeigt mir das EDV-System und lässt mich Vorgänge scbreiben. Wir trinken Kaffee dazu, ich sitze am PC und er guckt mir über die Schulter, ob ich alles richtig mache; es geht recht gemütlich zu und wir verbringen so fast drei Stunden. Es ist eine sebr rubige Früh- 
schicht. Ich werde, eingearbeitet' und meinen Protokollen ist mittlerweile auch eine gewisse Identifikation anzumerken: Ich schreibe sie mittlerveile meistens in der Wir-Perspektive.

Jan wird aus dem Funkraum gerufen: Einsat\%. Er springt auf, es wird hektisch. Es gibt eine Bedrohung mit Messer. Ich solle mich bereit machen. Jan ruft laut durch die Wache nach Sebastian. Sabrina rennt und ruft wiederum nach Dieter, sie sollen auch mit. Wir laufen raus zum Auto und fabren bzw. rasen mit Wegerecht los, Jan ist ein rasanter Fahrer. Im Auto wird noch über Funk durchgegeben, dass die bedrobte Frau angerufen babe.

Mit diesem Vorwissen gehen die Polizist*innen in die Einsatzsituation: Es hat eine Frau angerufen, die damit vermutlich als Opfer wahrgenommen wird. Es handelt sich um eine wie auch immer geartete Bedrohungssituation. Hinweis für diese Einschätzung ist die Zahl, die als Kürzel im polizeilichen Funkverkehr genutzt wird. In diesem Fall wird eine 058 aus der Leitstelle gemeldet: Eine Bedrohung/Belästigung. Bestimmte Ziffern sind mit bestimmten polizeilichen Lagen verbunden. Die Funkabkürzungen sind manchmal der einzige Hinweis, mit dem die Polizist*innen in einen Einsatz hineingehen. Eine Bedrohung kann sich aber in sehr verschiedenen konkreten Formen äußern und der Handlungshorizont ist noch sehr offen.

Die verwendete Ziffer ist bereits eine Interpretation der Situation: Die Beamt*innen, die in der Leitstelle Anrufe entgegennehmen, verarbeiten die Informationen, die sie in einem Notruf erhalten, zu einer Nummer, die sie dann weitergeben. Die Situation wird von Beamt*innen, die nicht an dem Einsatz teilnehmen, vorgedeutet. Das Vertrauen darauf, dass die Hinweise ,richtig ${ }^{6}$ verarbeitet und weitergegeben werden, ist bei den Einsatzbeamt*innen prinzipiell vorhanden (und notwendig). Dennoch herrscht leichte Skepsis. Nachdem mir zwei Polizist*innen in einer Nachtschicht die Leitstelle gezeigt bzw. wir sie gemeinsam besichtigt hatten, unterhielten sie sich darüber, dass manchmal auch falsche oder fragwürdige Informationen weitergegeben würden und nicht alle, die in der Leistelle arbeiten, dies auch gut machen würden. Den Grund dafür sahen sie in mangelnder Erfahrung im ESD. Ohne die Erfahrung auf der Straße könne nicht immer angemessen zwischen wichtigen und unwichtigen Informationen für die Einsatzbeamt*innen differenziert werden.

In diesem Fall ist die Meldung der Leitstelle noch spezifiziert durch die zusätzliche Angabe, dass ein Messer benutzt wurde. Das Vorwissen über diese Situation und das bisherige Wissen und die Erfahrungen über und in Situationen wie dieser - die mit der gleichen Funkabkürzung verknüpft sind - führt zu schnellem, hektischem Handeln. Dass es sich um eine Frau handelt, die bedroht wird, unterstützt dies: Eine Bedrohung an einem Freitagabend in z.B. Bahnhofsnähe, an der zwei Männer beteiligt sind, löst, so meine Erfahrung während meiner Feldforschung, nicht eine solche Hektik aus wie, im vorliegenden Fall, an einem Donnerstagmittag in einem Wohnhaus in einem Stadtteil, der von der (unteren) Mittelschicht, Angestellten und Arbeiter*innen bewohnt wird und nicht als „Brenn- 
punkt" gilt. Relevant ist also neben dem Geschlecht auch das Zeit- und Raumwissen (vgl. Hunold 2016) als Teil des polizeilichen Erfahrungswissens.

Neben dem vorhandenen Wissen ist aber auch das,fehlende' Wissen relevant für die Interpretation des Einsatzes im Vorfeld: Es gibt noch kein Einsatzwissen über diese Familie und die beteiligten Personen, soweit sich dies zu diesem Zeitpunkt sagen lässt. Den Beamt*innen ist die Familie nicht bekannt und sie haben hier nicht schon mehrfach „Einsätze fahren“ müssen.

Die Beamt*innen haben aber Erfahrungswissen zu Einsätzen wie diesen. Dieses Wissen über solche Situationen führt vermutlich auch dazu, dass die Beamt*innen der Leitstelle drei Autos zu dem Einsatz schicken. Zum einen ist unklar, was genau los ist oder wie viele Personen in der Wohnung sind. Klar scheint nur, dass es sich um eine vermeintlich aggressive und gewaltvolle Situation handelt, die möglicherweise mit zwei Polizist*innen nicht gelöst bzw. ,unter Kontrolle gebracht werden kann. Auch durch die Anzahl der angeforderten Streifenwagen wird der Einsatz für die Polizist*innen, die den Einsatz anfahren, von der Leitstelle als ein zumindest potenziell gefährlicher qualifiziert. Solche Situationen bedeuten von vornherein außerdem, dass sie auch für die Beamt*innen selbst gefährlich sein können.

\section{(2) Die Deutungen in der und über die Situation selbst}

Am Einsatzort angekommen, müssen die Beamt*innen sich schnell ein Bild von der ,Lage' machen und unverzüglich handeln. Dieses Bild beruht zum einen auf ihrem Vorwissen und zum anderen auf den Deutungen in der Situation und über die Situation.

Wir steigen aus und die beiden laufen los. Jan bittet mich, mich zurück:zuhalten. Die beiden anderen laufen binterher. Ich gehe also langsam binterher und bleibe zunächst an der Tür stehen. Währenddessen kommt ein weiterer Wagen einer anderen Dienststelle, sie grüßen mich und laufen schnellen Schrittes an mir vorbei die Treppe hoch. Ich gehe jetzt langsam die Treppe hoch. Im zweiten Stock sebe ich, wie eine halbe Treppe weiter oben ein junger Mann mit den Händen oben an die Wand gedrückt steht und von Sebastian durchsucht wird, während Jan mit der Taschenlampe leuchtet, einer der beiden anderen steht dabinter. Ich bleibe auf der halben Treppe stehen. Aus der Wohnung hört man eine Frauenstimme, sie spricht schnell, recht laut, möglicherweise weint sie auch. Jan fragt, nachdem Sebastian fertig ist, was passiert sei. Der Mann erklärt aufgeregt, aber recht rubig sprechend in unstruk.turierten Brocken ca. 10 Minuten lang Folgendes: Sie hätten sich gestritten und er wollte eigentlich schon gehen und dann habe sie ihn zweimal ins Gesicht geschlagen mit voller Wucht. Seine Exfrau wolle, dass er die Kinder nimmt, obwobl er sie gerade eine Woche gehabt habe, während sie in Urlaub gewesen sei, und dass sie jeţt dran sei, er wolle jetrt auch ein bisschen Zeit für sich. Sie wolle nur weggehen und feiern. Jan fragt nach, ob sie noch zusammen seien bzw. ob er sie wiederhaben wolle. Er verneint beides. Jan: „Gut, dann müssen sie sich ja auch nicht streiten wegen solchen Sachen, ob sie weggeht oder so. "Er: „Ja, aber sie lässt die Kinder alleine. Ich habe auch gesagt, sie kann sie ja einfach ganz mir geben. Und wenn irgendwas ist, droht sie mir die Kinder wegzunehmen. "Jan: „So einfach ist das 
ja nicht, aber das ist ja alles kein Grund für Handgreiflichkeiten. " Er fragt, ob er wirklich ein Messer in der Hand gehabt habe. Der Mann bestätigt dies und meint er sei einfach so wütend gewesen, er wisse, dass das falsch sei.

Die beiden Kollegen der anderen Dienststelle verabschieden sich wieder. Jan geht in die Wohnung, wo Dieter und Sabrina mit der Frau sprechen. Die Tür steht dabei die ganze Zeit offen, so dass man im Flur zwischendurch verstehen kann, was drinnen gesprochen wird. Ich bleibe mit Sebastian im Flur und gehe dann auch die Treppe bis zu den beiden hoch.

Nachdem also keine Gefahr mehr von der Situation auszugehen scheint bzw. die Beamt*innen die Gefahr des Einsatzes heruntergestuft haben - zwei Kollegen wurden aus dem Einsatz entlassen -, versuchen die Beamten zu rekonstruieren, was passiert ist. Sie erweitern ihr Wissen über den Fall. Mit Goffman gesprochen: „Was geht hier eigentlich vor?" (Goffman 1980: 16). In diesem Fall geschieht dies getrennt. Der Mann, der als Täter vermutet wird, wird außerhalb der Wohnung durchsucht und befragt, die Frau in der Wohnung. Sabrina, als weibliche Polizistin, spricht mit der Frau in der Wohnung. Jan übernimmt nun eine wissensvermittelnde Rolle. Nachdem er sich einen Eindruck von der Perspektive des Mannes verschafft hat, geht er rein und versucht nun dort die Perspektive der Frau zu erfahren. Wie auch in anderen Situationen, in denen mehrere Personen und Polizist*innen beteiligt sind, versuchen sie sich ein Bild von der Gesamtsituation zu machen, um zu entscheiden, wie es weitergeht. Auch wenn die anwesenden Beamt*innen im Anschluss die Ermittlungsarbeit an das zuständige Fachkommissariat weitergeben, müssen sie doch entscheiden, was genau jetzt geschehen soll. Notwendig ist dafür auch bestimmen zu können, wer die beschuldigte Person ist. Sie müssen also den vermeintlichen Täter identifizieren, um ihn zum Beispiel des Platzes zu verweisen, aber auch um später beim Anlegen der Akte Beschuldigte und Geschädigte angeben zu können. In diesem Fall ist die Lösung für die Beamten insofern eine einfache, als der Mann nicht mehr in der vormals gemeinsamen Wohnung wohnt. Außerdem zeigt sich der Mann aus polizeilicher Perspektive inzwischen ruhig, geständig und einsichtig. Dies führt dazu, dass die Situation nun als kontrolliert und entspannt eingeschätzt wird, so dass zwei der Polizisten wieder gehen und Sebastian mit dem Mann allein im Flur stehen bleibt.

Dieter kommt irgendwann auf den Flur und spricht mit dem Mann - er macht hier das Gleiche wie Jan: Er besorgt sich die Informationen der anderen Partei. Er beginnt seine Befragung jedoch mit einer Belehrung, die seine Rahmung der Situation offenlegt:

Dieter: „In Deutschland haben wir ja das Sprichwort: Frauen sind das schwache Geschlecht. Kennen Sie das? Frauen schlägt man in Deutschland nicht. "Der Mann: „Ja, ich bin Deutscher, ich bin hier geboren, natürlich weiß ich das. "Dieter sagt noch so einen Satz. und irgendwas von anderen Kulturen. Mir ist das total unangenehm. Danach hört er sich an, was der Mann auch vorher schon zu Jan gesagt hat. Dieter sagt dazu nichts. Er rät 
ihm, vorerst nicht dorthin zu kommen, sondern, dass die Frau sich einen Babysitter besorgen soll. Er geht wieder in die Wohnung und redet wieder mit der Frau.

Wir stehen weiter im Flur rum. Sebastian sagt irgendwann: „Diesen Bart (der Mann hat einen langen Bart, kurze Haare, trägt enge Jeans, Turnschuhe, T-Shirt und eine lange Kette aus Holzperlen, scheint ein Rosenkranz. zu sein, vielleicht ein bisschen Hipster) baben sie aber noch nicht immer gehabt oder? Auf dem Bild da baben sie ja noch keinen ". Er deutet auf ein Bild das im Flur der Wohnung zu sehen ist, wo der Mann mit einem der Kinder zu sehen ist. Mann: „Ne, jetzt kommen sie mir aber nicht damit. "Sebastian: „Ja ich meine ja nur. "Der Mann wird wieder aufgeregt und aufgebracht, es wird wieder kury laut.

Dieter unterstellt dem Mann, die Frau geschlagen zu haben - auch wenn die Frau, soweit mir bekannt ist, ihrem Ex-Mann dies nicht vorgeworfen hat. Ohne hier die Bedrohung der Frau zu relativieren, hat Dieter ihm damit aber doch einen anderen Tatbestand vorgeworfen. Grundlage dafür ist eine rassistische Zuschreibung seinerseits, dass Männer in anderen Ländern ihre (Ehe-)Frauen (ungestraft) schlagen könnten und dass der Mann sich entsprechend der ihm zugeschrieben Zugehörigkeit verhalte. Sebastian, der noch sehr junge Kollege, hat das Deutungsmuster, das ihm von seinem Kollegen angeboten wurde, übernommen und versucht nun Belege für diese Interpretation zu finden. Der Mann versteht offenbar sofort, worauf Sebastian hinaus möchte. Die von den Beamten geschaffene Situationsdefinition, dass hier ein Mann seine Ex-Frau bedroht, weil er „kulturell bedingt einen anderen Umgang mit Frauen“ pflegt, führt dazu, dass der Mann sich angegriffen fühlt, und die Situation droht wieder zu eskalieren.

(3) Die biographische Situation

Wie ich später zeigen werde (Kapitel 5 und 6.2), sind die biographischen Erfahrungen und die biographische Situation verknüpft mit den Handlungsmustern im Polizeialltag. Der Wissensvorrat und damit auch die Auslegung der Situation sind „,biographisch artikuliert“ (Schütz/Luckmann 1979/2003: 163 ff.).

Mit Jan und Dieter, den zentralen Akteuren in dieser geschilderten Situation, konnte ich leider keine biographischen Interviews führen, ich habe aber beide während meiner teilnehmenden Beobachtung oft begleitet und ethnographische Gespräche mit beiden geführt. Dieter äußert sich sehr häufig stark abfällig und rassistisch über „Asylanten, Ausländer“ sowie über schwarze Menschen und Roma und Sinti und verbindet gleichzeitig bestimmte Delikte mit der jeweiligen Gruppierung. Er hat ein starkes Bedürfnis, sich nach ,oben und unten' abzugrenzen. Seine Interpretation der Einsatzsituation ist sichtlich verknüpft mit seiner Perspektive auf die Welt und seine Umwelt. Jan hingegen ist in einem ähnlichen Alter wie der mutmaßliche Täter, er lebt getrennt von seiner Frau und hat zwei Kinder. Aus dieser Perspektive heraus interpretiert er die Situation als Streit um die Kinder. Die eigene biographische Situation im Zusammenhang der Perspektiven auf die eigene alltägliche Lebenswelt steht in Wechselwirkung mit ihrem beruflichen Deuten und Handeln. 
Abschließend können auf Grundlage der Rekonstruktion dieser handlungsstrukturierenden Typisierungen und Wissensbestände vier Wissensformen analytisch differenziert werden:

\section{a) Polizeiliches Erfahrungswissen}

Für die Einschätzung der Situation vor der Interaktionssituation ist vor allem das Erfahrungswissen interpretationsrelevant, aber auch in der Situation selbst ist das Erfahrungswissen über Einsätze und Situationen wie diese maßgebend. Erfahrungswissen ist neben Raum- und Zeitwissen auch ein Gefühl für die passende Ansprache des Gegenübers oder für die Stimmung. Wann z.B. ist eine Situation ruhig? In der geschilderten Situation führt das dazu, dass ohne große Abstimmung untereinander die Stimmung von allen anwesenden Polizist*innen als ruhig eingeschätzt wird. Der vormals aggressive Mann bleibt mit Sebastian und mir alleine im Flur des Hauses stehen. Die Lage wird offensichtlich so gedeutet, dass Sebastian keiner weiteren Unterstützung bedarf und er mit dem Beschuldigten gefahrlos alleine bleiben kann. Auch die zwei weiteren Beamten der anderen Dienststelle fahren wieder ohne größere Abstimmung mit den Verbleibenden, da es ein geteiltes (und sozial vermitteltes) Erfahrungswissen darüber gibt, wann eine Situation als ruhig und kontrolliert gilt.

\section{b) Befragungs- und Interaktionswissen}

Das Wissen über den Fall wird durch Aussagen der involvierten Personen nun erweitert. Zu dem Vorwissen, dass es eine Bedrohung mit einem Messer gab, kommt nun hinzu, dass es keine physischen Verletzungen gibt; dass weiterhin drei Kinder involviert sind und deren Versorgung ein Streitthema ist. Dann ging laut Aussage beider Beteiligten die Gewalt zunächst von der Frau aus. Dieses Wissen wird in Jans Deutung der Situation relevant, der die Situation als Handgreiflichkeiten und Streit um die Kinder interpretiert. In seine Deutung geht auch ein, dass er erfahren hat, dass beide berufstätig sind und außerdem Berufe haben, die als bodenständig betrachtet werden können: Sie arbeitet in der Öffentlichen Verwaltung als Sekretärin und er ist Angestellter im Dienstleistungssektor. Sie werden als eigentlich vernünftige, bodenständige Personen typisiert und Jans Ansprache zeigt, dass er den Mann als, normalerweise' vernünftigen Menschen anspricht.

\section{c) Beobachtungswissen}

In die Interpretation, dass es sich um einen Streit zwischen normalerweise vernünftigen Personen handelt, wird auch die Beobachtung über die Wohnung eingeschlossen. Der Zustand der Wohnung ist gut und auch die Kinder machen auf die Beamt*innen keinen vernachlässigten Eindruck. Auch wenn den Beamt*innen klar ist, dass sich Vernachlässigung und häusliche Gewalt ebenso in ordentlichen Wohnungen und allen gesellschaftlichen Schichten zeigen können, sind Wohnungszustand sowie Verhalten und Aussehen der Kinder relevant für ihre Interpretation respektive starke Indizien für sie. Bei der Suche nach Belegen für das Geschehene oder vielmehr für ihren Interpretationsrahmen werden auch bei Diet- 
er und Sebastian Beobachtungen der Wohnung und der Personen relevant. Der Migrationshintergrund von beiden dient als Interpretationsrahmen für Dieter und auch Sebastian, die den Grund für die Bedrohung in der „Macho-Kultur“ suchen und den Mann diesbezüglich adressieren. Sebastian sucht subsumptionslogisch nach Belegen für seine bzw. Dieters Situationsdefinition. In diesem Fall wird die Typisierung des Mannes durch sein Äußeres und das Foto im Flur im Zusammenhang mit dem Migrationshintergrund zum Indiz.

\section{d) Ausgetauschtes Wissen}

Sowohl durch die Besprechung untereinander wie auch durch die Befragung beider Parteien durch dieselbe Person wird versucht eine Gesamtsicht zu schaffen und sich gegenseitig in der Interpretation zu bestärken und abzusichern. Die gegenseitige Absicherung des Wissens und der Interpretation ist wichtig, um Entscheidungen über den Fortgang der Situation treffen zu können. In diesem Fall führt es dazu, dass der Mann gehen kann und ihm geraten wird, sich vorrübergehend von seiner Ex-Frau fern zu halten; dies ist aber eben als Ratschlag formuliert. Da der Mann woanders wohnt, scheint dies unproblematisch. Außerdem halten es die Polizist*innen wohl aufgrund der Gespräche für unwahrscheinlich, dass er wiederkommt, um seine Exfrau abermals zu bedrohen. Die gesamte Definition, was hier die Situation ist, führt zu dieser Entscheidung.

Analytisch lassen sich die Wissensformen unterscheiden. Sie zeigen, welches Wissen in Deutungsprozessen Relevanz entfaltet. In dem Beispiel wurde aber auch deutlich, dass die Wissensformen sich überschneiden und gegenseitig bedingen. Beobachtungs- und Erfahrungswissen sind z.B. immer miteinander verknüpft und nur analytisch zu trennen. Auf Grundlage von Erfahrungen werden Beobachtungen mit mehr oder weniger Relevanz versehen, fraglos typisiert oder aber problematisiert. Der Erwerb dieser Wissensformen ist, wie der Wissensvorrat selbst, biographisch strukturiert. Wie ich mit den nicht-polizeilich Anderen interagiere, was ich in einer Wohnung beobachte, was in den Fokus meiner Aufmerksamkeit gelangt und wie ich eine Situation bewerte, hat sich nicht allein im Kontext der Polizei, sondern auch biographisch ausgebildet.

Bevor ich die Spur des Zusammenhangs von polizeilichem Handeln und biographischen Erfahrungen weiterverfolge (Kap. 5 und 6), werde ich mich den Situationsdefinitionen in problematischen Situationen widmen (4.2.2). Was passiert, wenn Situationsinterpretationen und Deutungsmuster nicht problemlos angewendet werden können?

\subsubsection{Situationsdefinitionen in problematischen Situationen}

Ohne hier eine weitere detaillierte Darstellung der handlungsstrukturierenden Deutungen vorzunehmen, sei zur Kontrastierung eine zweite Situation häuslicher Gewalt kurz zusammengefasst. An ihr wird deutlich, wie sich die Aushandlung, 
was die Situation sei, vollzieht, wenn es sich um eine „problematische Situation“ (Schütz/Luckmann 1979/2003: 169) handelt.

In einer Freitagnacht werden die Beamt*innen, Anke und Thorsten, mit denen ich in dieser Nacht unterwegs bin, zu einer Wohnung geschickt, in der zwei Männer ärztliche Hilfe benötigten und der Rettungsdienst die Polizei zur Hilfe angefordert hat. Als wir ankommen, sind die Sanitäter*innen schon da und befinden sich in der Wohnung bei zwei Männern im Alter von ca. Anfang 50 und Anfang 60. Der ältere Mann blutet am Bein und hält sich den Arm. Er beschuldigt den Jüngeren; der wiederum bezichtigt den älteren Mann der Lüge. Anke stellt kelar, dass es auch strafbar ist, falsche Anschuldigungen zu machen, und versucht nun durch Fragen zu rekonstruieren, was passiert ist, wer überhaupt bier wohnt und warum sie beide zusammen in der Wobnung sind. Der ältere Mann scheint eingeschüchtert und der jüngere Mann ist recht aggressiv und laut, während sie befragt werden. Die Aussagen sind etwas konfus und erscheinen mir ausweichend. Ich habe den Verdacht, dass es sich bei den zwei Männern um ein Paar handelt. Der ältere Mann sagt dies nach einiger Zeit und vielen Fragen dann auch, aber erst nachdem der andere Mann nach einiger Zeit von Thorsten mit hinaus in den Flur der Wohnung genommen wird. Die Fragen, die dem Mann gestellt werden, führen zunächst nicht daqu, dass Anke verstehen kann, was passiert ist.

Das Vorwissen über die Situation, dass zwei betrunkene Männer ärztliche Hilfe brauchen und die Sanitäter*innen nicht alleine dort sein möchten, rahmt die Situation zunächst anders. Es ist Freitag spät nachts und das Erfahrungswissen, dass sich freitagnachts betrunkene Männer häufig um eine Nichtigkeit streiten, legt eine Typisierung der Situation als häusliche Gewalt nicht besonders nahe. Das Befragungswissen der herbeigerufenen Beamt*innen wird nur unstrukturiert erweitert, da die Antworten keinen Interpretationsrahmen für eine konkrete Situation liefern. Stattdessen bleiben sie unspezifisch bzw. können vielleicht unter der Typisierung „Streit zwischen betrunkenen Männern, der nicht zu verstehen ist, weil sie betrunken sind“ zusammengefasst werden. Dies führt auch dazu, dass der verletzte Mann nicht eindeutig als Opfer typisiert wird. Darauf deutet die an ihn gerichtete Bemerkung von Anke bezüglich einer möglichen Falschaussage hin.

Diese Rahmung - im Vorfeld, wie auch in der Situation selbst - verhindert es zunächst, dass eine Situation häuslicher Gewalt erkannt und entsprechend gehandelt wird (wie z.B. Täter und Opfer zu trennen und nicht gemeinsam zu befragen wie in der zuvor geschilderten Situation). Neben der physischen Verfassung des einen Mannes, vermeintlich betrunken oder unter Drogeneinfluss und etwas aggressiv, spielt aber vermutlich in erster Linie das Geschlecht beider Beteiligten eine große Rolle bei der Interpretation der Situation. Die Typisierung einer Situation als häusliche Gewalt ist unter anderem damit verbunden, dass es sich um ein heterosexuelles Paar handeln müsste, um dem Typus zu entsprechen.

In der weiteren Entwicklung dieses Einsatzes wird der jüngere Mann im Treppenhaus ausfallend. Thorsten ruft nach Anke. Sie wollen, dass er vor ihnen und nicht hinter ihnen die Treppe hinuntergeht, um unten beim Streifenwagen 
einen Alkoholtest zu machen. Der Mann versucht Thorsten zu schubsen und die beiden Beamt*innen versuchen ihn daraufhin zu fixieren, schaffen es aber auch mit Hilfe des Sanitäters nicht und funken um Hilfe. Mit vier weiteren Beamten schaffen sie es schließlich, den Mann ,unter Kontrolle zu kriegen. Der weitere Verlauf des Dienstes ist dann davon bestimmt, diesen Mann in Polizeigewahrsam zu bringen und von einem Arzt untersuchen zu lassen sowie sich selbst ärztlich begutachten zu lassen. Und dann beginnt die bürokratische Papierarbeit, die es bei solchen Einsätzen gibt (vgl. 4.3.2). Der Einsatz hat sich um den Tatbestand eines Widerstandes gegen Polizeibeamt*innen erweitert. Dies führt dazu, dass die eigentliche Situation, die Grund des Einsatzes war, in den Hintergrund rückt. In allen anschließenden Gesprächen darüber überlagert dieses Erlebnis das vorher Geschehene.

Auf Grundlage der proto-soziologischen Überlegungen von Alfred Schütz können wir davon ausgehen, dass Wissensvorrat und Typisierungen infrage gestellt werden, wenn eine neue Erfahrung nicht passt (vgl. Schütz/Luckmann 1979/2003: 193 ff.). Neue Wissenselemente können dann in den Wissensvorrat integriert werden. In dieser Situation führt der Fortgang der Situation aber wahrscheinlich dazu, dass die neue Erfahrung eben nicht Teil der Typisierung von Situationen häuslicher Gewalt wird, weil sie überlagert wird von dem widersetzlichen und als aggressiv wahrgenommenen Verhalten des Mannes. In die Typisierung, was eine Situation häuslicher Gewalt ist, wird diese Situation von häuslicher Gewalt bei einem gleichgeschlechtlichen älteren Paar vermutlich kaum aufgenommen werden, nachdem die Entwicklung und Bearbeitung der Situation die Erfahrungen zuvor überlagert bzw. als Situation eines Widerstandes typisiert werden wird. Bei der eingangs geschilderten Situation war die Definition dessen, was die Situation sei, recht schnell klar und es ging vielmehr um die Frage, warum geschehen ist, was geschehen ist. Bei der zweiten Situation war die Definition der Situation unklar und wurde schwerfällig ausgehandelt, weil die Vorannahmen nicht zur Situation ,passten'. Daran zeigt sich, dass die Vorannahmen, mit denen die Beamt*innen in eine Einsatz-Interaktions-Situation gehen, deutungsstrukturierend und damit handlungsrelevant sind. Unter dieser Prämisse wird dann auch die weitere Deutung in der Interaktions-Situation vollzogen.

Zusammenfassend konnte in diesem Kapitel gezeigt werden, welche verschiedenen Wissensformen und Typisierungen deutungsstrukturierend und handlungsrelevant sind. Für die Beamt*innen ist es wichtig, einer Situation einen Sinn verleihen zu können, um zu verstehen, warum etwas passiert ist (s. auch Jacobsen 2001: 138 f.). Durch diese Sinngebung und die oben beschriebene strukturelle Machtasymmetrie haben sie mehr Möglichkeiten als die anderen beteiligten Akteur*innen, ihre Situationsdefinition interaktiv durchzusetzen. Andererseits sind sie in ihrer Rolle als Polizist*innen aber auch gefragt, die Situation zu definieren. Da nicht nur die Definition der Situation bestimmend ist, sondern auch der Interaktionsprozess die Definition der Situation bestimmt, kommt es in der Interaktion immer wieder zu 
Veränderungen der Definition. Polizist*innen müssen eine Rahmung ,anwenden', aber auch in der Lage sein, den Rahmen schnell zu modifizieren oder zu wechseln. Die Definition von Situationen erfolgt zunächst routiniert. Nur wenn Situationen problematisch sind, die Interaktionen nicht zur Situationsdefinition passen, müssen sie modifiziert werden - dies ist nicht nur in der polizeilichen Arbeit so, sondern ein grundlegender Prozess. Im Falle der Polizei drückt sich Machtasymmetrie aber gerade dadurch aus, dass Polizist*innen zwar gefordert sind, Situationsrahmungen schnell zu modifizieren, es aber nicht tun müssen. Sie können ihre Rahmungen oft auch gegen (Deutungs-)Widerstände durchsetzen.

\subsection{Strukturen und Ambivalenzen polizeilicher Arbeit}

Die Arbeit des ESD ist sehr vielfältig. Polizist*innen sind in der Regel diejenigen, die als erste an einem Tatort, einem Unfallort, bei einem Konflikt oder auch zur Hilfeleistung da sind - die Polizist*innen des Streifendienstes ergreifen die ersten Maßnahmen bei Soforteinsätzen und kommen als Erste mit dem jeweiligen Gegenüber in einem polizeilichen Arbeits-/Interaktionsprozess in Kontakt. Die Arbeit ist, auch durch die Vielfältigkeit, anspruchsvoll und herausfordernd.

Im Folgenden sollen Deutungs- und Handlungsmuster polizeilicher Arbeit rekonstruiert werden. Dabei können nicht alle für polizeiliche Arbeit relevanten Dimensionen gleichermaßen betrachtet werden. Die Auswahl orientiert sich einerseits an dem, was ich als strukturierend und relevant erlebt habe, und andererseits daran, was sich als bedeutsam bei der Analyse der biographischen Selbstdarstellungen (Kap. 5) erwiesen hat.

Nachdem polizeiliche Wir- und Sie-Bilder sowie die Deutungsprozesse in Einsatzsituationen rekonstruiert wurden, möchte ich mich nun der konkreten polizeilichen Alltagspraxis widmen. Polizeiliche Arbeit kann entlang ihrer Ambivalenzen und ambivalenten Anforderungen beschrieben werden: Routine und Ausnahme (4.3.1), Schreiben und Rausfahren (4.3.2), erfolgreiche/-lose polizeiliche Arbeit (4.3.3), (ir-)relevante polizeiliche Arbeit (4.3.4), Grenzüberschreitungen (4.3.5), die Herstellung und Bearbeitung von Hierarchien (4.3.6) und Geschlecht (4.3.7).

\subsubsection{Routine und Ausnahme}

Die Routine des Tages. Der Verlauf eines Arbeitstages ist in seiner Abwechslung und Unberechenbarkeit insgesamt Routine, obwohl sich zugleich auch (die Herstellung von) Routinen in der Unberechenbarkeit erkennen lassen. Durch sie erhält der Arbeitstag Struktur.

Der Ablauf eines Arbeitstages beginnt und endet auf der Dienststelle mit Begrüßungs- und Abschiedsritualen. Wenn man die Dienststelle betritt, begrüßt man sich per Handschlag, manche Polizistinnen umarmen sich, manche Polizisten ,schlagen ein‘. Es gibt eine persönliche Begrüßung aller Anwesenden - mich als Gast/Beobachterin in der Regel eingeschlossen. Dies gilt nicht nur für die eigene 
Dienstgruppe, sondern auch für die abzulösende. Auch Kolleg*innen anderer Abteilungen oder Dienststellen werden in einer solchen freundlich-formalisierten Form begrüßt, was als eine Vergemeinschaftungsform begriffen werden kann. Während der Schichtwechsel ist es unruhig in den Räumen. Die Vorbereitungen für den Dienst wie für den Feierabend laufen. Sachen werden zusammengesucht und weggeräumt, man zieht sich um. Es wird geredet und gelacht. Immer 15 Minuten vor dem eigentlichen Wechsel, vor Beginn von Früh-, Spät- und Nachtschicht, schließt sich die Tür zum Aufenthaltsraum und es beginnt die Besprechung für die kommende Schicht. Für die einen ist es der Beginn der Arbeit, für die anderen ist es das Zeichen für Feierabend. Danach wird es zunächst ruhiger. Manche gehen nach der Besprechung recht bald zum Auto und ,fahren raus', andere setzen sich zunächst in ein Büro und ,schreiben' (4.3.2).

In der von mir beobachteten Dienststelle hat jede Schicht leicht variierende Routinen, die sich aber unter anderem durch Mahlzeiten bzw. deren Beschaffung gleichen. In der Frühschicht gibt es eine gemeinsame Brötchenbestellung bei einer Metzgerei, die ca. zwei Stunden nach Dienstbeginn von einer Streife abgeholt wird - hier trifft man u.U. auch auf Kolleg*innen anderer Dienstabteilungen/-stellen, die offenbar eine ähnliche Routine haben. Die gemeinsame Bestellung führt aber nicht zu einer gemeinsamen Frühstückspause. Die Bestimmung des Tages durch Soforteinsätze lässt geplante, gemeinsame Pausen in der Regel nicht zu. Mit Pausen und (gemeinsamem) Essen werden Routinen hergestellt, die aber nicht so strukturiert ablaufen können wie in vielen anderen Berufsfeldern. Körperliche Bedürfnisse zu befriedigen wird durch die unberechenbare und wechselnde Struktur des Tages reglementiert. Neben dem Dienstverlauf ist auch der Tagesablauf wechselhaft. An maximal zwei aufeinanderfolgenden Tagen beginnt und endet der Arbeitstag zur selben Zeit, meistens wechseln die Arbeitszeiten täglich zwischen Früh-, Spät- und Nachtschicht und die freien Tage nach einem System, das sich alle zwei Wochen wiederholt. So ist einerseits zwar eine langfristige Planung der eigenen Arbeitszeiten gewährleistet, andererseits reglementiert dieses System den Schlafrhythmus stark bzw. ist ein regelmäßiger Schlafrhythmus nicht möglich. Für mich war dieser tägliche Wechsel der Schlaf- und Wachzeiten körperlich sehr anstrengend und ich habe mich ständig müde gefühlt. Die Polizist*innen, mit denen ich über diese Belastung gesprochen habe, haben es alle damit relativiert, dass man sich daran gewöhnen würde. Von manchen wurde allerdings geäußert, dass sie dies auch nicht bis zur Pensionierung machen möchten und es teilweise eine Herausforderung für die Organisation von Familie und Kindern sei.

Neben Dienstbeginn und Essen lassen sich auch für das (nahende) Dienstende Routinen beschreiben. Um pünktlich Feierabend machen zu können, ist es wichtig, nicht kurz vor Dienstende noch einen aufwändigeren und voraussichtlich länger dauernden Einsatz zu haben, sondern mit ausreichend zeitlichem Abstand einen weniger (schreib-)aufwändigen, einen „Feierabendeinsatz“. Alternativ dazu fährt man so lange umher und macht dabei präventiv Kontrollen oder schreibt Knöllchen, bis ein guter Zeitpunkt gekommen ist, an dem man zur Dienststelle 
zurückkehrt respektive zurückkehren kann, ohne Gefahr zu laufen, eventuell noch einmal rausfahren zu müssen. Ein Zeichen für die Beendigung des Dienstes ist unter anderem auch, das Auto an einem bestimmten Platz zu parken. Das Parken des Autos für den Feierabend und die Übergabe an die nächste Schicht dürfen nicht zu früh geschehen.

Für die verschiedenen Schichten lassen sich auch unterschiedliche Routinen in Bezug auf die Art der Einsätze ausmachen. In der Frühschicht gibt es oft eine große Anzahl an Parkunfällen und Diebstahlanzeigen - Dinge, die auffallen, wenn Menschen morgens das Haus verlassen. In einer Nachtschicht gibt es dafür z.B. öfter Ruhestörungen, die tagsüber selten vorkommen. Ob ein Einsatz im Vorfeld als Routine oder Ausnahme gerahmt wird, hängt unter anderem damit zusammen, zu welcher Tageszeit etwas passiert.

Die Ambivalenz von Routine und Ausnahme. Neben den Routinen des Dienstablaufs verläuft polizeiliche Arbeit auch sonst routiniert bzw. wird es angestrebt, dass sich Routinen ausbilden. Routinen sind auf zwei Ebenen notwendig für die Polizei. Zum einen ist es auf Ebene der einzelnen Polizist*innen und ihrer Interaktion miteinander relevant. Zum anderen sind Routinen relevant für die Aufrechterhaltung der Institution Polizei (vgl. Berger/Luckmann 1969/2012). Routiniertes polizeiliches Handeln wird eingeübt, womit überhaupt erst die Möglichkeit entsteht, dass es von allen ähnlich ausgeführt wird. Dies ist notwendig, damit Polizist*innen zusammenarbeiten können und nicht bei gemeinsamen Einsätzen mit neuen oder fremden Kolleg*innen alles jeweils ausgehandelt werden muss. Routiniertes Handeln führt zu Institutionalisierung. Routinemäßig ausgeführtes polizeiliches Handeln konstituiert die Institution Polizei.

Gleichzeitig darf es nicht , $\mathrm{zu}^{\prime}$ routiniert werden und es wir versucht, gewisse sich einschleichende Routinen zu unterbinden, z.B. durch Wechsel der Streifenwagenbesetzung. In dem folgenden Protokollausschnitt zeigen sich Relevanz wie auch Gefahren von Routine:

In einer Nachtschicht werden wir zu einer Diskothek geschickt, in der es Streit gegeben haben soll. Nur Sekunden nach uns trifft ein weiterer Streifenwagen ein und sie gehen schnellen Schrittes Richtung Eingang der Diskothek. Es hat eine Auseinandersetzung zimischen den Türstehern und einer Gruppe junger Männer gegeben, die nun alle zusammen in einer kleineren Menschenansammlung von 20-30 Personen vor der Tür stehen. Die Gruppen werden getrennt und Richard befragt einen der Türsteher, was passiert sei. Christoph steht bei zweien der Männer, die wohl in erster Linie in den Streit verwickelt waren. Ich bleibe bei Kristina und Sebastian stehen, die mit einem Kleinen Abstand die Situation beobachten. Kristina zu Sebastian: „Siehst du nicht, dass Christoph da alleine mit zuveimal männlich steht?" Sebastian: „Ja. "Kristina: ,Ja, vielleicht gehst du dann mal da hin."

In dieser (von Kristina so gedeuteten) potenziell gefährlichen Situation mit vermeintlich aggressiven und mutmaßlich betrunken Männern, die vor einer größeren Gruppe von weiteren Gästen zusammen stehen, vernachlässigt Sebastian, so ist 
Kristinas Kommentar zu verstehen, die Sicherung seines Kollegen. Eigensicherung muss habitualisiert werden, damit sie routiniert ablaufen kann. Die ,Gefährdungsanalyse und Eigensicherung muss Routine sein. Die Einsatzsituation selbst darf wiederum nicht zu einer unaufmerksamen Routine werden, damit Gefahren nicht übersehen und richtig eingeschätzt werden können, während die (Ausnahme-)Situation selbst aber routiniert bewältigt werden soll. Polizeiliche Arbeit ist strukturiert durch eine Ambivalenz von Routine und Ausnahme. Ausnahmen sind Routine. Schutzpolizeiliche Arbeit kann als Versuch, Ausnahmen routiniert zu bearbeiten, verstanden werden.

Ausnabmen. Ausnahmen können als Unterbrechung der Routine beschrieben werden. In dem folgenden Protokollauszug aus einer Nachtschicht wird sichtbar, wie sich der Wechsel von routinierter Aufgabenerfüllung und plötzlicher Ausnahmesituation vollzieht.

Ich sitze im Aufenthaltsraum, während Verena und Richard noch schreiben, als wir von Thorsten im Funkraum gegen 1 Uhr zu einem PKW-Einbruch geschickt werden, ein Zeuge habe gerade zwei Personen gesehen. Wir rennen raus, auch Kristina und Julian. Über Funk werden Neuigkeiten gemeldet, während wir mit Wegerecht hinfahren: Wabrscheinlich awei männliche Verdächtige, die in verschiedene Richtungen gelaufen sind. Es werden vermutete Positionen durchgeben und dass eine Zivilstreife schon da sei. [...] Ein Täter wird gefasst. Als ich dort ankomme, liegt er auf dem Boden. Ein Polizist sitzt auf ihm drauf und Richard legt Handschellen an, dann wird er hochgezogen und aufgerichtet. Julian und Kristina führen ihn zum Auto und nebmen ihn mit zur Dienststelle. Es sind noch zwei Zivilkeräfte da, die losfahren und den zweiten Täter suchen. Wir fahren zu dem Auto und dem Zeugen und Verena entdeckt ein weiteres Auto, das an der Fabrertür offen ist. Richard schickt mich los, um die geparkten Autos an der Straße zu überprüfen. Verena spricht mit dem Zeugen. Ich gehe zu einem Auto, an dem der Zeuge die Täter ebenfalls gesehen hat. Es ist verschlossen und ich gehe zu den Autos auf der anderen Straßenseite und kontrolliere sie. Richard geht kurz. danach nochmal zu dem Auto; offenbar kontrolliert er in die Richtung weiter, in der ich aufgehört habe. Ich böre Geschrei und drehe mich um, ich stehe zu dieser Zeit bei Verena und dem Besitzer des einen Autos, das aufgebrochen wurde. Ich qu Verena: „Da ist irgendwas los. "Sie dreht sich um, sagt zu dem Mann: „Bleiben sie hier", und rennt dann los. Ich hinterher. Näherkommend sehe ich wie ein Mann, hinter dem von mir als letztes kontrollierten Wagen, auf dem Boden liegt. Richard: „Down, stay down. “Er versucht zu funken dabei. Der Mann liegt auf dem Boden. Verena bleibt stehen und will leuchten, ihre Taschenlampe geht nicht an. Richard wird laut: „Ist doch egal, gib mir deine Handschellen. Meine hat der andere an. "Es kommen in wenigen Sekunden zwei weitere Streifenwagen, während der Mann noch auf dem Boden liegt und Richard auf ihm drauf kniet. Der Mann wird durchsucht. Es kommt noch ein Zivilwagen. Plötzlich sind ca. acht Leute da, gucken sich den $W$ agen an und nehmen den Verdächtigen mit. Es wird genauso schnell wieder rubig. Verena versucht die Eigentümer*innen ausfindig zu machen. Wir bleiben und sichern Spuren: Richard spannt mich wieder ein, ich tüte die Folien mit den Faserproben ein, trage den Koffer hinter ibm her, bringe die Sachen zum Auto, hole Tüten, neue 
Handschube etc. Verena befragt die Besitzer*innen der Autos, nachdem sie die meisten von ihnen aus dem Bett geholt hat. Ich entdecke einen weiteren geöffneten Wagen auf einem Parkplatz, nachdem Richard mich gebeten hat, die weiteren Autos zu kontrollieren. Insgesamt waren es dann sechs Autos. Gegen 3.30 Uhr sind wir dort fertig und fahren rein.

Neben der Rolle als Praktikantin oder Hilfspolizistin, die mir hier verliehen wird, ist hier vor allem der Wechsel von An- und Entspannung interessant. Die Routinearbeit des Schreibens wird plötzlich durch einen aufregenden Einsatz unterbrochen. Durch schnelles Handeln scheint es möglich, Täter fassen zu können. Dies gelingt auch nach einer kurzen Verfolgung zu Fuß. Dann handeln die Beamt*innen wieder routiniert: Der vermeintliche Täter wird mit routinemäßigen Griffen festgenommen, es werden Zeug*innen befragt und umstehende Autos kontrolliert. Auch diese Arbeit wird dann wieder plötzlich unterbrochen, als Richard den in einem Auto versteckten vermeintlichen zweiten Täter findet. Nach dieser Aufregung beginnt erneut Routinearbeit: Die Autobesitzer*innen werden ausfindig gemacht und Aussagen aufgenommen.

Dieser Wechsel von An- und Entspannung, von Routine und Ausnahme, kann mit dem Sprung und dem zugehörigen Schockerlebnis zwischen verschiedenen Sinngebieten 93 , wie Schütz es beschreibt, verglichen werden (vgl. Schütz/Luckmann 1979/2003: 56 ff.), auch wenn An- und Entspannung in der Realitätserfahrung der alltäglichen Lebenswelt liegen. Dennoch wird durch das Schockerlebnis die Aufmerksamkeit erhöht und drückt sich auch durch gesteigerte (körperliche) Aktivität und körperliche Anspannung aus.

Die Struktur polizeilicher Arbeit ist bestimmt von solchen Wechseln. Jede Routinesituation birgt potenziell die Möglichkeit, eine Ausnahmesituation zu werden. Die Herstellung von Routinen ist aber gerade deshalb für die Aufrechterhaltung der Handlungsmöglichkeiten und der Möglichkeit, als Polizist*in zu arbeiten, relevant. Die Herstellung von Routinen erlaubt es, den Arbeitsalltag nicht ständig als potenziellen Ausnahmezustand, in dem hohe Aufmerksamkeit und körperliche Anspannung notwendig sind, zu erleben.

Trotz der Beschreibung von Ausnahmen als Routine und Struktur polizeilicher Arbeit existieren routinemäßig durchgeführte Tätigkeiten und auch ein Arbeitstag mit Routinen, wie oben beschrieben. Routinemäßiges Handeln stützt nicht nur die Organisation, sondern auch die Arbeit der einzelnen Beamt*innen.

\footnotetext{
93 Schütz (Schütz/Luckmann 1979/2003: 54 ff.) unterscheidet vom Wirklichkeitsbereich der Alltagswelt weitere Sinngebiete mit geschlossener Sinnstruktur wie Phantasie(n) und Traum. Die verschiedenen Sinngebiete haben unterschiedliche Erlebnis- und Erkenntnisstile, unterscheiden sich z.B. in der Form der Zeitstruktur und Sozialität. Wichtig ist hier der Unterschied in der Bewusstseinsspannung. Während das Bewusstsein in der Alltagswelt im Zustand vollkommener Wachheit ist, es aktiv und aufmerksam auf die Verrichtung seiner Vorhaben konzentriert ist, ist die Bewusstseinsspannung im Traum passiv(er) und entspannt. Der Wechsel zwischen den verschiedenen Sinngebieten wird von Schütz (in Anlehnung an Kierkegaard) als Sprung beschrieben, der immer von einem Schockerlebnis begleitet wird: dem Wechsel der Bewusstseinsspannung (wie beim Aufwachen aus einem Traum).
} 
Auch in Ausnahmesituationen werden in der Regel routinemäßige eingeübte Handlungs- und Deutungsprozesse abgerufen. Routinemäßiges Handeln kann sowohl bei Ausnahme- als auch Routinesituationen aufgenommen werden, sobald es einen bekannten Deutungsrahmen für eine Situation gibt, und bietet damit eine Struktur, auf die man sich beziehen kann. Problematische Situationen können in eine Routinesituation überführt werden, wenn die offenen Elemente einer Situation ausgelegt und eingeordnet werden können (vgl. Schütz/Luckmann 1979/2003: 168 f.). Anhand von routiniert nutzbaren Handlungs- und Deutungsmustern können die Polizist*innen sich einer problematischen Situation bemächtigen und sie dann auch definieren, um sie so wieder routiniert bearbeiten zu können (vgl. 4.2).

\subsubsection{Schreiben und Rausfahren}

Schreiben. Mit dem Wechsel von An- und Entspannung verbundene Tätigkeiten sind Rausfahren und Schreiben. In dem oben zitierten Protokoll notierte ich weiter Folgendes:

Jetżt beginnt für alle ein riesiger Schreibkeram, weil es zwei Verdächtige und viele PKW ₹u bearbeiten gibt, viele Polizist*innen beteiligt sind, es vermeintliches Diebesgut gibt, ein Auto abgeschleppt werden musste, es Spuren/Proben gibt etc. Michael koordiniert, wer was schreibt. Die ganze Dienststelle ist damit beschäftigt. Es ist keiner mehr draußen.

Die bürokratische Arbeit ist enorm und ich war immer wieder davon überrascht, wieviel Zeit mit Dokumentationstätigkeiten zugebracht wird bzw. werden muss. Auch wenn es Einsätze gibt, die keine oder nur wenig Dokumentationstätigkeit verlangen, ist sie bei Einsätzen, wie dem oben geschilderten, sehr aufwändig. Natürlich müssen nicht täglich solche dokumentationsaufwändigen Einsätze bearbeitet werden. Sie sind aber während meiner teilnehmenden Beobachtung mehrfach vorgekommen und in der geschilderten Nacht gab es z.B. gleich zwei solcher Einsätze. Die Einsatzkräfte waren für die Dokumentationstätigkeit in diesem Fall alle an die Dienststelle gebunden und in dem Einsatzgebiet war kein Streifenwagen der Dienststelle mehr unterwegs.

Bei einsatzreichen Schichten kann es dazu kommen, dass Schreibarbeiten, verschleppt ${ }^{6}$ werden und zu einem späteren Zeitpunkt gemacht werden müssen. Genutzt werden dazu häufig Anfang und Ende der Dienstzeit, wenn man sich sowieso auf der Dienststelle aufhält. Schreiben stellt neben dem Rausfahren einen großen Teil polizeilicher Arbeit dar, womit auch Tatsachen in Form von Akten hergestellt werden; es wird so auch zu einem eigenen soziologisch interessanten Bereich polizeilicher Arbeit. ${ }^{94}$ Die Relevanz dieses Bereiches ist mir erst gegen Ende meiner Feldforschung bewusst geworden, was mehrere Gründe hat. Zum einen drängt er sich neben dem Erlebnischarakter der Arbeit auf der Straße weniger auf. Dies gilt nicht nur mich, die als Außenstehende die Tätigkeit auf der Stra-

94 Zur allgemeinen Einführung siehe Wolff (2007) und über den Status von Dokumenten im polizeilichen Arbeitsprozess Jacobsen (2001: 38-42). 
Be aufregender und interessanter fand, sondern auch für die Polizist*innen. Zum anderen verstehen sie Schreibarbeit weniger als , die ${ }^{6}$ Arbeit der Polizei und präsentierten sie mir in den Gesprächen auch selten. Damit zusammenhängend habe ich diesem Bereich weniger Aufmerksamkeit gewidmet. Auch wenn ich selbst unter Anleitung zwei Vorgänge angelegt habe bzw. anlegen durfte und ich erklärt bekam, was man wie tun muss und worauf zu achten sei, habe ich viel öfter Folgendes gehört: „Wir müssen jetzt noch viel schreiben, hier passiert jetzt sowieso nichts mehr, du kannst auch schon gehen, wenn du willst". Schreiben wird auch von den Polizist*innen als wenig aufregend und vielleicht sogar eher als Last empfunden. Schreiben bringt sie auch näher an die Sachbearbeiter*innen, von denen sich die im ESD tätigen Beamt*innen gerne abgrenzen (vgl. 4.1.1).

Die Tätigkeit des Schreibens kann aber auch als funktional im Arbeitsprozess gelesen werden. Das Schreiben kann Ruhe und Entspannung in die hektische Situation nach einem Einsatz bringen. Zwar sind Polizist*innen teilweise auch in den Schreibräumen noch mit Verdächtigen oder Zeug*innen konfrontiert, beim Schreiben auf der Dienststelle sind sie dennoch weniger unter Interaktionsdruck als auf der Straße. Auf der Dienststelle ist man zumeist unter sich und seltener sowie unter anderen Bedingungen mit einem nicht-polizeilichen Anderen konfrontiert. Natürlich bedeutet auch der Umgang mit Kolleg*innen und Vorgesetzten Interaktionsarbeit, aber dort stehen sie nicht unter dem gleichen Druck (haben aber auch nicht die gleiche Macht) bei der Definition der Situation wie in einer Interaktion mit den nicht-polizeilichen Anderen. Auch diese Entlastung von Interaktions- und Handlungsdruck macht es möglich, die Anspannung eines Einsatzes abzubauen. Außerdem kann sie Distanz zum Erlebten und den involvierten Personen schaffen, wenn Dokumente ausgefüllt und berichtsartig angelegt werden.

Eine Perspektive, die Bürokratie und das Schreiben als bürokratische Praxis positiv rahmt, ist mir in meiner Feldforschung nicht begegnet, sondern vielmehr negativ als Belastung infolge zunehmender Bürokratisierung. Aus Perspektive des nicht-polizeilichen Anderen kann Schreiben, das Festhalten von polizeilich aufgenommenen Vorkommnissen, aber zu Nachvollziehbarkeit und Rechtssicherheit beitragen, wenn polizeiliches Einschreiten und polizeiliche Beteiligung dokumentiert werden. ${ }^{95}$ Oder, um es mit Weber zu formulieren: Schreiben wird aus polizei-

${ }^{95}$ Biecker und Schlichte (2014) entwickeln in Bezug auf die ugandische Polizei und die bürokratische Organisation durch Akten die Lesart, dass Personen, die bei der Polizei ihren ,Fall' vortragen, diesen dokumentiert sehen wollen, in der Annahme, dass er dann auch bearbeitet wird. Die Dokumentation vermittelt ihnen, dass ihre Fälle ernst genommen werden (vgl. ebd.: 28). Vorher habe ich den Hinweis, dass Dokumentation auch Rechtssicherheit bedeuten kann, von meinem palästinensischdeutschen Kollegen Ahmed Albaba, der nicht nur mit deutschen Behörden vertraut ist, erhalten. Hier zeigte sich (m)ein ,blinder Fleck'. Dieser Gedanke kam mir einerseits biographisch bedingt nicht und andererseits hatte ich die Perspektive der Beamt*innen, mit denen ich viel Zeit verbracht habe, unhinterfragt übernommen. Hier wird die Relevanz eines (nicht nur west- oder nordeuropäisch) vergleichenden Vorgehens und von biographisch- und wissensheterogenen Diskussions- und Auswertungsgruppen deutlich. 
lich-alltagspraktischer Perspektive nicht als Praxis der legalen, bürokratischen Herrschaft betrachtet, in der das „Prinzip der Aktenmäßigkeit“ herrscht und alle Entscheidungen schriftlich nachvollziehbar fixiert werden (Weber 1921/2008: 162). Eine solche Perspektive, die die polizeiliche Praxis des Schreibens im Rahmen eines rechtsstaatlichen Prinzips einordnen würde, entspricht einerseits nicht dem Wir-Bild der Polizist*innen und wird andererseits durch die erlebte Belastung aufgrund von hohem Einsatzaufkommen und damit verbundener Schreibarbeit eher ausgeschlossen.

Rausfahren. Die ,richtige' Polizeiarbeit findet, dem Diskurs zufolge, auf der Straße, beim Rausfahren (in der Interaktion mit den nicht-polizeilichen Anderen), statt. Nur in Bezug auf diese, richtige' Arbeit kann sich das Wir-Bild des ESD konstituieren. Bei der Arbeit auf der Straße können verschiedene Formen polizeilicher Arbeit unterschieden werden: Herumfahren, seltener: Herumlaufen ${ }^{96}$, und Einsätze (Sofortlagen). Neben Sofortlagen können noch sogenannte Zeitlagen unterschieden werden: Einsätze, die vorhersehbar sind, wie z.B. angemeldete Demonstrationen, und personell und zeitlich im Vorfeld geplant werden können. Für die Arbeit des ESD sind aber, neben täglich anfallenden Kontrolltätigkeiten, Sofortlagen relevanter als Zeitlagen. Daher werde ich mich hier auf Sofortlagen beschränken.

Einsätze, auf die sie reagieren (müssen), bekommen die Streifenwagenbesatzungen in der Regel per Funk von der Leitstelle. Hier gibt es eine große Spanne von Dringlichkeit und Erlebnischarakter abhängig von der Art des Vorfalls, der gemeldet wird. Weniger dringliche Einsätze korrespondieren häufig mit einem geringeren Erlebnischarakter. Parkunfälle, Einbrüche in Autos, Sachbeschädigungen oder Ähnliches - Vorfälle, bei denen keine Gefahr für Personen besteht werden je nach allgemeiner Einsatzlage auch mal ,liegen gelassen' und erst nach einiger Zeit an die Streifenwagenbesatzungen weitergegeben. Aber prinzipiell haben auch diese Einsätze das Potenzial aufregend zu werden.

Andere Einsätze wiederum sind äußerst dringlich und versprechen sofort Aufregung. Allein die Information, dass z.B. schon mit Wegerecht angefahren werden soll, erhöht den Erlebnischarakter eines Einsatzes. Auch wenn ich es, bis auf Ausnahmen, als kontrolliertes Fahren und nicht wildes Rasen erlebt habe, trägt der Umstand, mit hohem Tempo durch die Stadt zu fahren, bereits dazu bei, dass Spannung aufgebaut wird. Neben einem gesteigerten Erlebnischarakter für die Polizist*innen kann die gesteigerte Spannung und Anspannung auch als funktionale Vorbereitung auf einen Einsatz gelesen werden: Das Schockerlebnis, der Sprung von Ent- zu Anspannung, wie oben beschrieben, findet vor der konkreten Interaktionssituation mit dem nicht-polizeilichen Anderen statt. Beim Eintreffen

\footnotetext{
96 Das Herumlaufen spielte in der von mir beobachteten Dienststelle eine untergeordnete Rolle was manche der Polizist*innen auch beklagt haben. In einem räumlich und organisatorisch anders strukturierten Bereich kann das Herumlaufen aber eine größere Rolle spielen, ebenso z.B. für Kontaktbereichsbeamte.
} 
am Einsatzort sind die Polizist*innen schon aufmerksam, körperlich angespannt und präsent und aus dem Routinemodus ,rausgeworfen'.

Das Herumfahren kann als Teil präventiver polizeilicher Arbeit beschrieben werden. Die Polizei zeigt Präsenz im Straßenbild und die Polizist*innen können tätig werden, wenn sie etwas polizeilich Relevantes sehen, oder rein präventive ,verdachtsunabhängige Kontrollen von z.B. Autos und Personen durchführen so würden es Polizist*innen ausdrücken. Habe ich das einfache Herumfahren teilweise als eher langweilig empfunden, musste ich doch nach einiger Zeit feststellen, dass Polizist*innen währenddessen anderes wahrnehmen als ich. Immer wieder war ich überrascht, wenn plötzlich das Auto an den Straßenrand fuhr, Gas gegeben wurde oder ein Auto angehalten wurde, weil die Polizist*innen etwas gesehen hatten, das sie zum Handeln veranlasste. Dies mag zum einen an meiner Perspektive aus dem Fond des Autos liegen, zum anderen liegt es aber an der unterschiedlichen Wahrnehmung der Umwelt. Polizist*innen sehen anderes und fokussieren anderes, wenn sie sich durch die Stadt bewegen. Auch wenn solche Kontrollen nicht auf Basis eines formulierbaren polizeilichen Verdachts beruhen, sind sie nicht, verdachtsunabhängig', wie der polizeilich genutzte Begriff suggeriert. Was oder wer die Aufmerksamkeit der Polizist*innen bekommt, beruht auf ihren (polizeilichen) Erfahrungen und Typisierungen, die ihre Wahrnehmung der Umwelt strukturieren. Personen, die nicht durch Äußerlichkeiten, ihr Verhalten oder ihr Handeln in die Wahrnehmung von Polizist*innen dringen, werden auch nicht kontrolliert werden, sehr wohl aber Personen, denen eine bestimmte Ethnie, ein Alter oder Geschlecht zugeschrieben wird und/oder die sich zu einer bestimmten Zeit an einem bestimmten Ort aufhalten, kurz: wenn sie durch Tun und/oder Aussehen von einer Normalitätsvorstellung abweichen (vgl. auch Feest/Blankenburg 1972: 35-57).

Das Herumfahren wird unterschiedlich praktiziert. Man kann es sehr intensiv betreiben und bei allem, was einem auffällt, anhalten. Man kann aber auch nicht so genau hinschauen bei Kleinigkeiten und sich nur dem widmen, was ,wirklich relevant erscheint (vgl. 4.3.4) bzw. wo ein Wegschauen (juristisch) schwer möglich ist. Hier drückt sich auch Macht aus bzw. lässt dieser Handlungsspielraum es zu, dass man sich selbst in einer machtvollen Position erleben kann, wenn man bis zu einem gewissen Grad entscheiden kann, wer angehalten wird und wer noch mal ,davonkommt‘. Herumfahren bietet vergleichsweise viele Freiheitsgrade in einem hierarchischen System. Man kann sich aber durch das Herumfahren auch eine Art Pause gönnen und auf Einsatzbefehle von der Leitstelle warten - wobei selbstverständlich auch das als polizeiliche Arbeit gelabelt werden kann, schließlich zeigt man dabei Präsenz. Auch wenn sich beobachten lässt, dass einzelne Polizist*innen mehr zu dem einen oder dem anderen neigen, wechseln sich die verschiedenen Modalitäten häufig auch innerhalb eines Dienstes ab. Außerdem wechseln die Streifenwagenteams, man fährt nicht täglich mit derselben Person. Dieser Wechsel trägt außerdem dazu bei, dass die wechselnden Teams zwar ebenfalls eine gemeinsame Routine ausbilden, dies aber in Interaktion und in Abstimmung geschieht 
und sich persönliche Vorlieben nicht immer ohne Weiteres umsetzen lassen. Dennoch gibt es Teams, die lieber zusammenarbeiten als andere; bei denen der Arbeitsstil und die Haltung zu ihrer Arbeit besser miteinander harmonieren als bei anderen. Bei unterschiedlichen Teams lassen sich auch die oben beschrieben unterschiedlichen Praktiken beobachten. So haben die einen eine gemeinsame Routine, die stark davon bestimmt ist, immer beschäftigt zu sein und präventiv viele Kontrollen durchzuführen, während andere eine gemeinsame Praxis entwickeln, die Zeit des Herumfahrens ohne Soforteinsätze eher entspannt anzugehen. Die Etablierung eines individuellen Arbeitsstils wird aber unter anderem durch eine wechselnde Streifenwagenbesatzung eingeschränkt.

Wie beim Herumfahren lassen sich korrespondierende Praktiken beim Schreiben beobachten. Auch das kann man schnell erledigen und wieder rausfahren, oder man kann dies recht gemütlich tun. Aber auch hier bedarf es der Abstimmung untereinander. Nicht unerheblich ist dabei auch die Sympathie, die die Polizist*innen füreinander haben. Ein Streifenwagen ist klein und eine Schicht kann sehr lang werden, wenn man auf diesem engen Raum viel Zeit mit einer Person verbringen muss, die man nicht sympathisch findet. Entziehen kann man sich z.B., indem man viele Kontrollen durchführt, um nicht nur mit dem*der Streifenwagenpartner*in zu interagieren, oder auch viel Schreibarbeit macht, um andere Kolleg*innen auf der Dienststelle zu treffen. Auch aus Gründen dieser engen Zusammenarbeit und der vielen Zeit, die man zu zweit verbringt, muss es weitgehend harmonisch zugehen: In welche Form der Auseinandersetzung geht man mit seinen Kolleg*innen bzw. wieviel Kritik übt man an ihrer Arbeit oder ihrer Haltung, wenn man so viel Zeit miteinander verbringen muss?

\subsubsection{Erfolgreiche polizeiliche Arbeit}

Wann ist polizeiliche Arbeit aus Perspektive der Polizist*innen erfolgreich? Wie kann Erfolg hergestellt werden? Was als erfolgreiche polizeiliche Arbeit konstruiert wird, ist stark verschränkt mit der Konstruktion (ir-)relevanter polizeilicher Arbeit und dem Wir-Bild. In meiner Beobachtung zeigte sich, dass ein Erfolgserleben gekoppelt ist an das Erleben, etwas Sinnhaftes zu tun. Erfolge können von den Polizist*innen auch hergestellt werden, wie an der folgenden Situation mit einem Mann, der Asyl beantragt hat, ersichtlich wird:

In der Wache versucht Martin, der heute am Funk ist, Einträge aus dem Ausländerzentralregister zu bekommen, offenbar von der Bundespolizei. Bei der zuständigen Ausländerbehörde erreicht er niemanden, ruft deshalb bei der in X-Stadt an. Die sagen: Gehen lassen, wenn sie niemanden erreichen. Das ist für alle im Raum offenbar unbefriedigend, denn Julian ruft dann bei dem diensthabenden Staatsanwalt an. Der sagt, sie sollen ibn dabehalten und morgen ins beschleunigte Verfabren bringen, dann entscheidet der Richter, ob er gehen kann oder eventuell bis Montag in Arrest bleibt und dann abgeschoben wird. 
Dies habe ich protokolliert, nachdem die Beamt*innen, mit denen ich an diesem Tag unterwegs war, zu einem Diebstahl in einer Drogerie gerufen wurden. Dort soll ein Mann Waren im Wert von ca. 40 Euro gestohlen haben. Der LadenDetektiv habe ihn beim Verlassen der Filiale festgehalten, die Waren bei ihm gefunden und es soll auch ein Video geben, auf dem der Diebstahl zu sehen ist; außerdem soll es andere Videos geben, die ihn auch schon bei vorherigen Diebstählen zeigen, so die Aussage des Detektivs. Julian lässt sich die Papiere des Mannes aushändigen und macht eine Datenabfrage, dessen Ergebnis er mir so präsentiert:

„Der Mann ist Georgier, hat Asyl beantragt, das wurde abgelehnt, in drei Tagen muss er Deutschland verlassen, er ist aber schon zur Zurückschiebung ausgeschrieben, außerdem bat er seinen erlaubten Aufenthaltskreis verlassen."

Das Ergebnis dieser Datenabfrage führt nun dazu, dass sie den Mann mitnehmen; in anderen ,einfachen' Fällen von Diebstählen geschieht dies in der Regel nicht. Dem Mann wird nun nicht nur Diebstahl vorgeworfen, sondern auch ein Verstoß (vermutlich) gegen die durch das Asylgesetz auferlegte Residenzpflicht. Den Polizist*innen eröffnet dies weitere Handlungsmöglichkeiten bzw. es verpflichtet sie zu bestimmten Handlungen. Weniger der Umstand, dass sie den Beschuldigten mitnehmen, ist hier interessant, sondern vor allem das sonstige Vorgehen. Sie akzeptieren die Auskunft der Ausländerbehörde, den Mann gehen zu lassen, wenn sie niemanden bei der zuständigen Behörde erreichen sollten, nicht. Stattdessen unternehmen sie einen weiteren Versuch, rufen den diensthabenden Staatsanwalt an und erreichen so, dass der Mann in Gewahrsam bleibt, bis er am nächsten Tag zu einem beschleunigten Verfahren vor Gericht erscheinen soll. Auf die Beamt*innen kommt nun eine mehrstündige Schreibarbeit zu, da alle nötigen Unterlagen am nächsten Morgen fertiggestellt sein müssen. Diese eigentlich eher unliebsame Arbeit wird den Polizist*innen wahrscheinlich im Vorfeld bewusst gewesen sein, es überwiegt aber der Wunsch nach einem Erfolg. Was sie aus ihrer Perspektive erreichen, ist, dass sie einerseits erleben, dass ein vermeintlicher Täter dem Gericht (schnell) zugeführt wird. Dies führt andererseits dazu, dass sich ein, aus ihrer Perspektive, Wiederholungstäter für seine Taten verantworten muss. Für die Polizist*innen erhöht sich damit die Chance nicht, umsonst' gearbeitet zu haben.

Wichtig für das Erleben, dass ihre Arbeit erfolgreich ist, ist unter anderem, dass eine Person Konsequenzen für ihr Tun tragen muss. Polizist*innen erleben immer wieder, dass sie „Kunden“ wiederholt treffen, dass ihre Maßnahmen augenscheinlich keine Konsequenzen haben und ihre Arbeit in dem Sinne erfolglos ist. Im eben beschriebenen Fall haben sie ihre Möglichkeiten genutzt, um, aus ihrer Perspektive, Erfolg herzustellen.

In dem obigen Beispiel ist es am Ende das Gericht, das über eine Strafe und/oder über Zurückschiebungshaft entscheidet. Für Polizist*innen eröffnen sich aber auch Möglichkeiten, selbst zu maßregeln und zu strafen: Bei einem anderen Ladendiebstahl hat ein Mann Zigaretten entwendet und die Schachteln in den 
Ärmeln seiner Jacke, die er über die Schultern gehängt hatte, versteckt. In der Jacke waren die Ärmel von innen mit Sicherheitsnadeln verschlossen, so dass die Zigaretten in dem Ärmel hängen blieben. Die beiden Beamten diskutieren miteinander darüber, ob die Jacke deswegen als ein Tatwerkzeug gedeutet werden könnte und sie sie aus diesem Grund sicherstellen könnten. Der Mann, so mein Eindruck aufgrund seines Äußeren, scheint in finanziell prekärer Situation zu sein. Als ihm klar wird, dass sie die Jacke einbehalten könnten, sagt er mehrfach, dass er die Jacke brauche, weil es seine einzige sei. Die Polizist*innen nehmen die Jacke mit. Sicherlich sind sie hier juristisch auf der sicheren Seite. ${ }^{97}$ Ihre Diskussion zeigt aber, dass es nicht vollkommen eindeutig ist, ob sie die Jacke einbehalten müssen oder können. Ihre Entscheidung sie mitzunehmen kann als Strafmaßnahme für den Mann gelesen werden. Solche Interpretationsspielräume eröffnen (legale) Möglichkeiten für Maßregelungen, die zumindest eine kleine Befriedigung und damit einen kleinen unmittelbaren Erfolg für die Beamt*innen ermöglichen.

Einsätze werden auch dann als erfolgreich oder befriedigend gewertet, wenn ein*e Verdächtige* ${ }^{*}$ gestellt werden kann, z.B. nach einer Verfolgung; oder, allgemeiner, wenn eine Person gefunden wird, die vermisst, entlaufen, geflüchtet etc. ist. In einer Nachtschicht konnte ,meine' Streifenwagenbesatzung einen entflohenen, mutmaßlich gewalttätigen Freigänger nach einer Suche und Verfolgung zu Fuß stellen. Neben Anspannung - ein solcher Fall ist keine Routine - herrschte dann im Anschluss aber auch Euphorie. Ein solcher Einsatz ist ein Erfolg und eignet sich auch als solcher weitererzählt zu werden. Der eine Beamte erzählte schon im Auto - obwohl der andere Polizist und ich dabei gewesen waren mehrfach, wie der Mann weggelaufen sei und dann „mit dem Gesicht gebremst“ habe. Das hört sich spektakulärer an, als es war, da der Mann schlichtweg hingefallen war und sie ihn deswegen schnell einholen konnten. Diese Geschichte erzählte er dann auch auf der Dienststelle mehrfach den anderen Kolleg*innen. Am nächsten Tag wurde auch ich darauf angesprochen, dass wir ja einen "großen Fang" gemacht hätten, und der Ausdruck „mit dem Gesicht bremsen“ wurde dabei auch von dem Kollegen benutzt, der nachts nicht da gewesen war. In solchen Geschichten können Erfolge präsentiert werden, später auch wieder ,hervorgeholt ${ }^{\natural}$ werden und sich so als Erfolgsgeschichten tradieren (vgl. Mensching 2008: 86 ff.; Reichertz 2003a: 38-45).

\subsection{4 (Ir-)relevante polizeiliche Arbeit}

Am Sprechen über Einsätze und am Handeln werden Konstruktionen dessen sichtbar, was Polizist*innen als relevante und was sie als irrelevante polizeiliche

\footnotetext{
${ }^{97}$ Die Polizei kann Sachen sicherstellen, unter anderem um eine gegenwärtige Gefahr abzuwenden. Sicherstellungen sind in verschiedenen Gesetzestexten geregelt, so z.B. in der Strafprozessordnung ( $\sqrt{ } 94 \mathrm{StPo}$ ) und für Niedersachsen im Niedersächsischen Polizei- und Ordnungsbehördengesetz (\$26 NPOG).
} 
Arbeit werten. ${ }^{98}$ Allgemein lässt sich formulieren, dass polizeiliche Arbeit dann als relevant konstruiert wird, wenn Personen Opfer anderer werden. Dies gilt aber eingeschränkt: Werden die Opfer als (mit-)schuldig gedeutet, wird die polizeiliche Tätigkeit als weniger relevant verhandelt. Potenziell vermeidbare Situationen werden nur bedingt als Aufgabe der Polizei betrachtet. An meinem ersten Beobachtungstag notierte ich recht knapp:

Wir fahren wieder raus. Einer jungen Frau ist das Portemonnaie in einer Filiale der Verkebrsbetriebe geklaut worden, als sie am Tresen stand. Die Anzeige wird aufgenommen. Ich habe den Eindruck, dass sie denken: selbst schuld, wenn man nicht auf sein Zeug aufpasst. Das sagen sie dann auch hinterher so im Gespräch untereinander. Ich frage mich: Das ist doch euer Job, für so Sachen seid ibr doch zuständig. Potenziell vermeidbare Sachen sehen sie eigentlich wohl nicht als ibre Aufgabe.

Hier wird die Bestohlene mitverantwortlich gemacht. Wenn sie ihr Portemonnaie nicht auf dem Tresen hätte liegen lassen, hätte es auch nicht geklaut werden können. Die Polizisten unterstellen dem Opfer des Diebstahls Naivität und dass sie sich damit als Opfer angeboten habe. ${ }^{99}$ Außerdem wird vermutlich kein Täter gefasst werden können. Damit steht hier kein Erfolg in Aussicht und sie sehen die reine Anzeigenaufnahme als weniger relevant an.

Als irrelevante polizeiliche Arbeit bzw. als nicht originär polizeiliche Arbeit werden auch Bereiche gedeutet, für die andere Behörden oder Organisationen als zuständig gesehen werden. Dies betrifft z.B. Einsätze, die im Zusammenhang mit „Asyl“ stehen. Dabei geht es nicht unbedingt darum, infrage zu stellen, dass Geflüchtete Asyl beantragen, sondern um die Frage, wer dafür zuständig ist. In einer Situation, in der ,mein' Streifenwagenteam einen Einsatz zur Bearbeitung eines Falles unerlaubter Einreise erhalten hatte und dann wieder aus ihm entlassen wurde, fand folgende Unterhaltung, die exemplarisch ist, statt:

Sebastian: „Ja, dann wären wir jetæt zwei drei Stunden beschäftigt. “ Christoph: „Ja, wenn sie englisch können, wenn nicht, dann noch länger. Das ist echt so doof, die sollen wirklich kommen und Asyl beantragen, aber diese Verfahren sind ein Witz und unsere Ressourcen werden vollkommen verschleudert."

Die Polizei ist nicht nur für Aufenthaltsdelikte zuständig, sondern als eine der Behörden, bei denen Menschen um Asyl nachsuchen können (AsylG), auch für Asylanträge. Der Polizist beklagt zum einen diese Zuständigkeit, indem er sie als Verschwendung von Ressourcen ansieht. Der ESD habe demnach andere, wichti-

98 Vergleiche dazu auch die Ausführungen von Fest und Blankenburg (1972) zur (Nicht-)Verfolgung und Konstruktion von Bagatelldelikten, auch in Zusammenhang mit den Zuschreibungen an die ,Täter*innen' und den Umgang mit ihnen (vgl. ebd.: 58-85).

${ }^{99}$ In diesem Fall ist es durchaus ärgerlich, der Schaden für die Frau aber (zumindest finanziell) gering. Deutungsmuster, die Opfern eine Mitschuld zuschreiben, sind aber höchst problematisch, wenn man z.B. an Fälle von (sexueller) Belästigung und Gewalt denkt. Es wäre zu fragen, inwieweit z.B. die Schwere des Vergehens und Geschlechterkonstruktionen solche Deutungen mitbestimmen. 
gere, Aufgaben als die Bearbeitung von unerlaubter Einreise. Dies wird in anderen Gesprächen als allenfalls für die Bundespolizei relevante Aufgabe konstruiert. Zum anderen wird das Verfahren selbst als nicht sinnvoll betrachtet. Die Polizist*innen schreiben eine Anzeige wegen unerlaubter Einreise. Diese Anzeigen werden in der Regel nicht weiterverfolgt oder ausgesetzt, da sich dann ein Asylverfahren anschließt, während dessen ein Aufenthalt im Bundesgebiet ohnehin gestattet ist. Für die Beamt*innen wird der Tatbestand von unerlaubter Einreise eigentlich erst relevant, wenn ein Asylersuchen abgelehnt worden ist.

Durch den Verweis auf die Sprachkompetenz der Asylsuchenden wird außerdem sichtbar, dass die Polizist*innen zum einen (in der Regel) keine Kompetenzen in den relevanten Herkunftssprachen haben (zu dieser Zeit vor allem Arabisch). In Bezug auf ihre Englischkenntnisse werden ihnen manchmal auch ihre eigenen Limitationen bewusst, wenn sie Kontakt zu den teils sehr hochqualifizierten Geflüchteten haben, die gut oder sogar besser Englisch sprechen. Zum anderen bekommt die Polizei nicht die nötigen Ressourcen zur Bearbeitung zur Verfügung gestellt, wie z.B. eine*n Dolmetscher*in. Auch durch erschwerte Kommunikationsmöglichkeiten sehen die Polizist*innen sich zeitlich zu lange an die Bearbeitung eines Falles gebunden. Die Deutung, die eigenen Ressourcen zu verschwenden, hängt auch mit Ressourcenmangel zusammen. Nicht zuletzt handelt es sich um Schreibarbeit, die ohnehin als weniger relevante polizeiliche Arbeit konstruiert wird. Polizist*innen sehen sich hier eher als ,Verwalter' (der Politik), was den eigenen Kompetenzen nicht entspreche und die vorhandenen Kompetenzen nicht ausschöpfe.

Als ,Verwalter ${ }^{6}$ oder auch ,Opfer' von politischer Steuerung sehen sie sich auch in Bezug auf die Erfüllung von Statistiken in Zusammenhang mit der Ökonomisierung der Polizei; die Arbeit, die damit verknüpft wird, sehen sie ebenfalls als wenig relevant bzw. nicht als ihr Aufgabenfeld an.

Wir fahren wieder raus: Zwei Parkempler, ein paar Deppen, unter anderem einer wegen telefonieren beim Fabren und nicht anschnallen. Gespräch darüber, wie scheiße das ist mit dem Deppen schreiben. Christoph: „Solche Sachen wie telefonieren und nicht anschnallen sind ja sinnvoll, da geht es ja um die Sicherheit, aber Falschparken, naja. "

„Deppen schreiben“ oder ein ,Knöllchen“ ausstellen, d.h. eine Verwarnung für Ordnungswidrigkeiten, die den stehenden Verkehr betreffen und damit nur begrenzt sicherheitsrelevant für den Straßenverkehr sind, wird in das Aufgabengebiet des Ordnungsamtes respektive der Stadt verwiesen. Nur die für die Sicherheit die so natürlich mitkonstruiert wird - wichtigen Ordnungswidrigkeiten werden als relevante und sinnvolle Arbeit betrachtet, die die Kompetenzen von Polizist*innen und die Ausstattung der Polizei erfordern. Das „Deppen schreiben“ war wiederkehrendes Thema in meinem Beobachtungszeitraum. Einerseits aus den gerade genannten Gründen, andererseits aber auch, weil die Polizist*innen in ihren Abteilungen bestimmte Quoten erfüllen müssen (vgl. Kap. 2.2.5). Wie konkret dieses Quotensystem aufgeschlüsselt ist, z.B. nach Art der Ordnungswidrigkeit, 
ist mir nicht bekannt - unter anderem weil mir dieser Teil polizeilicher Aufgaben, wie das Schreiben, weniger interessant erschien und ich ihm wenig Aufmerksamkeit gewidmet habe. Am Monatsende sollen aber bestimmte Zielvorgaben erfüllt sein. Dies führt zu absurden Situationen, wie der, dass sich in einer Nachtschicht zwei Streifenwagen an einem für Falschparken bekannten Platz zufällig treffen, um Knöllchen zu verteilen, damit die monatliche Quote erfüllt werden kann, da sich das Monatsende nähert. Dieses Vorgehen konterkariert zum einen die (offizielle) Idee ${ }^{100}$ Präsenz zu zeigen und Verkehrsdelikte zu reduzieren, zum anderen zeigt es, wie die Polizist*innen diese Idee interpretieren. Nicht die Präsenz, die durch das ,Knöllchen' schreiben demonstriert wird, sondern die ökonomischen Interessen und das Messbarmachen ihrer Arbeit ist der Interpretationsrahmen. Sie kommen ihrer Arbeit und der Zielvorgabe zwar durch das Aufschreiben von falsch parkenden Autos nach, handeln aber in geringem Maße auch subversiv gegenüber der Organisation. Und obwohl der Ausdruck „Deppen“ eine Abkürzung für Datenermittlungsbeleg ist und eigentlich „DEBen“ geschrieben werden müsste, so deutet die geläufige Aussprache über die Abkürzung hinaus. „Deppen schreiben“ ist eine Tätigkeit für Deppen. Auch wenn die Deutung, dass es sich bei den Deppen um ,Bürger' handelt, wahrscheinlicher ist.

Neben dieser Tätigkeit, für die sie die Stadt zuständig sehen, gibt es aber auch Einsätze, die weiteren Organisationen zugerechnet werden, wie z.B. der Sozialen Arbeit oder dem medizinischen Feld. Darunter fallen z.B. Einsätze mit (vermeintlich) obdachlosen Personen, die eigentlich medizinische Hilfe benötigen, und, wie oben beschrieben, auch oft als mitschuldig für ihre Situation und/oder den konkreten Einsatz konstruiert werden. Es ist daher nicht verwunderlich, dass Einsätze an bestimmten Plätzen oder solche, in die bestimmte Personen(gruppen) involviert sind, nicht immer so schnell angefahren werden, wie andere. Der konkrete Umgang in einer Einsatzsituation kann in der Regel zwar als bestimmt-freundlich beschrieben werden, da er einerseits auf der konkreten Interaktionsgeschichte, andererseits aber auch auf einer Art Gleichgültigkeit gegenüber dieser Gruppierung und dem konkreten Einsatzanlass beruht. ${ }^{101}$

Allgemein kann festgehalten werden, dass die Konstruktionen dessen, was relevante und weniger relevante Arbeit ist, mit dem Wir-Bild verknüpft ist und in

100 Die diskursiven Begründungen und der Grad der (geldwerten) Ökonomisierung variiert in den Bundesländern. Teilweise geht es um die Vergleiche, die zwischen Dienststellen und Abteilungen gezogen werden können. Teilweise wird auch auf das Füllen der städtischen Kassen hingewiesen. Siehe z.B.:

https://www.focus.de/auto/ratgeber/sicherheit/gurtsuender-handy-am-steuer-alkohol-stuttgarterpolizei-muss-geheime-fangquoten-bei-verkehrskontrollen-erfuellen_id_9299782.html [letzter Zugriff: 17.09.2019 ]; http:/ /www.general-anzeiger-bonn.de/bonn/Bonns-Polizei-gibt-Quotef\%C3\%BCr-Kn\%C3\%B6llchen-vor-article204936.html [letzter Zugriff: 17.09.2019]; https://www.welt.de/print-welt/article382598/Knoellchen-Quote-fuer-Polizisten.html [letzter Zugriff: 17.09.2019]. Zur Rolle des ökonomischen Kapitals in der Polizei siehe Schöne 2011, 114 ff. 101 Strasser und van den Brink (2008) beschreiben Ähnliches auf Grundlage von Interviews mit Wohnungslosen und Mitarbeiter*innen der Wohnungslosenhilfe. 
Wechselbeziehung steht mit dem Dualismus von Schreiben und Rausfahren und der Konstruktion von erfolgreicher Arbeit.

\subsubsection{Grenzüberschreitungen}

Polizeiliche Arbeit ist auf verschiedene Arten grenzüberschreitend, wie sich an folgendem Auszug meines ersten Beobachtungsprotokolls exemplarisch zeigen lässt:

Ich hatte gerade erst ein paar der Beamt*innen kennengelernt und eine kurze Unterhaltung mit einem der Polizisten, die ich an diesem Tag begleiten würde, geführt, da wurden sie zu einem Einsatz, mit einem möglichen Suizidversuch (,da steht jemand im Fenster") gerufen. Wir laufen schnell zum Auto und ich werde währenddessen lediglich eingewiesen, wo ich mich im Auto binsetzen soll. Ich frage, wie wir das gleich machen - ich bin verunsichert und dachte, wir müssten irgendwie klären, wie ich mich verhalten soll oder was ich darf und was nicht. Lukas sagt: „Du kommst einfach immer hinterher, bis wir sagen, dass es nicht geht, wenn es irgendwie zu gefährlich erscheint. " [... $]^{102}$ Am Einsatzort angekommen, ist schon ein weiterer Streifenwagen vor der Tür. Vor der Tür stebt eine Frau, wie sich später herausstellt die Betreuerin der Person, sie unterhalten sich kurz. mit ihr und gehen in das Haus, ich zögere nachzukommen, frage, ob ich mit kann. Dieter: „Na klar. "Ich gehe also hinterber und warte an der Wobnungstür, dort steht noch jemand, offenbar vom Gericht, es gibt wobl eine Anordnung, dass sie in eine Klinik eingewiesen werden soll. Beide betreten direkt die Wobnung, ich zögere und gehe 2-3 Minuten später langsam hinterher, bleibe aber im Flur der Wohnung.

An dieser Szene wird deutlich, dass ich Probleme hatte, einfach eine fremde Wohnung zu betreten und unaufgefordert in die Privatsphäre einer anderen Person einzudringen. Was mir schwer fällt, ist für die Polizist*innen hier unproblematisch. Polizist*innen überschreiten, oft sehr selbstverständlich, Grenzen. Es sind nicht nur räumliche Grenzen, wie die einer Wohnung, sondern auch körperliche und psychische Grenzen. So auch hier: Sie stehen im Schlafzimmer der Frau, die sich in Anwesenheit der Polizist*innen aus- bzw. umziehen soll. Sie greifen bei ihrer Arbeit häufig ganz erheblich in den Nahbereich von Personen ein. Zum einen stellen sie Fragen zu privaten und intimen Themen. Sie werden unter anderem in Situationen gerufen, in denen Menschen (physisch wie psychisch) entblößt sind. Zum anderen, und dies kann direkt damit verwoben sein, überschreiten sie regelmäßig körperliche Grenzen. Eine solche Grenzüberschreitung kann dazu

102 Das Gespräch ging so weiter: Ich: „Okay, ich wollte nur wissen, ob das so geht, dass ich einfach immer mitgehe.“ Lukas: „Klar, wir haben ja auch immer Schülerpraktikanten, das ist kein Problem, die nehmen wir ja auch mit." Meine mir zugewiesene Rolle ist die einer Praktikantin. Hier ist es recht manifest, aber auch im sonstigen Umgang mit mir wurde ich oft als Lernende und Interessierte adressiert - mit dem Unterschied, dass ich zum einen , mehr' sehen konnte, da die Praktikant*innen in der Regel in Nachtschichten nicht da sind. Aufgrund ihres Alters dürfen sie nach $22 \mathrm{Uhr}$ nicht mehr arbeiten. Zum anderen wurde ich wegen meines Alters anders adressiert (evtl. sogar einfach mehr angesprochen), da ich in einem ähnlichen Alter wie die jüngeren der Polizist*innen war. 
führen, dass ihr Gegenüber entblößt wird - auch hier: physisch wie psychisch -, auch durch die Anwendung von Zwangsmaßnahmen respektive durch Gewalt.

In einer Nachtschicht wurde ein Mann, gegen den ein offener Haftbefehl vorliegen soll, nach einer Verfolgung gestellt und verhaftet.

Der Mann ist in einer Zelle, als wir ankommen. Zwei Polizisten stehen vor der offenen Zellentür. Offenbar ist er nun gewalttätig gegenüber sich selbst und hat immer wieder mit dem Kopf gegen die Wand gehauen. Er habe sich ausgezogen und an seinem Penis rumgespielt und Sabrina dabei Küsse zugeworfen. Ich kann nicht bis zur Zelle gehe, stehe aber im Raum um die Ecke, er reagiere offenbar auf Frauen und ich soll außerhalb seiner Sichtweite bleiben. Ich kann aber kurz sehen, dass Basti neben ibn sitzt und seinen Kopf unter seinem Arm fixiert, vermutlich damit er ihn nicht gegen die Wand haut. Er sitzt nach vorne gebeugt/gedrückt und sie haben ihm Hand-und Fußfesseln angelegt. [...] Abwechselnd verharren Polizisten bei dem Mann in der Zelle - mir ist unklar, ob er auch durchgängig in dieser Körperhaltung war - bis nach fast zwei Stunden geklärt ist, wo sie den Mann hinbringen können. Vier Polizisten bringen den Mann, weiterbin fixiert, in eine forensische Psychiatrie.

Hier zeigt sich, dass ein Eindringen in den Nahbereich des Anderen auch in den eigenen Nahbereich eindringt. Solche Grenzerfahrungen sind konstitutiver Teil polizeilicher Arbeit. Zwangsmaßnahmen anzuwenden, ganz selbstverständlich eine Person durch Gewaltanwendung zu etwas zu zwingen, muss erlernt werden. Nicht nur, wie man es praktisch tut, sondern auch, es überhaupt (und ohne Nachdenken) zu tun, muss erlernt werden und kann eine Grenzerfahrung sein. Es muss im Sinne Schütz' zu Routinewissen werden (vgl. Schütz/Luckmann 1979/2003: 156 ff.). Prinzipiell kommen Polizist*innen in Situationen, denen andere sich eher entziehen: Wenn man Angst bekommt, sich ekelt, beleidigt wird, es gefährlich werden könnte. Eine Grenzerfahrung kann auch sein, als Erstretter an einem Unfallort eine verletzte Person nicht retten zu können bzw. sterben zu sehen und dann mit Angehörigen von Verstorbenen umgehen zu müssen. Wie über Erfolge können auch über schwierige Erlebnisse und Gefühle Geschichten erzählt werden. Geschichten können helfen, das Erlebte zu verarbeiten und (gemeinschaftlich) einzuordnen (vgl. Mensching 2008: 86). ${ }^{103}$

Es werden aber auch Grenzen ganz anderer Art überschritten: ,Klassengrenzen'. Polizist*innen werden mit Menschen konfrontiert, deren Lebenswelt und Erfahrungen sie nicht teilen oder von deren Lebenswelt sie sich keine Vorstellung

103 Peggy Szymenderski rekonstruiert die Notwendigkeit von „Gefühlsarbeit als Arbeitshandeln und berufliche Kompetenz sowie Gefühlsarbeit als Bewältigungshandeln und Selbstsorgekompetenz" (Szymenderski 2013: 180). Für das Arbeitsfeld des Streifendienstes, das mit hoher Arbeitsbelastung und schnellen Wechseln von unterschiedlichen Einsatzsituationen korrespondiert, sieht sie das „Wegstecken“als typische Gefühlsarbeitspraktik; sie entspricht einer „,männlich geprägten innerpolizeilichen Gefühlskultur“" (Szymenderski 2013: 178). Dies widerspricht m.E. nicht der Praktik, Geschichten zur Verarbeitung zu erzählen, sondern kann damit korrespondieren, denn auch sie ermöglichen ein Wegstecken, ohne sich eingehender damit auseinanderzusetzen. 
machen können. Über das Herkunftsmilieu der Polizist*innen kann ich nur spekulieren. Aufgrund von Gesprächen wurde mir aber schnell deutlich, dass auch ich offenbar eine andere Lebenswelt habe. Viele der Polizist*innen waren in einem ähnlichen Alter wie ich. Während ich damals in einer großen WG wohnte, jahrelang studiert hatte, nun mit Promotion beschäftigt war, nur befristete Arbeitsverträge kannte und kaum feste Arbeitszeiten hatte, ging es in den Gesprächen im Streifenwagen oft um Heirat, Kinder, Hausbau oder Kredite für eben diesen und das alles im Rahmen eines durch den Schichtdienst festgelegten Arbeitsrhythmus. Auch wenn die Herkunftsmilieus der Polizist*innen unterschiedlich sein mögen, erfahren sie von Beginn des Studiums an relative Sicherheit durch Besoldung im Studium, Verbeamtung und damit einhergehend einen sicheren Arbeitsplatz. Manchmal wurde auf beiden Seiten Verwunderung deutlich: Ich konnte, in Anbetracht meiner Lebens- und ökonomischen Situation nicht verstehen, wie man mit Mitte 20 ein Haus bauen kann und dafür einen Kredit bekommt. Manche Polizist*innen konnten nicht nachvollziehen, dass ich noch immer in einer WG wohnte, und wunderten sich, wie ich diese Unsicherheit bezogen auf meinen Arbeitsplatz bzw. meine berufliche Perspektive aushalten könne. Kurz und überspitzt: Für mich war ihr Leben zu strukturiert und konservativ und für sie führte ich ein unstetes ,Lotterleben'. So wie wir nur begrenzt Verständnis für die jeweilige Lebenssituation aufbringen konnten, haben die Polizist*innen oft auch keine Vorstellung von der Lebenswelt ihrer „Klientel“ - hier nutze ich den Begriff bewusst (vgl. 4.1.2). Polizist*innen sind eben nicht nur mit Vertreter*innen des eigenen Milieus mit ähnlichen Vorstellungen konfrontiert, sondern mit Angehörigen aller Milieus. Dies ist nun keine allein der polizeilichen Arbeit eigene Situation. Im Rahmen ihrer Arbeit werden aber Deutungen über die Sie-Gruppen machtunbalanciert interaktionsrelevant. Dabei machen Polizist*innen auch für sie befremdliche Erfahrungen, auch weil sie daran ,scheitern', Situationen einen Sinn zu verleihen im Kontakt mit Personen, deren Erfahrungen sie nicht teilen.

\subsubsection{Hierarchische Verhältnisse}

Die Polizei ist stark hierarchisch gegliedert. Dies drückt sich unter anderem dadurch aus, dass es vielfältige vertikale und horizontale Führungsebenen und positionen gibt. Eine Arbeit über die Polizei kommt nicht umhin, sich mit den hierarchischen Arbeitsstrukturen zu beschäftigen. Ich möchte mich hier auf einige wesentliche Punkte konzentrieren: die Sichtbarkeit formaler Hierarchie, Erfahrung und Vertrauen als Basis für informelle Hierarchie und die dadurch und im $\mathrm{Zu}$ sammenhang mit dem Wir-Bild entstehende ,Undeutlichkeit' hierarchischer Beziehungen. ${ }^{104}$

${ }^{104}$ Eine umfassende empirische Rekonstruktion von Hierarchiebeziehungen in der Schutzpolizei hat Anja Mensching (2008) vorgelegt, die die Aushandlung von formeller und informeller Hierarchie auf der alltagspraktischen Ebene als ,gelebte Hierarchien“ (Mensching 2008) untersucht hat. 
In Zusammenhang mit den fragmentierten Wir-Bildern innerhalb der Polizei, der Binnenperspektive auf andere organisationale Arbeitsbereiche, habe ich schon thematisiert, welche Zuschreibungen sich bei Polizist*innen des ESD über den Kriminalermittlungsdienst rekonstruieren lassen. Daran anschließend ließen sich Deutungen von informellen hierarchischen Beziehungen zwischen unterschiedlichen Abteilungen rekonstruieren. Hier interessieren mich allerdings vorrangig die hierarchischen Verhältnisse innerhalb des Einsatz- und Streifendienstes.

Eine formelle Hierarchie ist bei der uniformierten Polizei äußerlich sichtbar sowohl für andere Polizist*innen als auch für Nicht-Polizist*innen - sofern sie die Zeichen zu lesen verstehen. Die Abzeichen auf den Schulterklappen der Uniform geben Auskunft über die Amtsbezeichnung und damit auch über formalhierarchische Verhältnisse. Die Amtsbezeichnung ist dabei nicht direkt mit einer bestimmten Tätigkeit oder formal hierarchischen Position verbunden. Und ein Aufstieg innerhalb einer Laufbahngruppe führt nicht unbedingt zu einer anderen Position mit veränderten Aufgaben. So kann es in einer Dienstabteilung z.B. drei Polizeihauptkommissar*innen geben, die nicht alle die gleiche Führungsposition ausfüllen, sondern es gibt je eine*n Leiter*in und Stellvertreter*in der Dienstabteilung und alle anderen, gleich welcher Amtsbezeichnung, sind hierarchisch nachgeordnet. Unter den ,Nachgeordneten“ finden sich dann wiederum Polizeikommissar*innen und Polizeioberkommissar*innen, die trotz unterschiedlicher Amtsbezeichnung und Besoldung die gleiche Tätigkeit ausüben.

Unter den Polizist*innen ohne Führungsfunktion, den ,normalen' Polizist*innen, ist mir in den Dienstabteilungen, in denen ich war, nicht aufgefallen, dass die Amtsbezeichnung untereinander von besonderer Bedeutung wäre. Prinzipiell werden alle als Kolleg*innen bezeichnet - hier drückt sich das starke polizeiliche Wir-Bild aus. Die Sterne auf der Schulter geben aber Auskunft über Beförderungen respektive über nicht erfolgte Beförderungen. Beförderungen beruhen auf Beurteilungen durch Vorgesetzte. In den „Beförderungsrunden“ treten die Polizist*innen dann regelmäßig um die frei werdenden oder zusätzlich geschaffenen Stellen gegeneinander an. Dass diese Praxis zu Konflikten führen kann, erscheint mir naheliegend (vgl. dazu Mensching et al. 2004: 39-47). Mir sind solche Konflikte aber verschlossen geblieben bzw. waren in meinem Feld (für mich) nicht beobachtbar.

Für den Arbeitsalltag relevanter ist Erfahrung. Arbeitserfahrung und ein darauf beruhender Führungsstil (bei den Vorgesetzten) und praktisches Handlungswissen (bei den Vorgesetzten und den ,einfachen' Schutzpolizist*innen) sind die zentralen Kategorien, um eine anerkannte Position in der Hierarchie zu erhalten und/oder zu festigen. So wurde z.B. in einem Interview von einer im ESD tätigen Polizistin hervorgehoben, dass ihr Dienstabteilungsleiter (DAL), der seinen Arbeitsplatz eigentlich auf der Dienststelle im Büro hat, regelmäßig auch selbst mit rausfahre und dadurch einerseits seinem Stellvertreter die Möglichkeit gebe, den Posten des DALs auszufüllen, und andererseits auch mitbekomme, mit was und wem sie sich täglich „draußen“ beschäftigen müssten. Hervorgehoben wird hier, 
dass der Vorgesetzte den Bezug zur ,richtigen' polizeilichen Arbeit aufrechterhält. Dies sichert ihm Anerkennung. Theoretisch erworbenes Wissen z.B. durch ein Masterstudium, das zum Aufstieg in den höheren Dienst befähigt, verschafft zunächst keine solche Anerkennung, wie in diesem von mir protokollierten Gespräch über Aufstiegsmöglichkeiten deutlich wird:

Sie erklärt mir, dass man früh damit anfangen muss. Wenn man zu lange im ESD bleibe, gehe es eigentlich kaum noch. Man müsse immer wieder Lehrgänge machen und für den hö-beren Dienst nach Hiltrup an die deutsche Polizeihochschule. Wenn man aber Spaß am ESD habe, und das sei ja die Basis, dann bekommt man eigentlich nur die zwei Sterne. Marco: „Die, die oben sitzen, die haben nie lange ESD gemacht. Eigentlich haben sie nichts lange gemacht. Die gehen mal für 6-9 Monate überall bin und erzählen dann viele Geschichten von dem, was sie gemacht baben."

Hier wird der Verweis auf die, richtige' polizeiliche Arbeit manifest und es zeigt sich ein Bezug zum Wir-Bild des ESD. Ein formaler Aufstieg durch Aufbaustudium und die Kenntnis verschiedener Arbeitsbereiche, das Geschichtenerzählen über die vielen Arbeitsbereiche, in denen man war, bringen keine anerkannte Position, solange man sich nicht in der Handlungspraxis mit dem richtigen Handlungswissen als kompetent beweisen kann. Und die Position muss , verteidigt ${ }^{6}$ werden, z.B. dadurch, auch weiterhin „mal mit rauszufahren“. Über- und Unterordnung folgen einem „Prinzip der Hierarchie in actu“ (Mensching 2010: 160). Damit zusammenhängend wird Kontinuität geschätzt und Durchlauf - die, die „mal für 6-9 Monate überall hin“ gehen - wird nicht anerkannt (vgl. Mensching et al. 2004: 89 ff.). Die Etablierung einer anerkannten Position braucht Zeit und einen geteilten Erfahrungshintergrund.

Den Vorgesetzten weiter ,oben', wie dem Inspektionsleiter und dem Polizei(vize)präsidenten, spricht man einen geteilten Erfahrungshintergrund und ausreichende praktische Erfahrung in ,richtiger ${ }^{\varsigma}$ Polizeiarbeit ab. Mit ihnen gibt es nur wenig bis keine Face-to-Face-Interaktion und sie werden vor allem als Initiatoren oder Durchsetzer von Regeln, die oft nicht als Verbesserung gesehen werden, wahrgenommen. Damit ist auch die Rolle der unteren Führungsebene, die der Dienstabteilungsleiter*innen, berührt: Ihre Aufgabe ist es unter anderem (neue) Regeln zu vermitteln. Sie müssen sie durchsetzen und dürfen dabei ihre eigene Position, sofern sie eine etablierte haben, nicht gefährden, sie müssen dabei trotzdem Kolleg*innen bleiben - eine ähnliche Position bekleidet meine Interviewpartnerin Melanie Wegener (vgl. 5.1).

Auf der Ebene der ,normalen' Polizist*innen ohne Führungsposition lässt sich in Bezug auf praktisches Handlungswissen zur Etablierung einer anerkannten Position im Kolleg*innenkreis Ähnliches beobachten. Als zentrale Kategorien könnte man Verlässlichkeit und Vertrauen formulieren. In einer Raucherpause vor der Tür erzählt mir eine Polizistin, was sie an ihrem morgigen freien Tag machen wolle. Sie bezieht sich dann weiter auf ihren heutigen Streifenwagenpartner Marco: 
Marco hat deswegen morgen das große Los. Ich frage nach, was das bedeute. Sie: „Marco fährt morgen mit Sebastian“. Ich: „Aha?" Sie: „Merkt man das eigentlich, dass wir alle ein bisschen ein Problem mit ihm haben?" Ich: „Ja, schon. So in Andeutungen. "Sie erklärt mir, er sei schwierig, ein Klugscheißer und belegt das anhand von Beispielen [...], er sei auch nicht lernfähig. Außerdem schätze er in seiner heilen Welt Situationen falsch ein. Sie gibt ein weiteres Beispiel, in dem er sich von seinem Streifenpartner weggedreht hat und unaufmerksam war in einer Situation, in der es ein bisschen Gedränge gab und der Kollege dann was abbekommen habe. Sie meint, dass man das manchmal sowieso nicht verhindern könne, aber man müsse sich vertrauen, so wie bei ibr und Marco, aber sie fübren halt auch schon ewig zusammen raus.

Kolleg*innen vertrauen zu können, sich auf sie verlassen zu können, ist im Arbeitsalltag der Polizei als Gefahren- und „Schicksalsgemeinschaft“ (Behr 2010: 61) essenziell. Jemand, auf den man sich nicht verlassen kann im Einsatz - das beinhaltet auch den falschen Umgang mit dem Bürger -, erhält keine etablierte Position im hierarchischen Gefüge, sondern wird zum Außenseiter. In diesem Fall handelt es sich um einen eher jungen Polizisten mit noch wenig Erfahrungswissen, der als Polizeikommissar auch formal-hierarchisch ,unten' steht - wie aber eben viele seiner Kolleg*innen auch. Seine Außenseiterposition speist sich nicht aus der formalen Hierarchie, sondern aus fehlendem Praxiswissen über angemessenes Handeln in der Zusammenarbeit mit Kolleg*innen und in der Interaktion mit den nicht-polizeilichen Anderen und, auch daraus resultierend, aus dem Mangel an Vertrauen ihm gegenüber.

Unklar geblieben ist mir hingegen, ob in Entscheidungssituationen in Einsätzen, in denen zwei ,normale' Polizist*innen unterschiedlicher Amtsbezeichnungen (z.B. PK'in und POK'in) miteinander interagieren, die formale Hierarchie eine Rolle spielt. Es liegt aber nahe, dass Erfahrungswissen in Verbindung mit dem Dienstalter auch hier die relevanteren Kategorien sind und in der Einsatzsituation unter Handlungsdruck die formale Hierarchie keine Rolle spielt - in der Nachbesprechung eines Einsatzes kann sich dies dann aber anders gestalten.

Deutlich wird die Hierarchie, wenn es um Sanktionierungen (und Belobigungen) geht. Nach einer sehr rasanten Einsatzfahrt von Jan - Dieter und ich waren Beifahrer*innen -, die offenbar über das angemessene Fahren mit Wegerecht hinausging, passierte Folgendes:

Dieter kommt zu mir, als ich alleine draußen stehe, und erklärt mir, dass Jan zu schnell gefahren sei, dass ihm das leid tue und dass er Eberhard (dem Dienstabteilungsleiter) davon berichtet habe. Normalerweise würde er zunächst zu den Leuten selbst gehen und er werde auch noch mit Jan darüber sprechen. Aber ich solle nicht denken, dass das normal sei.

Man könnte nun davon ausgehen, dass Dieter sich bei mir entschuldigt, obwohl er ja nicht der Fahrer war, damit ich kein ,falsches' Bild erhalte. Da er es aber auch dem Vorgesetzten gemeldet hat, scheint es keine nur an mich adressierte Ent- 
schuldigung zu sein, ${ }^{105}$ sondern auch ein Vorkommnis, das eben gemeldet wird. Dies verweist darauf, dass es sich um einen Vorfall handelt, der von ,oben' sanktioniert werden muss und wofür ein Gespräch unter Kollegen nicht ausreicht. Dinge, unter sich zu regeln' statt sich an Vorgesetzte zu wenden, scheint aber trotzdem die gängigere Praxis zu sein. Am nächsten Tag sucht dann Jan das Gespräch mit mir. Er fragt nach, ob er zu schnell war und ob ich Angst gehabt hätte. Er entschuldigt sich bei mir und versichert, dass er mir keine Angst machen wollte. Dieter hatte offensichtlich inzwischen mit ihm gesprochen und ihm eventuell auch (als der Dienstältere) aufgetragen, sich bei mir zu entschuldigen. Zwei weitere Tage später werden dann alle zu einer Besprechung, an der ich nicht teilnehme, zusammengerufen, in der es um diesen Vorfall geht. Hier wird Jans Verhalten gemeinsam besprochen. Eine Sanktionierung findet offenbar in der und mit der Öffentlichkeit der Dienststabteilung statt. Diese Form der Sanktionierung ist vom Dienstabteilungsleiter (DAL) initiiert, indem dieser alle zusammenruft, wird aber offenbar gemeinschaftlich vollzogen. Aber auch diese scheinbar gemeinschaftliche Praxis verdeutlicht die Position des Vorgesetzten auf zweierlei Ebenen: Zum einen ist er derjenige, der entscheidet, welche Sanktionierung folgt und in welcher Form sie verhandelt oder verkündet wird. Zum anderen scheint seine Position in der Dienstabteilung anerkannt, wenn man ihn bei solchen Vorfällen hinzuzieht und man es nicht nur untereinander, regelt'. Die Position des DAL scheint etabliert, sonst hätte Dieter sich nicht an ihn gewandt. Die gemeinschaftliche Sanktionierungsform führt wiederum zu Vergemeinschaftung - in der der Vorgesetzte hier ebenso einen Platz hat wie die Untergebenen.

Oben habe ich schon Begrüßungsrituale als Vergemeinschaftungsform beschrieben. In der Dienststelle meiner Feldforschung haben sich alle Polizist*innen inklusive DAL geduzt, und auch mit Kolleg*innen anderer Dienststellen war dies Usus. Vorgesetzte oberhalb des DAL, wie der*die sogenannte Leiter*in Einsatz, sind aber meines Wissens nicht mehr geduzt worden bzw. nur noch von den Dienstabteilungsleiter*innen. Ob die Dienstabteilungsleiter*innen die hierarchisch höherstehende Inspektionsleitung duzen, habe ich nicht mitbekommen. So wie es mir unklar geblieben ist, so ist es das auch zunächst für neue/junge Kolleg*innen. Das dahinterstehende System - sofern es eines gibt und es nicht auf Bekanntschaften und eingelebten Regeln einzelner Abteilungen beruht - ist kein formales, sondern muss in der Praxis erlernt werden. In einer eigentlich hierarchisch stark gegliederten Organisation wird die Hierarchie durch Duzen zum einen undeutlich und dadurch zum anderen schwerer beherrschbar, wenn die formalen Positionszuweisungen nicht mit einem eindeutigen Verhaltenskodex einhergehen. Dies

${ }^{105}$ Für eine solche Lesart spricht auch, dass Dieter es sonst kaum interessierte, welches Bild er mir vermittelt. Er war derjenige, der sich offen rassistisch äußerte - gegenüber oder in Anwesenheit einer Soziologin und in einer Zeit, in der (Bundes-)Polizisten aktuell mit Foltervorwürfen, die er rechtfertigte, konfrontiert waren. 
verstärkt wiederum das Gemeinschaftsgefühl derer, die die je individuellen Regeln kennen, gegenüber den unwissenden Außenseitern.

\subsubsection{Doing police: doing gender}

Frauen sind in der Polizei noch immer unterrepräsentiert: Auch wenn die Einstellungszahlen unter den Studienanfänger*innen in Niedersachsen in Bezug auf Geschlechterverhältnisse mittlerweile nahezu ausgeglichen sind, waren im Jahr 2015 nur rund 24 Prozent der Beschäftigten im niedersächsischen Polizeivollzugsdienst Frauen (vgl. Niedersächsischer Landtag 2016: 2). In den von mir beobachteten Dienstabteilungen lag der Anteil mit ca. einem Drittel etwas höher. ${ }^{106}$ Behr (2008) beschreibt den Polizeialltag in seiner Studie aus dem Jahr 2000 als eine hegemoniale Männlichkeitskultur (im Anschluss an Connell (1999)). Seit dem Erscheinen der Studie hat sich der Frauenanteil in der Polizei insgesamt und auch in Führungspositionen erhöht; zu einer deutlich veränderten Polizeikultur hat dies aber vermutlich nicht geführt, da „autoritäre und machtvolle Alltagspraktiken, die polizeiliche Arbeit strukturieren und letztlich mit gesellschaftlichen Vorstellungen vom Mann-Sein verbunden“ (Hunold 2019: 52) sind, in den polizeilichen Auftrag eingelassen sind. Der Frage, ob und wie sich die hegemoniale Männlichkeitskultur in der Polizei verändert hat, z.B. auch in Bezug auf die hierarchischen Strukturen und den ,Kampf' um Führungspositionen, kann ich im Rahmen dieser Arbeit nicht nachgehen. Ich möchte hier vielmehr die Relevanz von „doing gender“ (West/Zimmermann 1987) unter der Perspektive von ambivalenten Anforderungen und Aushandlungen im Arbeitsalltag beschreiben und mich auf die Herstellung von ,Weiblichkeit' fokussieren - damit ist aber gleichzeitig auch die Herstellung von ,Männlichkeit‘ berührt. ${ }^{107}$

Allgemein, so ein Ergebnis meiner Beobachtungen und Interviews, müssen Polizistinnen ein Spannungsverhältnis interaktiv austarieren - dies ist auch von anderen ähnlich rekonstruiert worden (z.B. Pfeil 2006; Rabe-Hemp 2009). In der

106 Zu Frauen in der Polizei siehe auch Kapitel 2.2.5. Zur Aushandlung im Arbeitsalltag und auf biographischer Ebene außerdem die Fallrekonstruktion von Melanie Wegener (Kapitel 5.1).

${ }^{107}$ Ich habe mich für eine Verwendung des Gender-Sternchen entschieden, um alle Personen anzusprechen und einzuschließen. In diesem Kapitel befasse ich mich nun aber explizit und ausschließlich mit der Herstellung von Weiblichkeit und Männlichkeit und verzichte daher auf eine Markierung von Personen, die sich jenseits von Zweigeschlechtlichkeit verorten. Ich mache dies hier bewusst, da ich die Polizei als Organisation kennengelernt habe, die wenig Handlungsraum jenseits einer zweigeschlechtlichen Verortung bietet. So brauchen z.B. Männer für die Einstellung bei der Bundespolizei mindestens einen funktionsfähigen Hoden, was Transmänner eigentlich ausschließt (vgl. Hecht 2018) - es gibt aber Bestrebungen der Innenministerkonferenz, die entsprechende Dienstvorschrift (PDV 300, Diensttauglichkeit) zu ändern (vgl. Martus 2018), nachdem das Personenstandsrecht endlich auch ,divers“ als Eintragung ermöglicht. Der Verband VelsPol („Verein lesbischer und schwuler Polizeiangehöriger") engagiert sich seit 1994 für homosexuelle Mitarbeitende in Polizei und Justiz und seit einigen Jahren sind dort auch Trans*- und Inter*-Personen organisiert. Es existieren also Räume zum Austausch und Engagement für LSBTIQ-Polizist*innen, zur organisationalen Alltagsnormalität einer männlichkeitsdominierten Polizei gehören sie aber noch nicht. 
Interaktion mit Kollegen stehen Polizistinnen vor der Herausforderung, eine passende Form der Weiblichkeit zu präsentieren: nicht zu weiblich, nicht zu burschikos; frau muss sich nicht alles gefallen lassen, aber sie darf sich auch nicht bei jeder sexistischen Äußerung aufregen; Polizistinnen sollen anpacken können, sich dabei aber nicht wie ein Mann verhalten. Um von den Kollegen als Kollegin anerkannt zu werden, muss frau im Einsatz das Gleiche leisten können. Um von den Kollegen als Frau anerkannt zu werden, muss frau jedoch gleichzeitig heteronormativen Zuschreibungen an Frauen entsprechen. Beides steht in einem Spannungsverhältnis, dass von Polizistinnen immer wieder neu gelöst werden muss. Ich war davon zumindest teilweise ausgenommen. Während die Polizistinnen bis zu einem gewissen Grad sexistische Äußerungen hinnehmen mussten, habe ich es zweimal erlebt, dass sich ein Polizist bei mir - als Soziologin, Nicht-Polizistin und/oder Frau? - entschuldigt hat, wenn dies in meiner Anwesenheit geschah. Dies zeigt ein grundsätzliches Bewusstsein dafür, dass solche Äußerungen problematisch sind. Polizistinnen (und auch Polizisten) müssen sie aber ertragen können, um akzeptierte Kolleginnen (oder Kollegen) zu sein. Dies verweist auf gesellschaftliche Strukturen, in denen Frauen immer noch Unterdrückungsmechanismen ausgesetzt sind, indem sie zum (Sexual-)Objekt gemacht werden.

In diesem Zusammenhang stehen auch die Zuschreibungen an Frauen, sie seien emotionaler und fürsorglicher. Im polizeilichen Arbeitsalltag korrespondiert dies mit einer alltagspraktischen Zuweisung von Aufgaben, die als funktional für die polizeiliche Arbeit gelabelt wird (s. auch Pfeil 2006: 121 ff.; Mangold 2011). Frauen (und Männer) tun in der Polizei jeweils das, was sie ,am besten können“. Dies führt zu einer Re-Produktion und Festschreibung von Geschlechterrollen gesellschaftlich wie polizeilich. In Niedersachsen konnten Frauen ab den 1950er Jahren bis 1973 nur innerhalb der Kriminalpolizei bei den Dienststellen der „Weiblichen Polizei“, die im Bereich von Kinder- und Jugendkriminalität ermittelte, eingestellt werden; erst 1981 wurden Frauen auch in die Schutzpolizei eingestellt (vgl. Götting/Rose 2008: 286, sowie Kap. 2.2.4).

In der Alltagspraxis werden Polizistinnen - in historischer Kontinuität - ,vorgeschickt', wenn es sich um Einsätze handelt, in denen Kinder (und weibliche Gewaltopfer) involviert sind. Ihnen wird - auch in meinen ethnographischen Gesprächen und Interviews - mehr Einfühlungsvermögen attestiert. Und dies nicht nur durch die Polizisten (und auch Polizistinnen), sondern auch durch die anderen in die Einsatzsituation Involvierten. So kam es sowohl in einer Situation, in der es um einen Sorgerechtsstreit ging, als auch in einer Situation, in der eine junge Frau ihren Ex-Freund wegen Stalkings bei der Polizei anzeigen wollte, dazu, dass ich selbstverständlich in die Situation integriert wurde - beide Male begleitete ich eine männliche Streifenwagenbesatzung. Ich trug natürlich keine Uniform während meiner Beobachtung, wohl aber eine Sicherheitsweste, die mich als irgendwie der Polizei zugehörig markierte. Und obwohl ich mich in die Befragungen und den Vorgang, z.B. durch das Anfertigen von Notizen oder Nachfragen, nicht einmischte, wurde ich von der jungen Frau und den Eltern im Sorgerechtsstreit im- 
mer wieder direkt adressiert. Für sie war es ganz selbstverständlich, dass eine Frau dazukommt, wenn in einer Situation Einfühlungsvermögen gefordert ist oder Kinder involviert sind. Es ist davon auszugehen, dass auch Polizistinnen in solchen Situationen eher adressiert werden als ihre männlichen Kollegen.

Die Relevanz von Geschlecht wird nicht nur innerhalb der Polizei hergestellt, sondern gesellschaftliche Zuschreibungen an Frauen und Männer als fürsorglich und empathisch bzw. als beschützend und rational werden auch in Interaktionen mit den nicht-polizeilichen Anderen reproduziert und tragen so auch zur Reproduktion einer geschlechtlichen Aufgabenteilung innerhalb der Polizei bei. Ein typisches, immer wieder (während meiner Beobachtung, aber auch in den Medien) herangezogenes Beispiel dafür ist, dass (muslimische) Männer mit Migrationshintergrund Polizistinnen nicht ernst nehmen würden und es daher nötig sei, dass bei solchen Interaktionen ein Polizist dabei sei. So kam es während meiner Feldforschung eher selten und allenfalls in den Frühschichten, in denen auch mit weniger Widerstandshandlungen und Gewalt gerechnet wird, vor, dass zwei Frauen zusammen Streife fuhren - von den Kollegen und Kolleginnen mit dem sexistischen, abwertenden Begriff „Hühnerstreifen“ bezeichnet. Und das, obwohl Polizistinnen durch ihre Ausbildung und Ausstattung vermutlich ebenso in der Lage wären sich ,Respekt zu verschaffen“ - im Zweifel durch ,Zwangsmaßnahmen“ (s. auch Hunold 2019: 65).

Durch eine geschlechtliche Zuweisung von Aufgaben und die Zuschreibung von typisch weiblichen Eigenschaften wird aber auch bestimmtes polizeiliches Handeln von sowohl Polizistinnen als auch Polizisten abgewertet, wie unter anderem an dem folgenden Beispiel zu sehen ist:

In einer Spätschicht wird ,mein' heutiges Streifenwagenteam, Richard und Christoph, zu einem Supermark. geschickt. Hier soll es einen versuchten Diebstabl gegeben haben.

Im Hinterz̨immer des Supermarktes sitz̧t ein aufgelöstes, weinendes, ca. 8-jähriges Mädchen, zusammen mit dem Detektiv des Ladens. Richard versucht in einem Wechsel aus empathischem und deutlichem Sprechen herauszufinden, was passiert ist, wer das Mädchen ist und wo sie wohnt. Immer wenn Richard weniger empathisch wird und deutlicher mit ihr spricht, wendet sie sich an mich. Sahar, das junge Mädchen, widersetzt sich zunächst und versucht Richard das Versprechen abzunehmen, sie nicht nach Hause zu bringen, weil sie dann jeder mit der Polizei sähe. Sie erzählt, dass eine Schulfreundin sie zu diesem Diebstahl erpresst habe. Richard geht darauf ein und nach einiger Zeit gibt sie ibren Widerstand auf, bittet aber weiter darum, sie einfach gehen zu lassen. Richard macht ihr dann ein Angebot: „Wir gehen jetzt gleich zu deinen Eltern. Du kannst gleich aber mit Miriam zusammen raus gehen, sie zieht ihre Weste aus und dann sieht man nicht, dass sie zur Polizei gehört. Wir gehen dann ein bisschen hinterher, dann siebt dich keiner mit der Polizei, okay?" (Auszug stark gekürzt)

An dieser Stelle werde ich eingebunden, eventuell nicht nur als Frau, sondern auch als ,Zivilistin'. Im weiteren Verlauf ändert sich dies: Wir fahren los und Sahar hält 
nun seit Verlassen des Hinterzimmers die ganze Zeit meine Hand fest - sie spricht mich als fürsorgliche Frau an.

Unterwegs fällt ihr ein, dass sie auf ibre kleine Schwester aufpassen sollte. Wir fahren also zu dem Spielplatz, wo sie ibre Schwester vermutet. Sahar sieht sie auf der Tischtennisplatte sitzen. Richard hält an und sagt zu mir: „Magst du sie mal holen? Vielleicht geht sie mit dir eher mit, als wenn da ein Mann kommt. "Ich: „Klar, kann ich machen."

Hier werde ich erneut einbezogen. Geht man davon aus, dass eine Uniform Zugehörigkeit zur Polizei ausdrückt, die unter anderem darauf hindeutet, dass man es mit Gesetzesvertretern zu tun hat und nicht mit ,irgendeinem ' fremden Menschen - mit dem Kinder in der Regel nicht mitgehen sollen -, so ist Richards Vorschlag ein Ausdruck davon, dass mein Frau-Sein seine Uniform, übertrumpft‘. Er schreibt mir als Frau zu, dass ich bei dem kleinen Mädchen mehr Vertrauen hervorrufe als ein männlicher uniformierter Polizist. An dieser Situation wird deutlich, wie einerseits Sahar mich als Frau adressiert und dies andererseits von Richard aufgegriffen wird und er mich in die Arbeit einbindet. Das Geschlecht erhält hier eine größere Relevanz als die Uniform. Deutlich wird aber auch eine Sensibilität für Faktoren, die Abläufe beschleunigen oder vereinfachen. Anstatt sich noch länger mit Sahar auseinanderzusetzen und womöglich mit einem weinenden Kind durch den Supermarkt laufen zu müssen, reagieren die Polizisten auf eine pragmatische Weise empathisch, indem sie mich einbinden.

In der gesamten Szene - hier gekürzt und deswegen weniger deutlich - verhält sich Richard (streng-)väterlich-zugewandt gegenüber Sahar. Und auch an anderer Stelle haben er und andere Kollegen sich bei Einsätzen sehr um Kinder bemüht und z.B. ein Buch vorgelesen, während die Eltern (von der weiblichen Kollegin) vernommen wurden. Die Zuschreibung, dass Polizistinnen solche Situationen besser lösen können, wertet gleichzeitig Kompetenzen und das situative Einfühlungsvermögen von Polizisten ab, ebenso wie andere, nicht hegemoniale Formen und Ausdrucksweisen von Männlichkeit.

Oben wurde bereits die Zugehörigkeitsmarkierung durch Uniformen angesprochen. Die Polizist*innen des ESD tragen Uniformen, die sich jenseits der Schnittführung nicht unterscheiden (es gibt z.B. keine Röcke etc.). Polizist*innen sind durch ihre Uniform entpersonalisiert, sie re-präsentieren die Organisation. Eine Uniformierung bewirkt neben einer Zugehörigkeitsmarkierung auch eine DeMarkierung von Individualität. Die Uniform zeigt „,dem Bürger verhaltenskontrollierende Polizeipräsenz" (Krasmann 1993: 145) an, egal, wer in der Uniform ,steckt'. Die Re-Präsentation der Organisation wird aber unter anderem dann infrage gestellt, wenn Geschlecht interaktiv Relevanz erhält, wie sich in der folgenden Szene zeigt:

Mittags erhalten Justus und Verena beim Herumfahren einen Einsatz. Sie sollen in die XStraße fahren, ein Platz der polizeilich bekannt ist als Treffpunkt für (alkoholisierte) Obdachlose, dort würde jemand herumbrüllen und sich auszieben. Nach einigen Aushandlun- 
gen mit dem stark alkoholisierten Mann stellt sich heraus, dass er Schmerzen in der Brust habe, er zeigt eine Narbe in der Herzgegend. Justus ruft einen Rettungswagen. Während wir auf den Rettungswagen warten, spricht Justus mit den umstehenden Personen, die in einer Gruppe einige Meter entfernt stehen. Verena und ich bleiben bei dem Mann stehen und Verena versucht persönliche Daten von ihm in Erfahrung zu bringen. Dann löst sich einer der Männer aus der Gruppe und kommt auf uns zu: Er tritt an Verena heran und sagt etwas zu ibr, er tritt noch einen Schritt an sie heran. Verena tritt einen Schritt zurück: „Bleiben sie mal da stehen. "Er bleibt stehen. Justus hat dies offenbar bemerkt und kommt dazu: „Bleib mal weg von denen, die sind nicht mehr zu haben." Der Mann lacht. Eine Frau kommt angelaufen, sie geht unsicher und ruft irgendwas. Justus: „Ah, Caro ist auch da". Justus dreht sich wieder um und redet mit ihr und den anderen Männern. Der Mann tritt jetzt wieder näher an Verena, er steht jetzt einen knappen Meter vor ihr. Verena geht ein Stück zurück. Er (zu mir gewandt): „Wer bist du denn? Bist du in der Ausbildung?" Verena: „Ne, sie ist auch eine Kollegin, die ist schon fertig. "Mann: „Aha. "Er tritt wieder näher an Verena: „Bleib mal da stehen, ich mag es nicht wenn Leute so dicht an mich heran kommen, da fühl ich mich nich wobl. "Er tritt noch ein kleines Stück vor. Ich gehe weiter zurück. Ich füble mich unwohl und empfinde das als bedroblich, er hat eine Bierflasche in der Hand. Verena, lauter als bisher, wieder: „Bleib mal da stehen jetzt."

Die Sirene des RTW [Rettungswagen] ist zu hören, ich drehe mich um und gucke in diese Richtung. Als ich mich zurückdrehe, höre ich den Mann etwas sagen, kann es aber nicht verstehen. Justus kommt dazu. Der RTW kommt und die beiden gehen in seine Richtung und winken, ich gehe binterher mit dem Blick zurück, ich füble mich unwobl und ungeschützt. Dann kommen die zwei Sanitäter. [...] Die Sanitäter helfen dem Mann beim Aufstehen und gehen mit ihm zum RTW. Wir bleiben noch kurz dastehen. Die anderen stehen ein paar Meter weg, nur der aufdringliche Mann steht näher bei uns. Justus steht zwischen ibm und uns. Verena leise: „Der ist auch nicht obne, der hat zu mir eben gesagt, ich bätte ihm gar nichts zu sagen und ich könne ibm auch nix. "Justus: „Ja, beim dem muss man aufpassen, der kann auch ganz, anders. Der schlägt auch mal aus dem Nichts beraus zu."

Hier zeigt sich, wie der männliche Polizist Justus die Situation, in der seine Kollegin versucht einen Mann auf Abstand zu halten, sexualisiert, indem er uns als Frauen, die „nicht mehr zu haben“ seien, präsentiert. Sein Versuch, die Situation vermeintlich humorvoll aufzulösen, schafft aber erst den Rahmen, in dem wir, aber vor allem seine Kollegin Verena, von dem aufdringlichen Mann als Frauen wahrgenommen werden. Verena ist nun nicht mehr Re-Präsentantin der Ordnungsmacht Polizei, sondern Frau. Auch wenn der Mann Polizist*innen prinzipiell nicht in ihrer Rolle zu respektieren bereit ist, worauf ein späterer Kommentar Justus' hindeutet, so eröffnet Justus' Rahmung nun die Möglichkeit (und billigt sie gewissermaßen), Verena nicht mehr als Polizistin zu sehen, sondern als Frau. Der Mann bedient diese Rahmung nun und verhält sich grenzüberschreitend, indem er immer weiter an Verena herantritt und ihre Aufforderung zurückzubleiben nicht akzeptiert. Dass der Mann dann in einem Moment, in dem Verena alleine ist, ihr 
zuraunt, dass sie ihm nichts zu sagen habe, plausibilisiert die Hypothese, dass er Verena als Polizistin und Frau nicht ernst nimmt. Er zeigt insofern Respekt vor Justus, dem Mann, als er sich mit seiner Bekundung nur an Verena und nicht auch an Justus wendet. Justus bietet sich durch seinen Spruch als Koalitionspartner des Aggressors an - auch wenn Justus dies nicht intendiert hat. Verena wird durch die vergeschlechtlichte Rahmung ihrer Uniform entkleidet und die Funktion der Uniform wird unterminiert. Mehr noch: Verena erfährt hier eine Degradierung als Frau und als Polizistin. Das Geschlecht erhält mehr Relevanz als die professionelle Rolle. Zu fragen ist, ob Polizistinnen ihre Rolle professioneller ausfüllen müssen, um dies auszugleichen; ob oder inwiefern es für sie überhaupt möglich ist, aus ihrer professionellen Rolle herauszutreten und mal einen ,lockeren Spruch ${ }^{6}$ zu machen, wie Justus es hier tut. Oder: ob Polizistinnen als Frauen ,lockere Sprüche“ ebenso wie ihre männlichen Kollegen als Form ihrer professionellen Rolle nutzen können.

Während Frauen also einerseits das Gleiche leisten (müssen), werden sie andererseits auf ihre zugeschriebene Rolle als Frau zurückgeworfen: „One mechanism of hegemonic masculinity in policing organizations is to maintain female police in roles that male officers have historically not defined as ,real police work' (i.e. crime fighting)“ (Rabe-Hemp 2009: 120). Dadurch müssen Polizistinnen viel mehr leisten als ihre männlichen Kollegen. Während Frauen beweisen müssen, dass sie alles können, müssen Männer dies nicht; diese müssen z.B. nicht beweisen, dass sie auch gut im Umgang mit Kindern sind, um in ihrer Rolle als Polizist anerkannt und respektiert zu werden.

In der Alltagspraxis erfährt dieses ,Arrangement' der Aufgabenverteilung Bestätigung durch Erleichterung. Es ist einfacher für die Polizisten, eine Kollegin für bestimmte Tätigkeiten, vorzuschicken', wenn angenommen und womöglich auch von den Interaktionspartner*innen gespiegelt wird, sie könne es aufgrund ihres Frauseins besser. Umgekehrt ist es einfacher für eine Polizistin, den Kollegen mit dem Mann, der sie nicht ernst nimmt, sprechen zu lassen, anstatt im Zweifel ihre Position durch Zwangsmaßnahmen durchsetzen zu müssen. Die alltägliche Arbeit wird so erleichtert, es bleiben Routinesituationen statt Ausnahmensituationen zu werden bzw. die Routinesituationen bleiben gleich, statt dass sie - mit Umweg über Ausnahmesituationen - zu neuen Routinesituationen werden. Die Aufgabenverteilung bestätigt sich und wird dadurch reproduziert. 


\section{Polizist*in werden und Polizist*in sein}

Im vorangehenden Kapitel habe ich Handlungs- und Deutungsmuster der Polizist*innen im Interaktionskontext polizeilicher Arbeit dargestellt. In diesem Kapitel werde ich nun die zweite Untersuchungsebene, die Biographie bzw. biographisch aufgeschichtete Handlungs- und Deutungsmuster betrachten. Mit dieser biographietheoretische Perspektive blicke ich hier nun auf den biographischen Verlauf der Polizist*innen in seiner Wechselwirkung mit gesellschaftlichen Prozessen. Neben der Verflechtung von kollektiver und individueller Geschichte geht es auch um die Frage der organisationalen Interdependenzen.

An den dargestellten zwei Fällen von Polizist*innen werde ich zeigen, wie sich Handlungsmuster familien- und lebensgeschichtlich herausbilden. Beantwortet werden kann dabei, welche Handlungsmuster meine Interviewpartner*innen entwickelt haben, in welchem biographischen Zusammenhang ihre Berufswahl steht, wie sich die Sozialisation in die Polizei vollzieht und wie sich im Kontext ihrer Erfahrungen ihre Laufbahn in der Polizei entwickelt.

Beide Fälle repräsentieren einen Typus, bei dem die Berufswahl Polizist*in eine Form der Bearbeitung ihrer biographischen Erfahrungen ist. Die Polizei hält für beide - in je unterschiedlicher Weise - einen organisationalen Möglichkeitsraum bereit, in dem sie sich in biographisch bedeutsame Situationskonstellationen, die bearbeitungsbedürftig sind, begeben können. Dies wirkt sich auf ihr Erleben von Polizei und ihre Laufbahnentwicklung aus. Aufgrund unterschiedlicher le- 
bensgeschichtlicher Verläufe kommt es folglich zu ebenso divergenten Verläufen in der Polizei.

Zunächst werde ich den Fall von Polizeihauptkommissarin Melanie Wegener vorstellen (5.1). Als zweites präsentiere ich den Fall von Polizeikommissar Markus Holtzmann (5.2).

\subsection{Polizistin-Werden und Polizistin-Sein als Bearbeitung biographischer Unsicherheit: Der Fall von Melanie Wegener}

Im Folgenden stelle ich detailliert die Rekonstruktion des biographischen Verlaufs von Melanie Wegener - wie ich meine Interviewpartnerin nennen möchte - vor. Melanie Wegener ist, als ich sie im Sommer 2016 kennenlerne, 36 Jahre alt, Polizeihauptkommissarin und Einsatzführerin/stellvertretende Dienstabteilungsleiterin im Einsatz- und Streifendienst im Bereich der Polizeiinspektion Salzgitter/Peine/Wolfenbüttel.

Den Kontakt mit ihr habe ich über Facebook hergestellt. Sie meldete sich auf meine Suchanfrage nach Interviewpartner*innen, die ihr ein Kollege, den ich aus meiner Feldforschung kannte, weitergeleitet hatte. Nachdem wir ein paar Nachrichten über mein Forschungsvorhaben und meine bisherigen Feldforschungsaktivitäten - diese sind wichtig, da sie zeigen, dass ,die ${ }^{6}$ Polizei mich unterstützt hat - ausgetauscht hatten, machte sie einen Vorschlag für einen Interviewtermin einige Wochen später, wenn sie in der Nähe von Göttingen ihre Mutter besuchen würde. Kurz vor dem verabredeten Termin meldete sie sich bei mir und wir verabredeten, dass wir uns bei ihr treffen würden und dann gemeinsam in ein Café in der Nähe gehen würden. Diesen Verlauf deute ich als einen Hinweis darauf, dass sie, einerseits, eine engagierte Polizistin ist und einen Beitrag zu meiner Forschungsarbeit leisten möchte. Andererseits zeigt die Fallrekonstruktion, dass dies Ausdruck ihrer spezifischen biographischen und organisationalen Position ist. Sie ist sehr aktiv innerhalb der Organisation und sucht zugleich Kontakte außerhalb der Polizei.

Der Fall von Melanie Wegener repräsentiert einen Typus, bei dem die Berufswahl eine Form der Bearbeitung von biographischer Unsicherheit darstellt. Familiale Loyalitätskonflikte bearbeitet sie durch ihre Berufswahl und findet in der Polizei zunächst Sicherheit und strukturierte Geborgenheit. Aus dieser gestärkten Position heraus sucht sie sich Tätigkeiten, in denen Rollen- und Loyalitätskonflikte strukturell angelegt sind. Hier kann sie ihre lebensgeschichtlich etablierten Handlungsmuster zum Umgang mit solchen Situationen nutzen und bearbeiten. 


\subsubsection{Die Präsentation ihrer Lebensgeschichte}

Melanie Wegeners Selbstpräsentation ist in drei thematische Teile gegliedert. Im ersten Teil widmet sie sich ihrer Kindheit bis zum Eintritt in die Polizei. Im zweiten Teil ihrer biographischen Präsentation ist ihre Laufbahn in der Polizei Thema, vollkommen frei von Bezügen zu anderen Lebensbereichen. Angekommen bei ihrer beruflichen Situation zum Zeitpunkt des Interviews wechselt sie das Thema und es folgt ein weiterer Teil zu ihrem ,Privatleben' und ihrer Familie. Wie ich auch in anderen biographischen Selbstpräsentationen beobachten konnte, ist dies eine typische Präsentation von Polizist*innen, die sich an Stationen der Laufbahn orientiert und so Struktur erhält. Dennoch ist dieses Auseinanderhalten von Familie und Arbeit bei Melanie Wegener insofern verwunderlich, da sowohl ihr Vater als auch ihr ehemaliger Lebensgefährte Polizisten sind und sie also eine Trennung zwischen einer ,privaten' und ,beruflich-polizeilichen' Sphäre erst herstellt. Wie im Folgenden gezeigt wird, ist diese Trennung nicht allein Ausdruck eines polizeitypischen Sprechens über die Polizei, sondern auch ihrer biographischen Erfahrungen. In diesem dritten und letzten Teil der Eingangspräsentation erfahre ich, dass ihr Vater sich von ihrer Mutter getrennt hat, als Melanie Wegener 17 Jahre alt war. Sie wertet die Bedeutung dieser Erfahrung zunächst ab, indem sie evaluiert, dass es für sie „nicht so schlimm“ gewesen sei. Der Vater sei durch seine Aufstiegsausbildung und Tätigkeit in der Bereitschaftspolizei in ihrer frühen Kindheit selten zu Hause gewesen „und das diese Prägung da irgendwie nie entstanden ist“. Bis zum Ende der eigenständigen Präsentation spricht sie beschreibend und argumentativ. Melanie Wegener lässt sich kaum auf Erinnerungsprozesse ein, sondern beschreibt Abläufe und versucht recht präzise Daten zu nennen. Je länger das Interview jedoch andauert und nachdem ich einige narrative Nachfragen gestellt habe, weicht sie zunehmend von ihrer kontrollierten Darstellung ab und lässt sich auf die Erzählung von Erinnerungen ein. Dabei zeigt sich, dass die Erinnerung an die Scheidung der Eltern für Melanie Wegener durchaus schwierig ist. Ein Problem für die Interviewpartnerin ist, dass sie ihren Vater aus ihrer heutigen Perspektive argumentativ abwertet und auch abwerten muss, aber entgegen ihrer Darstellung keine Beziehung zu ihm zu haben, Erinnerungen an schöne Erlebnisse mit dem Vater vorstellig werden.

Durchgängig sind die berufliche und die private Sphäre im Interview getrennt präsentiert worden. Wenn diese Trennung aufgehoben wurde, war es zumeist funktional; es bedurfte des Einbezugs ihres ,Privatlebens' für die Erklärung ihres Handelns auf beruflicher Ebene. Sprachlich zeichnet sich die Präsentation bei der Thematisierung der Laufbahn durch die Verwendung des Passivs aus. Erst mit zunehmenden Freiheiten in der Gestaltung ihrer Laufbahn ist sie auch in der Präsentation öfter eine aktiv Handelnde. Die Einheitslaufbahn bietet (zunächst) auch fast nur einen Weg in und durch die Polizei an. Dies ist strukturierend nicht nur für die Interviewpräsentation, sondern deutet auch eine berufsbedingte Fremdbestimmung des Privatlebens an. Obwohl Melanie Wegener ihre Laufbahn sehr aktiv 
gestaltet, vermittelt sie nicht den Eindruck Karrieristin zu sein. Die Orientierung der Präsentation entlang der Laufbahn und der verschiedenen Arbeitsbereiche vermittelt Erfolg und Kompetenz, gleichzeitig Bescheidenheit. Die Polizei bzw. das Polizistin-Werden und Polizistin-Sein bietet nicht nur auf der Ebene der Präsentation Orientierung, sondern auch Sicherheit in ihrer Biographie.

\subsubsection{Die Fallgeschichte}

Melanie Wegener wird im Juni 1979 im heutigen Landkreis Northeim in Südniedersachsen als erstes Kind ihrer Eltern geboren. Melanies Eltern haben ein Jahr vor ihrer Geburt geheiratet und leben im Haus der Eltern von Melanies Vater in einer Dachgeschosswohnung. Beide sind Mitte der 1950er Jahre geboren und bei der Geburt ihrer ersten Tochter Anfang/Mitte Zwanzig.

Melanies Vater Joachim ${ }^{108}$ wird 1951 als erstes Kind seiner Eltern in einem großen Dorf in Südniedersachsen geboren. Von einer kleinen, landwirtschaftlichen Dorfstelle hat es sich in den Nachkriegsjahren zu einer großen Wohnsiedlung mit nur noch wenigen bäuerlichen Strukturen entwickelt.

Melanies Opa Friedrich, der Vater von Joachim, ist Jahrgang 1928 und bei der Geburt seines ersten Sohnes 23 Jahre alt. Er ist zu dieser Zeit als Postbote bei der Deutschen Post beschäftigt. Nach Melanies Erzählung war der Großvater Mitglied der Hitlerjugend und gegen Kriegsende in sowjetische Kriegsgefangenschaft geraten. Die Geschichte über die Verwicklungen des Opas bzw. Vaters in den Nationalsozialismus werden in der Familie nicht thematisiert. Wie genau der Großvater in das Kriegsgeschehen involviert war, ist Melanie nicht bekannt und sie erzählt von einem Redeverbot und vermutet, dass der Großvater „,wahrscheinlich ganz schlimme Erfahrungen gemacht" habe und es deswegen „totgeschwiegen“" werde. Die Perspektive, dass der Großvater nicht nur Schlimmes erfahren, sondern auch Schlimmes getan haben könnte, wird im Interview aber latent angedeutet. Es kann vermutet werden, dass eine solche Perspektive auf die Familiengeschichte mit dem Redeverbot unterdrückt werden soll. So wird z.B. von ihren Eltern auch unterbunden, beim Opa nachzufragen, was er erlebt hat, als der Nationalsozialismus Thema im Schulunterricht ist.

Melanie Wegeners Großmutter väterlicherseits, Helene, ist Hausfrau. Melanie geht davon aus, dass sie keinen Beruf erlernt hat, da sie nicht berufstätig war; sie weiß es aber nicht. Dies ist ein Hinweis darauf, dass auch über ihre Jugend nicht gesprochen wurde. Helene wurde ca. 1930, vermutlich in der gleichen Region, geboren. Auch sie war Mitglied in der NS-Jugendorganisation, dem Bund Deutscher Mädel, dem HJ-Äquivalent für Mädchen, dem die politische und geschlechtsspezifische Sozialisation im Sinne der NS-Ideologie oblag. Über einen Einbezug in den erweiterten Kriegsdienst ist nichts bekannt. Wie ihre Großeltern

108 Die Namen der Eltern und Großeltern verwende ich für eine leichtere Lesbarkeit, Melanie Wegener nennt die Namen nicht. 
sich kennengelernt haben, ist Melanie Wegener unbekannt. Sie heiraten ca. 1949, sehr bald nach Friedrichs Rückkehr nach Deutschland. Vermutlich hat auch damals gegenüber seiner Frau und später seinen zwei Kindern ein Redeverbot geherrscht. Die Kriegsverwicklungen und die Erlebnisse in Kriegsgefangenschaft stellen mindestens gegenüber der Enkelgeneration ein Familiengeheimnis dar.

Durch die Tätigkeit des Vaters im öffentlichen Dienst wachsen Joachim und seine nur gut ein Jahr jüngere Schwester in einem finanziell abgesicherten Haushalt auf, wenn auch auf einem sicherlich niedrigen Niveau. Sie haben zudem eine sehr kleine Nebenerwerbslandwirtschaft für die eigene Versorgung, die sie auch in Melanies Kindheit noch betreiben. Joachim wächst in einem eher bildungsfernen Milieu auf - beide Elternteile haben vermutlich keine Ausbildung und waren in den Kriegsjahren schulpflichtig, als der Schulbetrieb nicht immer durchgängig aufrechterhalten werden konnte. Es ist davon auszugehen, dass sie beide maximal acht Jahre die Volksschule besuchten. Joachims spätere Ausbildung bei der Polizei ist somit auch ein Bildungsaufstieg und knüpft gleichzeitig an die Beschäftigung des Vaters im öffentlichen Dienst an, sowie an eine möglicherweise recht autoritäre Erziehung der beiden in NS-Jugendorganisationen sozialisierten Eltern. 1968, mit 17 beginnt Joachim bei der niedersächsischen Polizei eine Ausbildung im mittleren Dienst. In der Bundesrepublik der Nachkriegszeit wurde nach einer einjährigen Ausbildung an einer Polizeischule die Ausbildung innerhalb der Bereitschaftspolizei kaserniert fortgeführt. Das heißt, Joachim zieht mit 17 Jahren aus und wohnt für die nächsten drei Jahre in einer ehemaligen Kaserne in Hannoversch Münden. Die Ausbildung der Schutzpolizisten und der Führungsstil in der Polizei blieben bis Ende der 1960er Jahre militärischen Vorbildern verpflichtet (vgl. Dams 2008: 10 ff. und Kap. 2.2.5). Auch wenn ab Ende der 1960er Jahre Reformen die Polizei veränderten, vollzog sich dies langsam. Ausbilder, die in einer ,militärischen' Polizei der jungen Bundesrepublik oder sogar noch in der Polizei des nationalsozialistischen Staates sozialisiert worden waren, haben wahrscheinlich Drill und Gehorsam als zentrale Elemente der Ausbildung weitergegeben. Joachims Ausbildungs- und ersten Dienstjahre sind geprägt von politischen Krisen, Umbrüchen und Veränderungen. Für die Polizei und den jungen Polizisten Joachim Wegener sind sicherlich die Geschehnisse um die Geiselnahme israelischer Sportler bei den Olympischen Spielen in München 1972 und der Terror der Rote Armee Fraktion in den 1970er Jahren prägende Bezugspunkte, die den Polizeiberuf und den Diskurs unter den Polizisten bestimmen und die ,militärischen Prinzipien eher aufrechterhalten, als dass sie zu einer Veränderung innerhalb der Polizei führen.

Für die väterliche, männliche Familienseite sind Disziplin und eine Identifikation mit dem Staat relevant - wenn auch für Vater und Sohn in unterschiedlichen staatlichen Systemen.

Melanies Mutter Anne ist ca. 22 Jahre alt, als sie heiratet. Sie arbeitet als Erzieherin in einem Kindergarten im gleichen Landkreis. Polizist und Erzieherin - eine sehr geschlechterstereotype Berufsverteilung, die sich auf die familiäre Dynamik 
auswirken wird. Kurz nach der Hochzeit, vor Melanies Geburt, stirbt Annes Mutter Hannelore nach längerer Krankheit an den Folgen einer Darmerkrankung. Anne hat ab diesem Zeitpunkt keine Herkunftsfamilie mehr, denn ihr Vater hatte seine Frau verlassen, als Anne vier Jahre alt war. Anne blieb ein Einzelkind. Seither besteht kein Kontakt zu ihm und die Versuche von Anne mit ihm Kontakt aufzunehmen scheitern, da sie ihn nicht ausfindig machen kann. Möglicherweise gibt es auch hier ein Familiengeheimnis, da Melanie Wegener dies alles unter der Prämisse erzählt, dass das „laut der Erzählung meiner Mutter“ so sei.

Anne wird also in den 1950er Jahren von ihrer Mutter allein großgezogen und versorgt. Hannelore kann sicherlich als Vorbild einer eigenständigen Frau dienen, die es auch alleine schafft. So könnte man annehmen, dass Anne von Hannelore eben diese Eigenständigkeit vermittelt bekommen hat. Anne heiratet aber sehr früh und schafft sich so eine, intakte ${ }^{6}$ Familie und mit der Heirat eines Beamten auch finanzielle Absicherung. Daher kann auch vermutet werden, dass sie das ,alleine Schaffen' als Belastung erlebte. Die Wahl eines Polizeibeamten als Ehemann kann neben der finanziellen Absicherung auch als eine Wahl von Beständigkeit und Sicherheit verstanden werden. Anne kann nun also den Wunsch nach einer Familie verwirklichen. Ihre Mutter stirbt, nachdem Anne Wegener, versorgt ${ }^{6}$ ist.

In dieser Familie bedeutet der Staatsdienst eine sichere Versorgung. Der Großvater, der Vater und auch die Mutter von Melanie Wegener erfahren dadurch direkt oder indirekt finanzielle Absicherung. Sowohl eine Beschäftigung bei der Post als auch bei der Polizei garantierten weitestgehend finanzielle Sicherheit. Außerdem waren Post und Polizei als Staatsbetriebe bürokratische Organisationen mit Möglichkeiten für einen Laufbahnaufstieg und mit einer Amts- und Beamtenmentalität (vgl. Weber 1921/2008: 157 ff.), die klare Strukturen vorgibt. Während dem Großvater eine Karriere nur begrenzt gelingt, sind Joachim und Melanie Wegener dabei umso erfolgreicher. Der Staatsdienst ermöglicht in dieser Familie sozialen Aufstieg.

\section{Die ,normale' Familienkonstellation der Kindheit}

Ein Jahr nach dem Tod von Annes Mutter wird Melanie Wegener geboren. Sie ist vermutlich ein Wunschkind, das vor allem von ihrer Mutter, nach deren Verlust der eigenen Mutter, viel Zuwendung erfährt. Anne gibt ihren Beruf auf und ist für den Haushalt zuständig. Joachim und Anne haben noch vor der Geburt von Melanie im Herkunftsort von Joachim ein Grundstück erworben und ziehen mit der ca. einjährigen Melanie dort zunächst in eine Mietwohnung in der Nähe des neuen Grundstückes. Zur selben Zeit beginnt der Vater eine Aufstiegsaus- bzw. Aufstiegsfortbildung, um aus dem mittleren in den gehobenen Dienst befördert zu werden. Diese findet im ca. 70 Kilometer entfernten Hannoversch Münden statt und bedeutet für die junge Ehe und Familie, dass sie teilweise eine Wochenendbeziehung bzw. eine Wochenendfamilie leben. In Melanies ersten beiden Lebensjah- 
ren ist der Vater oft abwesend. Melanie Wegener sieht hierin ihr heute schlechtes Verhältnis zu ihrem Vater begründet:

,ja, ich glaub das, ich kein gutes Verhältnis oder enges Verbältnis zu meinem Vater hab, liegt daran, dass ich in den zwei also als ich so zwei drei Jahre war, mein-war mein Vater kaum zubause, der war viel in Hann Münden, / / hmb// für seine Fort-polizeiliche Weiterbildungen"

Entgegen dieser Darstellung weiß sie von ihrer Mutter, dass ihr Vater viel mit ihr gespielt habe, wenn er da war, sich aber nicht mit so „Mädchen-Sachen“ beschäftigt, sondern mit ihr mit Bauklötzen gespielt habe. Trotz des heute schlechten Verhältnisses zu ihrem Vater stellen sich im Interview schöne Erinnerungen an ihn und die gemeinsam verbrachte Zeit in ihrer Kindheit ein.

Während der Vater an seinem Aufstieg in der Polizei arbeitet, der auch eine höhere Besoldung verspricht, beginnt die Familie nun ein Haus auf das erworbene Grundstück zu bauen und Anne wird erneut schwanger. 1981 kommt Melanies kleiner Bruder Christoph zur Welt. In dieser Phase haben die Eheleute sicherlich wenig Zeit füreinander und sind vollauf mit der Organisation des Alltags und dem Hausbau beschäftigt. Nach dem Umzug wird es ruhiger. Sie sind im eigenen Haus angekommen, der Vater hat seine Ausbildung beendet und tritt eine Stelle als Leiter einer nahe gelegenen Polizeistation an. Anne geht nun in einem doppelten Sinne vollkommen in der Familie auf: Zum einen hat sie nun zwei kleine Kinder, für die sie verantwortlich ist. Zum anderen ist sie auch lokal an ihre Schwiegerfamilie gebunden; sie ist aus ihrer Heimat weggezogen und lebt nun mit einem Eigenheim dauerhaft in fußläufiger Entfernung zu ihren Schwiegereltern. Insgesamt ist das Familienleben sicherlich stark bestimmt von den An- und Abwesenheitszeiten des Vaters. Auch wenn er in der Regel im Tagesdienst arbeitet, ist seine Dienstzeit maßgeblich tagesstrukturierend - im Gegensatz zur Mutter, die nicht berufstätig ist.

Drei Jahre später, 1984, wird Melanie Wegeners jüngere Schwester Katharina geboren. Sie sind nun drei Kinder und es könnte angenommen werden, dass es vermehrt zu Eifersucht unter den Geschwistern kommt, die jeweils nur zwei bis drei Jahre Altersunterschied haben. Melanie kommt aber bald darauf in den Kindergarten und hat damit auch eine Bezugsgruppe außerhalb des Elternhauses. Sie durchläuft dann ziemlich geradlinig die Bildungsinstitutionen. Nach dem Grundschulbesuch in ihrem Wohnort wechselt sie für die Orientierungsstufe die Schule. Nach der zweijährigen Orientierungsstufe erhält sie eine Empfehlung für das Gymnasium. Spricht sie über diese Zeit im Interview zunächst nicht - „da gibt es jetzt nichts Nennenswertes zu erzählen aus dieser Zeit“ - ändert sich dies im Nachfrageteil. Hier beginnt sie auch zu erzählen, spricht ausführlich und lebendig über ihre Freundinnen aus der Schulzeit und erinnert sich offenbar sehr gerne an die Zeit ihrer Kindheit und Schulzeit zurück. Mit ihren Freundinnen hat sie viel gespielt und auch außerhalb der Schule viel Zeit verbracht. Sie war fest eingebunden in ein soziales Netz mit Gleichaltrigen. Auch schon in der Grundschulzeit 
machte Melanie Wegener viel Sport, teilweise auch zusammen mit einer ihrer Schulfreundinnen. In erster Linie ist es aber ihr Vater, mit dem sie ihre sportlichen Interessen teilt bzw. er ist es, der seine Tochter für ,seinen' Sport begeistert: Melanie beginnt im Alter von fünf Jahren Fußball zu spielen. Ihr Vater wird ihr Trainer, als sie einige Jahre später in die Jugendmannschaft wechselt, und er ist auch im Verein ehrenamtlich aktiv. Man kann annehmen, dass der Vater sehr bestimmend für ihren Alltag wird. Nicht nur das Familienleben zu Hause ist von den An- und Abwesenheitszeiten des Vaters strukturiert, nun ist er auch bestimmender Teil ihrer Freizeit. Spricht sie einerseits davon, dass sie und ihr Bruder „Fußball spielen mussten“, begleitet sie der Sport andererseits bis in ihr Erwachsenenalter und wird später für sie eine wichtige Freizeitbeschäftigung werden/bleiben. Dennoch zeigt es, dass die Wahl der Sportart von den Wünschen des Vaters bestimmt wurde. Sie entwickelt hier aber auch Kompetenzen, die für ihren beruflichen Weg relevant werden. Fußball ist ein körperlicher und kompetitiver Sport, der als Mannschaftssportart jedoch auch Teamfähigkeit erfordert. Sie spielt zunächst in einem gemischten Team und später in einer reinen Frauenmannschaft. In einem in dieser Zeit typischen ,Jungensport“ mit wenigen weiblichen Vorbildern bzw. wenig medialer Präsenz von Frauenfußball lernt sie, sich als Mädchen in einem von Jungen dominierten Feld zu bewegen.

Als Melanie Wegener elf Jahre alt ist und die Schule wechselt, beginnt ihre Mutter wieder als Erzieherin zu arbeiten. Bis dahin erlebt sie eine klassische Rollenverteilung ihrer Eltern. Die Mutter ist Hausfrau und der Vater Alleinverdiener. Diese Familienkonstellation erlebt Melanie als normale Familie. Sie ist so normal, dass Melanie im Interview offensichtlich keinen Bedarf für eine weitere Beschreibung der Konstellation sieht, sie ist als Normalität vorausgesetzt. Zu dieser Normalität gehört sowohl, dass der Vater die Kontrolle über das Einkommen hat und viele der Entscheidungen zu Hause trifft, als auch, dass die Mutter dies teilweise ,unterwandert ${ }^{\star}$, indem sie ihm Dinge verheimlicht und mit den Kindern ,paktiert über die Vorkommnisse zu Hause: Die Mutter ist die vertrautere Bezugsperson, der sie z.B. auch schlechte Noten beichtet und die sich schützend vor ihre Tochter stellt. Diese Rollenverteilung zu Hause korrespondiert mit der beruflichen. Auch wenn die Mutter jetzt ebenfalls wieder berufstätig ist, arbeiten die Eltern beide in geschlechterstereotypen Berufen. Die Mutter ist sowohl in ihrem Beruf diejenige, die andere versorgt, als auch zu Hause. Der Vater ist der strengere Polizist. In der Kindheit ist die Beziehung zu dem Vater aber auch ambivalent - dies wird sich in den folgenden Jahren deutlich verstärken. Der Vater ist sowohl der strenge Polizist als auch ein sich liebevoll kümmernder Vater, wenn er denn zu Hause ist. Er ist sowohl der in Bezug auf Schule und Sport fordernde Vater als auch der, mit dem sie schöne Freizeit- und Sporterfahrungen teilt. Im Interview werden kaum Erinnerungen, die sich explizit auf schöne Erlebnisse mit ihrer Mutter beziehen, vorstellig, wohl aber einige, die sie mit ihrem Vater verbindet. Die Mutter erlebt sie als die sich kümmernde, die immer da ist. Der Vater ist der strenge und eher 
abwesende, der aber, wenn er da ist, schöne Sachen mit ihr macht, die durch ihre vergleichsweise Seltenheit noch einmal extra Gewicht erhalten.

Nach der Orientierungsstufe wechselt Melanie Wegener auf das Gymnasium. Ihre schulischen Leistungen machen das ohne Probleme möglich. Für den Vater ist es wichtig, dass seine Tochter auf das Gymnasium kommt, und Melanie bringt dies mit seiner beruflichen Position in Zusammenhang:

„mein Vater: hat quasi: eh: mich, na wie sag ich denn das, genötigt hört sich ein bisschen streng an, //hmb// aber ich musste aufs Gymnasium gehen, // hmb// also mein Va-:; da kam gar nichts anderes infrage für meinen Vater, // hmb// hatte den Hintergrund, dass seine: er war der Chef, dass seine Arbeitskollegin, die Kinder warn alle aufem Gymnasium, aber das geht ja nicht an, dass die Tochter vom Chef das nicht macht"

In dem Zitat wird deutlich, dass es wichtig ist, ein bestimmtes Bild zu wahren, aber auch, dass Erfolg relevant ist. Beide Eltern haben kein Abitur gemacht, der Vater forciert nun aber einen Bildungsaufstieg für seine Kinder. Es scheint, als ob es dabei nicht um einen Aufstieg der Möglichkeiten wegen ging - im Sinne von: meine Kinder sollen machen können, was sie wollen, oder es besser haben als ich -, sondern um einen Aufstieg, der mit dem Status des Vaters zusammenhängt. Der Vater treibt ein soziales Etablierungs- oder Aufstiegsprojekt für seine Familie voran.

Der Schulwechsel fällt Melanie leicht. Auch auf dem Gymnasium schließt sie neue Freundschaften mit zwei Klassenkameradinnen, mit denen sie ein Interesse an Sport teilt. Zusammen machen sie auch die ersten „Verliebtheiten“ und Enttäuschungen durch. Mit ihnen hat sie stützende, freundschaftliche Beziehungen, die in den folgenden Jahren noch relevant werden.

\section{Loyalitätskonflikte und biographische Unsicherheit: Die Trennung der Eltern}

Als Melanie Wegener 17 Jahre alt ist, trennt sich der Vater von der Mutter. Die Eltern haben sich in Melanies Erinnerung immer mal wieder gestritten, das hat sie aber nicht als bedrohlich erlebt und sie stellt auch keinen Zusammenhang zu der Trennung her. Stattdessen leitet sie im Interview das Thema der Trennung damit ein, über eine Arbeitskollegin der Mutter zu sprechen:

„ich weiß das diese neue Kollegin dann da, plötzlich, die mochte ich nich rich- [...] aber ich mochte sie nicht sie hatt irgendwie ich kann dir nich sagen warum woran das lag aber ich hatt so ein komisches Gefühl bei der, vielleicht war das irgendne Vorahnung ich weiß es nicht, mochte sie auf jeden Fall nicht, // mh/ / sie hatte auch ein entsprechenden Ruf im Ort die war, sie hat schon zwei Kinder, und eins davon lebt noch nicht mal bei ibr, weil es auch noch einen anderen Vater hat (1) ähm, und hatte so den Ruf sich an Männer ran schmeißen zu wollen und hat se wohl auch schon bei anderen gemacht (1) ähm (2) war mir relativ egal ne, wollte-fands aber nich so gut das se mit meiner Mutter so dicke war, meine Mutter, ja meine Mutter hat ihr halt vollstes Vertrauen (1) hat dann auch wabrscheinlich auch über Eheprobleme gesprochen das weiß ich nicht, jo dann ham wir erfahren das äh 
mein Vater hat verkündet, der Familie das er ne neue Freundin hat und die Familie verlässt, das weiß ich noch, da saßen wir da, da saßen wir da meine Mutter war nicht dabei die war nebenan, er hat es uns Kindern quasi gesagt und ich weiß das meine Mutter, das weiß ich heut noch // mhmh// (3) und ich bin dann zu ibr gegangen zu meiner Mutter sie hat so geweint und nur da gesessen, und Weißwein getrunken (3) und ich war völlig bilflos weil ich überhaupt nich wusste ich musste das selber verarbeiten und ich wusste nich / / ja:/ / (2) und habe gesehen das es meiner Mutter schlecht geht wusste aber nicht wie ich ihr helfen konnte, das war ganz-"

Der Vater hat dann nach einigen Tagen, in denen die Familie unter komplizierten Verhältnissen noch zusammenwohnte, das Haus verlassen und ist zu seiner neuen Freundin, Annes Kollegin, in den Nachbarort gezogen. Es scheint, als sei die Trennung nicht nur für die Kinder überraschend gekommen, sondern auch für Anne, die sich in dieser Situation ,gehen' lässt. Sie schafft es nicht, für ihre Kinder stark zu sein bzw. einen gefassten Eindruck zu vermitteln und die Kinder zu beruhigen. Melanie ist überfordert, sie ist überrascht und versteht nicht sofort, was gerade passiert ist, sie fühlt sich ohnmächtig. Diese Überforderung und Ohnmacht werden auch heute noch deutlich. Im Vergleich zu ihrer sonstigen Sprechweise hat dieser Abschnitt mehr Abbrüche und Sprechpausen.

Ohne dass sie der Kollegin der Mutter hier explizit die Schuld zuweist, wird doch deutlich, dass sie in ihr die Verantwortliche sieht. Ihre Beschreibung als Frau, die hemmungslos Männer verführt, entlastet den Vater von der (Allein-) Schuld der Trennung. Außerdem deutet Melanie Wegener eine Verantwortung der Mutter an, die sich die falsche Freundin gesucht habe. Melanie hat die Phantasie, dass Anne zu viel über ihre Ehe preisgegeben und damit den Betrug erst möglich gemacht haben könnte. Es deutet sich ein Loyalitätskonflikt an: Ihre Loyalität gilt zunächst der Mutter, allerdings macht sie sie latent mitverantwortlich für die Trennung. Den Vater sieht sie als Schuldigen, entlastet ihn aber auch.

„dann hat sich mein Vater von uns Kindern also (meine Mutter) neue Frau und die Kinder warn nicht mehr wichtig"

Melanie Wegener erlebt den Weggang des Vaters nicht nur als eine Trennung des Vaters von der Mutter, sondern auch oder vielleicht in erster Linie als eine Trennung von ihr und ihren Geschwistern. Dass der Vater so schnell zu seiner neuen Freundin, die im Nachbarort wohnt, zieht, macht die Trennung sehr abrupt und augenscheinlich auch endgültig. Mit den zwei Kindern der Neuen hat er nun auch eine neue Familie. Es ist nicht unwahrscheinlich, dass sich bei Melanie das Gefühl, ersetzt worden zu sein, eingestellt hat. Gleichzeitig, wie oben schon angedeutet, dient die neue Freundin als eine gut passende Figur, der die Schuld zugewiesen werden kann. Mit der Betonung, dass sie schon zwei Kinder habe, für die sie nicht beide die Verantwortung trägt/tragen kann, und dem Hinweis auf ihren Ruf, sich an Männer ,ranzuschmeißen', wird sie als unmoralisch, sprunghaft und verantwortungslos markiert. Möglicherweise bestand auch die leise Hoffnung, dass es dem 
Vater ebenso ergehen werde wie seinen Vorgängern, mit denen sie nicht mehr zusammenlebt. Auch das trägt wiederum dazu bei, dass der Vater entschuldigt wird, denn dann ist er einfach auf diese Frau ,reingefallen' und es bestünde die Möglichkeit, dass er zurückkommt.

Für Melanie ist es in verschiedener Hinsicht eine schwierige Phase. Zum einen fühlt sie sich selbst verlassen von ihrem Vater. Zum anderen sieht sie ihre leidende Mutter, die auch Fürsorge bedarf. Sie, als die Älteste, ist es, die sich um die Mutter kümmert und ebenso um ihre jüngeren Geschwister. Gleichzeitig steht sie am Ende der Pubertät und müsste eigentlich mit ihrer Loslösung vom Elternhaus ,beschäftigt" sein. Dem steht nun die Trennung entgegen. Aufgrund der geschlechtsspezifischen Rollenverteilung war die Mutter auch zuvor die zentrale Bezugsperson und am wichtigsten für die Alltagsgestaltung. Diese Beziehung muss nun aber neu verhandelt werden. Nicht nur die Enge der Beziehung - angesichts der veränderten Bedürfnisse von Mutter und Kindern -, sondern auch das Verhältnis von Zuneigung und Disziplin muss neu ausagiert werden (vgl. Beham 2004: 133ff). Die Trennung der Eltern hat zu einer engeren Bindung von Melanie an ihre Mutter geführt.

Ihre Schwester, vor allem aber ihr Bruder trinken in den folgenden Monaten und Jahren immer wieder zu viel Alkohol. Melanie Wegener bringt dies mit der Belastung durch die Trennung in Zusammenhang, auch wenn es in dem Alter der Geschwister zum Austesten ihrer Grenzen gehören kann. Melanie kümmert sich in solchen Situationen immer wieder um sie. Auch wenn die je unterschiedlichen Beziehungen zu dem Vater Konfliktpotenzial geboten haben, rückt Melanie in der Beziehung zu ihren Geschwistern und der Mutter offensichtlich in eine FürsorgeRolle. Im Interview weiß sie aber viele Dinge über die Mutter nicht. Dies deutet darauf hin, dass trotz einer fürsorglichen Beziehung ein Eltern-Kind-Verhältnis bestehen blieb und Melanie Wegener in der Beziehung zur Mutter nicht die Stelle ihres Vaters als ,erwachsener' Gesprächspartner einnahm. Anne beginnt eine Therapie bei einer Psychologin, die ihr möglicherweise auch hilft, Melanie nicht als Ersatz-Gesprächspartnerin zu involvieren.

Anne Wegener beginnt in dieser Phase unter Tinnitus zu leiden. Ihr Leidensdruck wird dabei so groß, dass sie krankgeschrieben wird. Hierin kann auch eine Folge der stresshaften Trennungsphase gesehen werden, in der das intensive Erleben von Trauer, Verlust, Versagen und Kontrollverlust zu psychosomatischen Symptomen führen kann (vgl. Wilk/Zartler 2009: 458). Hinzu kommt damit nun auch eine ökonomische Unsicherheit, wenn Anne möglicherwiese längerfristig nicht erwerbstätig sein kann. Erschwert wird die ökonomische Unsicherheit noch durch den beginnenden Streit mit dem Vater um Geld und Unterhalt. Während Anne sich in einer beruflich und ökonomisch unsicheren Situation befindet, wird Joachim Dienststellenleiter eines Polizeikommissariats in einer nahe gelegenen Kleinstadt. Vermutlich ist die Übernahme dieser Tätigkeit auch mit einer Beförderung verbunden. Diese Konstellation führt zu einer weiteren Abkehr vom Vater, der als ,Gewinner‘ der Trennung gesehen werden kann. Das Gefühl der Verlas- 
senheit verstärkt sich und schlägt auch in Wut um. Vermutlich ist Melanie in der neu zusammengesetzten Kernfamilie in einer Position der Stärke, die ihr gleichzeitig auch zugeschrieben wird, erlebt sich aber als verletzlich dem Vater gegenüber.

Die Mutter sucht sich dann, nachdem sie einige Monate krankgeschrieben war, eine Arbeitsstelle als Betreuerin in einer Grundschule, in der sie halbtags arbeiten kann und mit der sie die Hoffnung verbindet, dass diese Tätigkeit weniger anstrengend sei als im Kindergarten. Diese berufliche Umorientierung und die Unterstützung einer zumindest kurzzeitigen Gesprächstherapie scheinen Anne zu helfen; der Tinnitus verliert an Intensität und verschwindet später vollständig. Es kommt im Zuge der Scheidung auch zu Unterhaltsregelungen, die Anne entlasten. Außerdem bleibt die Familie im gemeinsamen Haus wohnen und Melanie kann in ihrem gewohnten Umfeld bleiben - wenngleich dieses auch immer an das gemeinsame Leben mit dem Vater erinnert. Die Situation stabilisiert sich langsam und sie erfahren auch Unterstützung von den Großeltern, die, so Melanie, ihrem Sohn die Trennung vorwerfen.

Melanie schaffte es in der besonders belastenden Phase nicht ,unterzugehen', wenn auch angenommen werden kann, dass sie sehr angestrengt ist und unter der Situation leidet. Im Interview deutet sie an, dass sie in dieser Zeit Gewicht verloren habe. Es ist aber offenbar keine Essstörung diagnostiziert worden, zumindest spricht Melanie darüber nicht - vermutlich hätte sie dies jedoch getan, da sie über eine spätere, andere therapeutische Unterstützung durchaus spricht. Zu vermuten ist jedoch, dass der Gewichtsverlust nicht zufällig war - da er auch von ihr selbst im Zusammenhang mit der Trennung thematisiert wird -, sondern im Kontext der familialen Situation zu sehen ist: Es galt, die (körperlich) leidende Mutter zu unterstützen, Konflikte innerhalb der noch zusammenlebenden Familie eher zu unterdrücken und eigene Bedürfnisse nicht (immer) auszuleben. Der Gewichtsverlust kann Ausdruck eines unterdrückten adoleszenten Autonomiestrebens in dieser Situation und in diesem familialen System sein (vgl. Weber/Stierlin 1989) ${ }^{109}$. Melanie entwickelte vermutlich keine gesundheitlich bedenkliche Essstörung, die mit einer problematischen körperlichen Selbstwahrnehmung zusammenhing, bearbeitete die Situation aber vermutlich unter anderem durch die Kontrolle ihrer selbst und ihres Körpers.

Melanie Wegener erfährt aber auch Unterstützung von ihren Freundinnen, von denen zwei ebenfalls getrennt lebende Eltern haben. Sie sind wichtige Gesprächspartner*innen und stützende Bezugspersonen für sie. In dieser Zeit lernt sie außerdem ihren ersten Freund kennen. Mirko bewohnt eine Einliegerwohnung bei seinen Eltern in einem Ort bei Göttingen. Sie treffen sich auf der Geburts-

109 Diese Familienstrukturen entsprechen teilweise den „Magersuchtsfamilien“, wie sie Weber und Stierlin (1989) beschrieben haben. Aber auch familiensystemische Strukturen von „Bulimiefamilien“ lassen sich ansatzweise erkennen. Was beiden Familientypen gemeinsam ist, ist ein „Entweder-OderMuster“: „Es gibt keinen dritten Weg, keine Alternative dazu, kein Sowohl-als-auch“ (1989: 70). Melanie Wegener befindet sich in einem Entweder-Oder-Konflikt: entweder loyal zur Mutter oder zum Vater sein; entweder der Mutter weh tun oder den Vater meiden. 
tagsparty einer gemeinsamen Bekannten. Melanie findet ihn irgendwie interessant, hält ihn aber zunächst auf Abstand, auch „,weil der hat ja tota:l weit weg gewohnt in meinem damaligen Empfinden“. Dennoch geht sie eine Beziehung mit ihm ein, die sich aber erst später (funktional) intensivieren wird.

\section{Die Berufswahl als Bearbeitung von Unsicherheit und Loyalitätskonflikten}

Melanies schulische Leistungen sind auch unter den Bedingungen der Trennung und der veränderten Familienkonstellation nicht eingebrochen. Sie macht 1998 ein gutes Abitur und erfüllt damit auch den Wunsch des Vaters. Nun steht für Melanie Wegener die Entscheidung an, was sie beruflich machen möchte. Will sie weiterhin den Wünschen des Vaters entsprechen und sich gleichzeitig nicht zu weit aus ihrem Herkunftsmilieu entfernen, ist eine Ausbildung wahrscheinlich, ein Studium aber ebenfalls möglich. Sie verschiebt diese Entscheidung in die Zukunft und macht zunächst ein Freiwilliges soziales Jahr (FSJ) in einer Kindertagesstätte sie ,erkauft' sich Zeit für ihre Entscheidung.

Die Wahl der FSJ-Stelle folgt nun dem beruflichen Weg der Mutter, auch wenn Melanie Wegener zu diesem Zeitpunkt schon klar ist, dass sie „nie Erzieherin werden will“". Möglicherweise entspricht es dem Versuch, sich auch beruflich an der Mutter zu orientieren, doch kann sie dem in dieser konkreten Form nicht nachkommen. Für sie kommen zwei Optionen in Betracht: ein Studium der Erziehungswissenschaft, das sich inhaltlich teilweise mit dem Feld der Mutter deckt, oder der Beruf der Polizistin.

„und dann hab ich bin ich hin und hergeschwankt zwischen zwei Berufen und zwar Erziehungswissenschaft, und Polizei, // mbm/ / Polizei weil mein Vater Polizist ist und ich ganz oft bei ihm auf der Dienststelle war und das alles toll fand // mbm/ / wie das da so, abgelaufen ist, / / mbm/ / wie die, was die da gemacht haben, wie die das Binnenklima war, // mbm// das fand ich, da hab ich mich total wohlgefühlt"

Eine feinanalytische Analyse dieses Zitats zeigt sprachliche Ungenauigkeiten und die Verwendung einer physischen Metapher (hin und her schwanken) und damit ihre Unsicherheit und den Konflikt, in dem sie sich befindet: Es gibt keine Möglichkeit, eine Mitte zu finden, die väterliche mit der mütterlichen Seite zu verbinden, sondern sie muss sich entweder für das eine oder das andere entscheiden (s. Fn. 109). Auch die Wahl eines vollkommen anderen Berufes erscheint nicht möglich in diesem Loyalitätskonflikt, der wenig Freiheitsgrade bietet.

Melanie bewirbt sich während ihres FSJ sowohl bei der Polizei Niedersachsen, als auch für ein Studium in Göttingen und schiebt eine Entscheidung damit wiederum hinaus, hofft möglicherweise auf eine Entscheidung von außen, durch die Organisationen. Mit beiden Optionen bleibt sie in einem begrenzten regionalen Umfeld. Sie hat sich auch bei keiner anderen Landespolizei beworben, was ihre Chancen auf eine Ausbildung zur Polizistin im Falle einer Ablehnung erhöht hätte. Ein Grund hierfür kann sein, dass sie nicht weit weg wollte von ihrer Familie, dann wäre aber die Polizei Thüringens, Hessens oder Nordrhein-Westfalens unter 
Umständen ebenfalls eine gute Option gewesen. Man kann es daher so interpretieren, dass sie die Chancen, zur Polizei gehen zu können (oder zu müssen), gering gehalten hat.

Für das Studium in Göttingen erhält sie eine Zusage und schreibt sich ein. Damit steht fest, dass sie Erziehungswissenschaft studieren kann. Parallel macht sie aber auch noch die Aufnahmeprüfungen bei der Polizei. Nachdem sie den ersten mehrstündigen Test in Hannoversch Münden zu Allgemeinbildung, Sprache etc. erfolgreich besteht, kommt sie in die zweite Bewerbungsrunde. In einer zweiten Testrunde wird neben einer psychologischen Einschätzung und einem Sporttest auch eine medizinische Untersuchung gemacht. Sie besteht alle Tests und bekommt kurz darauf mitgeteilt, dass sie zum nächsten Einstellungstermin im Oktober ihr Studium in Hannoversch Münden beginnen kann. Nun sind wieder beide Wege offen und die Entscheidung muss fallen: Sie exmatrikuliert sich in Göttingen. In einer Situation biographischer Unsicherheit - familial und bezogen auf die (berufliche) Zukunft - entscheidet sie sich gegen das berufliche Feld der Mutter und für das des Vaters. Erscheint dies auf den ersten Blick als eine Hinwendung zum Vater und eine Abwendung von der Mutter, bietet ihr dies letztlich eine ganz andere Möglichkeit: Sie kann Polizistin werden und sich gleichzeitig als eine verlässlichere Polizistin und Person erweisen, als ihr Vater es für ihre Mutter und ihre Geschwister war. Damit bindet sie sich fester an die Mutter, denn sie muss ihre Verlässlichkeit nun auch beweisen, wenn sie sich loyal zur Mutter verhalten möchte. Sie handelt ausgleichend, um den Kontakt zu beiden Elternteilen aufrechtzuerhalten. Sie ergreift den Beruf des Vaters, bleibt aber bei der Mutter.

Daneben birgt ein Hochschulstudium angesichts ihres nicht-akademischen Familienumfelds zu viele Unsicherheiten für sie. Auch wenn die Entscheidung für die Polizei ebenfalls ein Studium bedeutet, ist dieses deutlich strukturierter, es handelt sich um ein familiär bekanntes Feld und vor allem steht am Ende des Studiums ein eindeutiger Beruf. Die Polizei bietet als Organisation mit klaren Strukturen und Rollen Sicherheit und eine klarere Zukunftsperspektive.

„und dann keam man durch so ne riesen Tü:r und überall war so glänzender Linoleum // hmb// und dann bin ich in diese ganzen Büros und durfte dann auch äh, vorne hintern Tresen und mal funken / / : lacht// / / ok// und durfte da überall äh, in der ganzen Dienststelle rumlaufen und war auch in dem riesigen Büro, also für mich riesich: von meinem Vater, / / I: jal / ich weiß noch dass er Bilder von uns an der Wand hatte, das kann (ich dir noch sagen) und ich weiß noch wie der Raum aussab, wo se dann gessesen haben, [...] so ah so, es war so schön da //I: lacht// die ham da so gesessen und erzähblt, und warn auch total hm, uns auch rumgeführt und ham uns dann, na setz dich mal auf den Stubl da, und darfst auch ma was, hier drück auf die Taste und sag mal was / / hmb// das war echt toll"

„so= so sicher auch irgendwie, //I: ja// also man hat sich sicher gefüblt da, //I: ja/ / also ja, die ham so Sicherheit ausgestrablt so, // hmb// es kann, nichts kann mir passieren, //hmb// (4)" 
Auch wenn sie es in dem Zitat weiter oben aus ihrer heutigen Perspektive und in der Organisationssprache mit einem guten Binnenklima beschreibt, verbindet sie doch sichtlich ein kindliches Gefühl von Sicherheit und Geborgenheit mit der Polizei. Neben diesen Erinnerungen, wie sie als Kind Polizei erlebt hat, sind es auch Erinnerungen an ihren Vater und ihre gemeinsamen Ausflüge. Die Polizei schafft ein Gefühl von Sicherheit in einer Situation biographischer Unsicherheit und die Berufswahl kann als eine Bearbeitung der biographischen-familialen Konstellation gelesen werden.

Irgendwann in dieser Zeit, während sie das FSJ absolviert, stirbt ihr Großvater. Nach dem Tod der Großmutter im Jahr zuvor hatte Anne Wegener sich um den Großvater gekümmert. Sicherlich war es in der Phase der Trennung eine zusätzliche Belastung, sich um den alternden Vater des getrennten Mannes zu kümmern. Verbunden mit Pflege sowie Tod und Beerdigung des Opas eröffnete sich ein neues familiales Konfliktfeld. Während Anne Wegener die Fürsorge übernahm, regelte Joachim Wegener die finanziellen Belange. Darüber entwickelte sich ein familialer Dialog der Ungerechtigkeit über die Pflege und das Erbe: Ihr Vater, so Melanie, habe das Haus geerbt, seine Schwester wiederum nur einen kleinen Anteil an Barvermögen erhalten und die Enkel, die der Großvater bedenken wollte, seien vollständig leer ausgegangen; vor allem aber habe ihre Mutter, die doch die Pflegearbeit geleistet habe, nichts bekommen. Auch wenn der Verlauf rechtlich anders gewesen sein kann, als es von Melanie Wegener im Interview präsentiert wird, erlebt sie dennoch eine erneute Ungerechtigkeit von Seiten ihres Vaters. Als der Vater dann mit seiner neuen Frau und deren Kind in das Haus des Großvaters einzieht, wird er als Eindringling wahrgenommen. Die Wohnkonstellationen sind nun, da alle im selben kleinen Ort wohnen, sehr herausfordernd. Auch wenn Melanie Wegener dies nie explizit formuliert, kann davon ausgegangen werden, dass das Verhältnis der Eltern schwierig ist und komplizierter wurde, da sie nun räumlich und auch im Sozialleben der Ortschaft zusammenleben. Möglicherweise spielten eingeschränkte finanzielle Möglichkeiten eine Rolle, sich für diese Wohnsituation zu entscheiden, was angesichts des mutmaßlichen Verdiensts des Vaters aber eher unwahrscheinlich ist. Der Kontakt zum Vater wird trotz oder wegen der neuen räumlichen Nähe zunehmend schlechter. Melanie Wegener kann dieser Situation entkommen, als sie ihr Studium beginnt, lässt aber ihre Geschwister und die Mutter in dieser Situation zurück, was für sie einen bedeutsamen Loyalitätskonflikt darstellt.

\section{Sicherheit in der Polizei vs. Unsicherheit im Privaten}

Melanie Wegener beginnt also im Herbst 1999 im Alter von 20 Jahren ein Studium an der Niedersächsischen Fachhochschule für Verwaltung und Rechtspflege in Hannoversch Münden. Sie lebt in einem Wohnheim auf dem Gelände der FH und teilt sich das Zimmer mit einer anderen Anwärterin. In Melanies Erinnerung scheint der Beginn des Studiums einer Klassenfahrt zu gleichen. Melanie und ihre Kommiliton*innen feiern Partys im Wohnheim und gehen gemeinsam aus. Sie ist 
in ihre Studiengruppe gut eingebunden und kommt im Studium inhaltlich gut mit: „war ne super Zeit". Auch wenn es in Melanies Erinnerung als lockere Zeit erscheint, wird zu Beginn des Studiums viel Sport gemacht, Selbstverteidigung und Schießen erlernt und geübt und es herrscht ein stark strukturierter Tagesablauf. Für Melanie Wegener stellt dies aber keine Belastung oder große Umstellung in einem negativen Sinne dar. Sie kann zurückgreifen auf ihre Erfahrungen aus dem Fußballtraining und mit einem liebevoll-strengen Vater und Polizisten. Darüber hinaus erlebt sie neben dem strukturierten Tagesablauf neue Freiheiten und macht die Erfahrung, dass sie gut ist im Studium und ihr vieles sehr leichtfällt.

Im Interview erwähnt sie, dass sie sich nach einigen Monaten Studium auch körperlich verändert habe, und begründet das mit dem Sport im Studium: ,ich hab irgendwie zugelegt und auch Muckis bekommen". Eine alternative Lesart ist, dass ihr die neue Umgebung, die neuen sozialen Beziehungen und der strukturierte Tagesablauf dabei helfen, Geborgenheit und Sicherheit zu erlangen, im Gegensatz zu der psychisch belastenden Situation von Verantwortungsgefühl und ambivalenten Konflikten zu Hause. Ihre jetzige Lebenssituation bedarf keiner Bearbeitung durch die Kontrolle von sich selbst und ihres Körpers wie nach der Trennung der Eltern, oder: die Organisation übernimmt jetzt diese Kontrolle und Strukturierung und schenkt ihr gleichzeitig Geborgenheit.

Studieren, Wohnen und die Freizeitgestaltung sind vollkommen auf die Polizei eingestellt. Die Abschottung der Polizeifachhochschulen von anderen Fachhochschulen und das gemeinsame Wohnen in einer kleinstädtischen Umgebung führt zu einer Sozialisation in die Polizei. Die Studierenden haben kaum Gestaltungsmöglichkeiten in ihrem Studium, das vor allem auf die Praxis fokussiert ist und weniger auf eine selbstständige wissenschaftliche Entwicklung von Interessen. Sie ,studieren' einen Beruf, nicht ein Fach/Fächer. Sie lernen im Studium und in dieser Umwelt „die soziale Welt aus einer polizeilichen Perspektive zu begreifen und zu deuten“ (Behr 2013: 27) und eben keine Perspektivverschiebung oder Distanzierung, wie das bei anderen Studiengängen ausdrücklich angestrebt wird. Die geringen Gestaltungs- und Wahlmöglichkeiten bedingen es vielleicht auch, dass Melanie wenig über den Beginn des Studiums spricht und die Thematisierung sich eher an den Beziehungen zu ihren Kommilitoninnen orientiert - es kann außerdem als Ausdruck dessen verstanden werden, dass und wie von Beginn an eine Solidargemeinschaft geschaffen und wichtig wird. Sie findet in ihrer Studiengruppe zwei Freundinnen, mit denen sie einen Großteil der Freizeit verbringt und zusammen lernt. Relevant wird hier nun auch, dass sie erlebt, eine von nur wenigen Frauen in der Studiengruppe respektive Polizei zu sein. Denn auch wenn sie mit ihren Kommilitonen gut auskommt, braucht sie ihre Kommilitoninnen nicht nur, um freundschaftliche Beziehungen aufzubauen, sondern auch als ,kleine Solidargemeinschaft in dieser männlich dominierten Umwelt.

Melanie schließt das einjährige Grundstudium im Frühjahr 2000 mit sehr guten Bewertungen ab. Sie beginnt ihr erstes Praktikum in einer Dienststelle des Einsatz- und Streifendienstes der Polizeiinspektion Göttingen und macht erste 
praktische Einsatz-Erfahrungen. Und sie zieht bei ihrem Freund ein - diesen erwähnt sie in diesem Kontext nur, um zu erklären, wie praktisch das gewesen sei, weil sie so nicht weit zur Praktikumsstelle fahren musste. Es ist aber davon auszugehen, dass sich ihre Beziehung nun auch veränderte. Zuvor haben sie sich kaum gesehen und nur wenig am Leben des/der anderen teilgenommen.

Nach dem sehr guten Abschluss des Grundstudiums geht Melanie hoch motiviert ins Praktikum und freut sich darauf, nun endlich praktische Polizeiarbeit zu machen. Es beginnt aber zunächst schwierig. Sie erlebt Ablehnung von den Kollegen, die Vorbehalte gegen die junge Frau haben.

„,meine Vorgängerin die hat sich wobl unmöglich da aufgeführt [...] es gab unter den älteren Kollegen eh so ne gewisse, ja Skepsis gegenüber den Kikos wurde sie genannt, Kinderkommissare"

Melanie bezieht sich auch auf den Umstand, dass die deutlich (dienst-)älteren Kollegen in der kleinstädtischen Polizeistation fast ausschließlich im mittleren Dienst waren. Sie wird nun aber, ebenso wie ihre Vorgängerin, aufgrund ihres Studiums direkt für den gehobenen Dienst eingestellt. Am Ende ihres Studiums wird sie formal-hierarchisch höher stehen, ohne jedoch über die Arbeitserfahrung ihrer Kollegen zu verfügen.

„Die hat sich dann auch so aufgeführt, als ob sie jetzt was Besseres is ne, und das kam überhaupt nich gut an und entsprechend, jetzt schon wieder so eine, ne äh, wieder Frau ne, fanden se irgendwie nich so gut"

Im vorherigen Zitat machte Melanie allein das Verhalten ihrer Vorgängerin als ,Kiko' für die Vorurteile ihr gegenüber verantwortlich, hier wird nun deutlich, dass sie es auch mit ihrem Geschlecht in Zusammenhang bringt. Ob sie diese Verbindung selber hergestellt hat oder von ihren Kollegen dort auch explizit verhandelt wurde, dass sie Frauen im Polizeidienst als problematisch ansehen, bleibt unklar. Da sie es hier zum Thema macht und sie außerdem eine weitere Erklärung für die Vorurteile ihr gegenüber gefunden hat, ist es wahrscheinlich, dass offen darüber gesprochen wird, dass Frauen in der männlich-strukturierten Polizei nicht das Gleiche leisten (können) und/oder als Frauen einfach nicht, reinpassen‘. Da die Vorurteile ihr gegenüber dann nicht ein Problem mit den hierarchischen Bedingungen und Umstrukturierungen in der Polizei widerspiegeln (vgl. Kap. 2.2.5 und 2.3), sondern auf ihr Geschlecht bezogen sind, kann sie diesem Problem eigentlich nichts entgegensetzen. Ihr Frau-Sein kann sie nicht ändern.

„Sie haben dann aber gemerk.t das ich gemacht habe wie sie gesagt haben"

Ihre Anerkennung des hierarchischen Systems und ihre Unterordnung darunter führen zu Anerkennung ihrer Person als Kollegin. Es lässt sich eine Parallele ziehen zu ihrem Vater, der in einem ähnlichen Alter wie ihre Kollegen ist und der in einer ähnlichen Polizei sozialisiert worden ist. Den ,richtigen' Umgang mit Polizisten dieses Typs hat sie somit möglicherweise schon zu Hause in der Interaktion 
mit dem Vater erlernt. Er ist zwar schon seit Melanies Kindheit Beamter des gehobenen Dienstes, hat aber im mittleren Dienst begonnen und sich hochgearbeitet. Die Skepsis gegenüber ,Kikos` erfährt Melanie also hier vielleicht nicht zum ersten Mal. Sie hat nicht nur biographische Ressourcen zum Umgang mit der Situation ausgebildet, sondern erhält gleichzeitig auch eine Chance, die Beziehung zu ihrem Vater zu bearbeiten. Sie kann hier als erwachsene Frau einen (neuen) Umgang mit diesem Typ Mann/Polizist entwickeln.

Aus ihrer heutigen Perspektive bewertet Melanie diese Zeit als sehr spannend, als Erfahrung, die ihr gezeigt habe, dass sie wirklich Polizistin werden will. Sie findet dann auch Unterstützung von einem Kollegen, der ihr als guter Gesprächspartner zur Verfügung steht, und einem Praxisanleiter, den sie sehr schätzt, weil er ihr viel erklärt und sie gleichzeitig sehr selbstständig arbeiten lässt.

Nach den drei Monaten im ESD wechselt sie für weitere drei Monate Praktikum zum Zentralen Kriminal Dienst (ZKD). Hier macht sie nun die Erfahrung, dass sie sich dem ESD zugehörig fühlt. Die Kripo-Beamten machen häufig Witze über Schutzpolizisten und Melanie fühlt sich ausgegrenzt und „von oben herab“ behandelt. Dies führt sie nun nicht darauf zurück, dass sie eine junge Polizeianwärterin ist, die von den ,alten Kripo-Beamten“ nicht ernst genommen wird, sondern darauf, dass sie als „einfache Schutzpolizistin“ nicht anerkannt wird. Trotz der zunächst ebenfalls schwierigen Anfangszeit beim ESD fühlt sie sich diesem polizeilichen Arbeitsbereich mehr verbunden und knüpft damit wiederum an den Vater und an das, was sie als Kind als Polizei erlebt hat, an.

Nach Ende des Praktikums geht das Hauptstudium in Hannoversch Münden weiter. Nach der praktischen Arbeit muss sie sich zunächst wieder einfinden in das Leben an der FH. Sie bezieht zwar wieder ihr Zimmer auf dem Gelände der Fachhochschule, das sie nun alleine bewohnen kann, sie wohnt aber weiterhin auch bei ihrem Freund. Die Beziehung zu ihrem Freund wird schwieriger in diesen Monaten. Während Melanie Wegener einen klar strukturierten Arbeits- und Studienalltag hat, weiß ihr Freund nicht genau, was er machen möchte, und jobbt „,nur“ in einem Geschäft, das Streetwear verkauft. Melanie beschreibt ihn als planlos. Für Melanie wird auch sein Freizeitverhalten zunehmend ein Problem: „,er hat dann auch angefangen mit so Skatern, so Sprayern rumzuhängen“. Auch wenn er selbst wohl nicht aktiv geskatet oder gesprayt hat, hat er mit ihnen viel Zeit verbracht und Melanie vermutet, dass dabei auch Marihuana „oder Schlimmeres“ konsumiert wurde. Melanie sieht in ,auf Abwegen', er bringt sie damit auch in einen Konflikt mit ihrem Beruf.

„Im Hauptstudium gings mir nicht ganz so gut, da war ich ich son bisschen, weiß gar nicht wo hers kommt, da war ich son bisschen (1) so depressiv son bisschen depressiv möchte ichs mal nennen, depressiv verstimmt"

Melanie Wegener fällt es schwer zu sagen, dass sie unter depressiven Verstimmungen gelitten hat. Sie brauchte wahrscheinlich auch damals einige Zeit, um sich das einzugestehen, und weiß selbst heute noch nicht, ob sie das überhaupt so 
benennen möchte - möglicherweise auch ein ,Makel` in der Polizei. Sie verbringt wieder mehr Zeit zu Hause bei ihrer Mutter, schläft wieder häufiger in ihrem Zimmer in der FH und zieht sich dadurch von ihrem Freund zurück, trennt sich aber nicht von ihm. Es ist aber nicht nur die Beziehung zu ihrem Freund, die belastend ist. Sondern es kann auch ein Hinweis darauf sein, dass die letzten Jahre, in denen sie trotz der Trennung der Eltern weiter ,funktioniert ${ }^{6}$ hat, sehr belastend waren und dieser Stress nun zu Tage tritt. In diesem Zusammenhang steht sicherlich auch, dass ihr Vater einige Monate zuvor seine neue Lebensgefährtin geheiratet hat. Dies ,besiegelt' die Trennung der Eltern und kann als endgültige Abkehr von ihr und ihren Geschwistern erlebt worden sein. Sie konsultiert den Allgemeinmediziner der Familie, der „,mich aber nich als Fall fürn Psychiater“ einstuft, ihr allerdings einen Kollegen empfiehlt, der Akupunktur anbietet. Auch wenn ihr die Akupunktur gutgetan habe, hält diese Phase weiter an und wird noch belastender, als sich ihr Freund gegen Ende des Hauptstudiums nach ca. zweijähriger Beziehung von ihr trennt. Melanie Wegener leidet zunächst stark unter der Trennung, schafft es aber weiter zu studieren und auch ihr Hauptstudium gut abzuschließen.

Nach dem Hauptstudium beginnt das nächste Praktikum, das sie wieder in Göttingen im ESD absolviert. Nach Beginn des Praktikums geht es ihr schnell besser. Sie interpretiert dies als Zeichen dafür, dass die Beziehung ohnehin schon am Ende gewesen sei. Außerdem sieht sie ihren (Ex-)Freund heute als Auslöser für ihre depressive Verstimmung, da es ihr nach der ersten Phase der Trauer deutlich besser gegangen sei als zuvor. Gestützt haben sie aber auch die Arbeit im Praktikum und die Struktur der Arbeitstage. Anschließend stürzt sich Melanie in ihr Abschlussstudium, an dessen Ende zwei Monate später Klausuren in fünf Fächern stehen. Sie lernt viele Stunden täglich, um einen guten Abschluss zu machen.

In dieser stressigen Phase kommt es erneut zu Konflikten mit dem Vater, als dieser vorübergehend Anspruch auf das vormals gemeinsame Haus der Familie erhebt. Melanie hat das Gefühl, dass er ihr bzw. ihnen alles nehmen möchte, und erlebt, wie der Vater seine ,alte' Familie mit einer ,neuen' im selben Haus ersetzen möchte. Aus Gründen, die nicht klar zu sein scheinen, lässt er dann aber wieder von seinem Begehr ab.

Einige Wochen später erfährt Melanie, dass sie alle Klausuren mit guten Ergebnissen bestanden hat. Auch die mündlichen Prüfungen schließt sie einen Monat später sehr gut ab und beendet ihr Studium insgesamt sehr gut. Sie ist nun Polizeikommissarin und Diplom-Verwaltungswirtin (FH). Direkt im Anschluss an das Ergebnis der mündlichen Prüfung erfährt sie auch, wo sie als erstes arbeiten wird. Ihre sogenannte Erstverwendung ist in der Bereitschaftspolizei in Braunschweig. 


\section{Die ersten Berufsjahre als Erfahrung von Kollegialität und Fremdbestimmung}

Sie zieht nach Braunschweig in ihre erste eigene Wohnung und wohnt nun zum ersten Mal alleine. Im Alter von 23 Jahren tritt Melanie Wegener ihre erste Stelle an. Sie kommt, wie es üblich ist, zunächst für ein Jahr in die Bereitschaftspolizei (Bepo). In der Bereitschaftspolizei agieren die Beamt*innen in geschlossenen Einheiten, sie sind (zumeist) recht jung und haben ihr Studium kurz zuvor beendet. Die jungen Polizist*innen machen hier gemeinsam die ersten Arbeitserfahrungen jenseits der Praktika während des Studiums. Neben den Einsätzen machen sie vor allem viel Sport und Einsatztraining. Sie haben häufig einen Dienstplan, der mit vielen Einsatzzeiten am Wochenende der zeitlichen Struktur des Alltags vieler Nicht-Polizist*innen widerspricht. Melanie Wegener verbringt entsprechend viel Zeit mit ihren Kolleg*innen, sowohl bei der Arbeit als auch in der Freizeit, und sie schließt wieder Freundschaft zu einer Kollegin, mit der sie ihre restliche Freizeit verbringt. Gemeinsam mit anderen Kolleg*innen gehen sie während der Werktage aus und feiern, da dies am Wochenende häufig nicht möglich ist. Melanie spricht immer wieder lachend über diese Zeit und es klingt an manchen Stellen erneut nach einer Erzählung über eine Klassenfahrt. Für Melanie ist es zunächst eine aufregende und gute Zeit.

Melanie Wegener beginnt eine Beziehung zu einem Kollegen: Jakob lädt sie zum Essen ein. Nachdem sie sich mit ihm getroffen hat, hat sie aber zunächst kein weitergehendes Interesse an ihm. Sie findet es zwar ,total sü:ß mit dem Kochen, aber irgendwie wie der mit der Schürze da stand (1) naja“. Auch hier zeigen sich Melanies Vorstellungen über Männer (und damit auch über Frauen), die anschlieBen an die stereotypen Geschlechterrollen, die sie zu Hause erlebt und erlernt hat. Dennoch werden die beiden schließlich ein Paar. Allerding erst, als Melanie merkt, dass Jakob Interesse an einer Kellnerin, die in ihrem Stammlokal arbeitet, zeigt und dieses Interesse, so Melanie Wegeners Perspektive, auch auf Gegenseitigkeit beruht. Interessant ist hier, dass Melanie die Beziehung eingeht, obwohl sie zunächst kein Interesse an Jakob hat. Infolge eines Konkurrenzverhältnisses zu einer anderen Frau oder der Angst, den ,Mann weggenommen zu kriegen', wie es auch ihre Mutter erlebt hat, lässt sie sich dennoch auf Jakob ein. Mit Blick auf ihr stereotypes Geschlechterbild ist dieses Verhalten auch schlüssig: Ein Mann wird männlicher, wenn er begehrt wird. Kurz darauf ziehen sie in eine gemeinsame Wohnung.

,Polizei' ist nun bestimmend in ihrem Leben. Sie umfasst nicht nur den Arbeitsalltag, der bestimmt ist von Zusammenarbeit und starker Hierarchie und Regeln. Polizei umfasst außerdem das Freizeitverhalten und nun auch ihre Beziehung. ,Polizei‘ wird in der Bepo, wie auch schon zu Beginn des Studiums, ganzheitlich gelebt (Pfeil 2006: 88 f.). Als Teil eines sekundären Sozialisationsprozesses wird Polizistin-Sein mit dem rollenspezifischen Wissen erlernt (Berger/Luckmann 1969/2012: 148 ff.), das eben auch alle diese Bereiche umfasst.

Melanie Wegener möchte aufgrund ihrer guten Erfahrungen ihre Zeit bei der Bepo verlängern. Nach einem weiteren halben Jahr fühlt sie sich in ihrer Position 
als Einsatzbeamtin dann aber gelangweilt und unterfordert. Sie ist frustriert, weil sie nichts Neues lernt und sie den Eindruck hat, dass die Einsätze immer gleich sind. Es kann vermutet werden, dass ihr die Arbeit nicht abwechslungsreich genug ist, von ihr nicht als die, richtige' Polizeiarbeit verstanden wird und es vor allem die kollegialen Beziehungen waren, die sie zur Verlängerung ihrer Bepo-Zeit bewegten. Im Interview wie im damaligen Erleben ändert sich die Stimmung: Die „Klassenfahrt“ endet. Man bietet ihr an, einen Lehrgang ${ }^{110} \mathrm{zu}$ machen und bei der Bepo zu bleiben, dies lehnt sie ab. Eine Karriere in diesem Bereich der Polizei verfolgt sie nicht weiter, auch wenn ihr die Möglichkeit dazu geboten wird. Nach zwei Jahren Bepo wird sie dann versetzt: Anfang 2004 kommt sie in eine Dienstgruppe in einer Dienststelle in Braunschweig - hier muss ich aus Gründen der Anonymisierung so undeutlich bleiben. In Braunschweig fühlt sie sich schnell wohl. Ihre Tätigkeit dort gefällt ihr, vor allem aber macht sie gute Erfahrungen mit ihren Kolleg*innen: „wir waren eine eingeschworene Truppe“. Nach dem Regierungswechsel 2003 von einer SPD-geführten Landesregierung zu einer Regierung von CDU und FDP unter Ministerpräsident Christian Wulff wird unter anderem die Auflösung von Bezirksregierungen beschlossen und es kommt in diesem Zuge zu einer Umorganisation der Polizei in Niedersachsen. Eine Folge ist, dass ihre Dienstgruppe im gleichen Jahr aufgelöst wird. Melanie Wegener ist darüber sehr traurig und erlebt neben der von der Politik initiierten Umstrukturierung auch eine Enttäuschung über die Umsetzung dieses Prozesses innerhalb der Polizei:

„ähm dann konnten wir alle schön sagen wo wir denn jetz. binwollen // mbm// was eigentlich überflüssich war weils schon feststand wo wir hingehen"

Melanie Wegener erlebt, dass für sie entschieden wird. Nach dem Ende ihres Studiums hat sie das noch akzeptiert bzw. es gilt als normal, zunächst für eine bestimmte Zeit in die Bepo zu gehen. Nun ist das anders, sie fühlt sich belogen. In Gesprächen mit den Kolleg*innen stellt sich heraus, dass fast niemand dorthin kommt, wo sie hinwollten, sondern fast alle, wie auch Melanie, in verschiedene Abteilungen der Polizeiinspektion Braunschweig versetzt werden. Neben der Erfahrung, von ,der' Polizei betrogen worden zu sein, erlebt sie, keinen Einfluss zu haben auf diese Entscheidung. Die Organisation bestimmt, wo sie arbeitet. Mit dem Gefühl, dort arbeiten zu müssen, beginnt sie im November 2004 ihren Dienst in einem Polizeikommissariat der PI Braunschweig. Der Start ist schwierig, sie kann sich zunächst nicht gut auf die neue Situation einlassen. Offensichtlich macht sie die Arbeit dennoch zuverlässig, denn sie erfährt Unterstützung von ihrem Dienstabteilungsleiter, der sie in einem „Mitarbeiter-VorgesetztenGespräch" darin bestärkt, einen Aufstieg im gehobenen Dienst zu verfolgen.

110 Über Lehrgänge werden weitere Qualifikationen für neue Tätigkeiten erworben. In der Bepo sind das z.B. Lehrgänge in Videotechnik für beweissichere Festnahmen oder auch Lehrgänge, um Gruppenführer*in zu werden etc. 
Auch ihr sehr guter Studienabschluss unterstützt sicherlich seine Entscheidung, Melanie Wegener zu fördern.

\section{Die aktive Gestaltung ibrer Laufbahn}

In den folgenden Jahren durchläuft Melanie Wegener verschiedene polizeiliche Stationen, während ihr Freund Jakob seit dem Studium in derselben Hundertschaft arbeitet. Die Struktur ihrer Beziehung ähnelt ihrer vorherigen. Sie ist die aktive und zielstrebige, während sie einen Partner hat respektive sich einen Partner ausgesucht hat, der im Gegensatz zu ihr beruflich ,träge‘ erscheint.

Mit 28, fünf Jahre nach Ende des eigenen Studiums, wird sie Anleiterin für Studierende im Praktikum und übernimmt die Verantwortung für die praktische Ausbildung ihr zugeteilter Studierender. Sie ist in verschiedenen Arbeitsgruppen tätig und bekleidet ihr erstes Führungsamt. Sie hat sechs Mitarbeiter*innen, deren Vorgesetzte sie ist. Melanie Wegener wird von ihnen auf die Probe gestellt. Sie erzählt, wie eine ihrer Kolleginnen einen Streit mit einem Kollegen begann und verkündete, dass sie keinen Dienst mehr mit ihm machen wolle und jetzt einfach nach Hause gehen werde. Der Streit stellte sich im Nachhinein als gespielt heraus. Melanie erzählt von dieser Situation mit einem Lachen, es wird aber auch deutlich, dass sie es erst in der Rückschau lustig findet und in der Situation zunächst unter Stress stand und sich überfordert fühlte. Ein solches Austesten scheint bei neuen Kolleg*innen und jungen Vorgesetzten auf unterer Führungsebene zur Normalität zu gehören - ich habe Ähnliches in anderen Interviews gehört - und Melanie erlebt dies auch später in anderer Form wieder. Es ist Teil der Solidaritätsbekundungen bzw. des Solidarität-Einforderns untereinander.

In diesen ersten Berufsjahren verfestigt sich auch die Beziehung zu ihrem Freund und es stellt sich die Frage nach einer gemeinsamen Familiengründung. Sie versuchen ein Kind zu bekommen, aber Melanie Wegener hat einen Abort. Ob es weitere Versuche gab, ein Kind zu bekommen, ist unklar, sie thematisiert es nicht.

„achso ich hab auch keine Kinder das stelle ich mir auch schwierig vor mit Kindern, ich wollte mal Kinder, [...] und hab dann glaube ich für mich irgendwie erkannt das ist zwar nett, aber ob ich das jeden Tag haben will weiß ich nich // mbm// (2) und dann dann bab ich dann irgendwann mit Anfang dreißich beschlossen okay es kommt wie es kommt"

Melanie Wegener sagt heute, dass es für sie nicht vorstellbar sei, zu Hause zu bleiben und nicht berufstätig zu sein. Man kann dies als ,Entschuldigung' kinderlos geblieben zu sein deuten. Während ihre Schwester ihren langjährigen Freund heiratet und ihr Bruder schon ein paar Monate zuvor ein Kind mit seiner Partnerin bekommen hat, bindet Melanie sich nicht in dieser Form an ihren Partner, sondern verfolgt ihre Karriere weiter und bindet sich stärker an die Polizei. Dennoch betont sie ihre gute Beziehung zu Kindern und ringt offenbar auch mit der Situation, keine Kinder zu haben. Sie rationalisiert dieses Thema unter dem Verlust von Unabhängigkeit. Zwischen Melanie, ihrer Schwester und ihrer Mutter gibt es eine geteilte Übereinkunft, dass es relevant ist, sich eigenständig versorgen zu 
können. Dies hängt auch mit der Erfahrung zusammen, dass die Großmutter wie auch die Mutter von ihren Ehemännern verlassen wurden. Aus dieser Perspektive ist aber auch die Lesart möglich, dass sie nicht ernsthaft eine Familiengründung mit Jakob anstrebte, denn sie hätte weiter versuchen können schwanger zu werden.

Melanie Wegener ist sehr aktiv und absolviert verschiedene Weiterbildungsmaßnahmen, unter anderem eine, die sich gezielt an Frauen in der Polizei richtet. 2008 tritt sie außerdem eine neue Stelle an, auf die sie sich zweimal beworben hatte und bei der sie sich im zweiten Versuch gegen ihre Mitbewerber*innen durchsetzen konnte. Dass sie die Stelle tatsächlich bekommen hat, erfährt sie zufällig im Gespräch mit einem Kollegen. Sie selbst wird erst nach den Kolleg*innen von offizieller Seite darüber informiert. Diese Informationspolitik sieht sie kritisch und sie empfindet es als Bevormundung und Übergangen-Werden. Sie erlebt wieder einmal, ,verwendet ${ }^{6}$ zu werden - so der polizeiliche Sprachgebrauch.

Ihre neue Stelle ist eher eine Verwaltungsstelle, mit nur wenigen Einsätzen außerhalb des Büros, aber mit enger Zusammenarbeit mit der Führungsebene der Polizeiinspektion und anderen Behörden. Kurz nachdem sie ihre neue Stelle angetreten hat, trennt sich ihr Freund nach sechsjähriger Beziehung von ihr.

„und ich sa- äh äh das war als ob mir jemand den Boden unter den Füßen wegreißt ne, ich konnt ich wusst gar nich wie ich am Anfang reagieren sollte, [...] und dann hab ich nur noch geheult, die ganze Zeit, und dann fing er an das liecht nich an dir und so dieses ganze Zeuch (1) aber es war ganz schlimm [...] und er hätt- das hat er mir dann auch gesacht er bätt jet?t was mit ner anderen, un äh ja“"

Melanie Wegener scheint die Trennung überrascht zu haben. Noch dazu wird sie nicht ,nur' von einem Mann, sondern sie wird von einem Polizisten für eine andere Frau verlassen - ebenso wie ihre Mutter. Erneut ist das Elternhaus ihr Rückzugsort - und die Arbeit. Mit ihrer Tätigkeit im neuen Einsatzgebiet und den zusätzlichen Weiterbildungsmaßnahmen kann sie sich, wie auch bei der Trennung zuvor, in die Arbeit „stürzen“. Melanie leidet sehr unter der Trennung und hält ihren Alltag durch ihre Arbeit aufrecht. Diese beschreibt sie als sehr fordernd, es ist stressig und sie macht viele Überstunden. Sie schöpft daraus aber auch sehr viel Selbstvertrauen und lernt viel über die Arbeitswege der Polizeiinspektion: Wie einsatzbezogene Entscheidungen zustande kommen, wie große Einsätze geplant werden und welche Wege Entscheidungen durch die Behörde nehmen. Sie erhält Einblicke in die polizeiliche Arbeit aus einer anderen, ihr bis dahin fremden Perspektive und erlernt den Umgang mit Führungskräften des gehobenen Dienstes. In der Rückschau evaluiert sie ihre Arbeit dort als sehr gute Erfahrung und als hilfreich für ihre weitere Laufbahn.

Sowohl bei ihrer Arbeit als auch in den Weiterbildungsmaßnahmen wird ihr Frau-Sein thematisch. Sie hat ausschließlich männliche Kollegen und begleitet bei Einsätzen die Einsatzleitung und Hundertschaftsführer: 
„in dem Bulli saßen fünf Leute manchma sechs, nur Männer, un ich, ne, entsprechend war das Gesprächsniveau, kannste dir ja vorstellen vielleicht / / ja/ / “

Ihre Strategie ist es, sich zurückzuhalten, sexistische Sprüche und sexualisierte Aussagen auszuhalten und nur, wenn es besonders schlimm wird, etwas zu sagen:

„im Bulli musst ich dann ab un zu ma ermahnen, jetzt reichts aber auch ma, hier is noch ne Frau anwesend, hallo:"

Damit prangert sie das Redeverhalten der Männer nicht grundsätzlich an, sondern deutet an, dass es nur nicht in Ordnung sei, wenn sie vor einer Frau so miteinander reden. Das bedeutet auch, dass sie sich einer Geschlechter-Struktur, in der Männer ,derbe' und Frauen feinfühliger sind, also Männer anders als Frauen sind, unterordnet und sie stützt. Diese Strategie der Unterordnung führt aber auch zu Anerkennung: Frau wirkt nicht kleinkariert und nervig, frau kann was aushalten. Sie vergleicht das Gesprächsniveau im Büro mit dem im Einsatzwagen, in dem dann die Hundertschaftsführer der geschlossenen Einheiten sitzen, und betont, dass es im „Bulli“ schlimmer gewesen sei als im Büro. In den geschlossenen Hundertschaften ist die Arbeit von einer anderen Körperlichkeit geprägt als im ESD und es wird eine bestimmte Form von, maskuliner' Männlichkeit deutlicher gelebt, als es im Streifendienst der Fall ist (vgl. Behr 2008).

Es ist davon auszugehen, dass Melanie Wegener zu dieser Zeit schon zur Polizeioberkommissarin befördert wurde. In der Polizei wird leistungsbezogen und mit bestimmten Wartezeiten befördert: Alle zwei Jahre werden Beurteilungen durch die Vorgesetzten angefertigt und eine Liste mit den beförderungswürdigen Kolleg*innen wird erstellt. Melanie Wegener hat sich gezielt eine sogenannte Verwendungsbreite geschaffen durch ihre unterschiedlichen Tätigkeiten, bei denen sie auch von wechselnden Vorgesetzten unterstützt wurde. Außerdem suchte sie sich auch selbst Möglichkeiten, um sich professionell weiterzuentwickeln. Angesichts der eher schlechten Beförderungslage ${ }^{111}$ in der niedersächsischen Polizei, schafft Melanie Wegener es recht schnell, wenn sie gut fünf Jahre nach ihrem Studium zum ersten Mal befördert wird. Melanie spricht im Interview nicht über ihre Beförderung(en), dies steht im Einklang mit ihrer Präsentation, in der sie sich zwar als erfolgreich, aber nicht als Karrieristin präsentiert. Gleichzeitig rücken damit ihre Erfolge - ,was sie alles gemacht hat ${ }^{6}$ - in den Vordergrund und nicht die formalen Hierarchieebenen. Diese Präsentationsform passt zu der Bedeutung der Bewertung von Führungskräften nach Erfahrung und nicht nach formaler Qualifikation (vgl. 4.3.6). Es ist außerdem ein Ausdruck ihrer konkreten beruflichen Position, wie ich unten noch diskutieren werde.

Sprachlich interessant an ihren Schilderungen dieser Jahre ist, dass Melanie Wegener - trotz dieser Aktivität - vor allem das Passiv nutzt, um über ihre Versetzungen zu sprechen: Sie wird verwendet. Dies korrespondiert mit der Erfah-

111 Wartezeiten auf das erste Beförderungsamt betrugen zu Beginn der 2010er Jahre durchschnittlich zehn Jahre (vgl. Niedersächsisches Ministerium für Inneres und Sport 2016). 
rung, dass Entscheidungen immer wieder auch, so Melanie, „über meinen Kopf hinweg“" getroffen wurden. Erst mit zunehmendem eigenen Engagement in der Gestaltung ihrer Laufbahn ändert sich dies. Wie auch in anderen Fällen zeigen sich hier die nur kleinen Freiräume bei den beruflichen Zukunftsentscheidungen im Rahmen einer Einheitslaufbahn. Das Konzept der Einheitslaufbahn hat sowohl Vor- als auch Nachteile: Innerhalb des internen Arbeitsmarktes der Polizei kann z.B. durch die Besetzung bestimmter Posten und gute Beurteilungen eine recht gezielte Karriereplanung betrieben werden. Verpasst man diese Möglichkeiten aber, wirkt sich dies dauerhaft aus, da es im Sinne einer Einheitslaufbahn eben nur einen Weg, nach oben' gibt (vgl. Pfeil 2006: 91 f.). Melanie Wegener nutzt jedoch Möglichkeiten, die es in diesem Rahmen gibt. Ihr wachsendes Engagement zeigt sich dann nach und nach auch in ihrem Duktus, indem sie sich als aktiv Handelnde, als Gestaltende, in die Erzählung ihrer Laufbahn einführt.

Nach der Trennung von Jakob sucht Melanie Wegener aktiv neue Beschäftigungen und Freundschaften, auch indem sie wieder beginnt Fußball zu spielen. Jakob und sie haben viele gemeinsame Freunde (und Kolleg*innen) gehabt und vermutlich auch aus der Enttäuschung heraus, dass manche von ihnen von der neuen Freundin wussten, sucht Melanie Wegener sich nun aktiv neue Freundschaften außerhalb der Polizei. Beim Fußball lernt sie Alicia kennen. Zu ihr entwickelt sich eine enge Freundschaft. Beide sind Single und verbringen fast ihre gesamte Freizeit gemeinsam, auch als Melanie Wegener nach einem Bänderriss wieder aufhört Fußball zu spielen. In Anbetracht der Enge ihrer Beziehung hat Melanie Wegener hier womöglich zunächst einen Ersatz für die Paarbeziehung zu ihrem Freund gefunden. Sie hat den Eindruck, „das so Ruhe eingekehrt is“ in ihr Leben. Dass sie die Freundschaft mit Alicia in dieser Form führen kann, hängt vermutlich auch mit ihrer Tätigkeit in dieser Zeit zusammen. 2009 wechselt Melanie Wegener in den Kriminalermittlungsdienst (KED). Diese Arbeit bedeutet zunächst vor allem Bürotätigkeit im Frühdienst und erlaubt es ihr sich regelmäßig nachmittags mit Alicia zu treffen, die als Erzieherin ähnliche Arbeitszeiten hat. Auch wenn sie keine sexuelle Beziehung zueinander haben, führt Melanie Wegener nun wie ihr Vater eine Beziehung zu einer Erzieherin.

Um die Stelle im KED zu bekommen, erhält sie Förderung von einem ehemaligen Vorgesetzten, denn „KED“-Zeit ist begehrt. Sie kommt, wie von ihr gewünscht und mithilfe seiner Unterstützung, in die Sachbearbeitung Betäubungsmittel. Sie arbeitet im Frühdienst im Büro, aber auch in der operativen Gruppe. Auch wenn die neue Arbeit spannend für sie ist, fehlt ihr die Abwechslung:

„war spannend war aber für mich nichts wo ich sage da möchte ich die nächsten zwanzig Jahre verbringen // hmb// ähm, es fehlte mir so dieser, der ESD ne, der Schichtdienst irgendwie so, das nicht heute wissen was morgen passiert, // mbm// also oder was in ner Stunde das finde ich zum Beispiel total spannend ich kann das nich haben meine Akten zu liegen und dann sehe ich jeden Morgen meinen Stapel voll, ich hab da gerne ( 
mit Arbeit und gucken was der Tag so mit sich bringt (3) aber man es muss zu machen um weiter zu kommen"

Melanie Wegener verbringt viele Stunden bei Observationen, viele davon auch alleine. Ist die KED-Zeit bei vielen Polizist*innen wohl auch unter der Perspektive begehrt, sich vom Schichtdienst im ESD erholen zu können, bleibt bei Melanie der ESD die ,richtige' Polizeiarbeit. Der KED ist wichtig für ihre Laufbahngestaltung, die Erfahrungen dort tragen aber auch dazu bei, ihre Perspektive, was (die für sie), richtige' Polizeiarbeit ist, weiter zu stabilisieren.

\section{Tätigkeiten mit Rollenkonflikten: ibre Nische in der Polizei}

Mit 31 Jahren geht Melanie Wegener 2010 zurück in den ESD. Hier bekommt sie nun zum ersten $\mathrm{Mal}$ auch vertretungsweise Führungsverantwortung im ESD. Wenn auch nur in Vertretung, ändert dies nun ihre Position. Sie ist zugleich Kollegin, die Streife fährt, und Vorgesetzte, wenn der Dienstabteilungsleiter oder der Einsatzführer nicht da sind. Auf dieser Stelle bleibt sie aber wieder nur einige Monate. Sie wird dann vertretungsweise Dienstgruppenleiterin in einer spezialisierten Einsatzeinheit. Dieser Posten ist Teil ihrer Personalentwicklungsmaßnahme für eine (weitere) Beförderung. Sie hat nun Verantwortung für zehn Mitarbeiter und ist die erste Frau, die diesen Posten in dieser Einheit bekleidet. Melanie Wegener hat „Bauchschmerzen bei der Zusage“, weil sie nicht weiß, ob sie von ihren neuen Kollegen und Mitarbeitern ,getestet" werden wird. Diese Befürchtung macht sie nicht direkt an ihrem Geschlecht fest, bringt es aber durchaus in diesen Zusammenhang, indem sie hier betont, dass sie die erste Frau auf diesem Posten war. Gleichzeitig schwingt auch etwas Stolz mit. Melanie Wegener kommt in ein schwieriges Teamgefüge, in dem Unzufriedenheit herrscht und es auch Unstimmigkeiten unter den Kollegen gibt. Von den Versuchen, mit ihr über andere zu ,lästern“, distanziert sie sich, versucht aber zu vermitteln, dass sie Verständnis für die Probleme hat: Sie versucht die Situation mit ,weiblichem Charme“ zu lösen und knüpft damit an ihre vertraute Strategie an. Sie versucht Situation zu ,heilen', indem sie Mitarbeiter-Vorgesetzten-Gespräche führt und dann vermittelnd tätig ist zwischen den Mitarbeitern.

Je größer ihre Führungsverantwortung, umso deutlicher wird, dass sich damit auch ihre Position innerhalb des Kolleg*innenkreises verändert:

„das du jetz nich mehr, im Team warst, innerhalb der Gruppe sondern plötzlich am Rande standest weil du warst ja der Vorgesetzte"

Dies weist auf ein Spannungsverhältnis hin, das in vielen Bereichen der polizeilichen Arbeit - auf der Straße - existiert: Solidarität unter hierarchischen Bedingungen. Es ist notwendig, sich untereinander zu solidarisieren, um in diesem Beruf, bei Einsätzen, handlungsfähig zu sein. Man muss sich aufeinander verlassen können. Diese Solidarität wird auch durch gemeinschaftliche Praktiken, wie z.B. ,halbprivate ${ }^{6}$ Treffen, hergestellt. Natürlich existieren, wie in anderen Arbeitskon- 
texten auch, Freundschaften unter Kolleg*innen. In der Polizei wird Gemeinschaftlichkeit aber, wie oben dargestellt, ab dem Studienbeginn verinnerlicht. Dem gegenüber steht die starke Hierarchie in der Polizei, die z.B. durch die Uniformen ständig sichtbar ist, sich in Wissensunterschieden (über Einsätze etc.) manifestiert, aber ständig ausgeblendet werden muss, damit man sich gemeinsam als Team betrachten kann. Dieses Spannungsverhältnis verändert sich je nach Positionierung. Hat sich Melanie in der Bereitschaftspolizei, wie üblich, in einem Team befunden, das Solidarität herstellt, so blieb dies als Einsatzbeamtin zunächst auch weiter so. Mit der Übernahme von Führungsverantwortung änderte sich dies, sie muss nun auch Anweisungen geben:

„,damit umgehen musste äh, Vorgänge auch durchzugucken und den Kollegen äh die ja vorher meine Kollegen warn, jetz in dem Moment bin ich in ner anderen Position, denen dann zu sagen äh mach mal [...] war komisch, ich fahr dann wieder Streifenwagen mit denen"

Diese spezielle, auch in anderen polizeilichen Arbeitsbereichen zu findende Position zeichnet sich durch eine Rollenkonfusion aus. Melanie Wegener ist nun Vorgesetzte, aber zugleich auch noch Kollegin. Infolge eines Aufstiegs innerhalb der Hierarchie gilt es nun, die Rolle einer Vorgesetzten auszufüllen - aber eben nur partiell. Die Entscheidungsfreiheit auf einer solchen unteren Führungsebene ist recht begrenzt, häufig geht es nur darum, Entscheidungen einer höheren Stelle an die Kolleg*innen zu vermitteln. Dass Melanie Wegener sich solche Posten sucht, hier und auch später, hängt sichtlich mit der von ihr forcierten Entwicklung ihrer Laufbahn zusammen. Dass sie sich aber dafür entscheidet, ihre Laufbahn in dieser Weise zu gestalten, kann ebenso als die (nicht notwendigerweise bewusst intendierte) Herstellung von Situationen, in denen sie wieder Loyalitätskonflikten ausgesetzt ist, verstanden werden. Sie begibt sich in eine der familialen Situation strukturell ähnliche Konstellation.

Melanie Wegener schlussfolgert, wie oben zitiert, dass man in einer solchen Position nicht mehr Mitglied im Team ist, sondern eine Position außerhalb hat. Damit sind Solidarisierungspraktiken teilweise erheblich erschwert, aber immer noch notwendig. Freundschaftliche Beziehungen zu Frauen, zu denen keine hierarchische Beziehung besteht, stehen innerhalb des direkten Arbeitsumfeldes nicht zur Verfügung. Dass sich Melanie Freund*innen außerhalb der Polizei sucht und Hobbies pflegt, die sie alleine betreibt, kann als Versuch verstanden werden, damit umzugehen.

Sie orientiert sich außerdem weiterhin Richtung „Heimat“. Ihre Mutter wohnt nach wie vor in dem Haus der Familie und beide Geschwister entweder im selben Ort oder nur wenige Kilometer entfernt. Mit ihnen verbringt sie viel Zeit. Beide haben mittlerweile zwei Kinder und führen das Leben ihrer Eltern mit Hochzeit, Kindern und Eigenheim. Auch wenn Melanies Schwester weiterhin arbeitet, hat sie doch Karrierenachteile in ihrem Beruf als Maklerin/Immobilienkauffrau in Kauf genommen. Im Interview ist Melanie Wegener dieser Lebensführung gegenüber ambivalent: Dass beide Geschwister Kinder haben, entlastet sie in gewisser 
Weise von dem gesellschaftlichen und möglicherweise auch familialen Druck, selbst Kinder in die Familie bringen zu müssen, gleichzeitig führt es ihr vor Augen, dass sie selber keine hat. Die Kinder ermöglichen ihr „so ja, eine tolle Tante“ zu sein und ihre Karriere zu verfolgen. Ihre Schwester hingegen hat ihre Karriere für die Familie aufgegeben: ,naja (1) sie arbeitet halt ein bisschen noch so ja nebenher". Man kann dies aus Melanie Wegeners Perspektive so deuten, dass ihre Schwester damit gegen die Übereinkunft, dass man sich selbst versorgen können muss, verstößt - obwohl sie dies sicherlich könnte, bliebe es im Falle einer Trennung wohl ähnlich (ökonomisch) schwer wie bei ihrer Mutter.

Auch ihr Vater bleibt bei den Besuchen zu Hause präsent, auch wenn Melanie Wegener keinen Kontakt zu ihm hat. Im Jahr 2012 gründet er mit ein, zwei anderen Personen aus dem Ort eine Bürgerinitiative, die sich einem ökologischinfrastrukturellen Problem widmet. Er wird Sprecher der Initiative, die sehr viel Unterstützung erfährt. Ihr Vater ist nun neben seinem Dienst als Polizist auch noch eine öffentliche Person, über die gesprochen wird. Zu Melanies Präsentation passend erzählt sie nicht von dem ehrenamtlichen Engagement des Vaters. Möglicherweise ist es also zu Hause kein Thema der familiären Gespräche oder aber der Diskurs über den Vater ist im Ort positiv besetzt und kann von Melanie nicht ohne Weiteres umgedeutet werden und wird daher nicht thematisiert. Im öffentlichen ,Diskurs' der regionalen Zeitung wird ihr Vater als „,ehrlicher Charakter, der sich für die Belange anderer und der Region einsetzt" ${ }^{\text {"112 }}$ beschrieben. Melanies Erleben steht nicht im Einklang mit dieser Beschreibung und diese Diskrepanz wird vermutlich immer wieder thematisch, wenn sie ihre Mutter besucht.

Nachdem ihre Zeit als Dienstgruppenleiterin geendet hat, geht Melanie Wegener im Herbst 2012 zurück in den ESD. Sie beginnt bald damit, sich auf verschiedene Posten im Braunschweiger Land zu bewerben. Es wäre naheliegend, dass sie sich auch auf Posten in Südniedersachsen bewirbt, wo sie näher bei ihrer Familie wäre. Dass sie dies nicht tut, liegt vermutlich nicht allein an mangelndem Angebot. Wenn sie sich auf Stellen innerhalb der Polizeidirektion Göttingen bewerben würde, wäre es möglich, dass sie irgendwann mit ihrem Vater konfrontiert ist, der mittlerweile auf der höchsten Laufbahnstufe, die im Bereich des gehobenen Dienstes angestrebt werden kann, angekommen ist und einige Führungsverantwortung trägt. Sie muss dabei nicht unbedingt mit ihm selbst in Kontakt kommen, aber sie würde dann häufiger die Erfahrung machen, dass sie ,die-Tochter-von“ ist. Solche Erfahrungen waren bisher selten, für sie aber immer schwierig, weil sie sich einerseits von ihm abgrenzen muss, andererseits innerhalb der Polizei nur in sehr begrenztem Umfang kritisch über ihn sprechen kann.

Neben zwei formalen Absagen erhält sie die Einladung zu zwei Bewerbungsgesprächen. Bei einem kann sie sich durchsetzen. Sie wird nur Wochen später, im Sommer 2013, Einsatzführerin im Polizeikommissariat Wolfenbüttel. Damit verbunden ist vermutlich eine weitere Beförderung zur Polizeihauptkommissarin

112 Aus Anonymisierungsgründen kann ich die Zeitung hier nicht nennen. 
(PHK'in). Es ist ein Dienstposten mit einer A11-Besoldung, der in der Regel an eine Stelle als PHK ${ }^{113}$ geknüpft ist. In dieser Position ist sie nun noch deutlicher in Führungsverantwortung, gleichzeitig fährt sie weiterhin mit den (untergebenen) Kolleg*innen Streife. Praktisch bedeutet dies nicht nur die Arbeit gemeinsam zu machen und sich koordinieren zu müssen, wer was wann bei einem Einsatz tut, sondern einfach auch viele Stunden gemeinsam zu verbringen, in denen viel Zeit ist, um miteinander zu sprechen - auch über das Privatleben, denn das ist gemeinschaftliche bzw. gemeinschaftsstiftende Praxis. Ihre Position hier erfordert freundschaftliche Kollegialität und Distanzierung zugleich, denn sie muss im Zweifel auch Entscheidungen durchsetzen können und die Arbeit ihrer Kolleg*innen zusammen mit dem Dienstabteilungsleiter überwachen. Auch hier begibt sie sich wieder in eine Situation, in der Loyalitätskonflikte angelegt sind.

In der ersten Zeit auf dieser neuen Stelle kommt es zu einem großen Streit mit ihrer engen Freudin Alicia. Melanie Wegener hat das Gefühl eingeengt zu werden: „von der ich mich jetzt auch, getrennt hört sich jetz komisch an=die Freundschaft musst ich beenden". Ihre Evaluation gleicht einer Trennungsgeschichte, wie sie viele Paarbeziehungen kennzeichnet: Am Anfang war alles super und wir haben viel miteinander gemacht und uns sehr gut verstanden. Dann hat Alicia meine Freizeit vollständig ge- und verplant und wollte nicht, dass ich etwas mit anderen Leuten und sogar meinen Geschwistern mache. Wir haben viel darüber gestritten, dass ich angeblich zu viel arbeite, aber ,ich musste ja jetz auchn Stück zu zur Arbeit fahrn un=und hatte nich mehr so viel Zeit halt". Melanie Wegener beendet die Freundschaft zu Alicia mit einem abschließenden (Trennungs-)Gespräch. „Das war dann wie ein Befreiungsschlag". Diesmal geht das Ende einer Beziehung von ihr aus und sie erlebt es als wiedergewonnene Freiheit. Wieder kann sie sich auf ihrer neuen Stelle in die Arbeit vertiefen und hat nun möglicherweise auch mehr Energie, um sich auf diese zu konzentrieren.

Um Redundanzen zu vermeiden, möchte ich hier abschließend statt einer Zusammenfassung - eine solche findet sich im Ergebniskapitel (Kap. 6.2.1) - die Situation von Melanie Wegener als Frau in der Polizei skizzieren. Melanie Wegener ist im Alter von 36 Jahren Polizeihauptkommissarin und hat Aufgaben mit Führungsverantwortung in einer männlich dominierten Arbeitsumwelt. Frauen sind in der Polizei nach wie vor unterrepräsentiert, und auch wenn sich ihr Anteil zwischen 1995 und 2015 mehr als verdreifacht hat, stellen Frauen dennoch nur ein Viertel der Beschäftigten im Polizeivollzugsdienst. In höheren Funktionen und Besoldungsgruppen sind sie deutlich unterrepräsentiert und es gibt eine verbreitete Skepsis gegenüber Frauen in Führungspositionen. ${ }^{114}$ Die oben beschriebenen

\footnotetext{
113 Als ich Melanie Wegener im Sommer 2016 kennenlerne, ist sie jedenfalls PHK'in. 114 Laut einem Forschungsbericht des Kriminologischen Forschungsinstituts Niedersachsen (Ohlemacher et al. 2002) sind die Vorurteile gegenüber Frauen in der Polizei deutlich zurückgegangen. Dennoch sehen 16,1 \% der befragten männlichen Polizisten einen tatsächlichen oder möglichen Nachteil von Frauen im Polizeidienst (Frauen: 2,4 \%). 18,3 \% der befragten Männer sehen Nachteile
} 
„Tests“ können als ein Ausdruck dieser Skepsis gelesen werden. Zwar mag es auch bei männlichen Vorgesetzten (und Kollegen) zu solchen Tests kommen, doch geht es hier darum, als Frau eine Stärke zu beweisen, die in verbreiteten geschlechterstereotypen Vorstellungen eher Männern zugeschrieben wird. Es lässt sich vermuten, dass Melanie Wegener intensiver getestet wird als ihre männlichen Kollegen. Gleichzeitig gibt es im näheren Umfeld nicht so viele Kolleginnen auf der gleichen Hierarchieebene, mit denen sie sich darüber austauschen könnte. Es gibt keine weibliche Bezugsgruppe.

Der Aufstieg von Frauen, so zeigt auch dieser Fall, wird strukturell z.B. durch Förderprogramme unterstützt, im Arbeitsalltag sind Frauen dann aber konfrontiert mit der Unterstellung, aufgrund ihres Geschlechts bevorzugt zu werden: „Wenn man Ausländer ist oder eine Frau, am besten beides, dann wird man gefördert. Und wenn man dann noch in den Arsch kriecht, dann schafft man es“, so äußert sich ein Polizist in einem Gespräch mit mir über die Beförderungspraxis in der Polizei. Dies weist auch im Kontext eines Diskurses um die Bevorzugung von Frauen auf die Zuschreibung hin, dass Frauen praxisferne Aufsteigerinnen seien; Männern hingegen wird bei gleicher Laufbahn Erfahrung attestiert (vgl. Pfeil 2006: 131 f.). Im Einsatz- und Streifendienst auf einer unteren Führungsebene zu verbleiben, löst die diskursiven Zuschreibungen etwas auf. Im Streifendienst wird ,richtige' Polizeiarbeit gemacht, dies hat Melanie Wegener in verschiedenen Positionen getan bzw. tut es noch. So hat sie die Möglichkeit solchen Zuschreibungen zu begegnen, im Gegensatz zu Frauen, die eine Laufbahn im höheren Dienst anstreben. Melanie Wegener macht aber auch jenseits ihrer Position in der Hierarchie diskriminierende Erfahrungen aufgrund ihres Geschlechts, wie in der oben geschilderten Situation in ihrem Praktikum, aber auch später als ,vollwertige' Polizistin. Diese Erfahrungen werden von ihr, auch auf direkte Nachfrage, im Interview nicht als diskriminierend präsentiert, sondern als ,normales' männliches Verhalten. Ihre Antwort auf dieses Verhalten ist, sich selbst unterordnend und ausgleichen zu verhalten.

Dass Melanie Wegener alleinstehend ist und keine Kinder hat, ist ein KarriereVorteil gegenüber anderen Polizist*innen, vor allem jedoch gegenüber ihren weiblichen Kolleginnen mit Kindern. Melanie ist sehr flexibel. Überstunden oder kurzfristige Änderungen der Arbeitszeiten stellen für sie keine Probleme in Bezug auf die Versorgung von Familienmitgliedern dar. Auch der Wechsel von Arbeitsorten und der Wechsel zwischen Tätigkeiten im Tagesdienst oder im Wechselschichtdienst sind unproblematisch. Sie kann Vollzeit arbeiten und hat keine Unterbrechungen durch Mutterschutz ${ }^{115}$ etc. Eine Karriere in der Polizei erfordert Einsatz

von Frauen in Führungspositionen (Frauen: 2,6 \%) (ebd.: 29). Auch wenn diese Befragung nun schon ca. 15 Jahre zurück liegt, ist davon auszugehen, dass sich dies nur langsam verändert. 115 Schon während der Schwangerschaft dürfen/können Frauen nur noch eingeschränkten Dienst leisten. Für die Tätigkeit im Streifendienst bedeutet dies unter anderem keinen Außendienst und keine Nachtschichten mehr. Zu den damit verbunden diskursiven Verschränkungen von Ausfallzeiten und Geschlecht siehe Pfeil (2006). 
von Zeit und Flexibilität (vgl. Pfeil 2006: 99). Melanie Wegener kann dies alles aufgrund ihrer biographischen Situation erfüllen, gleichzeitig schränkt sie ihre berufliche Eingebundenheit in anderen Lebensbereichen ein. Sie ist in einer herausfordernden Position, aber dennoch sehr gut eingebunden in ihren Kolleg*innenkreis, darüber hinaus sind es aber vor allem ihre Mutter und die Geschwister, zu denen sie eine enge Beziehung hat. Freundschaftliche Beziehungen existieren eher lose, auch weil die alten Kolleg*innen, mit denen sie freundschaftlich verbunden war, „jetz fast alle Kinder un Familie ham“. Gleiches gilt für ihre Freundinnen aus der Schulzeit. Ihre berufliche Karriere und die starke Einbindung in ihren Beruf lassen das Fehlen von engen Freundschaften jedoch in den Hintergrund treten. Enttäuschungen über einzelne Personen/Polizist*innen und Kontaktabbrüche mit Kolleg*innen kann sie ausblenden, da die Polizei als Institution für mehr als das Handeln einzelner Personen steht. Zugespitzt ließe sich formulieren, dass ihre Beziehung zur Polizei eine Paarbeziehung ersetzt, da sie in der Polizei das bekommt, was sie in der Beziehung ihrer Eltern nicht gesehen und in ihren eigenen Beziehungen nicht gefunden hat: Solidarität und Verbindlichkeit.

\subsection{Polizist-Werden und Polizist-Sein als Ermächtigungsprozess: Der Fall von Markus Holtzmann}

Im Folgenden soll die Rekonstruktion des biographischen Verlaufs von Markus Holtzmann - wie ich meinen Interviewpartner nennen möchte - dargestellt werden. Markus Holtzmann ist, als ich ihn kennenlerne, Polizeikommissar und arbeitet im Einsatz- und Streifendienst in Cloppenburg. Zum Zeitpunkt des Interviews, das im Spätsommer 2014 stattfindet, ist Markus Holtzmann 30 Jahre alt, seit Kurzem verheiratet und erwartet sein erstes Kind, das drei Wochen später geboren werden soll. Trotzdem, oder vielleicht auch gerade deswegen, erklärt er sich bereit mir ein Interview zu geben. Zum Zeitpunkt des Interviews blickt er, wie ich unten zeigen werde, sehr positiv auf seine gegenwärtige Lebenssituation.

Sein Kontakt wurde mir über eine Zufallsbekanntschaft, die ich in einem Workshop kennengelernt hatte, vermittelt. Sie selbst studierte Erziehungswissenschaften, hatte Jahre zuvor aber ein Studium bei der Polizei begonnen und abgebrochen. Markus Holtzmann war einer ihrer Kommilitonen gewesen. Nachdem ich ihm eine Interviewanfrage, die zunächst über seine ehemalige Kommilitonin übermittelt wurde, geschickt hatte, meldete er sich schnell zurück. Wir tauschten noch eine E-Mail aus, in der er sofort zusagte, dass er das Interview machen werde und er sich schon selbst gefragt habe, warum er Polizist geworden ist - ich hatte meine Interviewanfrage unter anderem damit gerahmt, dass ich an der Berufswahl interessiert bin. 
Im Folgenden werde ich zeigen, dass Markus Holtzmann einen Fall repräsentiert, bei dem die Berufswahl eine Ermächtigung über Außenseiter- und Mobbingerfahrungen in Kindheit und Jugend darstellt. Die Polizei stellt für ihn eine Organisation dar, die Autorität und Gelassenheit repräsentiert. In seiner konkreten Position in der Polizei ist es ihm möglich, sich aus einer machtstärkeren Interaktionsposition seinem nicht-polizeilichen Anderen zuwenden zu können und Erfahrungen von Machtlosigkeit zu vermeiden.

\subsubsection{Die Präsentation seiner Lebensgeschichte}

Wie auch andere Präsentationen von Polizist*innen, ist auch Markus Holtzmanns Darstellung fast gänzlich chronologisch an seiner Laufbahn orientiert. Die Präsentation ist dreigeteilt: Nach einem ersten Teil zu Geburt und Schule geht es im zweiten Teil um seine polizeiliche Laufbahn, um im dritten Teil seine heutige Lebenssituation zu beschreiben. Auch wenn diese Aufteilung grob ausgemacht werden kann, wird sie deutlich häufiger durchbrochen als in dem Fall von Melanie Wegener. Markus Holtzmanns polizeiliche Laufbahn ist, im Vergleich, auch auf der Handlungsebene stärker bestimmt von seinem Privatleben.

Markus Stil ist vor allem beschreibend und argumentativ. Erst im Nachfrageteil lässt er sich auf Erinnerungen ein und erzählt; die Erzählungen beziehen sich nur auf kurze Szenen und er kommt in keinen Erzählfluss. Markus Holtzmann erläutert mir, verglichen mit anderen Interviewten, recht wenig über polizeiliche Arbeit, sondern knüpft an mein vermeintliches Wissen an, das er mir zuschreibt, weil er weiß, dass ich bereits andere Interviews geführt habe und mich schon länger mit der Polizei beschäftige.

Markus Holtzmann präsentiert sich als durch und durch ,normal': Eine normale, heile Familie, eine gute und normale Kindheit und heute ein normales Familienleben mit seiner ,eigenen', gerade entstehenden Familie. Er thematisiert durchaus auch Probleme, wie Mobbing-Erfahrungen, aber er bleibt dabei stets der ,Normale ${ }^{6}$ - in seinem Deutungsmuster sind es die anderen, die dies nicht sind. Familiale Werte wie Ordnung und Angepasstheit sind ihm wichtig; sie fungieren in seiner Darstellung als Abgrenzung zu anderen, die in diesem Sinne eben nicht normal sind. Er präsentiert sich als ,Opfer ${ }^{6}$ der anderen, die nicht normal sind, aber auch als ,Opfer' der Organisation Polizei, die über ihn bestimmt. Diese Präsentation von heteronom produziertem Leid und Fremdbestimmung ändert sich im Verlauf seiner Selbstdarstellung allerdings und er präsentiert auch eigene Aktivität. Er zeichnet sich als Gemeinschaftsmensch: In seine Familie ist er eingebunden und sie ist sehr wichtig für ihn. Aber auch die Polizei erfüllt seinen Wunsch nach Gemeinschaft und Solidarität. Dem entgegen stehen seine Erfahrungen, wie schwierig es für ihn war, Zugang zu dieser polizeilichen Gemeinschaft zu bekommen.

Seine Präsentation hat ihren Höhepunkt in der Darstellung seiner jetzigen Lebenssituation und dem Umstand, dass er nun da ist, wo er sein möchte im Leben: 
Er hat einen guten Job, den er gerne macht, und eine eigene Familie gegründet. Die Präsentation seiner Lebensgeschichte wirkt dadurch so, als ob alles schicksalhaft auf seine jetzige Lebenssituation zugelaufen wäre.

\subsubsection{Die Fallgeschichte}

Markus Holtzmann wird 1984 in Ganderkesee im Kreis Oldenburg, ca. 20 Kilometer entfernt von Bremen, in Niedersachsen geboren. Markus ist das erste Kind seiner Eltern. Markus Mutter, Renate, ist bei der Geburt ihres ersten Kindes 25 Jahre alt und arbeitet seit ihrer Ausbildung als Zahntechnikerin in einer Zahnklinik in Bremen. Diesen Beruf gibt sie vorerst auf, um sich um ihren Sohn zu kümmern. Wann und wie Renate ihren Mann kennengelernt und geheiratet hat, ist nicht bekannt. Zum Zeitpunkt der Geburt sind Renate und Markus Vater, Matthias, verheiratet. Matthias ist 1957 geboren und damit zwei Jahre älter als seine Frau. Er hat eine Ausbildung im Bereich Informationstechnik bei der Deutschen Bundespost gemacht. Zum Zeitpunkt von Markus Geburt hatte er die Post bereits verlassen und eine Anstellung bei einem EDV-Unternehmen.

Beide Eltern haben nach der Mittleren Reife eine Ausbildung begonnen und arbeiten als Angestellte. Die Mutter bewegt sich dabei in einem teilweise akademischen Umfeld, ist aber als Zahntechniker*in immer auch in einer untergeordneten Position den Ärzt*innen gegenüber. Ob der Vater bei der Post noch verbeamtet wurde, ist nicht bekannt. Die Post kann in den 1980er Jahren aber wohl als solider Arbeitgeber verstanden werden und der Ausstieg aus diesem Unternehmen in den privatwirtschaftlichen EDV-Sektor zu dieser Zeit deutet ,Pioniergeist ${ }^{6}$ an, so wie die Wahl des Berufes selbst, da zu seinem Ausbildungsbeginn Mitte der 1970er Jahre der Bereich der Informationstechnik zu den historisch noch jungen, nicht traditionellen Berufen gehörte.

Markus wird in eine Familie der Mittelschicht geboren und in einem modernen, aber doch auch noch kleinbürgerlichen Arbeitnehmermilieu sozialisiert (vgl. Vester et al. 2001: 516 ff.). Zugehörige zu diesen Milieus zeichnen sich unter anderem dadurch aus, dass sie eine hohe Berufsqualifizierung als Angestellte und Arbeitnehmer*innen in modernen Berufen im Bereich von Technik und (Sozial-)Administration haben. Für diesen Teil der Mittelschicht gilt, dass ein sozialer Aufstieg nicht zentral ist, aber ein Vorankommen angestrebt wird, das ihnen eine gesicherte und anerkannte soziale Lage ermöglicht, wo die eigene Vorstellung von einem guten Leben verwirklicht werden kann (vgl. ebd.).

Auf der Ebene der Erwerbsarbeit können wir zunächst von Gleichberechtigung ausgehen, beide Eltern sind, noch dazu auf einer ähnlichen Qualifizierungsstufe, berufstätig. Möglicherweise ist es auch ökonomisch notwendig, dass beide Elternteile zum Lebensunterhalt beitragen. Dennoch zeigt sich ein durchaus traditionelles Verständnis von Geschlechterbildern und Fürsorgearbeit, wenn die Mutter von Markus Holtzmann eine längere Erziehungszeit nimmt - ein in den 1980er Jahren in Westdeutschland noch recht weit verbreitetes Modell (vgl. Allmendinger 
et al. 2008): Es gibt wenige Möglichkeiten sehr kleine Kinder betreuen zu lassen, Kindertagesstätten sind kaum verbreitet und die Fürsorgearbeit wird vor allem von den Müttern geleistet, während die Väter Hauptverdiener sind.

Über die Großeltern spricht Markus Holtzmann kaum. Auf Nachfrage werden einige Rahmendaten genannt, die in der Art ihrer Präsentation darauf hinweisen, dass darüber hinaus kaum Wissen über die Familiengeschichte besteht und auch kaum darüber gesprochen wird. Da dies aufgrund der Familiengeschichte erstaunlich ist, werde ich die wenigen bekannten Daten nennen. Markus Holtzmann thematisiert im Interview lediglich seine Großmutter väterlicherseits, die auch in Ganderkesee lebt und zu der er in seiner Kindheit ein enges Verhältnis hat. Den Großvater väterlicherseits lernt Markus nicht mehr kennen. Seine Oma ist 1930 geboren. Für den Großvater kann ein ähnliches Alter angenommen werden, er ist vermutlich aber älter als seine Frau und damit wahrscheinlich ein 1920er Jahrgang. Während Markus Holtzmanns Großmutter aus der Nähe von Ganderkesee kommt, ist sein Großvater in Schlesien geboren und nach seiner „Flucht dann hier gewesen“. Die Großeltern haben im selben Betrieb im lederverarbeitenden Gewerbe gearbeitet, sich vermutlich dort kennengelernt und in den 1950er Jahren geheiratet. Aus der Ehe gehen Markus Vater und drei weitere Kinder hervor, unter anderem ein Onkel von Markus Holtzmann, bei dem Markus während seiner Schul- und Studienzeit phasenweise wohnen wird. Zum Zeitpunkt von Markus Geburt lebt die Großmutter alleine in Ganderkesee, der Großvater ist schon verstorben.

Auch über die Großeltern mütterlicherseits ist wenig bekannt. Sie sind vermutlich beide zwischen 1928 und 1930 in Pommern geboren, die Stadt in der sie gelebt haben, ist Markus nicht bekannt. Sie haben bis 1958 in Polen gelebt und beide im Bereich der Fischerei bzw. dem Fischhandel gearbeitet. Dass sie nach 1945 nicht ,vertrieben' wurden, kann eventuell ein Hinweis darauf sein, dass ihre Familien in Polen nach Ende des Krieges nicht als Nazis angesehen oder denunziert wurden und sich vermutlich auch nicht als solche verstanden haben und daher zunächst für ein Bleiben entschieden. Dass sie 1958 ausgereist sind bzw. nach Deutschland einreisen konnten, deutet außerdem darauf hin, dass sie als sogenannte Volksdeutsche galten. Sie sind in der Region Bremen ansässig geworden und der Großvater hat weiter im Bereich der Fischerei gearbeitet. Geheiratet haben sie vermutlich schon in Polen, ihre beiden Kinder sind dann aber erst nach ihrer Migration geboren: Markus Mutter Renate 1959/1960 als erstes von zwei Kindern.

Auf beiden Seiten der Familie können wir Erfahrungen des Verlustes von Heimat feststellen. Für die Großelterngeneration, die in Pommern und Schlesien geboren ist, kann außerdem angenommen werden, dass sie zu Zeugen der NSVerbrechen wurden und dass sie bei Kriegsende selbst viel Leid erlebt haben. Sowohl das Leben in Polen nach Kriegsende als auch das Leben als ,Flüchtlinge in den Nachkriegsjahren in Deutschland war vermutlich entbehrungsreich für die damals noch Jugendlichen/jungen Erwachsenen. Da weder die genaueren Um- 
stände noch Orte bekannt sind, kann darüber nur spekuliert werden. Relevanter erscheint mir daher die Frage, warum es so wenig Wissen über die Lebensgeschichten der Großeltern gibt bzw. nicht mehr Wissen über sie präsentiert wird. Einerseits sind alle Großeltern von Markus Holtzmann mit Migrationsgeschichte vor seiner Geburt oder in seiner frühen Kindheit gestorben. Ein direktes Nachfragen war ihm so kaum möglich. Es bedeutet aber auch, dass weder seine Mutter noch sein Vater über die Erfahrungen ihrer Eltern sprechen und/oder auch selbst nur wenig darüber wissen. Andererseits wird eine solche Dethematisierung auch im Kontext der Lebensgeschichte von Markus Holtzmann plausibel: Markus Holtzmann, der sich mit seiner Berufswahl über Ausgrenzungserfahrungen ermächtigt, wie ich später zeigen werde, kann Migrations-, Opfer- und Leiderfahrungen in der Präsentation seines Lebens nur begrenzt unterbringen. Dass dies anscheinend auch familial nicht thematisiert wird, kann als eine Distanzierungsbewegung von diesen Erfahrungen sowie dem einfachen Handwerks- und Hilfsarbeitermilieu gedeutet werden.

Auch wenn unklar ist, ob und wie stark die Großeltern die NS-Ideologie internalisiert hatten, ob und wie sehr sie in die Jugendorganisationen des ,Dritten Reiches` eingebunden waren, hat das Kriegsende 1945 ihre Zukunfts- und Lebenspläne mindestens verändert, wenn nicht zerstört (vgl. Rosenthal 1986). Das Ende des ,Dritten Reiches' fällt für sie in eine Phase, in der ein Loslösungsprozess vom Elternhaus beginnt - auch auf dieser Ebene kann also Verunsicherung vorherrschen. Wenn dies auch nicht abschließend geklärt werden kann, kann eine Bearbeitung, im Kontext der Unsicherheit, wie das Leben sich im NachkriegsPolen entwickeln wird, und dem Verlust von Heimat, eine Konzentration auf die Familie sein, die im Vergleich zu den Umständen Stabilität verspricht. Die engen Familienbindungen, die für Markus Holtzmann relevant werden, und die lokale Gebundenheit an seine Herkunftsregion haben hier möglicherweise ihren familialen Ursprung.

Insgesamt kann für die Großelterngeneration festgehalten werden, dass sie in Kindheit und Jugendjahren vermutlich alle kriegsbedingt belastende Erfahrungen gemacht haben und es scheint viele Themen zu geben, die familial nicht verhandelt werden können. Markus lernt in seiner Familie vermutlich keine Auflehnung dagegen oder ein Hinterfragen kennen, sondern eine Orientierung an konservativen Werten wie Rechtschaffenheit, Ordnung und Disziplin. Obwohl beide Elternteile moderne und anspruchsvolle Berufe ergreifen, sind sie doch in einem zumindest teilweise kleinbürgerlichen, aber modernen Arbeitnehmermilieu verhaftet und orientieren sich an und in ihrer Lebenswelt an einem Milieu, das Familie, ökonomische Sicherheit und private Zufriedenheit in den Mittelpunkt stellt.

\section{Kindheit und Jugend: Die Sicherheit der Familie und die unsichere Außenwelt}

Als Markus Holtzmann 1984 als erstes Kind seiner Eltern geboren wird, leben sie in einem Mehrfamilienhaus in Ganderkesee. Vorwiegend kümmert sich Renate 
um ihn. Sie ist jetzt Hausfrau und Mutter. In dieser Rolle wird Renate für Markus eine wichtige Bezugsperson:

„meine Mutter, also meine Mutter war immer (richtig) so typisch wie man sich das vorstellt mit ner Mutter ne, die Mutterfigur, also mit der hab ich keine großen Interessengemeinschaften aber, das war immer so meine Vertrauensperson Nummer eins ne //I: hmbm// also $d$-, wie man sich das eigentlich wünschen, sollte"

Hier deutet sich Markus Vorstellung von einer guten Mutter an: Eine fürsorgliche Mutter, die für ihn da ist und der er sich anvertrauen kann. Sie ist immer für ihn da, während der Vater arbeitet. Mit diesem verbindet Markus im Gegensatz dazu eine „Interessengemeinschaft“. Hier zeigt sich eine traditionelle Geschlechterrollenverteilung, in der der Vater für die Freizeitaktivitäten ,zuständig' ist und die Mutter für die körperliche und emotionale Versorgungsarbeit.

Als Markus Holtzmann fast vier Jahre alt ist, wird 1988 sein jüngerer Bruder Christoph geboren und er selbst kommt in den Kindergarten. Markus beschreibt ihr Verhältnis in seiner Kindheit als „ganz gutes“. Es kann aber davon ausgegangen werden, dass die Geburt seines Bruders zunächst Eifersucht auslöste. Nachdem seine Mutter drei Jahre ausschließlich für ihn da gewesen ist, muss er sich nun die Aufmerksamkeit teilen und der Beginn der Kindergartenzeit kann in dieser Konstellation auch als Ausschluss aus der Familie erlebt werden. Es deutet sich an, dass Markus Holtzmann und sein Bruder miteinander verglichen, aneinander gemessen wurden:

„also er war auch als Kind immer so der=der Rubigere und Klügere und (_ ) so Niedliche, und ich war als Kind, ähm, [...] so richtig, richtig, so=n richtiger Wildfang und richtig anstrengend ne"

Wenn auch manche der Zuschreibungen sicherlich nicht aus der frühen Kindheit stammen, zeigt sich doch eine Konkurrenzsituation, die schon mit der Geburt des kleinen Bruders ihren Anfang nahm und später weitere Relevanz erhält. Man kann annehmen, dass Markus Holtzmann im Vergleich zu seinem Bruder, „dem Ruhigen und Klügeren“, öfter gemaßregelt wurde. Auf der erzählerischen Ebene thematisiert Markus aber sein gutes Verhältnis zu seinem Bruder, nur getrübt von dem „üblichen Zank“ unter Geschwistern. Von ihrem gemeinsamen Spielen erzählt er detailliert.

Markus Holtzmann, wie auch später sein Bruder, absolvieren die Grundschule und die Realschule. ${ }^{116}$ Erlebt er die Grundschule noch als gute Zeit, wird es nach dem Schulwechsel in die Orientierungsstufe schwieriger für ihn. Markus erlebt ausgeschlossen zu werden:

116 Es ist nicht bekannt, wann genau Renate wieder anfing zu arbeiten. Sie arbeitete jedenfalls seit Markus Kindheit wieder in einem Dentallabor. Vermutlich hat sie aber nicht vor Markus 7. Lebensjahr wieder begonnen zu arbeiten, da Christoph wahrscheinlich mindestens in den Kindergarten ging, als sie ihre (Teilzeit-)Erwerbstätigkeit wieder aufgenommen hat. 
„, da hatts de dann so=n paar Arschlöcher dabei und, die, die dann irgendwie, ja (2) die einen da irgendwo teilweise das Leben schwer gemacht haben, so (2) und ich war halt erzogen weißte ich hab halt da nicht den Streit gesucht oder so oder die Konfrontation sondern ich bin dem eigentlich immer mehr so aus dem Weg gegangen wollt meine Ruhe haben ne [...] ja ( ) war man so=n bisschen in=er Ecke wo man so immer so=n bisschen der Typ war der so der, so, na ich will jetzt sagen Opfertyp aber schon so wo man dachte irgendwie es macht halt nicht mehr so=n Spaß zur Schule zu gehen "

Markus Holtzmann hat Probleme mit einigen seiner Mitschüler. Auch wenn er es eigentlich nicht sagen möchte, spricht er sich selbst doch als „Opfertyp“ an. Er begibt sich damit in die passive Rolle, Spielball anderer zu sein; sein ,Leid‘, das er auch heute noch nicht richtig benennen kann, ist heteronom produziert. Er macht eine Unrechtserfahrung, gegen die er sich nicht wehren kann, da ihm seine Erziehung im Wege steht. Er bettet sich in seine Familie und ihre Werte ein. Ein Bestandteil dieser Werte scheint unter anderem zu sein, dass man sich nicht streitet. Möglicherweise bedeutet dies auch, dass es in der Familie wenig Auseinandersetzungen über Probleme gibt und die Familienmitglieder einander bei Meinungsverschiedenheiten nicht konfrontieren. Markus grenzt sich von Kindern aus „Assifamilien“ ab, die schmutzige Kleidung tragen und die Schule schwänzen. Ordnung, Sauberkeit und Pflichtgefühl - „anständig sein“ - werden von ihm als familiale Werte transportiert. Diese Distinktionsbemühungen sind Teil seiner Strategie, seine Opfererfahrungen zu bearbeiten. Ein anderer Weg ist für ihn Rückzug: Er sucht sich Hobbies, die er alleine und im Schutz der Familie machen kann. Unterstützt wird er dabei von seinem Vater. Er entdeckt z.B. die Musik-/Schallplattensammlung seines Vaters für sich, beginnt Musik zu machen und passende Videos zur Musik zu drehen. Neben der Nähe, die er so zu seinem Vater herstellen kann - oder der Vater zu seinem Sohn herstellt -, lernt Markus sich mittels anderer Medien als der Sprache auszudrücken. Auch dies kann als Hinweis darauf verstanden werden, dass Probleme nicht besprochen werden, sondern anders kanalisiert bzw. anders kommuniziert werden müssen.

Nach dem Wechsel auf die Realschule - viele Mitschüler*innen bleiben die gleichen - wird es für Markus nicht besser:

„also es gab nie irgendwie, wie Schlägereien oder Gewalt oder so //I: hmhm// das war immer mehr so dieses, ja: (2) man kanns vielleicht schon Mobbing nennen"

Markus Holtzmann fühlt sich ausgeschlossen und belächelt, möglicherweise auch aufgrund seiner eher kreativen Hobbys, die in diesem Alter zwischen 10 und 15 Jahren nicht den geschlechterstereotypen Hobbys entsprechen. Spricht er heute aus seiner stärkeren Position (als Polizist) darüber und bezeichnet es als Mobbing, kann man davon ausgehen, dass er diese Zeit als sehr hart erlebt hat und er sich auch unter diesen Umständen auf seine Familie und einige wenige Freunde aus der Kindergartenzeit zurückgezogen hat. Die Familie bietet ihm Sicherheit, die 
Außenwelt der Schule ist wiederum der Raum, in dem er Unsicherheit und Ausgrenzung erfährt.

Markus rationalisiert diese Erfahrungen unter der fehlenden intellektuellen Reife seiner ,Kontrahenten“ und hebt im Gegensatz dazu Personen hervor, mit denen er „mehr anfangen konnte“ - diese kamen aus Akademiker*innen-Familien, gingen aufs Gymnasium oder waren schon etwas älter. Er verortet sich dabei in einem anderen Herkunftsmilieu bzw. schließt seine Familie und sich in ein anderes Milieu ein und grenzt sich nach ,unten“ von den „Assis“ in der Realschule, zu der er selbst geht, ab.

In der neunten Klasse muss er ein zweiwöchiges Praktikum absolvieren. Unterstützt von seinen Eltern bewirbt er sich bei Radio Bremen. Seine Eltern haben ihn auf die Idee gebracht, dass er mit seinen kreativen Fähigkeiten und Interessen im Bereich Film, TV oder Radio arbeiten könnte. Damit weisen sie ihn auf eine moderne Branche hin, in der Berufe viel Entwicklungspotenzial bieten - ein ähnlicher Weg, wie der des Vaters. Im Praktikum macht er jedoch die Erfahrung, dass er als Praktikant nicht kreativ arbeiten darf, sondern vor allem Hilfstätigkeiten erledigt und in der Hierarchie ganz unten steht. Markus problematisiert dies im Interview als generelles Problem in diesem Bereich und nicht im Zusammenhang mit seiner Position als Praktikant.

Markus Holtzmann muss nun, trotz der Schwierigkeiten mit seinen Mitschüler*innen, die Mittlere Reife abschließen, um zumindest das Bildungsniveau der Eltern zu halten. Entgegen seiner oben beschriebenen Verortung ist er ein nur mittelmäßiger Schüler. Seine Eltern drängen ihn nicht zu hohen schulischen Leistungen, sondern haben ihn bisher, wie beim Praktikum, eher entlang seiner Interessen unterstützt. Gibt es von ihrer Seite einen Bildungsauftrag, so ist er nicht an formaler (Schul-)Bildung orientiert. Die familialen Distanzierungsbewegungen weg vom einfachen Handwerks- und Hilfsarbeitermilieu - zeichnen sich bis dahin nicht durch einen universitären Bildungsaufstieg, sondern vielmehr durch moderne Berufe mit Entwicklungspotenzial aus. Ein Realschulabschluss ist dafür aber dennoch notwendig.

\section{Berufswahl - Polizei als Ambivalenz von Ermächtigung und Durchbalten}

Im Frühjahr 2000, im Alter von 16 Jahren, muss Markus Holtzmann sich Gedanken über seine berufliche Zukunft machen. Seine belastenden Erfahrungen in der Schule fördern sicherlich den Wunsch, die Schule zu beenden und eine Ausbildung zu machen, anstatt ein Abitur anzustreben und so weiter in die Schule gehen zu müssen. Auch mit Blick auf die (Aus-)Bildungsinteressen des Elternhauses ist ein Abitur nicht notwendig. Seine Eltern unterstützen weiterhin eine Berufswahl in einem kreativen Bereich. Er bewirbt sich um zwei verschiedene Ausbildungsplätze im Bereich von Ton-, Medien- und Veranstaltungstechnik im nahe gelegenen Bremen.

Außerdem bewirbt er sich auch bei der Fachoberschule für Wirtschaft und Verwaltung in Oldenburg, die nach einem zweijährigen Schulbesuch inklusive 
einjährigem Praktikum, unter anderem im Polizeivollzugsdienst, ein fachgebundenes Abitur ermöglicht. ${ }^{117}$ Markus erzählt, dass er auf die Idee kam, Polizist werden zu können, als er in der Fußgängerzone zwei Polizisten beobachtete, die eine Gruppe Jugendliche kontrolliert hatten und sich dann im Anschluss einen Döner kauften.

„,da dacht ich so das ist eigentlich doch $n$ ziemlich cooler Job also diese Vorstellung, einfach dass du balt nicht irgendwo in deinem Büro sitzt oder in deinem Geschäft oder so und nicht rauskommst (2) und dann du balt ( ) überall bist, du fährst umber du bist riemlich spontan mal hier mal da je nach dem wo du gebraucht wirst / / : hmhm/ / und gehst zwischendurch mal lässig irgendwo rein und holst dir was zu Essen und so / / I: ((lacht))//, vorher noch kurz für Ordnung sorgen (1) du lebst halt so in=er Öffentlichkeit, so also (2) jetzt nicht dass alle auf dich gucken so Öffentlichkeit sondern einfach dass du so am öffentlichen Leben überall so, überall so $=n$ bisschen //I: hmhm// mit rumwuselst so //I: $\mathrm{hmhm//} \mathrm{das=das,} \mathrm{ich} \mathrm{weiß} \mathrm{nicht} \mathrm{wie-wo} \mathrm{ich} \mathrm{dachte} \mathrm{irgendwie} \mathrm{die} \mathrm{sind} \mathrm{so,} \mathrm{überall} \mathrm{so} \mathrm{mit-}$ tendrin //I: hmhm// und das hat mich irgendwie (inspiriert), so, wie, ich weiß, da hab ich das erste Mal so gedacht irgendwie so, Polizei und Streife fahrn das is doch eigentlich ganz, gan₹, lässig"

Markus Holtzmanns Idee, Polizist werden zu können, entwickelt sich erst, als er in der Phase ist, sich konkret Gedanken über eine Ausbildung machen zu müssen. Er ist beeindruckt von der Spontaneität, der Vorstellung, sich frei in der Öffentlichkeit bewegen zu können, überall dabei zu sein und sich seinen Tag selbst einteilen zu können, wie eben augenscheinlich selbst gewählte Pausen. Diese Vorstellungen implizieren, dass Polizist*innen sich selbstbewusst und respektiert in der Öffentlichkeit bewegen können - Erfahrungen, die Markus Holtzmann bisher in der Schule vermisste.

Markus Holtzmanns Bewerbungen um Ausbildungsplätze bleiben ohne Erfolg. Es ist möglich, dass sich dies schon abzeichnete und er auf der Suche nach einer Alternative zu einer beruflichen Zukunft in diesem Bereich war, als die Idee ,Polizei‘ entstand. Die Polizei wäre damit zweite Wahl. Er rationalisiert diesen Misserfolg im Interview, indem er betont, wie gut er es mit seinem jetzigen Beruf

117 Die Fachoberschule kann unter anderem nach Abschluss der Realschule besucht werden. In der 11. Klasse muss ein Praktikum abgeleistet werden, der Schulunterricht findet nur an 1-2 Tagen pro Woche statt. In der 12. Klasse ist nur Schulunterricht. Die Fachoberschulen sind in verschiedene Fachrichtungen gegliedert; das Praktikum muss in der jeweiligen Fachrichtung absolviert werden. Nach erfolgreichem Abschluss der 12. Klasse ist man zum Fachhochschulstudium berechtigt (vgl. Niedersächsisches Kultusministerium o.J.).

Bei der FOS für Wirtschaft und Verwaltung kann das Praktikum im Bereich Verwaltung unter anderem im Polizeivollzugsdienst geleistet werden, neben allgemeiner (öffentlicher) Verwaltung und dem Bereich Rechtspflege. Für Realschüler*innen ist dies der einzige (direkte) Weg in die niedersächsische Polizei. Vgl. https://bbs-wechloy.de/bildungsangebot/vollzeitschulformen/zweijaehrigefachoberschule-wirtschaft-und-verwaltung-schwerpunkt-verwaltung-und-rechtspflegeeinschliesslich-polizeivollzugsdienst/kurzportrait.html [letzter Zugriff: 26.03.2020]; https://www.polizei-studium.de/mittlere_reife_realschule,9.html [letzter Zugriff: 26.03.2020]. 
getroffen habe und dass manche Dinge wie die Musikvideos einfach Hobby bleiben sollten. In der damaligen Situation kann er es aber als eine Absage an seine Fähigkeiten gedeutet haben. Der von den Eltern unterstützte Berufsweg scheint für den Moment verschlossen. Markus Holtzmann erhält zwar praktische Unterstützung von seinen Eltern bei der Bewerbung bei der Polizei, gleichzeitig äußert sein Vater Bedenken gegenüber dem Beruf:

„,und da hat er gesagt das kann ich mir bei dir irgendwie nicht so vorstellen du bist für $=n$ Polizist eigentlich viel zu nett / / : hmhm// das weiß ich noch wie er das gesagt hat ne"

Matthias traut seinem Sohn nicht zu, dass er sich durchsetzen kann. Der Beruf des Polizisten passt außerdem nicht in das Bild von modernen, sich entwickelnden Berufsfeldern. Markus bewirbt sich trotz dieser Bedenken seines Vaters um einen Praktikumsplatz bei der Polizei. Dies wiederum steht der Lesart, Polizist zu werden könnte die zweite Wahl sein, entgegen. Dann wäre der kreative Bereich mehr der Wunsch der Eltern als sein eigener gewesen. Geht man von einem Familiensystem aus, in dem Probleme nicht besprochen werden, um das System zusammenhalten, dann ermöglichen Markus Holtzmann erst die Absagen, seinem Wunsch nachzugehen.

In dem Bewerbungsverfahren bei der Polizei muss er einen kleinen schriftlichen Test ablegen. Er besteht diesen Test. Es ist ein Erfolgserlebnis nach all den vorherigen Absagen. Damit erhält er auch die Zusage der Fachoberschule. Dies kann auch als ein Erfolg gegenüber seinem Vater gelesen werden, der ihm den Beruf nicht zutraut. Mit dieser Zukunftsperspektive und dem Wissen darum, dass die Realschulzeit bald vorbei ist, erlebt er das letzte halbe Jahr vor dem Schulabschluss positiver. Seine Perspektive ist nun auch eine längerfristige. Es ist für ihn nun nicht nur möglich, das Fachabitur zu erlangen, sondern sich auch auf ein Studium für den Polizeidienst vorzubereiten.

Mit 16 Jahren beendet Markus Holtzmann im Sommer 2000 die Realschule und erhält den Bescheid, dass sein Praktikumsplatz nicht, wie er dachte, zu Hause in Ganderkesee, sondern im 20 Kilometer entfernten Wildeshausen sein wird. Dies ist ein Rückschlag für ihn und die erste Erfahrung damit, dass bei der Polizei „gewisse Sachen einfach gesetzt werden“. Im September beginnt sein Praktikum bei der Polizei, begleitet von ein bis zwei Schultagen in der Woche. Die Fachoberschule für Wirtschaft und Verwaltung ist in Oldenburg. Hier wohnt ein Onkel, ein Bruder seines Vaters, mit seiner Frau und ihren zwei Söhnen, die etwas älter als Markus sind. Bei ihnen übernachtet er, wenn er an zwei aufeinanderfolgenden Tagen Unterricht hat. Hier ist er gerne und er konnte sich im Gegensatz zu seiner Praktikumstelle darauf einstellen, dass er die Schule in Oldenburg besuchen wird, und ein solches Wohnarrangement planen. Die Fahrt mit öffentlichen Verkehrsmitteln nach Wildeshausen wiederum schreckt ihn ab. Obwohl die beiden Orte nur 20 Kilometer auseinander liegen, muss er mit Bus und Bahn fahren. Diese Anstrengung und der Umstand, den gewünschten Praktikumsplatz nicht bekommen zu haben, lassen ihn vorübergehend an seiner Entscheidung zweifeln: 
„,da war ich echt schon wieder kurz davor zu sagen boah nee wenn das nicht klappt dann lass ich das lieber weil da hab ich kein Bock drauf also, ich war wirklich nich so dass ich sage ja, jetzt ( ) das muss es jetzt werden und das will ich unbedingt machen, koste es was es wolle sondern das war echt so, na ja, hab mir das ziemlich kurafristig überlegt und hab das dann (2) diesen Weg dann so eingeschlagen aber ich war oft am Überlegen na ja, mal gucken ob ich das wirklich weitermache und ob ich die Ausbildung (also dann) das Studium wirklich mache oder nich"

Es wird deutlich, dass Markus Holtzmann schon zu Beginn seiner Praktikumszeit mit dem Gedanken spielt, das Praktikum nicht zu beenden. Es zeigt sich, dass seine Vorstellung von Polizei nicht mit der gelebten Praxis übereinstimmt. Die Polizei bestimmt über den Einsatzort und es herrscht weniger Autonomie als erwartet. Wie auch schon zu Schulzeiten nimmt er seine Schwierigkeiten als heteronom produziert wahr.

Nachdem er sich nach einigen Wochen jedoch daran gewöhnt hat, es durchgehalten hat, und er feststellt, dass sein Praktikum auch interessant ist, wird es weniger problematisch. Es kann davon ausgegangen werden, dass seine Eltern hier auch auf ihn eingewirkt haben durchzuhalten, es weiter zu probieren und vor allem nicht ohne Ausbildungsstelle zu sein. Er muss aber auch durchhalten, wenn er sich nicht den väterlichen/elterlichen Berufsvorstellungen beugen möchte.

Nach diesen Schwierigkeiten erlebt er sein Praktikum durchaus positiv:

„ich bin auf die Wache gekommen da, //I: hmbm// da war auch ein so=n Kollege da hab ich nur kurz. gesagt ja ich bin jetzt bier der neu- ich bin Markus und der neue Fachoberschulpraktikant dann hat der nur gesagt ja los komm rum hier, du gehörst jetzt dazu und du setat dich bier mit an unsern Tresen ne"

An seinem ersten Praktikumstag wird er freundlich aufgenommen. Auch wenn er zu dieser Art der Gemeinschaftlichkeit als 17-Jähriger noch wenig Zugang hat, erlebt er dies zunächst positiv. Er ist beeindruckt von dem, was in einer kleinen Stadt alles vor sich geht, wovon man sonst nichts mitbekommt. In den ersten Wochen ist alles sehr aufregend und die Tätigkeit an sich scheint seinen Vorstellungen wieder zu entsprechen. Er fährt mit Streife, ist viel unterwegs; die bürokratische Schreibtischarbeit lernt er kaum kennen. Nach einiger Zeit werden aber auch viele dieser Erfahrungen alltäglich und es kommen Langeweile und Ernüchterung auf. Er ist ein stiller Praktikant, der ,alles aufgesaugt“, aber sich zurückhaltend verhält. Er ist nur wenig integriert - er bleibt ein Jugendlicher unter erwachsenen Polizist*innen, die teilweise Kinder in seinem Alter haben. So bekommt er in dem Praktikum einen Einblick in den polizeilichen Alltag und auch eine Idee davon, was polizeiliche Gemeinschaft bedeuten kann, ohne jedoch ein integraler Teil dieser zu sein.

Nach einem Jahr Praktikum muss er ein zweites Jahr ausschließlich in der Schule in Oldenburg absolvieren. Dieses Schuljahr erlebt Markus Holtzmann als befreiend. Er übernachtet nun wochentags wieder bei der Familie seines Onkels, 
er hat eine gute Beziehung zu ihnen und unternimmt viel mit seinen Cousins. Neben seinen familiären Kontakten macht er nun aber auch gute Erfahrungen mit seinen Mitschüler*innen. Mit einigen versteht er sich sehr gut und sie treffen sich zum Lernen oder auch, um gemeinsam etwas zu unternehmen. Seine Mitschüler*innen sind nun zum Großteil auch Praktikant*innen bei der Polizei mit dem gemeinsamen Ziel, nach der Fachoberschule ein Studium an der Fachhochschule für Verwaltung und Rechtspflege zu beginnen - unter anderem dieses geteilte Interesse verbindet sie.

Markus Holtzmann bewirbt sich bei der Polizei in Niedersachsen, Hamburg und Bremen. Dass er es bei mehreren Stellen parallel versucht, zeigt, dass er sich nun festgelegt hat Polizist zu werden. Er macht in allen drei Bundesländern einen mehrtägigen Einstellungstest, bei dem Allgemeinbildung, die sportlichen Fähigkeiten und der Gesundheitszustand überprüft werden, außerdem gibt es ein Gespräch bzw. einen psychologischen Test. Er erhält eine Zusage für Niedersachsen und Hamburg und entscheidet sich für Niedersachsen, da er hofft sein Studium recht heimatnah absolvieren zu können.

Im Oktober 2002 beginnt Markus mit 18 Jahren ein Studium an der Fachhochschule für Verwaltung und Rechtspflege in Oldenburg. Das erste Studienjahr besteht vor allem aus theoretischem Unterricht und Sport, es gibt kaum Spielraum für eine eigene Gestaltung der Studieninhalte. Das Studium gleicht mehr schulischem Unterricht in einem engen Klassenverband. Nach einem Jahr Praktikum ist es für Markus schwer sich darauf einzulassen. Während die meisten anderen Studienanfänger*innen in seiner Studiengruppe auf dem Gelände der Fachhochschule leben, wohnt er wieder bei der Familie seines Onkels. Dies ist einerseits eine pragmatische Entscheidung, da er dort kostenlos wohnen kann. Andererseits zeigt es seine enge familiale Bindung, wenn er es vorzieht, bei ihnen zu leben anstatt mit gleichaltrigen Kommiliton*innen zusammenzuwohnen. Weiterhin drückt es eine gewisse (räumliche) Distanz zur Polizei aus. Für die in den Wohnheimen der Fachhochschule lebenden Studierenden ist Studieren, Wohnen und auch die Freizeit vollkommen auf die Polizei eingestellt. Diese isolierte Situation führt zu einer Sozialisation in die Polizei und im Sinne der Polizei, hier wird neben den Inhalten des Studiums auch Gemeinschaft erlernt (vgl. Weidmann 2001; Behr 2013 und die Fallrekonstruktion von Melanie Wegener). Markus zieht sich zum Lernen zu seiner Familie zurück und nimmt nicht an den Freizeitaktivitäten seiner Kolleg*innen teil: ,irgendwie hab ich da in dieses Gefüge nicht reingepasst“". Er findet den Anschluss an eine Gruppe, die sehr auf Gemeinschaft ausgelegt ist, nicht und erlebt sich erneut in einer Außenseiterposition. Auch dieses ,Leid' bzw. diese Situation erlebt er heteronom produziert. Es deutet sich aber an, dass seine enge familiale Bindung und seine Entscheidung, beim Onkel zu wohnen, diese Situation durchaus mitproduzieren. Die ,konkurrierende' Gemeinschaft der Polizei kann er nicht zulassen. Er befindet sich wieder in einer Situation sozialer Isolation, die er aushalten und durchhalten muss. 
Obwohl er viel lernt, bekommt er auch im Studium nur mittelmäßige Noten, hat aber immer wieder kleine Erfolgserlebnisse, wenn er Wissen aus seinem Praktikum bei praktischen Übungen (z.B. Funken, Rollenspiele) anwenden kann. Diese Erfahrungen geben ihm Sicherheit und er freut sich darüber gelobt zu werden möglicherweise auch darüber, etwas besser zu können als andere.

Sein erstes halbjähriges Praktikum beginnt im Herbst 2003, das er aus organisatorischen Gründen durchgängig im Bereich der Ermittlungsarbeit ableistet, anstatt, wie es üblich ist, zwischen Einsatz- und Streifendienst und dem Ermittlungsdienst aufgeteilt. Im Kriminalermittlungsdienst (KED) macht er Tagesdienst im Büro bei der Sachbearbeitung Betäubungsmittel. Er stellt fest, dass diese Arbeit nicht seinen Vorstellungen entspricht. Da er aus seinem FOS-Praktikum schon Vergleichsmöglichkeiten zu der „Arbeit auf der Straße“ hat, frustriert ihn diese Tätigkeit. Sie erfüllt nicht die Erwartungen, die er an den Beruf hat: lässig und recht autonom auf der Straße unterwegs sein mit aufregenden Einsätzen zwischendurch. Den zweiten Teil seines KED-Praktikums leistet er dann aber teilweise in der operativen Gruppe des gleichen Bereichs ab. Hier macht ihm die Arbeit mehr Spaß, hier werden auch Einsätze gefahren und Überwachungen vorgenommen. Er betont, wie lässig und locker es da zu gegangen sei. Zwar ein bisschen Adrenalin, aber insgesamt nicht zu viel Stress auf der Arbeit zu haben, scheint eines seiner zentralen Bewertungskriterien zu sein.

Nach seinem Praktikum geht das Studium weiter. Auch wenn ihn das Praktikum immer wieder gelangweilt hat und nicht seinen Vorstellungen entsprach, zieht er es dem theoretischen Teil des Studiums deutlich vor. Er erlebt es als Rückschritt, nun wieder „nur“ studieren zu können, und freut sich sehr auf sein nächstes Praktikum, das er im Einsatz- und Streifendienst ableisten wird.

Dieses beginnt im fünften Studienabschnitt. Diesmal kommt er auf die Polizeidienstelle in Delmenhorst, nur wenige Kilometer von seinem Elternhaus entfernt. Er wohnt nun wieder vollständig zu Hause in seinem Zimmer in der elterlichen Wohnung.

Markus Holtzmann freut sich darauf, endlich ,raus auf die Straße zu dürfen. In seiner ersten Praktikumswoche muss er direkt zweimal nacheinander ,lange Nacht"118 machen. Nachtdienste und 12-Stunden-Dienste sind für ihn eine neue Erfahrung, da er dies im FOS-Praktikum nicht machen durfte, da er noch nicht volljährig war, und im KED-Praktikum nur sehr vereinzelt vorkam. Er kann morgens nicht einschlafen und ist übermüdet.

„da dacht ich so Alter was is=n das für ne Scheiße ne und dann nächster Nachtdienst wieder und dann, das hat sich so= so komisch so= so fremd so falsch irgendwie alles angefühlt dass man dachte, dass da wieder so dieses Gefühl so kam na=ja, mal gucken ob ich das

118 Lange Nacht/Langer Tag werden die Wochenenddienste genannt. Samstags und sonntags werden die Schichten nicht in drei, sondern nur in zwei Schichten unterteilt. Die Tagesdienste beginnen um 6 Uhr morgens und enden um 18 Uhr abends, die Nachtdienste gehen entsprechend von 18-6 Uhr. 
wirklich $n$ Leben lang machen will wo man echt dachte irgendwie is das doch, ziemlich (2) befremdlich so"

Auch dieser Abschnitt beginnt für ihn mit Ernüchterung und er stellt sofort wieder infrage, ob er diesen Beruf tatsächlich ergreifen möchte. Wie in den vorherigen Phasen von Unzufriedenheit ändert er jedoch nichts, sondern harrt aus und wartet darauf, dass es besser wird. Die Erfahrung, dass sich irgendwann Besserung einstellt, hat er schließlich schon mehrfach gemacht, insofern kann seine Haltung von Abwarten und Durchhalten auch als Strategie verstanden werden. Und sie ist auch diesmal erfolgreich. Nach einiger Zeit der Eingewöhnung macht ihm die Arbeit Spaß.

„,das war ja, jetzt warste ja wirklich das erste Mal so komplett, so in Uniform und die Knarre an $=a$ Hüfte und saßt im Streifenwagen und //I: hmbm// warst erstmal davon ab dass ( ) fehlte, warst du für=n Bürger ganz normaler Polizist so ne //I: hmbm// wurdest ja auch so wahrgenommen //I: hmbm// das war nochma ganz. anders als im KED vorber (2) ich hab mich dort ziemlich schnell reingefunden, ne hab aber auch viel selbst probiert dann so, nicht bei allem nachgefragt wie geht das wie geht das sondern hab so $=n$ bisschen, aus $=m$ Bauch raus gehandelt, ich hab so (2) mich da so dann reingefunden"

Markus sieht für die nicht-polizeiliche Öffentlichkeit wie ein ausgebildeter Polizist aus. Obwohl er tatsächlich ein unerfahrener Student ist, muss er nun, begleitet von seinem Anleiter, kompetent handeln. Die Uniform vermittelt dabei nicht nur nach außen, dass er Polizist ist - nur kundige Bürger*innen werden die fehlenden Abzeichen bemerken und richtig deuten können - sondern sie gibt auch ihm Sicherheit, ist zugleich aber auch etwas beängstigend für ihn.

Markus Holtzmann betont hier, wie an anderen Stellen auch, dass er nicht viel nachgefragt und öfter intuitiv gehandelt habe: ein Ausdruck von Selbstbewusstsein. Es kann aber auch als ein Ausdruck seiner Einschätzung des Berufes und einer Überschätzung des eigenen Könnens gedeutet werden. Polizeiliches Agieren, das ,aus dem Bauch heraus' geschieht, ist möglicherweise wenig fundiert, entspricht aber dem Bild des lässigen Polizisten. Außerdem kann polizeiliches Handeln so nur bedingt auf rechtlichen Grundlagen beruhen, dafür mehr auf dem eigenen, individuellen' Wertekanon.

Markus hat einen Praxisanleiter, den er für seine Professionalität und Ruhe schätzt. Er ist ein erfahrener Kollege, der zuvor lange in Hannover Dienst getan hat. Markus glaubt, dass er wegen dem Dienst in der Großstadt auch so engagiert war: Er ist viele Einsätze, bei denen um Unterstützung gebeten wurde, mit angefahren, er hat viele Kontrollen gemacht und war sehr aktiv im Dienst und „noch nich so gemütlich und gesetzt wie mancher andere vielleicht". Der Anleiter ist ein offener Typ, der viel erzählt. Für Markus ist diese Situation nicht unproblematisch: 
,ja und wenn de so=n Anfänger bist wie ich dann, in dem Moment war dann, da is so ne gewisse Distanz irgendwie zwischen //I: hmbm// da weiß=te nich richtig wie, wie wie du dich (geben sollst) ne //I: hmhm// wo sowieso das ganze ganze Gefüge neu ist"

Er braucht einige Zeit, um mit seiner neuen Situation umgehen zu können. Er weiß nicht genau, wie er sich seinen Kolleg*innen gegenüber verhalten soll und vor allem bei seinem Anleiter, der ihn auch bewertet. Markus befindet sich in einer Situation, in der es darum geht, Kollegialität zu lernen und zu beweisen, in der aber auch in bestimmten Bereichen Distanz und Vorsicht geboten ist. Neben der einerseits strukturell schwierigen Situation fehlt ihm hier andererseits wohl auch die polizeiliche Sozialisation des Wohnheimlebens. Zwar hat er den polizeilichen Umgang untereinander im Praktikum kennengelernt, dabei aber eine weniger aktive Rolle gespielt: eben die des Praktikanten und nicht die eines Polizisten.

Auch wenn Markus während seines Fachoberschulpraktikums schon viele verschiedene polizeiliche Handlungssituationen erlebt hat, sind für ihn die Nachtschichten auch auf einer anderen Ebene als der oben beschriebenen eine neue Erfahrung. Nachts erlebt er zum ersten Mal Auseinandersetzungen zwischen Betrunkenen und deutlich aggressiveres Verhalten des ,polizeilichen Gegenübers‘.

„da hat der Typ mir noch so=n bisschen leidgetan, weil die den echt so da rein bugsiert ham ziemlich -, aber das war ja doch $n$ Arschloch ne, der bat -, heute würd ich sagen na der hat=s verdient ne //I: ja// der soll sich nicht so anstelln, ne //I:ja // die ham da welche zusammengeschlagen und (Koppnuss) gegeben und alles und denn wurden se halt mitgenommen weil se keine -, die hatten glaube ich keinen Ausweis dabei der Typ, konnten se die Identität von dem nicht feststellen"

Markus Holtzmann berichtet von einer Situation, in der er erlebt, wie eine Person gegen ihren Willen und mit körperlichem Widerstand in eine Zelle gesperrt wird. Diese Erfahrung ist für ihn befremdlich und sein Sprechen in der 3. Person Plural macht seine Distanz zu dem Handeln in der damaligen Situation deutlich. Er kann sich noch nicht mit dem Handeln der Polizisten identifizieren. Aber auch seine veränderte, heutige Perspektive wird deutlich. Das physische (gewaltvolle) Handeln gegen andere Personen muss erlernt werden, ebenso das Ausblenden von Empathie (wenigstens) in der konkreten Handlungssituation.

Nach dem Praktikum muss Markus Holtzmann weiter an der Fachhochschule studieren. Im Frühjahr 2005 geht er erneut sehr unmotiviert zurück nach Oldenburg.

"und da dacht ich schon die ganze Zeit so Alter jetzt kommt noch $n$ halbes Jabr richtig hart Studium an der, an der Polizeischule ich hatte überhaupt kein Bock drauf ne, dacht ich bin jetzt hier, ich krieg das hin ne //I: hmbm//, also ich könnte jetzt auch, wenn man mich nochmal richtig an die Hand nimmt und bier nochmal $n$ bisschen näher einfübrt //I: hmbm// und das nochmal n bisschen genauer durcbübt ich würd das auch so binkriegen" 
Markus Holtzmann glaubt, dass er mit ein wenig mehr Praxiserfahrung den Beruf auch ohne die letzten Studienmonate angemessen ausüben könnte bzw. würde er eine praxisnähere Ausbildung bevorzugen. Dazu tragen neben der oben schon angesprochenen Selbsteinschätzung zwei weitere Umstände bei: Zum einen fühlt er sich von seinen Kolleg*innen im Praktikum als Kollege adressiert, als Kollege, der eben mehr oder weniger vollwertig mitarbeitet. Zum anderen sind seine Erfahrungen mit Schule und auch dem Studium negativ. Auch im Studium hat sich für ihn kein Gemeinschaftsgefühl eingestellt, dagegen erlebt er in der polizeilichen Praxis nach einer Eingewöhnungsphase ein kollegiales Miteinander.

Entgegen Markus Holtzmanns Erwartungen und Unmut wird das Abschlussstudium für ihn zu einer guten Erfahrung. Die Studiengruppe setzt sich durch den Wechsel von Personen an andere Studienorte neu zusammen. Er knüpft neue Kontakte und trifft auch zwei Kollegen ${ }^{119}$, mit denen er im Praktikum in Kontakt war, wieder. Mit ihnen freundet er sich an. Neben der individuellen Freundschaft zu den Kollegen hat Markus mittlerweile aber auch den (polizeilichen) Umgang untereinander gelernt und so erlebt er sich nun auch im letzten Studienabschnitt als Teil der Gruppe. Er wohnt zwar wieder bei seinem Onkel, verbringt aber auch zum Lernen Zeit mit seinen Kollegen und zieht sich weniger zurück. Die Monate sind aber durchaus von vielem Lernen bestimmt, Markus Holtzmann hat den Anspruch, den Abschluss gut zu schaffen. Die Abschlussklausuren im Frühjahr 2005 schließt er alle befriedigend ab. Es folgen noch einige Wochen Unterricht, die für ihn aber keine große Rolle mehr spielen, da sie nicht mehr relevant sind für seinen Abschluss. Im Sommer 2005 beendet er mit 21 Jahren sein Studium und ist nun Polizeikommissar.

\section{Die ersten Berufsjahre als Erfahrung von Fremdbestimmung und Kollegialität}

Nach Abschluss des Studiums wird Markus Holtzmann, wie üblich, in die Bereitschaftspolizei Oldenburg versetzt. Er ist froh, in Oldenburg bleiben zu können, hat aber auch hier zunächst Einfindungsschwierigkeiten.

„auf jeden Fall, Bereitschaftspolizei war am Anfang auch erst so, na ja das war, gar nicht mein Ding / / I: hmhm//, aber ähm, als ich mich da so=n bisschen reingefunden hatte (3) war die, die das ganze (Gefübl über die Kollegen) die ganze, Truppe unternander war / / I: hmbm// cool / I: hmbm/ / ja das hat Spaß gemacht also"

Markus Holtzmann hat mittlerweile das Miteinander unter Polizist*innen erlernt und findet über diesen Weg dann auch Spaß an der Polizei. Er vergleicht die Stimmung teilweise mit der einer Klassenfahrt. ${ }^{20}$ Die Tätigkeit in der Bereit-

119 In allen Interviews sprechen meine Interviewpartner*innen von ihren Kommiliton*innen in der Regel als Kolleg*innen. Ein deutlicher Hinweis darauf, dass sie sich selbst kaum als Studierende wahrnehmen, sondern als Polizist*innen (in Ausbildung).

120 In der Fallrekonstruktion von Melanie Wegener sind der Beginn des Studiums und das Leben im Wohnheim der Fachhochschule mit einer Klassenfahrt vergleichbar. Dieses Gefühl, das bei Markus Holtzmann erst viel später einsetzt, transportiert polizeiliches Miteinander. 
schaftspolizei selbst mag er nicht. In der Bereitschaftspolizei, die fast ausschließlich bei sogenannten Großlagen in hierarchisch organisierten Verbänden auftritt, ist die Arbeit wenig autonom organisiert: „das ist halt nur was was die Masse machen konnte für den einzelnen alleine war das völlig unbedeutend völlig, schwachsinnig“. Markus findet keine Erfüllung in dieser Tätigkeit, da ihn das polizeiliche Handeln dort persönlich nicht bereichert. Er kann hier nicht lässig, locker und autonom handeln, sondern ist eng eingebunden in eine Hierarchie, in der er als einfacher Einsatzbeamter ganz unten steht. Nur das ,polizeiliche Gegenüber' steht , unter ${ }^{6}$ ihm - mit diesem kann er aber nicht so interagieren, wie er es selbst für richtig hält, und auch nicht ,aus dem Bauch heraus', sondern in der Regel nur so, wie es von Vorgesetzten angeordnet wird.

Markus Holtzmann zieht in dieser Zeit, mit 22 Jahren, bei seinen Eltern aus. Er zieht allerdings nicht nach Oldenburg, sondern bleibt in Ganderkesee. Trotz eigener Wohnung bleibt er also sehr nah an der elterlichen Wohnung und zieht nicht in die Stadt, die für einen Anfang 20-Jährigen auch attraktiv sein könnte. Wie schon während des Studiums zieht er das Leben (nah) bei seiner Familie dem Leben mit Kommilitonen oder dem Leben in der etwas lebendigeren Stadt vor. Diese Zeit erlebt er neben dem Unmut über seine Tätigkeit als frei. Er hat keinen Prüfungsdruck mehr, keine Probleme mit den Personen in seinem sozialen Umfeld und ein bisschen Eigenständigkeit. Er nutzt diese Zeit ohne weitere Verpflichtungen, um sich wieder vermehrt mit alten Freunden zu treffen. Außerdem hat er einige Kollegen, mit denen er sich gelegentlich in seiner Freizeit trifft und die er als Freunde, nicht nur als Kollegen bezeichnet. Er hat ein gutes erstes Jahr bei der Bepo.

Nach dem ersten Jahr, das Polizist*innen nach dem Studium üblicherweise in der Bepo verbringen, verlassen dann jedoch die ersten seiner Kollegen, mit denen er sich gut verstanden hat, die Bepo. Das Gefühl der Klassenfahrt verblasst. Markus hat keine Versetzungsgesuche in andere Städte geschrieben, weil er seine jetzige Lebens- und Wohnsituation nicht verändern möchte bzw. sich nicht vorstellen kann, in einer Stadt zu arbeiten, die nicht mehr in täglicher Pendelentfernung liegt. Die Stellen, die ihn interessieren, wie der ESD in Oldenburg, sind jedoch sehr beliebt. Nach fast drei Jahren bei der Bepo und zunehmender Unzufriedenheit mit seiner Tätigkeit und dem vermehrten Weggang von Kollegen muss er feststellen, dass es ein Fehler war, so lange damit zu warten und zu hoffen, dass er einfach so eine Stelle in Oldenburg bekommt. Er entschließt sich, sich nach anderen Stellen umzuschauen. Er möchte in der Stadt arbeiten und weiß, dass in Hannover Stellen frei werden. Er berät sich mit seinen Eltern, wo er arbeiten könnte. Schließlich schreibt er einige Versetzungsgesuche, unter anderem nach Hannover, obwohl er eigentlich nicht so weit entfernt von seiner Heimat arbeiten und leben möchte. Diese Entscheidung trifft er gemeinsam mit seinen Eltern. Er schafft es nicht, diese Entscheidung alleine zu treffen. Dass Markus Holtzmann sich zu diesem Zeitpunkt dazu entscheidet, nicht bei der Bepo zu bleiben und es nicht, wie so oft in der Vergangenheit, einfach auszuhalten, ist auch im Kontext seiner Beziehung 
zu seinem Bruder und dessen Entwicklung zu sehen: Christoph hat bisher einen ähnlichen schulischen Weg beschritten wie Markus. Er hat nach dem Schulabschluss eine Ausbildung zum Vermessungstechniker gemacht und nach dem Ende der Ausbildung noch ein duales Studium der Vermessungstechnik/Geoinformatik angeschlossen; während des praktischen Studienanteils arbeitete er bei der Stadt Bremen. Christoph wählte damit eine Form des Studiums, das ähnliche Sicherheit bietet wie das Studium von Markus. Markus Holtzmann hat zwar formal auch studiert und genauso wie sein Bruder einen Bildungsaufstieg vollzogen, dabei letztlich aber eine Ausbildung für nur einen möglichen Beruf gemacht. Damit hat er zwar einen formal höheren Bildungsabschluss als seine Eltern, dennoch wird Christoph im Sinne der bisherigen beruflichen Orientierungen der Familie eher zum Bildungsaufsteiger: Er ist in einem technisch-handwerklichen Beruf hoch qualifiziert, durch Ausbildung und die Form des Studiums sowohl theoretisch als auch praktisch gebildet und wird beruflich vielfältige Möglichkeiten haben. Die Zielstrebigkeit und Aktivität des Bruders wirken sich angesichts von eigener Unzufriedenheit und beruflicher Wartehaltung möglicherweise auch auf Markus Holtzmann aus, der in Konkurrenz zu seinem Bruder nun ebenfalls aktiv wird.

Nach dreieinhalb Jahren bei der Bereitschaftspolizei wird Markus Holtzmann nach Cloppenburg versetzt. Damit ist er zunächst sehr zufrieden, da sich sowohl sein Wunsch erfüllt, in einer Stadt zu arbeiten, als auch derjenige, nicht so weit entfernt von seiner Familie zu sein. Er entscheidet sich aber trotzdem dafür, eine Wohnung in Cloppenburg zu suchen und umzuziehen, da die Verbindung des ÖPNV nicht gut genug ist, um täglich zu pendeln. Sein Zimmer zu Hause behält er dennoch.

Im Frühjahr 2009 tritt Markus Holtzmann mit 25 Jahren seine neue Stelle in Cloppenburg an. Markus hat sich in Cloppenburg beworben, weil er in den ESD möchte, wird nun aber in einer Abteilung eingesetzt, die sich aus einem aktuellen Anlass mit Verkehrsdelikten beschäftigt. Er macht hier erneut die Erfahrung, dass die Organisation bestimmt und er nur begrenzte Wahlmöglichkeiten hat. Als er davon erfährt, wendet er sich sofort an die Personalabteilung und an Vorgesetzte mit dem Anliegen in den ESD versetzt zu werden. Hier wird er beschwichtigt, erst einmal abzuwarten und zu schauen, ob es ihm nicht doch gefällt:

„von ein zwei Leuten, Vorgesetzten oder Personalmenschen wurde man da schon so=n bisschen komisch angegucket (von wegen) äh, warten $S_{i e}=s$ doch ab, sie sin ja noch nich ma hier //I: hmbm// wo ich dachte ja ich weiß trotzdem, welcher Bereich mir liegt und welcher nicht".

Markus Holtzmann erlebt dies als Bevormundung. Mittlerweile ist er aber Polizist mit etwas Organisationserfahrung und kein junger Praktikant mehr; er wartet nun nicht, wie bisher, einfach ab, sondern äußert seinen Unmut und leistet Widerstand gegen eine Entscheidung, die ohne ihn getroffen wurde. Dies zu tun, ist sicherlich Ergebnis eines Lernprozesses, wie die Organisation Polizei funktioniert, und ein Ausdruck von Ermächtigung. 
Markus Holtzmanns neue Abteilung ist erst vor Kurzem zusammengestellt worden. In dieses sich noch nicht ganz festgelegte „Gefüge“ kann er sich gut integrieren und er findet wieder ein paar Kollegen, mit denen er sich auch gelegentlich in seiner Freizeit trifft. Markus erlebt diese Zeit trotzdem als einsam und er ist unzufrieden. Die Integration in die Kolleg*innenschaft kann seine Unzufriedenheit mit der beruflichen Tätigkeit und seinen Wunsch, wieder in Ganderkesee zu leben, nicht kompensieren. Er hat nun eine Wohnung in Cloppenburg und lebt im Alter von 25 Jahren zum ersten Mal nicht in kurzer Distanz zu seiner Familie. Obwohl er in Ganderkesee auch nur noch wenige Freunde hat, da die meisten zum Studium weggegangen sind, und befreundete Kollegen aus Oldenburg mittlerweile ebenfalls versetzt wurden, möchte er wieder nach Ganderkesee bzw. Oldenburg zurück.

„dann war ich immer noch lange Zeit in Cloppenburg so darauf aus ich muss irgendwie nach Oldenburg zurück //I: hmbm// ne, und hab gleich geschrieben und überlegt, notfalls pendeln oder so //I: hmbm// also, ich hab mir teilweise gar keine Chance gegeben mich in Cloppenburg anzunehm weil ich immer nur in Gedanken dabei, ich muss irgendwie wieder zurück"

Markus Holtzmann fällt es wie auch zuvor schwer, sich an die neuen Umstände zu gewöhnen. Auch wenn es dieses Mal weniger am konkreten beruflichen Umfeld liegt, trägt sicherlich der Umstand, dass er nicht in den ESD gekommen ist, dazu bei. Er ist beruflich unzufrieden und fühlt sich entwurzelt. Die Situation wird für Markus Holtzmann noch frustrierender, als er erfährt, dass eine baldige Versetzung in den ESD aussichtslos erscheint. Markus ist aber mittlerweile in seinem Beruf und der Polizei so angekommen, dass er nicht mehr grundsätzlich infrage stellt, ob er Polizist bleiben möchte, wie er es zuvor bei solchen Erfahrungen von Fremdbestimmung gemacht hat. Dann aber erhält er nach einigen Wochen plötzlich die Zusage, dass er doch in drei Monaten in den ESD innerhalb der gleichen Polizeiinspektion wechseln kann. Mit dieser Nachricht ändert sich seine Haltung.

\section{Die biographische Bedeutung polizeilicher Arbeit}

Markus Holtzmann ist beruflich nun, wenn auch nicht in Ganderkesee/Oldenburg, so doch zumindest organisational dort angekommen, wo er hinwollte, und ist zufrieden mit seiner Arbeit:

„was ich so unter Streifendienstleben verstehe hat man da auch //I: hmhm// so (2) ne man macht sich nicht kaputt aber es ist auch genng zu tun und, ja, weiß nicht das ist halt so meine Welt dann, was das betrifft, ich wollt nie irgendwas machen, was so bedeutungslos ist irgendwie ich hatte da immer-, ich brauchte irgendwie immer so=ne Philosophie oder ne Bedeutung hinter dem was / / I: hmbm// ich so mache also ich könnt nicht einfach irgendwo am Schreibtisch sitzen und so (2) so $=$ so ja, scheinbar, sinnlose oder bedeutungslose Arbeit machen" 
Markus Holtzmann möchte Sinn in seiner Arbeit sehen können. Polizeiliche Arbeit erfüllt dies für ihn nicht per se, denn auch die Arbeit in der Bepo oder im KED könnte als sinnvolle Betätigung empfunden werden. Der Schutz von Demonstrationen bzw. die Durchsetzung von Demonstrationsfreiheit könnte als demokratisches Prinzip durchaus mit Sinnhaftigkeit versehen werden. Und auch die Tätigkeit von Kriminalitätsbekämpfung und -aufklärung des KED könnte trotz der Arbeit am Schreibtisch als sinnvoll verstanden werden.

Sinnvoll ist eine Tätigkeit für Markus Holtzmann aber vielmehr dann, wenn sie für ihn selbst befriedigend ist. Polizeiliche Arbeit ist für ihn hier nicht an sich sinnvoll, sondern wenn sie (s)einen biographischen Sinn erfüllt. Die Arbeit im ESD ist im Vergleich zu seinem bisherigen Tätigkeitsgebiet recht autonom gestaltet und er kann direkter eingreifen und entscheiden.

„also, damit merkt man schon dass man irgendwie doch ganz schön, ja:, Einfluss, weiß ich nich (2) hat und das is schon so=n Gefühl wo de merkst das, ne das hat ne Außenwirkung das hat irgendwie, ja, ne Bedeutung was man bier macht, ne das, das wird wahrgenommen //I: hmbm//, positiv oder negativ //I: hm// is erstmal egal aber es wird halt wahrgenommen"

Individuell wahrgenommen zu werden als Polizist und in seinem Handeln, sind Erfahrungen, die er in der Bereitschaftspolizei kaum gemacht hat. Vor dem Hintergrund seiner Erfahrungen, dass er oft nicht richtig wahrgenommen wurde und wenig Einfluss auf Situationen hatte - in der Schule wie auch innerhalb der Organisation Polizei - und sich eher als Opfer adressierte, ermöglicht ihm die Struktur der Arbeit des ESD, sich dieser Erfahrungen zu ermächtigen. Er kann im ESD (im Vergleich zur Bepo) teilautonom handeln und er ist grundsätzlich in einer Interaktionsposition, in der er wahrgenommen wird und machtstärker ist bzw. in der er dafür sorgen kann, dass er wahrgenommen wird.

Bereits die Vorstellungen, die er vor und während seines Studiums hatte, dass Polizist*innen lässig und locker auf der Straße unterwegs sind, spiegeln den Wunsch nach Anerkennung und Respekt, vielleicht auch Autorität, wider. Markus Holtzmann macht im ESD die Erfahrung, dass sein Handeln Einfluss hat. Er geht nicht davon aus, dass sein Handeln (in allen Fällen) Veränderung bewirkt, aber er erlebt eben, dass er Einfluss auf die Entwicklung von Situationen hat. Die Struktur der Arbeit im ESD ermöglicht es ihm, sich handlungsmächtig zu erleben. Er kann Situationen aus einer machtvollen Interaktionsposition heraus definieren. Außerdem kann er sich als Polizist von der „Klientel““ (vgl. Kap. 4.1.2), von der er sich schon als Jugendlicher abgegrenzt hat, weiter distinguieren.

Markus Holtzmann ist nun nicht nur zufrieden, weil er beruflich dort angekommen ist, wo er hinwollte, sondern er lernt im Winter 2009 bei einem Weihnachtmarktbesuch mit ehemaligen Kolleg*innen in Oldenburg außerdem Kathrin kennen. Kathrin ist eine Freundin einer Kollegin. Markus erzählt vergleichsweise lebendig von der Situation, wie sie sich vorgestellt wurden. Er evaluiert: 
„da haste balt gleich gemerkt dass es //I: hmbm// bei manchen Leuten merkste einfach die Chemie stimmt ne da kannste einfach locker gleich reden //I: hmhm// da haste keine äb Hemmnisse irgendwie".

In den darauffolgenden Wochen treffen sie sich regelmäßig und werden schnell ein Paar. Mit 25 Jahren hat Markus seine erste Beziehung. Kathrin studiert zu diesem Zeitpunkt noch Germanistik in Oldenburg. Markus übernachtet so oft wie möglich bei ihr in Oldenburg. Recht schnell wird es eine sehr enge Beziehung und Markus stellt sie seinen Eltern vor - und auch umgekehrt. In Anbetracht der engen Beziehung, die Markus zu seinen Eltern hat, ist es relevant, dass die Eltern seine Freundin akzeptieren. Eine längerfristige Beziehung zu Kathrin wäre sicherlich nicht möglich, wenn Matthias und Renate Vorbehalte ihr gegenüber hätten. Aber auch Kathrin, einziges Kind ihrer Eltern, hat offenbar eine enge Beziehung zu ihren Eltern. Sie hat für ihr Studium ihre Heimatstadt Oldenburg nicht verlassen und wohnt noch bei ihren Eltern. Ihr Familienhintergrund - der Vater ist Beamter und die Mutter Angestellte im Einzelhandel - macht es ökonomisch sehr wahrscheinlich nicht notwendig, dass Kathrin für ihr Studium im Elternhaus bleibt. Eine Partnerin, die aus einem ,stabilen' Elternhaus kommt und Markus Vorstellung davon, was das bedeutet, teilt, verspricht eine verlässliche Partnerin zu sein. Sie beginnen schon nach einigen Monaten nach einer gemeinsamen Wohnung zu suchen. Nachdem sie ungefähr ein Jahr zusammen sind, entscheiden sie dann, in die Dachgeschosswohnung im Haus von Kathrins Großeltern am Rande Oldenburgs zu ziehen. Markus pendelt nach Cloppenburg und hat nun einen Arbeitsweg, der je nach Verkehrsmittel zwischen 30 und 60 Minuten dauert. Im Gegensatz zu seiner Praktikumszeit nimmt er dies nun gerne in Kauf. Er lebt wieder in Oldenburg, nah bei seiner Familie, und zusammen mit seiner Partnerin.

Kathrin schließt im Frühjahr 2011 ihr Studium ab und bewirbt sich in verschiedenen Städten im Umkreis auf verschiedene Stellen. Markus Holtzmann möchte gerne in der Region bleiben und ist bereit, auch weiterhin eine gewisse Entfernung zur Arbeit zurückzulegen. Kurz nach dem Abschluss ihres Studiums tritt Kathrin eine Stelle im öffentlichen Dienst an: als Verwaltungsangestellte in der Universitätsbibliothek in Oldenburg. Ihre konkrete Tätigkeit dort hat keinen Bezug zu ihrem Studium und entspricht nicht ihrer Qualifikation. Kathrin scheint eine sichere Anstellung vorzuziehen und sucht ihre Erfüllung vermutlich weniger im Berufs- als im Privatleben, wie auch ihre und Markus weiteren Entscheidungen zeigen. Das haben die beiden offenbar gemeinsam: Auch Markus hat sich für einen sicheren Beruf und eine „heimatnahe Verwendung“ entschieden. Er hat bisher keine Schritte für einen Laufbahnaufstieg unternommen - vergleicht man dies mit Melanie Wegener, die innerhalb des gleichen Zeitraums diverse Fortbildungen gemacht und erste kleine Führungsämter übernommen hat, hat Markus Holtzmann seine beruflichen Entscheidungen bisher nicht aus der Perspektive einer gezielten Laufbahnentwicklung getroffen. Sein Fokus liegt auf der Nähe zu seiner Familie und nun auch auf seiner Beziehung zu Kathrin. 
Auch Markus Holtzmanns Vater kehrt in dieser Zeit in die Sicherheit des öffentlichen Dienstes zurück. Er beginnt im Sommer 2011, wie sein Sohn Christoph, bei der Stadt Bremen zu arbeiten. Beide Söhne, seine Schwiegertochter und er arbeiten nun im öffentlichen Dienst.

Nachdem Kathrin und Markus beide in sicheren Berufen angekommen sind, konkretisieren sie ihre Zukunfts- und Familienplanung: Sie beginnen im Laufe des Jahres 2013 mit Renovierung und Umbau ihrer Wohnung im Haus von Kathrins Großeltern, nachdem Markus einen Heiratsantrag gemacht hat. Mit dem Gefühl der Sicherheit, dass diese Beziehung durch eine Heirat auf Dauer angelegt ist, schaffen sie ein ,Heim` für sich. Während sie ihre Hochzeit für den Sommer 2014 planen, wird Kathrin schwanger. Sie heiraten wie geplant im Juli 2014 und erwarten ihr erstes Kind im Herbst. Zwischen Hochzeit und Geburt findet das Interview statt.

Auch hier möchte ich auf eine Zusammenfassung der gesamten Falldarstellung verzichten, eine solche findet sich in Kap. 6.2.1, und stattdessen Markus Holtzmanns jetzige Arbeits- und Lebenssituation skizzieren: Wie zu Beginn angedeutet, rahmt er die Präsentation seiner Lebensgeschichte am Ende des Interviews so, als sei seine heutige Lebenssituation der Höhepunkt, auf den alles hinausgelaufen ist. Markus Holtzmann evaluiert am Ende des Interviews:

,ja also insofern kann man sagen (3) is eigentlich alles drin wenn man mal zurückblickt, was alles so gefehlt hat so immer mal, is da ne also, der Job macht jetzt wirklich Bock. / I: ja/ / da bin ich sicher dass ich dabei bleibe und, das, da geh ich gerne bin und geh mit nem guten Gefühl nach Hause (3) ähm und, jo, Lebenspartnerin is auch da und Kind is unterwegs"

Markus Holtzmann ist zufrieden. Mit 30 Jahren arbeitet er nun in einem polizeilichen Bereich, der ihm Spaß macht, er ist verheiratet und erwartet sein erstes Kind. In seiner aktuellen Lebenssituation ist Markus Holtzmann vor allem auf seine Familie und die Gründung seiner, eigenen' Familie konzentriert. Kathrin ist in Mutterschutz und wird nach der Geburt in Elternzeit gehen. Sie reproduzieren traditionelle Geschlechterrollen, so wie sie sie beide aus ihren Elternhäusern kennen.

Die Zufriedenheit im Beruf ist eng verknüpft mit dieser ,privaten' Lebenssituation. Seine berufliche Zufriedenheit ist aber auch Ausdruck davon, dass sich seine Vorstellungen über die Polizei nun teilweise realisiert haben und er seiner Tätigkeit einen Sinn verleihen kann, die er in Einklang mit seinem Selbstbild und seinen Erfahrungen sieht.

,,deswegen, mein ich ja ne, wir gucken mal was, was bleibt am Ende davon übrig und das ist meist nicht viel //I: hmbm// (5) aber, in dem Moment macht man halt was und das ist trotzdem, hat ja trotzdem n Effekt (2) //I: hm// (3) schwer zu sagen (6) also, wenn man sagt hats $n$ Sinn dass ich (bierber gehöre) wenn man sagt hat das $n$ Sinn gehabt dass ich hier war denn ich glaube das ist oft einfach so dass wir, dass wir irgendwie Sicherheit 
vermitteln weißte dass wir dann da so sagen wir haben jetzt die Situation im Griff wir klären das jetzt hier oder man spendet Trost allein durch die Anwesenheit was immer da einem passiert ist und man kümmert sich um die Sorgen und Nöte der Leute ne, man ist einfach da: und äh //I: hm// und wird halt tätig //I: hmhm// dass man merkt okay die Leute sind jetzt berubigter als vorher"

Markus ist in einer Position, eingreifen und Schutz geben zu können. Auch wenn ihm vollkommen klar ist, dass viele Einsätze keine längerfristige Wirkung haben, ist es wichtig für ihn, einen Einfluss auf Situationen zu haben. Die Erfahrungen, Situationen nicht beeinflussen zu können bzw. sich einer Situation ausgesetzt zu erleben, sind Erfahrungen seiner Kindheit und Jugend. Seine Berufswahl kann als Bearbeitung dieser Erfahrungen interpretiert werden. Die Arbeit im ESD ermöglicht ihm sich als wirkmächtig zu erleben. Der Beruf gibt ihm außerdem die Möglichkeit, sich in seinem Berufsalltag nach ,unten“, von „Knastis“, „Assis“ und „Junkies“ deutlich abzugrenzen. Als Polizist ist Markus Holtzmann in einer strukturell mächtigeren Interaktionsposition als sein Gegenüber.

Die Polizei ist für ihn dabei eine Organisation, die ihn zunächst auch immer wieder in Situationen gebracht hat, in denen er sich den Organisationsentscheidungen ausgeliefert erlebte. Nun ist er, auch nach Widerstand gegen seine Versetzung zu den Verkehrsdelikten, im ESD und damit dort, wo er die Art polizeilicher Arbeit leisten kann, die für ihn - bewusst oder nicht - biographisch bedeutsam ist und wo er seine Erfahrungen bearbeiten kann. Da ihm seine Tätigkeit in anderen polizeilichen Arbeitsbereichen gezeigt hat, dass dies dort nicht möglich ist, wird er perspektivisch im ESD bleiben und wahrscheinlich auch keine Führungsposition anstreben, da ihm vor allem die Interaktion mit der „Klientel“ und nicht die komplexen Aushandlungsprozesse mit untergebenen Kolleg*innen (wie bei Melanie Wegener) eine Bearbeitung seiner biographischer Erfahrungen ermöglicht. Markus Holtzmann ist nach neun Jahren Polizeidienst bisher nicht befördert worden. Er wartet vermutlich ab, bis er aufgrund seines Dienstalters , an der Reihe“ ist. Hier wird er einfach ,durchhalten', während er sich durch seine tägliche Arbeit auf der Straße ermächtigen kann. 



\section{Zentrale Ergebnisse und theoretische Verallgemeinerungen}

In diesem Kapitel werden die zentralen Ergebnisse der beiden vorherigen Kapitel zusammengefasst und aufbauend auf den empirischen Befunden verdichtet und verallgemeinert. Bisher wurden die Ebenen des Interaktionskontextes sowie die Ebene der Biographie einzelner Polizist*innen weitgehend getrennt betrachtet. Diese Trennung werde ich zunächst beibehalten, mit Fortschreiten des Kapitels aber immer weiter auflösen, um den Zusammenhang von lebensgeschichtlichen Erfahrungen und beruflichem Handeln theoretisch zu konkretisieren und zu diskutieren.

Zunächst geht es um die Frage, wie der Handlungs- und Interaktionskontext der Schutzpolizei strukturiert ist (6.1). Unter welchen Bedingungen arbeiten Polizist*innen? Was konstituiert das Handlungsfeld Schutzpolizei respektive des Einsatz- und Streifendienstes?

In der Folge lassen sich Fragen danach beantworten, welche verallgemeinernden Aussagen sich auf der Fallebene Biographie treffen lassen (6.2). Diskutiert wird, welche kollektiv- und lebensgeschichtlichen Verläufe dazu führen, dass der Beruf gewählt wird, außerdem wie die Sozialisation in den Beruf bzw. in die Institution Polizei verläuft. Das Kapitel gibt Antworten auf folgende Fragen: In welchem Wirkungszusammenhang stehen die biographischen Erfahrungen, die zur 
Berufswahl führen, die Sozialisation in den Beruf und die Strukturen des Arbeitsfeldes mit der konkreten Handlungspraxis der Polizist*innen?

Abschließend werden die zentralen Befunde über das Passungsverhältnis von Biographie und Arbeit im Handlungsfeld ,Schutzpolizei‘ noch einmal kurz zusammengefasst (6.3).

\subsection{Strukturen des Handlungs- und Interaktionskontextes polizeilicher Arbeit}

Ausgehend von der Rekonstruktion des Handlungs- und Interaktionskontextes polizeilicher Arbeit, ihrer Deutungs- und Handlungsmuster und ambivalenten Anforderungen (Kap. 4), werden hier nun allgemeine Aussagen über Strukturen schutzpolizeilicher Arbeit getroffen. Als konstitutiven Modus schutzpolizeilicher Arbeit konzeptualisiere ich den Wechsel von Routine und krisenhaften Momenten (6.1.1). Anschließend beschreibe ich die Interaktionsposition der Polizist*innen als zugunsten der Polizei machtasymmetrisch angelegte, die zugleich steter interaktiver Herstellung und Aufrechterhaltung bedarf (6.1.2). Zur Bearbeitung der Strukturen und Ambivalenzen sowie als Voraussetzung der Binnenbeziehungen in der Polizei fungiert das Wir-Bild (6.1.3).

\subsubsection{Routine und krisenhafte Momente als typische Situations- und Wahrnehmungsmodi}

In meinen empirischen Analysen habe ich den Arbeitskontext des Einsatz- und Streifendienstes als durch Routinen und Ausnahmen strukturiert beschrieben (Kap. 4.3.1). Außerdem habe ich die Wissensbestände und Typisierungen in fraglosen wie in problematischen (Einsatz-)Situationen rekonstruiert: Situationen, in denen die Situationsdefinitionen problemlos in vorhandene Wissensbestände integriert werden können, und Situationen, in denen dies nicht funktioniert und die weiterer Auslegung bedürfen (Kap. 4.2). Routine und Ausnahme bzw. problematische Situation lassen sich im Anschluss daran auf zwei Ebenen betrachten: (a) im Verlauf des Arbeitstages und (b) innerhalb einer Einsatzsituation. Dabei muss gleichzeitig ein begriffliches Problem gelöst werden. Ich habe bei der ethnographischen Deskription des Arbeitsalltags bisher mit den Begriffen Routine, Ausnahme bzw. problematische Situation zumeist alltagsweltlich oder deskriptiv operiert. Beides kann mit einer weiteren theoretischen Reflexion adäquater gefasst werden. Daher werde ich die Strukturen des Handlungskontextes beschreiben und diese als Wechsel von Routine und krisenhaften Momenten konzeptualisieren.

(a) Innerhalb eines Dienstablaufs habe ich Ausnahmen als Unterbrechung der Routine verstanden. Der Dienstablauf unterliegt Routinen, die den Polizist*innen durch die Organisation vorgegeben werden, die sich ihnen als objektive Strukturen darstellen. Polizist*innen schaffen sich aber auch Routinen: innerhalb der Dienst- 
abteilung, in Streifenwagenteams sowie individuelle. Diese Routinen strukturieren den Verlauf einer Schicht. Unterbrechungen dieser Routine(n) strukturieren den Verlauf aber ebenso, denn schutzpolizeiliche Arbeit kennzeichnet, dass immer ,etwas' passieren kann. Routinemäßiges Handeln hilft dann einerseits dabei, den Dienst nicht als permanente Ausnahmesituation zu erleben. Andererseits können Polizist*innen, wenn etwas passiert, auf ihre Routinen zurückgreifen, um handlungsfähig zu bleiben. Mit graduellen Unterschieden trifft dies auf alle Arbeitsund Lebensbereiche zu; wir können immer vor ein Handlungsproblem gestellt werden, das unsere Routine unterbricht. Bei schutzpolizeilicher Arbeit gehört es aber konstitutiv zur Routine des Tagesablaufs dazu, dass unvermittelt etwas passiert. Plötzlich bekommt man einen (dringenden) Einsatz, der (schnellstmöglich) angefahren werden muss. Und hier liegt nun ein begriffliches Problem: Dass etwas plötzlich passiert, ist in der schutzpolizeilichen Arbeit eben nicht unerwartet, wenngleich es in der konkreten Situation überraschend kommen kann. Dieses plötzliche ,Passieren' ist Teil der Routine eines polizeilichen Dienstverlaufs und damit eigentlich keine Ausnahme. Es ist zunächst lediglich eine Unterbrechung der aktuellen Handlung.

Nun sollte deutlicher geworden sein, dass die Begriffe Routine und Ausnahme, als eine Unterbrechung der Routine, den Gegenstand nur begrenzt treffen bzw. es nicht möglich ist, zwischen einer tatsächlichen Unterbrechung der Handlungsroutine und der Unterbrechung der Routine des Tagesverlaufs, bei dem immer etwas passiert, zu unterscheiden. Das ,Passieren' kann sich aber durchaus zu einer ,echten' Ausnahme von der Routine qualifizieren: Wenn plötzlich etwas passiert, kann es sich um eine typische Situation handeln, die als Routine wahrgenommen wird. Gleichzeitig birgt sie aber immer auch das Risiko, eine ,echte ${ }^{6}$ Ausnahmesituation zu werden, also eine Situation, für die es kein oder wenig Erfahrungswissen gibt, die selten vorkommt, u.U. auch gefährlich(er) für die Polizist*innen selbst ist und auch zu (zumindest kurzzeitiger) Handlungsunfähigkeit führen kann. Ausnahmen sind also Teil der Routine und gleichzeitig hat jede ,routinierte Ausnahme، das Potenzial, eine ,echte Ausnahme zu werden. Ein Streit in einer Kneipe ist zu einer bestimmten Tageszeit insofern Routine, als so etwas häufiger vorkommt und Polizist*innen Erfahrungen aus und in solchen Situationen haben und daher wissen, was zu tun ist. Die Situation kann sich entwickeln, wie sie antizipiert wurde. Gleichzeitig ist die Situation entwicklungsoffen und kann sich z.B. durch einen unerwarteten Angriff mit einem Messer zu einer, echten“ Ausnahme wandeln.

(b) Zur Klärung dieser Begriffsproblematik ist ein Blick auf die zweite Ebene von Routine und krisenhaftem Moment hilfreich, so lässt sich besser verdeutlichen, wann eine ,routinierte Ausnahme' zu einer, echten' Ausnahme wird.

Bekommt ein Streifenteam einen Einsatz, erhalten die Polizist*innen von der Leitstelle Deutungsangebote über die Situation. Die Definition der Situation beginnt vor der konkreten Interaktionssituation eines Einsatzes. Damit verbunden 
sind erfahrungsbasierte Handlungsentwürfe und institutionelle Vorgaben für den je konkreten Fall. Am Einsatzort angekommen herrscht dann Handlungsdruck; die Polizist*innen müssen etwas tun, um die in welcher Form auch immer angegriffene Ordnung wiederherzustellen. Im für sie optimalen Fall erweist sich die Einsatzsituation dann als nicht widerständig. Sie können ihrem Handlungsentwurf folgen und bestätigen damit auch ihre Situationsdefinition. In diesem Fall hat die konkrete Situation wenig Einfluss auf den mit der Situationsdefinition verbundenen Handlungsentwurf.

Es kann nun aber dazu kommen, dass sich die Einsatzsituation anders darstellt als erwartet und die Beteiligten anders handeln als antizipiert. Die Einsatzsituation ist widerständig gegenüber der Situationsdefinition im Vorfeld. Die Situation wird dadurch problematisch und bedarf weiterer Interpretation. ${ }^{121}$ Es muss eine neue Situationsdefinition vorgenommen werden, die sich dann erneut im Handeln als passend oder problematisch erweisen kann. In diesem zweiten Fall, in dem die Situation sich widerständig gegenüber der vor dem Einsatz vorgenommenen Situationsdefinition zeigt, drängt sich die Situation selbst mehr auf als in dem ersten Fall. Die Polizist*innen müssen die Situation in ihre transformierte oder Neu-Definition einschließen.

Im Anschluss an Alfred Schütz (Schütz/Luckmann 1979/2003) kann man in dem ersten Fall von einer routinemäßigen Deckung von Thema (der Einsatzsituation) und Wissenselementen (der angebotenen und erfahrungsbasierten Situationsdefinition) sprechen (vgl. ebd.: 272 ff.); in dem zweiten Fall von einer situationsbedingten Interpretationsrelevanz (vgl. ebd.: 279 ff.). Zwischen diesen beiden idealtypischen Polen eines Kontinuums sind natürlich vielfältige Überschneidungen möglich: Von sehr geringer Handlungsirritation mit nur einer notwendigen Konkretisierung oder Erweiterung der Situationsdefinition über eine größere Handlungsirritation mit vollkommen neuer Situationsdefinition bis hin zu einer anhaltenden Handlungsunfähigkeit, weil alle Situationsdefinitionen versagen und eine NeuInterpretation unter dem situativen Handlungsdruck nicht gelingt.

Problematische Situationen, die ausgelegt werden müssen, sind insofern krisenhaft, als Situationsdefinition und Handlungsentwurf nicht aufrechterhalten werden können. Im polizeilichen Handlungskontext können Einsätze auch immer im Zusammenhang mit dem Zufügen und/oder Erleiden von Gewalt stehen (selbst wenn dies nicht ständig der Fall ist) - auch dies kann als krisenhaft erlebt werden durch den (plötzlichen) Wechsel zu gewaltförmiger Interaktion und/oder dem Erleben von Gewalt allgemein. Der bisher verwendete Ausdruck der problematischen Situation bezeichnet aber Interpretations- und Handlungsprobleme aller Art (vgl. Schütz/Luckmann 1979/2003: 35-42); wenn ich morgens feststelle, dass auf meinem routinemäßig genutzten und in der zur Verfügung stehenden Zeit problemlos bewältigbaren Arbeitsweg eine Baustelle den Weg versperrt, ist

121 Aufgrund ihrer interaktionsmächtigen Position können Polizist*innen ihre Definition der Situation der widerständigen Empirie aber teilweise aufoktroyieren. Siehe dazu Kap. 4.2 und 6.1.2. 
auch dies eine problematische Situation. Dieser Begriff scheint mir daher für den Kontext der Polizei nur begrenzt passend.

Situationen, die einer Neuinterpretation durch die Polizist*innen bedürfen, lassen sich aber auch nicht einfach als Krise im Sinne von Schütz bezeichnen. Die von Schütz in Anlehnung an W. I. Thomas gebrauchte Definition, dass eine Krise entsteht, wenn „die aktuellen Relevanzsysteme mit einem Mal um[gestürzt]“ (Schütz 1972: 59) werden und das „Denken-wie-üblich“ (ebd.) unwirksam wird, erweist sich in diesem Zusammenhang als nicht treffend (auch wenn eine problematische Situation im Grenzfall durchaus zu einer so definierten Krise führen kann). Das „Denken-wie-üblich“ ist möglich, wenn folgende Annahmen gültig sind: 1. Das soziale Leben wird weiterhin so sein wie bisher. Unsere Erfahrungen reichen aus, um zukünftige Situationen meistern zu können; 2. wir können uns auf unser Wissen verlassen; 3. im normalen Ablauf der Dinge ist es ausreichend, etwas über den allgemeinen Typus oder Stil von Ereignissen zu wissen; 4. diese Annahmen und unsere Rezepte zur Auslegung werden von unseren Mitmenschen akzeptiert und auch angewandt (vgl. ebd.: 58-59). Ist nur eine der Annahmen nicht mehr gültig, kann das „Denken-wie-üblich“ nicht aufrechterhalten werden (vgl. ebd.: 59). Bei problematischen Situationen werden diese Grundannahmen normalerweise nicht außer Kraft gesetzt, sie werden aber angetastet oder infrage gestellt, wenn das Erfahrungswissen nicht ausreicht und die nicht-polizeilichen Interaktionspartner*innen Auslegungen nicht akzeptieren (auch, weil sie sich evtl. tatsächlich in einer so verstandenen Krise befinden).

Ich möchte deshalb sowohl die problematischen Situationen als auch die ,echten' Ausnahmen von der Routine - als Teil der Routine - krisenhafte Momente nennen. Beiden Fällen ist gemein, dass sie einer gesteigerten Zuwendung zur Situation bedürfen. Ein krisenhafter Moment erlegt den Handelnden auf, sich ihr stärker zuwenden zu müssen, und bedeutet, dass ihr aktueller Handlungsentwurf unterbrochen wird. Ich habe dies mit dem Sprung und dem zugehörigen Schockerlebnis zwischen verschiedenen Sinngebieten verglichen (vgl. Schütz/Luckmann 1979/2003: 54-60 sowie Kap. 4.3.1 und Fn. 93). Hier bleiben die Handelnden zwar in der Realitätserfahrung der Alltagswelt, müssen sich ihr aber mit höherer Anspannung des Körpers und/oder des Bewusstseins zuwenden, als es in der Routine des Tagesverlaufs oder innerhalb einer unproblematischen Einsatzsituation notwendig ist. Der Wechsel des Wabrnehmungsmodus ist ein krisenhafter Moment. Damit bleiben die ,routinierten Ausnahmen' begrifflich Teil der Routine und nur Situationen mit einem krisenhaften Moment sind eine Unterbrechung der Routine. So verstanden lässt sich auch beschreiben, wann eine Situation eine Ausnahme von der Routine wird, denn allein eine Unterbrechung der aktuellen Handlung bedeutet für die Polizist*innen noch nicht, dass sie eine Ausnahmesituation erleben. Nicht alle Einsätze, in denen plötzlich etwas passiert, sind Ausnahmesituationen für die Beamt*innen. Polizist*innen haben für viele Situationen, in denen plötzlich etwas passiert, Erfahrungswissen und routinierte Handlungsabläufe internalisiert. Die Routinisierung verhilft auch dazu, Situationen 
nicht als Ausnahme zu betrachten und zu erleben - zumindest wenn keine vollkommene Handlungsirritation eintritt.

Wissenssoziologisch banal ist die Feststellung, dass polizeiliche Routinen die Institution Polizei konstituieren. Für den schutapolizeilichen Arbeitsprozess lässt sich daran anschließend formulieren, dass er durch Routine und krisenhafte Momente konstituiert ist. Dieser konstitutive Charakter von Routine und krisenhaften Momenten unterscheidet diesen spezifischen Arbeitskontext von anderen. Ähnliche Strukturen gibt es vermutlich auch in anderen Bereichen von ,Notfallarbeit', wie z.B. Feuerwehr oder Notfallmedizin. Allerdings mit einer geringeren Gefahr der eigenen körperlichen Versehrtheit durch Gewalt Anderer.

\subsubsection{Herstellung und Aufrechterhaltung einer machtvollen Interaktionsposition}

Polizeiliche Arbeit entfaltet sich in einem Interaktionskontext, in dem Polizist*innen qua Definition in einer mächtigen Interaktionsposition sind. Sie sind die Repräsentant*innen des staatlichen Gewaltmonopols und als solche ermächtigt, auf eine Art und Weise zu handeln, wie es nicht-polizeiliche Akteur*innen nicht dürfen. Die Re-Präsentation des Gewaltmonopols erlaubt es den Polizist*innen, Gewalt auszuüben und andere in ihren Grundrechten ${ }^{122}$ zu beschneiden. Sie müssen das Gewaltmonopol aber im Zweifel eben auf diese Weise auch aufrechterhalten. Alltagspraktisch bedeutet dies unter anderem sogenannte Zwangsmaßnahmen anzuwenden.

Gewalt verstehe ich als physische Gewalt (vgl. Kap. 2.1.1). Ich halte es für wichtig, deutlich zu machen, dass die Polizei physische Gewalt ausübt und auch, dass sie dazu legitimiert ist. Natürlich ist sie das nur in einem bestimmten Rahmen, es ist aber (phänomenologisch) oft nicht zu unterscheiden, ob eine ,legitime Zwangsmaßnahme' angewendet oder ungerechtfertigte Gewalt ausgeübt wird. Für die Betroffenen bleibt es eine Erfahrung von physischer Gewalt - genauso wie es für die Polizist*innen eine Gewalterfahrung ist, auch wenn sie ,Widerstand gegen Vollstreckungsbeamte oder Ähnliches genannt wird. Es bleibt eine Erfahrung der Gewaltausübung und von Gewalterleiden, egal ob die jeweilige Gewalt legitimiert ist oder nicht.

Ich halte es außerdem für wichtig, Beleidigungen und Subordinationen von Gewalt zu unterscheiden. Im Kontext schutzpolizeilicher Arbeit sind solche Machtpraktiken viel häufiger vorzufinden als die Anwendung von Gewalt. So sind

122 Für Niedersachsen: \10 NPOG Einschränkung von Grundrechten. Eingeschränkt werden im Rahmen schutzpolizeilicher Arbeit alltagspraktisch vor allem das Recht auf körperliche Unversehrtheit (Art. 2 Abs. 2 Satz 1 GG), das Recht auf Freiheit der Person (Art. 2 Abs. 2 Satz 2 GG) und das Recht auf die Unverletzbarkeit der Wohnung (Art. 13 GG). \10 NPOG umfasst weiterhin die Einschränkung von Art. 8 Abs. 1 GG, Art. 10 Abs. 1 GG und Art. 11 Abs. 1 GG (Versammlungsfreiheit, Fernmeldegeheimnisse und Freizügigkeit). Die Einschränkung der letztgenannten sind eher im Bereich der Tätigkeit von Kriminal- und Bereitschaftspolizei angesiedelt und vermutlich seltener Teil der alläglichen Arbeit des ESD. 
Beleidigungen und die Herabwürdigung von Personen keine ,Zwangsmaßnahmen', sondern reine Machtdemonstrationen. Sie entfalten ihre Effektivität aber auch dadurch, dass die nicht-polizeilichen Anderen wissen, dass ein Aufbegehren dagegen eine Machtdemonstration mithilfe von Gewalt - mit Aktionsmacht - zur Folge haben kann.

Die Polizei ist aber nicht nur Vertreterin des Gewaltmonopols, sondern gerade die Schutzpolizei scheint vielmehr ,ein Monopol der ersten Bearbeitung problematischer Alltagssituationen“ (Mensching 2008: 72) innezuhaben. Dabei rücken „allgemeine Dienstleistungs- und Hilfefunktionen in den Vordergrund und unterstreichen den diffusen Auftrag der Polizei, für Sicherheit im öffentlichen wie privaten Raum zu sorgen“" (ebd.: 72). Das Gewaltmonopol zeigt sich, bei der Bearbeitung problematischer Alltagssituationen gleich welcher Art, in der Möglichkeit, Situationen aus machtstärkerer Position $2 u$ definieren und auf Grundlage dieser Definition zu bandeln. Polizist*innen haben eine bessere Chance als andere an der Interaktion beteiligte Personen, ihre Situationsdefinitionen durchzusetzen (vgl. Kap. 4.2). ${ }^{123}$ Die starke Beteiligung an der Herstellung der Situation bedeutet oft aber auch, dass ihre Situationsdefinition und die damit verbundene eigene Interaktionsposition aufrechterhalten werden muss, wenn sie ihre Definition der Situation einmal (handelnd) kommuniziert und festgelegt haben. Sie müssen ihre Situationsdefinition im Zweifel auch gegen Widerstand durchsetzen, um ihre machtvolle Position aufrechterhalten zu können. Teil der Machtposition ist dabei, dass sie Macht erhalten durch das Wissen, dass sie Widerstand brechen können.

Polizist*innen erleben sich in ihrem Arbeitsalltag regelmäßig in Situationen, in denen sie ihre Position infrage gestellt sehen. Wenn z.B. ihren Anweisungen nicht Folge geleistet wird oder sie angelogen werden, kann dies als Infragestellung ihrer Position interpretiert werden. Die Position der „Definitionsmacht“ (Feest/Blankenburg 1972) bietet prinzipiell immer die Möglichkeit infrage gestellt zu werden. Die Polizei wird eben vor allem dann tätig, wenn, Ordnung' infrage gestellt wurde. Die Wiederherstellung der Ordnung (gegen Widerstand) korrespondiert dann häufig mit einer Infragestellung der ,Ordnungshüter*innen' bzw. ihrer Legitimation oder der Legitimität ihres Handelns: Die machtvolle Interaktionsposition wird angezweifelt und muss von den Polizist*innen verteidigt werden, um die Institution und ihre Legitimation nicht zu gefährden. Aus der Perspektive von Polizist*innen müssen sie ihre Interaktionsposition aufrechterhalten, um einerseits die mit dem Amt verbundene Position erfüllen zu können und um andererseits eine Erfahrung von Machtschwäche oder Machtlosigkeit zu verhindern (s. auch Reuter 2014).

Für den Handlungszusammenhang polizeilicher Arbeit sind Grenzüberschreitungen Normalität (vgl. Kap. 4.3.5). So wie die räumlichen, physischen und psy-

${ }^{123}$ Insofern Macht im Sinne Webers als die „Chance, innerhalb einer sozialen Beziehung den eigenen Willen auch gegen Widerstreben durchzusetzen, gleichwohl worauf diese Chance beruht" (Weber 1921/2014: 38). 
chischen Grenzen ihrer Interaktionspartner*innen überschritten werden, werden auch ihre eigenen physischen und psychischen Grenzen überschritten oder verschoben. Von Polizist*innen wird verlangt, ihre konkrete physische und symbolische Position im Zweifel auch grenzüberschreitend, im Rahmen legaler Mittel, zu verteidigen. In diesem Geflecht von der Normalität von Grenzüberschreitungen und dem Erleben von Machtlosigkeit in ihrer eigentlich machtstarken Position bietet der Handlungskontext polizeilicher Arbeit grundlegend die Voraussetzungen zum Missbrauch ihrer Möglichkeiten.

Polizeiliche Arbeit bietet also einerseits eine starke und machtvolle Interaktionsposition, die im Arbeitsalltag aber strukturell infrage gestellt wird. Daher müssen Polizist*innen andererseits ihre eigentlich starke Position immer wieder, verteidigen'. Eine Ausgestaltung der Handlungsmöglichkeiten bei der Bearbeitung eines konkreten polizeilichen Falles entfaltet sich unter anderem entlang der Herstellung und Aufrechterhaltung ihrer Interaktionsposition. Je nach Ablauf der Interaktion bei einem polizeilichen Einsatz rückt die Verteidigung der eigenen Interaktionsposition - bei wiederholter Infragestellung - in den Vordergrund und die Bearbeitung des Einsatzanlasses wird sekundär.

Schutzpolizeiliche Arbeit bietet dabei, vor allem gegenüber der Arbeit in geschlossenen Einheiten, relative Autonomie. Schutzpolizist*innen haben innerhalb klar vorgegebener Strukturen gewisse Freiheitsgrade in der Gestaltung ihrer Arbeit. Der vorgegebene Handlungsrahmen ist dabei gesetzlich bestimmt; Gesetze regulieren die Möglichkeiten und Grenzen polizeilichen Handelns. Gleichzeitig lassen Gesetze Auslegungsspielräume zu, die Polizist*innen zu nutzen wissen (vgl. Kap. 4.3.3 und 4.3.4). So haben Polizist*innen Möglichkeiten, ihr Handeln zu einem für sie befriedigenden Ergebnis zu bringen - dies kann durchaus auch zum Vorteil der nicht-polizeilichen Anderen sein. Ein befriedigendes Ergebnis stellt z.B. auch das Aussprechen einer Verwarnung dar, anstatt des Ausschöpfens der vollen gesetzlichen Möglichkeiten zu Ungunsten des ,Bürgers‘. Diese Spielräume tragen zum Autonomieerleben bei. In anderen Fällen haben sie keine Möglichkeiten, ein für sie befriedigendes Ergebnis (legal) zu erreichen, und erleben sich in ihrem Handlungsspielraum eingeschränkt und in ihrer machtvollen Interaktionsposition beschnitten. Das Gesetz verleiht Polizist*innen Interaktionsmacht und beschränkt diese zugleich. Diese Spielräume zu haben bedeutet aber auch, sie füllen zu müssen; sie lassen Leerstellen, die nicht nur genutzt werden können, sondern die auch aufgebürdet werden.

Im Arbeitsalltag der Schutzpolizei ist es möglich, den Dienst zu gestalten - in Aushandlung mit dem*der Kolleg*in - innerhalb einer fremdbestimmten Struktur von Organisationsregeln, Gesetzen und Soforteinsätzen. Diese Gestaltungsspielräume und Möglichkeiten von Machtausübung tragen zum Erleben von relativer Autonomie bei (im Vergleich zu anderen polizeilichen Arbeitsbereichen), aber auch zum Erleben von Frustration über die Begrenzung ihrer Möglichkeiten. Auch in diesem Kontinuum von Macht- und Autonomieerleben und dem Erleben von Ohnmacht und Frust kann sich gewalttätiges Handeln entfalten, intendiert 
oder aus dem Affekt heraus. Gewalthandeln kann sich als Reaktion auf einen als Angriff erlebtes Handeln im Affekt Bahn brechen. Es kann sich aber auch als gezielte Maßregelung oder Provokation zeigen: als eine Strafe, in der Antizipation, dass die legal-juristische (aus Perspektive der Polizist*innen) nicht angemessen sein wird; oder als Provokation eines, Widerstandes', der es erlaubt, ,richtig', in welcher Form auch immer, tätig zu werden.

Die hier beschriebene machtvolle Interaktionsposition und die damit verbundenen Handlungsstrukturen und -bedingungen begünstigen gewaltvolle Konfliktlösungen. Dennoch, so zeigte es sich während meiner Feldforschung, sind $\mathrm{Zu}$ rechtweisungen und (implizite) Beleidigungen eher der Regelfall als physisches Eingreifen. Der Prozess, der $¥ u$ Gewalthandeln fübrt, ist in diesem Kontext strukturgleich zu dem, der zu verbaler Subordination führt. In beiden Fällen geht es um die Herstellung der Machtbalance (Elias 1970/2004) zugunsten der Polizei respektive der Polizist*innen.

Wie in Kapitel 4 gezeigt, sind Polizist*innen in ihrer Arbeit mit ambivalenten Anforderungen konfrontiert. Die Notwendigkeit, eine machtvolle Interaktionsposition aufrechtzuerhalten, speist sich auch aus diesen Ambivalenzen und dem diffusen polizeilichen Auftrag, zugleich ,Ordnungshüter*innen' zu sein und ,bürgernah ${ }^{`} \mathrm{zu}$ handeln; polizeiliches Handeln spannt sich auch zwischen Helfen und Unterstützen sowie Deeskalation und gewaltförmigem Handeln auf. Polizeiliche Arbeit bedeutet auch Gefühlsarbeit, sich z.B. hart oder empathisch zu zeigen. Entweder um dadurch (intendiert) eine bestimmte Reaktion beim Gegenüber hervorzurufen und z.B. Mitarbeit anzuregen oder auch weil das eigene Erleben der Situation danach verlangt bzw. Emotionen nicht unterdrückt werden können. Peggy Szymenderski (2013) hat Gefühlsarbeitspraktiken im Polizeidienst rekonstruiert. Was Szymenderski als emotionale Belastungen herausarbeitet, habe ich als Strukturen polizeilicher Arbeit beschrieben. Sie fokussiert in ihrer Arbeit auf den „Umgang mit emotionalen Dissonanzen“ (ebd.: 173) in dem von ambivalenten Anforderungen strukturierten Polizeidienst. Auch wenn sich das zugrundeliegende theoretische Konzept von Arlie Hochschild (1990) kritisieren ${ }^{124}$ lässt und ich manche ihrer Schlussfolgerungen aus einer sozialkonstruktivistischbiographietheoretischen Perspektive anders formulieren würde, leistet sie mit ihrer Untersuchung und ihren Ergebnissen einen wichtigen Beitrag zur Beschreibung von Emotionen als (interaktions-)relevant - in einem (Forschungs- und) Handlungsfeld, in dem die Handelnden (von sich selbst) (manchmal) als affektloser Staat aufgefasst werden. Szymenderski betont außerdem die Notwendigkeit von Gefühlsarbeit, um überhaupt dauerhaft in der Lage zu sein, als Polizist*in zu arbeiten, und als „zentrale berufliche Kompetenz“ (ebd.: 179) in einem Beruf, der hohe emotionale Anforderungen stellt. Aus soziologischer Perspektive würde ich

${ }^{124}$ Für einen Überblick siehe Flam (2002: 200-205). Eine umfassendere Kritik und Erweiterung findet sich bei Artur Bogner und Cas Wouters, die dafür plädieren, Hochschilds Ausführungen in eine „breiter ansetzende Theorie sozialer Machtrelationen und soziogener Selbstzwänge“ zu integrieren (Bogner/Wouters 1990: 258). 
jedoch vor allem die Notwendigkeit von, Gefühlsarbeit für polizeiliches Handeln auf der „Vorderbühne“ (Goffman 1969) und als berufliche Kompetenz betonen und sie weniger als „strategische Selbstinszenierung“ (Szymenderski 2013, 179) auffassen, wie es bei Szymenderski erscheint. Der Einsatz von Emotionen mag zwar für den Arbeitsprozess funktional sein, jedoch weniger als Selbstinszenierung denn als Versuch, interaktiv ein Arbeitsbündnis herzustellen (vgl. Kap. 4.3.7). Selbstkontrolle stellt eine Ressource dar, mit der die Interaktionen mit (dem nichtpolizeilichen) Anderen beeinflusst werden können; „Selbstkontrolle und Kontrolle der ,äußeren“ Situation sind [...] überall untrennbar miteinander verwoben“ (Bogner/Wouters 1990: 270).

Aus sozialkonstruktivistisch-biographietheoretischer Perspektive ist es wichtig zu betonen, dass auch Emotionen sozialisiert und diskursiv hergestellt sind und Polizist*innen auch auf Grundlage ihrer biographischen Erfahrungen, eingebettet in sozio-historische und diskursive Verflechtungen, handeln.

In ihrem Arbeitsalltag sind Polizist*innen mit Situationen konfrontiert, in denen nicht nur die nicht-polizeilichen Anderen in einer (emotional) extrem belastenden Situation sein können, sondern auch sie selbst. Nicht zuletzt um Ohnmachtserleben entgegenzuwirken oder zu unterdrücken, muss Interaktionsmacht aufrechterhalten oder wiedererlangt werden - Polizist*innen müssen handlungsfähig bleiben.

\subsubsection{Das schutzpolizeiliche Wir-Bild und die Zugehörigkeit zur Wir-Gruppe}

Das in Kapitel 4.1 dargestellte starke Wir-Bild (und die damit korrespondierenden Sie-Bilder) kann auf seine Funktion für den polizeilichen Arbeitskontext hin befragt werden: das Wir-Bild von ,uns Polizist*innen' als die guten und unpolitischen Vertreter*innen des Gesetzes und der richtigen Werte; als Respektspersonen, die Ordnungshüter*innen, aber auch ,Freund und Helfer' sind; als die, die viel zu ertragen haben; die nicht gewalttätig sind, sich nur wehren und für die "Zwang' (nur) notwendiges Mittel ist. Ich verstehe das Wir-Bild als sich wechselseitig bedingend und funktional für die Bearbeitung der Handlungsbedingungen und Voraussetzung für die Interaktionspraxis im Binnenberng.

\subsubsection{Das Wir-Bild als Bearbeitung der Handlungsbedingungen}

Das polizeiliche Wir-Bild ist Ausdruck einer starken Wir-Gruppe, die sich auf die berufliche Tätigkeit bezieht. Insofern wirkt es vergemeinschaftend und homogenisiert die Gruppe der Polizist*innen, erfüllt somit die Funktionen eines Wir-Bildes. Das Wir-Bild macht es möglich, sich positiv darauf zu beziehen, um die eigene Arbeit und das eigene Dasein als Teil der Gruppe und als einzelne*r Polizist*in zu bestätigen. Das Wir-Bild idealisiert die berufliche Tätigkeit, erlaubt dadurch, problematische Aspekte des eigenen Handelns zu negieren, und ermöglicht so auch Handlungsfähigkeit im Arbeitsalltag. Die Zugehörigkeit zur polizeilichen WirGruppe vermag den Zusammenhalt innerhalb der Gruppe zu stärken, verpflichtet 
aber auch auf sie und macht es schwer, gegen Gruppenregeln zu verstoßen, da dies zu einem Ausschluss aus der Gruppe führen kann. Sie schließt nach außen ab und bindet nach innen. Die Wir-Gruppen-Zugehörigkeit fungiert stützend im Arbeitsalltag.

Die Möglichkeit, verschiedene Bestandteile des Wir-Bildes stärker zu betonen als andere, sozusagen die Flexibilität des Bildes, macht es möglich, dass alle Polizist*innen Bestandteile finden können, die sich in ihr berufliches Selbstbild integrieren lassen. Das Wir-Bild lässt es zu, dass polizeiliche Gewalttäter*innen aus der Wir-Gruppe ausgeschlossen werden können, weil sie eben nicht Gutes tun und nicht ,Freund und Helfer' sind. Es lässt aber auch zu, sie als harte ,Ordnungshüter*innen', die sich Respekt verschaffen, zu sehen und als Teil der Wir-Gruppe zu akzeptieren. Die Flexibilität des Wir-Bildes lässt Differenzierungen, die Zugehörigkeiten und Orientierungen zu unterschiedlichen Wir-Gruppen innerhalb der Polizei ausdrücken, zu. Dies ist möglich, da das Wir-Bild sehr gefestigt ist und die grundlegenden Muster von allen Personen ${ }^{125}$, mit denen ich in meiner Forschung gesprochen habe, bedient werden können (gegenüber mir respektive einer nichtpolizeilichen Öffentlichkeit). Differenzierungen und Ein- und Ausschluss von polizeilichen Arbeitsbereichen werden durch das Wir-Bild nach außen unter einem Bild von ,wir Polizist*innen' - oder vermutlich treffender: ,wir Polizisten ${ }^{6}$ - verdeckt. Interne Differenzierungen des Wir-Bildes sind unter anderem Ausdruck unterschiedlich strukturierter innerpolizeilicher Tätigkeitsfelder. Bestandteil des schutzpolizeilichen Bildes über die eigene Sub-Wir-Gruppe ist es, dass in der Schutzpolizei die ,richtige' Polizeiarbeit gemacht wird - eine Abgrenzung gegenüber z.B. den ,Schreibtisch-Polizist*innen' der Kriminalpolizei. Das interne Abgrenzungsbedürfnis beruht vermutlich auf einer wahrgenommen Geringeschätzung der schutzpolizeilichen Arbeit innerhalb der organisationalen Figuration. Das schutzpolizeiliche Wir-Bild bearbeitet auch die Herausforderungen, die mit relativer Autonomie innerhalb starker, wenig flexibler Strukturen einhergehen.

Das Wir-Bild macht es möglich, im Arbeitsalltag ständig handlungsfähig zu sein und zu bleiben, indem es eine Infragestellung des eigenen Handelns nicht notwendig macht oder auch unterdrückt - damit ist nicht ausgeschlossen, dass ohne Handlungsdruck eine reflexive Hinwendung zum eigenen Handeln oder dem polizeilichen Auftrag stattfindet. Eine Infragestellung von bestimmten polizeilichen Aufgaben wird durch das Wir-Bild ebenfalls angeregt: Eine Abgrenzung von ,der ${ }^{6}$ Politik, ein Selbstverständnis als Ordnungshüter*innen (nicht im Sinne des städtischen Ordnungsamtes) und ein damit verbundenes berufliches Selbstbewusstsein verhindern, die (empfundene) Bürokratisierung und Ökonomisierung der Polizei positiv bewerten zu können (vgl. Kap. 4.3.4).

125 Dies ist kein Verallgemeinerungsargument für die numerische Verbreitung des Musters. Neben der teilnehmenden Beobachtung rekrutiert sich mein Gesamtsample jedoch aus verschiedenen Bereichen (Schutz-, (Landes-)Kriminal- und Bereitschaftspolizei; verschiedene Bundesländer). Dies verweist darauf, dass es in den verschiedenen polizeilichen Arbeitsbereichen eine geteilte Vorstellung von ,Polizei‘ gibt, die unabhängig von der konkreten Tätigkeit besteht und grundlegende Bedingungen des Arbeitsfeldes bearbeitet. Zur Sozialisation in die Wir-Gruppe siehe Kap. 6.2.3. 
Polizist*in-Sein bietet also eine starke Wir-Gruppen-Zugehörigkeit. Gleichzeitig ist es notwendig, dieser Wir-Gruppe auch anzugehören. Es ist notwendig, sich ihr unterzuordnen oder das Wir-Bild zumindest partiell bedienen zu können. Es erscheint einerseits als Bedingung für die Aufrechterhaltung der Handlungsfähigkeit und ist andererseits gruppendynamisch problematisch, wenn man sich außerhalb der Gruppe verortet - die Gruppe muss nicht die Polizei ,an sich', sondern kann durchaus nur die Dienstabteilung sein. Es ist fraglich, ob Polizist*innen längerfristig in der Schutzpolizei bestehen können, wenn sie nicht Teil der WirGruppe werden (können) - und dies ist im Vergleich mit anderen Arbeitskontexten von besonderer Bedeutung: (Schutz-)Polizist*innen sind auch in Bezug auf ihre Sicherheit und körperliche Unversehrtheit voneinander abhängig.

Hier ist durchaus kritisch eine Begrenzung meiner Arbeit festzustellen. Für wen die Polizei kein dauerhaftes Arbeitsfeld bietet, wem es dort eventuell nicht gelungen ist, Teil der Gruppe zu werden, oder wer mit den Anforderungen und Strukturen der Polizei nicht kompatibel ist, kann empirisch nur durch Interviews mit Aussteiger*innen aus dem Polizeidienst rekonstruiert werden.

Durch die Konzeption der Wir-Gruppen-Zugehörigkeit als stützend soll die Problematik der Gruppen-Verpflichtung nicht negiert werden. Das Schweigen in der Polizei und die damit zusammenhängenden, teils sehr schwerwiegenden Folgen für die Opfer von polizeilicher Gewalt und/oder Falschaussagen sind durchaus im Zusammenhang der Wir-Gruppen-Zugehörigkeit zu sehen. Unter dem medial oft gebrauchten Label von (falsch verstandenem) Korpsgeist ${ }^{126}$ werden die Prozesse jedoch nicht soziologisch erklär- und verstehbar. Die Rekonstruktionen der Strukturen polizeilicher Arbeit und des Wir-Bildes über die eigene Gruppe sind aufschlussreicher: Das Berufsbild und Handeln von Polizist*innen muss mit der Ambivalenz auskommen, Gewalt mit Gewalt, die zu willkürlicher Gewalt werden kann, zu begrenzen (vgl. Reemtsma 2003: 16). Das Wir-Bild und die starke Wir-Gruppe können als Bearbeitung dieses Paradoxons des Gewaltmonopols

${ }^{126}$ Der Begriff „Korpsgeist“ oder „Esprit de Corps“ ist soziologisch nicht ausreichend definiert. Wird mit ihm gearbeitet, bezieht er sich häufig auf das Militär, aber auch auf Professionen oder Unternehmen im Zusammenhang mit Berufszufriedenheit (z.B. Boyt/Lusch/Naylor 2001; Vitell/Singhapakdi 2008), und drückt etwas wie Gemeinschaftsgefühl, Teamgeist oder Gruppenkohäsion aus. Manchmal wird betont, dass in Gruppen mit Korpsgeist das Wohl aller über das des Einzelnen gesetzt werde. Die Undeutlichkeit des Begriffs zeigt sich auch beim Blick in die Militärsoziologie: Samuel P. Huntington und Morris Janowitz, die sich beide seit/in den 1950er Jahren unter anderem mit der Beziehung von Militär und Staat bzw. Gesellschaft auseinandergesetzt haben, stimmen darin überein, dass es einen Esprit de Corps beim (amerikanischen) Militär gebe, sind sich aber uneins über die Elemente, die er beinhaltet (zusammenfassend Sørensen 1994). In einem Einführungsbuch zu Militärsoziologie (Leonhard/Werkner 2012) z.B. werden die Begriffe Esprit de Corps und Korpsgeist von verschiedenen Autor*innen verwendet, ohne dass sich eine Erklärung findet, was genau Korpsgeist allgemein oder soldatischer Korpsgeist im Speziellen sei. In Zusammenhang mit der Polizei im deutschsprachigen Raum wird der Begriff im wissenschaftlichen Diskurs fast nicht genutzt, eine Ausnahme stellt Behr dar, der den Begriff diskutiert und zu dem Schluss kommt, dass der Begriff im wissenschaftlichen Diskurs keinen analytischen Mehrwert bringe (Behr 2010). 
verstanden werden. Ebenso dient es der Bearbeitung dessen, was man als Polizist*in jeden Tag erlebt bzw. was antizipiert wird, was man als Polizist*in erleben könnte, wie etwa schwierige Situationen, in denen man sich respektlos behandelt oder machtschwach fühlt. Die Überzeugung, prinzipiell das Richtige und Gute zu tun, hilft nicht nur in Situationen von Machtschwäche, sondern auch bei der Verteidigung der eigenen Interaktionsposition als legitim. Hinzu kommt das Erleben, dass die eigene Arbeit oft unwirksam ist und keine Folgen für vermeintliche Straftäter*innen hat. So sind die Bedingungen der Arbeit und das Wir-Bild als sich wechselseitig bedingende und hervorbringende Strukturen ein Erklärungsansatz, für das Schweigen in der Wir-Gruppe der Polizei.

Das Wir-Bild umfasst außerdem nur eine sehr eingeschränkte Verortung, als Exekutive Teil des politischen Systems Deutschlands zu sein; innerhalb dieser Figuration präsentieren sich Polizist*innen als machtschwächere Gruppe gegenüber ,der ${ }^{6}$ Politik oder ,der ${ }^{6}$ Verwaltung. Polizist*innen präsentieren und erleben sich als durch Politik und Verwaltung reglementiert, nicht nur in Bezug auf die tägliche Arbeit - hier exekutieren sie Vorgaben oder werden durch Gesetze handlungsunfähig gemacht, so die Wahrnehmung -, sondern auch bezogen auf die Entwicklungsmöglichkeiten der eigenen Laufbahn, die unter anderem auch politischer Steuerung unterworfen ist. Diese - auch historisch gewachsenen - Deutungen und das Fehlen eines demokratischen Bezugs im Wir-Bild begünstigen eine mangelnde oder falsch verstandene Unterstützung der Judikative und anderer Bereiche der Exekutive.

Das Wir-Bild lässt sich nicht nur als funktional für die Bearbeitung der Handlungsbedingungen deuten, sondern auch als Voraussetzung für die Interaktionspraxis innerhalb der Wir-Gruppe der (Schutz-)Polizei. Dies werde ich im Folgenden ausführen.

\subsubsection{Das Wir-Bild als Voraussetzung für die Interaktionspraxis im Binnenbezug}

Das Wir-Bild umfasst einerseits alle Polizist*innen, andererseits lässt es Differenzierungen innerhalb der Organisation zu. Diese Differenzierung wirkt bei den doch recht unterschiedlich strukturierten Tätigkeitsfeldern innerhalb der Polizei einer Fragmentierung der Organisation entgegen. Das sowohl starke und homogenisierende als auch differenzierte Wir-Bild kann als innerpolizeiliche Legitimation der verschiedenen Rollen in der Institution gesehen werden. Ich möchte das Wir-Bild als Voraussetzung und Legitimation für die innerpolizeiliche Interaktionspraxis verstehen.

Die Organisationsstruktur der Polizei ist hierarchisch stark gegliedert und gleichzeitig von einer ,Undeutlichkeit' hierarchischer Beziehungen geprägt. Wie ich in Kapitel 4.3.6 gezeigt habe, sind die Über- und Unterordnungsverhältnisse in der Schutzpolizei einerseits davon bestimmt, dass die Uniformen die formalhierarchischen Positionen anzeigen. Eine Hierarchie ist so ständig sichtbar und insofern nicht hintergehbar. In der Face-to-Face-Interaktionspraxis des Arbeitsall- 
tags erweist sich andererseits aber eine informelle, erfahrungsbasierte hierarchische Praxis als relevanter. Die sichtbare Uniform garantiert keine Unter- oder Überordnung in der Alltagspraxis. Vielmehr erweist sich hier erfahrungsbasiertes Wissen um ,richtige' polizeiliche Arbeit als maßgeblich für eine anerkannte Position innerhalb der Dienstabteilung. Theoretisches Wissen in Form von innerpolizeilicher Weiterqualifikation kann nur dann zu Anerkennung als Vorgesetzte*r und Kolleg*in führen, wenn im Arbeitsalltag auch Praxisverständnis gezeigt werden kann und akzeptiert wird, dass die ,einfachen“ Beamt*innen einer Dienstabteilung ihren Vorgesetzten die Unterstützung auch entziehen können, wenn er*sie die informelle, erfahrungsbasierte Hierarchie nicht anerkennt.

Es existiert also einerseits eine formale Hierarchie, die umso deutlicher ist, je weniger direkte Face-to-Face-Interaktion erfolgt - aus Perspektive der ,einfachen“ Beamt*innen vor allem mit den Vorgesetzten des höheren Dienstes. Andererseits wird durch die Betonung von Kollegialität im Wir-Bild undeutlich, wie weit nach ,oben' diese reicht. Die je geltenden Regeln einer Dienstabteilung oder Inspektion müssen erst gelernt werden. Wer z.B. darf außerhalb der Ebene der Dienstabteilungen geduzt werden und wer nicht?

Das Wir-Bild kann als Voraussetzung für die ,gelebte Hierarchie“ (Mensching 2008) und die ,Undeutlichkeit“ hierarchischer Beziehungen innerhalb einer formal hierarchischen Struktur interpretiert werden. Nur unter der Voraussetzung eines starken Wir-Bildes - ,wir Polizist*innen' und ,wir Kolleg*innen' - können sich die konkreten organisationsinternen Strukturen und Binnenbeziehungen entwickeln. Gleichzeitig braucht die Interaktionspraxis das Wir-Bild, um überhaupt in dieser Form aufrechterhalten werden zu können. Nur mithilfe des vergemeinschaftenden Wir-Bildes, das alle zu Kolleg*innen macht, kann die polizeiliche Hierarchie prozessiert werden. Unter der Voraussetzung von Kollegialität lassen sich Statusdifferenzen in der Hierarchie verbergen und die Sichtbarkeit formaler Positionszuweisungen unterdrücken. Gleichzeitig lässt sich die weiterhin wirksame formale Hierarchie dadurch aushalten. Beobachtet habe ich durchaus auch Konflikte mit und negative Zuschreibungen an Vorgesetzte(n) (des höheren Dienstes). Die Bedeutung des Wir-Bildes als ,Bindemittel' schränkt dies aber nicht ein. Die Differenzierungen des Wir-Bildes, bezogen auf verschieden strukturierte Tätigkeitsbereiche, können solche Differenzen integrieren. Im Sinne Berger und Luckmanns (1969/2012) kann das Wir-Bild als Legitimation verstanden werden. „Legitimation als ein Prozeß, als Legitimierung“ (ebd.: 98) erklärt und rechtfertigt institutionale Ordnung über ihre Entstehung hinaus; der Sinn einer Ordnung wird objektiviert und historisiert. Das Wir-Bild ist nicht nur die Voraussetzung zur Aufrechterhaltung der Interaktionspraxis, sondern legitimiert sie auch, indem die vergemeinschaftenden Bestandteile stark gemacht, Differenzierungen integriert werden und größere Konflikte verdeckt bzw. auf ein Außen (die verschiedenen Sie-Gruppen, Medien, Politik etc.) projiziert werden. Kurzum: Das Wir-Bild rechtfertigt die Strukturen der Binnenbeziehungen. 
Auch die Geschlechterpraktiken des Arbeitsalltags (Kap. 4.3.7) unter den Kolleg*innen können aus dieser Perspektive erklärt und verstanden werden. Polizistinnen müssen sich in der Interaktion mit ihren Kollegen in einer bestimmten Form von Weiblichkeit präsentieren, die einerseits nicht ,zu weiblich ‘ und andererseits nicht ,zu burschikos' sein darf. Frauen sollen das Gleiche leisten wie ihre männlichen Kollegen und werden aber gleichzeitig auf die ihnen zugeschriebenen ,weiblichen' Kompetenzen zurückgeworfen: Männer und Frauen seien für verschiedene Einsätze prädestiniert. Polizistinnen müssen daher in einem doppelten Sinne mehr leisten als ihre Kollegen. Sie müssen zum einen mehr interaktive Präsentationsarbeit ihrer selbst leisten - nicht nur gegenüber einem nichtpolizeilichen Anderen, sondern auch gegenüber ihren Kollegen. Zum anderen müssen sie beweisen, dass sie alles können - bei Männern wird dieses umfassende Können nicht grundlegend infrage gestellt. Können Polizistinnen dies austarieren - ,richtige' Polizeiarbeit machen und ,weibliche' Ordnungshüterinnen sein -, können sie akzeptierte und respektierte Kolleginnen und Teil der Wir-Gruppe sein.

Das geteilte Wir-Bild und die Zugehörigkeit zur Wir-Gruppe machen es möglich, dass interne Differenzen verdeckt werden. Eine Infragestellung der Männlichkeitskultur kann sich zwar durch einen wachsenden Anteil von Frauen grundsätzlich vollziehen, wird aber vermutlich durch das geteilte Wir-Bild und die damit verbundenen eingelebten Gruppenregeln erschwert: Macht, Respekt und Ordnung sind männlich konnotierte Eigenschaften und tief in das Wir-Bild eingelassen. Und dieses Wir-Bild als Abgrenzungsmechanismus gegenüber einem nichtpolizeilichen Außen, welches als feindlich erlebt werden kann, verbindet Polizist*innen. Das Wir-Bild legitimiert auch die Geschlechterpraktiken in der Binnenbeziehung.

\subsection{Biographische Strukturierungen und Handlungsmuster}

An dieser Stelle sollen nun die Ergebnisse auf der Fallebene Biographie zusammengefasst werden. Zunächst möchte ich die beiden in dieser Arbeit rekonstruierten Fallgeschichten in Bezug auf das Forschungsinteresse zusammenfassen (6.2.1). Bei der Darstellung der weiteren Ergebnisse werde ich mich am zeitlichen Verlauf orientieren und zunächst Eintritt in die Polizei und die Funktion der Berufswahl (6.2.2) und das Polizist*in-Werden als sozialisatorischen Prozess (6.2.3) diskutieren. Abschließend betrachte ich das Polizist*in-Sein im Zusammenhang mit den biographisch bedingten Handlungsmustern im Arbeitsalltag (6.2.4).

\subsubsection{Die biographische Struktur. Kondensierte Fallzusammenfassungen}

Beide hier dargestellten Fälle repräsentieren einen Typus, bei dem die Berufswahl Polizist*in eine Form der Bearbeitung ihrer biographischen Erfahrungen ist. Die 
Polizei hält für beide - in je unterschiedlicher Weise - einen organisationalen Möglichkeitsraum bereit, in dem sie sich in biographisch bedeutsame Situationskonstellationen, die bearbeitungsbedürftig sind, begeben können. Dies wirkt sich auf ihr Erleben von Polizei und ihre Laufbahnentwicklung aus. Aufgrund unterschiedlicher lebensgeschichtlicher Verläufe kommt es also zu ebenso divergenten Verläufen in der Polizei.

Für beide ist die Polizei mit ambivalenten Erfahrungen verbunden: Erlaubt sie ihnen einerseits, sich ihren biographisch bedeutsamen Situationen aus einer gestärkten Position zuzuwenden, so machen andererseits beide auch Erfahrungen von organisationaler Fremdbestimmung.

\section{Melanie Wegener - Die Bearbeitung von biographischer Unsicherbeit}

Zusammengefasst zeigt die Rekonstruktion der Lebensgeschichte von Melanie Wegener, dass ihre Berufswahl eine Bearbeitung ihrer biographischen Situation ist, die sich nach der Trennung ihrer Eltern durch biographische Unsicherbeit und familiale Loyalitätskonflikte auszeichnet. Auch wenn sie sich in beruflicher Hinsicht in diesem Konflikt für die väterliche Seite entscheidet - gegen ein Studium und das berufliche Feld der Mutter - und wie ihr Vater Polizistin wird, bindet sie sich dadurch zugleich stärker an ihre Mutter, der gegenüber sie nun eine Loyalität beweisen muss, die der Vater eben nicht bewiesen hat. Der Fall von Melanie Wegener repräsentiert einen Typus, bei dem die Berufswabl eine Form der Bearbeitung der biographischen Situation ist. Die Polizei stellt dabei eine Organisation dar, die Sicherbeit bietet. Sicherheit zum einen unter dem Aspekt des Herkunftsmilieus, das weniger ein Hochschulstudium und mehr eine sichere Berufsausbildung nahelegt. Zum anderen, und dies ist relevanter, bedeutet Polizei auch unter einem emotionalen Aspekt Sicherheit: Die kindlichen Erfahrungen mit Polizei (und ihrem Polizisten-Vater) und auch die strukturierte Sicherheit, die Polizei ihr nach den erlebten Trennungen - der ihrer Eltern sowie ihrer eigenen - bietet, binden sie an die Polizei. Gleichzeitig bindet sie sich durch die Gestaltung ihrer Karriere aktiv eng an die Organisation Polizei und vermeidet damit vermutlich eine Partnerschaft und Familiengründung bzw.

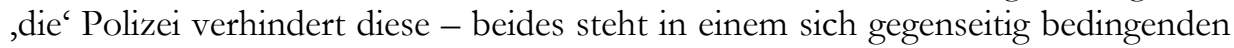
Verhältnis.

Die spezifische Organisation der Polizei übernimmt Strukturierungsaufgaben. Das Hinnehmen oder sogar Einfordern der berufsbedingten Fremdbestimmung erfüllt einen biographischen Sinn. Die Strukturen der Institution Polizei erlauben es ihr außerdem, die Situationskonstellationen, die sie mit der Berufswahl bearbeitet, zu reproduzieren und sich in hierarchische Positionen, in denen Loyalitätskonflikte strukturell angelegt sind, zu begeben. Hier kann sie Sicherheit im Umgang mit solchen Konflikten erlangen und ihre biographisch etablierten Handlungsmuster, ausgleichend und vermittelnd zu handeln, nutzen und auch weiterentwickeln. Ein wichtiges Ergebnis ist daher, dass die Berufswahl eine Bearbeitung der konkreten biographischen Situation darstellt, indem in einer biographisch unsicheren Phase Sicherheit hergestellt wird. Dass es sich bei dieser Sicherheitsherstellung 
eben nicht (nur) um die Ebene einer ökonomischen Sicherheit handelt, zeichnet ein komplexeres Bild als andere Studien zur Berufswahl von Polizist*innen, die die finanzielle Absicherung als ein zentrales Motiv der Berufswahl (vgl. 3.1) herausarbeiten. Gleichwohl bietet die Polizei, auch im hier dargestellten Fall, eine ökonomische Absicherung in dem Sinne, dass sie eine klare Zukunftsperspektive bietet im Gegensatz zu einem Hochschulstudium, das in der Regel zunächst mit einer beruflich unklaren Zukunft korrespondiert.

Bei ihrem Laufbahnaufstieg kann Melanie Wegeners familiale Herkunft als Ressource betrachtet werden. Die Polizei ist ihr nicht fremd. Melanie Wegener verfügt über einen biographisch vermittelten Wissensvorrat in Bezug auf die Polizei bzw. den Umgang mit Polizist*innen. Sie hat den Aufstieg des Vaters vom mittleren Dienst in die hohen Positionen des gehobenen Dienstes miterlebt. Auch wenn sie teilweise noch sehr jung war bzw. später kaum Kontakt zu ihrem Vater hatte, kann doch davon ausgegangen werden, dass ihr eine Aufstiegsorientierung vermittelt wurde und sie einen Laufbahnaufstieg als Normalität erlebt hat - bevor sie selbst Polizistin wurde. Ihr Vater repräsentiert einen Typus Polizist, der in den 1970er Jahren in einer noch stärker militärisch geprägten Polizei sozialisiert wurde, in der Ordnung und Unterordnung eingeübt wurden. Die Interaktion zwischen Vater und Mutter wie auch deren berufliche und private Aufgabenverteilung vermitteln ein stereotypes Bild von Geschlechterrollen, in dem Männer machtvoller und dominanter sind. Melanie Wegener begegnet in ihrer Laufbahn immer wieder dem Typus Polizist, der ähnlich (polizeilich) sozialisiert ist wie ihr Vater. Die Interaktionserfahrungen zwischen den Eltern und mit dem Vater können, beruflich betrachtet, eine Ressource sein, mit eben diesem Typus Polizist umzugehen. Melanie Wegener ordnet sich unter und harmonisiert in schwierigen Situationen, sie übernimmt Ordnungsaufgaben und knüpft dabei an erlernte, vergeschlechtlichte Handlungsoptionen an.

Ihr Laufbahnaufstieg vollzieht sich bisher in den Grenzen des gehobenen Dienstes und wird sehr wahrscheinlich auch nicht darüber hinausgehen. Ein Eintritt in den höheren Dienst wäre sicherlich möglich, wird aber begrenzt durch ihre Orientierung am ,Richtige-Polizistin-Sein': Sie arbeitet in ihrer jetzigen Position noch immer auch an der ,Basis', sie fährt Streife, ist im Schichtdienst, ihr polizeiliches Wissen ist Erfahrungswissen aus der polizeilichen Praxis auf der Straße. Dieses Wissen hat einen höheren Stellenwert als das theoretisch erworbene Wissen (des Studiums) (vgl. Kap. 4.3.6). Ein Verbleib auf dieser Hierarchieebene garantiert, dass sie weiterhin, zumindest teilweise, ,richtige Polizeiarbeit ${ }^{`}$ macht, es schafft biographische Kontinuität und es birgt kein Risiko.

Melanie Wegener hat durch die vielen verschiedenen Funktionen, die sie innerhalb der Polizei und des Einsatz- und Streifendienstes hatte, vielfältige Einblicke in diesen Teil der Organisation erhalten. Durch dieses Wissen versteht sie, wie die Behörde funktioniert, wie Befehle zustande kommen und welche Wege sie nehmen. Dies hilft ihr bei der Vermittlung von Befehlen und Organisationsentscheidungen an ihre untergebenen Kolleg*innen. Sie befindet sich dabei allerdings 
in einer schwierigen Position auf der unteren Führungsebene, in der eine BerufsRollenkonfusion strukturell angelegt ist. Gerade solche Positionen, die von Rollen- und Loyalitätskonflikten geprägt sind, sind für Melanie Wegener biographisch bedeutsame Situationskonstellationen. Besonders als Frau, so zeigt die Fallrekonstruktion, ist es schwierig diese Position auszufüllen. Diese Handlungsprobleme bearbeitet und löst Melanie Wegener mithilfe ihres biographisch-polizeilich artikulierten Wissensvorrats.

\section{Markus Holtzmann - Die Ermächtigung über Außenseitererfahrungen}

Zusammengefasst zeigt die Rekonstruktion der Lebensgeschichte von Markus Holtzmann, dass die Berufswahl eine Bearbeitung seiner biographischen Erfahrungen als Außenseiter, der nur wenig Einfluss auf seine Situation hatte, ist. Auch der Fall von Markus Holtzmann repräsentiert einen Typus, bei dem die Berufswabl eine Form der Bearbeitung der biographischen Situation darstellt. Die Organisation stellt in diesem Fall eine Organisation dar, die Ermächtigung erlaubt.

Seine Vorstellungen von Polizei sind dabei konträr zu seinen Erfahrungen in seiner Kindheit und Jugend. Markus erlebt sich ausgeschlossen und als Opfer seiner Mitschüler. Polizei repräsentiert für ihn dagegen Autonomie, Autorität, Gemeinschaft und Gelassenheit. Durch sie ist er in einer strukturell machtvollen Interaktionsposition. Aus dieser heraus erlebt er sich handlungsmächtig(er). Insofern bearbeitet die Berufswahl seine biographischen Erfahrungen. Einige Jahre lang ist die Polizei aber auch ambivalent für ihn. Neben der biographischen Funktion, die die Polizei erfüllt, bedeutet sie für ihn auch ,Aushalten und Durchhalten“ - dies ist seine präferierte Handlungsstrategie, um mit (belastenden) Situationen umzugehen. Neben den Erfahrungen, dass die Organisation über seine Tätigkeiten und teilweise seine Arbeitsorte bestimmt und er unzufrieden mit seinem polizeilichen Aufgabenbereich ist, ist auch die polizeiliche Gemeinschaft problematisch für ihn. Markus findet im Studium keinen Anschluss und er erlernt die polizeiliche Gemeinschaftlichkeit erst im Praktikum und später in der Bereitschaftspolizei. Gemeinschaft hat er vor allem innerhalb seiner Familie kennengelernt. Die Berufswahl kann aber auch als eine Suche nach Gemeinschaft außerhalb der Familie interpretiert werden. Die Gemeinschaft der Polizei scheint für ihn aber erst dann wirklich unproblematisch, als er die Sicherheit seiner, eigenen' Gründungsfamilie hat.

Markus Holtzmann lernt, sich innerhalb der Organisation in bestimmtem MaBe durchzusetzen und Forderungen zu stellen. Seine heute deutlich stärkere Position erlaubt es ihm (im Interview) auch, Probleme, seine ,schwache“ Position in der Schule und seine Unzufriedenheit zu thematisieren. Diese Thematisierung erfolgt häufig entlang einer Abgrenzung zu anderen und nach ,unten'. Die Polizei ermöglicht ihm ebenfalls diese Abgrenzung - weiterhin und deutlicher. Als Ordnungsmacht haben Polizist*innen, und damit er, die Möglichkeit sich durchzusetzen und in einem bestimmten Maß Werte - was richtig und falsch ist - zu definieren. Die Werte seiner Familie und seines Herkunftsmilieus harmonieren mit poli- 
zeilichen Aufgaben und einem bestimmten Bild über die Polizei: Ordnung und Sauberkeit herstellen und Pflichtgefühl zeigen bzw. ordentlich und sauber sein und sich anständig und verlässlich verhalten.

Neben der biographischen Funktion der Ermächtigung bietet die Polizei auch in diesem Fall Sicherheit. Es zeigt sich, dass Sicherheit in der Familie relevant ist: Vater, Bruder und Markus Holtzmann selbst machen Ausbildungen bzw. ein Studium in einem staatlichen ,Betrieb،. Wenn auch der Vater diesen Arbeitgeber verlässt, wechselt er später doch wieder in den öffentlichen Dienst. Familiär bieten Staatsbetriebe Statusaufstieg bzw. -sicherheit und in diesem Rahmen gleichzeitig verschiedene Möglichkeiten. Außerdem bietet die Polizei als sicherer Arbeitgeber Markus die Möglichkeit, sich auf sein Privatleben und seine Familie zu konzentrieren. Er hat finanziell ausgesorgt und geregelte Arbeitszeiten. Unter anderem sein Fokus auf seine Familie hat bisher einen Laufbahnaufstieg verhindert und wird dies vermutlich auch zukünftig tun. Der ESD erfüllt, wie kein anderer Bereich polizeilicher Arbeit, für Markus Hotzmann seinen biographischen Sinn. Dazu gehört, in Situationen konkret und direkt eingreifen zu können und sich in einer strukturell machtvolleren Interaktionsposition zu befinden als das Gegenüber. Für einen Laufbahnaufstieg müsste er dies zumindest zeitweilig und ab einer bestimmten Hierarchiestufe vermutlich vollständig aufgeben. Eine Position als Vorgesetzter kann dies nicht ersetzen, da die Vorgesetzten-Mitarbeiter*innen-Figuration zu komplexe hierarchische Aushandlungsprozesse innerhalb der polizeilichen Gemeinschaft mit sich bringt.

\subsubsection{Die Funktion der Berufswahl}

Auf der Fallebene Biographie lässt sich als zentrales Ergebnis das gute Passungsverhältnis von biographischer Struktur und den Bedingungen des Alltags- und Organisationskontextes der Polizei konstatieren. ${ }^{127}$ Bei beiden Biograph*innen kann die Berufswahl als eine Form der Bearbeitung ihrer biographischen Erfahrungen gedeutet werden.

Die Polizei bietet als Organisation, auch aus der Außenperspektive von Nichtbzw. Noch-nicht-Organisationsmitgliedern betrachtet, eine Struktur mit klaren Regeln, Vorstellungen von ,richtig' und ,falsch“ sowie die Idee, als Polizist*in eine Respektsperson zu sein. Neben diesen Zuschreibungen an die Polizei ist der Beruf mit Planungssicherheit assoziiert: Ökonomische Sicherheit durch eine besoldete Ausbildung und eine sich anschließende Laufbahn als Beamt*in, die bis zur Pensionierung andauern kann. Die Polizei macht - in den Bundesländern, in denen die Ausbildung als Studium organisiert ist, wie in Niedersachsen - einen sicheren Bildungsaufstieg oder -erhalt möglich. Im Gegensatz zu vielen anderen Studiengängen ist mit dem Studium an einer Polizeifachhochschule ein eindeutiger Beruf

127 Nicole Witte (2010) kommt für Ärzt*innen bzw. für ärztliches Handeln zu demselben Ergebnis und stellt „das enge Passungsverhältnis zwischen Biographie und professioneller Institution“ (2010: 381) fest; sie konstatiert, dass die Wahl des Ärzt*innen-Berufes familien- und lebensgeschichtlich bedingt ist. 
verbunden, der im Anschluss an das Studium auch direkt ausgeübt werden kann. Die Organisation Polizei und die Rolle Polizist*in bieten so einen Arbeitskontext, der von (Planungs-)Sicherheit und Klarheit gekennzeichnet erscheint und mit einer symbolischen Position in Form von gesellschaftlicher Anerkennung und Macht der Organisation verbunden wird.

Von meinen Interviewpartner*innen - auch den hier nicht dargestellten Fällen - werden diese Aspekte in unterschiedlicher Gewichtung bei der Darstellung ihrer Berufswahlgründe implizit wie explizit aufgegriffen. Dies bedeutet jedoch nicht, dass die Berufswahl als Wahl zwischen verschiedenen Berufs-, Ausbildungs- oder Studienoptionen vollständig bewusst und rational verläuft. Auch wenn sich die von den Biograph*innen explizit genannten Berufswahlgründe mit der rekonstruierten biographischen Funktion teilweise überschneiden, erfüllt die Berufswahl weitere oder andere biographische Funktionen, die den Biograph*innen nicht vollständig reflexiv zugänglich sind. Neben den beschriebenen Strukturen, die den Biograph*innen mehr oder weniger bewusst sind, bietet der Alltags- und Organisationskontext der Polizei den Biograph*innen den für sie passenden Kontext, um biographische Arbeit leisten zu können. Die Biograph*innen können in dem Handlungsfeld Polizei ,etablierte Handlungs- und Entscheidungsmuster und damit biographische Bewältigungs- und Reparaturmechanismen" (Witte 2010: 382) aufrechterbalten, entwickeln und ausbauen. Die Berufswahl ist demnach nicht (nur) eine Reproduktion von biographischen Strukturen und Situationskonstellationen, sondern vielmehr eine aktive Herstellung und Bearbeitung derselben. Biographische Arbeit in diesem Sinne ist eine aktive, biographische Leistung (vgl. Fischer-Rosenthal 1995; Rosenthal 1999). ${ }^{128}$ Die Funktion der Berufswahl als biographische Bearbeitung oder Reparatur entzieht sich der sprachlichen Explikation und wird im Handeln sichtbar (vgl. Witte 2010: 382). Die Rekonstruktion nicht nur der Präsentationsmuster, sondern auch der Handlungsmuster im Rahmen einer biographischen Fallrekonstruktion kann diese Mechanismen zeigen: Für die Biograph*innen bietet sich die Institution Polizei und die Rolle als Polizist*in als passend für die Bearbeitung der biographischen Erfahrungen an. Für Melanie Wegener bietet die Polizei Sicherheit in einer biographisch unsicheren Phase und erlaubt eine Bearbeitung von Unsicherheit und familiären Loyalitätskonflikten. Sie begibt sich in die Organisation, mit der sie kindliche Erfahrungen von Sicherheit verbindet und die die Organisation ihres Vaters ist, zu dem sie ein ambivalentes Verhältnis hat. Sie kann

128 Das Konzept wird von Rosenthal (1999) unter anderem im Zusammenhang einer von ihr geleiteten Forschung zu Generationenbeziehungen von Täter*innen- und Opferfamilien der nationalsozialistischen Herrschaft genutzt. Die Forscherinnen wollen damit eine Pathologisierung und Bewertung von bewusstem Coping oder unbewusster Abwehr von Symptomen bzw. Symptomträger*innen unterlassen und vielmehr die biographische und familiensystemische Bedeutung rekonstruieren (vgl. ebd.: 15 f.).

Fischer-Rosenthal (1995) verdeutlicht, dass der alltägliche biographische Prozess biographische Arbeit ist, da er mit der Anstrengung von Aufrechterhaltung oder Restrukturierung der alltäglichen Ordnung zusammenhängt (vgl. ebd.: 52 f.). 
in der Polizei einerseits Sicherheit erfahren, andererseits eine Position, die von Loyalitätskonflikten bestimmt ist, in der Hierarchie der Polizei reproduzieren bzw. sich in eine solche Konstellation begeben. Markus Holtzmann bietet die Polizei die Möglichkeit, seine Kindheits- und Jugenderfahrungen von Machtlosigkeit zu bearbeiten, indem er sich in eine Interaktionsposition begibt, die verspricht, machtvoll zu sein - er begibt sich sozusagen auf die ,sichere Seite' einer Interaktionsbeziehung. In dieser sicheren Position sind krisenhafte Momente mit Handlungsirritationen im Arbeitsalltag für ihn biographisch bedeutsame Situationskonstellationen. Hier kann er sich der Situation ermächtigen und sie definieren und sich selbst als machtvoll erleben. Ähnliche Funktionen lassen sich auch für andere, in dieser Arbeit nicht dargestellte Fallanalysen konstatieren. Für Polizeioberkommissar Mustafa Ateş zum Beispiel, der sich als Sohn türkischer Gastarbeiter*innen mit seinem Beruf vor allem zweierlei versichert: Zum einen distanziert er sich von (gleichaltrigen) Personen in seinem Wohnumfeld, von denen einige straffällig geworden sind. Auch er begibt sich auf eine Seite. Die Seite, die er wählt, ist zum anderen die vermutlich dauerhaft etabliertere, mit der er eine eindeutige Verortung in Deutschland, als Rechtsstaat, vornimmt. Er bearbeitet das Erleben, als Kind von Migrant*innen eine Außenseiterposition in Deutschland zugewiesen bekommen zu haben, indem er sich in eine Organisation des deutschen Staates begibt. In dieser bleibt seine Außenseiterposition zwar auf verschiedenen Ebenen erhalten, er hat sich durch Erfolge, die gerade durch seinen Migrationshintergrund und seine Sprachkenntnisse möglich sind, aber Etablierungsmöglichkeiten geschaffen.

Im Fall von Markus Holtzmann ermöglicht der Handlungskontext der Polizei auch eine Transformation der biographisch etablierten Handlungsmuster: Er reproduziert zunächst seine Außenseiterposition und hält, wie bisher, einfach durch. Der schutzpolizeiliche Interaktionskontext, der ihn in eine machtvolle Interaktionsposition versetzt, schafft schließlich den Rahmen, in dem er sich ermächtigen kann - bei gleichzeitiger Reproduktion einer machtarmen Position innerhalb der Polizeiorganisation. Eine solche Form der Ermächtigung kann man durchaus kritisch sehen, da sie über Subordination anderer erfolgt. Für ihn selbst ist es biographisch aber eine stärkende Entwicklung.

Im Anschluss an Studien zur Berufswahl von Polizist*innen, die soziale oder ökonomische Sicherheit als zentrale Berufswahlmotive angeben (vgl. Kap. 3.1.2), kann der Sicherheitsaspekt auf Grundlage der vorliegenden Untersuchung erweitert werden: Die Polizei bietet auch ökonomische Sicherheit, sie bietet aber vor allem biographische Sicherbeit, indem biographische Unsicherbeiten durch die Aufrechterbaltung und Weiterentwicklung biographisch etablierter Handlungsmuster bearbeitet werden können. Inwiefern sich diese Bearbeitung innerhalb der Polizeilaufbahn zeigt und biographisch bedingte Handlungsmuster entwickelt und/oder (weiter) etabliert werden, werde ich in den folgenden Kapiteln zeigen. 


\subsubsection{Polizist*in werden: Die Sozialisation in die Berufsrolle}

Das Studium an der Polizeifachhochschule ist eine wichtige Institution zur Sozialisation in die Berufsrolle. Im Sinne einer sekundären Sozialisation, wie sie Berger und Luckmann beschreiben, wird rollensperifisches Wissen und Vokabular erlernt und viel grundlegender noch die Polizei als institutionelle ,Subwelt' internalisiert (vgl. Berger/Luckmann 1969/2012: 148). Viele Studierende wohnen in Wohnheimen auf dem Gelände der Fachhochschulen; Studieren und Wohnen sind oft eng miteinander verbunden. Viele der Polizei(fachhoch)schulen sind eher kleinstädtisch angesiedelt und in der Regel von anderen Fachhochschulen bzw. Studiengängen getrennt. Während des Studiums werden sie als Beamt*innen auf Widerruf besoldet und haben auch die Pflichten von Beamt*innen wahrzunehmen. Die Struktur des Studiums ist an den Anforderungen der Berufspraxis orientiert, weniger an Kriterien einer kritischen Wissenschaftlichkeit, wird aber zugleich von meinen Interviewpartner*innen als sehr theoretisch beschrieben. Die angehenden Polizist*innen sind durch diese Strukturen schon von Beginn des Studiums an stark in die Organisation Polizei eingebunden. Sie lernen im Studium und in dieser abgeschotteten Umwelt „die soziale Welt aus einer polizeilichen Perspektive zu begreifen und zu deuten" (Behr 2013: 27) und eben nicht kritisch zu hinterfragen. Als Sozialisationsinstitution ist die Fachhochschulausbildung „Bestandteil einer autoritären Organisation“ (Weidmann 2001: 121), in der Polizei ganzheitlich gelebt und internalisiert wird bzw. werden soll. ${ }^{129}$ Kurzum, das Studium ist der Ort, an dem einerseits das polizeiliche, Wir ${ }^{6}$ gelernt wird und andererseits eine Aneignung von fachspezifischem Wissen stattfindet.

Die beiden diskutierten Fälle zeigen hier zwei verschiedene Verläufe der Berufsrollensozialisation (allgemein dazu Lüscher 1972). Für Melanie Wegener ist die Zeit an der Fachhochschule eine gute Erfahrung. Sie ist erfolgreich im Studium und integrierter Teil ihrer Studiengruppe, mit der sie auch ihre Freizeit verbringt. Hatte sie zuvor schon eine Idee vom polizeilichen Wir-Gefühl, vermittelt durch ihren Vater, lebt sie dieses nun. Und auch in den zum Studium gehörenden Praktika lernt sie, eine sich unterordnende und die Hierarchie anerkennende Kollegin zu sein - die dadurch eben auch als Kollegin anerkannt wird. Das Studium ,funk-

\footnotetext{
129 Ich würde die Polizei bzw. die Polizeiausbildung aber nicht als ,totale Institution` im Sinne Goffmans (1973) beschreiben, wenn auch einzelne Merkmale zumindest ähnlich erscheinen. Totale Institutionen definiert Goffman als „Wohn- und Arbeitsstätte“ von ähnlich gestellten Individuen, „die für längere Zeit von der übrigen Gesellschaft abgeschnitten sind und miteinander ein abgeschlossenes, formal reglementiertes Leben führen“ (ebd. 1973: 11). Dies trifft auf die Studierenden nicht zu. Der von Lewis Coser (1974) in die Diskussion gebrachte Begriff der ,greedy institutions“ ist zutreffender, geht es hier doch eher um allumfassende und ungeteilte Loyalitätsbeziehungen zu der Institution. Dennoch würde ich die Polizei auch nur mit Einschränkungen als solche bezeichnen, da eine Aufgabe von Privat- oder Familienleben nicht gefordert wird und z.B. auch eine zeitliche Aufopferung in der Schutzpolizei durch klare Dienstpläne zumindest teilweise verhindert wird. Das Konzept bildet an dieser Stelle keinen Mehrwert bei der Analyse der Polizei als Institution, es ließe sich höchstens danach fragen, für wen die Polizei biographisch zu einer „greedy institution“ werden kann.
} 
tioniert' bei ihr als Sozialisationsinstanz im Sinne der Polizei. Melanie Wegener repräsentiert hier einen Verlaufstypus der Berufsrollensozialisation, in dem die sekundäre Sozialisation mit der Primärsozialisation korrespondiert; die familiale Sozialisation erscheint passfähig zu der sekundären Sozialisation in die Berufsrolle. Bei ihr muss die internalisierte Wirklichkeit nicht transformiert werden. Die „Verschränkung von ursprünglichen und hinzukommenden Internalisierungen“ (Berger/Luckmann 1969/2012: 150) sind bei diesem Verlaufstypus nur wenig problematisch. Bei Markus Holtzmann ist der Verlauf - aus der Perspektive der Organisation - zunächst weniger erfolgreich und bringt für Markus erneute Außenseiter-Erfahrungen mit sich. Obwohl Markus Holtzmann polizeiliche Gemeinschaft schon in seinem Praktikum kennengelernt hat, findet er im Studium keinen Anschluss an seine Studiengruppe. Zunächst reproduziert sich seine Außenseiterposition und er bewältigt sie, indem er wie bisher ,durchhält' und sich auf seine Familie stützt. Markus Holtzmann erhält erst am Ende seines Studiums eine Vorstellung von einem polizeilichen ,Wir ${ }^{6}$ internalisieren kann er es erst nach seinem Studium bei der Bereitschaftspolizei. Markus Holtzmann repräsentiert einen Verlaufstypus, bei dem die Anforderungen der Berufsrollensozialisation - bier: Teil der Wir-Gruppe ,Polizei“ zu werden - biographisch problematisch sind, die pädagogischen Maßnahmen der Sekundärsozialisation sich nicht vollkommen entfalten können und sich der Beruf erst in einem längeren Prozess als biographisches Ermächtigungsprojekt erweist. Pädagogische Maßnahmen sollen die Inhalte vertraut und relevant machen (vgl. Berger/Luckmann 1969/2012: 153 ff.). Markus Holtzmann entzieht sich den Maßnahmen, unter anderem indem er bei der Familie seines Onkels wohnt. Die Wir-Gruppe der Institution Polizei steht hier außerdem in Konkurrenz zur Institution Familie.

Bei beiden Biograph*innen knüpft das Erleben des Studiums an die Erfahrungen der Schulzeit an. Melanie Wegener war eine gute Schülerin, die in ihrer Schulzeit von engen Schulfreundschaften begleitet wurde. Markus Holtzmann wiederum hat seine Schulzeit als mittelmäßiger Schüler durchlebt (oder auch durchlitten) und sich auch hinsichtlich der sozialen Beziehungen zu seinen Klassenkamerad*innen nicht eingebunden gefühlt. Für beide Fälle, so kann hier festgehalten werden, ist der Verlauf der Sozialisation, wenn auch unterschiedlich, doch biographisch passfähig. Melanie Wegener findet eine sichere Gemeinschaft, in der sie an bekannte Strukturen anknüpfen kann und in der sie zunächst keinen Loyalitätskonflikt erlebt. Markus Holtzmann reproduziert zunächst seine Außenseiterposition innerhalb einer Gruppe, die es ihm auf längere Sicht jedoch ermöglicht sich zu ermächtigen. 
Die „Erstverwendung“"130 bei der Bereitschaftspolizei im Anschluss an das Studium sollte, ebenso wie das Studium selbst, als Sozialisationsinstanz des polizeilichen Rollenerlernens betrachtet werden. ${ }^{131}$ Nicht nur kann, oder muss, hier das Wir-Gefühl weiter erlernt werden, sondern auch die für die Polizei wichtige Struktur von Befehl und Gehorsam bzw. von Unterordnung unter hierarchische Strukturen. Die Station bei der Bereitschaftspolizei ist auch eine Disziplinierungsmaßnahme für junge Polizist*innen, bevor die meisten, früher oder später, in andere Arbeitsbereiche wechseln. Weiterhin ist die Bereitschaftspolizei der Ort, an dem körperliche Grenzüberschreitungen in der Berufspraxis erlernt werden. Wird im Studium im Rahmen von polizeilichem Training geübt, wie Zwangsmaßnahmen korrekt - im Sinne der Anwendung der richtigen Griffe etc. - durchgeführt werden, wird es hier in der Praxis weiter geübt und habitualisiert. Dies ist sicherlich eine wichtige Vorbereitung auf eine spätere einzeldienstliche Tätigkeit, in der die Polizist*innen im Zweifel nur auf sich und ihre*n Partner*in angewiesen sind. Das Lernen von Gewaltanwendung findet so jedoch in der Praxis und in Situationen der, wenigstens anfänglich, potenziellen Überforderung statt und ist damit die Grundlage für Gewalteskalation (vgl. auch Krasmann 1993: 154 ff.). Polizist*innen lernen dabei körperliche Grenzen zu überschreiten und körperliche Bedürfnisse $^{132} \mathrm{zu}$ disziplinieren - sowohl die anderer als auch die eigenen. Wie Inhetveen in Bezug auf Studien über professionalisierte (ökonomisierte) Gewaltausübung zusammenfassend konstatiert, beinhaltet die „Professionalisierung von Gewalt immer beide Seiten des menschlichen Gewaltverhältnisses [...], Verletzungsoffenheit und Verletzungsfähigkeit, und beides [wird] durch disziplinierte Akkumulation von Fähigkeiten und Wissen kalkulierbar zu machen versucht" (Inhetveen 2017: 109 f.). Geübt wird hier also nicht nur Gewalt auszuüben, sondern auch sie zu erleiden.

130 Der polizeilich gängige Begriff der „Verwendung“ verweist auf den Körper als Objekt der Verwendung. Dinge/Objekte werden verwendet. Neben einem solchen sprachlichen Hinweis und dem im weiteren Textverlauf diskutierten Bezug zur Disziplinierung (der Körper), finden sich vor allem in Kapitel 3.3.2 Hinweise auf Körperlichkeit und meine leiblich-körperlichen Erfahrungen während der teilnehmenden Beobachtung. Eine gewalt- und organisationssoziologische Perspektive in Verbindung mit einer körpersoziologischen Perspektive würde wahrscheinlich sowohl die Organisationsforschung als auch die empirische Polizeiforschung bereichern. Inwiefern der Körper als Materialität und Erfahrung (im Sinne Plessners (1928)) Organisationen konstituiert, ist eine Lehrstelle der Organisationsforschung und Körpersoziologie (vgl. Gärtner/Ortmann 2017).

131 In den Ausführungen zur Bereitschaftspolizei beziehe ich mich neben den Fallrekonstruktionen, die ich im Rahmen dieser Arbeit angefertigt habe, auch stark auf die Interviews und Ergebnisse meiner Masterarbeit (Schäfer 2013) für die ich ausschließlich Bereitschaftspolizisten interviewt habe. 132 Dabei geht es nicht nur um Gewalt, sondern auch um z.B. stundenlanges Stehen und Warten vor und während Einsätzen. In den mehrstündigen Interviews zeigte sich dies z.B. an der Frequenz der Toilettengänge. Während ich immer wieder um Pausen bitten musste, nachdem ich mich schon einige Zeit sehr unwohl gefühlt hatte, sind meine Interviewpartner*innen fast alle nicht austreten gegangen. Von den Frauen wurden Toilettengänge in den Interviews durchaus problematisiert. Eine Kriminalpolizistin berichtete etwa, dass sie bei Überwachungen das Trinken einschränke, wenn nicht klar ist, ob und wann sie wieder zur Toilette gehen kann. 
Dieses Üben findet in einer recht großen und alters- und berufserfahrungshomogenen Gruppe statt, deren Mitglieder durch ihre Arbeits- und Einsatzzeiten viel Zeit miteinander verbringen. Diese Strukturen wirken gruppenbildend und so wird diese Zeit von meinen Interviewpartner*innen - auch von Markus Holtzmann - als gemeinschaftlich erlebt. Sie werden zu einer Leidens- und Gefahrengemeinschaft. War für beide Biograph*innen die Bereitschaftspolizei in sozialer Hinsicht eine gute Erfahrung, so erleben sie diese Zeit auf der Ebene der beruflichen Tätigkeit als anspruchslos, nachdem die Bereitschaftspolizei ihren sozialisatorischen Zweck erfüllt hat. Die Tätigkeit passt jeweils nicht zu der biographischen Funktion ihrer Berufswahl. Weder können hier (bei der Tätigkeit als ,einfache Einsatzbeamtin) Loyalitätskonflikte ausagiert werden, noch ist man in einer starken Interaktionsposition, wenn man nur auf Befehl handeln darf und dabei vom ,polizeilichen Gegenüber' oft genug beschimpft wird. In Bezug auf die biographische Struktur ist es also folgerichtig, dass beide Interviewpartner*innen sich später in andere Bereiche polizeilicher Arbeit orientieren.

Der Schwerpunkt polizeilicher Ausbildung liegt damit neben fachlichen Inhalten auf dem Erlernen eines polizeilichen, Wir ${ }^{6}$ und der Disziplinierung - wobei das Erlernen des polizeilichen Wir als Teil der Disziplinierung zu verstehen ist. Diese Disziplinierung bzw. die Methoden der Kontrolle und Subordination in der polizeilichen Ausbildung verkettet gesteigerte Tauglichkeit und eine Unterwerfung im Körper; Disziplin steigert einerseits (körperliche) Fähigkeiten und lenkt gleichzeitig die daraus erwachsende Macht in Unterwerfung um (vgl. Foucault 1977: 119).

Dies bedeutet, dass die jungen Polizist*innen der Schutzpolizei, wenn sie die Bereitschaftspolizei verlassen, kaum Erfahrung im Bereich schutzpolizeilicher Arbeit haben. Schutzpolizeiliche Arbeit erfordert aber, wie oben beschrieben, schnelles und autonomes Agieren bzw. eine Abstimmung mit dem*der Streifenpartner*in - das Gegenteil bereitschaftspolizeilicher Arbeit ${ }^{133}$. Das Erlernen konkreter schutzpolizeilicher Arbeit wird in die Praxis verschoben. Als ihre Grundlage dient jedoch gerade die vorangegangene Disziplinierung. Denn, wie Meuser in Bezug auf Foucault formuliert, die „Disziplinierung der Körper macht den einzelnen Körper zu einem Element, das an die anderen Körper angeschlossen ist" (Meuser 2017: 69). Das Studium, die praktische Ausbildung und die Bereitschaftspolizei schaffen einen ,Polizeikörper', der dann wiederum (teil-)autonom zu agieren imstande ist.

\subsubsection{Polizist*in sein: Handlungsmuster im Arbeitskontext}

Hier soll nun zusammengefasst werden, welche Handlungsmuster die Polizist*innen im Kontext ihrer Arbeit entwickelt und weshalb sie ihre je konkreten Handlungsmuster ausgebildet haben. Auch hier, ebenso wie bei der Funktion der

${ }_{133}$ Mir ist bewusst, dass auch die Bereitschaftspolizei die Schutzpolizei tageweise unterstützt und die Bepo-Beamt*innen zwischenzeitlich auch schutzpolizeiliche Arbeit durchführen - aber eben nicht als Daueraufgabe. 
Berufswahl, zeigt sich, dass sie biographisch entwickelt und passfähig sind. Zunächst werde ich dies auf Ebene der konkreten Tätigkeit erläutern. Wie kam es dazu, dass die beiden Polizist*innen nun in der jeweiligen Position in der Schutzpolizei arbeiten? Daran anschließend soll die Frage beantwortet werden, wie biographisch etablierte Handlungsmuster in Interaktionen mit (nicht-) polizeilichen Anderen relevant werden.

\subsubsection{Der Verbleib und die Tätigkeit in der Organisation}

Was ich bereits als Möglichkeit eines sicheren Bildungsaufstiegs beschrieben habe - das besoldete, strukturierte Studium mit anschließender Übernahme in den Polizeidienst - ist gleichzeitig eine Verengung von Möglichkeiten. Ein Studium an der Polizeifachhochschule qualifiziert im Gegensatz zu den meisten universitären Studiengängen nur sehr begrenzt für andere Berufszweige. Außerdem ist ein Abbruch des Studiums nach einer kurzen Anfangsphase oder auch ein Verlassen der Polizei nach Abschluss des Studiums mit ökonomischen Nachteilen verbunden: Es droht eine Teil-Rückzahlung der Bezüge, wenn man nach Abschluss des Studiums nicht, zumindest eine Zeit lang, bei der Polizei oder einem anderen öffentlichen Dienstherren arbeitet. ${ }^{134}$ Neben einer nur sehr eingeschränkten Qualifizierung für andere Berufsfelder bindet auch diese Regelung zumindest für einige Jahre an die Polizei. Ein Austritt erfolgt vermutlich nur unter hohem Leidensdruck und ist auch nur mit anderweitiger finanzieller Absicherung z.B. aus dem Elternhaus möglich, ein Verbleib in der Polizei daher wahrscheinlich. Trotz dieser Umstände kann gefragt werden, welche Konstellationen dazu führen, dass beide Biograph*innen (bzw. alle meine Interviewpartner*innen) nach Ablauf dieser Fristen in der Polizei bleiben (können). Auch hier lässt sich allgemein feststellen, dass die biographische Funktion der Berufswabl sowohl den Verbleib in der Polizei als auch das Handeln innerhalb der Organisation erklärt. Markus Holtzmann folgt seinem etablierten Handlungsmuster ,Durchhalten“, obwohl er im Praktikum, im Studium und auch auf einem frühen Dienstposten immer wieder unzufrieden und unglücklich ist, bis er in der Schutzpolizei einen Ort findet, der ihm sein Ermächtigungsprojekt ermöglicht. Ein Abbruch des Studiums bzw. eine Neuorientierung nach den ersten Berufsjahren wäre biographisch nicht passfähig bzw. eine große Transformation gewesen. Für Melanie Wegener lässt sich auch hier der Aspekt der Sicherheit aufgreifen. Zunächst bietet die polizeiliche Wir-Gruppe ihr Sicherheit. Aus dieser Sicherheit heraus kann sie dann als (weibliche) Vorgesetzte auf unterer Führungsebene eine Position mit Rollenkonfusion und Loyalitätskonflikten reproduzieren. Den Umgang mit einer solchen Position hat sie biographisch gelernt und sie kann diese innerhalb der Polizei (ohne dass ihr das bewusst sein muss oder ist) aufrechterhalten und sich an ihr außerhalb des familiären Umfeldes abarbeiten. Dies macht einen Laufbahnaufstieg innerhalb des gehobenen Dienstes einerseits lo-

${ }^{134}$ Dies ist unter anderem geregelt im Bundesbesoldungsgesetz ( $\left.\$ 63 \mathrm{BBesG}\right)$ und für Niedersachsen im Niedersächsischen Besoldungsgesetz (\$ $60 \mathrm{NBesG).}$ 
gisch, verhindert aber andererseits vermutlich einen weiteren Laufbahnaufstieg in den höheren Dienst, wo die Vorgesetztenfunktion eindeutiger wird.

Beide erleben, früher oder später, Zugehörigkeit zur polizeilichen WirGruppe. Dabei bindet sich Melanie Wegener deutlich enger an die Organisation als Markus Holtzmann. Die konkrete Ausgestaltung der Bindung an die Polizei ist lebensgeschichtlich bedingt. Melanie Wegener kann durch die enge Bindung an die Polizei zum einen eine Familiengründung umgehen sowie damit verbundene mögliche Enttäuschungen, wie sie ihre Mutter und Großmutter erlebt haben. Zum anderen kann sie durch das Aufgehen in Arbeit und Organisation eine Laufbahnkarriere vollziehen, die der des Vaters ähnelt, sie aber prognostisch übersteigen wird. Die weniger starke Bindung von Markus Holtzmann an die Organisation im Sinne einer nur begrenzten Nutzung der Möglichkeiten, die sich innerhalb der Polizei bieten, und einer prognostisch nur begrenzten Laufbahnentwicklung - ist ebenfalls bedingt durch die biographische Funktion seiner Berufswahl. Für Markus Holtzmann ist im Gegensatz zu Melanie Wegener, für die die Binnenverhältnisse in der Polizei biographisch relevanter sind, das Außenverhältnis relevant: In der Interaktion mit den nicht-polizeilichen Anderen kann er sich eindeutiger auf die interaktionsmächtigere Seite begeben, als es in den Binnenverhältnissen möglich ist.

Die Orientierung an den Binnen- oder Außenverhältnissen zeigt sich nicht nur auf der Handlungsebene, sondern auch auf Ebene der Präsentation im Interview und der dort vorgenommenen Verortung im polizeilichen Wir-Bild. Ich habe das polizeiliche Wir-Bild als eine Bearbeitung der Handlungsbedingungen des Polizeialltags und als Voraussetzung für die Interaktionen im Binnenbezug konzeptualisiert. Das Wir-Bild wird von meinen Interviewpartner*innen auch entsprechend ihrer organisationalen Orientierung bedient. Ausgestaltet wurden jeweils vor allem die Bestandteile, die für ihre Orientierung innerhalb der Organisation bzw. in der Interaktion mit nicht-polizeilichen Anderen relevant sind. Markus Holtzmann versteht sich als ,Ordnungshüter ${ }^{6}$ und ,Freund und Helfer ${ }^{6}$ - beides bezieht sich auf die Außenverhältnisse. Melanie Wegener betont mehr das polizeiliche Wir des Einsatz- und Streifendienstes und damit zusammenhängend die organisationsinternen Differenzierungen.

Der Verbleib in der Polizei und die Wahrnehmung der verschiedenen Möglichkeiten innerhalb der Organisation sind durch Funktion der Berufswahl biographisch bestimmt. Die biographisch bedingte Orientierung an den Außen-oder Binnenverbältnissen führt zu unterschiedlichen Handlungsmustern innerhalb der Organisation. Festhalten lässt sich zudem, dass die konkrete polizeiliche Tätigkeit im Kontext der biographisch etablierten Handlungsmuster passend scheint. Beide können bei ibrer Arbeit in der Schutzpolizei ibre biographischen Bewältigungsmechanismen aufrechterhalten bzw. ausbauen. Für beide wäre dies an anderer Stelle innerhalb der Organisation nicht in dieser Form möglich. 


\subsubsection{Biographisch bedingte Handlungsmuster im Einsatz- und Organisationsalltag}

$\mathrm{Zu}$ den Handlungsmustern in Interaktion mit nicht-polizeilichen Anderen in Einsatzsituationen lassen sich auf Ebene der Biographie nur bedingt allgemeine Ergebnisse formulieren. Die Frage, welche spezifischen Handlungsmuster sich im Kontext der Einsatz-Interaktion etabliert haben, lässt sich also nur begrenzt beantworten. Wie oben gezeigt wurde, lebt polizeiliche Arbeit auch von Formalisierung und Routine, die ab der Ausbildung eingeübt und gefestigt wird. Das Arbeiten mit wechselnden Kolleg*innen und die daraus resultierende Notwendigkeit, sich auf eine polizeiliche Routine stützen zu können, erschweren es, biographisch bedingte Handlungsmuster herauszuarbeiten. Die Interaktion mit dem nichtpolizeilichen Anderen ist immer auch Interaktionsprodukt, nicht nur mit ibnen, sondern auch mit dem*der jewveiligen Kolleg*in. Grundsätzlich jedoch haben Polizist*innen, wie oben gezeigt, die bessere Chance ihre Situationsdefinition durchzusetzen und auch ihre Handlungsentwürfe aufrechtzuerhalten. Diese sind nicht nur berufsbiographisch, sondern gesamtbiographisch ausgebildet.

Die Triangulation von Interview- und Beobachtungsdaten erlaubt hier präzisere Einsichten. Aus Gründen der Anonymisierung muss ich jedoch auf eine Darstellung der Interviews, die ich mit Polizist*innen aus der Polizeiinspektion, in der ich meine teilnehmenden Beobachtungen durchgeführt habe, verzichten. Dies ist in erster Linie ein Problem für die intersubjektive Nachvollziehbarkeit der folgenden Ergebnisse. Trotz dieser Einschränkungen lassen sich dennoch empirisch geerdete Hypothesen aufstellen, die zumindest anhand der Interviewpräsentationen nachvollziehbar gemacht werden können.

Was sich auf der Ebene der Erzählungen in den Interviews deutlich zeigt, ist, dass, entsprechend der Orientierung an den Binnen- oder Außenverhältnissen der interviewten Personen, die Erzählungen sich jeweils eher auf das eine oder das andere richten. Für Melanie Wegener war die Präsentation von Interaktionen in Einsatzsituationen im Interview deutlich weniger relevant als für Markus Holtzmann. Melanie Wegener fokussierte mehr auf die Darstellung ihrer Laufbahn und die damit zusammenhängenden Interaktionen mit Kolleg*innen.

Im Fall Markus Holtzmann ist es einfacher, biographisch bedingte Handlungsmuster im Einsatzalltag auszumachen. Anhand seiner Erzählungen und der Auswahl der Themen und Einsätze, über die er spricht, zeigt sich, dass seine Interaktionen mit dem nicht-polizeilichen Anderen darauf abzielen, sich nach ,unten', von vermeintlich ,anderen', abzugrenzen. Dabei geht es vor allem um die Verteidigung seiner Interaktionsmacht bzw. das Verschieben der Machtbalance zu seinen Gunsten. Er versucht dies nicht durch Zwangsmaßnahmen zu erreichen, sondern durch eine implizite oder explizite sich abgrenzende, sein Gegenüber subordinierende, teilweise beleidigende Ansprache. Denjenigen, die er für , ordentliche Bürger*innen` hält, begegnet er freundlich, solange sie in der Interaktion signalisieren, dass sie seine Rolle anerkennen. Stellt man dies nun in den (hier nur kursorischen) Kontext seiner Lebensgeschichte, wird Folgendes deutlich: Markus 
Holtzmann, sein Bruder und seine Eltern haben alle einen, jeweils im Vergleich zur vorherigen Generation höheren, Bildungsaufstieg vollzogen. Familial deuten sich also Distinktionsbestrebungen von dem Herkunftsmilieu bzw. von der Familiengeschichte an. Zumindest bei Markus hat sich außerdem durch die Erfahrungen seiner Jugend ein starkes Distinktionsbedürfnis entwickelt. Der Polizeiberuf bietet ihm nun den Interaktionskontext, in dem er dieses befriedigen kann. Für Markus Holtzmann gilt, dass die Polizei einen Rahmen bietet, in dem er etablierte Handlungsmuster (Durchhalten) sowohl aufrechterhalten als auch weiterentwickeln kann. Sein Abgrenzungsbedürfnis kann er im polizeilichen Alltag als Bewältigungsmechanismus und professionelles Handlungsmuster etablieren, geht es doch bei polizeilicher Arbeit ständig um die Herstellung und Aufrechterhaltung von Interaktionsmacht. Für ihn ist in Einsatzsituationen relevant, dass er sich autoritativ und instrumentell mächtig erleben bzw. so handeln kann. Aktionsmacht in Form von Gewalt und Zwangsmaßnahmen auszuagieren ist nicht sein primäres Handlungsmittel; dies ist nicht biographisch passfähig bzw. ermöglicht nicht eine Bearbeitung seiner Erfahrung.

Auch bei Melanie Wegener zeigt sich, dass sie ihr Handlungsmuster (Ausgleich) in anderen Lebensbereichen ausgebildet hat und in der Polizei als professionelles etablieren konnte. Aufgrund ihrer Orientierung an den Binnenverhältnissen - im Interview aber auch in ihrem Arbeitsalltag - ist es jedoch nicht möglich, es bezogen auf die Interaktion mit nicht-polizeilichen Anderen zu formulieren. Es ist vielmehr die Interaktion mit ihren Kolleg*innen, für die sie sowohl Vorgesetzte als auch Kollegin ist, in der sie vermittelnd und heilend agiert und für eine Anerkennung der hierarchischen Beziehung durch Distanzierung von ihren Kolleg*innen sorgt. Wie in der familialen Figuration ordnet sie sich unter (unter die Hierarchie des Vaters, der Polizei oder später unter die Bedürfnisse anderer); sie harmonisiert und übernimmt Ordnungsaufgaben und knüpft damit an vergeschlechtlichte Handlungsmuster an. Ähnlich, wie die Beziehung zu ihrem Vater strukturiert ist - distanziert und gleichzeitig ambivalent zugewandt -, ist auch die Beziehung zu ihren Kolleg*innen.

Es zeigt sich also auch bier, dass die polizeilichen Handlungsmuster nicht (allein) auf der Ausbildung oder der interaktiven Aushandlung mit dem*der Kolleg*in beruben, sondern lebensgeschichtlich auch in anderen Bereichen ausgebildet wurden und werden.

\subsection{Das Passungsverhältnis von Biographie und Beruf}

Zusammenfassend lässt sich in Bezug auf die Frage, wie die biographischen Erfahrungen, die zu der Berufswahl geführt haben, die Strukturen des Arbeitsfeldes und die Handlungspraxis der Polizist*innen zusammenhängen, Folgendes festhalten: Wichtigstes Ergebnis ist, dass der Handlungs- und Interaktionskontext Schutapolizei passfähig zur biographischen Struktur der Polizist*innen ist und die Handlungsmuster der Polizist*innen gesamtbiographisch ausgebildet sind. Dass sich biographisch bedingte 
Handlungsmuster in der Polizei aufrechterhalten und auch weiterentwickeln lassen, scheint zunächst überraschend angesichts des von routiniertem, habitualisiertem Handeln und Teamarbeit geprägten Arbeitsfeldes. Die Arbeit der Schutzpolizei bietet aber genügend Freiheitsgrade, um sowohl routiniert und körperlich habitualisiert als auch autonom zu handeln.

In ihrem Arbeitskontext bringen die Akteur*innen sich ,freiwillig in Situationen von (Handlungs-/Interaktions-)Unsicherheit, die jeweils anders definiert ist: Ist es beim einen der krisenhafte Moment im Einsatz, ist es bei der anderen das bestimmten hierarchischen Positionen inhärente Interaktionsproblem. Den Akteur*innen bietet der Arbeitsalltag der Schutzpolizei die Möglichkeit, biographisch bedeutsame Situationskonstellationen zu reproduzieren und zugleich zu bearbeiten. So können biographische Unsicherheiten und Probleme bearbeitet werden und biographische Bewältigungsmechanismen aufrechterhalten und weiterentwickelt werden. Dies geschieht in einer Umgebung, in der sie, durch die Wir-Gruppe und in der Organisation, die das Gewaltmonopol innehat, selbst Sicherheit erlangen. Der Beruf unterstützt die Aufrechterhaltung der vertrauten Bearbeitungsmechanismen, ohne dass den Akteur*innen diese Funktion bewusst scheint.

Damit das Arbeitsfeld biographische Arbeit in dieser Form erlaubt, müssen die etablierten biographischen Handlungsmuster mit den Handlungs- und Interaktionsbedingungen der Polizei kompatibel sein. Die ausgebildeten Handlungsmuster und biographischen Wissensbestände müssen in hierarchische Verhältnisse und das Wir-Bild der Polizei integrierbar sein. In diesem Zusammenhang werden in einem organisationalen Setting spezifische Handlungsmöglichkeiten hervorgebracht, andere werden hingegen begrenzt. Die (Schutz-)Polizei bietet als Arbeitskontext verschiedene Möglichkeiten an, die je nach biographischer Situation unterschiedlich passfähig sein können. In den hier diskutierten Fällen zeigt sich dabei in dem einen Fall eine biographisch bedingte Orientierung an der Bearbeitung von Hierarchie- und Geschlechterverhältnissen - ein ,doing police organization; in dem anderen Fall eine Orientierung an der Polizeiarbeit auf der Straße als einem ,doing police powver. In beiden Fällen erfolgt dies sowohl auf alltäglicher Handlungsebene als auch auf der Ebene ihrer Verortung im Wir-Bild bzw. der Wir-Gruppe.

Angesichts der vielfältigen und ambivalenten Anforderungen des Handlungsfeldes Schutzpolizei erscheint es geradezu notwendig, auf etablierte Handlungsmuster zurückzugreifen. Aufgrund der Vielfalt an polizeilichen Lagen, die Schutzpolizist*innen bewältigen müssen, der Macht- und ,Gefühlsarbeit', die sie leisten müssen, und angesichts des situativen Handlungsdrucks greifen sie auf bewährte Handlungsmuster zurück. Dies gilt wahrscheinlich nicht nur für die hier dargestellten Fälle, bei denen sich die Berufswahl als Form biographischer Bearbeitung zeigt. Denkbar sind andere Typen von Berufswahlprozessen, bei denen die Berufswahl nicht diese Funktion hat. In jedem Fall aber ermöglicht oder erfordert die Struktur polizeilicher Arbeit den Rückgriff auf biographisch ausgebildete Handlungsmuster. Gerade zur Bewältigung der ,Leerstellen' und Deutungsspielräume sowie angesichts der Notwendigkeit, eine machtvolle Interaktionsposition herzustellen und aufrechtzuerhalten, 
müssen Polizist*innen auf diese etablierten Handlungsmuster zurückgreifen. Je nach biographischem Verlauf und biographischem Sinn polizeilicher Arbeit zeigen sich so auch unterschiedliche polizeiliche Handlungs- und Deutungsmuster im Arbeitsalltag. Die Deutung organisationaler Prozesse sowie die konkrete Berufsausübung wird nicht (nur) in der beruflichen Sozialisation in der Organisation erlernt, sondern knüpft wesentlich an biographische Wissensbestände und Erfahrungen an. 



\section{Fazit und Ausblick}

Abschließend möchte ich die Ergebnisse meiner Studie und mein empirisches Vorgehen kritisch betrachten und im Zusammenhang weiterer Fragen diskutieren. Die Ergebnisse dieser Arbeit zeigen, dass die Berufswahl und das Handeln von Polizist*innen in ihrem Arbeitsalltag biographisch bedingt sind. Die Analyse nicht nur der Um-zu-Motive, sondern auch der Weil-Motive im Sinne Schütz' verdeutlicht, dass polizeiliches Handeln nicht nur an der jeweils vorliegenden Situation orientiert ist, sondern sich strukturell im Zusammenhang lebensgeschichtlicher Erfahrungen ausbildet. Zwar ist dies für soziologische Biographieforscher*innen aus einer sozialkonstruktivistischen Perspektive heraus ein Allgemeinplatz, dennoch kann diese Arbeit mit ihren konkreten Ergebnissen und ihrer Gesamtkonzeption einen Beitrag im Bereich der empirischen Polizeiforschung leisten sowie Impulse für die Organisationssoziologie und in methodischer Hinsicht geben. Ziel der Arbeit war es, das Passungsverhältnis von Biographie und Beruf zu untersuchen. Mit diesem Anspruch war ein Vorgehen, das sowohl den Handlungs- und Interaktionskontext polizeilicher Arbeit als auch die biographischen Verläufe von Polizist*innen untersucht und zueinander in Relation setzt, verbunden. Polizeiliches Handeln wurde dadurch nicht nur in seinen institutionellen Kontext eingebettet, sondern eben auch aus gesamtbiographischer Perspektive betrachtet.

In den (auch divergenten) organisationsinternen und öffentlichen Diskursen über polizeiliche Arbeit gibt es Positionen, die nach außen und innen und inner- 
halb und außerhalb von Führungsstäben unterschiedlich kommuniziert werden. Finden lassen sich, so mein Eindruck, übereinstimmend Fragmente, in denen zum einen Polizist*innen als affektlos - in gewisser Weise also mechanisch - handelnde Repräsentant*innen des Staates erscheinen und zum anderen die Organisation und ihr Handeln als hierarchisch gut strukturiert sowie als auf der soliden Ausbildung ihrer Polizist*innen und verbindlichen gesetzlichen Grundlagen beruhend beschrieben wird. Ähnliche Argumente brachte ein Polizeiinspektionsleiter mir gegenüber vor, um damit zu begründen, warum meine Forschungsarbeit eigentlich nicht notwendig sei: Polizist*innen würden auf Grundlage des Gesetzes und entsprechend ihrer (einheitlichen) Ausbildung arbeiten; verschiedene polizeiliche Handlungstypen könne es deshalb kaum geben. Dass polizeiliches Handeln, dem Anspruch nach, selbstverständlich regel- und gesetzeskonform sein sollte und dies in der Außenpräsentation (mir gegenüber) auch so vertreten wird, ist nachvollziehbar. Diese Argumentationslinie impliziert jedoch auch, dass Varianz im Handeln der Schutzpolizist*innen Devianz bedeutet. Meine Arbeit zeigt demgegenüber deutlich, dass Polizist*innen nicht (einfach mechanisch) Gesetze exekutieren, sondern sie deutend anwenden. Die Rekonstruktion der Handlungsbedingungen zeigt zudem, dass sie dies auch tun müssen. Polizeiliche Arbeit geht mit großen Deutungsspielräumen einher und von den handelnden Polizist*innen wird erwartet, Eindeutigkeit herzustellen. Zudem sind sie mit der Macht ausgestattet, ihre Situationsdeutungen durchzusetzen. Trotz strukturierter Ausbildung und Routinisierung polizeilichen Handelns können diese Deutungsspielräume, genau wie in allen menschlichen Interaktionen, nicht vollständig formalisiert werden. Die vorliegende Arbeit hat nun entgegen der verbreiteten, eher mechanistischen Perspektive gezeigt, dass polizeiliches Handeln und Deuten biographisch ausgebildet ist und die Handlungsorientierungen und -entwürfe stets auch verbunden sind mit dem jeweiligen Sinn, den polizeiliche Arbeit für die Polizist*innen biographisch erfüllt. Daran anschließend wird ebenfalls deutlich, dass Polizist*innen in Einsätzen nicht nur ihre Interaktionsposition als Repräsentant*innen des Gewaltmonopols erfüllen und verteidigen müssen, sondern auch ihre ganz eigene, personale Position. Für beides stehen ihnen strukturell mehr Machtmittel zur Verfügung als ihren nicht-polizeilichen Interaktionspartner*innen. Auch deshalb kann Varianz im Handeln, neben der Frage der Legitimität polizeilichen Handelns, ein prekäres Thema sein, schließen sich doch daran Fragen nach Machtmissbrauch und Gewaltanwendung unmittelbar an. Man muss dabei gar nicht an Fälle denken, in denen Polizist*innen zum Nachteil der ,Bürger*innen“ handeln. Situationen mit Deutungsspielräumen, die Polizist*innen ja durchaus zugestanden werden bzw. auferlegt sind - ob sie z.B. nur verwarnen oder ein Bußgeld verhängen -, können prekär werden, wenn offensichtlich wird, dass die Deutungen und polizeilichen Maßnahmen nicht allein an der Situation orientiert sind. Die vorliegende Arbeit konnte zeigen, dass solche Deutungen eben nicht nur Interaktionsprodukt sind - das haben bereits andere Studien gezeigt - sondern, dass sie auch biographisch motiviert sind oder zumindest sein können. Die Organisation Polizei zeigt 
sich in der Alltagspraxis nicht nur in Form von routiniertem Handeln ihrer Akteur*innen, sondern auch als biographisch artikuliertes, das sich nicht nur entlang des allgemeinen polizeilichen Auftrags und der spezifischen Einsatzsituation, sondern auch entlang der je spezifischen biographischen Bedeutung polizeilicher Arbeit entfaltet. Was bedeutet das nun für die Anwendung von Gewalt, unter der Annahme, dass aus der Delegation des Gewaltmonopols an Polizist*innen jederzeit auch willkürliche Gewaltanwendung werden kann? Unter der Prämisse, dass Gewalt eine Form der Machtausübung ist, kann hier das Gleiche wie für andere Machtformen festgehalten werden: Ob polizeiliche Zwangsmaßnahmen zu willkürlicher Gewalt werden bzw. wie schnell zu Zwangsmaßnahmen gegriffen wird, ist nicht allein situativ begründet, sondern auch abhängig davon, für wen in der Interaktion welche Form der Macht biographisch bedeutsam ist.

Ich habe polizeiliches Handeln aus sozialkonstruktivistisch-biographietheoretischer Perspektive untersucht. Mein Fokus lag dabei unter anderem auf den Prozessen, wie die Sozialisation in die Polizei verläuft - wie man Polizist*in wird -, aber auch auf den historisch hervorgebrachten Handlungsbedingungen, die die Polizist*innen in ihrer täglichen Arbeit deutend umsetzen, mithin verändern und reproduzieren. Die Arbeit zeigt damit, wie Organisationen auf Biographien wirken und wie Biographien auf Organisationen wirken. Biographien und Organisationen konstituieren sich wechselseitig. Durch die Analyse beider Konstrukte werden auch ihre Interdependenzen beschreibbar. Ich habe mit meiner Arbeit jedoch keine dezidiert organisations- oder professionssoziologischen Perspektiven verbunden. Dennoch kann hier abschließend auch zu Fragen der Organisationsforschung festgehalten werden, dass ein biographietheoretischer Ansatz innerhalb der Organisationsforschung einem Dualismus von ,Individuum hier und ,Organisation dort' entgegenwirken kann. Eine prozesshafte Perspektive sowohl auf die biographische Genese als auch auf die tägliche organisationale Handlungspraxis ist sinnvoll, um die interaktiven Verflechtungen innerhalb und außerhalb der Organisation in den Blick zu nehmen. Den Blick nicht nur darauf zu richten, wie Organisationsmitglieder handeln, sondern auch darauf, warum sie handeln, wie sie handeln, eingebettet in einen organisationalen und soziohistorischen Kontext, ermöglicht es, organisationale Prozesse besser zu verstehen. Die in die Organisation eingebrachten Erfahrungen und Wissensbestände erweitern und begrenzen die Karrieremöglichkeiten und das Handeln von Akteur*innen in der Organisation. Organisationen aus der Binnenperspektive der in und ,mit ${ }^{`}$ ihr handelnden Akteur*innen zu untersuchen ist daher gewinnbringend, und die Untersuchung einer Organisation darf sich nicht auf die Analyse ihrer formalen Strukturen oder Entscheidungen beschränken. Ähnliches gilt für die Professionssoziologie, in der nicht selten ausschließlich die Berufsrolle oder die Rolle des Berufes in Sozialität betrachtet wird. Analog zu meinen Ausführungen zur Organisation gilt es auch hier, eine Betrachtung von ,Polizist*in hier und ,Mensch dort ${ }^{\natural} \mathrm{zu}$ vermeiden. Oder einfacher ausgedrückt: Es ist immer ein Mensch, der die Uniform trägt. 
Darüber hinaus zeigt sich m.E., dass weder durch Formen von (Expert*innen-)Interviews noch teilnehmende Beobachtungen allein das Handeln und die Handlungsmotivationen der Akteur*innen einer Organisation erschlossen werden können. Denn mit letzterem verbleibt man unter Umständen auf der Ebene der Um-zu-Motive und mit ersterem auf der Ebene organisationaler Diskurse. Das in dieser Arbeit genutzte methodenplurale Vorgehen - die Verbindung eines ethnographischen und eines biographieanalytischen Verfahrens - ist meines Wissens bisher weder im Bereich der Organisationsforschung noch im Rahmen von Polizeiforschung zu finden. Aber auch im Bereich der empirischen sozialkonstruktivistischen Wissenssoziologie, die nicht selten mit einem ethnographischen Vorgehen verbunden ist, bringt diese Methodenverknüpfung einen Mehrwert. Werden historische Prozesse des untersuchten Phänomens dabei zumeist über Artefakte und historische Quellen rekonstruiert, so bietet eine Kombination mit biographischen Interviews die Möglichkeit, (die Genese von) Teilnehmer*innenperspektiven auch über einen längeren zeitlichen (lebens- und familiengeschichtlichen) Prozess zu rekonstruieren.

Neben den Vorteilen des von mir gewählten Vorgehens möchte ich jedoch auch einige Defizite bei seiner konkreten Umsetzung diskutieren. So wären meiner Ansicht nach eigentlich mehrere Feldphasen sinnvoll gewesen. Wie ich schon in Kapitel 3.3. kritisch angemerkt habe, wären eine Unterbrechung und ein Rückzug an den Schreibtisch und/oder in die Diskussion mit Kolleg*innen hilfreich gewesen, um (früher) auf einige Phänomene und blinde Flecken aufmerksam zu werden. Um die Perspektive auf den Einsatz- und Streifendienst in seiner organisationalen Besonderheit sowie dessen Wir-Bild zu schärfen, wäre auch eine weitere Binnenperspektive - eine Feldphase in einer anderen Abteilungen jenseits des ESD - hilfreich gewesen.

Mein zweites theoretisches Interviewsample - die drei Interviews, die ich fallrekonstruktiv bzw. globalanalytisch ausgewertet habe - habe ich kontrastiv anhand des Geschlechtes und der Annahme unterschiedlicher Erfahrungen in der Polizei ausgewählt. Dadurch hat sich ein sehr altershomogenes und formalhierarchisch wenig diverses Sample ergeben. In Bezug auf die formalhierarchische Varianz halte ich dies für wenig problematisch, da sie auch innerhalb der Dienstabteilungen des Einsatz- und Streifendienstes recht klein ist. Aber Erfahrungen älterer Polizist*innen, die noch ,klassisch ${ }^{`}$ ausgebildet wurden und die vielen organisationalen Veränderungen miterlebt haben, hätten das Sample vermutlich theoretisch bereichert.

Damit wäre auch eine Suche nach anderen Typen der Berufswahl verbunden gewesen. Für die hier dargestellten Fälle ist die Berufswahl eine Form der biographischen Bearbeitung von lebensgeschichtlichen Erfahrungen. Es sind aber durchaus andere Typen denkbar wie etwa eine familiale Delegation. Trotzdem gehe ich auf Grundlage der Ergebnisse dieser Arbeit auch für andere Berufswahltypen davon aus, dass die konkrete Berufsgestaltung eine Form biographischer Arbeit ist. Ich halte es für sehr plausibel, dass die organisationalen Nischen, in die 
Polizist*innen sich begeben, biographisch motiviert sind und sie sich einen Bereich polizeilicher Arbeit suchen, der biographischen Sinn erfüllt.

Die Ergebnisse dieser Arbeit ließen sich erweitern bzw. kontrastieren mit Interviews von ,Aussteiger*innen' aus dem Polizeidienst, um Antworten auf die Frage zu erhalten: Welche biographischen Verläufe sind nicht passfähig zu dem Handlungs- und Interaktionskontext Polizei? Auch dieser Bereich scheint eine Leerstelle zu sein. Ich habe keine Kenntnis von Studien, die sich mit dem (vorzeitigen) Beenden der Polizeilaufbahn befassen. ${ }^{135}$ Eigentlich müsste die Polizei selbst Interesse an solchen Erkenntnissen haben, mit Blick auf Personalmaßnahmen, die einem Ausstieg aus der Organisation entgegenwirken könnten. Eventuell erhält die Frage, wer den Polizeidienst verlässt und warum, keine größere Aufmerksamkeit, da die Zahl der Fälle gering ist - so zumindest meine Vermutung. Häufiger als eine faktische Kündigung bei der Polizei ist vermutlich ein Rückzug in eine polizeiliche Nische, wo man unbehelligt von anderen - dem nichtpolizeilichen Anderen und/oder Vorgesetzten - arbeiten kann. Oder, wenn das nicht möglich ist: Dienst nach Vorschrift, bei dem nur das Nötigste erledigt wird. Auch eine solche Person findet sich nicht in meinem Interviewsample. Nach Polizist*innen, die sich aus der Organisation zurückgezogen haben, müsste man vermutlich gezielt und vor allem auf anderen Wegen suchen, weil die Bereitschaft solcher Polizist*innen, eine solche Untersuchung zu unterstützen, eher gering sein könnte.

In den Dienstabteilungen, die ich beobachtet habe, war durchaus eine unterschiedliche Gestaltung des Dienstes zu erkennen. Manche machten nur das Nötigste und das auch eher gemütlich. Unter ihnen fanden sich einzelne Polizist*innen, bei denen sich ein Rückzug andeutete, der sich aber (noch) in (der Äußerung von) Frustration bahnbrach und damit vermutlich noch keinen vollständigen (offenen oder verdeckten) Ausstieg bedeutet. Unter der Prämisse, dass es dieses Phänomen gibt, kann es für das Fehlen in meinem Beobachtungssample zwei naheliegende Erklärungen geben: Den Vorgesetzten ist bewusst, wer sich langsam zurückzieht, und ich wurde diesen Polizist*innen nicht zugeteilt. Eine andere mögliche Erklärung liegt in der Struktur und Dynamik der Dienstabteilungen. Es ist großstädtisches Gebiet und die Dienstelle ist eine Durchlaufdienststelle, wo oft junge Polizist*innen nach Studium und Bepo eingesetzt werden - im Gegensatz zu anderen Dienststellen mit mehr oder weniger gleichbleibendem Personal gibt es in dieser vergleichsweise viel Wechsel. Die Dienstabteilungen sind neben wenigen älteren Beamt*innen daher eher jung und die Polizist*innen noch am Anfang ihrer Laufbahn. Frustration und Rückzug finden vermutlich erst im weiteren Verlauf des Arbeitslebens und in ,ruhigeren` Dienststellen statt.

\footnotetext{
$135 \mathrm{Zu}$ finden sind Studien, die Polizist*innen - allerdings aktive, keine ehemaligen - nach deren „intention to leave“ befragt haben. Sie kommen unter anderem zu dem Schluss, dass schlechte Aufstiegschancen den Ausstieg aus dem Beruf wahrscheinlicher machen (z.B. Boag-Munroe et al. 2016; Chan/Doran 2009).
} 
Was könnten nun aber Gründe für einen faktischen oder inneren Rückzug aus der Polizei sein? Auf Grundlage der in dieser Arbeit gewonnenen Erkenntnisse können dazu einige Annahmen formuliert werden. Für beide Fälle kann angenommen werden, dass polizeiliche Arbeit ihren biographischen Sinn nicht erfüllt bzw. er sich nicht (dauerhaft) verwirklichen lässt, wenn er nicht passfähig zur Struktur polizeilicher Arbeit oder der Organisation ist. Bei einem inneren Rückzug ließe sich weiterhin vermuten, dass es nicht die Struktur polizeilicher Arbeit ist, die für Frustration sorgt, sondern vielmehr die organisationalen Strukturen. Die Ergebnisse zeigen an, dass das Erleben von Fremdbestimmung - von „Verwendung" - hoch sein kann und Anerkennung in Form von Beförderungen zwar mitgestaltet werden kann, dass diese aber Aktivität, Flexibilität und ,organisationale Hingabe' (hier im Kontrast zur familiären Hingabe) voraussetzen. Kann man diese Bedingungen, biographisch bedingt, nicht erfüllen, kann ,die` Organisation enttäuschen.

Im Falle einer faktischen Kündigung kann im Gegensatz zu einem inneren Rückzug angenommen werden, dass das Leiden unter den Arbeits- und Organisationsbedingungen stärker ist und/oder es eine (biographische) Alternative gibt und in diesem Zusammenhang auch weitere etablierte Handlungsmuster vorhanden sind, die einen solchen ,Bruch` ermöglichen. Bei einer Kündigung sind verschiedene Typen denkbar. Die biographisch etablierten Handlungsmuster können nicht zu den Arbeitsbedingungen auf der Straße passen; krisenhafte Momente und eine machtvolle Interaktionsposition sind nicht passfähig. Die Handlungsmuster können sich aber auch als nicht anschlussfähig an das Wir-Bild und die damit verbundenen Gemeinschafts- und Hierarchiepraxen erweisen. Wichtig erscheint mir jedoch mit Blick auf meine Ergebnisse, dass für einen Verbleib in der Organisation nicht beides (vollständig) passfähig oder biographisch bedeutsam sein muss, sondern dass eine Orientierung an organisationalen Außen- oder Binnenverhältnissen je verschiedene biographische Bearbeitungsmöglichkeiten eröffnet, die die weniger passenden Strukturen zu integrieren vermögen. Im Falle einer Kündigung ist dieser Ausgleich vermutlich nicht (mehr) möglich.

Abschließend möchte ich zu dem Zitat aus der Einleitung zurückkommen: „Eine Karriere bei der Polizei Niedersachsen ist mehr als nur ein Beruf.“ Was macht nun das ,Mehr' aus? Im Anschluss an die Ergebnisse dieser Arbeit ließe sich dazu formulieren: Das Handlungs- und Interaktionsfeld Polizei ermöglicht, dass biographisch etablierte Handlungs- und Deutungsmuster aufrechterhalten und weiterentwickelt werden können; das Feld ermöglicht biographische Arbeit. Ein ,Mehr ${ }^{`}$ ist aber auch, dass polizeiliche Arbeit nur möglich ist unter Rückgriff auf eben diese Handlungs- und Deutungsmuster. Man kann nur Polizist*in sein, wenn man die Deutungs- und Handlungsspielräume, die polizeilicher Arbeit inhärent sind, passend füllen kann aufgrund der biographischen Wissensbestände und Erfahrungen, die wiederum zur Struktur der Polizei passfähig sein müssen. Dann ist der Beruf auch ,Berufung. 


\section{Anhang}

\subsection{Abkürzungen}

$\begin{array}{ll}\text { Bepo } & \text { Bereitschaftspolizei } \\ \text { Btm } & \text { Betäubungsmittel } \\ \text { DA } & \text { Dienstabteilung } \\ \text { DAL } & \text { Dienstabteilungsleiter*in } \\ \text { ESD } & \text { Einsatz- und Streifendienst } \\ & \text { Fachoberschule } \\ \text { FSJ } & \text { Freiwilliges soziales Jahr } \\ \text { KED } & \text { Kriminalermittlungsdienst/Kriminal- und Ermittlungsdienst } \\ \text { PHK } & \text { Polizeihauptkommissar*in } \\ \text { PI } & \text { Polizeiinspektion } \\ \text { PK } & \text { Polizeikommissar*in } \\ & \text { Polizeioberkommissar*in }\end{array}$




\subsection{Transkriptionsregeln}

\begin{tabular}{|c|c|c|}
\hline , & $=$ & kurzes Absetzen \\
\hline (4) & $=$ & Dauer der Pause in Sekunden \\
\hline Ja: & $=$ & Dehnung eines Vokals \\
\hline$(($ lachend $))$ & $=$ & Kommentar der Transkribierenden \\
\hline / & $=$ & Einsetzen des kommentierten Phänomens \\
\hline nein & $=$ & betont \\
\hline NEIN & $=$ & laut \\
\hline viel- & $=$ & Abbruch eines Wortes oder einer Äußerung \\
\hline$(\quad)$ & $=$ & $\begin{array}{l}\text { Inhalt der Äußerung ist unverständlich; Länge } \\
\text { der Klammer entspricht etwa der Dauer der Äu- } \\
\text { ßerung }\end{array}$ \\
\hline (sagte er) & $=$ & unsichere Transkription \\
\hline $\mathrm{Ja}=\mathrm{ja}$ & $=$ & schneller Anschluss \\
\hline $\begin{array}{l}\text { ja so war } \\
\text { nein ich }\end{array}$ & $=$ & gleichzeitiges Sprechen ab „so“ \\
\hline
\end{tabular}

Vgl. Rosenthal 2011: 93 


\section{Literaturverzeichnis}

Alber, Ina (2016): Zivilgesellschaftliches Engagement in Polen. Ein biographietheoretischer und diskursanalytischer Zugang. Wiesbaden: Springer.

Alber, Ina/Griese, Birgit/Schiebel, Martina (Hrsg.) (2018): Biografieforschung als Praxis der Triangulation. Wiesbaden: Springer.

Albrecht, Thomas (1999): Für eine wehrhafte Demokratie. Albert Grzesinski und die preußische Politik in der Weimarer Republik. Bonn: Dietz.

Allmendinger, Jutta/Leuze, Kathrin/Blanck, Jonna M. (2008): 50 Jahre Geschlechtergerechtigkeit und Arbeitsmarkt. In: Aus Politik und Zeitgeschichte, 24-25, 18-25.

Amann, Klaus/Hirschauer, Stefan (1997): Die Befremdung der eigenen Kultur. Ein Programm. In: Amann, Klaus/Hirschauer, Stefan (Hrsg.), Die Befremdung der eigenen Kultur. Zur ethnographischen Herausforderung soziologischer Empirie. Frankfurt/Main: Suhrkamp, 7-52.

Apelt, Maja/Häberle, Andreas (2012): Das Paradox des Gewaltmonopols in der Selbstdarstellung von Polizisten. In: Ohlemacher, Thomas/Werner, Jochen-Thomas (Hrsg.), Polizei und Gewalt. Interdisziplinäre Analysen zu Gewalt gegen und durch Polizeibeamte. Frankfurt/Main: Verlag für Polizeiwissenschaft, 159-176. 
Bahl, Eva/Worm, Arne (2018): Biographische und ethnographische Zugänge zu Wir-Bildern, Sie-Bildern und Handlungspraktiken in einer Organisation. Die spanische Polizeieinheit Guardia Civil in Ceuta und Melilla. In: ZQF - Zeitschrift für Qualitative Forschung, 19 (1-2), 233-251.

Baumann, Imanuel/Stephan, Andrej/Wagner, Patrick (2012): (Um-)Wege in den Rechtsstaat. Das Bundeskriminalamt und die NS-Vergangenheit seiner Gründungsgeneration. In: Zeithistorische Forschungen/Studies in Contemporary History, 9, 33-53.

Becker, Howard S. (1963/1973): Outsider. Studies in the sociology of deviance. New York: Free Press.

Becker, Johannes (2017): Verortungen in der Jerusalemer Altstadt. Lebensgeschichten und Alltag in einem engen urbanen Raum. Bielefeld: transcript.

Beek, Jan (2019): Selbstverständliche Staatlichkeit. Ghanaische und deutsche Polizeiarbeit im Vergleich. In: Howe, Christiane/Ostermeier, Lars (Hrsg.), Polizei und Gesellschaft. Wiesbaden: Springer, 105-129.

Beham, Martina (2004): Mutter-Kind-Beziehungen in Nachscheidungsfamilien. In: Zartler, Ulrike/Wilk, Lieselotte/Kränzl-Nagel, Renate (Hrsg.), Wenn Eltern sich trennen. Wie Kinder, Frauen und Männer Scheidung erleben. Frankfurt/Main: Campus, 133-153.

Behr, Rafael (2000): Cop culture - der Alltag des Gewaltmonopols. Männlichkeit, Handlungsmuster und Kultur in der Polizei. Wiesbaden: VS Verlag.

Behr, Rafael (2008): Cop Culture - Der Alltag des Gewaltmonopols. Männlichkeit, Handlungsmuster und Kultur in der Polizei. 2. Aufl. Wiesbaden: VS Verlag.

Behr, Rafael (2010): Intimität oder Abschottung - warum Polizisten am liebsten unter sich sind. Ein Essay zu den Ambivalenzen im polizeilichen Selbstverständnis. In: Groß, Hermann/Bornewasser, Manfred/Frevel, Bernhard/Liebl, Karlhans/Ohlemacher, Thomas/Schmidt, Peter (Hrsg.), Polizei - Polizist - Polizieren? Frankfurt/Main: Verlag für Polizeiwissenschaft, 59-73.

Behr, Rafael (2012): Die „Gewalt der Anderen“ oder: Warum es bei der aktuellen Gewaltdebatte nicht (nur) um Gewalt geht. In: Ohlemacher, Thomas/Werner, Jochen-Thomas (Hrsg.), Polizei und Gewalt. Interdisziplinäre Analysen zu Gewalt gegen und durch Polizeibeamte. Frankfurt/Main: Verlag für Polizeiwissenschaft, 177-196.

Behr, Rafael (2013): Bildung oder Ausbildung? Bedingungen einer zeitgemässen Berufsvorbereitung für eine moderne Polizei. In: Albrecht, Jan Philipp (Hrsg.), Wege zu einer alternativen Sicherheitspolitik. 24-31. https://www.janalbrecht.eu/fileadmin/material/Dokumente/20130426GE-Innenbroschuere-online-01.pdf [letzter Zugriff: 24.08.2017]. 
Behr, Rafael (2019): Verdacht und Vorurteil. Die polizeiliche Konstruktion der ,gefährlichen Fremden“. In: Howe, Christiane/Ostermeier, Lars (Hrsg.), Polizei und Gesellschaft: Transdisziplinäre Perspektiven zu Methoden, Theorie und Empirie reflexiver Polizeiforschung. Wiesbaden: Springer, 17-45.

Berg, Eberhard/Fuchs, Martin (Hrsg.) (1993): Kultur, soziale Praxis, Text. Die Krise der ethnographischen Repräsentation. Frankfurt/Main: Suhrkamp.

Berger, Peter L./Luckmann, Thomas (1969/2012): Die gesellschaftliche Konstruktion der Wirklichkeit. 24. Aufl. Frankfurt/Main: Fischer.

Bergmann, Jörg (1985): Flüchtigkeit und methodische Fixierung sozialer Wirklichkeit. Aufzeichnungen als Daten der interpretativen Soziologie. In: Bonß, Wolfgang/Hartmann, Heinz (Hrsg.), Entzauberte Wissenschaft. Zur Relativität und Geltung soziologischer Forschung. Göttingen: Schwarz, 299-320.

Bessel, Richard (1992): Militarisierung und Modernisierung: Polizeiliches Handeln in der Weimarer Republik. In: Lüdtke, Alf (Hrsg.), „Sicherheit“ und „Wohlfahrt“. Polizei, Gesellschaft und Herrschaft im 19. und 20. Jahrhundert. Frankfurt/Main: Suhrkamp.

Betterman, Ulf (2015): „Lässig bleiben?!“ Respektlosigkeit und Autoritätsverlust im Erleben von uniformierten Streifenpolizistinnen und -polizisten. In: Frevel, Bernhard/Behr, Rafael (Hrsg.), Empirische Polizeiforschung XVII: Die kritisierte Polizei. Frankfurt/Main: Verlag für Polizeiwissenschaft, 164-185.

Biecker, Sarah/Schlichte, Klaus (2014): Policing Uganda, Policing The World. InIIS-Arbeitspapier 40. Bremen: Institut für Interkulturelle und Internationale Studien. https://www2.iniis-neu.uni-bremen.de/personen/ klaus-schlichte/publikationen-/?publ=1661\&page=1 [letzter Zugriff: 02.04.2019].

Bittner, Egon (1970): The Functions of Police in Modern Society. Washington, D.C.: National Institute of Mental Health.

Blum, Bettina (2009): Weibliche Polizei - soziale Polizei? Weibliche (Jugend-) Polizei zwischen Demokratie und Diktatur 1927-1952. In: Schulte, Wolfgang (Hrsg.), Die Polizei im NS-Staat. Frankfurt/Main: Verlag für Polizeiwissenschaft, 511-537.

Boag-Munroe, Fran/Donnelly, Joan/van Mechelen, Denis/Elliott-Davies, Mary (2016): Police Officers' Promotion Prospects and Intention to Leave the Police. In: Policing, 11 (2), 132-145.

Bogner, Artur (1989): Zivilisation und Rationalisierung. Dir Zivilisationstheorie Max Webers, Norbert Elias' und der Frankfurter Schule im Vergleich. Opladen: Westdeutscher Verlag. 
Bogner, Artur (2003): Macht und die Genese sozialer Gruppen. In: Sociologus, 53 (2), 167-181.

Bogner, Artur/Rosenthal, Gabriele (2017): Biographien - Diskurse - Figurationen. Methodologische Überlegungen aus einer sozialkonstruktivistischen und figurationssoziologischen Perspektive. In: Spies, Tina/Tuider, Elisabeth (Hrsg.), Biographie und Diskurs: Methodisches Vorgehen und Methodologische Verbindungen. Wiesbaden: Springer, 43-67.

Bogner, Artur/Wouters, Cas (1990): Kolonialisierung der Herzen? Zu Arlie Hochschilds Grundlegung der Emotionssoziologie. In: Leviathan, 18 (2), 255-279.

Boyt, Thomas E./Lusch, Robert F./Naylor, Gillian (2001): The Role of Professionalism in Determining Job Satisfaction in Professional Services. In: Journal of Service Research, 3 (4), 321-330.

Breckner, Roswitha (2010): Sozialtheorie des Bildes. Zur interpretativen Analyse von Bildern und Fotografien. Bielefeld: transcript.

Breidenstein, Georg/Hirschauer, Stefan/Kalthoff, Herbert/Nieswand, Boris (2015): Ethnografie. Die Praxis der Feldforschung. 2. Aufl. Konstanz: UVK.

Brennan, Adrianne M./Davis, Robert D./Rostow, Cary D. (2005): An Investigation of Biographical Information as a Predictor of Employment Termination among Law Enforcement Officers. In: Journal of Police and Criminal Psychology, 20 (2), 1-7.

Brewer, John D. (1991): Inside RUC. Routine policing in a divided society. Oxford: Clarendon.

Brodeur, Jean-Paul (2002): Gewalt und Polizei. In: Heitmeyer, Wilhelm/Hagan, John (Hrsg.), Internationales Handbuch der Gewaltforschung. Wiesbaden: Westdeutscher Verlag, 259-283.

Brodeur, Jean-Paul (2005): Police Studies Past and Present: A Reaction to the Articles Presented by Thomas Feltes, Larry T. Hoover, Peter K. Manning, and Kam Wong. In: Police Quarterly, 8 (1), 44-56.

Brodeur, Jean-Paul (2010): The policing web. New York: Oxford University Press.

Browning, Christopher R. (1993): Ganz normale Männer. Das ReservePolizeibataillon 101 und die „Endlösung“ in Polen. Reinbek bei Hamburg: Rowohlt.

Brusten, Manfred/Feest, Johannes/Lautmann, Rüdiger (Hrsg.) (1975): Die Polizei. Eine Institution öffentlicher Gewalt. Neuwied [u.a.]: Luchterhand.

Bundespolizeipräsidium (Hrsg.) (o. J.): Die Bundespolizei - Sicherheit durch Kompetenz. https://www.bundespolizei.de/Web/DE/Service/ 
Mediathek/Downloads/160506_imagebroschuere_bpol.pdf?_blob= publicationFile\&v=1 [letzter Zugriff: 04.03.2020].

Burzan, Nicole (2016): Methodenplurale Forschung. Chancen und Probleme von Mixed Methods. Weinheim und Basel: Beltz Juventa.

Busch, Heiner/Funk, Albrecht/Kauß, Udo/Narr, Wolf-Dieter/Werkentin, Falco (1988): Die Polizei in der Bundesrepublik. Frankfurt/Main: Campus.

Campion, Jonas/López, Laurent/Payen, Guillaume (2019): Policing in Wartime: Without Any Disruption? General Introduction. In: Campion, Jonas/López, Laurent/Payen, Guillaume (Hrsg.), European Police Forces and Law Enforcement in the First World War. Cham: Springer Nature, $1-13$.

Carstens, Peter (2011): Kriminalisten in eigener Sache. In: FAZ, 12. April 2011. https://www.faz.net/aktuell/politik/inland/ns-vergangenheit-desbka-kriminalisten-in-eigener-sache-15085.html [letzter Zugriff: 17.04.2019].

Chan, Janet/Doran, S. (2009): Staying in the Job: Job Satisfaction among MidCareer Police Officers. In: Policing, 3 (1), 66-77.

Clifford, James/Marcus, George E. (Hrsg.) (1986): Writing culture. The Poetics and Politics of Ethnography. Berkeley: University of California Press.

Connell, R. W. (1999): Der gemachte Mann. Konstruktion und Krise von Männlichkeiten. Opladen: Leske + Budrich.

Coser, Lewis A. (1974): Greedy Institutions. Patterns of Undivided Commitment. New York: Free Press.

Dams, Carsten (2008): Die Polizei in Deutschland 1945-1989. In: Aus Politik und Zeitgeschichte, 48, 9-14.

Dausien, Bettina (1994): Biographieforschung als „Königinnenweg“? Überlegungen zur Relevanz biographischer Ansätze in der Frauenforschung. In: Diezinger, Angelika/Kitzer, Hedwig/Anker, Ingrid (Hrsg.), Erfahrung mit Methode. Wege sozialwissenschaftlicher Frauenforschung. Freiburg: Kore, 129-153.

Dausien, Bettina/Kelle, Helga (2005): Biographie und kulturelle Praxis. Methodologische Überlegungen zur Verknüpfung von Ethnographie und Biographieforschung. In: Völter, Bettina/Dausien, Bettina/Lutz, Helma/Rosenthal, Gabriele (Hrsg.), Biographieforschung im Diskurs. Wiesbaden: VS Verlag, 189-212.

Davis, Belinda (2011): Polizei und Gewalt auf der Straße. Konfliktmuster und ihre Folgen im Berlin des 19. und 20. Jahrhunderts. In: Lüdtke, Alf/Reinke, Herbert/Sturm, Michael (Hrsg.), Polizei, Gewalt und Staat im 20. Jahrhundert. Wiesbaden: VS Verlag, 81-103. 
Della Porta, Donatella (1995): Social Movements, Political Violence, and the State. A Comparative Analysis of Italy and Germany. New York: Cambridge University Press.

Denkowski, Cordula von / Denkowski, Charles A. von (2011): Von der Notwendigkeit einer auch außerpolizeilich betriebenen Polizeiwissenschaft. In: Möllers, Martin H. W./Ooyen, Robert Chr. van (Hrsg.), Jahrbuch Öffentliche Sicherheit 2010/2011, Bd. 1. Frankfurt/Main: Verlag für Polizeiwissenschaft.

Denzin, Norman K. (1970): The Research Act: A Theoretical Introduction to Sociological Methods. London: Butterworth.

Deppisch, Sven (2017): Täter auf der Schulbank. Die Offiziersausbildung der Ordnungspolizei und der Holocaust. Baden-Baden: Tectum Verlag.

Deutsche Hochschule der Polizei (o. J.): Die Deutsche Hochschule der Polizei. https://www.dhpol.de/die_hochschule/index.php [letzter Zugriff: 18.09.2019].

Dewey, John (1938/2004): Die Struktur der Forschung. In: Strübing, Jörg/Schnettler, Bernt (Hrsg.), Methodologie interpretativer Sozialforschung. Klassische Grundlagentexte. Konstanz: UVK, 223-244.

Donk, Ute/Reichertz, Jo/Schröer, Norbert (1996): Polizeiforschung ohne Grabenkämpfe. In: Kriminalistik, 4, 263-267.

Duden (Hrsg.) (2007): Das Fremdwörterbuch. 9., aktual. Aufl. Mannheim: Dudenverlag.

Eder, Christian (2003): Soziale Arbeit und Polizei. Problematiken und Potentiale in der Beziehung zweier Berufsgruppen im niedrigschwelligen Bereich. https://www.socialnet.de/materialien/attach/106.pdf [letzter Zugriff: 03.01.2019].

Elias, Norbert (1939/1997a): Über den Prozeß der Zivilisation. Soziogenetische und psychogenetische Untersuchungen. Erster Band. Wandlungen des Verhaltens in den weltlichen Oberschichten des Abendlandes. Frankfurt/Main: Suhrkamp.

Elias, Norbert (1939/1997b): Über den Prozeß der Zivilisation. Soziogenetische und psychogenetische Untersuchungen. Zweiter Band. Wandlungen der Gesellschaft. Entwurf zu einer Theorie der Zivilisation. Frankfurt/Main: Suhrkamp.

Elias, Norbert (1970/2004): Was ist Soziologie? 10. Aufl. Weinheim: Beltz Juventa.

Elias, Norbert (1981): Zivilisation und Gewalt. Über das Staatsmonopol der körperlichen Gewalt und seine Durchbrechungen. In: Matthes, Joachim (Hrsg.), Lebenswelt und soziale Probleme: Verhandlungen des 20. Deutschen Soziologentages zu Bremen 1980. Frankfurt/Main: Campus, 98- 
122. https://nbn-resolving.org/urn:nbn:de:0168-ssoar-135461[letzter Zugriff: 17.11.2020].

Elias, Norbert (2010): Figuration. In: Kopp, Johannes/Schäfers, Bernhard (Hrsg.), Grundbegriffe der Soziologie. 10. Aufl. Wiesbaden: VS Verlag, 75-78.

Elias, Norbert/Scotson, John Lloyd (1993): Etablierte und Außenseiter. Frankfurt/Main: Suhrkamp.

Emerson, Robert M./Fretz, Rachel I./Shaw, Linda L. (1995): Writing Ethnographic Fieldnotes. Chicago: University of Chicago Press.

Endreß, Martin (2006): Alfred Schütz. Konstanz: UVK.

Endruweit, Günter (1979): Struktur und Wandel der Polizei. Organisationsund berufssoziologische Untersuchungen über die Polizei in der Bundesrepublik Deutschland und in den USA. Berlin: Duncker \& Humblot.

Evans, Richard J. (1996): Polizei, Politik und Gesellschaft in Deutschland 1700-1933. In: Geschichte und Gesellschaft, 22, 609-628.

Fairchild, Erika S. (1988): German Police. Ideals and Reality in the Post-War Years. Springfield: C.C. Thomas.

Fairchild, Erika S. (1990): The Uses of Research: Politics, Academics, and the Police in the United States of America and the Federal Republic of Germany. In: Criminal Justice Research, 15 (1), 5-21.

Feest, Johannes/Blankenburg, Erhard (1972): Die Definitionsmacht der Polizei. Strategien der Strafverfolgung und soziale Selektion. Düsseldorf: Bertelsmann.

Feest, Johannes/Lautmann, Rüdiger (Hrsg.) (1971): Die Polizei. Soziologische Studien und Forschungsberichte. Opladen: Westdeutscher Verlag.

Fischer, Wolfram (1978): Struktur und Funktion erzählter Lebensgeschichten. In: Kohli, Martin (Hrsg.), Soziologie des Lebenslaufs. Darmstadt: Luchterhand, 311-336.

Fischer-Rosenthal, Wolfram (1995): Schweigen - Rechtfertige - Umschreiben. Biographische Arbeit im Umgang mit deutschen Vergangenheiten. In: Fischer-Rosenthal, Wolfram/Alheit, Peter (Hrsg.), Biographien in Deutschland. Soziologische Rekonstruktionen gelebter Gesellschaftsgeschichte. Opladen: Westdeutscher Verlag, 43-86.

Flam, Helena (2002): Soziologie der Emotionen. Konstanz: UVK.

Flick, Uwe (2004): Triangulation. Eine Einführung. Wiesbaden: VS Verlag.

Foley, Pamela F./Guarneri, Cristina/Kelly, Mary E. (2008): Reasons for Choosing a Police Career: Changes over Two Decades: In: International Journal of Police Science \& Management, 10 (1), 2-8. 
Foucault, Michel (1977): Überwachen und Strafen. Die Geburt des Gefängnisses. Frankfurt/Main: Suhrkamp.

Frevel, Bernhard (2008): Polizei, Politik und Wissenschaft. In: Aus Politik und Zeitgeschichte, 48, 3-8.

Froschauer, Ulrike (2006): Veränderungsdynamik in Organisationen. In: Tänzler, Dirk/Knoblauch, Hubert/Soeffner, Hans-Georg (Hrsg.), Zur Kritik der Wissensgesellschaft. Konstanz: UVK, 189-215.

Froschauer, Ulrike (2012): Organisationen in Bewegung. Beiträge zur interpretativen Organisationsanalyse. Wien: Facultas.

Fuchs-Heinritz, Werner (2005): Biographische Forschung. Eine Einführung in Praxis und Methoden. 3., überarb. Aufl. Wiesbaden: VS Verlag.

Funk, Albrecht (1986): Polizei und Rechtsstaat. Die Entwicklung des staatlichen Gewaltmonopols in Preußen 1848-1918. Frankfurt/Main: Campus.

Funk, Albrecht (2000): Die Entstehung der Exekutivpolizei im Kaiserreich. In: Lange, Hans-Jürgen (Hrsg.), Staat, Demokratie und innere Sicherheit in Deutschland. Opladen: Leske + Budrich, 11-27.

Fürmetz, Gerhard/Reinke, Herbert/Weinhauer, Klaus (2001): Nachkriegspolizei in Deutschland. Doppelte Polizeigeschichte 1945-1969. In: Fürmetz, Gerhard/Reinke, Herbert/Weinhauer, Klaus (Hrsg.), Nachkriegspolizei. Sicherheit und Ordnung in Ost- und Westdeutschland 1945-1969. Hamburg: Ergebnisse Verlag, 7-35.

Gärtner, Christian/Ortmann, Günther (2017): Organisation und Institution. In: Gugutzer, Robert/Klein, Gabriele/Meuser, Michael (Hrsg.), Handbuch Körpersoziologie, Bd. 2: Forschungsfelder und Methodische Zugänge. Wiesbaden: Springer, 175-186.

Gewerkschaft der Polizei (2016): Alle 67 Minuten ein Angriff auf die Polizisten in NRW. https://www.gdp.de/gdp/gdp.nsf/id/DE_GdP-NRW2015-Alle-67-Minuten-ein-Angriff-auf-die-Polizisten-in-NRW- [letzter Zugriff: 06.03.2020].

Giesecke, Jens (2003): Volkspolizei und Staatssicherheit - Zum inneren Sicherheitsapparat der DDR. In: Lange, Hans-Jürgen (Hrsg.), Die Polizei der Gesellschaft. Zur Soziologie der Inneren Sicherheit. Opladen: Leske + Budrich, 93-120.

Girtler, Roland (1980): Polizei-Alltag. Strategien, Ziele und Strukturen polizeilichen Handelns. Opladen: Westdeutscher Verlag.

Glaser, Barney G./Strauss, Anselm L. (1967/2008): The Discovery of Grounded Theory: Strategies for Qualitative Research. 3. paperback printing. New Brunswick: Aldine. 
Goffman, Erving (1969): Wir alle spielen Theater. Die Selbstdarstellung im Alltag. München: Piper.

Goffman, Erving (1973): Asyle. Über die soziale Situation psychiatrischer Patienten und anderer Insassen. Frankfurt/Main: Suhrkamp.

Goffman, Erving (1980): Rahmen-Analyse. Ein Versuch über die Organisation von Alltagserfahrungen. Frankfurt/Main: Suhrkamp.

Goffman, Erving (1996): Über Feldforschung. In: Knoblauch, Hubert (Hrsg.), Kommunikative Lebenswelten. Zur Ethnographie einer geschwätzigen Gesellschaft. Konstanz: UVK.

Götting, Dirk (2009): Die „Weiblich Kriminalpolizei“; ein republikanisches Reformprojekt zwischen Krise und Neuorientierung im Nationalsozialismus. In: Schulte, Wolfgang (Hrsg.), Die Polizei im NS-Staat. Frankfurt/Main: Verlag für Polizeiwissenschaft, 481-510.

Götting, Dirk/Rose, Carsten (2008): Niedersachsen. In: Groß, Hermann/Frevel, Bernhard/Dams, Carsten (Hrsg.), Handbuch der Polizeien Deutschlands. Wiesbaden: VS Verlag, 261-288.

Groß, Hermann (2019): Polizei(en) und innere Sicherheit in Deutschland. Strukturen, Aufgaben und aktuelle Herausforderungen. In: Aus Politik und Zeitgeschichte, 21-23, 4-10.

Groß, Hermann/Frevel, Bernhard/Dams, Carsten (2008): Die Polizei(en) in Deutschland. In: Groß, Hermann/Frevel, Bernhard/Dams, Carsten (Hrsg.), Handbuch der Polizeien Deutschlands. Wiesbaden: VS Verlag, 11-43.

Groß, Hermann/Schmidt, Peter (2010): Wer wird Polizist in Hessen? Berufsentscheidung und Studienmotivation 2009. In: Groß, Hermann/Bornewasser, Manfred/Frevel, Bernhard/Liebl, Karlhans/Ohlemacher, Thomas/Schmidt, Peter (Hrsg.), Polizei - Polizist Polizieren? Frankfurt/Main: Verlag für Polizeiwissenschaft, 75-92.

Gurwitsch, Aron (1975): Das Bewußtseinsfeld. Berlin: De Gruyter.

Hammersley, Martyn/Atkinson, Paul (2007): Ethnography. Pinciples in Practice. 3. Aufl. London, New York: Routledge.

Harten, Hans-Christian (2018): Die weltanschauliche Schulung der Polizei im Nationalsozialismus. Paderborn: Ferdinand Schöningh.

Haselow, Reinhard/Noethen, Stefan/Weinhauer, Klaus (2000): Die Entwicklung der Länderpolizeien. In: Lange, Hans-Jürgen (Hrsg.), Staat, Demokratie und innere Sicherheit in Deutschland. Opladen: Leske + Budrich, 131-150. 
Hecht, Patricia (2018): Diskriminierung bei der Polizei. Keine Chance für den Transmann. In: taz, 10. März 2018. https://www.taz.de/!5487463/ [letzter Zugriff: 18.02.2019].

Heuer, Hans-Joachim (2009): Über das polizeiliche Töten im Dritten Reich. In: Schulte, Wolfgang (Hrsg.), Die Polizei im NS-Staat. Frankfurt/Main: Verlag für Polizeiwissenschaft.

Hirschauer, Stefan (2001): Ethnografisches Schreiben und die Schweigsamkeit des Sozialen. Zu einer Methodologie der Beschreibung. In: Zeitschrift für Soziologie, 30 (6), 429-451.

Hitzler, Ronald (1999): Gewalt als Tätigkeit. Vorschläge zu einer handlungstypologischen Begriffserklärung. In: Neckel, Sighard/Schwab-Trapp, Michael (Hrsg.), Ordnungen der Gewalt. Beiträge zu einer politischen Soziologie der Gewalt und des Krieges. Opladen: Leske + Budrich, 9-19.

Hitzler, Ronald/Eisewicht, Paul (2016): Lebensweltanalytische Ethnographie - im Anschluss an Anne Honer. Weinheim: Beltz Juventa.

Hochschild, Arlie R. (1990): Das gekaufte Herz. Zur Kommerzialisierung der Gefühle. Frankfurt/Main: Campus.

Hochschulrektorenkonferenz (2004): Zur Zusammenarbeit mit verwaltungsinternen Fachhochschulen (FHöD). Entschließung des Plenums der HRK vom 9. November 2004. https://www.hrk.de/positionen/beschluss/ detail/zur-zusammenarbeit-mit-verwaltungsinternen-fachhochschulenfhoed/ [letzter Zugriff: 18.09.2019].

Hoffmann-Riem, Christa (1980): Die Sozialforschung einer interpretativen Soziologie. In: Kölner Zeitschrift für Soziologie und Sozialpsychiatrie, 32 (2), 339-371.

Honer, Anne (1993): Lebensweltliche Ethnographie. Ein explorativinterpretativer Forschungsansatz am Beispiel von Heimwerker-Wissen. Wiesbaden: DUV.

Hopf, Christel (2007): Forschungsethik und qualitative Forschung. In: Flick, Uwe/Kardorff, Ernst von/Steinke, Ines (Hrsg.), Qualitative Forschung. Ein Handbuch. 5. Aufl. Reinbek bei Hamburg: Rowohlt, 589-600.

Hunold, Daniela (2013): Polizeiliches Handeln in sozial benachteiligten Stadtvierteln Deutschlands und Frankreichs. In: Frevel, Bernhard/Groß, Hermann (Hrsg.), Konzepte polizeilichen Handelns. Frankfurt/Main: Verlag für Polizeiwissenschaft, 140-154.

Hunold, Daniela (2016): Raumwissen: Die Produktion von Raum bei der Polizei. In: Grutzpalk, Jonas (Hrsg.), Polizeiliches Wissen. Formen, Austausch, Hierarchien. Frankfurt/Main: Verlag für Polizeiwissenschaft, 50-71. 
Hunold, Daniela (2019): „Wer hat jetzt die größeren Eier?!“ - Polizeialltag, hegemoniale Männlichkeit und reflexive Ethnografie. In: Howe, Christiane/Ostermeier, Lars (Hrsg.), Polizei und Gesellschaft. Transdisziplinäre Perspektiven zu Methoden, Theorie und Empirie reflexiver Polizeiforschung. Wiesbaden: Springer, 47-69.

Imbusch, Peter (2012a): Macht und Herrschaft in der wissenschaftlichen Kontroverse. In: Imbusch, Peter (Hrsg.), Macht und Herrschaft. Sozialwissenschaftliche Konzeptionen und Theorien. 2., aktual. und erw. Aufl. Wiesbaden: Springer, 9-35.

Imbusch, Peter (2012b): Machtfigurationen und Herrschaftsprozesse bei Norbert Elias. In: Imbusch, Peter (Hrsg.), Macht und Herrschaft. Sozialwissenschaftliche Konzeptionen und Theorien. 2., aktual. und erw. Aufl. Wiesbaden: Springer, 169-193.

Inhetveen, Katharina (2017): Gewalt. In: Gugutzer, Robert/Klein, Gabriele/Meuser, Michael (Hrsg.), Handbuch Körpersoziologie, Bd. 2: Forschungsfelder und Methodische Zugänge. Wiesbaden: Springer, 101-115.

Jacobsen, Astrid (2001): Die gesellschaftliche Wirklichkeit der Polizei. Eine empirische Untersuchung zur Rationalität polizeilichen Handelns. Bielefeld. https://pub.uni-bielefeld.de/record/2304180 [letzter Zugriff: 22.06.2016].

Jacobsen, Astrid (2015): „Ohne die hätten wir einen entspannten Dienst“. Zur Bedeutung kultureller Herkunft im polizeilichen Diskurs des Einsatz- und Streifendienstes. In: SLAK-Journal - Zeitschrift für Polizeiwissenschaft und polizeiliche Praxis, 1, 41-52.

Jessen, Ralph (2003): Polizei im Kaiserreich - Tendenzen und Grenzen der Demilitarisierung und „Professionalisierung“. In: Lange, Hans-Jürgen (Hrsg.), Die Polizei der Gesellschaft. Zur Soziologie der inneren Sicherheit. Opladen: Leske + Budrich.

Jung, Werner (2005): Wessen Freund und wessen Helfer? Didaktische Materialien zur Kölner Polizei im Nationalsozialismus. Köln: NSDOK Selbstverlag.

Junge Polizei (Hrsg.) (o. J.): Freund und Helfer. Nützliches für den Streifenalltag! https://www.jungepolizei.de/freundundhelfer/ [letzter Zugriff: 08.02.2019].

Kallmeyer, Werner/Schütze, Fritz (1977): Zur Konstitution von Kommunikationsschemata der Sachverhaltsdarstellung. In: Wegner, Dirk (Hrsg.), Gesprächsanalysen. Hamburg: Buske.

Kalogrias, Vaios/Dordanas, Stratos N. (2009): Deutsche Polizeibehörden im besetzten Griechenland, 1941-1944. In: Schulte, Wolfgang (Hrsg.), Die 
Polizei im NS-Staat. Frankfurt/Main: Verlag für Polizeiwissenschaft, 425-449.

Kapp, Sebastian (2020): Polizei verbittet sich Kritik. Neue Polizeiordnung soll „linksradikale Parolen“ im Stadion des 1. CfR Pforzheim verbieten. In: Pforzheimer Kurier, 5. März 2020. https://bnn.de/lokales/pforzheim/neuepolizeiordnung-soll-linksradikale-parolen-im-stadion-des-1-cfr-pforzheimverbieten [letzter Zugriff: 09.03.2020].

Keller, Reiner (2006): Wissenssoziologische Diskursanalyse. In: Keller, Reiner/Hirseland, Andreas/Schneider, Werner/Viehöver, Willy (Hrsg.), Handbuch Sozialwissenschaftliche Diskursanalyse, Bd. 1: Theorien und Methoden. 2., aktual. und erw. Aufl. Wiesbaden: VS Verlag, 115-146.

Keller, Reiner (2012): Das interpretative Paradigma. Eine Einführung. Wiesbaden: Springer.

Kersten, Joachim (2012): „Polizeiwissenschaft“. Eine programmatische Standortbestimmung. In: SIAK-Journal - Zeitschrift für Polizeiwissenschaft und polizeiliche Praxis, 1, 4-18.

Kirchhof, Steffen (2013): Forschungen zum Polizeiberuf. In: Pahl, JörgPeter/Herkner, Volkmar (Hrsg.), Handbuch Berufsforschung. Bielefeld: Bertelsmann, 762-774.

Klemp, Stefan (2009): Ganz normale Männer, ganz gewöhnliche Leben, ganz übliche Ermittlungen? In: Schulte, Wolfgang (Hrsg.), Die Polizei im NSStaat. Frankfurt/Main: Verlag für Polizeiwissenschaft, 181-199.

Knatz, Christian (2003): Polizei in der Weimarer Republik - Orientierungssuche zwischen Tradition und Modernisierung. In: Lange, Hans-Jürgen (Hrsg.), Die Polizei der Gesellschaft. Zur Soziologie der inneren Sicherheit. Opladen: Leske + Budrich, 37-55.

Knöbl, Wolfgang (1998): Polizei und Herrschaft im Modernisierungsprozeß. Staatsbildung und innere Sicherheit in Preußen, England und Amerika 1700-1914. Frankfurt/Main: Campus.

Knoblauch, Hubert (1991): Die Welt der Wünschelrutengänger und Pendler. Erkundungen einer verborgenen Wirklichkeit. Frankfurt/Main: Campus.

Knoblauch, Hubert (2001): Fokussierte Ethnographie. In: Sozialer Sinn, 1, 123-141.

Knoblauch, Hubert (2014): Wissenssoziologie. 3., überarb. Aufl. Konstanz: UVK.

Kohli, Martin/Fischer, Wolfram (1987): Biographieforschung. In: Voges, Wolfgang (Hrsg.), Methoden der Biographie- und Lebenslaufforschung. Opladen: VS Verlag. 
Koloma Beck, Teresa/Schlichte, Klaus (2014): Theorien der Gewalt zur Einführung. Hamburg: Junius.

Köttig, Michaela (2004): Lebensgeschichten rechtsextrem orientierter Mädchen und junger Frauen. Biographische Verläufe im Kontext der Familien- und Gruppendynamik. Gießen: Psychosozial-Verlag.

Köttig, Michaela (2005): Triangulation von Fallrekonstruktionen: Biographie und Interaktionsanalysen. In: Völter, Bettina/Dausien, Bettina/Lutz, Helma/Rosenthal, Gabriele (Hrsg.), Biographieforschung im Diskurs. Wiesbaden: VS Verlag, 65-83.

Krasmann, Susanne (1993): Kontingenz und Ordnungsmacht: phänomenologischer Versuch über die Polizei. Münster: LIT Verlag.

Kwiet, Konrad (1996): The Onset of the Holocaust: The Massacre of the Jews in Lithuania in June 1941. In: Bonnell, Andrew/Munro, Gregory/Travers, Martin (Hrsg.), Power, conscience, and opposition. Essays in German history in honour of John A. Moses. New York: Peter Lang, 107-121.

Kwiet, Konrad (2003): Von Tätern zu Befehlsempfängern. Legendenbildung und Strafverfolgung nach 1945. In: Matthäus, Jürgen/Kwiet, Konrad/Förster, Jürgen/Breitman, Richard (Hrsg.), Ausbildungsziel Judenmord? „Weltanschauliche Erziehung“ von SS, Polizei und Waffen-SS im Rahmen der „Endlösung“. Frankfurt/Main: Fischer, 114-138.

Landespolizeipräsidium (o. J.): Organisation der Polizei Niedersachsen. https://www.polizei-nds.de/wir_ueber_uns/organisation/die-polizeiniedersachsen-1394.html [letzter Zugriff: 18.09.2019].

Lange, Hans-Jürgen (2003): Polizeiforschung, Polizeiwissenschaft oder Forschung zur Inneren Sicherheit? - Über die Etablierung eines schwierigen Gegenstandes als Wissenschaftsdisziplin. In: Lange, Hans-Jürgen (Hrsg.), Die Polizei der Gesellschaft. Zur Soziologie der Inneren Sicherheit. Opladen: Leske + Budrich, 427-453.

Lange, Hans-Jürgen/Schenck, Jean-Claude (2003): Neue Steuerungsmodelle in der Polizei. In: Lange, Hans-Jürgen (Hrsg.), Die Polizei der Gesellschaft. Zur Soziologie der Inneren Sicherheit. Opladen: Leske + Budrich, 247-264.

Lange, Hans-Jürgen/Schenck, Jean-Claude (2004): Polizei im kooperativen Staat. Wiesbaden: VS Verlag.

Lau, Thomas/Wolff, Stephan (1983): Der Einstieg in das Untersuchungsfeld als soziologsicher Lernprozess. In: Kölner Zeitschrift für Soziologie und Sozialpsychologie, 35, 417-437.

Leonhard, Nina/Werkner, Ines-Jacqueline (2012): Militärsoziologie - Eine Einführung. 2., aktual. und erg. Aufl. Wiesbaden: VS Verlag. 
Leßmann, Peter (1989): Die preußische Schutzpolizei in der Weimarer Republik. Streifendienst und Straßenkampf. Düsseldorf: Droste.

Levy, Ruth J. (1967): Predicting police failures. In: Journal of Criminal Law, Criminology and Police Science, 58, 265-276.

Lewin, Kurt (1930): Der Übergang von der aristotelischen zur galileischen Denkweise in Biologie und Psychologie. In: Erkenntnis, 1 (1), 421-466.

Ley, Thomas (2013): Zum Verhältnis von Polizei zum Bürger - oder Kunden? In: Polizei \& Wissenschaft. Unabhängige interdisziplinäre Zeitschrift für Wissenschaft und Polizei, 1, 57-70.

Liebert, Frank (2001): „Die Dinge müssen zur Ruhe kommen, man muß einen Strich dadurch machen“. Politische „Säuberung“ in der niedersächsischen Polizei. In: Fürmetz, Gerhard/Reinke, Herbert/Weinhauer, Klaus (Hrsg.), Nachkriegspolizei. Sicherheit und Ordnung in Ost- und Westdeutschland 1945-1969. Hamburg: Ergebnisse Verlag, 71-103.

Liebl, Karlhans (2002): Wer geht zur Polizei? - Zur Soziologie der Berufswahl. In: Frevel, Bernhard/Asmus, Hans-Joachim/Groß, Hermann (Hrsg.), Soziologie: Studienbuch für die Polizei. Hilden: Verlag Deutsche Polizeiliteratur, 181-215.

Liebl, Karlhans (Hrsg.) (2006): Polizeiberuf und Transfergesellschaft. Motive, Entscheidungsgründe und Einflüsse auf die Berufswahl. Rothenburg/OL: Fachhochschule für Polizei Sachsen.

Loader, Ian (2011): Where Is Policing Studies? In: British Journal of Criminology, 51 (2), 449-458.

Löbbecke, Peter (2004): Abgesichert sein und gutes Geld verdienen. Eine qualitativ-empirische Untersuchung über Berufsbilder von studierenden Polizisten. Frankfurt/Main: Verlag für Polizeiwissenschaft.

Löbbecke, Peter (2010): Studieren zwischen System und Lebenswelt: Über den Status des „studierenden (Polizei-)Beamten“" und seine sozialisatorischen Folgen. Vorüberlegungen zu einem empirischen Projekt. In: Polizei - Polizist - Polizieren? Frankfurt/Main: Verlag für Polizeiwissenschaft, 149-162.

Lüders, Christian (2007): Beobachten im Feld und Ethnographie. In: Flick, Uwe/Kardorff, Ernst von/Steinke, Ines (Hrsg.), Qualitative Forschung. Ein Handbuch. 5. Aufl. Reinbek bei Hamburg: Rowohlt, 384-401.

Lüscher, Kurt (1972): Berufliche Sozialisation. In: Luckmann, Thomas/Sprondel, Walter M. (Hrsg.), Berufssoziologie. Köln: Kiepenheuer \& Witsch, 219-238.

Mangold, Anne (2011): Die friedfertige Polizistin? Die Praxis der Deeskalation aus der Sicht von Männern und Frauen im Streifendienst. In: Lüdtke, 
Alf/Reinke, Herbert/Sturm, Michael (Hrsg.), Polizei, Gewalt und Staat im 20. Jahrhundert. Wiesbaden: VS Verlag, 145-168.

Manning, Peter K. (1977): Police Work. The Social Organization of Policing. Cambridge: MIT Press.

Manning, Peter K. (2005): The Study of Policing. In: Police Quarterly, 8 (1), 23-43.

Martus, Theresa (2018): Polizei: Auch Männer ohne Hoden sind bald erlaubt. In: Morgenpost, 31. Dezember 2018. https://www.morgenpost.de/politik/ article216109259/Auch-Maenner-ohne-Hoden-koennen-bald-Polizistwerden.html [letzter Zugriff: 19.02.2019].

Matthäus, Jürgen (2002): An vorderster Front. Voraussetzungen für die Beteiligung der Ordnungspolizei an der Shoah. In: Paul, Gerhard (Hrsg.), Die Täter der Shoah. Fanatische Nationalsozialisten oder ganz normale Deutsche? Göttingen: Wallstein, 137-166.

Matthäus, Jürgen (2003): Die „Judenfrage“ als Schulungsthema von SS und Polizei. In: Matthäus, Jürgen/Kwiet, Konrad/Förster, Jürgen/Breitman, Richard (Hrsg.), Ausbildungsziel Judenmord? „Weltanschauliche Erziehung“ von SS, Polizei und Waffen-SS im Rahmen der „Endlösung“. Frankfurt/Main: Fischer, 35-86.

Matthäus, Jürgen/Kwiet, Konrad/Förster, Jürgen/Breitman, Richard (Hrsg.) (2003): Ausbildungsziel Judenmord? „Weltanschauliche Erziehung“ von SS, Polizei und Waffen-SS im Rahmen der „Endlösung“. Frankfurt/Main: Fischer.

Mead, George Herbert (1934/1995): Geist, Identität und Gesellschaft - Aus der Sicht des Sozialbehaviorismus. 10. Aufl. Frankfurt/Main: Suhrkamp.

Mensching, Anja (2008): Gelebte Hierarchien. Mikropolitische Arrangements und organisationskulturelle Praktiken am Beispiel der Polizei. Wiesbaden: VS Verlag.

Mensching, Anja (2010): „Goldfasan“ versus „Kollege vom höheren Dienst“. Zur Rekonstruktion gelebter Hierarchiebeziehungen in der Polizei. In: Bohnsack, Ralf/Przyborski, Aglaja/Schäffer, Burkhard (Hrsg.), Das Gruppendiskussionsverfahren in der Forschungspraxis. 2., vollständig überarb. und aktual. Aufl. Opladen: Verlag Barbara Budrich.

Mensching, Anja/Kleuker, Mirja/Linke, Yvonne/Nack, Michaela (2004): Polizei im Wandel. Binnenverhältnisse in der niedersächsischen Polizei am Beispiel des Einsatz- und Streifendienstes und der für ihn vorgesetzten Ebenen. Forschungsbericht 92. Hannover: Kriminologisches Forschungsinstitut Niedersachsen e.V. https://kfn.de/wp-content/uploads/ Forschungsberichte/FB_92.pdf [letzter Zugriff: 23.01.2019]. 
Merton, Robert K. (1959): Notes on Problem-Finding in Sociology. In: Merton, Robert K./Broom, Leonard/Cottrell, Leonard S. (Hrsg.), Sociology Today. Problems and Prospects. New York: Basic Books, IX-XXXIV.

Meuser, Michael (2017): Macht. In: Gugutzer, Robert/Klein, Gabriele/Meuser, Michael (Hrsg.), Handbuch Körpersoziologie, Bd. 1: Grundbegriffe und theoretische Perspektiven. Wiesbaden: Springer, 67-72.

Mokros, Reinhard (2009): Polizeiforschung für Studium und Praxis. Hilden: Verlag Deutsche Polizeiliteratur.

Mokros, Reinhard (2013): Polizeiwissenschaft und Polizeiforschung in Deutschland. Versuch einer kritischen Bestandsaufnahme. 2. überarb. und erg. Aufl. Holzkirchen/Obb: Felix-Verlag.

Möllers, Martin H. W./van Ooyen, Robert Chr. (2015): Auf der Suche nach den Polizeiwissenschaften. In: Möllers, Martin H. W./Ooyen, Robert Chr. van (Hrsg.), Wissenschaft und Polizei. Brühl/Rheinland: Hochschule des Bundes für Öffentliche Verwaltung.

Moon, Byongook/Hwang, Eui-Gab (2004): The reasons for choosing a career in policing among South Korean police cadets. In: Journal of Criminal Justice, 32 (3), 223-229.

Müller, Hans-Peter (2007): Max Weber. Eine Einführung in sein Werk. Köln: Böhlau.

Naas, Stefan (2003): Die Entstehung des Preußischen Polizeiverwaltungsgesetzes von 1931. Ein Beitrag zur Geschichte des Polizeirechts in der Weimarer Republik. Tübingen: Mohr Siebeck.

Niedersächsischer Landtag (2016): Frauen in Führung bei der Polizei. Kleine Anfrage zur schriftlichen Beantwortung mit Antwort der Landesregierung. Drucksache 17/5792.

Niedersächsisches Kultusministerium (o. J.): Die Fachoberschule (FOS). https://www.mk.niedersachsen.de/startseite/schule/unsere_schulen/ber ufsbildende_schulen/fachoberschule/die-fachoberschule-fos-6473.html [letzter Zugriff: 03.04.2018].

Niedersächsisches Ministerium für Inneres und Sport (2016): Beantwortung der mündlichen Anfrage der FDP zu Beförderungen bei der Polizei Niedersachsen. https://www.mi.niedersachsen.de/aktuelles/ presse_informationen/beantwortung-der-muendl-anfrage-der-fdp-zubefoerderungen-bei-der-polizei-niedersachsen--146174.html [letzter Zugriff: 24.03.2020].

Niedersächsisches Ministerium für Inneres und Sport (2018): Polizei Niedersachsen. 9.Aufl. https://www.pa.polizei-nds.de/aktuelles/ imagebroschuere-polizei-niedersachsen-110292.html [letzter Zugriff: 04.03.2020]. 
Niedersächsisches Ministerium für Inneres und Sport (o. J.): Polizei Niedersachsen.

https://www.mi.niedersachsen.de/themen/innere_sicherheit/polizei/allg emeines_ueber_polizei/polizei-niedersachsen-62316.html [letzter Zugriff: 14.01.2019].

Nienhaus, Ursula (1992): Einsatz für die „Sittlichkeit“: Die Anfänge der weiblichen Kriminalpolizei im Wilhelminischen Kaiserreich und in der Weimarer Republik. In: Lüdtke, Alf (Hrsg.), „Sicherheit“ und „Wohlfahrt“. Polizei, Gesellschaft und Herrschaft im 19. und 20. Jahrhundert. Frankfurt/Main: Suhrkamp, 243-267.

Nitschke, Peter (2000): Polizei im NS-System. In: Lange, Hans-Jürgen (Hrsg.), Staat, Demokratie und innere Sicherheit in Deutschland. Opladen: Leske + Budrich, 53-63.

Oevermann, Ulrich (1981): Fallrekonstruktionen und Strukturgeneralisierung als Beitrag der Objektiven Hermeneutik zur SoziologischStrukturtheoretischen Analyse. http://publikationen.ub.unifrankfurt.de/frontdoor/index/index/docId/4955 [letzter Zugriff: 23.07.2019].

Oevermann, Ulrich/Allert, Tillman/Konau, Elisabeth/Krambeck, Jürgen (1979): Die Methodologie einer „objektiven Hermeneutik“ und ihre allgemeine forschungslogische Bedeutung in den Sozialwissenschaften. In: Soeffner, Hans-Georg (Hrsg.), Interpretative Verfahren in den Sozial- und Textwissenschaften. Stuttgart: Metzler, 58-156.

Ohlemacher, Thomas (1999): Empirische Polizeiforschung in der Bundesrepublik. Versuch einer Bestandsaufnahme. Forschungsbericht 75. Hannover: Kriminologisches Forschungsinstitut Niedersachsen e.V. https://kfn.de/wp-content/uploads/Forschungsberichte/FB_75.pdf [letzter Zugriff: 17.04.2019].

Ohlemacher, Thomas (2010): Empirische Polizeiforschung 1999-2009: Einfach klasse, schlicht Masse oder marginal erfolgreich? In: Groß, Hermann/Bornewasser, Manfred/Frevel, Bernhard/Liebl, Karlhans/Ohlemacher, Thomas/Schmidt, Peter (Hrsg.), Polizei - Polizist Polizieren? Frankfurt/Main: Verlag für Polizeiwissenschaft.

Ohlemacher, Thomas/Bosold, Christine/Fiedler, Anja/Lauterbach, Oliver/Zitz, Alexandra (2002): Polizei im Wandel. Abschlussbericht der standardisierten Befragung der Vollzugsbeamtinnen und -beamten der niedersächsischen Polizei 2001 sowie erste Ergebnisse der Gruppendiskussion 2002. Forschungsbericht 87. Hannover: Kriminologisches Forschungsinstitut Niedersachsen. http://kfn.de/wp-content/uploads/ Forschungsberichte/FB_92.pdf [letzter Zugriff: 24.08.2017]. 
Petri, Thomas (2018): Die Polizei seit 1960. In: Bäcker, Matthias/Denninger, Erhard/Graulich, Kurt (Hrsg.), Handbuch des Polizeirechts. Gefahrenabwehr - Strafverfolgung - Rechtsschutz. 6., vollst. überarb. Aufl. München: C.H. Beck, 36-62.

Pfeifer, Wolfgang/Braun, Wilhelm/Zentralinstitut für Sprachwissenschaft Berlin (Hrsg.) (1993): Klient. Etymologisches Wörterbuch des Deutschen. 2., durchges. und erg. Aufl. Berlin: Akademie Verlag.

Pfeil, Patricia (2006): Polizei und Geschlecht. Thematisierungen, DeThematisierungen, Re-Thematisierungen. Opladen: Verlag Barbara Budrich.

Pick, Alexander (1995): Polizeiforschung zwischen Wissenschaft und Scharlatanerie. In: Kriminalistik, 11, 697-703.

Pick, Alexander (1996): Polizeiforschung ohne Grabenkämpfe. In: Kriminalistik, 5, 349-352.

Plessner, Helmuth (1928): Die Stufen des Organischen und der Mensch. Einleitung in die philosophische Anthropologie. 3. Aufl. Berlin: De Gruyter.

Pohn-Weidinger, Maria (2014): Heroisierte Opfer. Bearbeitungs- und Handlungsstrukturen von „Trümmerfrauen“ in Wien. 2. Aufl. Wiesbaden: Springer.

Polizei Hessen (2016): Die Schutzpolizei. Die Aufgaben der Schutz- und Kriminalpolizei. http://www.polizei.hessen.de/icc/internetzentral/nav/305/ broker.jsp?uMen=30570ee1-825a-f6f8-6373-a91bbcb63046 [letzter Zugriff: 13.04.2020].

Polizeiakademie Niedersachsen (o. J.a): Das Studium. https://polizeistudium.de/studium/\#Studium [letzter Zugriff: 18.09.2019].

Polizeiakademie Niedersachsen (o. J.b): Mehr als nur ein Job: Polizist / Polizistin. Polizei Niedersachsen. https://polizei-studium.de/der-berufpolizistin-polizist/ [letzter Zugriff: 13.04.2020].

Popitz, Heinrich (1992): Phänomene der Macht. 2., stark erw. Aufl., Nachdruck 2004. Tübingen: Mohr Siebeck.

Pudlat, Andreas (2012): Gewaltdarstellungen in der polizeilichen Öffentlichkeitsarbeit. In: Ohlemacher, Thomas/Werner, Jochen-Thomas (Hrsg.), Polizei und Gewalt. Interdisziplinäre Analysen zu Gewalt gegen und durch Polizeibeamte. Frankfurt/Main: Verlag für Polizeiwissenschaft, 197-214.

Raab, Jürgen (2008): Visuelle Wissenssoziologie. Theoretische Konzeption und materiale Analysen. Konstanz: UVK.

Rabe-Hemp, Cara E. (2009): POLICEwomen or PoliceWOMEN? Doing Gender and Police Work. In: Feminist Criminology, 4 (2), 114-129. 
Rabitz-Suhr, Simone (2016): Wer wird heute warum Polizist? Die Anwärterbefragung der Polizei Hamburg. In: Frevel, Bernhard/Groß, Hermann (Hrsg.), Empirische Polizeiforschung XIX: Bologna und die Folgen für die Polizeiausbildung. Frankfurt/Main: Verlag für Polizeiwissenschaft, $61-78$

Rauber, Birgit (2013): Beruf Polizist - Motive zur Berufswahl zwischen Kindheitstraum und Sicherheitsdenken - Eine empirische Untersuchung zur Motivation junger Menschen bei der Wahl des Polizeiberufes. In: Feltes, Thomas/Fischer, Thomas A. (Hrsg.), Polizeiliche Ausbildung und polizeiliches Handeln. Empirische Studien und Ergebnisse. Frankfurt/Main: Verlag für Polizeiwissenschaft, 13-44.

Reemtsma, Jan Philipp (2003): Organisationen mit Gewaltlizenz - ein zivilisatorisches Grundproblem. In: Die Polizei als Organisation mit Gewaltlizenz: Möglichkeiten und Grenzen der Kontrolle. Münster: LIT Verlag, $7-23$.

Reemtsma, Jan Philipp (2008): Vertrauen und Gewalt. Versuch über eine besondere Konstellation der Moderne. Hamburg: Hamburger Edition.

Reese-Schäfer, Walter (2007): Klassiker der politischen Ideengeschichte. Von Platon bis Marx. München: Oldenbourg.

Reichertz, Jo (1991): Aufklärungsarbeit: Kriminalpolizisten und Feldforscher bei der Arbeit. Stuttgart: F. Enke.

Reichertz, Jo (2003a): Die Abduktion in der qualitativen Sozialforschung. Opladen: Leske + Budrich.

Reichertz, Jo (2003b): Hermeneutische Polizeiforschung. In: Möllers, Martin H. W./Ooyen, Robert Chr. van (Hrsg.), Jahrbuch Öffentliche Sicherheit 2002/2003. Frankfurt/Main: Verlag für Polizeiwissenschaft, 29-56.

Reichertz, Jo (2007): Abduktion, Deduktion und Induktion in der qualitativen Forschung. In: Flick, Uwe/Kardorff, Ernst von/Steinke, Ines (Hrsg.), Qualitative Forschung. Ein Handbuch. 5. Aufl. Reinbek bei Hamburg: Rowohlt, 276-286.

Reichertz, Jo (2015): Die Polizeiwissenschaft auf dem Weg in die Nische? In: Polizei \& Wissenschaft. Unabhängige interdisziplinäre Zeitschrift für Wissenschaft und Polizei, 1 (1), 11-17.

Reichertz, Jo/Schröer, Norbert (Hrsg.) (1992): Polizei vor Ort. Studien zur empirischen Polizeiforschung. Stuttgart: F. Enke.

Rein, Leonid (2009): Das 322. Polizeibataillon und der Mord an den weißrussischen Juden. In: Schulte, Wolfgang (Hrsg.), Die Polizei im NS-Staat. Frankfurt/Main: Verlag für Polizeiwissenschaft, 219-237.

Reinke, Herbert (1992): „,.. hat sich ein politischer und wirtschaftlicher Polizeistaat entwickelt". Polizei und Großstadt im Rheinland vom Vorabend 
des Ersten Weltkrieges bis zum Beginn der zwanziger Jahre. In: Lüdtke, Alf (Hrsg.), „Sicherheit" und „Wohlfahrt". Polizei, Gesellschaft und Herrschaft im 19. und 20. Jahrhundert. Frankfurt/Main: Suhrkamp, 219-242.

Reinke, Herbert (1996): Polizeigeschichte in Deutschland. Ein Überblick. In: Nitschke, Peter (Hrsg.), Die deutsche Polizei und ihre Geschichte. Beiträge zu einem distanzierten Verhältnis. Hilden: Verlag Deutsche Polizeiliteratur, 13-26.

Reinke, Herbert (1997): Policing Politics in Germany from Weimar to the Stasi. In: Mazower, Mark (Hrsg.), The Policing of Politics in the Twentieth Century. Providence: Berghahn Books, 91-106.

Reinke, Herbert (2012): The Politics of Police History in Germany since the 1990s. A Participant Observation. In: Crime, History \& Societies, 16 (2), 99-106.

Reinke, Herbert/Fürmetz, Gerhard (2000): Polizei-Politik in Deutschland unter alliierter Besatzung. In: Lange, Hans-Jürgen (Hrsg.), Staat, Demokratie und innere Sicherheit in Deutschland. Opladen: Leske + Budrich, 67-86.

Reuter, Jana (2014): Polizei und Gewalt. Eine handlungstheoretische Rekonstruktion polizeilicher Konfliktarbeit. Frankfurt/Main: Verlag für Polizeiwissenschaft.

Richter, Jeffrey S. (2001): „Entpolizeilichung“ der öffentlichen Ordnung. Die Reform der Verwaltungspolizei in der britischen Besatzungszone 1945-1955. In: Fürmetz, Gerhard/Reinke, Herbert/Weinhauer, Klaus (Hrsg.), Nachkriegspolizei. Sicherheit und Ordnung in Ost- und Westdeutschland 1945-1969. Hamburg: Ergebnisse Verlag, 35-50.

Rosenthal, Gabriele (Hrsg.) (1986): Die Hitlerjugend-Generation. Biographische Thematisierungen als Vergangenheitsbewältigung. Essen: Die Blaue Eule.

Rosenthal, Gabriele (1995): Erlebte und erzählte Lebensgeschichte. Gestalt und Struktur biographischer Selbstbeschreibungen. Frankfurt/Main: Campus.

Rosenthal, Gabriele (Hrsg.) (1999): Der Holocaust im Leben von drei Generationen: Familien von Überlebenden der Shoah und von Nazi-Tätern. 3. korr. Aufl. Gießen: Psychosozial-Verlag.

Rosenthal, Gabriele (2011): Interpretative Sozialforschung. Eine Einführung. 3., aktual. und erg. Aufl. Weinheim: Beltz Juventa.

Rosenthal, Gabriele (2012): A plea for a More Interpretive, More Empirical and More Historical Sociology. In: Kalekin-Fishman, Devorah/Denis, Ann (Hrsg.), The Shape of Sociology for the 21st Century. Tradition and Renewal. London: Sage. 
Rosenthal, Gabriele (Hrsg.) (2015): Etablierte und Außenseiter zugleich. Selbst- und Fremdbilder von Palästinensern im Westjordanland und in Israel. Frankfurt/Main: Campus.

Rosenthal, Gabriele (2016): Die Erforschung kollektiver und individueller Dynamik - Zu einer historisch und prozess-soziologisch orientierten interpretativen Sozialforschung. In: Forum Qualitative Sozialforschung, 17 (2).

Rosenthal, Gabriele/Bogner, Artur (2019): Sozialkonstruktivistischfigurationssoziologische Biographieforschung. In: Hitzler, Ronald/Reichertz, Jo/Schröer, Norbert (Hrsg.), Kritik der Hermeneutischen Wissenssoziologie. Weinheim: Beltz Juventa, 67-80.

Ruch, Andreas (2017): Polizeiarbeit zwischen Definitionsmacht und Diskriminierung. Zur sozialen Selektivität polizeilicher Ermittlungen. In: Liebl, Karlhans (Hrsg.), Polizei und Minderheiten. Frankfurt/Main: Verlag für Polizeiwissenschaft, 197-213.

Santos, Hermílio (2016a): Biography and Action: A Schutzian Perspective to Life-World. In: Societá Mutamento Politica, 6 (12), 231-243.

Santos, Hermílio (2016b): On Biography: A Schutzian Perspective. In: Schutrian Research, 8, 163-178.

Sawicki, Gérald (2019): A War-Time Secret Police: Activities of the Geheime Feldpolizei on the Western Front During the First World War. In: Campion, Jonas/López, Laurent/Payen, Guillaume (Hrsg.), European Police Forces and Law Enforcement in the First World War. Cham: Springer Nature, 75-88.

Schäfer, Miriam (2013): Berufsbiographische Präsentationen als RePräsentationen. Unveröffentlichte Masterarbeit. Göttingen: GeorgAugust-Universität.

Schäfer, Miriam (2018): Biographieforschung als Organisationsforschung. Zum Zusammenhang von biographischen Erfahrungen von Polizist*innen und dem Handeln in der Organisation Polizei. In: Schilling, Elisabeth (Hrsg.), Verwaltete Biografien. Wiesbaden: Springer, 111-138.

Scheffer, Thomas (2018): Kapazitäten und Ansprüche polizeilicher Kriminalprävention. Ein Plädoyer für die mitlaufende Bearbeitung prekärer Autorität und Legitimation. In: Mensching, Anja/Jacobsen, Astrid (Hrsg.), Polizei im Spannungsfeld von Autorität, Legitimität und Kompetenz. Frankfurt/Main: Verlag für Polizeiwissenschaft, 11-25.

Schmidt, Daniel (2010): Keine Kommissare. Preußische Polizeioffiziere zwischen soldatischem Selbstverständnis und polizeilicher Professionalität 1919 bis 1935. In: Militärgeschichtliche Zeitschrift, 69, 37-58.

Schöne, Marcel (2011): Pierre Bourdieu und das Feld Polizei. Ein besonderer Fall des Möglichen. Frankfurt/Main: Verlag für Polizeiwissenschaft. 
Schröer, Norbert (1997): Wissenssoziologische Hermeneutik. In: Hitzler, Ronald/Honer, Anne (Hrsg.), Sozialwissenschaftliche Hermeneutik. Eine Einführung. Opladen: Leske + Budrich, 109-129.

Schröer, Norbert (2002): Verfehlte Verständigung. Kommunikationssoziologische Fallstudie zur interkulturellen Kommunikation. Konstanz: UVK.

Schütz, Alfred (1932/2003): Der sinnhafte Aufbau der sozialen Welt. Eine Einleitung in die verstehende Soziologie. Konstanz: UVK.

Schütz, Alfred (1971/2004): Common-Sense und wissenschaftliche Interpretation menschlichen Handelns. In: Strübing, Jörg/Schnettler, Bernt (Hrsg.), Methodologie interpretativer Sozialforschung. Klassische Grundlagentexte. Konstanz: UVK.

Schütz, Alfred (1972): Der Fremde. Ein sozialpsychologsicher Versuch. In: Brodersen, Arvid (Hrsg.), Gesammelte Aufsätze II. Studien zur soziologischen Theorie. Den Haag: Nijhoff.

Schütz, Alfred/Luckmann, Thomas (1979/2003): Strukturen der Lebenswelt. Konstanz: UVK.

Schütze, Fritz (1976): Zur Hervorlockung und Analyse von Erzählungen thematisch relevanter Geschichten im Rahmen soziologischer Feldforschung. In: Arbeitsgruppe Bielefelder Soziologen (Hrsg.), Kommunikative Sozialforschung. München: Fink, 159-260.

Schütze, Fritz (1977): Die Technik des narrativen Interviews in Interaktionsfeldstudien. Dargestellt an einem Projekt zur Erforschung von kommunalen Machtstrukturen. Bielefeld: Universität Bielefeld.

Schütze, Fritz (1983): Biographieforschung und narratives Interview. In: Neue Praxis. Kritische Zeitschrift für Sozialarbeit und Sozialpädagogik, 13, 283-293.

Skolnick, Jerome H. (1966): Justice without Trial: Law Enforcement in Democratic Society. New York: Wiley.

Soeffner, Hans-Georg (1989): Der Alltag der Auslegung - Zur wissenssoziologischen Konzeption einer sozialwissenschaftlichen Hermeneutik. Frankfurt/Main: Suhrkamp.

Soeffner, Hans-Georg (2007): Sozialwissenschaftliche Hermeneutik. In: Flick, Uwe/Kardorff, Ernst von/Steinke, Ines (Hrsg.), Qualitative Forschung. Ein Handbuch. 5. Aufl. Reinbek bei Hamburg: Rowohlt, 164-175.

Sørensen, Henning (1994): New Perspectives on the Military Profession: The I/O Model and Esprit de Corps Reevaluated. In: Armed Forces \& Society, 20 (4), 599-617.

Stolleis, Michael (2018): Die Polizei nach 1945. In: Bäcker, Matthias/Denninger, Erhard/Graulich, Kurt (Hrsg.), Handbuch des Poli- 
zeirechts. Gefahrenabwehr - Strafverfolgung - Rechtsschutz. 6., vollst. überarb. Aufl. München: C.H. Beck, 29-36.

Strack, Markus (2011): Berufswahlmotive von PolizeibeamtInnen in den neuen Bundesländern: biographieanalytische Fallrekonstruktionen. Frankfurt/Main: Verlag für Polizeiwissenschaft.

Strasser, Hermann/van den Brink, Henning (2008): Die Obdachlosen. In: Schweer, Thomas/Strasser, Hermann (Hrsg.), Das da draußen ist ein Zoo, und wir sind die Dompteure: Polizisten im Konflikt mit ethnischen Minderheiten und sozialen Randgruppen. Wiesbaden: VS Verlag.

Streng, Franz (1993): Der Beitrag der Kriminologie zu Entstehung und Rechtfertigung staatlichen Unrechts im „Dritten Reich“. In: Monatsschrift für Kriminologie und Strafrechtsreform, 76, 141-168.

Strübing, Jörg/Hirschauer, Stefan/Ayaß, Ruth/Krähnke, Uwe/Scheffer, Thomas (2018): Gütekriterien qualitativer Sozialforschung. Ein Diskussionsanstoß. In: Zeitschrift für Soziologie, 47 (2), 83-100.

Sturm, Michael (2015): Zwischen Apologetik, Traditionsbildung und kritischer Reflexion. Der Gebrauch von „Geschichte“ in der Polizei der Bundesrepublik. In: Oranienburger Schiften. Beiträge aus der Fachhochschule der Polizei des Landes Brandenburg, 23-36.

Szymenderski, Peggy (2013): Gefühlsarbeit im Polizeidienst. In: Österreichische Zeitschrift für Soziologie, 38 (2), 167-183.

Thomas, William I./Thomas, Dorothy S. (1928): The child in America. Behavior problems and programs. New York: Knopf.

Treiber, Hubert (2007): Macht - ein soziologischer Grundbegriff. In: Gostmann, Peter/Merz-Benz, Peter-Ulrich (Hrsg.), Macht und Herrschaft. Zur Revision zweier soziologischer Grundbegriffe. Wiesbaden: VS Verlag, 49-62.

Trotha, Trutz von (1997): Zur Soziologie der Gewalt. In: Trotha, Trutz von (Hrsg.), Soziologie der Gewalt. Opladen: Westdeutscher Verlag, 9-56.

Tuma, René/Knoblauch, Hubert/Schnettler, Bernt (2013): Videographie. Einführung in die interpretative Video-Analyse sozialer Situationen. Wiesbaden: Springer.

Ullrich, Peter (2017): „Normalbürger“ versus „Krawalltouristen“. Polizeiliche Kategorisierungen von Demonstrationen zwischen Recht und soziologischem Ermessen. In: Liebl, Karlhans (Hrsg.), Polizei und Minderheiten. Frankfurt/Main: Verlag für Polizeiwissenschaft, 61-97.

Van Maanen, John (1978): The Asshole. In: Manning, Peter K./Van Maanen, John (Hrsg.), Policing. A View from the Street. Santa Monica, Calif.: Goodyear Publishing, 307-328. 
Vester, Michael/von Oertzen, Peter/Geiling, Heiko/Hermann, Thomas/Müller, Dagmar (2001): Soziale Milieus im gesellschaftlichen Strukturwandel. Zwischen Integration und Ausgrenzung. Frankfurt/Main: Suhrkamp.

Vitell, Scott John/Singhapakdi, Anusorn (2008): The Role of Ethics Institutionalization in Influencing Organizational Commitment, Job Satisfaction, and Esprit de Corps. In: Journal of Business Ethics, 81 (2), 343-353.

Vorwerk, Andreas (1992): Zwischen Pickelhaube und Tschako - Preußens Schutzpolizei im Wandel vom Kaiserreich zur Republik. In: Archiv für Polizeigeschichte. Zeitschrift der Deutschen Gesellschaft für Polizeigeschichte, 3, 65-69.

Wagner, Patrick (2009): Der Kern des völkischen Maßnahmenstaates - Rolle, Macht und Selbstverständnis der Polizei im Nationalsozialismus. In: Schulte, Wolfgang (Hrsg.), Die Polizei im NS-Staat. Frankfurt/Main: Verlag für Polizeiwissenschaft.

Weber, Gunthard/Stierlin, Helm (1989): In Liebe entzweit. Ein systematischer Ansatz zum Verständnis und zur Behandlung der Magersuchtsfamilie. Reinbek bei Hamburg: Rowohlt.

Weber, Max (1904/2004): Die Objektivität sozialwissenschaftlicher und sozialpolitischer Erkenntnis. In: Strübing, Jörg/Schnettler, Bernt (Hrsg.), Methodologie interpretativer Sozialforschung. Klassische Grundlagentexte. Konstanz: UVK, 45-100.

Weber, Max (1921/2008): Wirtschaft und Gesellschaft. Grundriss der verstehenden Soziologie. Frankfurt/Main: Zweitausendeins.

Weber, Max (1921/2014): Wirtschaft und Gesellschaft: Soziologie. Unvollendet 1919-1920. Tübingen: Mohr Siebeck.

Weidmann, Thomas (2001): Strukturen der Polizeiausbildung. In: Kriminalistik. Unabhängige Zeitschrift für die kriminalistische Wissenschaft und Praxis, 55 (2), 121-131.

Weinhauer, Klaus (1999): Polizei und innenpolitische Spannungen in der Weimarer Republik. In: Internationale wissenschaftliche Korrespondenz zur Geschichte der deutschen Arbeiterbewegung, 3, 554-563.

Weinhauer, Klaus (2000): „Staatsbürger mit Sehnsucht nach Harmonie“. Gesellschaftsbild und Staatsverständnis in der westdeutschen Polizei. In: Schildt, Axel/Siegfried, Detlef/Lammers, Christian (Hrsg.), Dynamische Zeiten. Die 60er Jahre in den beiden deutschen Gesellschaften. Hamburg: Christians, 444-470.

Weinhauer, Klaus (2001): Innere Unruhe. Studentenproteste und die Krise der westdeutschen Schutzpolizei in den sechziger Jahren. In: Fürmetz, Gerhard/Reinke, Herbert/Weinhauer, Klaus (Hrsg.), Nachkriegspolizei. 
Sicherheit und Ordnung in Ost- und Westdeutschland 1945-1969. Hamburg: Ergebnisse Verlag, 303-325.

Weinhauer, Klaus (2003): Schutzpolizei in der Bundesrepublik. Zwischen Bürgerkrieg und innerer Sicherheit: Die turbulenten sechziger Jahre. Paderborn: Schöningh.

Weinhauer, Klaus (2004): Terrorismus in der Bundesrepublik der Siebzigerjahre. Aspekte einer Sozial- und Kulturgeschichte der Inneren Sicherheit. In: Archiv für Sozialgeschichte, 44, 219-242.

Wendt, Rainer/Voigt, Aurel (1994): Polizei. Ein fröhliches Wörterbuch. München: Tomus.

West, Candace/Zimmermann, Don H. (1987): Doing Gender. In: Gender \& Society, 1 (2), 125-151.

Whitehead, Alfred North (1917): The Organisation of Thought Educational and Scientific. London: Williams.

Wiechmann, Gerhard/Payen, Guillaume (2019): The Complex Policing System of Oldenburg, a Middle German State Far Away from the War? In: Campion, Jonas/López, Laurent/Payen, Guillaume (Hrsg.), European Police Forces and Law Enforcement in the First World War. Cham: Springer Nature, 121-139.

Wilk, Lieselotte/Zartler, Ulrike (2009): Dynamiken und Veränderungen im Familienverlauf: Scheidung und Trennung. In: Bundesministerium für Wirtschaft, Familie und Jugend (Hrsg.), 5. Österreichischer Familienbericht 1999 bis 2009. Die Familie an der Wende zum 21. Jahrhundert, Bd. 1. Wien: Bundesministerium für Wirtschaft, Familie und Jugend, 447-501. https://www.parlament.gv.at/PAKT/VHG/XXIV/III/III_00157/imfna me_190010.pdf [letzter Zugriff 25.06.2020].

Wilson, Thomas P. (1970): Normative and Interpretative Paradigms in Sociology. In: Douglas, Jack (Hrsg.), Understanding Everyday Life. Toward the Reconstruction of Sociological Knowledge. Chicago: Aldine.

Winter, Martin (1998): Politikum Polizei: Macht und Funktion der Polizei in der Bundesrepublik Deutschland. Münster: LIT Verlag.

Winter, Martin (2000): Polizeiphilosophie und Protest policing in der Bundesrepublik Deutschland - von 1960 bis zur staatlichen Einheit 1990. In: Lange, Hans-Jürgen (Hrsg.), Staat, Demokratie und innere Sicherheit in Deutschland. Opladen: Leske + Budrich, 203-220.

Witte, Nicole (2010): Ärztliches Handeln im Praxisalltag. Eine interaktionsund biographieanalytische Studie. Frankfurt/Main: Campus.

Wolff, Stephan (2007): Dokumenten- und Aktenanalyse. In: Flick, Uwe/Kardorff, Ernst von/Steinke, Ines (Hrsg.), Qualitative Forschung. Ein Handbuch. 5. Aufl. Reinbek bei Hamburg: Rowohlt, 502-513. 
Worm, Arne (2019): Fluchtmigration aus Syrien. Eine biographietheoretische und figurationssoziologische Studie. Göttingen: Universitätsverlag Göttingen.

Wu, Yuning/Sun, Ivan Y./Cretacci, Michael A. (2009): A Study of Cadets' Motivation to Become Police Officers in China. In: International Journal of Police Science \& Management, 11 (3), 377-392.

Znaniecki, Florian/Thomas, William I. (1918-1920/1958): The Polish peasant in Europe and America. New York: Dover Publications 
In öffentlichen Diskursen wird die Polizei sowohl als „Freund und Helfer" und Garant von Ordnung und Gesetz präsentiert, als auch als Institution eines Gewaltmonopols verhandelt, das (illegitim) Gewalt ausübt. Polizist*innen werden korrespondierend als Akteure im Bereich Sicherheit und Gewaltprävention sowie als Opfer oder Täter*innen von illegitimer Gewalt präsentiert. Jenseits der Reflexion über diese komplementären Bilder richtet die vorliegende soziologische Studie den Blick auf den schutzpolizeilichen Alltag und rekonstruiert diesen als komplex strukturiertes Handlungsfeld. Die empirische Untersuchung des Einsatz- und Streifendienstes in Niedersachsen zeigt auf Basis einer Verknüpfung von biographietheoretischen, sozialkonstruktivistischen und figurationssoziologischen Perspektiven, wie polizeiliches Handeln im Kontext von spezifischen Organisationsbedingungen und den lebensgeschichtlichen Erfahrungen von Polizist*innen prozessiert wird. Strukturmerkmale polizeilichen Handelns und Deutens zeigen sich genau an der Schnittstelle von Organisation und Biographie: Organisationale Handlungsorientierungen und deren interaktive Durchsetzung in polizeilichen Einsatzsituationen und innerhalb des Organisationsalltags sind eng verwoben mit den lebensgeschichtlichen Verläufen von Polizist*innen. Die Studie zeigt, dass die konkrete Berufsausübung nicht nur von der beruflichen Sozialisation in der Organisation geprägt wird, sondern wesentlich an biographische Erfahrungen und Wissensbestände anknüpft.

Diese Untersuchung trägt damit zum Verstehen von Berufskarrieren, polizeilicher Arbeit und Alltagspraxis bei. Sie liefert darüber hinaus generelle Erkenntnisse zu den Wechselwirkungen zwischen Organisationen und Biographien.

ISBN: $978-3-86395-483-3$

ISSN: 2699-0989

eISSN: 2699-0997 